JOINT TRANSPORTATION RESEARCH PROGRAM

FHWA/IN/JTRP-2010/4

Final Report

CONTROL AND REPAIR OF BRIDGE DECK CRACKING

Robert Frosch

Sergio Gutierrez

Jacob Hoffman

November 2010 


\section{TECHNICAL Summary}

Technology Transfer and Project Implementation Information

INDOT Research

TRB Subject Code:25-1 Bridges

Publication No.FHWA/IN/JTRP-2010/4, SPR-3104

November 2010

Final Report

\section{Control and Repair of Bridge Deck Cracking}

\section{Introduction}

A large number of bridges across the state of Indiana have exhibited early age deck cracking. This presents a major threat to the lifespan of these bridges, as deck cracking often leads to corrosion of the reinforcing steel by creating a path for water and deicing salts to reach the steel. Therefore, there is a need to develop design and construction guidelines to control deck cracking in newly constructed bridges. In addition, a method to repair deck cracks must be developed to prevent corrosion of the reinforcement in bridges already in service. The objective of this research is to develop effective design, construction, and repair methods for the control of bridge deck cracking.

\section{Findings}

The research was conducted in four phases. The first phase consisted of a field investigation of a new bridge that is experiencing significant deck cracking. The second phase evaluated the influence of curing and concrete mix design on the control of deck cracking. The third phase evaluated the effectiveness of a variety of commercially available crack repair products. Finally, the fourth phase evaluated deck reinforcement design parameters to effectively control crack widths and mitigate cracking in future construction. Based on conclusions made from this research project, the following design, construction, and repair recommendations are made:

\section{Design and Construction of New Bridges:}

1. The amount of deck reinforcement should be calculated according to the following expression:

$$
\rho_{g}=\frac{\sqrt[6]{f^{\prime}{ }_{c}}}{f_{y}}
$$

2. For special structures where enhanced durability is desired, reinforcement amounts greater than that recommended above should be considered.

3. Alterations to the concrete mix design used on bridge decks (Class $\mathrm{C}$ concrete) are strongly recommended, specifically a reduction in the cement and water contents and the addition of fly ash.

4. Casting of concrete decks should not be conducted when temperatures below $40^{\circ} \mathrm{F}$ are expected on the day of casting or the 7 days following casting. In addition, weather conditions such as low humidity and high wind speeds should be avoided on the day of casting.

5. Continuous wet cure procedures, initiated as early as possible after concrete placement, should be strictly followed.

6. The minimum 7 day continuous wet cure should be provided.

\section{Repair of Existing Bridges:}

1. The selection of crack repair material should be performed considering crack widths. For narrow cracks, methacrylates should be considered as they provide deeper penetration into the crack than epoxies. For wide cracks (> $0.016 \mathrm{in}$.), epoxies are recommended because of their higher bond strength and their demonstrated performance in this investigation. Methacrylates should not be used as a repair solution for the repair of wide cracks (> 0.016 in.) as indicated by their poor performance in this investigation. 
2. A list of repair products demonstrated to enhance the durability of the deck is provided within this report. It is important that the application procedures for the product be followed to provide for proper performance of the material.
3. A pretreatment stripe should be incorporated into all gravity feed crack repair procedures.

4. All overlay repair should be conducted in conjunction with a gravity feed crack repair.

\section{Implementation}

The design, construction, and repair recommenddations provided in this study can be implemented to improve the durability and lifespan of bridge decks and consequently the entire structure. It is suggested that these recommendations become standard practice across the state with implementation into appropriate design and construction standards such as the INDOT Design Manual and the INDOT Standard Specifications.

\section{Contacts}

For more information:

Prof. Robert Frosch

Principal Investigator

School of Civil Engineering

Purdue University

West Lafayette IN 47907

Phone: (765) 494-5904

Fax: (765) 496-1105

E-mail: frosch@ecn.purdue.edu
Indiana Department of Transportation

Office of Research \& Development

1205 Montgomery Street

P.O. Box 2279

West Lafayette, IN 47906

Phone: (765) 463-1521

Fax: (765) 497-1665

Purdue University

Joint Transportation Research Program

School of Civil Engineering

West Lafayette, IN 47907-1284

Phone: (765) 494-9310

Fax: (765) 496-7996

E-mail: jtrp@ecn.purdue.edu

http://www.purdue.edu/jtrp 
Final Report

FHWA/IN/JTRP-2010/4

\title{
CONTROL AND REPAIR OF BRIDGE DECK CRACKING
}

\author{
by \\ Robert J. Frosch \\ Principal Investigator \\ Professor of Civil Engineering \\ and \\ Sergio Gutierrez \\ Graduate Research Assistant \\ Jacob S. Hoffman \\ Graduate Research Assistant \\ School of Civil Engineering \\ Purdue University \\ Joint Transportation Research Program \\ Project No. C-36-56HHHH \\ File No. 7-4-85 \\ SPR-3104 \\ Conducted in Cooperation with the \\ Indiana Department of Transportation \\ and the Federal Highway Administration
}

The contents of this report reflect the views of the authors, who are responsible for the facts and the accuracy of the data presented herein. The contents do not necessarily reflect the official views or policies of the Indiana Department of Transportation or the Federal Highway Administration at the time of publication. This report does not constitute a standard, specification, or regulation.

Purdue University

West Lafayette, IN 47907

November 2010 


\begin{tabular}{|c|c|c|}
\hline $\begin{array}{l}\text { 1. Report No. } \\
\text { FHWA/IN/JTRP-2010/4 }\end{array}$ & 2. Government Accession No. & 3. Recipient's Catalog No. \\
\hline \multirow{2}{*}{\multicolumn{2}{|c|}{$\begin{array}{l}\text { 4. Title and Subtitle } \\
\text { Control and Repair of Bridge Deck Cracking }\end{array}$}} & $\begin{array}{l}\text { 5. } \quad \text { Report Date } \\
\text { November } 2010\end{array}$ \\
\hline & & 6. Performing Organization Code \\
\hline \multicolumn{2}{|c|}{$\begin{array}{l}\text { 7. Author(s) } \\
\text { Robert Frosch, Sergio Gutierrez, and Jacob Hoffman }\end{array}$} & $\begin{array}{l}\text { 8. Performing Organization Report No. } \\
\text { FHWA/IN/JTRP-2010/4 }\end{array}$ \\
\hline \multirow{2}{*}{\multicolumn{2}{|c|}{$\begin{array}{l}\text { 9. Performing Organization Name and Address } \\
\text { Joint Transportation Research Program } \\
\text { 1284 Civil Engineering Building } \\
\text { Purdue University } \\
\text { West Lafayette, IN 47907-1284 }\end{array}$}} & 10. Work Unit No. \\
\hline & & $\begin{array}{l}\text { 11. Contract or Grant No. } \\
\text { SPR-3104 }\end{array}$ \\
\hline \multirow{2}{*}{\multicolumn{2}{|c|}{$\begin{array}{l}\text { 12. Sponsoring Agency Name and Address } \\
\text { Federal Highway Administration } \\
575 \text { N. Pennsylvania, Room } 254 \\
\text { Indianapolis, IN } 46204\end{array}$}} & $\begin{array}{c}\text { 13. Type of Report and Period Covered } \\
\text { Final Report }\end{array}$ \\
\hline & & 14. Sponsoring Agency Code \\
\hline
\end{tabular}

15. Supplementary Notes

Prepared in cooperation with the Federal Highway Administration and the Indiana Department of Transportation.

\section{Abstract}

Cracking of bridge decks poses a significant threat to the lifespan of our nation's bridges. Cracking has been shown to occur in various climates and geographical areas and can be seen on various types of superstructures. Often these cracks appear before or shortly after opening the bridge to live loads. Cracks in the deck create a path for water and deicing salts to reach the steel, often leading to corrosion of the reinforcement, greatly reducing the durability of the deck. Measures must be taken during design and construction to control bridge deck cracking and prolong the lifespan of bridges. In addition, there is a need to develop effective methods to repair cracks in existing bridge decks. This project consisted of four phases of research to investigate methods to control and repair deck cracking. The first phase of the study was a field investigation of a new bridge that is experiencing significant deck cracking. The second phase was an evaluation of previous recommendations regarding curing and concrete mix design and their effect on the control of deck cracking. The third phase of the study evaluated the effectiveness of a variety of commercially available crack repair products. The fourth phase evaluated the influence of the design and layout of the deck reinforcement in controlling crack widths. Based on the findings of this study, inadequate deck reinforcement and poor construction practices, particularly deck casting during poor weather conditions, were identified as major causes of bridge deck cracking for the structure investigated. Recommendations are provided for the design and construction of new bridge decks as well as for the repair of existing bridge decks. In particular, a minimum 7 day minimum wet cure is recommended along with alterations to the concrete mix to reduce bridge deck cracking through the reduction of concrete shrinkage. Recommendations are also provided regarding the amount of reinforcement required to optimally control crack widths and improve the durability of bridge decks. Finally, guidance is provided regarding both the selection and application of deck repair materials.

$$
\text { . }
$$

17. Key Words

Bridge deck cracking, transverse bridge deck cracking, restrained shrinkage cracking, bridge deck crack repair, bridge deck crack control, shrinkage and temperature reinforcement, concrete curing.

\section{Distribution Statement}

No restrictions. This document is available to the public through the National Technical Information Service, Springfield, VA 22161

\begin{tabular}{|c|c|c|c|}
\hline $\begin{array}{c}\text { 19. Security Classif. (of this report) } \\
\text { Unclassified }\end{array}$ & $\begin{array}{c}\text { 20. Security Classif. (of this page) } \\
\text { Unclassified }\end{array}$ & $\begin{array}{c}\text { 22. } \text { No. of Pages } \\
329\end{array}$ & \\
\hline
\end{tabular}




\section{ACKNOWLEDGEMENTS}

This work was supported by the Joint Transportation Research Program (JTRP) administered by the Indiana Department of Transportation (INDOT) and Purdue University through contract SPR-3104. The support of the Indiana Department of Transportation (INDOT) and the Federal Highway Administration (FHWA) are gratefully acknowledged. The authors would like to thank Dr. Tommy Nantung from the INDOT Division of Research for serving as Project Administrator and for his support throughout the project. In addition, thanks are extended to members of the Study Advisory Committee for their participation and thoughtful comments throughout the project. These members include Shakeel Baig, Gregory Carleton, Bill Dittrich, Keith Hoernschemeyer, Dan Kinder, Don Leonard, Jim Mickler, Scott Newbolds, George Synder, Robert Turner, and Tony Zander. 


\section{TABLE OF CONTENTS}

LIST OF TABLES ...........................................................................................................

LIST OF FIGURES .................................................................................................................................................

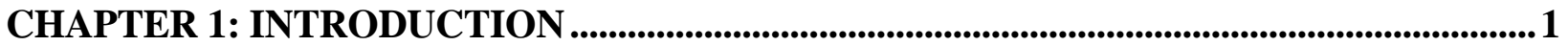

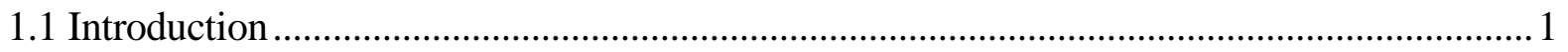

1.2 Bridge Deck Cracking ..........................................................................................................

1.2.1 Transverse Cracking ..............................................................................................

1.2.2 Longitudinal Cracking.................................................................................................

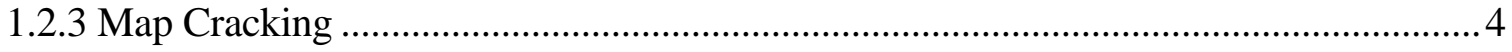

1.3 Restrained Shrinkage .........................................................................................................

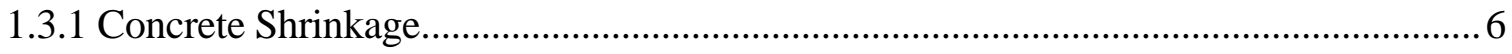

1.3.1.1 Plastic Shrinkage........................................................................................6

1.3.1.2 Drying Shrinkage ........................................................................................

1.3.1.3 Carbonation Shrinkage..................................................................................

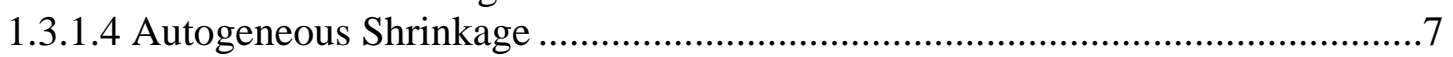

1.3.2 Thermal Volumetric Changes ...................................................................................

1.3.3 Creep Effects on Restraint Shrinkage ...................................................................... 8

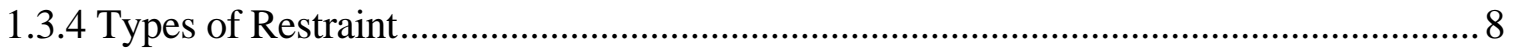

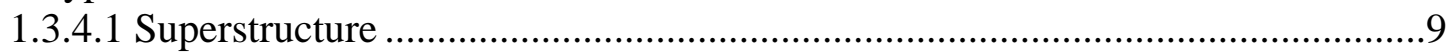

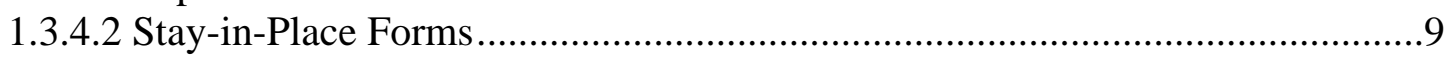

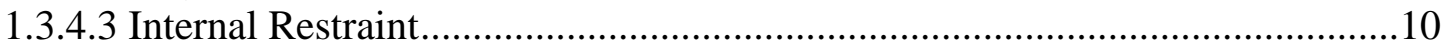

1.4 Factors Affecting Deck Cracking..................................................................................10

1.4.1 Material Properties ..........................................................................................11

1.4.2 Design Practices...................................................................................................... 12

1.4.2.1 Shrinkage and Temperature Reinforcement ..................................................12

1.4.3 Construction Practices ............................................................................................... 14

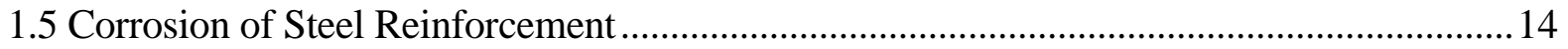

1.6 Repair of Bridge Deck Cracking .........................................................................................17

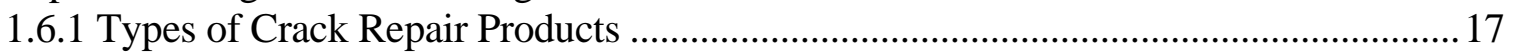

1.6.1.1 Epoxy Injection ........................................................................................17

1.6.1.2 Gravity Feed Repair ...................................................................................18

1.6.1.3 Routing and Sealing ..................................................................................19

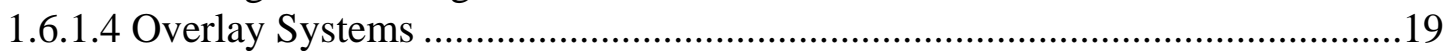

1.6.2 Factors affecting Repair Performance..................................................................19

1.6.2.1 Repair Product Variables ..............................................................................20

1.6.2.2 Field Condition Variables ............................................................................21

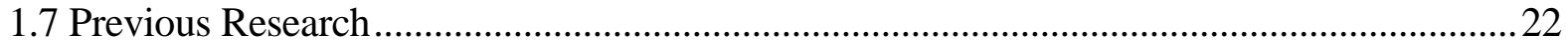

1.7.1 Krauss and Rogalla (1996) ..................................................................................2 22 
1.7.2 French, Eppers, Le, and Hajjar (1999)........................................................................22

1.7.3 Frosch, Blackman, and Radabaugh (2003)....................................................................2

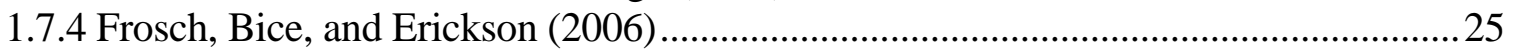

1.7.5 Altoubat and Lange (2001) .......................................................................................... 25

1.7.6 Tia, Subramanian, Brown, and Broward (2005) ……………………………………...26

1.7.7 Pincheira and Dorshorst (2005) .................................................................................26

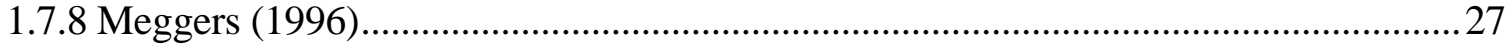

1.7.9 Johnson, Schultz, French and Reneson (2009) ...........................................................2 28

1.8 Objective and Scope ..........................................................................................................2

CHAPTER 2: FIELD INVESTIGATION ..........................................................................................30

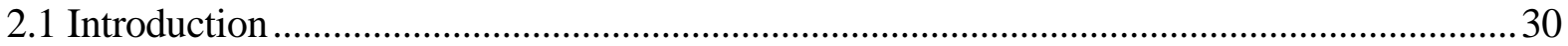

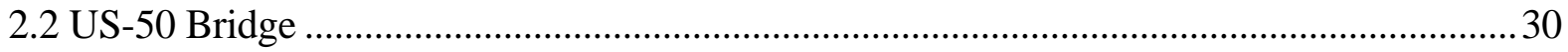

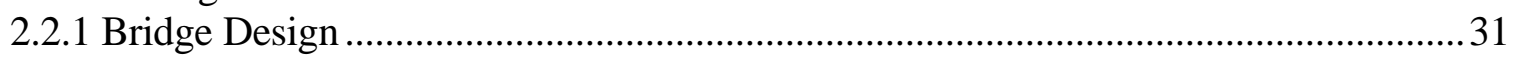

2.2.1.1 Superstructure Design...................................................................................32

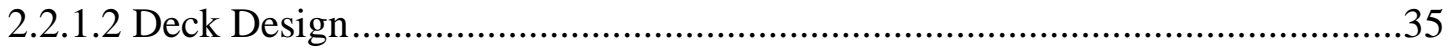

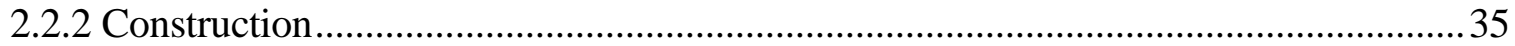

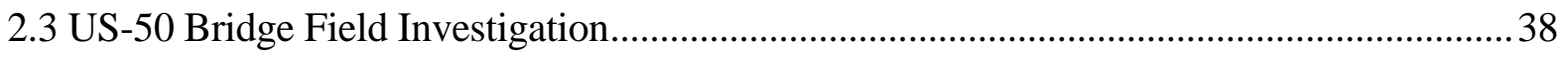

2.3.1 Westbound Structure ....................................................................................................... 39

2.3.1.1 Girder Spans (Spans B-G) .........................................................................39

2.3.1.2 Beam Spans (Spans A, J-T) .........................................................................40

2.3.2 Eastbound Structure.........................................................................................

2.3.2.1 Girder Spans (Spans B-G) .............................................................................4

2.3.2.2 Beams Spans (Spans A, J-T) ......................................................................46

2.4 Cracking Analysis.................................................................................................... 51

2.4.1 Effect of Reinforcement ......................................................................................51

2.4.2 Effect of Bridge Geometry ………………………….........................................52

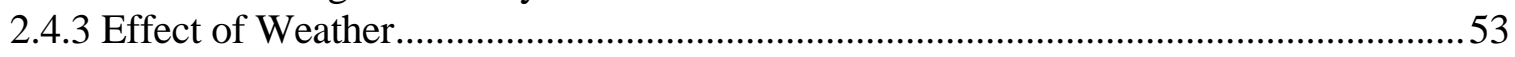

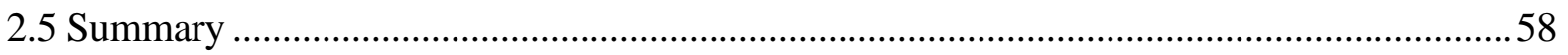

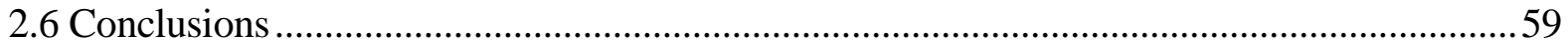

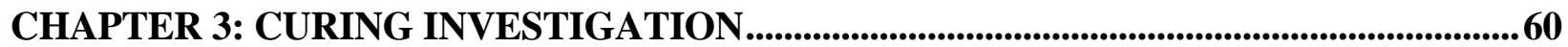

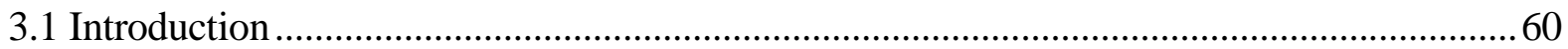

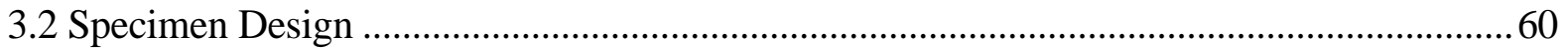

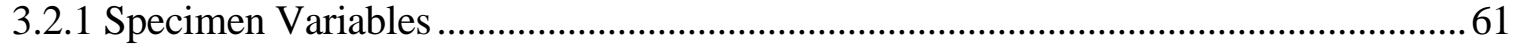

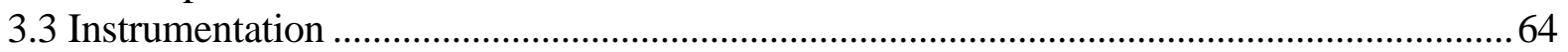

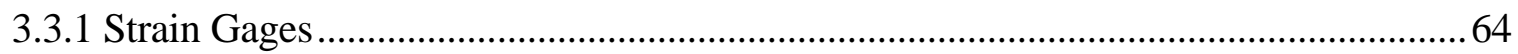

3.3.2 Relative Humidity Sensors .............................................................................................66

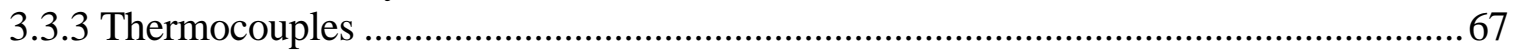

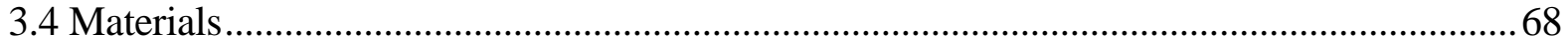

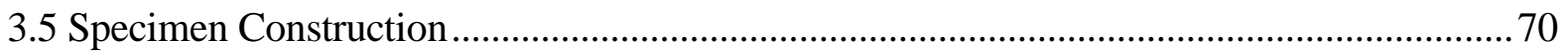

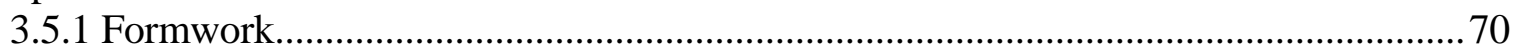

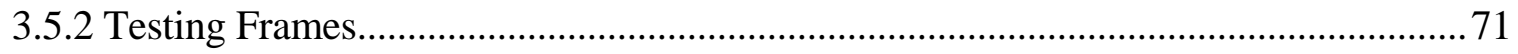

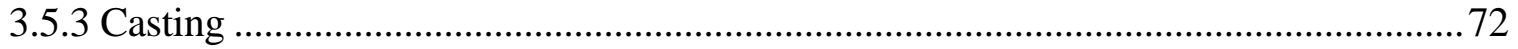

3.6 Test Procedure..........................................................................................................

3.6.1 Curing Procedure ....................................................................................................... 74 


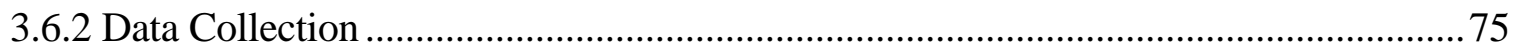

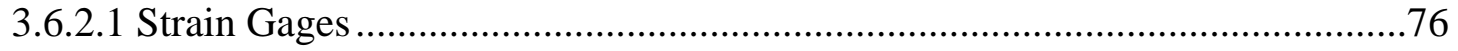

3.6.2.2 Humidity Sensors.....................................................................................76

3.6.2.3 Thermocouples...........................................................................................

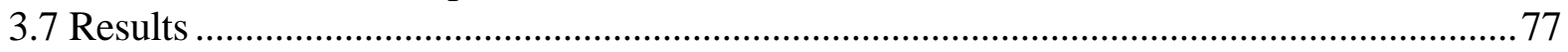

3.7.1 Shrinkage Behavior .................................................................................................... 77

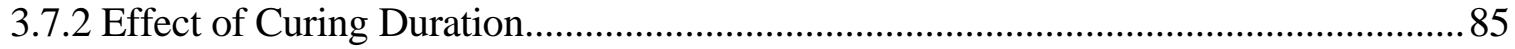

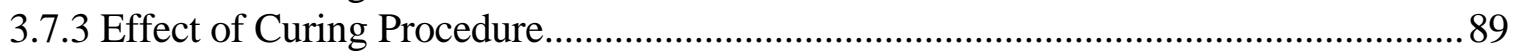

3.7.4 Effect of Concrete Mix..........................................................................................95

3.7.5 Curing Measurement Device........................................................................................ 104

3.7.5.1 Embedment Strain Gages.........................................................................104

3.7.5.2 Relative Humidity Sensors ……………………...........................................109

3.7.5.3 Thermocouples..............................................................................................110

3.8 Long Term Results..............................................................................................................113

3.8.1 Shrinkage Behavior …………………………………..............................................113

3.8.2 Effect of Curing Duration..........................................................................................117

3.8.3 Effect of Curing Procedure.....................................................................................121

3.8.4 Effect of Concrete Mix.............................................................................................123

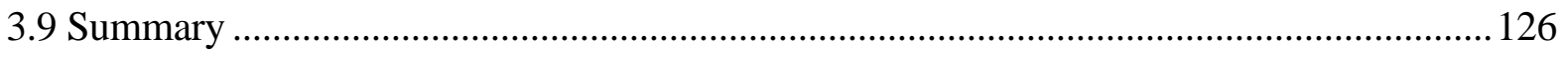

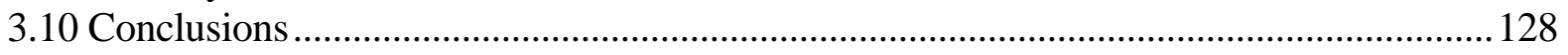

CHAPTER 4: CRACK REPAIR INVESTIGATION...........................................................129

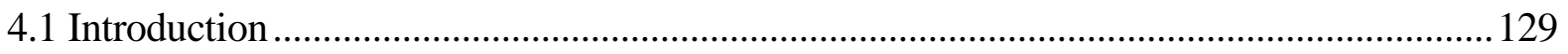

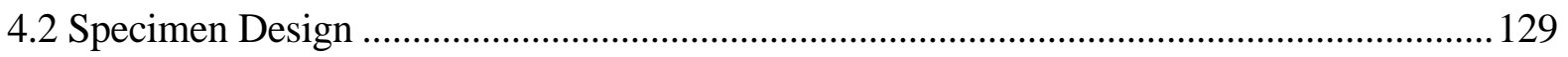

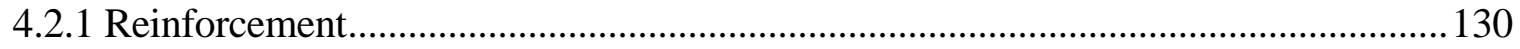

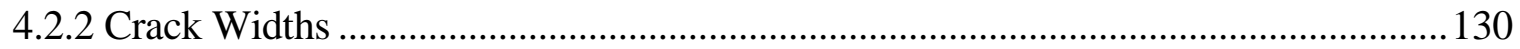

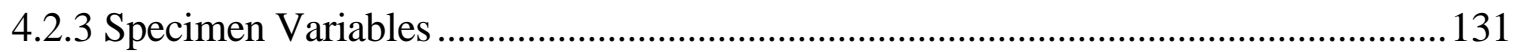

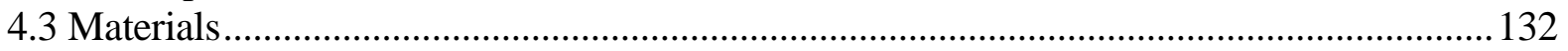

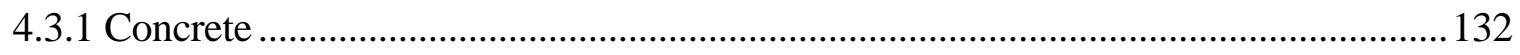

4.3.2 Reinforcement....................................................................................................133

4.3.3 Crack Repair Products..........................................................................................133

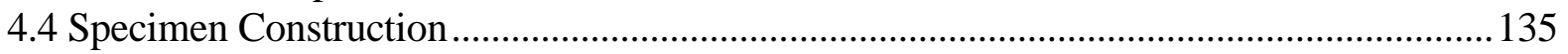

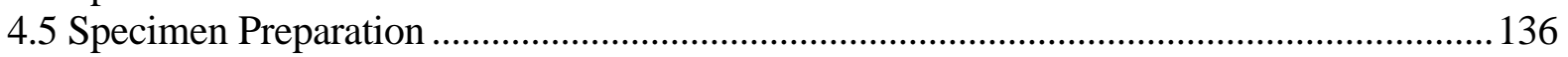

4.5.1 Cracking Procedure ……………………………………………………………....136

4.5.2 Crack Repair Application .....................................................................................139

4.5.2.1 Gravity Feed Repair Products ......................................................................140

4.5.2.2 Overlay Repair Products ................................................................................141

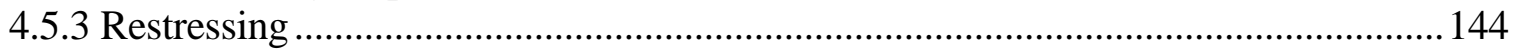

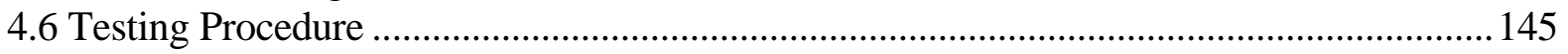

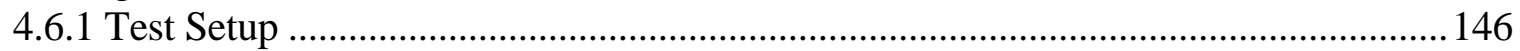

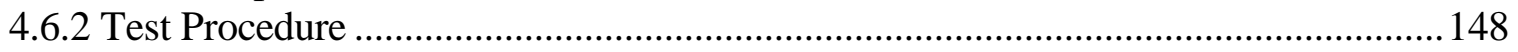

4.6.2.1 Macrocell Corrosion Test ...................................................................148

4.6.2.2 Visual Examination....................................................................................149

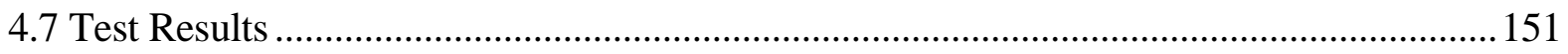

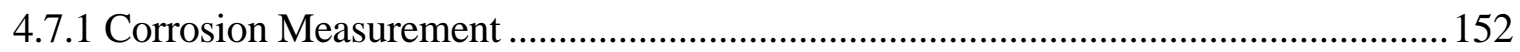

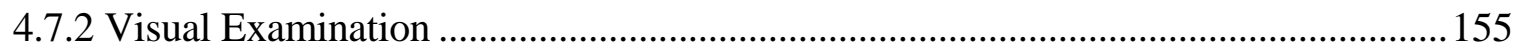




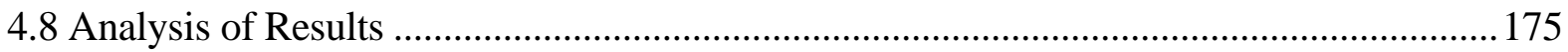

4.8.1 Corrosion Measurement ............................................................................................175

4.8.2 Visual Examination ............................................................................................ 179

4.8.3 Correlation of Results (Corrosion Measurement and Visual Examination)...............182

4.8.4 Repair Type Performance..............................................................................................183

4.8.5 Influence of Crack Widths ......................................................................................... 184

4.8.6 Properties of Repair Products.....................................................................................185

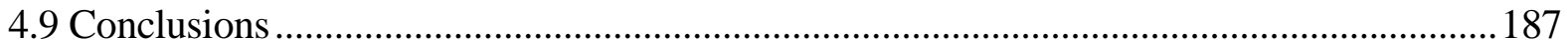

CHAPTER 5: CRACK CONTROL INVESTIGATION ............................................................189

5.1 Specimen Design .........................................................................................................189

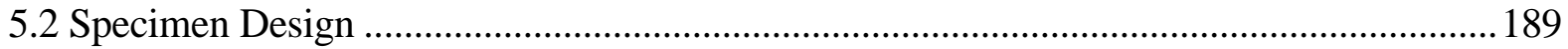

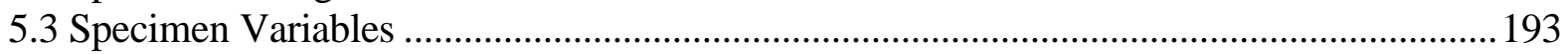

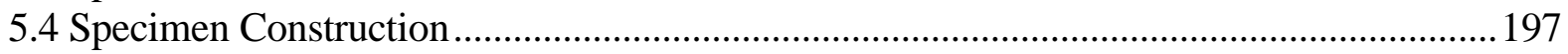

5.4.1 Pin and Roller Connections ...........................................................................197

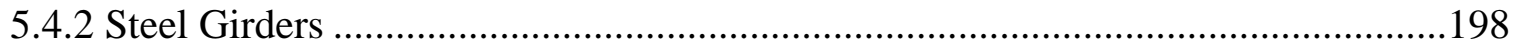

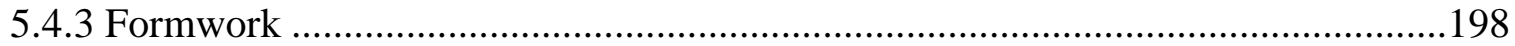

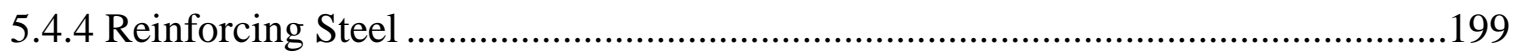

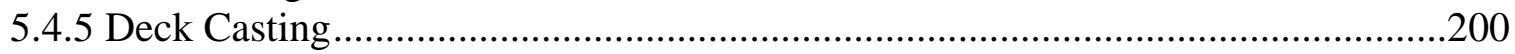

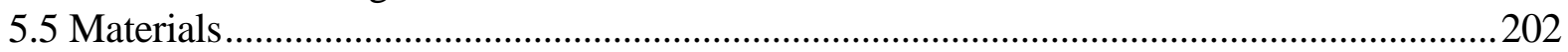

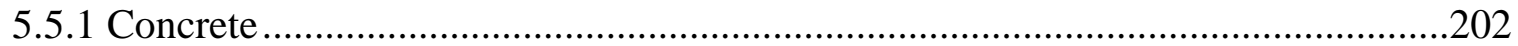

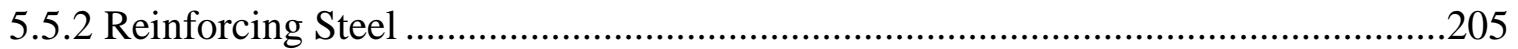

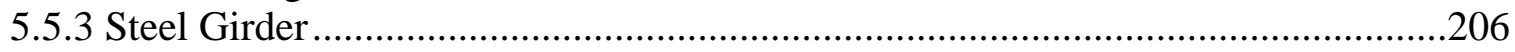

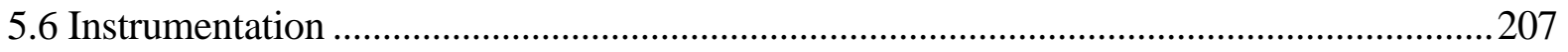

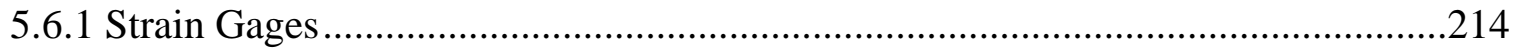

5.6.2 Linear Potentiometers ....................................................................................215

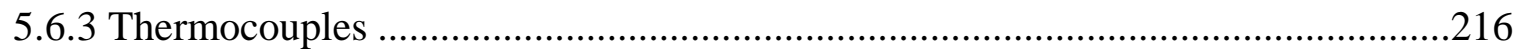

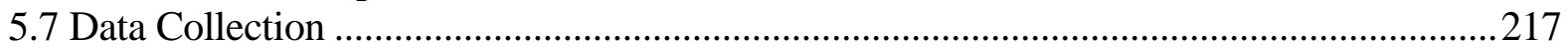

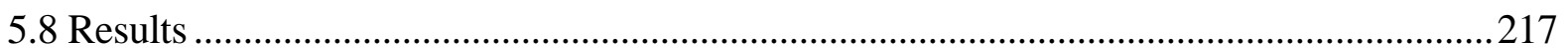

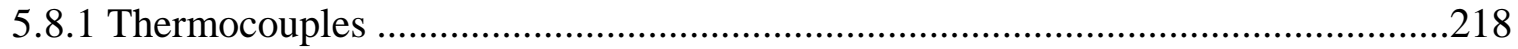

5.8.2 Reinforcement Strain Gages ..........................................................................220

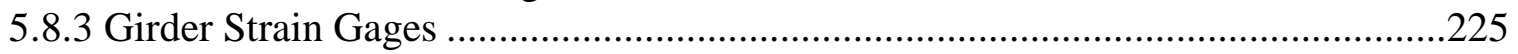

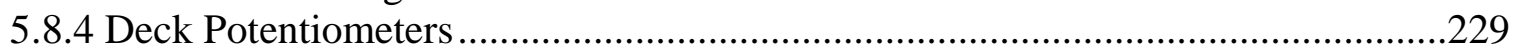

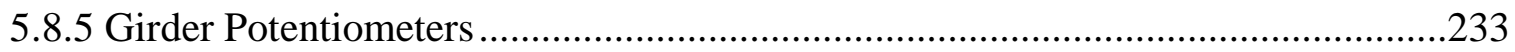

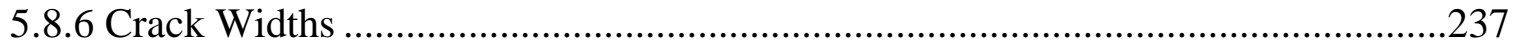

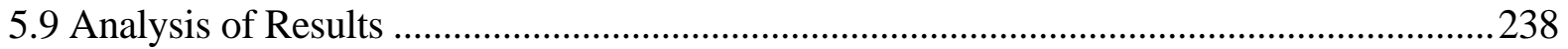

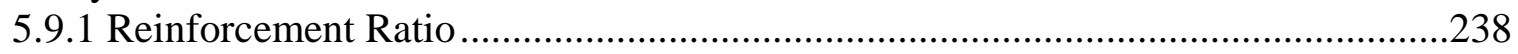

5.9.2 Reinforcement Spacing..............................................................................241

5.9.3 Reinforcement Diameter................................................................................242

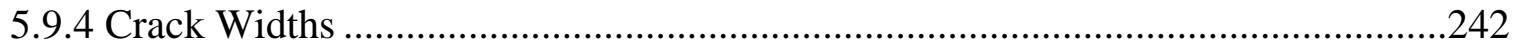

5.9.5 Girder Deflections ..........................................................................................247

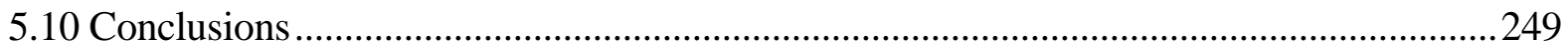

CHAPTER 6: SUMMARY AND CONCLUSIONS.......................................................................250

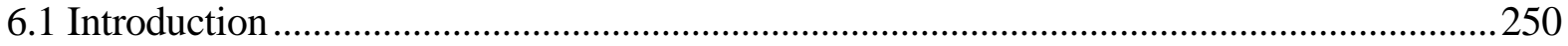

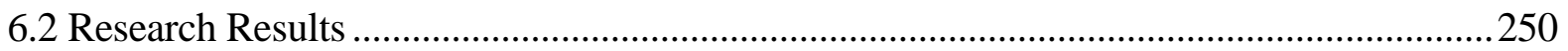




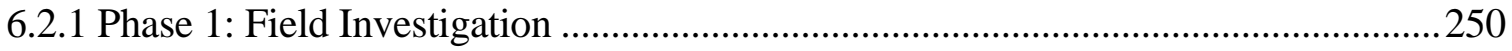

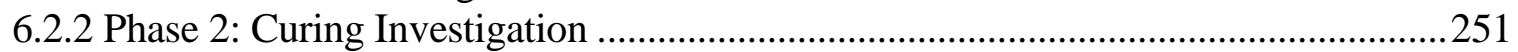

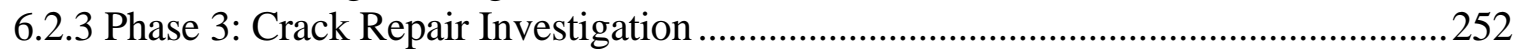

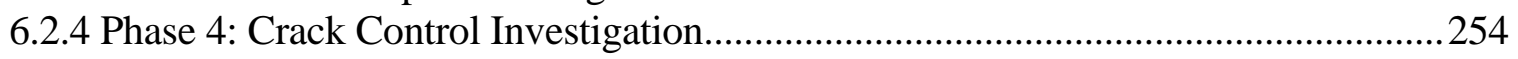

6.3 Design, Construction, and Repair Recommendations .................................................255

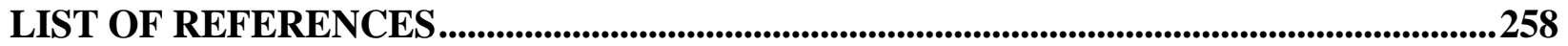

APPENDIX A: REPAIR PRODUCT TECHNICAL DATA SHEETS .....................................261

APPENDIX B: ELECTRIC CURRENT MEASUREMENT - REPAIR PRODUCTS..........305

APPENDIX C: VISUAL ASSESSMENT - REPAIR PRODUCTS ...........................................316 


\section{LIST OF TABLES}

Table 1.1: Shrinkage and temperature reinforcement requirements................................................13

Table 1.2: Maximum crack widths, ACI 224R-01 recommendation ..............................................16

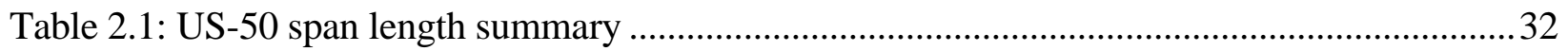

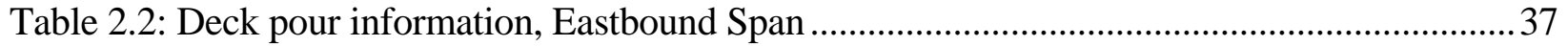

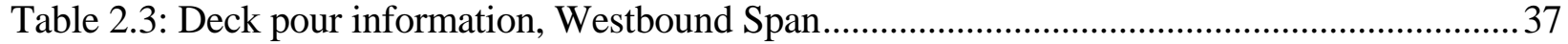

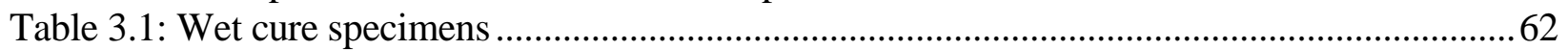

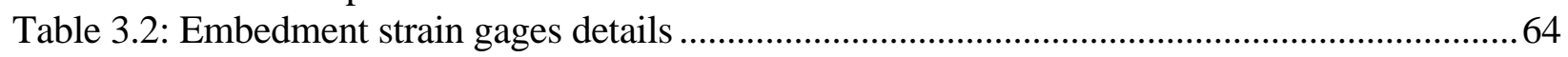

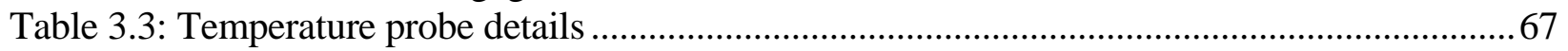

Table 3.4: Concrete mix proportions (amount per cubic yard) .....................................................68

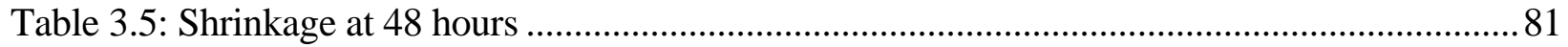

Table 3.6: Shrinkage from 48 hours through the end of wet cure ................................................... 81

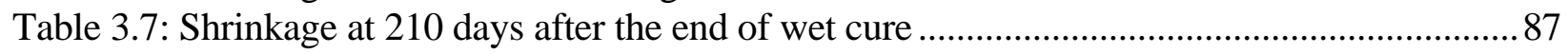

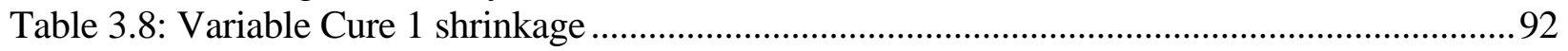

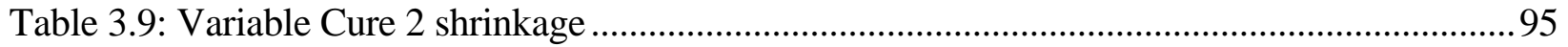

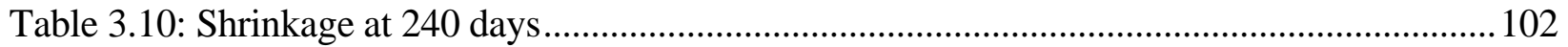

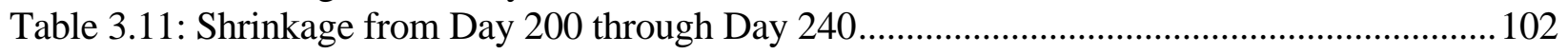

Table 3.12: Shrinkage at 518 days after the end of wet cure ........................................................119

Table 3.13: Variable Cure 1 shrinkage ....................................................................................... 122

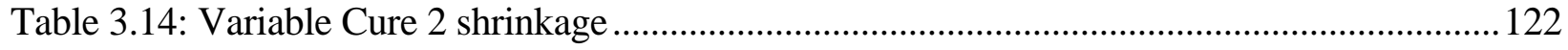

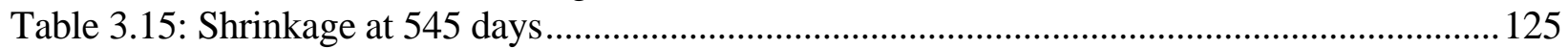

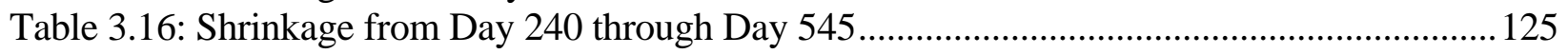

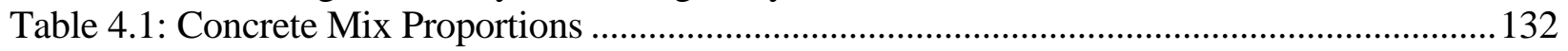

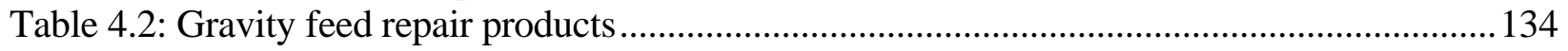

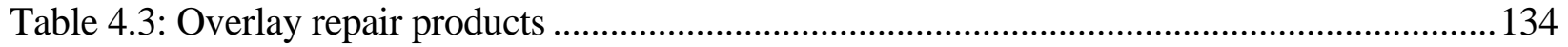

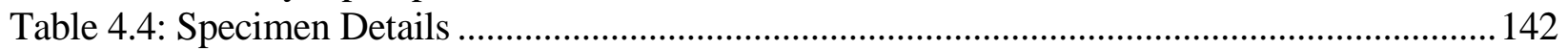

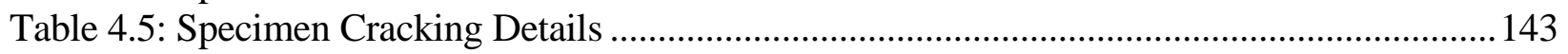

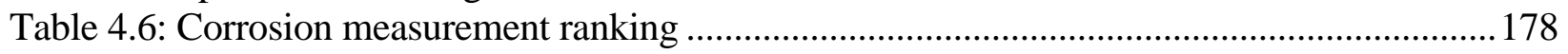

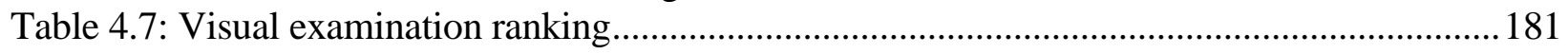

Table 4.8: Best performance (Corrosion Measurement and Visual Examination) ........................ 182

Table 4.9: Best product performance for each repair type ......................................................... 184

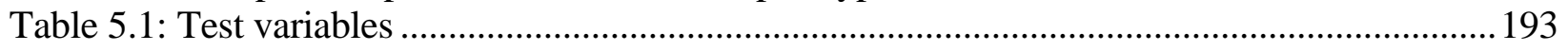

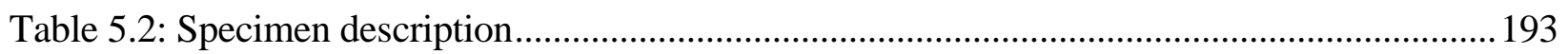

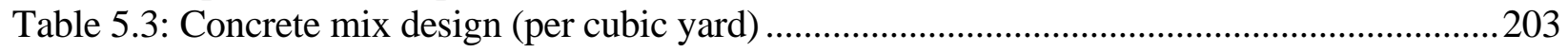

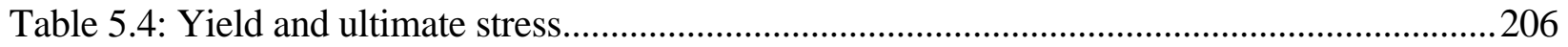

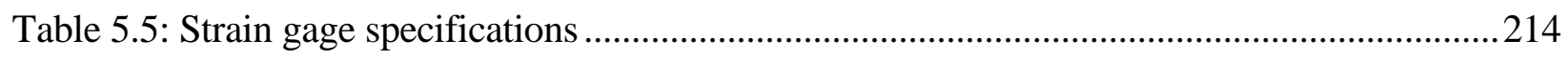

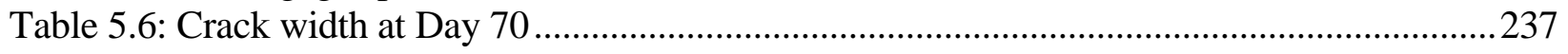

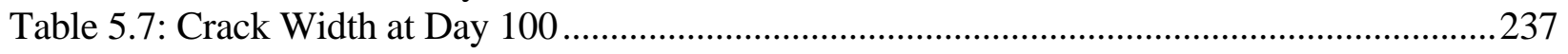




\section{LIST OF FIGURES}

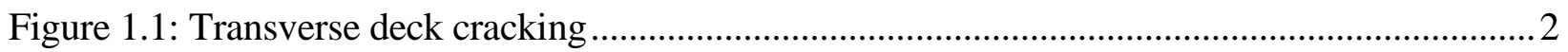

Figure 1.2: Full depth transverse cracking (Radabaugh 2001) ..............................................................

Figure 1.3: Longitudinal cracking (Radabaugh 2001) …….............................................................

Figure 1.4: Map cracking (Radabaugh 2001) ...............................................................................

Figure 1.5: Cracking due to restrained shrinkage (ACI 224R-01) ................................................. 6

Figure 1.6: Stay-in-place forms .............................................................................................

Figure 1.7: Microcell corrosion process of steel reinforcement ............................................................15

Figure 1.8: Macrocell corrosion process of steel reinforcement (Darwin et al. 1985) ....................... 16

Figure 1.9: Application of a gravity feed repair product ...............................................................18

Figure 2.1: US-50 bridge .......................................................................................................... 31

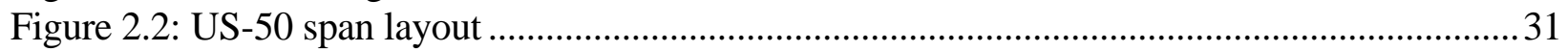

Figure 2.3: Superstructure and deck reinforcement details, Spans B-G...............................................33

Figure 2.4: Superstructure and deck reinforcement details, Spans A, J-T ..........................................34

Figure 2.5: Pour sequence ...................................................................................................... 36

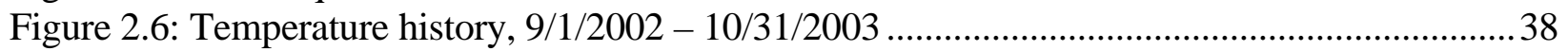

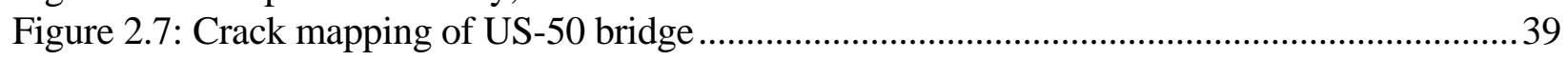

Figure 2.8: Girder span crack pattern (westbound) .............................................................................40

Figure 2.9: Beam span crack pattern (westbound) ..........................................................................40

Figure 2.10: Longitudinal cracking on US-50 bridge ……............................................................4

Figure 2.11: Map cracking on US-50 bridge...............................................................................42

Figure 2.12: Freeze/thaw damage on US-50 bridge.......................................................................4 42

Figure 2.13: Girder span crack pattern (eastbound) .........................................................................4

Figure 2.14: Transverse deck cracking on US-50 bridge..................................................................4

Figure 2.15: Transverse crack on an eastbound beam span.............................................................4

Figure 2.16: Beam span crack pattern (eastbound) ..............................................................................4 48

Figure 2.17: Span F crack pattern, eastbound and westbound.............................................................5

Figure 2.18: Temperature and humidity data, Span F.....................................................................55

Figure 2.19: Span K crack pattern, eastbound and westbound ...........................................................56

Figure 2.20: Temperature and humidity data, Span K .......................................................................57

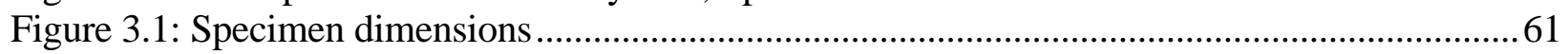

Figure 3.2: Variable Cure 1 timeline ..........................................................................................63

Figure 3.3: Variable Cure 2 timeline ...........................................................................................63

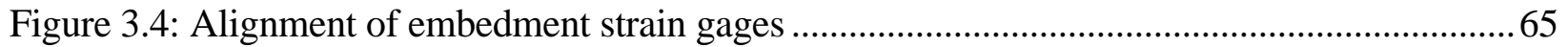

Figure 3.5: Concrete formwork and embedment strain gage.............................................................65

Figure 3.6: Strength gain curve.............................................................................................69

Figure 3.7: Specimen formwork .............................................................................................. 70

Figure 3.8: Testing frame....................................................................................................... 71

Figure 3.9: Concrete casting timeline ........................................................................................ 72

Figure 3.10: Aligning of concrete embedment gages ....................................................................... 73

Figure 3.11: Humidity-controlled room .......................................................................................... 75

Figure 3.12: Early age shrinkage and temperature........................................................................... 78

Figure 3.13: Early age shrinkage behavior .................................................................................

Figure 3.14: Early age shrinkage behavior (Specimen C-7) ................................................................ 82 


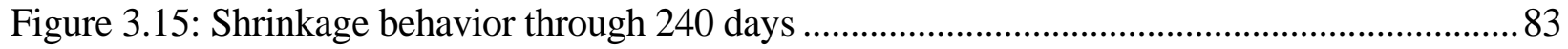

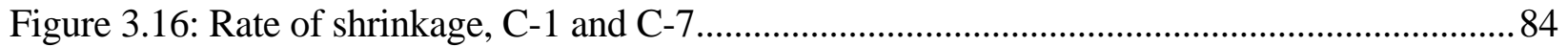

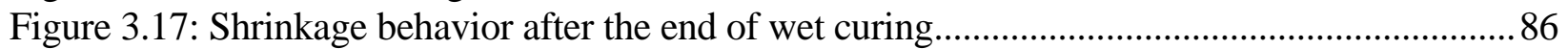

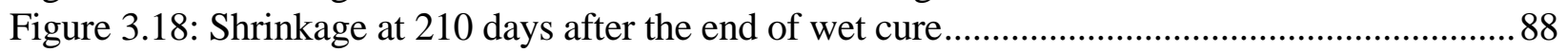

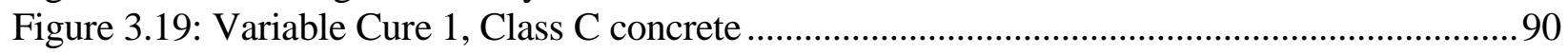

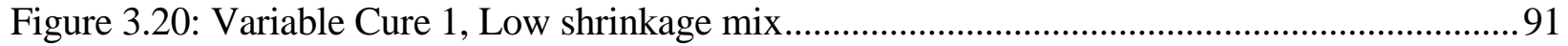

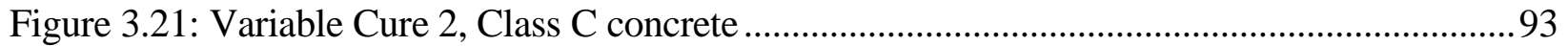

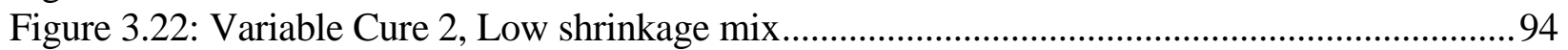

Figure 3.23: Influence of concrete mix on shrinkage..............................................................97

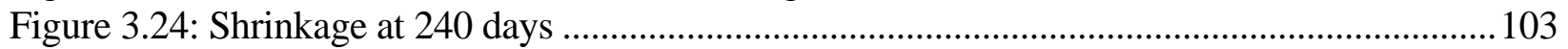

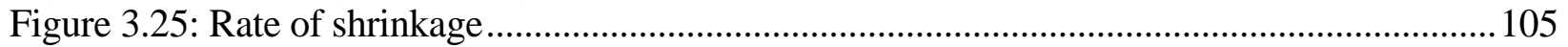

Figure 3.26: Rate of shrinkage (zeroed 1 day before end of wet cure) .........................................106

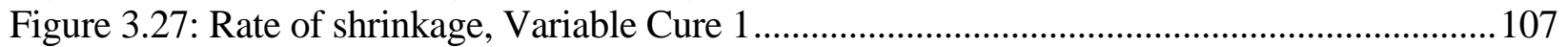

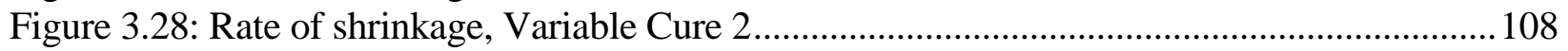

Figure 3.29: Internal temperature, continuously wet cured specimens .......................................110

Figure 3.30: Internal temperature, Variable Cure 1 specimens ...................................................111

Figure 3.31: Internal temperature, Variable Cure 2 specimens .................................................112

Figure 3.32 : Shrinkage behavior through 545 days (Class C concrete) ........................................114

Figure 3.33: Shrinkage behavior through 545 days (Low shrinkage concrete) ............................. 115

Figure 3.34: Rate of shrinkage, C-1 and C-7 ........................................................................ 117

Figure 3.35: Shrinkage at 518 days after the end of wet cure....................................................118

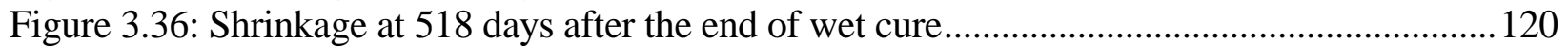

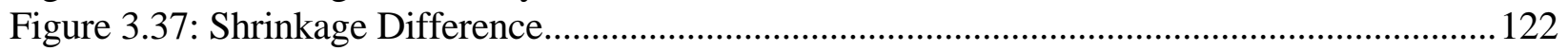

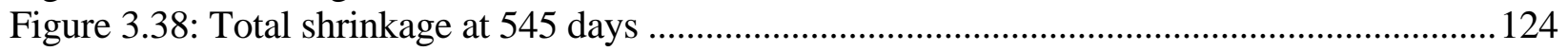

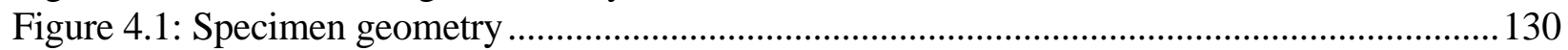

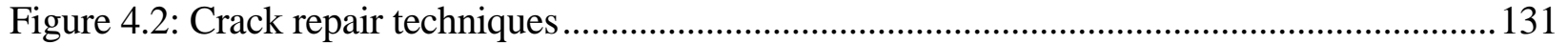

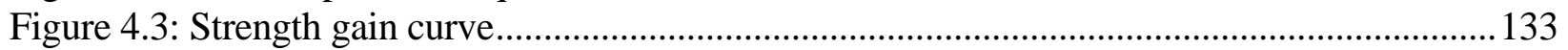

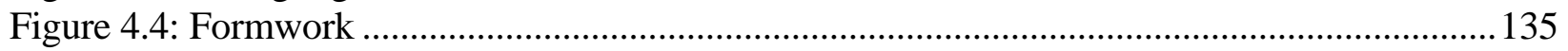

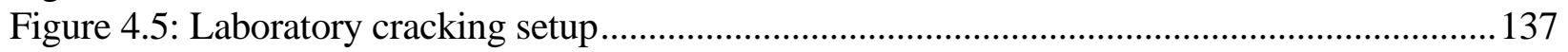

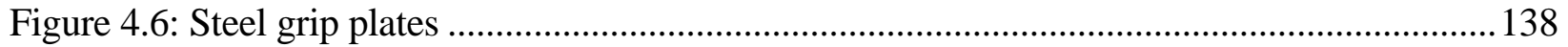

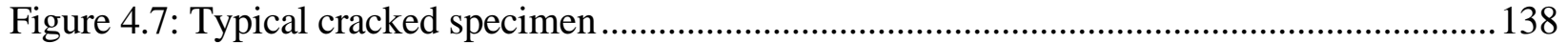

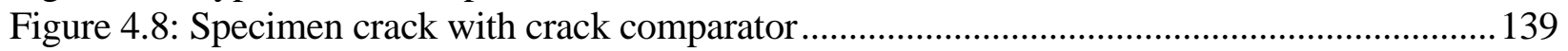

Figure 4.9: Field application of a pretreatment stripe .............................................................. 140

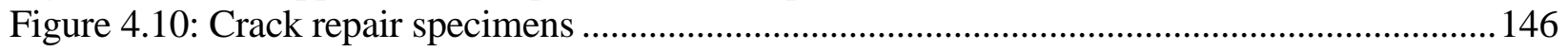

Figure 4.11: Macrocell corrosion test electrical connections .................................................147

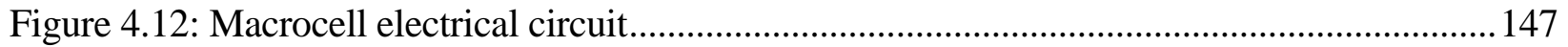

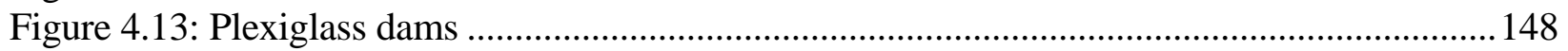

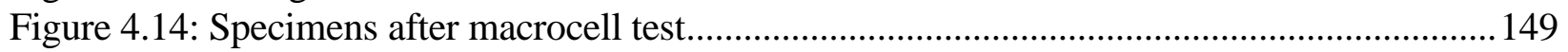

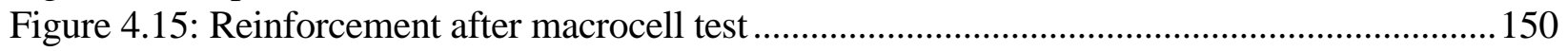

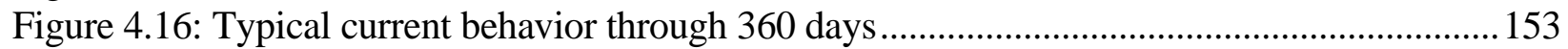

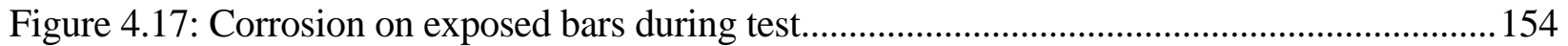

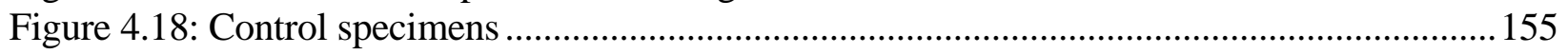

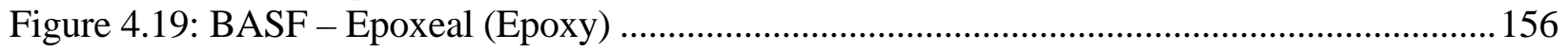

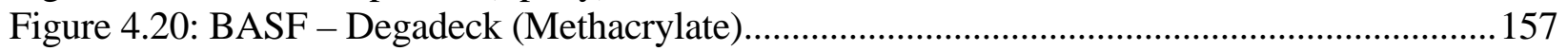

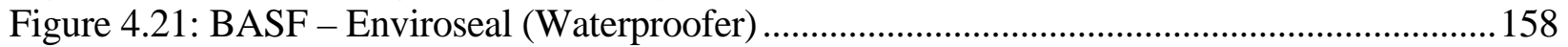

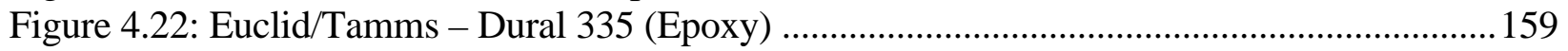


Figure 4.23: Euclid/Tamms - Dural 50 (Epoxy).........................................................................160

Figure 4.24: Euclid/Tamms - Dural 50 LM (Epoxy) …………………………………..................161

Figure 4.25: Fox Industries - FX 770 HM LV (Epoxy) ……………………………………….......162

Figure 4.26: Fox Industries - FX 821 MMA (Methacrylate) …………………………………..........163

Figure 4.27: Kaufman Products - SurePoxy HMSLV (Epoxy) …………………………………........164

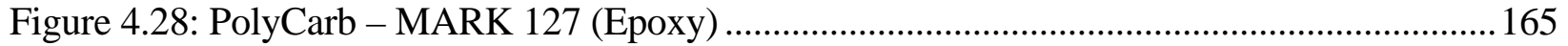

Figure 4.29: PolyCarb - MARK 135 Safe-T-Seal (Epoxy)..............................................................166

Figure 4.30: PolyCarb - MARK 163 FlexoGrid (Epoxy Overlay) .......................................................167

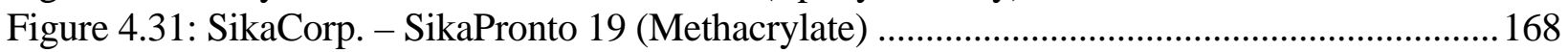

Figure 4.32: SikaCorp. - Sikadur 55 SLV (Epoxy) ....................................................................169

Figure 4.33: Unitex Chemicals - Bridge Seal (Epoxy) ....................................................................170

Figure 4.34: Unitex Chemicals - ProPoxy Type III D.O.T. (Epoxy Overlay) ..................................171

Figure 4.35: No Repair 1 - Small Cracks...................................................................................... 172

Figure 4.36: No Repair 2 - Medium Cracks ................................................................................. 173

Figure 4.37: No Repair 3 - Large Cracks..................................................................................174

Figure 4.38: Total corrosion of repair products............................................................................175

Figure 4.39: Corrosion on bottom bars, Enviroseal (Waterproofer) ……………………………......176

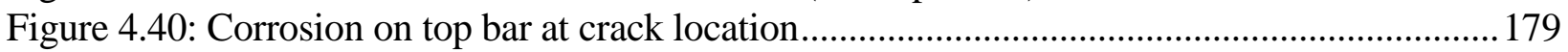

Figure 4.41: Assessment Average of repair products ......................................................................180

Figure 4.42: Viscosity vs. Assessment Ranking ............................................................................186

Figure 4.43: Tensile Strength vs. Assessment Ranking .................................................................186

Figure 4.44: Tensile Elongation vs. Assessment Ranking..................................................................187

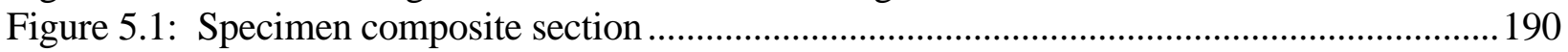

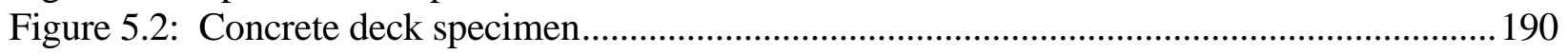

Figure 5.3: Shear stud spacing .............................................................................................191

Figure 5.4: Preformed crack location .........................................................................................192

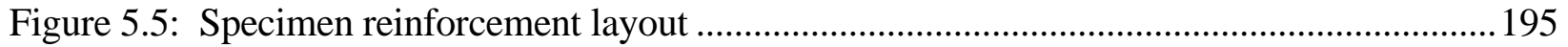

Figure 5.6: Connection between steel girder and support..................................................................197

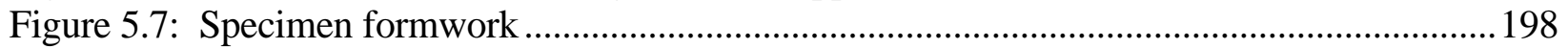

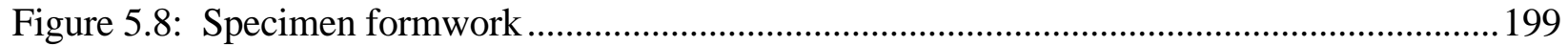

Figure 5.9: Reinforcing steel and plexiglass sheet ...................................................................20

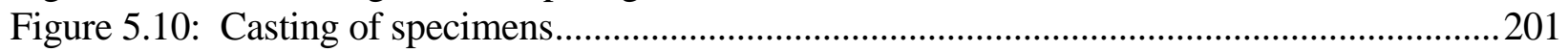

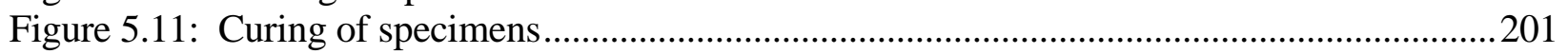

Figure 5.12: Timeline between casting and formwork removal.....................................................220

Figure 5.13: Strength gain curve for concrete (compressive cylinder test)....................................204

Figure 5.14: Strength gain curve for concrete (split cylinder test) ..................................................220

Figure 5.15: Reinforcement tensile strength (\#4 bar) ....................................................................2 205

Figure 5.16: Reinforcement tensile strength (\#5 bar) ......................................................................206

Figure 5.17: Instrumentation layout, Specimen 1 ………............................................................2.

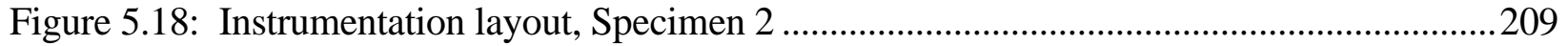

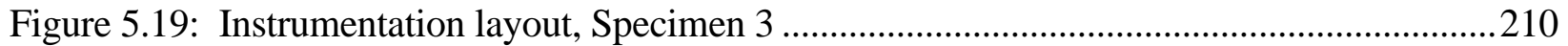

Figure 5.20: Instrumentation layout, Specimen 4 ………..........................................................2. 211

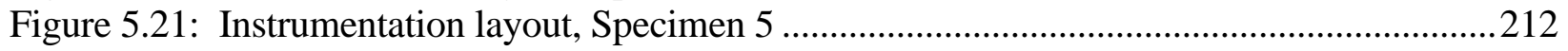

Figure 5.22: Instrumentation layout, Specimen 6 …………………………………….............213

Figure 5.23: Strain gages at midspan.......................................................................................2215

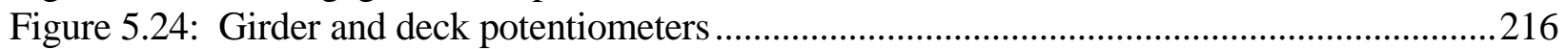


Figure 5.25: Typical early age strain behavior (Specimen 1) ..................................................218

Figure 5.26: Ambient and deck temperature (first week) .......................................................219

Figure 5.27: Ambient and deck temperature ...........................................................................219

Figure 5.28: Top longitudinal reinforcing steel strain..............................................................222

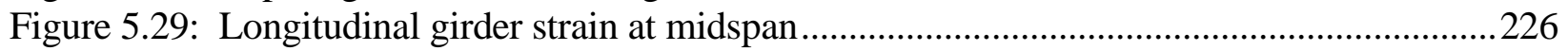

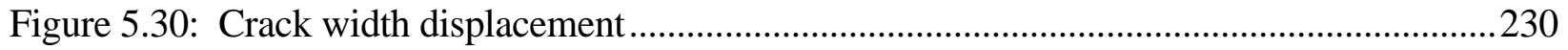

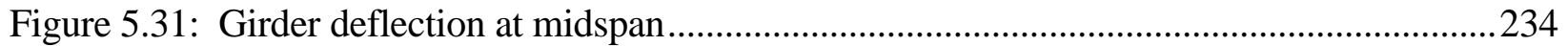

Figure A.1: Technical Data Sheet: SikaPronto 19 TF, SIKA Corp..............................................263

Figure A.2: Technical Data Sheet: Sikadur 55 SLV, SIKA Corp. ..............................................265

Figure A.3: Technical Data Sheet, Mark-127, Poly Carb, Inc....................................................267

Figure A.4: Technical Data Sheet, Mark-135 SAFE-T-SEAL, Poly Carb, Inc. ...........................269

Figure A.5: Technical Data Sheet, Epoxeal GS Structural, BASF ............................................271

Figure A.6: Technical Data Sheet, Degadeck Crack Sealer Plus, BASF .....................................2274

Figure A.7: Technical Data Sheet, Enviroseal 40, BASF .........................................................2. 277

Figure A.8: Technical Data Sheet, Dural 335, Euclid Chemical ...................................................280

Figure A.9: Technical Data Sheet, Dural 50, Euclid Chemical ...................................................282

Figure A.10: Technical Data Sheet, Dural 50 LM, Euclid Chemical..........................................284

Figure A.11: Technical Data Sheet, SurePoxy HMSLV, Kaufman Products, Inc.........................286

Figure A.12: Technical Data Sheet, FX-770 HM LV, Fox Industries .........................................28

Figure A.13: Technical Data Sheet, FX-821 MMA, Fox Industries ............................................290

Figure A.14: Technical Data Sheet, Bridge Seal, Unitex Chemicals ............................................291

Figure A.15: Technical Data Sheet, Mark-163 FLEXOGRID, Poly-Carb, Inc............................295

Figure A.16: Technical Data Sheet, Pro-Poxy Type III D.O.T., Unitex Chemicals.......................301

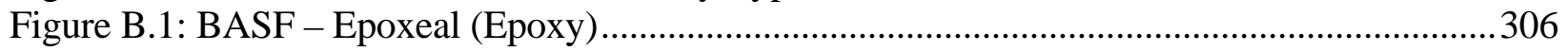

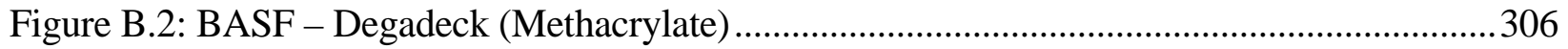

Figure B.3: BASF - Enviroseal (Waterproofer) …..........................................................................307

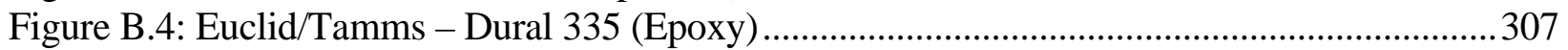

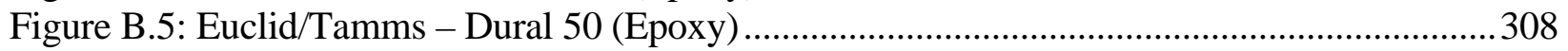

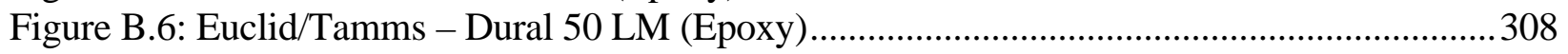

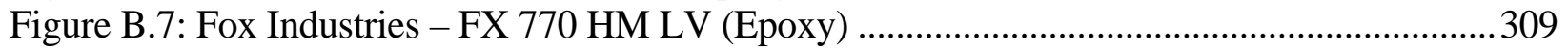

Figure B.8: Fox Industries - FX 821 MMA (Methacrylate) .......................................................309

Figure B.9: Kaufman Products - SurePoxy HMSLV (Epoxy)....................................................310

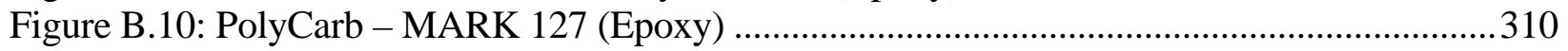

Figure B.11: PolyCarb - MARK 135 Safe-T-Seal (Epoxy) ............................................................311

Figure B.12: PolyCarb - MARK 163 FlexoGrid (Epoxy Overlay) ...............................................311

Figure B.13: SikaCorp. - SikaPronto 19 (Methacrylate)...........................................................312

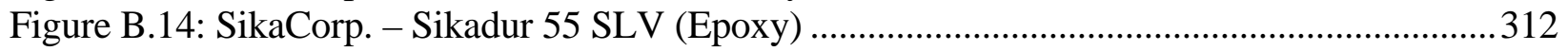

Figure B.15: Unitex Chemicals - Bridge Seal (Epoxy) ...............................................................313

Figure B.16: Unitex Chemicals - ProPoxy Type III D.O.T. (Epoxy Overlay)...............................313

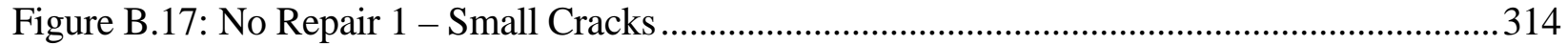

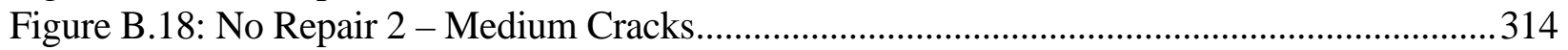

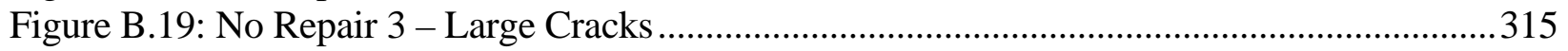




\section{CHAPTER 1 INTRODUCTION}

\section{$\underline{1.1 \text { Introduction }}$}

Cracking of bridge decks poses a significant threat to the lifespan of our nation's bridges. A survey of 52 transportation agencies identified more than 100,000 bridges across the United States that have exhibited early age bridge deck cracking (Krauss and Rogalla 1996). Cracking has been shown to occur in various climates and geographical areas and can be seen on various types of superstructures. Throughout the state of Indiana, a large number of bridges have exhibited deck cracking, much of which occurred during the early stages after construction. Often these cracks appear before or shortly after opening the bridge to live loads.

Cracks in the deck create a path for water and deicing salts to reach the steel, often leading to corrosion of the reinforcement. Most harmful to the health of the bridge are full depth, transverse cracks, such as those shown in Figure 1.1, which can reach widths of 0.025 in. or larger. These cracks can be problematic because cracks with widths of 0.002 in. or more have been shown to allow the penetration of water and chloride ions to reach the reinforcing steel (Krauss and Rogalla 1996).

Precautionary measures must be taken to control bridge deck cracking and prolong the lifespan of bridges. Construction practices are a significant factor that must be considered. Design of the deck reinforcement is also an important aspect in the control of bridge deck cracking. Both design and construction practices can decrease cracking and help prevent deck deterioration. 


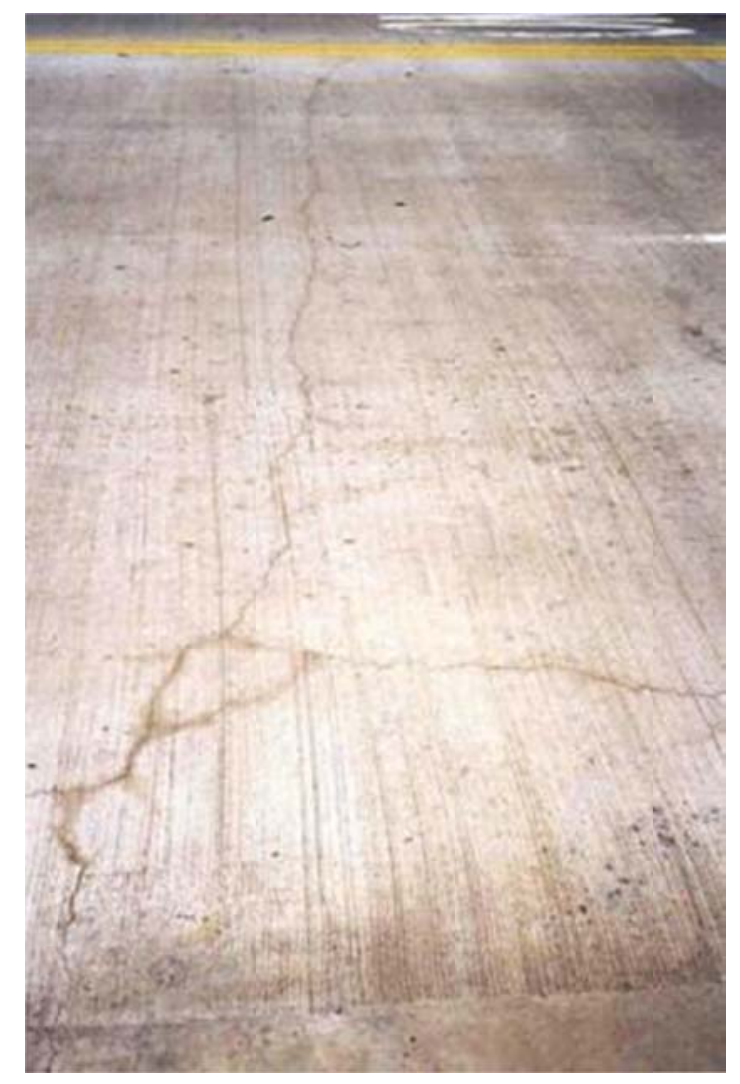

Figure 1.1: Transverse deck cracking

\subsection{Bridge Deck Cracking}

Cracks occur when tensile stresses in the deck, due to effects such as thermal changes, shrinkage, bending, and corrosion, exceed the tensile strength of the concrete. Cracks in bridge decks are typically categorized by their orientation relative to the bridge and are classified as either transverse, longitudinal, or map.

\subsubsection{Transverse Cracking}

Transverse cracks are the most commonly observed type and typically run perpendicular to the bridge girders but may also appear parallel to the skew near the abutments. These cracks are usually full depth (Figure 1.2) and spaced fairly regularly at 3 to 10-ft intervals (Krauss and Rogalla 1996). Cracks widths often exceed 0.002 in. and can reach widths of 0.025 in., leading to an increased probability of water and chloride ion 
penetration. The major cause of transverse cracking has been shown to be restrained shrinkage (Radabaugh 2001).

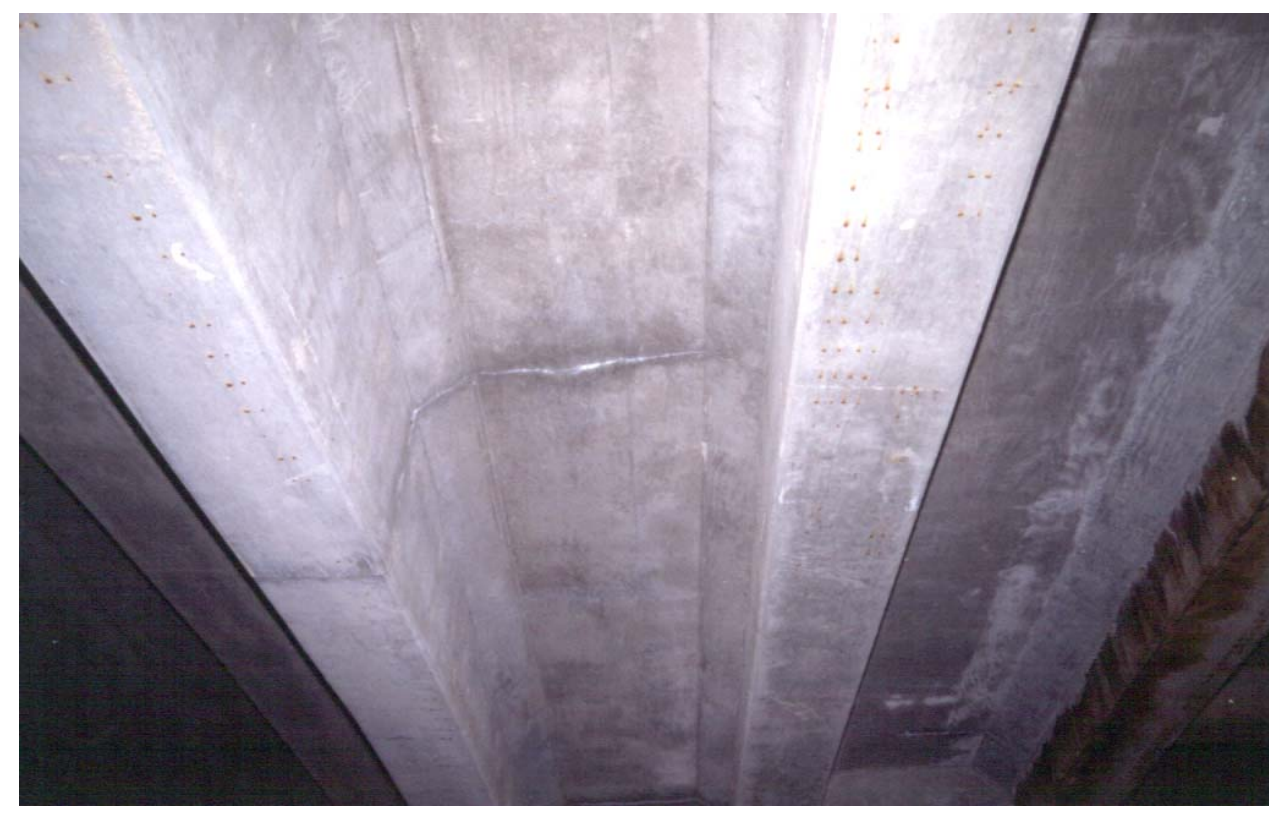

Figure 1.2: Full depth transverse cracking (Radabaugh 2001)

\subsubsection{Longitudinal Cracking}

Longitudinal cracks, an example of which is shown in Figure 1.3, run parallel to the bridge girders and generally form directly above the edges of the girders. This type of cracking in ordinary girder type bridges is thought to be due to the presence of steel angles at these locations that are used to secure stay-in-place metal deck pans and cause a stress concentration (Radabaugh 2001). Longitudinal cracks have also been shown to occur directly above top mat longitudinal reinforcement, likely due to obstructed settlement of the concrete during construction. 


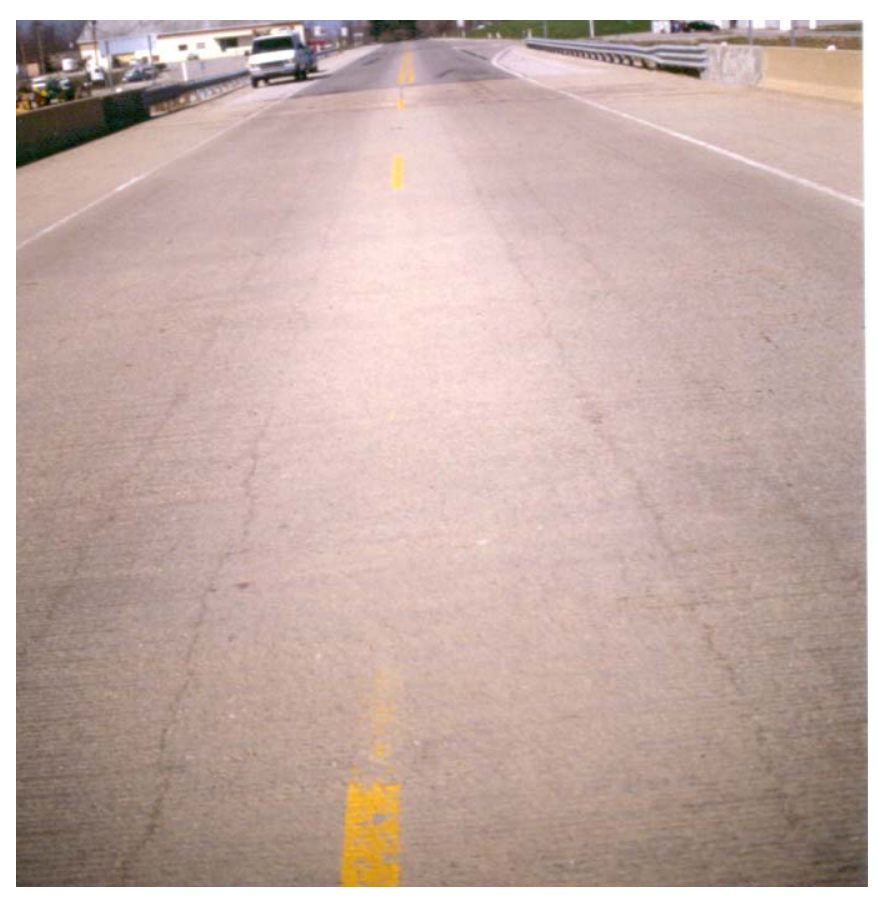

Figure 1.3: Longitudinal cracking (Radabaugh 2001)

\subsubsection{Map Cracking}

Map cracking, also known as pattern cracking, appears in more random locations and directions (Figure 1.4). Map cracks are often attributed to poor construction practices such as drying of the concrete surface during placement and improper curing. They are generally narrow and shallow and are not considered highly problematic (Radabaugh 2001). 


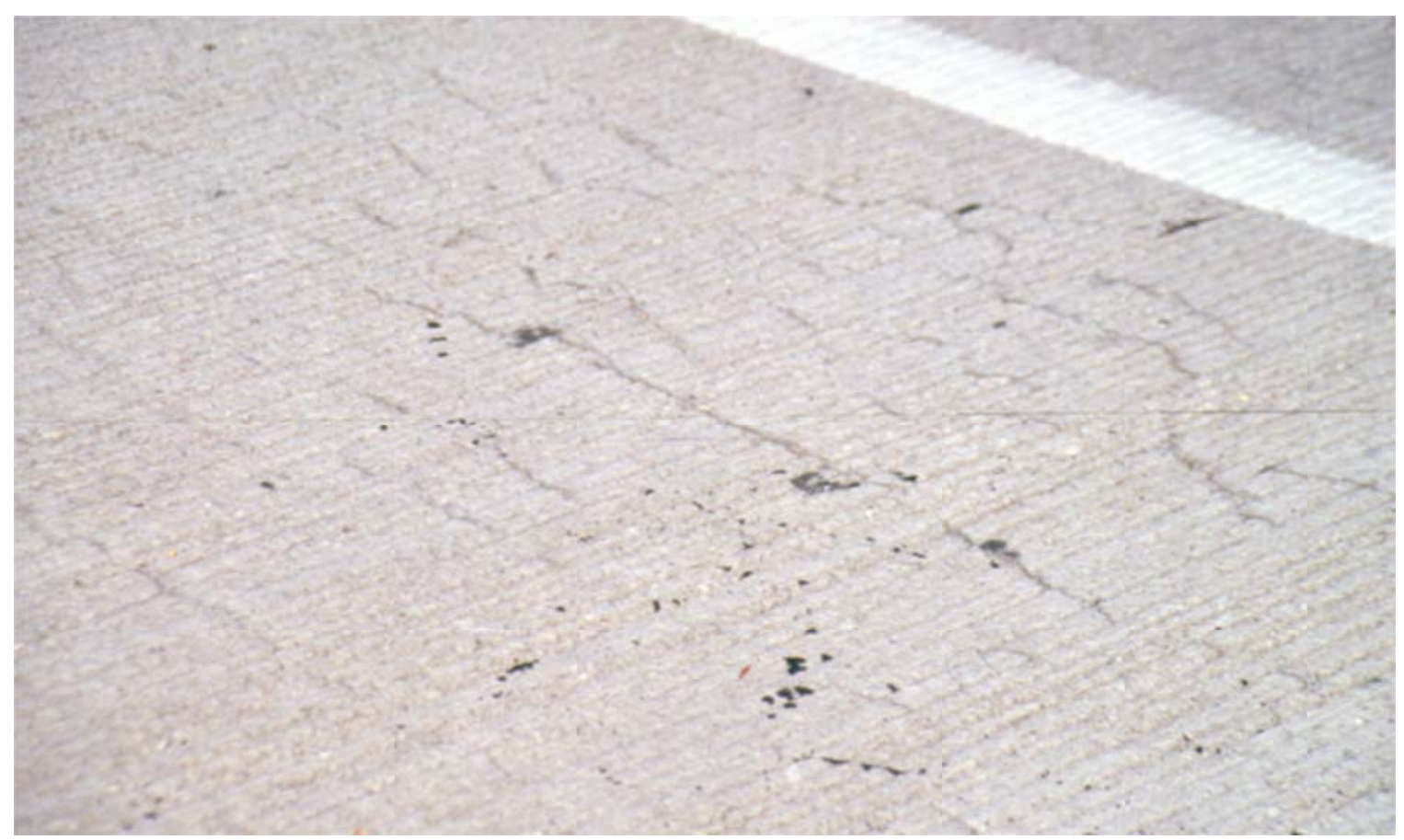

Figure 1.4: Map cracking (Radabaugh 2001)

\subsection{Restrained Shrinkage}

The most important factor causing transverse cracking has been determined to be restrained shrinkage of the bridge deck (Frosch et al. 2003). Because transverse cracks have been observed in bridge decks prior to or shortly after the introduction of live loads, it is unlikely that transverse cracks are caused by traffic loads. A previous study clearly showed no correlation between the onset of transverse cracking and the introduction of live loads (Radabaugh 2001). An analysis of core samples has also shown that the cracks pass through the aggregate, indicating that the cracks did not occur during the plastic phase (Purvis et al. 1995). These observations point to restrained drying shrinkage as the main cause of transverse deck cracking. Figure 1.5 illustrates the concept of cracking caused by restrained shrinkage. 


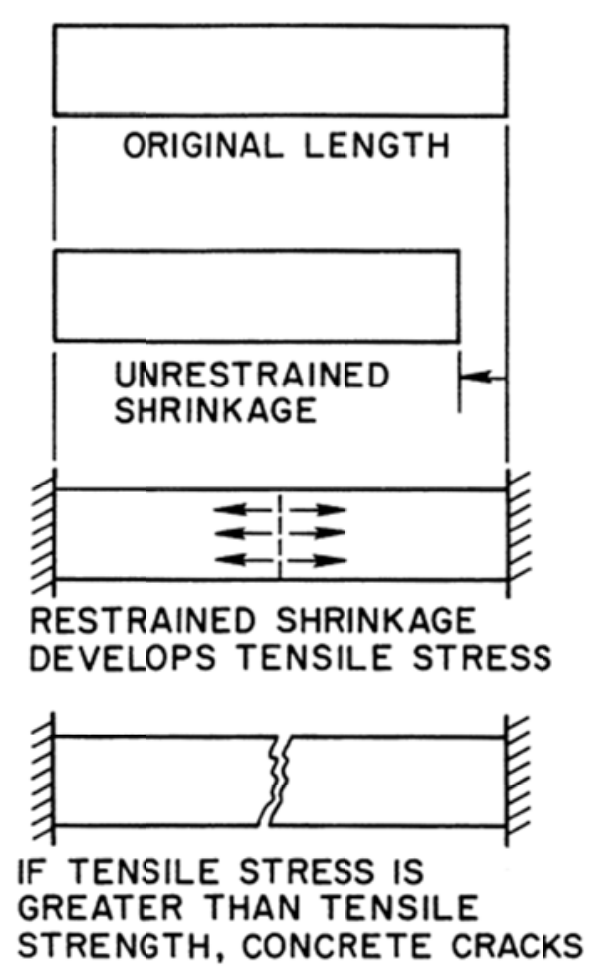

Figure 1.5: Cracking due to restrained shrinkage (ACI 224R-01)

\subsubsection{Concrete Shrinkage}

Shrinkage of concrete is a complex volumetric change caused by a loss of water due to drying (Tia et al. 2005). Thin structures, such as bridge decks, experience high shrinkage due to their large surface area to volume ratio. After placement, concrete undergoes shrinkage due to a number of causes, which are classified as plastic, drying, carbonation, and autogeneous shrinkage.

\subsubsection{Plastic Shrinkage}

Plastic shrinkage occurs when water evaporates from freshly placed concrete. Environmental conditions play a major role in determining the amount of plastic shrinkage that occurs. These conditions include humidity, temperature, and wind speed. Lower humidity, higher temperatures, and higher wind speeds all lead to increased plastic 
shrinkage (Tia et al. 2005). Consequently, proper construction practices and wet curing can significantly decrease the amount of plastic shrinkage.

\subsubsection{Drying Shrinkage}

Drying shrinkage, which occurs during the hardened concrete state and is similar to plastic shrinkage, is the dominant form of shrinkage on typical bridge decks (Radabaugh 2001). When the external humidity is lower than the internal humidity of the concrete, water tends to be drawn to the surface and evaporate. As the water travels to the surface, negative pore pressures develop, which causes a volumetric contraction of the concrete (Tia et al. 2005). Drying shrinkage can be significantly decreased during the period of wet curing. However, once wet curing is stopped, drying shrinkage will initiate.

\subsubsection{Carbonation Shrinkage}

Carbonation shrinkage occurs due to the reaction of hydrated cement with atmospheric carbon dioxide (Tia et al. 2005). This reaction causes concrete on the surface to shrink. Carbonation shrinkage is not significant when compared to plastic and drying shrinkage.

\subsubsection{Autogeneous Shrinkage}

Autogeneous shrinkage occurs due to internal chemical shrinkage and can occur even if the concrete experiences no water loss. This type of shrinkage is rare, only becoming significant when the water-to-cement ratio is less that 0.3 (ACI 224.1R-07). Therefore, when a typical concrete is used, bridge decks are unlikely to experience significant autogeneous shrinkage. However, the increased usage of High Performance Concrete (HPC) may increase this type of shrinkage in the future (Tia et al. 2005). 


\subsubsection{Thermal Volumetric Changes}

The concrete deck can experience volumetric changes due to temperature variations caused by the heat of hydration of fresh concrete or by ambient temperature cycles in its hardened state. As the concrete hydrates, heat is liberated causing the expansion of concrete while gaining strength. The temperature rises to a maximum and declines thereafter until the ambient and concrete temperature coincide. If the set of concrete occurs at the peak temperature, the maximum thermal stresses develop in the hardened concrete when cooling. After concrete set, thermal stresses develop from ambient temperature cycles. If concrete is restrained, volume changes associated with temperature variations can generate cracking.

\subsubsection{Creep Effects on Restraint Shrinkage}

Restrained concrete experiences significant deformation at early ages due to tensile creep (Altoubat and Lange 2001). The creep mechanism reduces the shrinkage stresses that are induced by the restraint of shrinkage. In the study by Altoubat and Lange (2001), it was determined that creep reduces shrinkage stresses by $50 \%$ and delays the time of cracking by two to three times.

\subsubsection{Types of Restraint}

Restrained shrinkage occurs when concrete is not permitted to shrink freely as a result of some type of restraint. Unrestrained shrinkage alone is not harmful to concrete and will not cause cracking; however, bridge decks are not unrestrained. Restraint of concrete bridge decks occurs due to many factors, but the most common type of restraint is composite action of the deck with the superstructure. Other types of restraint that are present in bridge decks include stay-in-place (SIP) forms and internal restraint provided by the reinforcement and the concrete itself. 


\subsubsection{Superstructure}

The identification of restrained shrinkage as the main cause of transverse cracking can be supported by analyzing the presence of transverse cracks on varying superstructures. More transverse cracks have been observed on bridges with steel girder superstructures than on those with concrete superstructures (Radabaugh 2001). While the concrete deck shrinks after placement, the steel girders do not which causes a high level of restraint. Furthermore, more transverse cracks have been observed on bridges incorporating precast girders as compared to cast-in-place girders. Despite the fact that the precast girders will experience shrinkage, a significant portion of the shrinkage occurs before the casting of the deck. Therefore, precast girders will shrink significantly less than the deck and provide significant restraint. Cast-in-place girders, especially those cast concurrently with the deck, shrink along with the deck and therefore provide less restraint.

\subsubsection{Stay-in-Place Forms}

The use of SIP forms during construction of bridge decks has been shown to increase transverse cracking by adding restraint to the deck and creating a phenomenon known as differential shrinkage (Blackman, 2002). SIP forms, such as those shown in Figure 1.6, are economical as compared to wood forms and are therefore commonly used in construction of concrete bridge decks (Radabaugh 2001). However, unlike wood forms, SIP forms are not removed after construction. Because SIP forms seal the bottom of the deck, a moisture gradient is created as water is permitted to evaporate from the top only. Therefore, the top of the deck tends to shrink more than the bottom. This differential shrinkage causes the deck to curl, which is resisted by the composite action of the deck and the superstructure (Frosch et al. 2003). Restrained curling introduces higher stresses in the upper portion of the deck than would otherwise be observed due to shrinkage alone (Krauss and Rogalla 1996). These effects can result in an increased potential for cracking. 


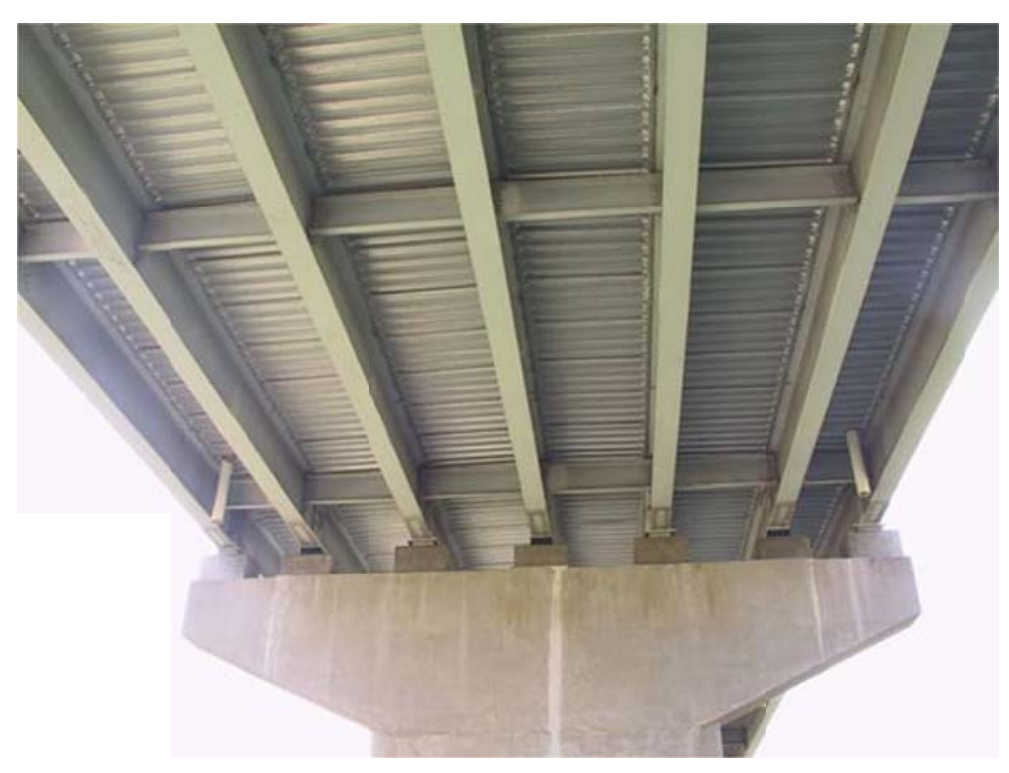

Figure 1.6: Stay-in-place forms

\subsubsection{Internal Restraint}

Internal restraint, due to the deck reinforcement and the concrete itself, is another factor affecting restrained shrinkage. The presence of deck reinforcement is an important type of restraint that often leads to early age cracking. Once the cracks are initiated, however, the deck reinforcement will limit crack widths.

The deck itself also provides a form of internal restraint which resists shrinkage. Lower surface area to volume ratios cause increased internal restraint as exposed surfaces tend to shrink more than internal sections (French et al. 1999). In cases of low surface area to volume ratios, internal shrinkage has been shown to cause cracking without external restraint. However, bridge decks typically are thin enough, with high enough surface area to volume ratios, that internal restraint is not a major factor in restrained shrinkage.

\subsection{Factors Affecting Deck Cracking}

Several factors affect in different ways the process in which cracks are formed in bridge decks. These factors are classified as material properties, design practices and 
construction practices. All of these aspects influence early age cracking by affecting concrete volumetric changes and the restraint provided.

\subsubsection{Material Properties}

In a concrete mix design, different variables affect the magnitude of concrete shrinkage. The main parameters considered are cement content and type, water to cement ratio, aggregate properties, and the addition of admixtures.

Higher strength concretes experience more shrinkage because more cement paste is required. Increased paste increases the amount of shrinkage. Finer cements and higher cement contents also produce higher temperatures from the heat of hydration, leading to more thermal contraction. Fast setting concrete mixtures tend to shrink more than normal concrete due to high early heat of hydration, while shrinkage compensating cements reduce shrinking significantly.

If the cement content is not varied, a higher water to cement ratio increases concrete shrinkage. Furthermore, weaker concrete develops as a result of the extra water, increasing the potential for cracking.

Aggregates provide restraint to the shrinkage of the cement paste. Therefore, a concrete is less susceptible to shrinkage with higher aggregate contents and larger aggregate sizes. Quality aggregates with a high modulus of elasticity help reduce shrinkage. A well graded aggregate will also help minimize shrinkage.

Admixtures used in concrete can improve the cracking performance of concrete. The effect depends on the type of admixture applied. Those that reduce the cracking tendency of concrete are water reducers and retarders. Accelerators and silica fume tend to increase the heat of hydration causing higher volumetric contraction. Air entrainment is useful to protect the deck from freeze-thaw cycles and for reducing the water content of concrete, without modifying its workability. Fly ash is another admixture that can reduce shrinkage by decreasing the amount of water in the mixture (Tia et al. 2005). It also can be used to reduce the amount of cement and reduce the heat of hydration. 


\subsubsection{Design Practices}

Structural design can significantly affect the tendency of cracking of a bridge deck. Parameters such as deck thickness, reinforcement amount and configuration, and the degree of restraint of the structural elements can influence deck performance.

\subsubsection{Shrinkage and Temperature Reinforcement}

The durability of bridge decks is highly affected by the width of cracks since water and deicing salts can penetrate into the deck, leading to corrosion of the reinforcement. After cracking, crack widths are controlled and limited by the longitudinal deck reinforcement. Shrinkage strains are distributed along the reinforcement to allow the formation of a large number of narrow cracks instead of a small number of wide cracks (ACI 224R-01). If the deck is over-reinforced, narrow cracks will form. However, if the deck is under-reinforced, the reinforcement will yield until shrinkage strains are distributed within the crack width, causing larger crack spacing and widths. Generally, deck cracks form halfway between other cracks or joints, where the tensile stresses of concrete are higher.

Different provisions and recommendations have been specified as presented in Table 1.1 to control crack widths caused by shrinkage and temperature. This table includes the required minimum amounts of reinforcement and maximum bar spacing. It should be noted that AASHTO and ACI provide minimum shrinkage and temperature reinforcement amounts for general structural elements. However, the ACI 224 amount is for the specific case of restrained shrinkage and the Frosch et al. $(2003,2006)$ amounts are specific to restrained shrinkage of bridge decks. 
Table 1.1: Shrinkage and temperature reinforcement requirements

\begin{tabular}{|c|c|c|c|c|c|}
\hline & $\begin{array}{l}\text { AASHTO } \\
1^{\text {th }} \text { Ed. }\end{array}$ & $\begin{array}{c}\text { AASHTO } \\
\text { (LRFD) } 3^{\text {rd Ed. }}\end{array}$ & $\begin{array}{c}\text { ACI } \\
318-08\end{array}$ & $\begin{array}{c}\text { ACI } \\
224 R-01\end{array}$ & $\begin{array}{c}\text { Frosch et al. } \\
\text { 2003, } 2006\end{array}$ \\
\hline $\begin{array}{l}\text { Minimum } \\
\text { Area }\end{array}$ & $\geq 1 / 8 \mathrm{in}^{2} / \mathrm{ft}$ & $\geq 0.11\left(\mathrm{~A}_{\mathrm{g}} / \mathrm{f}_{\mathrm{y}}\right)$ & $\geq 0.0018 \mathrm{bh}$ & $\geq 0.006 \mathrm{bh}$ & $\geq($ Eq. 1.1) \\
\hline Spacing & $\begin{array}{l}\leq 3 \mathrm{~h} \\
\leq 18\end{array}$ & $\begin{array}{l}\leq 3 \mathrm{~h} \\
\leq 18\end{array}$ & $\begin{array}{l}\leq 5 \mathrm{~h} \\
\leq 18\end{array}$ & $\begin{array}{c}\text { Not } \\
\text { Available }\end{array}$ & $\leq$ (Eq. 1.2) \\
\hline
\end{tabular}

$$
A_{s}=\frac{6 \sqrt{f^{\prime}}}{f_{y}} b h \rightarrow 0.0063 b h \quad \text { for } \mathrm{f}^{\prime}{ }_{\mathrm{c}}=4,000 \mathrm{psi}
$$

(Eq. 1.1)

$$
\begin{gathered}
\mathrm{f}_{\mathrm{y}}=60,000 \mathrm{psi} \\
s=9 \cdot \alpha_{r}\left[2.5-\frac{d_{c}}{2 \alpha_{r}}\right] \leq 9 \cdot \alpha_{r} \rightarrow 9^{\prime \prime} \quad \text { for } \mathrm{f}_{\mathrm{y}}=60,000 \mathrm{psi}
\end{gathered}
$$

(Eq. 1.2)

where:

$$
\mathrm{d}_{\mathrm{c}}=3 \text { in. }
$$

$$
\begin{aligned}
d_{c} & =\text { clear cover } \\
\alpha_{r} & =\frac{60}{f_{y}}
\end{aligned}
$$

As noted in Eq. 1.1 and Eq. 1.2, simplified expressions are provided for typical values used in bridge decks: compressive strength of 4,000 psi, Grade 60 steel and concrete cover of 3 ".

The maximum crack width in a bridge deck can be estimated by the following expression as proposed by Frosch et al. (2006) as:

$$
w=\frac{135}{E_{r}} \gamma \sqrt{\frac{f_{c}^{\prime}}{\rho_{g}}} \sqrt{d_{c}^{2}+\left(\frac{s}{2}\right)^{2}}
$$

where:

$$
\begin{aligned}
w & =\text { crack width, in. } \\
E_{r} & =\text { reinforcement modulus of elasticity, psi }
\end{aligned}
$$




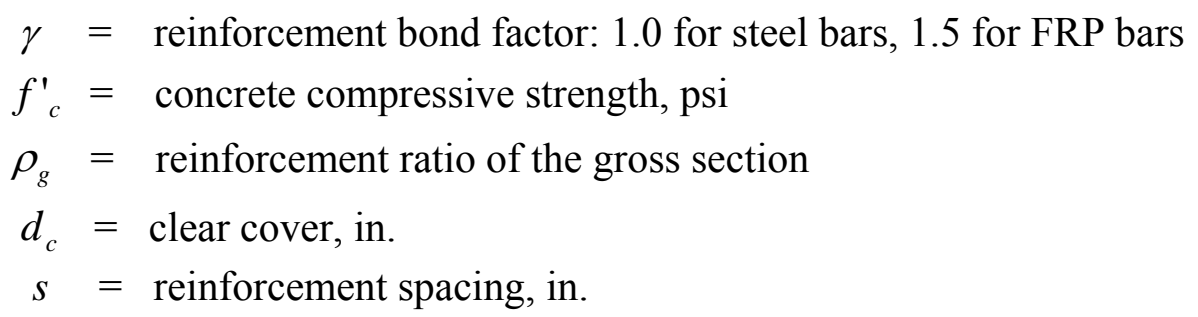

Transverse reinforcement also affects bridge deck cracking. This reinforcement can increase stresses by reducing the concrete cross section. Therefore, it is beneficial to use the minimum transverse bar size and spacing (NCHRP 2004).

\subsubsection{Construction Practices}

During placement of concrete, weather conditions can significantly increase the tendency of cracking in bridge decks. Temperatures below $40^{\circ} \mathrm{F}$ during wet curing can delay the development of concrete strength. (Mindess et al. 2003). The potential of cracking will increase if concrete is placed during temperatures above $90^{\circ} \mathrm{F}$, high wind speeds, and low relative humidity. Moisture evaporation can be reduced by the use of windbreaks and fogging equipment (NCHRP 2004).

Proper wet curing can reduce plastic shrinkage and delay drying shrinkage of the concrete deck. During curing, the tensile strength of concrete increases while experiencing little to no shrinkage. As a result, the concrete is able to gain sufficient strength to resist stresses induced by restrained shrinkage and prevent deck cracking. Some of the methods employed for wet curing are the use of sprinklers, covering the deck with wet burlap and plastic sheeting, and ponding water on the deck.

\subsection{Corrosion of Steel Reinforcement}

Corrosion of a metal is caused by an electrochemical process that occurs in the presence of moisture or an oxidizing agent. A high alkaline environment, generally provided by concrete in normal conditions, will not initiate corrosion of steel reinforcement (Mindess et al. 2003). In a high alkaline environment, the steel reinforcement develops a passive oxide coating which provides protection against corrosion. Corrosion initiates when this passive film is destroyed by a reduction of the 
alkalinity of concrete because of carbonation or more importantly, by aggressive ions such as chlorides. As shown in

Figure 1.7, an oxidation reaction occurs at the anode, where ions $(2 \mathrm{Fe}++)$ go into the solution and form iron oxides in the presence of water. The electrons released travel from the anode to the cathode through the reinforcing steel. At the cathode, a reduction reaction occurs in the presence of moisture and oxygen. As a result, hydroxide ions $\left(\mathrm{COH}^{-}\right)$move between the cathode and the anode through the moist concrete (electrolyte). This corrosion cycle continues as long as moisture and oxygen are present for reactions to occur. The overall rate of corrosion is controlled by the reactions at the cathode (Darwin et al. 1985). From the corrosion process, steel is transformed into iron oxides and hydroxides which are larger in size than the original steel. The greater volume causes tensile stresses that can lead to cracking of concrete when the tensile strength is exceeded. Furthermore, there is a reduction in the volume of steel at the location of the anode. Microcell corrosion occurs when the active corrosion and cathodic reaction are located at adjacent parts of the steel bar as shown in

Figure 1.7. As illustrated in Figure 1.8, macrocell corrosion occurs when the actively corroding steel bar is connected to another passive bar, which undergoes less or no corrosion at all, by vertical reinforcement or supporting elements such as reinforcement chairs. Macrocell corrosion is the main cause of corrosion in bridge decks.

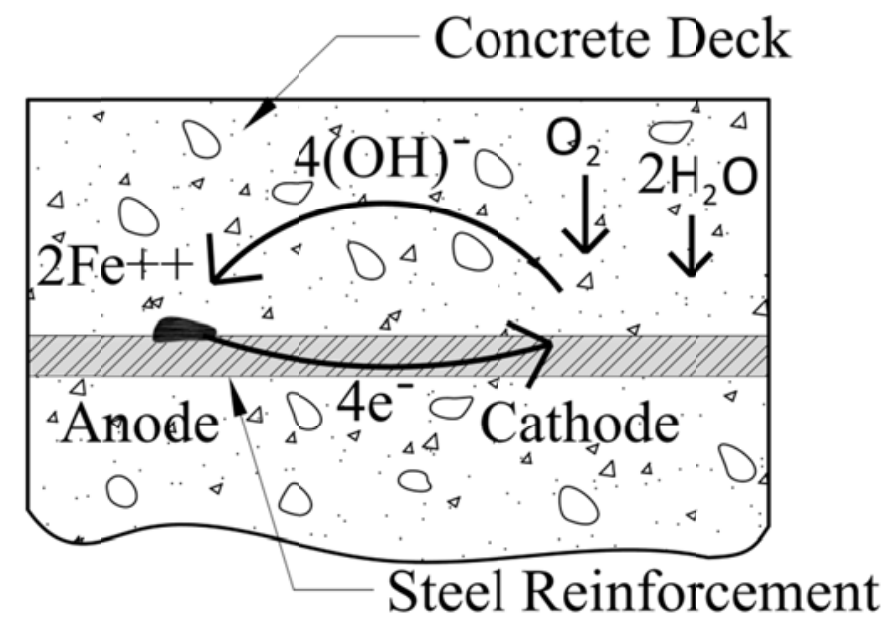

Figure 1.7: Microcell corrosion process of steel reinforcement 


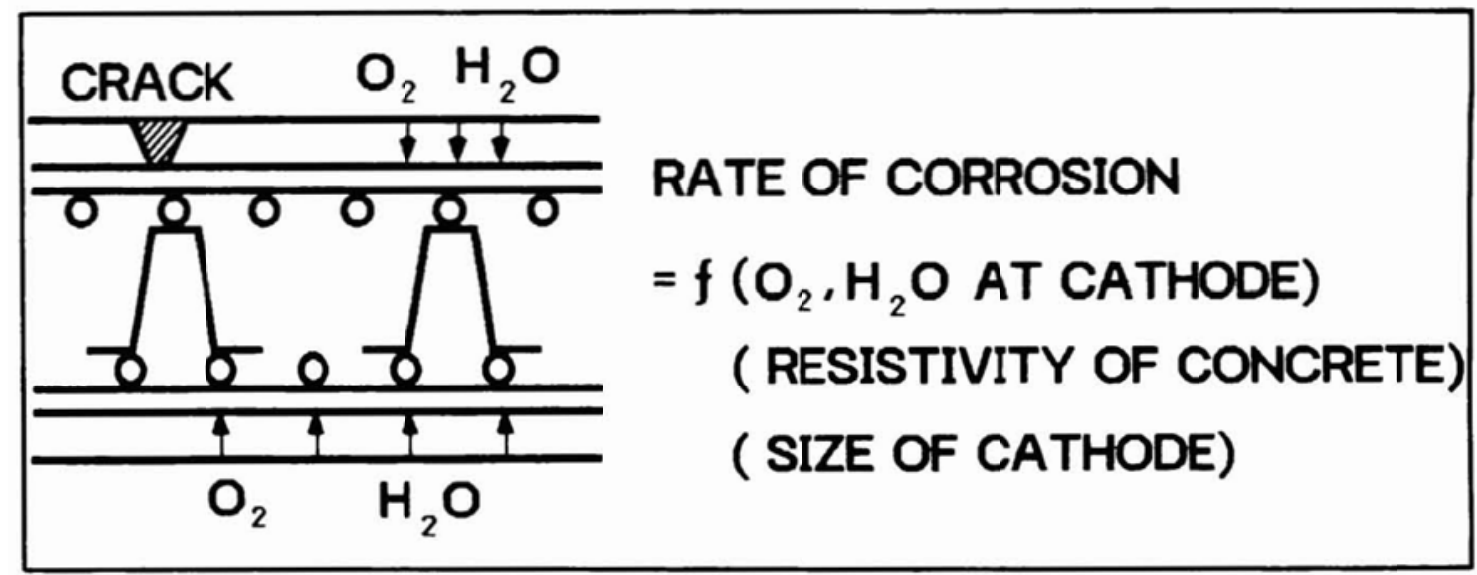

Figure 1.8: Macrocell corrosion process of steel reinforcement (Darwin et al. 1985)

Bridge deck cracking allows water, oxygen, and deicing salts to penetrate into the concrete, accelerating the process of corrosion and cracking of the deck. Therefore, it is important that the longitudinal reinforcement control and limit the width of cracks. ACI 224R-01 provides maximum crack widths that are recommended according to exposure conditions (Table 1.2).

Table 1.2: Maximum crack widths, ACI 224R-01 recommendation

\begin{tabular}{|c|c|}
\hline Exposure condition & $\begin{array}{c}\text { Maximum } \\
\text { crack width (in.) }\end{array}$ \\
\hline Dry air or protective membrane & 0.016 \\
\hline Humidity, moist air, soil & 0.012 \\
\hline Deicing chemicals & 0.007 \\
\hline Seawater and seawater spray, wetting and drying & 0.006 \\
\hline Water-retaining structures & 0.004 \\
\hline
\end{tabular}

Cracks that develop along the reinforcing bar can cause more corrosion than transverse cracks due to the larger area of exposure of the bar to moisture, oxygen and chlorides (NCHRP 2004). The use of low permeability concretes and adequate covers can improve the reinforcement protection against corrosion. Deck durability can also be increased by the use of FRP or epoxy-coated reinforcement. However, these two options 
can significantly affect the width of cracks. Epoxy coating can increase crack widths up to $70 \%$ when compared to black bars (Frosch et al. 2003). Crack widths must be scaled 1.5 times to consider the additional slip between the FRP reinforcement and concrete (Frosch et al. 2006).

\subsection{Repair of Bridge Deck Cracking}

Regardless of the design and construction practices implemented to reduce bridge deck cracking, it is not possible to completely eliminate it. Further, these practices can only be implemented to control cracking of newly constructed bridges. Therefore, there is a need to develop effective methods to repair cracks in existing bridge decks to increase the durability of the deck.

A variety of products have been used on bridge decks across the United States for the purpose of crack repair with varying results due to a wide range of field conditions and product quality. Some of the parameters affecting the performance of crack repair include the viscosity and bond strength of the product, as well as the quality of the repair. Field conditions affecting crack repair performance include crack width, temperature, and humidity.

\subsubsection{Types of Crack Repair Products}

Various types of products exist that are designed to repair cracks in bridge decks. These include injection repair, gravity feed repair, routing and sealing, and overlay systems (ACI 224 2007). The type of repair selected is based on the condition of the bridge, the cause of the cracking, and cost.

\subsubsection{Epoxy Injection}

Epoxy injection is a repair method best suited to cracks that are no longer active such as those due to early age shrinkage (ACI 224 2007). High-strength, low-viscosity epoxy is pressure injected into the crack. When hardened, the epoxy has a bond strength 
higher than the tensile strength of concrete. For a deck with active cracking, epoxy injection is only a temporary solution, as a crack is likely to form elsewhere. In the case of dormant cracks, epoxy injection is highly effective. Despite its effectiveness as a crack sealant, epoxy injection requires a high degree of technical skill and is labor intensive. In addition, injecting cracks individually increases the chances of some cracks being missed.

\subsubsection{Gravity Feed Repair}

Gravity feed repair can be accomplished with a number of materials including epoxy, high molecular weight methacrylates (HMWM), and urethanes. The product is spread evenly across the entire surface and fills the cracks wherever they are present. In some instances, a pre-treatment is applied in which the product is pooled over easily visible cracks prior to being broadcast on the rest of the deck surface (Figure 1.9). Gravity feed repair is a relatively easy process and, because the product is spread across the entire deck, eliminates the possibility of missing cracks (ACI 224 2007).

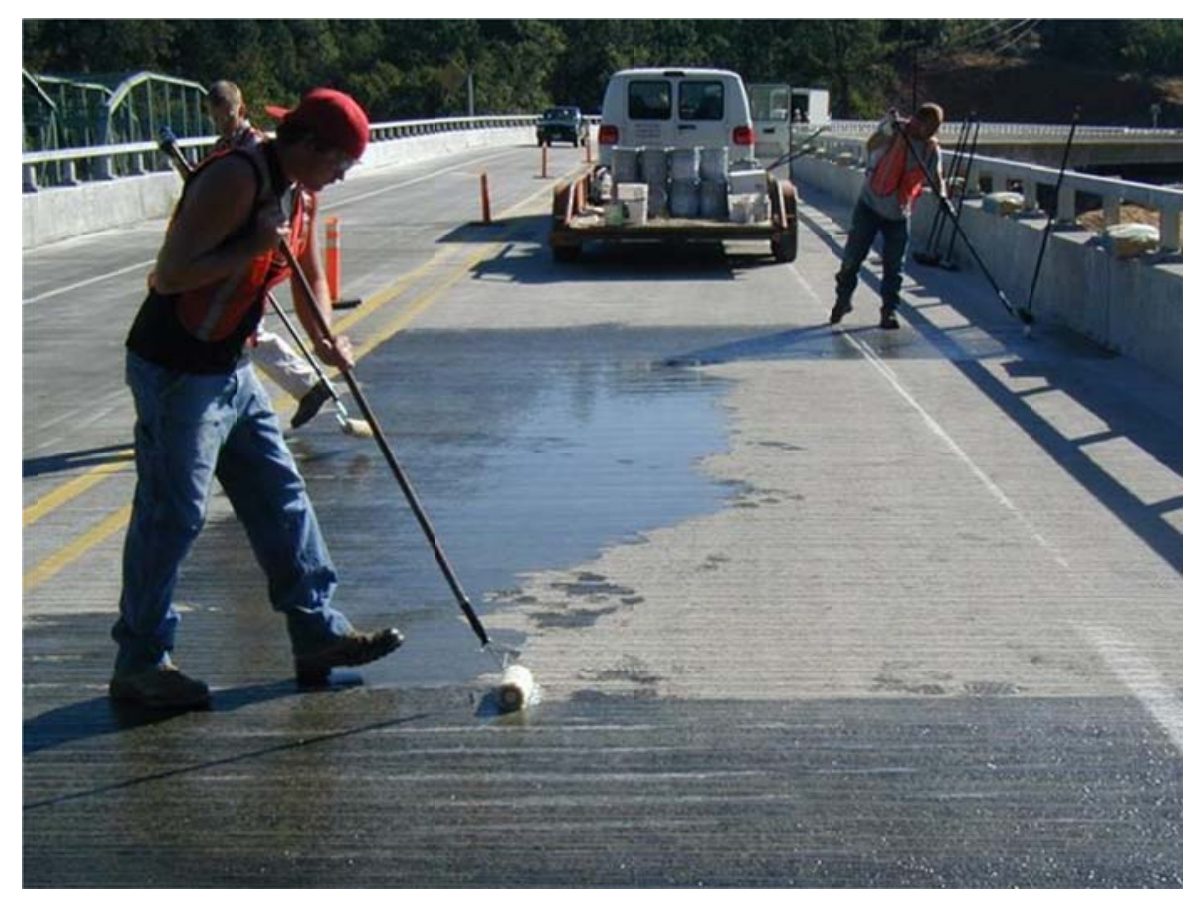

Figure 1.9: Application of a gravity feed repair product 


\subsubsection{Routing and Sealing}

Routing and sealing is a repair method generally used when a structural repair is not needed (ACI 224 2007). The crack is enlarged and filled with a joint sealer such as a lowstrength epoxy, silicone, or asphaltic material. Routing and sealing is effective as a waterproofing repair but not generally used when there is potential for movement across the crack. Therefore, routing and sealing is not recommended as a repair technique for bridge deck cracking.

\subsubsection{Overlay Systems}

Overlay repair systems are not intended to repair cracks but rather to repair the entire surface. By covering the deck surface, overlay repairs obscure the cracks and can prevent chloride penetration. Overlay systems are usually applied by spreading an epoxy across the entire surface and broadcasting a wearing surface of gravel, stone, or large sand particles. Multiple layers may be necessary to properly apply the overlay. Because overlay systems cover cracks rather than repairing them, they are often susceptible to cracking at the location of the original concrete crack. If the overlay has sufficient strength to remain intact under traffic loads, it may be ideal for repair of highly cracked bridge decks. Often it is recommended that overlay repair products be used in conjunction with a gravity feed or epoxy injection crack repair to maximize the effect of both products (ACI 224 2007).

\subsubsection{Factors affecting Repair Performance}

The performance of crack repair products used to repair bridge deck cracks has varied greatly due to a number of factors. The quality of the product itself is important, but field conditions such as temperature and humidity, as well as the application process, also influence the overall success of the crack repair. 


\subsubsection{Repair Product Variables}

The performance of repair products is dependent on a number of material properties including bond strength, viscosity, flexibility, and cure time. Most commercially available products have been designed to have optimal viscosity and high bond strength while remaining flexible and curing quickly, but there is significant variation. It is important to consider all of these factors when selecting a crack repair product.

\section{○ Bond Strength}

The bond strength of the repair product plays a major role in determining its effectiveness as a crack sealer. The crack must remain sealed under traffic loading to be considered effectively repaired. Most gravity feed repair products have a bond strength greater than the tensile strength of the concrete.

\section{$\circ$ Viscosity}

The viscosity of the repair product determines the depth of penetration into the crack. Increased penetration provides more bond surface and therefore more strength to seal the crack. In gravity feed applications, a high viscosity will not allow for full penetration and may not adequately repair the crack. Overlay products are especially problematic because they have very low penetration depths and therefore may crack under loading. Conversely, products with a very low viscosity may require too many pre-treatment applications to properly seal a crack, making such products impractical for bridge repair. Generally, low viscosity gravity feed repair products are considered optimal for crack sealing.

\section{- Flexibility}

Flexibility is an important factor to consider when choosing a repair product because it is necessary for a product to be adequately flexible under loads. Brittle products, even those with high bond strengths, may fracture under heavy or dynamic loads and allow chloride penetration. 


\section{$\circ$ Curing Time}

Curing time must be considered because faster curing times allow the bridge to be reopened to traffic sooner. Most gravity feed products will cure within a few hours and allow for same day bridge traffic. Overlay products have longer curing times because of the higher volume of material.

\subsubsection{Field Condition Variables}

Regardless of the quality of the crack repair product, other factors must be taken into account to achieve proper crack repair. The application of the product, including surface preparation, product mixing, and curing, must be conducted correctly. Weather must also be taken into account, as certain weather conditions can adversely affect the quality of the repair.

\section{- Application of Repair Product}

Improper application can negate the benefits of applying the repair products. Surface preparation, such as cleaning and drying of the bridge deck prior to application, is necessary to allow for full penetration and proper bond. It is also essential to follow all timing limits for mixing, pre-treating, flooding, and removing any excess product. For these reasons, simple, standard, application techniques are desired to eliminate potential mistakes.

\section{- Weather Conditions}

Conditions such as temperature and humidity at the time of application can also affect the repair quality. Many products require a certain temperature range during application or shortly after application, outside of which the product should not be applied. The same applies to humidity and inclement weather. If these specifications are not followed, the crack repair may be inadequate. Products that offer wider temperature and humidity ranges are desirable. 


\subsection{Previous Research}

Previous research has provided recommendations for control and repair of bridge deck cracking, including construction and design recommendations for controlling cracking of new bridge decks and recommendations for repair of existing bridge decks.

\subsubsection{Krauss and Rogalla (1996)}

A study by Krauss and Rogalla used theoretical analysis, field studies, and laboratory tests to determine the causes of bridge deck cracking. Recommendations were made to control cracking through design, material selection, and construction techniques. Because higher strength concrete generally leads to more shrinkage, it was recommended that concrete strengths be limited to minimum requirements. Additional longitudinal deck reinforcement was recommended, with a minimum of size 10M (\#4 bars) spaced at 150 $\mathrm{mm}$ (6 in.). In addition, it was noted that, because composite action with the girders during early age shrinkage is a major cause of deck cracking, non-composite decks could be implemented during construction and connected to the girders following initial shrinkage.

Concrete properties were noted as being especially significant in controlling deck shrinkage. To reduce shrinkage and lead to less cracking, concrete was recommended to have to following properties:

○ Low modulus of elasticity

$\bigcirc$ High creep

○ Low coefficient of thermal expansion

○ Low heat of hydration

○ High thermal conductivity

Finally, construction techniques were studied and recommendations were made regarding ways to control cracking through construction practices. It was noted that placement of the concrete should not take place during periods of elevated temperatures or low humidities. Other recommendations included initiating wet curing as soon as possible, extending curing as long as practical, and monitoring the evaporation rate to ensure proper curing. 


\subsubsection{French, Eppers, Le, and Hajjar (1999)}

A study was conducted to investigate reasons for and solutions to bridge deck cracking across the state of Minnesota. A field investigation was conducted on 72 bridges, a shrinkage study was conducted on two Minnesota Department of Transportation concrete bridge deck mixes, and a computer model was created to study time-dependant effects on bridge deck cracking.

Design-related parameters determined to affect shrinkage cracking included the degree of restraint and deck reinforcement. It was recommended that restraint could be reduced by using prestressed girders, increasing girder spacing, and increasing the use of deck expansion joints. A reinforcement spacing of 5.5 in. for \#5 bars or 6.5 to 7 in. for \#6 bars was also recommended.

Materials-related parameters found to affect shrinkage were cement content, watercement ratio, and aggregate type. An upward limit of 650 to $660 \mathrm{lb} / \mathrm{yd}^{3}$ of cement was recommended to reduce cement paste and the peak hydration temperature. In addition, low water-cement ratios were recommended. Finally, a well-graded aggregate was determined to positively affect the shrinkage performance of concrete mixes.

Construction-related parameters focused on the effect of temperature at the time of the deck pour. Temperatures below $45^{\circ} \mathrm{F}$ or above $85^{\circ} \mathrm{F}$ were determined to lead to increased deck cracking. In addition, more deck cracking was shown to occur on days where there is a large temperature range (greater than $50^{\circ} \mathrm{F}$ ). It was recommended that further research be conducted that considers the effect of curing period, curing methods, pour length and sequence, finishing procedures, vibration techniques, and additional weather conditions such as humidity and wind velocity.

\subsubsection{Frosch, Blackman, and Radabaugh (2003)}

Research was conducted including a field investigation and laboratory testing to determine the factors influencing deck cracking and to provide recommendations to minimize cracks. The research focused on the effect of restrained shrinkage, form type, and bar spacing on crack widths and spacing. 
It was recommended that the minimum wet cure duration in Indiana be increased from 96 hours to 7 days to reduce shrinkage cracking. Mix design and material selection were also noted as significant factors that must be considered in controlling the shrinkage of bridge decks. It was noted that required cement content could be altered to reduce the shrinkage of the concrete while still meeting minimum strength requirements. At the time, INDOT required a minimum of $659 \mathrm{lbs} / \mathrm{yd}^{3}$ of cement, producing concrete strengths often exceeding 6,000 psi which greatly exceed the minimum required strength of 4,000 psi. It was recommended that a change be made in the required cement content of bridge deck concrete.

Design of the reinforcement was also investigated, with recommendations made regarding maximum bar spacing and minimum reinforcement ratio to control cracking. A maximum bar spacing of 6 in. was recommended and the minimum amount of reinforcing steel, meant to prevent yielding of the steel and thereby reduce crack widths, was recommended to be:

$$
A_{s}=\frac{6 \sqrt{f^{\prime}}}{f_{y}} A_{g}
$$

where:

$$
\begin{aligned}
& \mathrm{A}_{\mathrm{g}}=\text { gross area of section, in. }{ }^{2} \\
& \mathrm{~A}_{\mathrm{s}}=\text { area of reinforcement in cross-section, in. }{ }^{2} \\
& \mathrm{f}_{\mathrm{c}}=\text { specified compressive strength of concrete, psi } \\
& \mathrm{f}_{\mathrm{y}}=\text { specified yield strength of reinforcement, psi }
\end{aligned}
$$

It was determined that the presence of SIP forms causes curling due to differential shrinkage which often leads to increased deck cracking. In addition, it was found that longitudinal cracks are often caused by the presence of upturned angles used to support SIP forms. It was recommended that flat, removable formwork be considered as an alternative. 


\subsubsection{Frosch, Bice, and Erickson (2006)}

The objective of this study was to evaluate the influence of design parameters on the cracking of bridge decks. A field investigation was conducted which instrumented four bridges. This information was used to develop design recommendations with respect to the amount and spacing of reinforcement in the deck.

This research confirmed the importance of a minimum reinforcement area to avoid yielding of the reinforcement. Furthermore, it confirmed the amount of reinforcement recommended by Frosch et al (2003), recommending the following reinforcement ratio:

$$
\rho_{g}=\frac{6 \sqrt{f_{c}^{\prime}}}{f_{y}}
$$

where:

$$
\begin{aligned}
& \rho_{\mathrm{g}}=\text { reinforcement ratio of the gross section, in. }{ }^{2} \\
& \mathrm{f}_{\mathrm{c}}=\text { specified 28-day concrete compressive strength, psi } \\
& \mathrm{f}_{\mathrm{y}}=\text { reinforcement yield stress, psi }
\end{aligned}
$$

In addition, a maximum bar spacing for Grade 60 steel was recommended to be 9 in. for the normal range of concrete covers used in bridge decks. Larger covers require closer bar spacings.

\subsubsection{Altoubat and Lange (2001)}

Uniaxial, restrained shrinkage tests were conducted to evaluate the behavior of restrained concrete specimens. Tensile creep, shrinkage strains and stress, and cracking were investigated on specimens that were subjected to varying humidities, initial curing, and alternate wet-dry cycles.

It was found that crack initiation often occurs at stresses lower than static tensile strength. In addition, tensile creep was determined to play a major role in predicting cracking. A reduction in shrinkage strains was observed due to tensile creep, extending the 
predicted time to first cracking (based on free shrinkage models) by two to three times. Finally, varying wet curing procedures were also studied as they relate to early age shrinkage and cracking. It was noted that increased wet curing durations lead to lower shrinkage but also leads to higher concrete stiffness which can increase the potential for cracking. A balance must be achieved between increased stiffness and decreased shrinkage to control cracking.

\subsubsection{Tia, Subramanian, Brown, and Broward (2005)}

The objectives of this study were to evaluate various concrete mixtures to determine their effectiveness in limiting shrinkage strains. Mixes incorporating varying cement contents, w/c ratios, aggregate size and gradation, and admixtures were examined. A laboratory test was conducted to evaluate these mixes under restrained shrinkage conditions.

It was found that shrinkage-reducing admixtures were very effective in reducing shrinkage and therefore providing increased resistance to restrained shrinkage cracking. Fly ash was recommended as a mineral admixture, as the mixes incorporating this material exhibited the lowest shrinkage strains.

\subsubsection{Pincheira and Dorshorst (2005)}

A study was conducted to assess the effectiveness of various commercially available crack repair products. Both deck sealers, which are broadcast across the entire deck, and crack sealers, which repair individual cracks, were considered. Tests were conducted to measure the depth of penetration and bond strength of the products as well as their response to freeze-thaw cycles. Other factors such as the time to open traffic and cost were also considered.

The study of deck sealants consisted of 13 commercially available products. None of the products was able to reach penetration depths specified by the manufacturer. In addition, penetration depth measured at different locations on the same specimen showed large variation. Most products were negatively affected by freeze-thaw cycles, which 
decreased their ability to prevent chloride penetration. The deck sealant products recommended by this study were Hydrozo Silane 40 VOC and Sonneborn Penetrating Sealer 40 VOC.

Ten crack sealants were also studied and compared to each other and to the deck sealant products. The crack sealants showed higher depths of penetration as compared to the deck sealants. It was determined that variation of crack width not exceeding $0.060 \mathrm{in}$. did not affect the performance of crack sealants. The crack sealers recommended by this study were Sikadur 55 SLV, Dural 335, Sikadur 52, Degadeck Crack Sealer, and Denedeck Crack Sealer.

The study recommended further research on chloride penetration and a study examining varying crack widths, especially wide cracks (greater than 0.060 in.). A field application was also recommended to test the best crack repair products under field conditions.

\subsubsection{Meggers (1996)}

A study was conducted to determine the ability of various crack sealers to repair cracks in older bridge decks. Both high molecular weight methacrylates (HMWM) and epoxy repair products were considered. Depth of penetration and ability to prevent chloride intrusion were studied, and the specimens were subjected to wet-dry cycles, freeze-thaw cycles, and salt water ponding.

The results were generally inconclusive but did offer some insight into the factors which determine the effectiveness of a repair product. It was found that performance was unrelated to the depth of penetration and rather was influenced by such properties as viscosity, flexibility, and bond strength. Both the epoxy and HMWM products performed well, and no conclusion was made as to which was generally more effective. The epoxies were effective due to their high bond strength while the HMWMs were effective because of their low viscosity and high flexibility despite their lower bond strength. 


\subsubsection{Johnson, Schultz, French and Reneson (2009)}

The objective of this research was to compile and determine the current application practices and performance of deck sealants and crack sealers. The information was collected from a literature review of current and significant studies in this field.

From the report, observations and recommendations were provided to improve crack repairs and ensure the durability of bridge decks. It was concluded that depth of penetration and chloride content tests were the QA/QC tests most frequently performed. Furthermore, it was determined that HMWM products usually provide better crack penetration while epoxies provide a higher bond strength and good resistance to freezethaw cycles.

An application temperature between 45 and $90^{\circ} \mathrm{F}$ was recommended. In addition,

the following properties for crack sealers were provided to enhance the effectiveness of repairs: viscosity less than $500 \mathrm{cP}$ (or $25 \mathrm{cP}$ for HMWM sealers), tensile strength more than $8 \mathrm{MPa}$ and a tensile elongation larger than $10 \%$.

The report recommended further research on epoxies regarding field performance, freeze-thaw testing, long term performance, and the occurrence of re-cracking.

\subsection{Objective and Scope}

While significant research has been conducted regarding causes, control, and repair of bridge deck cracking, previous studies have identified several areas where additional research is needed. Furthermore, new bridges continue to experience problems associated with deck cracking. There are several objectives of this research program: 1) investigate the reasons that bridge decks continue to experience cracking problems, 2) examine design and construction recommendations made by previous studies, and 3) evaluate crack repair methods that have the potential to extend the lifespan of existing bridges that are experiencing deck cracking. To fulfill these objectives, four phases of research will be conducted. The first phase of the study will be a field investigation of a new bridge that is experiencing significant deck cracking (Chapter 2). The second phase will evaluate previous recommendations regarding curing and concrete mix design and their effect on the 
control of deck cracking (Chapter 3). The third phase of the study will evaluate the effectiveness of a variety of commercially available crack repair products (Chapter 4). Finally, the fourth phase will evaluate design parameters to effectively control crack widths and mitigate cracking in future construction (Chapter 5). 


\section{CHAPTER 2 FIELD INVESTIGATION}

\subsection{Introduction}

Bridge deck cracking has been observed on a significant number of bridges throughout the state of Indiana. While design recommendations have been provided by previous research studies (Frosch et al. 2003, 2006), new bridges continue to exhibit extensive deck cracking. The objective of this phase of research was to evaluate the causes of cracking. Specific questions include whether design recommendations were implemented in new construction and whether the causes of cracking are the same as those previously identified.

\subsection{US-50 Bridge}

The US-50 bridge, located in Vincennes, IN, consists of two structures (eastbound and westbound) crossing the Wabash River (Figure 2.1). The structure is jointly maintained by the Indiana Department of Transportation (INDOT) and the Illinois Department of Transportation (IDOT). A rehabilitation of the bridge was completed in 2002 and 2003 which included the placement of a new concrete deck on both spans. Significant cracking in the bridge deck was observed in both spans shortly after placement. An investigation of this structure and in particular its design and construction was conducted to determine the causes of deck cracking. 


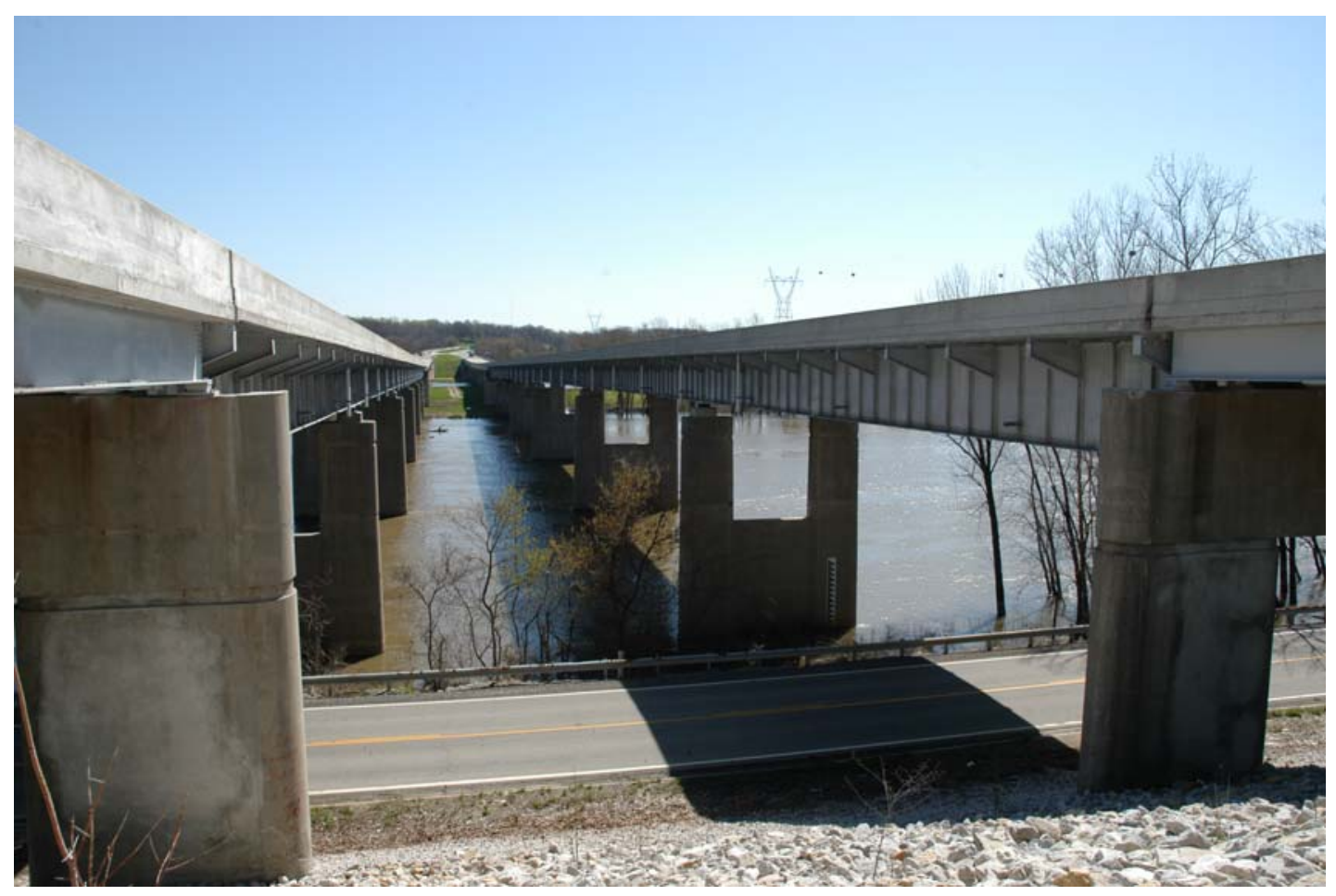

Figure 2.1: US-50 bridge

\subsubsection{Bridge Design}

The US-50 crossing consists of two $1745.5 \mathrm{ft}$ bridges, each with a width of 36'- 4” which includes two $12 \mathrm{ft}$ lanes and two 4'-8” shoulders. Each bridge consists of 17 total spans with lengths varying from 65 to $150 \mathrm{ft}$ (Figure 2.2). A summary of span lengths is provided in Table 2.1 .

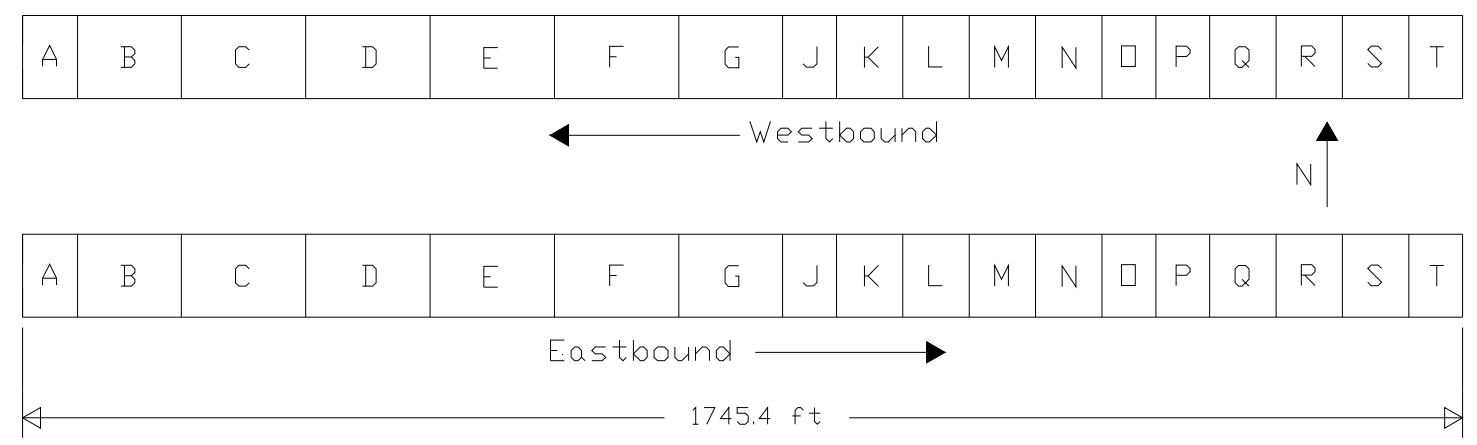

Figure 2.2: US-50 span layout 
Table 2.1: US-50 span length summary

\begin{tabular}{|c|c|c|c|}
\hline Span & Length (ft) & Span & Length (ft) \\
\hline A & 66.5 & L & 80 \\
\hline B & 125 & M & 80 \\
\hline C & 150 & N & 80 \\
\hline D & 150 & O & 65 \\
\hline E & 150 & P & 65 \\
\hline F & 150 & Q & 80 \\
\hline G & 125 & R & 80 \\
\hline J & 65 & S & 80 \\
\hline K & 80 & T & 65 \\
\hline
\end{tabular}

\subsubsection{Superstructure Design}

Spans B-G (girder spans) crossing the river are the longest (125 and $150 \mathrm{ft}$ ). These spans consist of two continuous plate girders with an overall depth of $8 \mathrm{ft}-0.5$ in. that are spaced at $26 \mathrm{ft}$ on-center. Floor beams are used to support four 14WF30 stringers that are spaced at $5 \mathrm{ft}-2$ in. on-center. Cross bracing is present throughout the length of these spans. A typical section is shown in Figure 2.3

Span A and Spans J-T are shorter approach spans, varying in length from 65 to 80 $\mathrm{ft}$. These spans consists of five 36WF160 interior beams spaced at $6 \mathrm{ft}$ on center and two 36WF160 exterior beams spaced $4 \mathrm{ft}-6$ in. from the interior beams. A typical cross section is presented in Figure 2.4. 


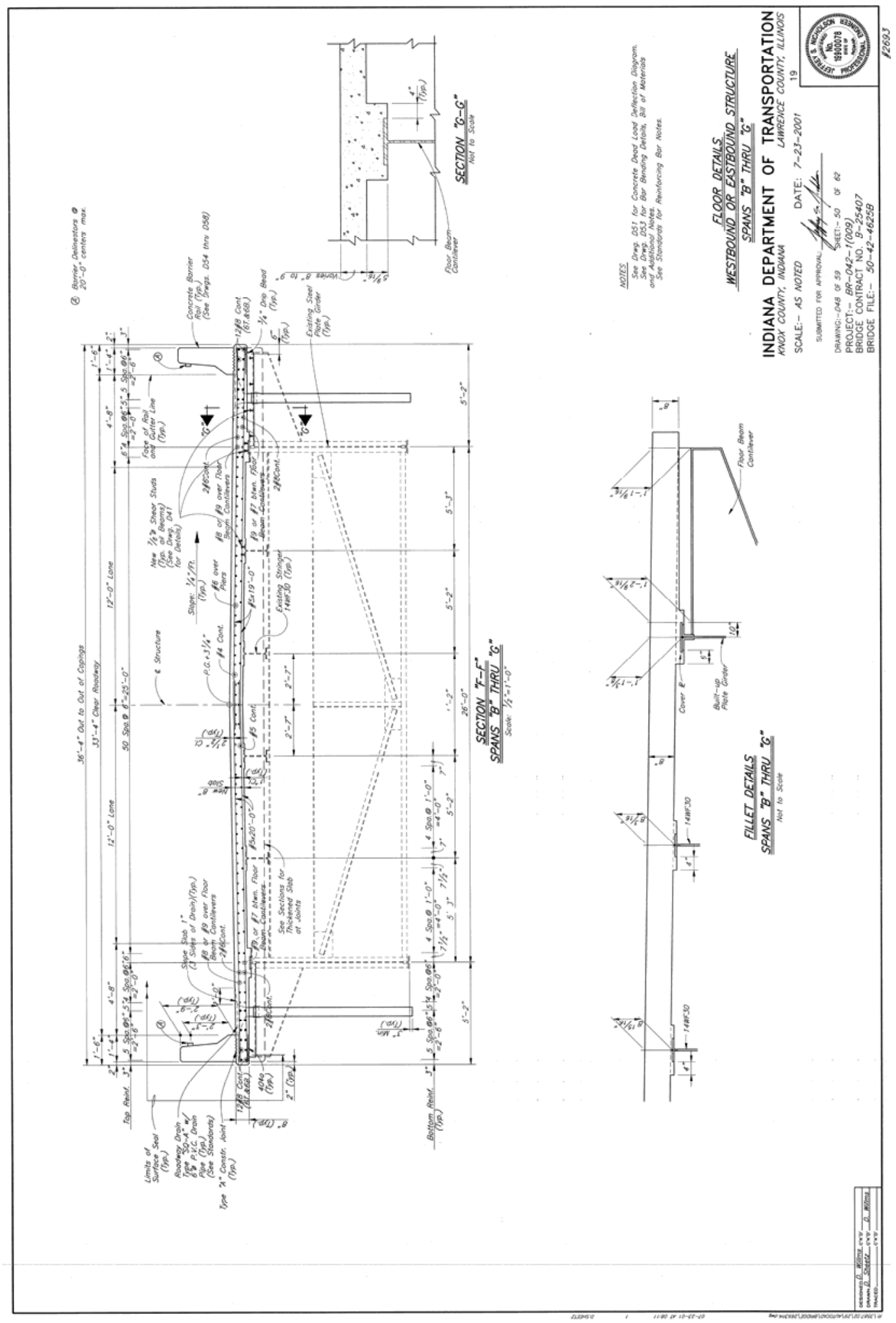

Figure 2.3: Superstructure and deck reinforcement details, Spans B-G 


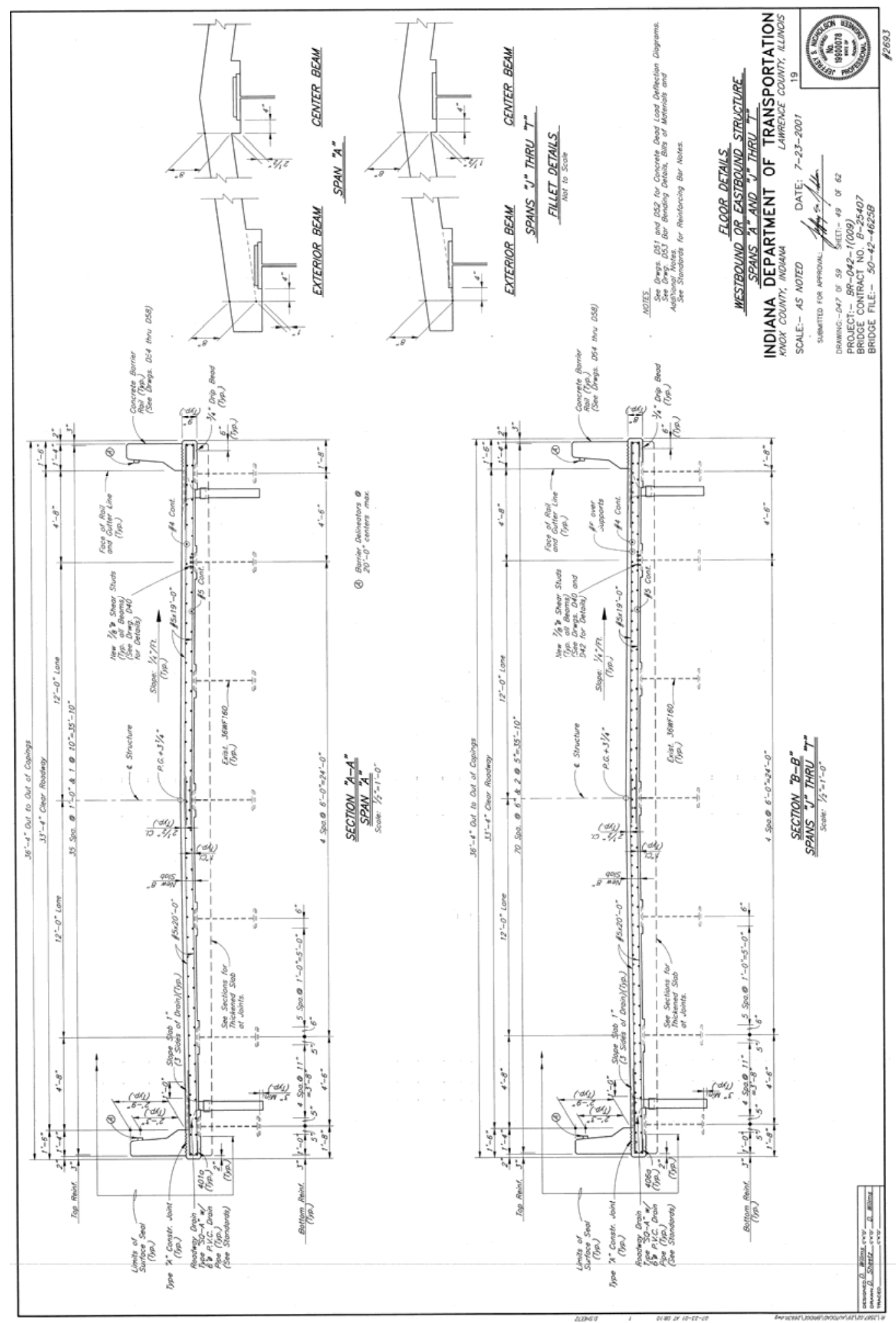

Figure 2.4: Superstructure and deck reinforcement details, Spans A, J-T 


\subsubsection{Deck Design}

The rehabilitation of the bridge included a complete replacement of the bridge deck of both the eastbound and westbound spans. The deck has a thickness of 8 in. Typical deck cross sections are provided in Figure 2.3 and Figure 2.4.

The deck is reinforced longitudinally in two mats. The top mat is continuously reinforced with \#4 bars spaced at 12 in. while the bottom mat is continuously reinforced with \#5 bars spaced at 12 in., resulting in a reinforcement ratio of $0.54 \%$. In addition to this continuous reinforcement, additional reinforcement was placed in the top mat in the negative moment region over the piers. The additional reinforcement consists of \#6 bars at 12 in., providing a total top mat reinforcement layout of alternating \#4 and \#6 bars spaced at 6 in. The reinforcement ratio in this region is $0.98 \%$. In Spans B-G, this additional reinforcement extended for approximately $40 \mathrm{ft}$ on either side of the centerline of the pier. In Spans J-T, the additional reinforcement extended approximately $17 \mathrm{ft}$ on either side of the centerline of the pier.

Transverse deck reinforcement consists of two layers of \#5 bars spaced at 8 in. The top mat of transverse reinforcement was placed above the top mat of longitudinal steel while the bottom mat of transverse steel was placed below the bottom mat of longitudinal steel to maximize eccentricity of the transverse reinforcement. This layout is consistent along the entire length of the bridge.

\subsubsection{Construction}

The bridge was rehabilitated from 2002 to 2003 . The deck of the eastbound span was cast over the period of October 22, 2002 to April 1, 2003. The westbound span was cast over the period of July 17, 2003 to September 5, 2003. Figure 2.5 indicates the sequence and locations of the deck pours. A summary of the weather conditions on all casting dates, measured at the Lawrenceville (IL) / Vincennes (IN) International Airport and provided by the National Oceanic and Atmospheric Administration, are provided in Table 2.2 and Table 2.3. High, low, and average temperatures, total precipitation, average humidity, and average wind speed are indicated. A temperature history from September 1, 2002 to October 31, 2003, with casting dates indicated, is provided in Figure 2.6. 
While the wet curing duration and procedure were not made available, the bridge rehabilitation took place after the minimum required wet curing duration was increased by INDOT from 4 days to 7 days. Therefore, it can be assumed that a 7 day wet cure was implemented throughout the bridge. However, it should be noted that many sections of the eastbound deck were cast on days when temperatures were below $39^{\circ} \mathrm{F}$.

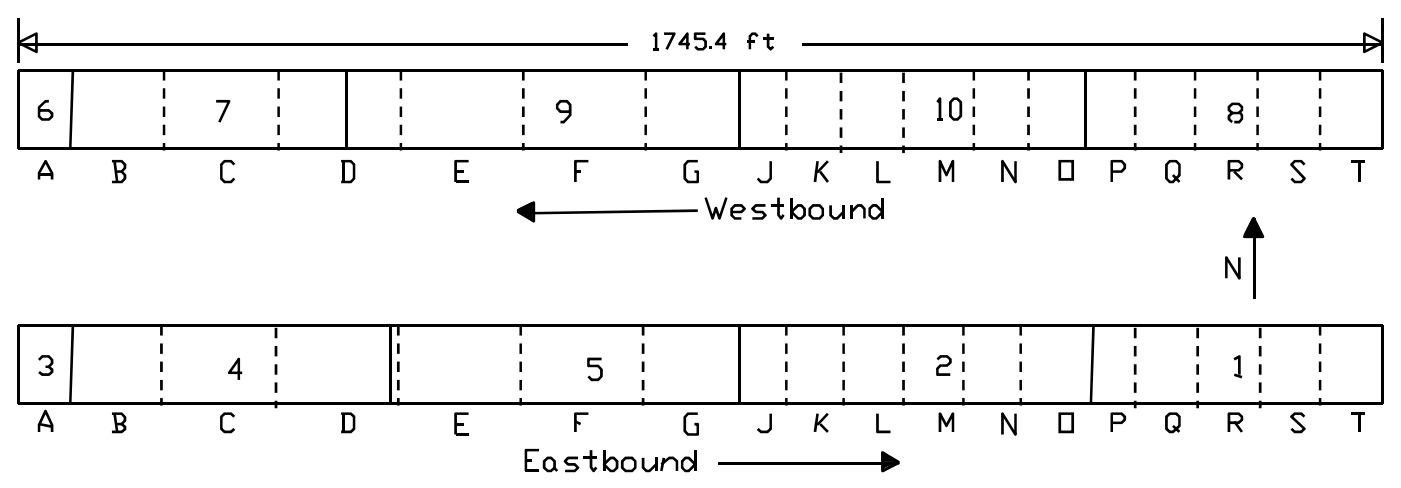

Figure 2.5: Pour sequence 
Table 2.2: Deck pour information, Eastbound Span

\begin{tabular}{|c|c|c|c|c|c|c|c|c|}
\hline \multirow{2}{*}{$\begin{array}{l}\text { Pour } \\
\text { No. }\end{array}$} & \multirow{2}{*}{ Span } & \multirow{2}{*}{$\begin{array}{c}\text { Date of } \\
\text { Cast }\end{array}$} & \multicolumn{3}{|c|}{ Temperature $\left({ }^{\circ} \mathbf{F}\right)$} & \multirow{2}{*}{$\begin{array}{c}\text { Total } \\
\text { Precip } \\
\text { (in.) }\end{array}$} & \multirow{2}{*}{$\begin{array}{c}\text { Avg. } \\
\text { Rel. } \\
\text { Hum. } \\
\text { (\% RH) }\end{array}$} & \multirow{2}{*}{$\begin{array}{c}\text { Avg. } \\
\text { Wind } \\
\text { Speed } \\
\text { (mph) }\end{array}$} \\
\hline & & & High & Low & Avg. & & & \\
\hline 1 & P-T & $10 / 22 / 2002$ & 67 & 35 & 51 & 0 & 76 & 4.1 \\
\hline 2 & $\mathrm{~J}-\mathrm{O}$ & $11 / 12 / 2002$ & 47 & 28 & 38 & 0 & 78 & 6 \\
\hline 3 & A & $12 / 10 / 2002$ & 36 & 24 & 30 & 0 & 85 & 4.7 \\
\hline 4 & B-Part D & $3 / 22 / 2003$ & 62 & 36 & 49 & 0 & 63 & 8.1 \\
\hline 5 & Part D-G & $4 / 1 / 2003$ & 78 & 51 & 65 & 0 & 41 & 19.9 \\
\hline
\end{tabular}

Table 2.3: Deck pour information, Westbound Span

\begin{tabular}{|c|c|c|c|c|c|c|c|c|}
\hline \multirow{2}{*}{$\begin{array}{c}\text { Pour } \\
\text { No. }\end{array}$} & \multirow{2}{*}{ Span } & \multirow{2}{*}{$\begin{array}{c}\text { Date of } \\
\text { Cast }\end{array}$} & \multicolumn{3}{|c|}{ Temperature $\left({ }^{\circ} \mathbf{F}\right)$} & \multirow{2}{*}{$\begin{array}{c}\text { Total } \\
\text { Precip } \\
\text { (in.) }\end{array}$} & \multirow{2}{*}{$\begin{array}{c}\text { Avg. } \\
\text { Rel. } \\
\text { Hum. } \\
\text { (\% RH) }\end{array}$} & \multirow{2}{*}{$\begin{array}{l}\text { Avg. } \\
\text { Wind } \\
\text { Speed } \\
\text { (mph) }\end{array}$} \\
\hline & & & High & Low & Avg. & & & \\
\hline 6 & A & 7/17/2003 & 89 & 63 & 76 & 0 & 73 & 3.5 \\
\hline 7 & B-Part D & 8/5/2003 & 84 & 64 & 74 & 0 & 79 & 2.6 \\
\hline 8 & P-T & $8 / 12 / 2003$ & 85 & 64 & 75 & 1.7 & 85 & 5.9 \\
\hline 9 & Part D-G & $8 / 26 / 2003$ & 97 & 68 & 83 & 0 & 69 & 7.8 \\
\hline 10 & $\mathrm{~J}-\mathrm{O}$ & $9 / 5 / 2003$ & 78 & 52 & 65 & 0 & 75 & 5.8 \\
\hline
\end{tabular}




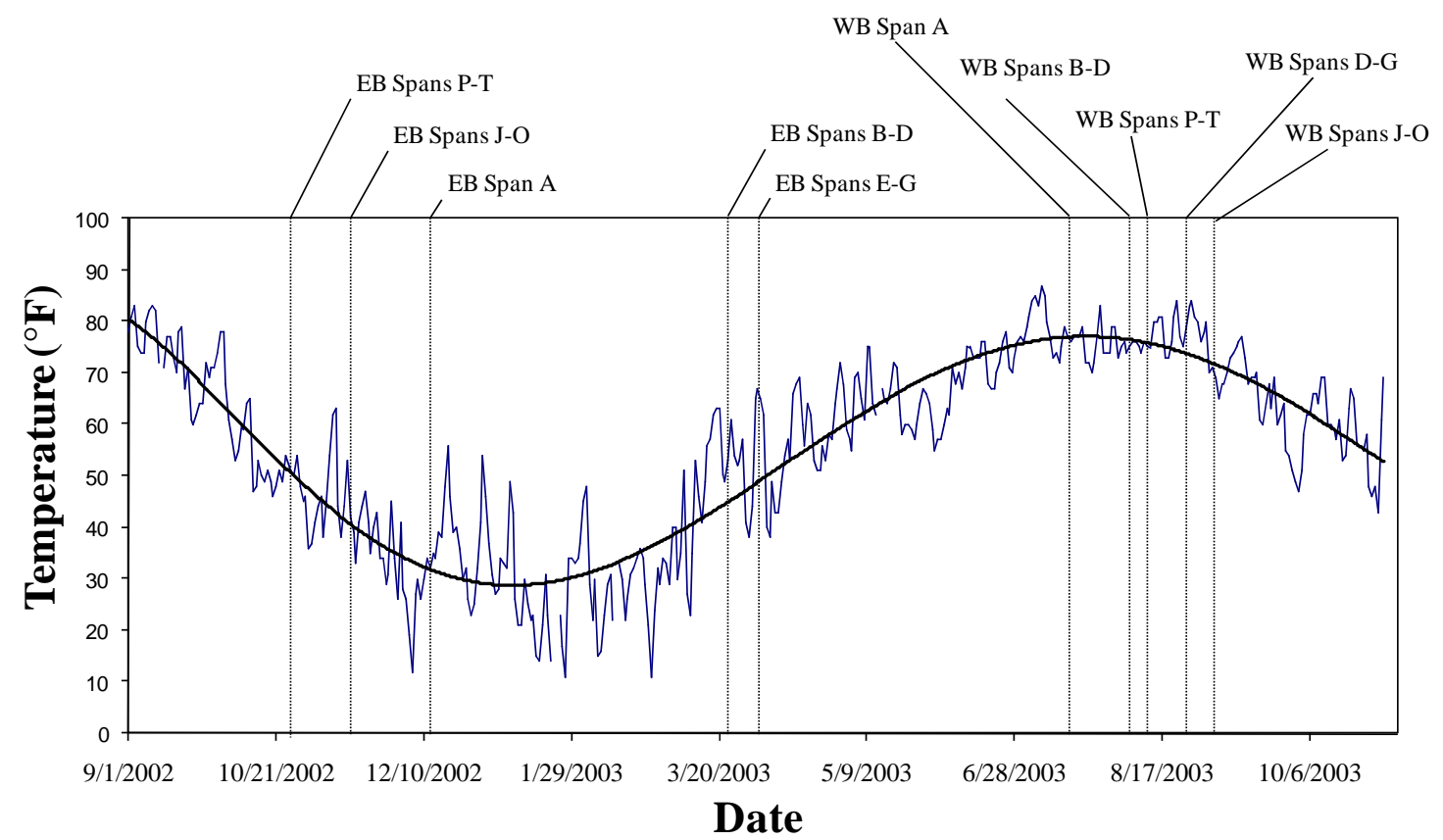

Figure 2.6: Temperature history, 9/1/2002 - 10/31/2003

\subsection{US-50 Bridge Field Investigation}

A field investigation of the US-50 bridge took place on April 15, 2008 (Figure 2.7). The investigation focused on bridge deck cracking and was conducted in two phases. The first phase consisted of a qualitative evaluation of the deck to identify problem areas for further investigation. The deck of the westbound bridge was determined to be in significantly better condition than the deck of the eastbound bridge. Second a qualitative evaluation was conducted of deck. For the westbound bridge, the general crack pattern was mapped along with representative crack widths. For the eastbound bridge, a more detailed crack mapping was performed to determine transverse crack locations, representative crack widths, and overall cracking pattern. 


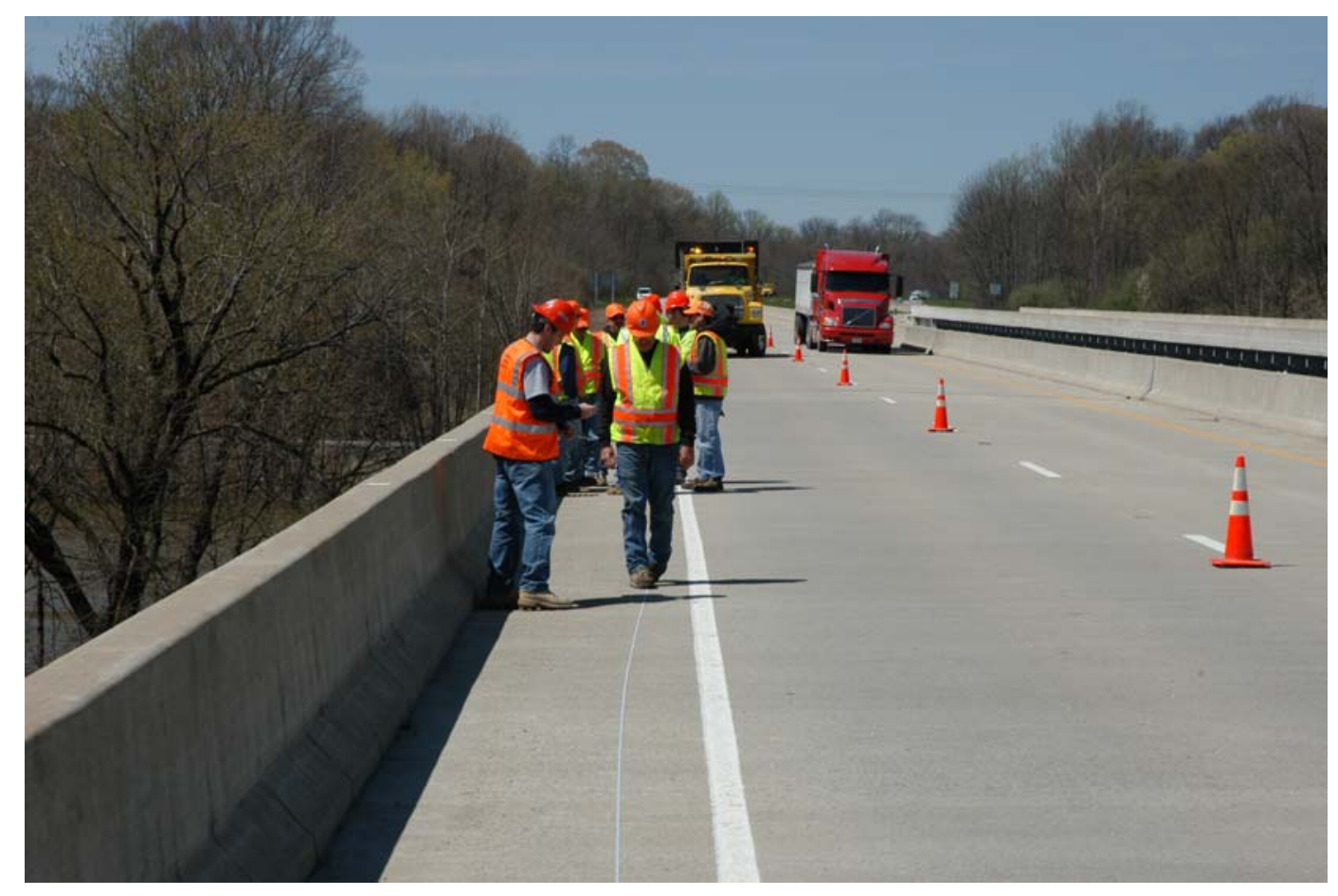

Figure 2.7: Crack mapping of US-50 bridge

\subsubsection{Westbound Structure}

Both a qualitative and quantitative crack mapping was performed of the westbound bridge. Because the westbound bridge exhibited less cracking than the eastbound bridge, a complete crack mapping was not performed. Rather, representative crack spacings and crack widths were measured in different regions of the deck. Complete crack spacings were recorded for one girder span (Span F) and one beam span (Span K), as these spans exhibited the most severe cracking.

\subsubsection{Girder Spans (Spans B-G)}

Cracking of the girder spans was observed in both the positive and negative moment regions. In the negative moment region, corresponding to the region with increased longitudinal reinforcement, transverse cracks were spaced fairly regularly in the range of 8 to $12 \mathrm{ft}$. Crack widths in the negative moment region were measured to be approximately 0.013 in. Less cracking was observed in the positive moment regions of the 
girder spans. Generally, a crack was observed at the third points and midpoint of the span. Crack widths in the positive moment region ranged from 0.010 to $0.020 \mathrm{in}$. but typically were 0.016 to 0.02 in. A representative crack pattern for the westbound girder spans is provided in Figure 2.8 which is for Span F.

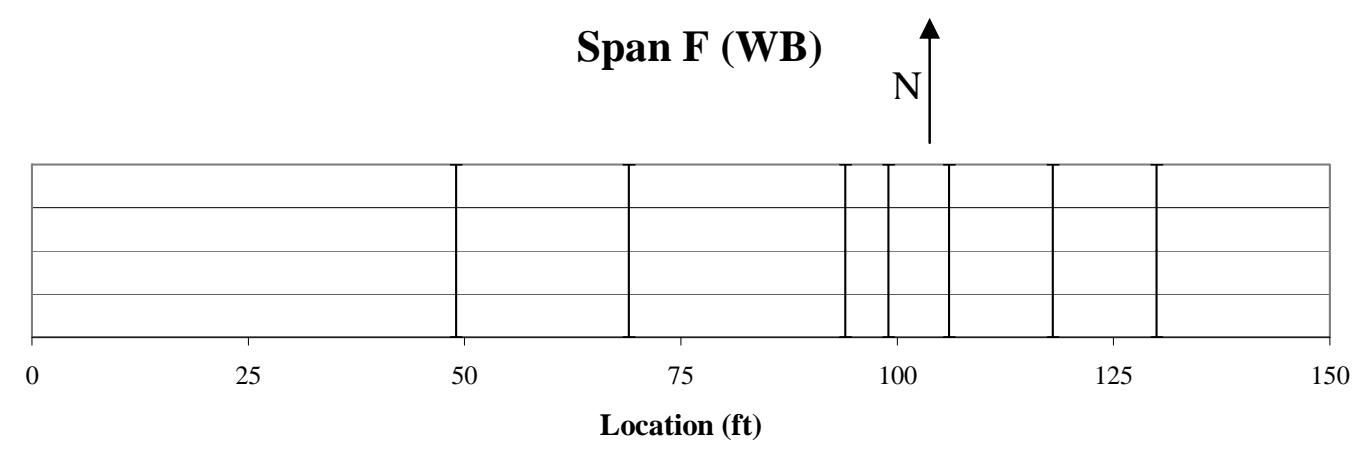

Figure 2.8: Girder span crack pattern (westbound)

\subsubsection{Beam Spans (Spans A, J-T)}

The beam spans exhibited a different cracking pattern than that of the girder spans. Relatively little cracking was observed in the negative moment region, with a transverse crack generally only occurring over or near the piers. In the positive moment region, transverse cracks were spaced between 3 and $10 \mathrm{ft}$ with average spacings of approximately $6 \mathrm{ft}$. Crack widths in the positive moment region were in the range 0.016 to $0.020 \mathrm{in}$. A representative crack pattern is provided in Figure 2.9, which is for Span K.

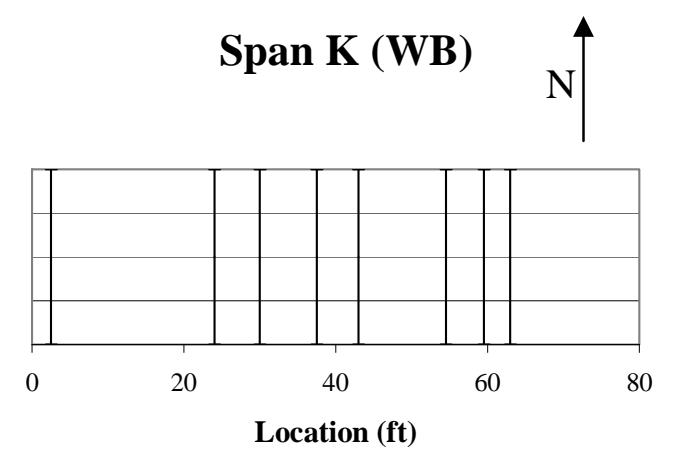

Figure 2.9: Beam span crack pattern (westbound) 


\subsubsection{Eastbound Structure}

The eastbound structure exhibited significantly more cracking than the westbound structure. For this reason, a detailed crack mapping was conducted over the entire length of the bridge. A qualitative and quantitative evaluation was performed, with locations of all transverse cracks noted and representative crack widths measured. Extensive transverse cracking was observed, as well as instances of longitudinal (Figure 2.10) and map cracking (Figure 2.11). In addition, evidence of damage due to freeze/thaw cycles was observed (Figure 2.12).

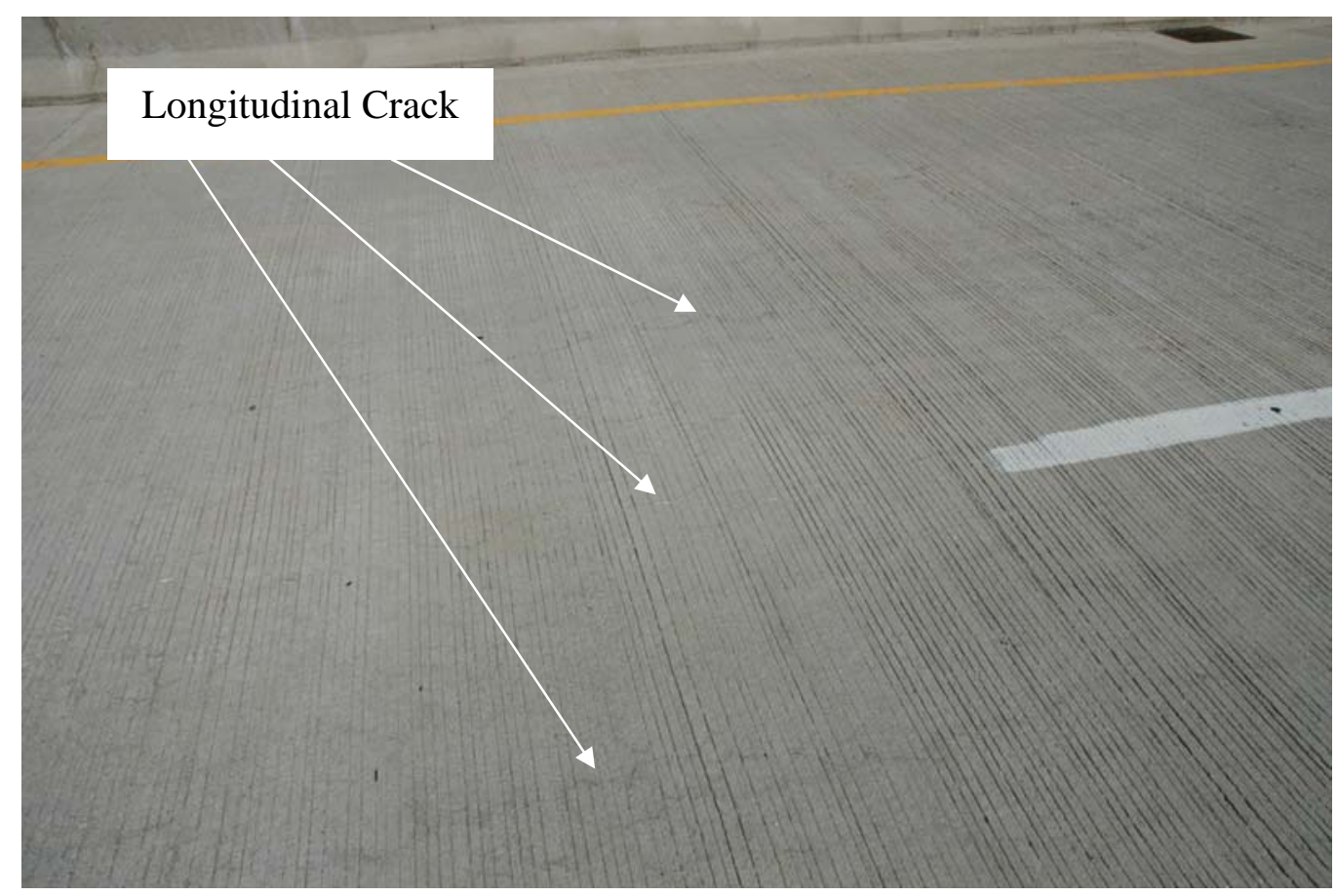

Figure 2.10: Longitudinal cracking on US-50 bridge 


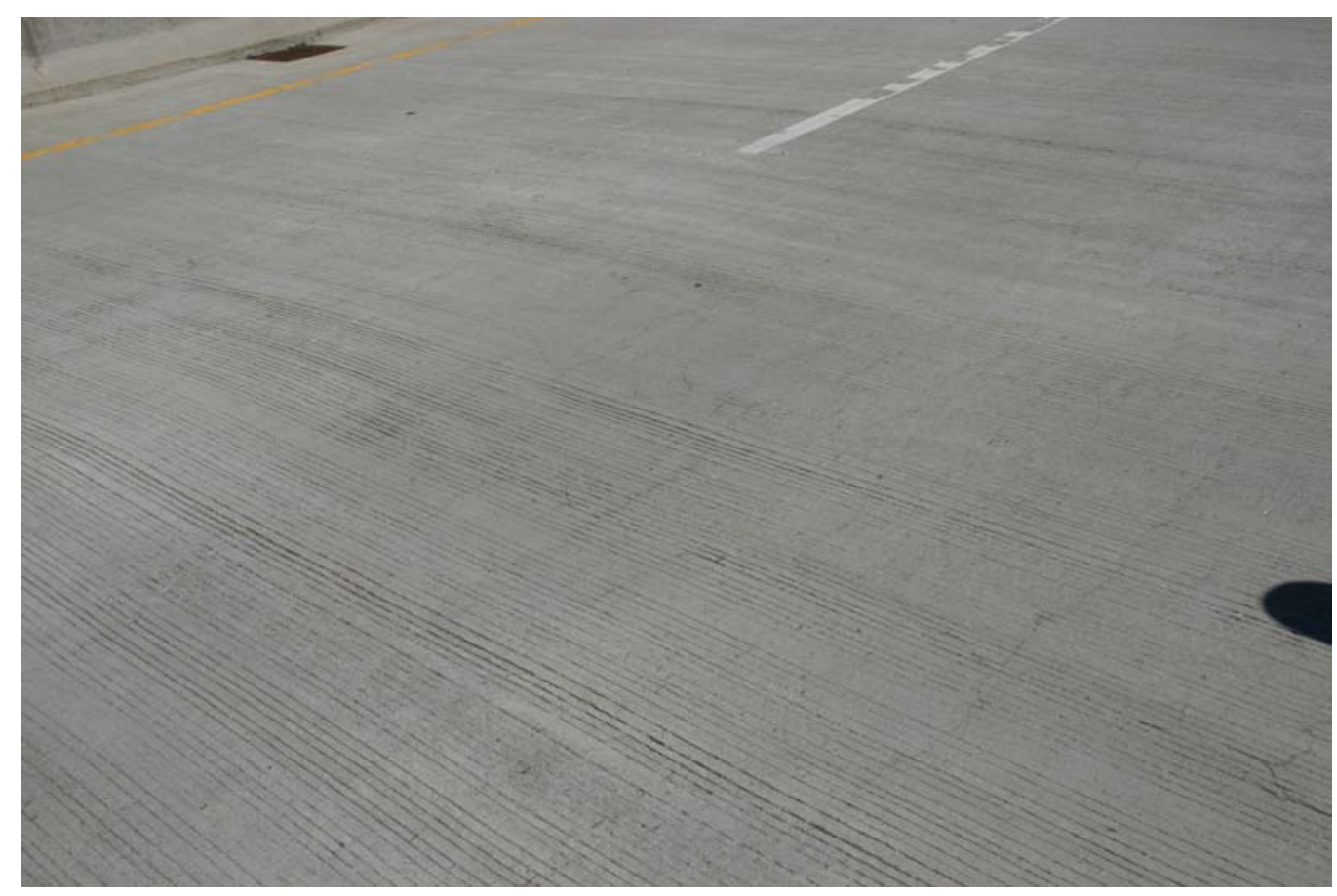

Figure 2.11: Map cracking on US-50 bridge

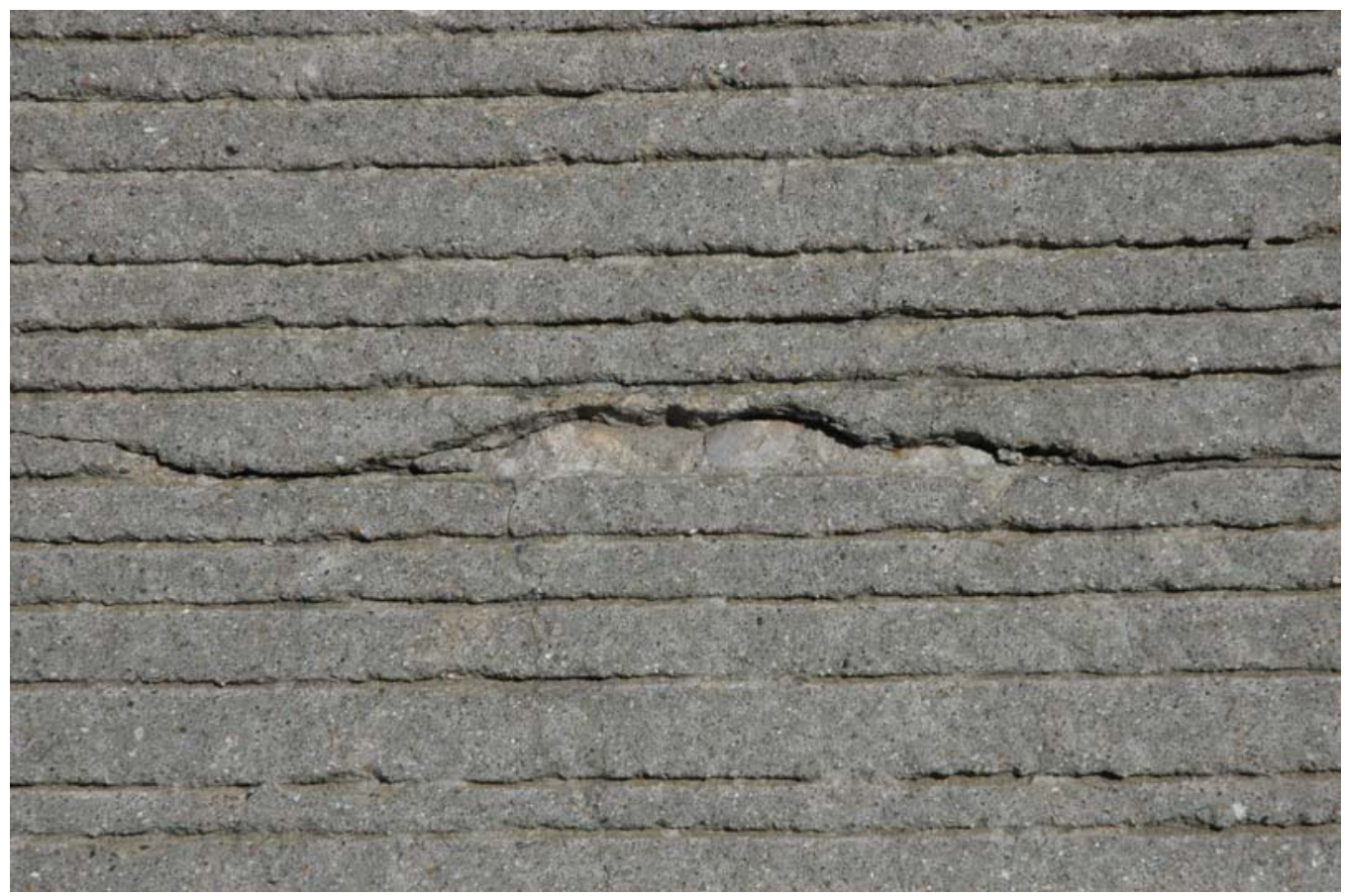

Figure 2.12: Freeze/thaw damage on US-50 bridge 


\subsubsection{Girder Spans (Spans B-G)}

Extensive transverse cracking was observed in the girder spans in both the positive and negative moment regions. A crack map of the transverse crack for each girder span is provided in Figure 2.13. The average crack spacing for these spans was approximately 6.5 $\mathrm{ft}$. Span $\mathrm{C}$ exhibited the most cracking, with an average crack spacing of approximately $4.5 \mathrm{ft}$ followed by Span F with an average crack spacing of approximately $5.5 \mathrm{ft}$. Fewer transverse cracks appeared near expansions joints, which are located as shown at the ends of Spans B and $G$ which are the transition points from beam spans to girder spans. In addition, very little cracking was observed in an $80 \mathrm{ft}$ region extending $40 \mathrm{ft}$. into both Span $\mathrm{D}$ and Span $\mathrm{E}$, the geometric center of the girder span structure.

Cracks in the positive moment region of the girder spans are fairly regularly spaced at approximately $6 \mathrm{ft}$ and have an average width in the range of 0.016 to $0.020 \mathrm{in}$. An example of typical transverse cracking is shown in Figure 2.14. The negative moment region exhibited a more irregular pattern, with crack spacings ranging from less than $1 \mathrm{ft}$ to over $10 \mathrm{ft}$. Cracks in this region were generally finer and more closely spaced than in the positive region. The finer crack widths exhibited in the region are likely a result of the increased reinforcement and decreased bar spacing.

Overall bridge geometry appears to play a role in the cracking pattern. The general crack pattern was symmetrical about the geometric center of the girder span structure (the pier between Spans D and E). The ends, which corresponded to locations of expansion joints, exhibited the least cracking. The most cracking occurred in Spans C and F, located at the approximate quarter points of the span. Less cracking was observed in Spans D and E, the center spans of the structure. It should be noted that a pourline exists within Span D and likely contributed to the decreased cracking in these spans. 

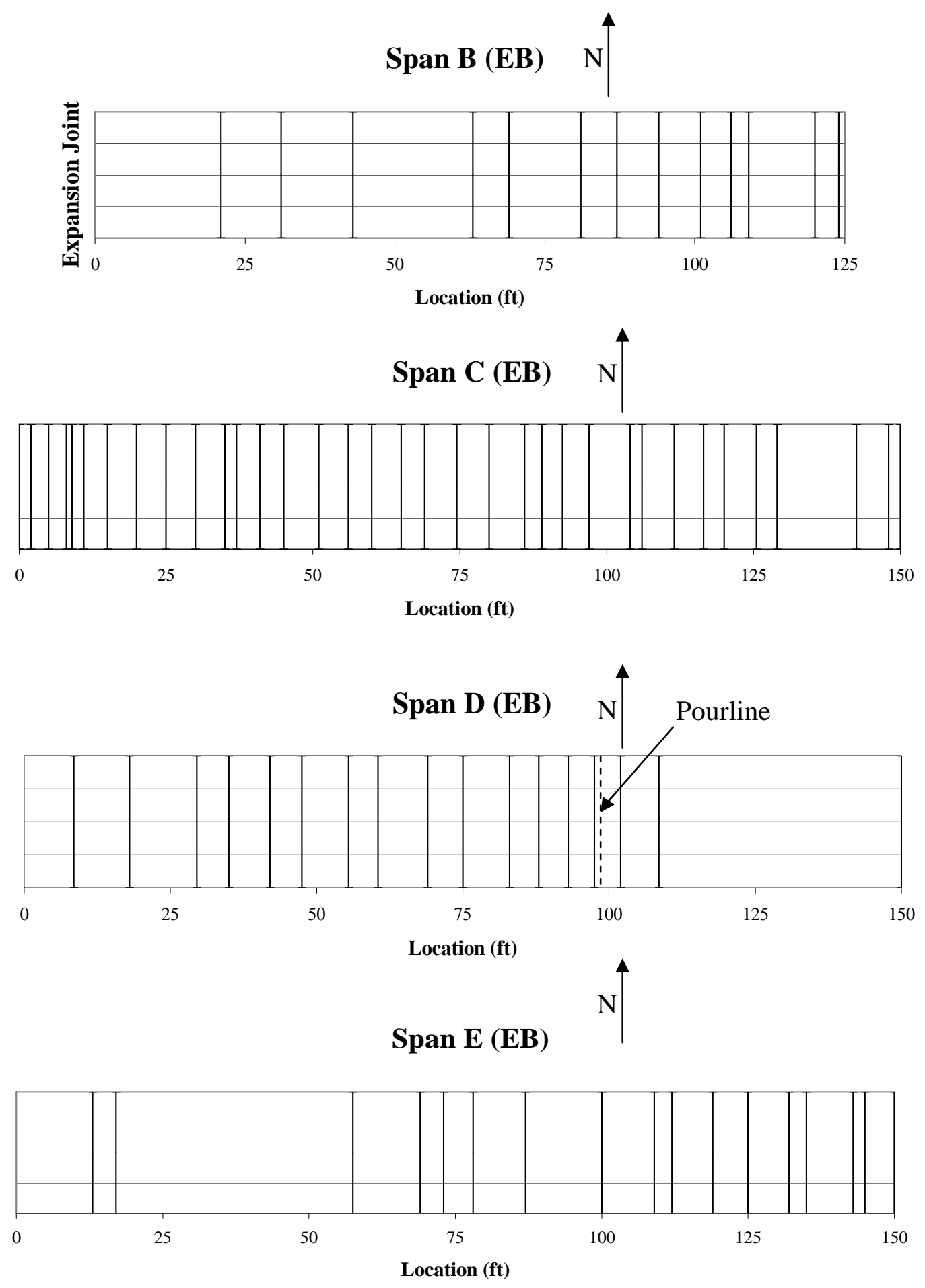

Figure 2.13: Girder span crack pattern (eastbound) 

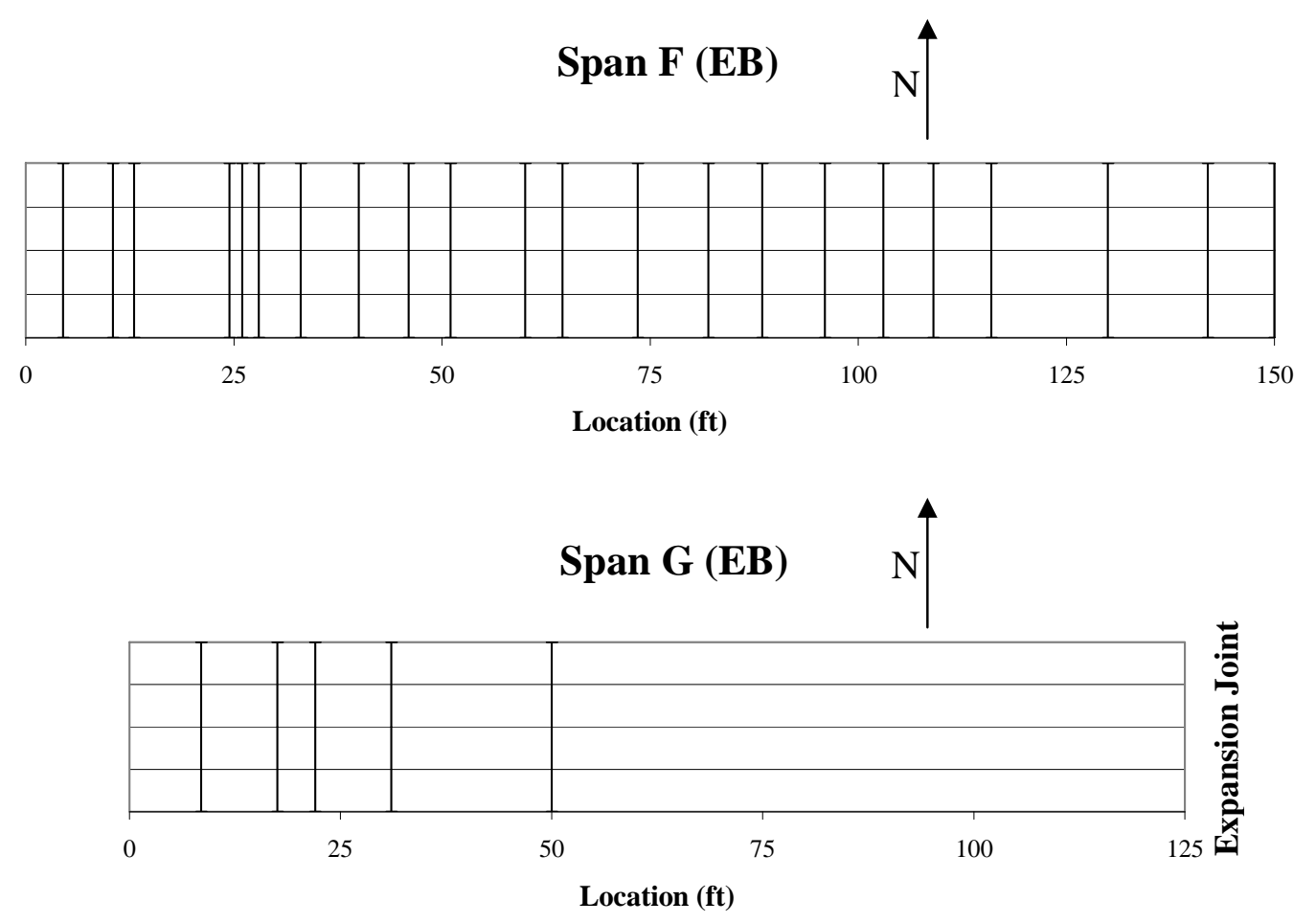

Figure 2.13 (cont.): Girder span crack pattern (eastbound) 


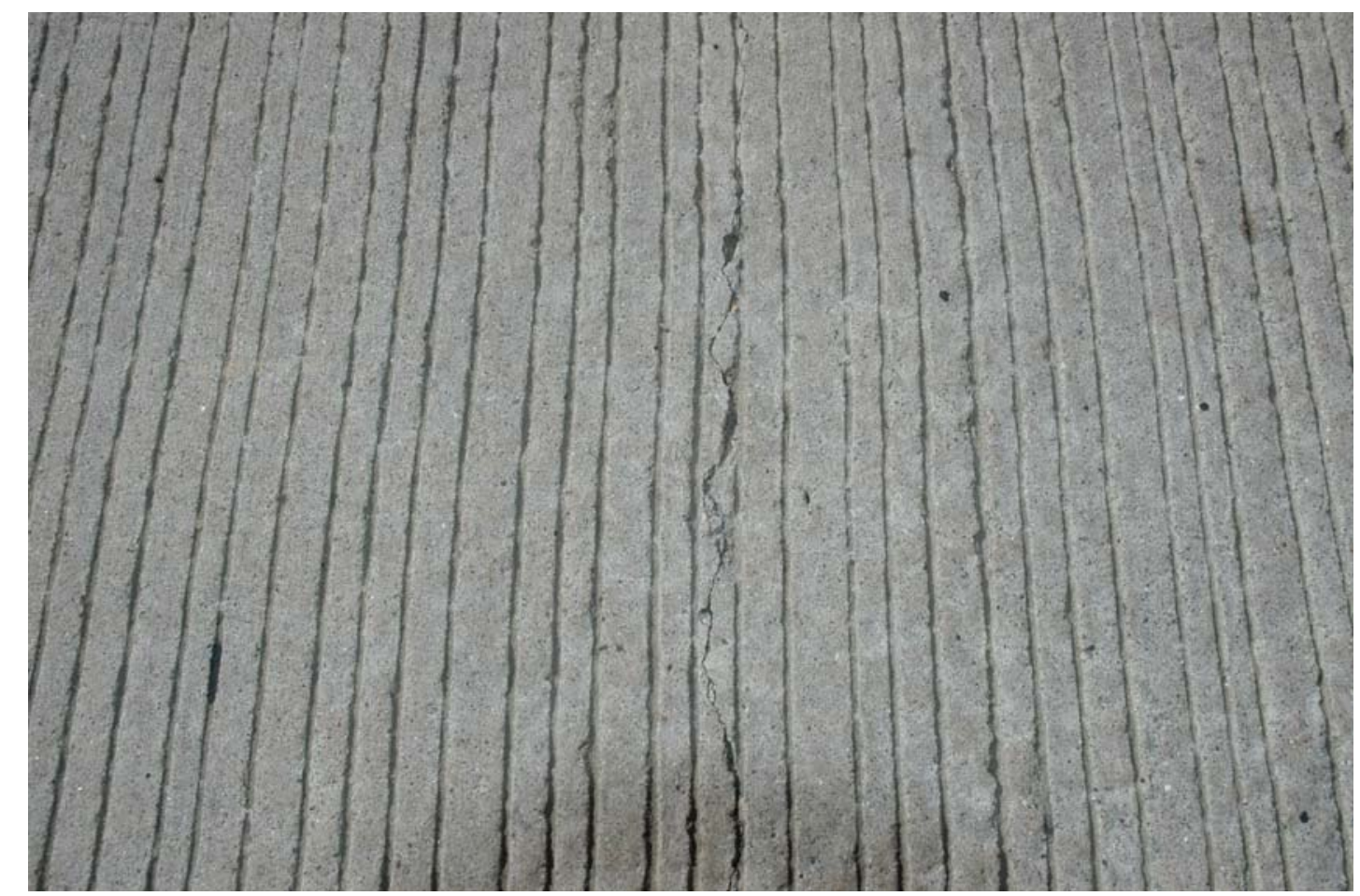

Figure 2.14: Transverse deck cracking on US-50 bridge

\subsubsection{Beams Spans (Spans A, J-T)}

The eastbound beam spans also exhibited significant transverse cracking in both the positive and negative moment regions (Figure 2.15). Transverse crack locations for each span are shown in Figure 2.16. Regions adjacent to expansion joints demonstrated the least amount of transverse cracks. Cracks in the negative moment region usually occurred directly over the pier and at irregular spacings between 1 and $25 \mathrm{ft}$ but generally were in a range of 3 to $7 \mathrm{ft}$. The positive moment region also exhibited a wide range of crack spacings, ranging from 3 to $20 \mathrm{ft}$. Crack widths in the positive moment region were generally between 0.016 and 0.020 in. while the crack widths in the negative moment region were finer, within a range of 0.010 to 0.013 in.

As in the girder spans, bridge geometry appears to play a role in determining the overall crack pattern. The beam spans consist of two regions bounded by expansion joints: Spans J-O and Spans P-T. Spans J-O exhibited a cracking pattern similar to the girder spans, symmetrical about the geometric center. Little cracking exists in Spans J and O which correspond to the locations of the expansion joints. Moving inward towards the 
geometric center, the most cracking occurs at the approximate quarter points of the region, Spans K and N. The center spans, L and M, exhibited less cracking than Spans K and N but more than Spans $\mathrm{J}$ and $\mathrm{O}$. As in the girder spans, the geometric center of this region occurs at a pier.

Beam Spans P-T also showed an overall crack pattern that was symmetrical about the centerline of the region. Cracking was minimal in the regions adjacent to expansion joints (Spans $\mathrm{P}$ and T). Cracking increased in Spans Q and S, the approximate quarter points of the region. The most cracking, however, was observed in Span R. It should be noted that in the case of the structure spanning from P-T, the geometric center occurs at the midpoint of Span $\mathrm{R}$ rather than over a pier.

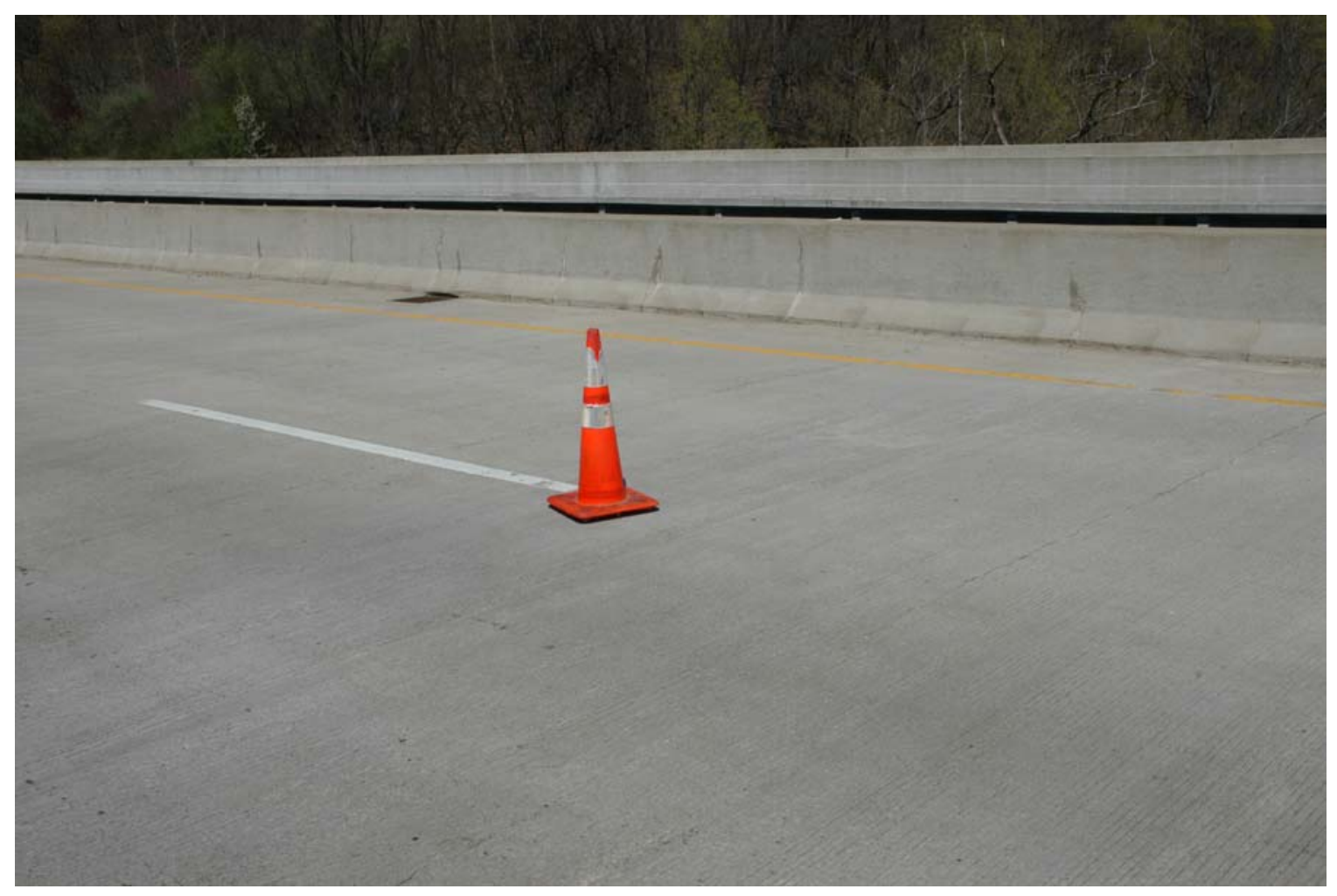

Figure 2.15: Transverse crack on an eastbound beam span 

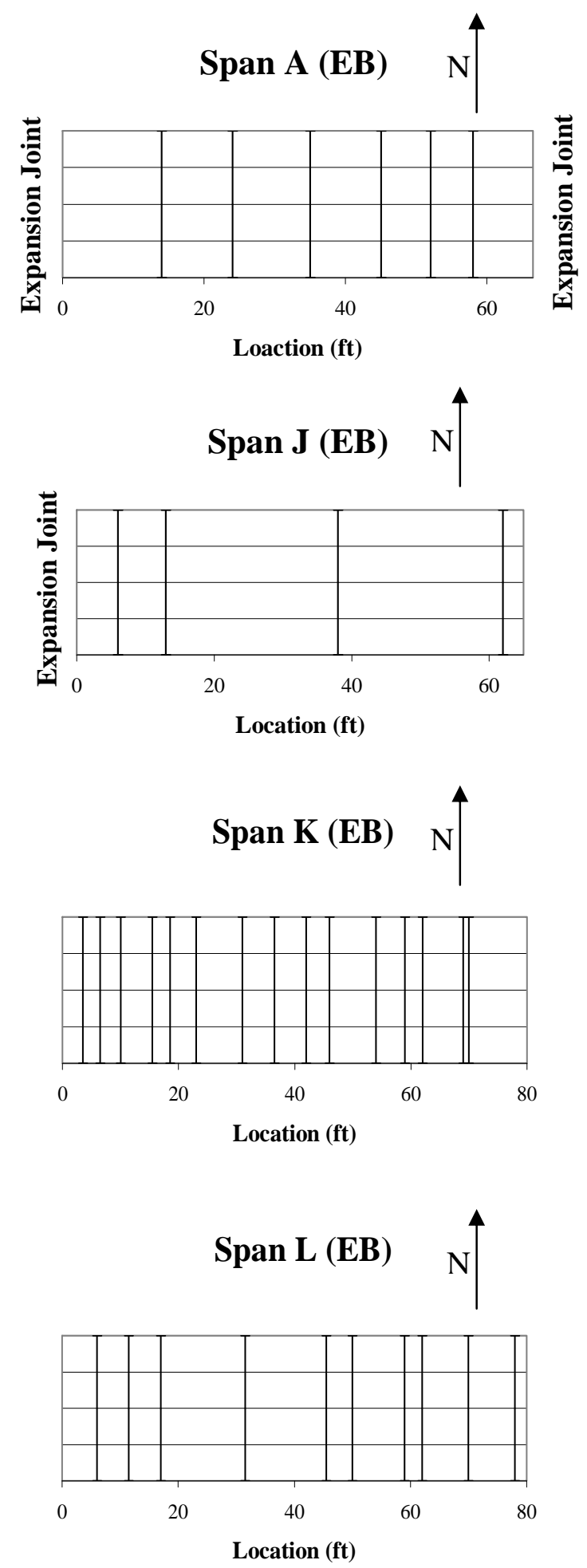

Figure 2.16: Beam span crack pattern (eastbound) 

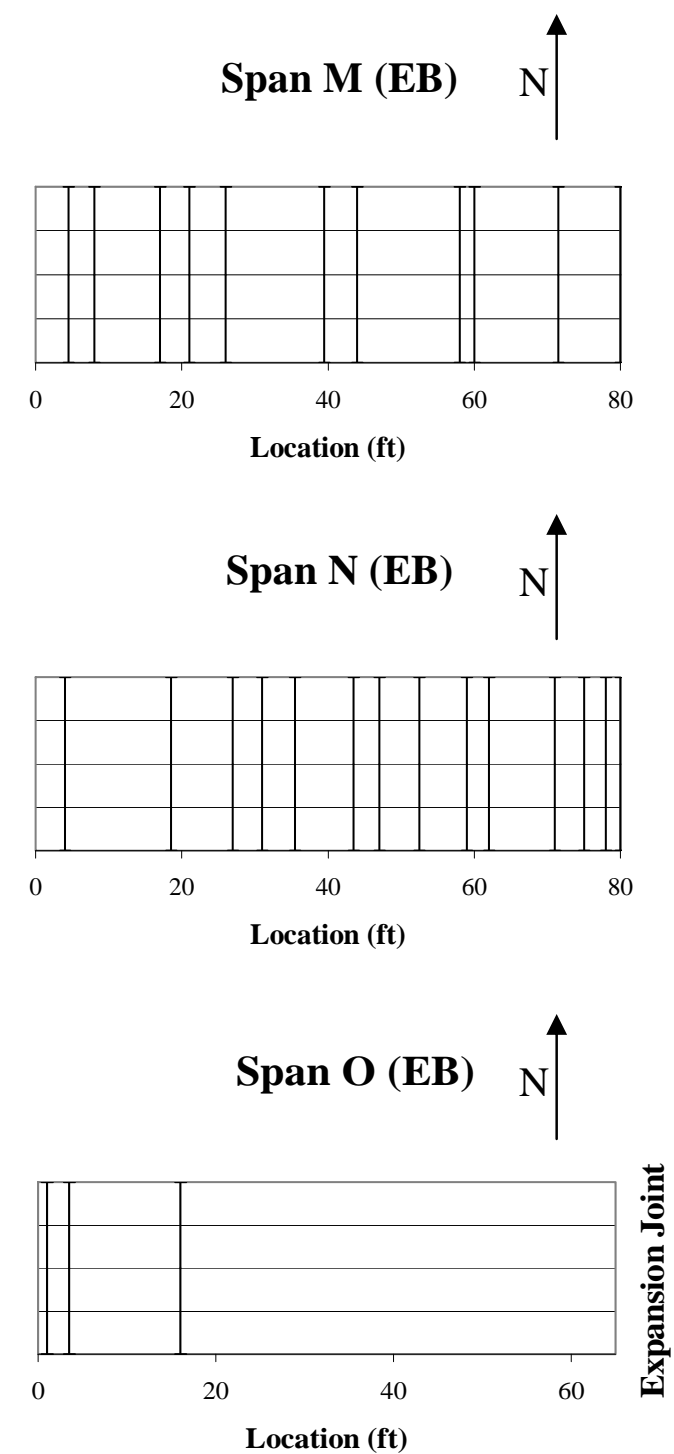

$\operatorname{Span} P(E B) \quad N$

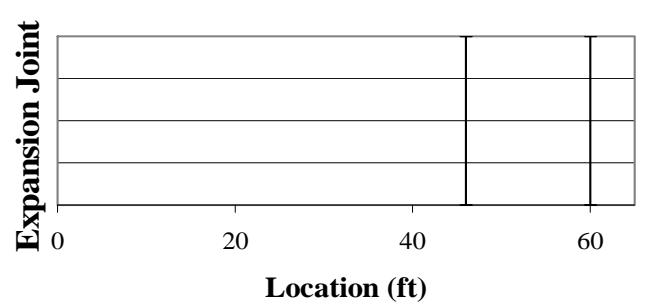

Figure 2.16 (cont.): Beam span crack pattern (eastbound) 
$\operatorname{Span} Q(E B) \quad \mathrm{N} \uparrow$

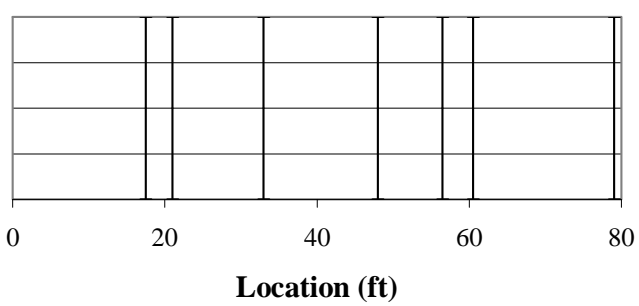

$\operatorname{Span} R(E B) \quad N \uparrow$

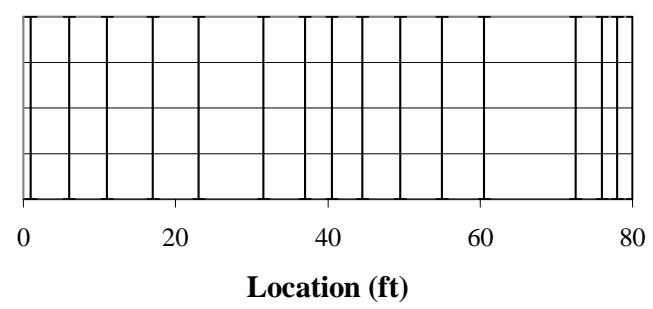

Span S (EB) $\quad \mathrm{N} \uparrow$

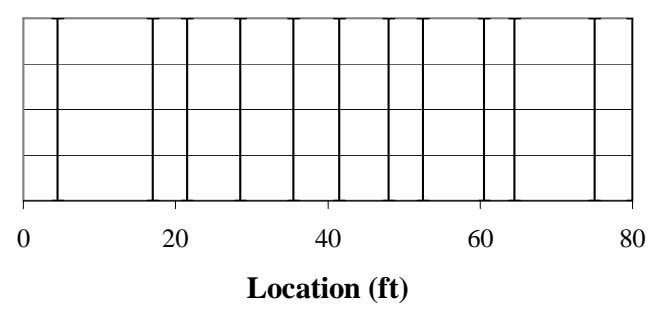

$\operatorname{Span} T(E B) \quad N \uparrow$

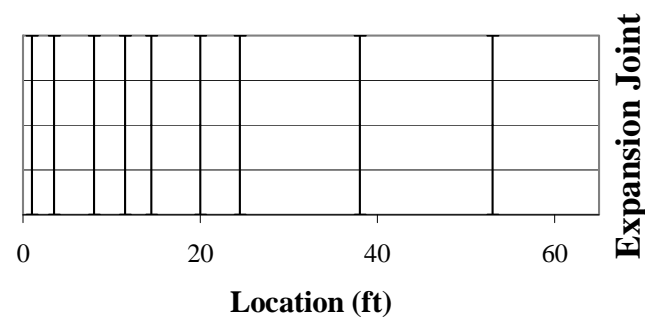

Figure 2.16 (cont.): Beam span crack pattern (eastbound) 


\section{$\underline{2.4 \text { Cracking Analysis }}$}

While cracking was observed in all regions of the bridge, crack spacing and widths varied throughout. The westbound structure exhibited significantly less cracking than the eastbound structure. In addition, different crack patterns were observed in different regions within the structure and at different locations within individual spans.

Transverse cracking in the positive moment region, likely cause by restrained shrinkage alone, was spaced at regular intervals generally varying from 3 to $7 \mathrm{ft}$. These cracks were generally larger, with widths falling between 0.016 and 0.020 in. Transverse cracks in the negative moment region were more tightly and irregularly spaced, likely because the cracks in this region are a result of both restrained shrinkage and negative moment bending. Cracks in this region were finer than those in the positive moment region, with widths generally falling between 0.010 and 0.013 in. Little cracking was observed in regions adjacent to expansion joints, as this greatly reduced the amount of restraint.

Factors that appeared to have a significant influence on the bridge deck pattern include deck reinforcement, bridge geometry, and weather during construction. It should be noted that the design of the deck was identical for both the eastbound and westbound structure. Furthermore, the same concrete mix design (INDOT Class C) was provided for both structures. Therefore, these parameters were not considered as variables that could explain variations in cracking other than the possibility of construction error.

\subsubsection{Effect of Reinforcement}

The design of the deck reinforcement was reviewed to evaluate its influence on the deck cracking of the US-50 bridge. The reinforcement ratio in the negative moment region of the deck is $0.98 \%$ with a bar spacing of 6 in. while the positive moment region contains a reinforcement ratio of only $0.54 \%$ and a bar spacing of 12 in. Generally, the negative moment region exhibited more tightly spaced and narrower cracks that the positive moment region. The lower amount of reinforcement used in the positive moment region likely experienced some yielding, causing larger crack widths. The negative moment region was reinforced with alternating \#4 bars and \#6 bars spaced at 6 in., which significantly 
improved the performance in this region and resulted in smaller crack widths. The reinforcement ratios in the deck were compared with those previously recommended for the control of bridge deck cracking by Frosch et al. (2006). Assuming 4000 psi concrete and Grade 60 reinforcing steel, the required reinforcement ratio to control cracking is $0.633 \%$. While the reinforcement in the negative moment region met this requirement as well as the maximum recommended bar spacing (6 in.), the reinforcement in the positive moment region was significantly below the recommended amount (approximately 16\% less). In addition, the bar spacing of $12 \mathrm{in}$. in this region was twice the recommended spacing. The difference in cracking performance between the positive and negative moment regions provide support for the recommended minimum reinforcement ratio and maximum bar spacing.

\subsubsection{Effect of Bridge Geometry}

A correlation was observed relating the cracking pattern of the bridge deck to the geometry of the bridge. Little cracking was observed in regions adjacent to expansion joints, likely due to the decreased restraint provided in these regions. In regions within expansion joints, extending between five and six spans, there was a general symmetry about the centerline of the region. Cracking increased towards the interior of the region and was especially high in spans at the approximate quarter points. In cases where the centerline of the region occurred at a pier (Spans B-G, J-O), there was a decrease in cracking at the centerline likely due to a higher amount of reinforcement in these regions. Span D, near the geometric center of structure B-G, may have also exhibited less cracking due to the presence of a pourline (Figure 2.13), which decreased the restraint in that region. In cases where the centerline of the region occurred at midspan (Spans P-T), the span containing the region's centerline exhibited extensive cracking due to the lower amount of reinforcement at midspan. Overall, there appears to be a correlation relating the distance of a region from an expansion joint to increased restrained shrinkage strains in that region. 


\subsubsection{Effect of Weather}

While the bridge geometry and deck reinforcement are identical in both the eastbound and westbound structures, differences in cracking performance were identified. Therefore, differences in weather conditions at the time of construction were reviewed. Because a large portion of the eastbound deck was poured during the late fall and winter, the ambient temperature at the time of the pour was relatively low. The extensive cracking of the deck may have been affected by a large temperature differential between the steel girders and concrete during hydration. In addition, the low temperatures likely caused a slow development of strength in the deck which may have led to increased cracking as the tensile strength was not adequate to resist the tensile stresses due to restrained shrinkage. It is also likely that the low temperatures made proper wet curing difficult if not impossible The westbound span was cast during summer months with temperatures averaging between $65^{\circ} \mathrm{F}$ and $83^{\circ} \mathrm{F}$, high enough to greatly reduce the temperature differential while not surpassing $90^{\circ} \mathrm{F}$, as recommended by ACI 224R-07.

Crack patterns of Span F for both the eastbound and westbound structures are presented in Figure 2.17. Temperature and humidity data for the 7 days following each corresponding pour is presented in Figure 2.18. As shown, eastbound Span F exhibited much more cracking that westbound Span F. Low temperatures from 4/5/2003 through 4/8/2003 may have influenced the cracking. Proper wet curing is difficult if not impossible at low temperatures, especially if the temperature is near freezing, as was the case on 4/6/2003. It is probable that proper wet curing was not carried out on eastbound Span F.

Crack patterns of Span K for both the eastbound and westbound structures are presented in Figure 2.19. Temperature and humidity data for the 7 days following each corresponding pour is presented in Figure 2.20. Similar to Span F, eastbound Span K exhibited much more cracking than westbound Span K. Eastbound Span K was cast on $11 / 12 / 2002$ and in the 7 days following the cast was frequently exposed to temperatures at or below freezing. These low temperatures caused a high temperature differential between the deck and the steel girders during casting. In addition, it is expected that wet curing was very difficult due to the low temperatures and may not have been performed. The 
increased cracking in eastbound Span K compared to westbound Span K was most likely due to these factors.

Other weather conditions such as precipitation, humidity, and wind speed did not appear to have a significant influence on the early age shrinkage of the decks (Table 2.2, Table 2.3). No precipitation occurred during the casting of the eastbound deck and occurred only once during the casting of the westbound deck. In addition, the average relative humidity and average wind speed during days of casting were similar for most castings. However, the casting of eastbound span D-G was performed on a day with both low humidity (41\% RH) and high winds (19.9 mph). As shown in Figure 2.18, the relative humidity was fairly low for the first few days following casting of eastbound Span F. This likely affected cracking, as higher humidities during the casting of westbound Span F led to better performance. Map cracking was evident in these spans, indicating significant plastic shrinkage that would be expected for low humidities and high wind speeds. These factors may have also increased surface evaporation, leading to higher early age shrinkage and increased cracking in these spans (Figure 2.13).

\section{Span F (EB)}

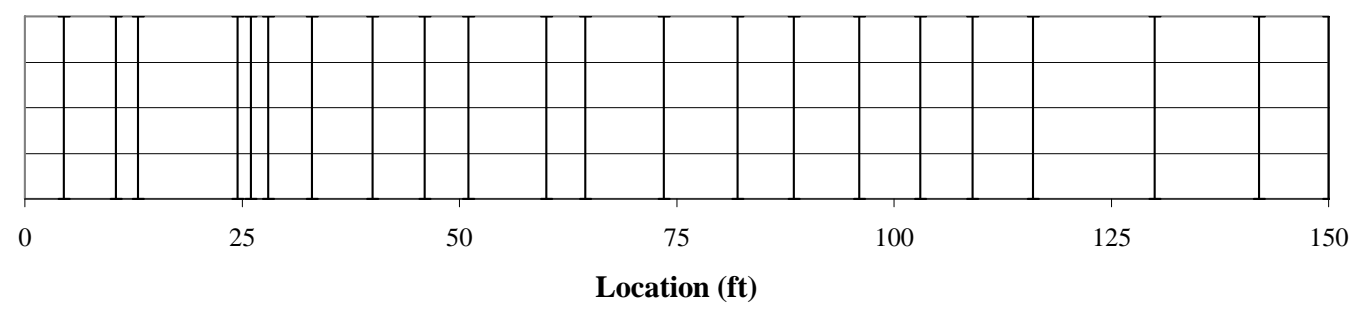

\section{Span F (WB)}

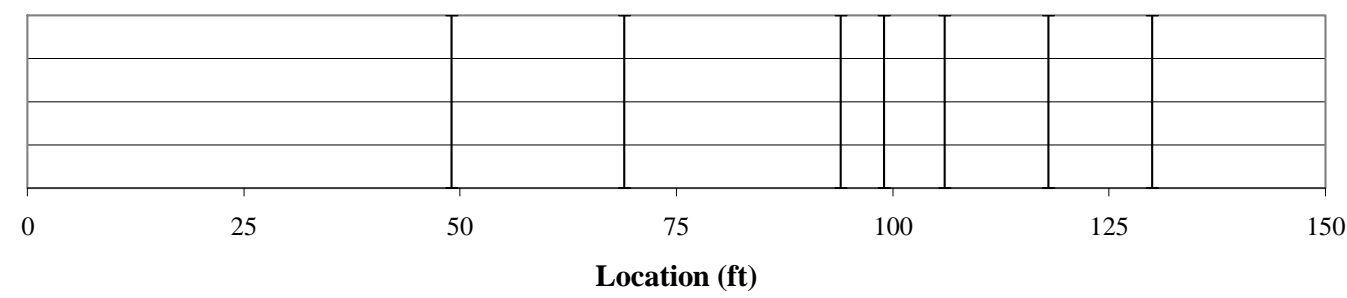

Figure 2.17: Span F crack pattern, eastbound and westbound 


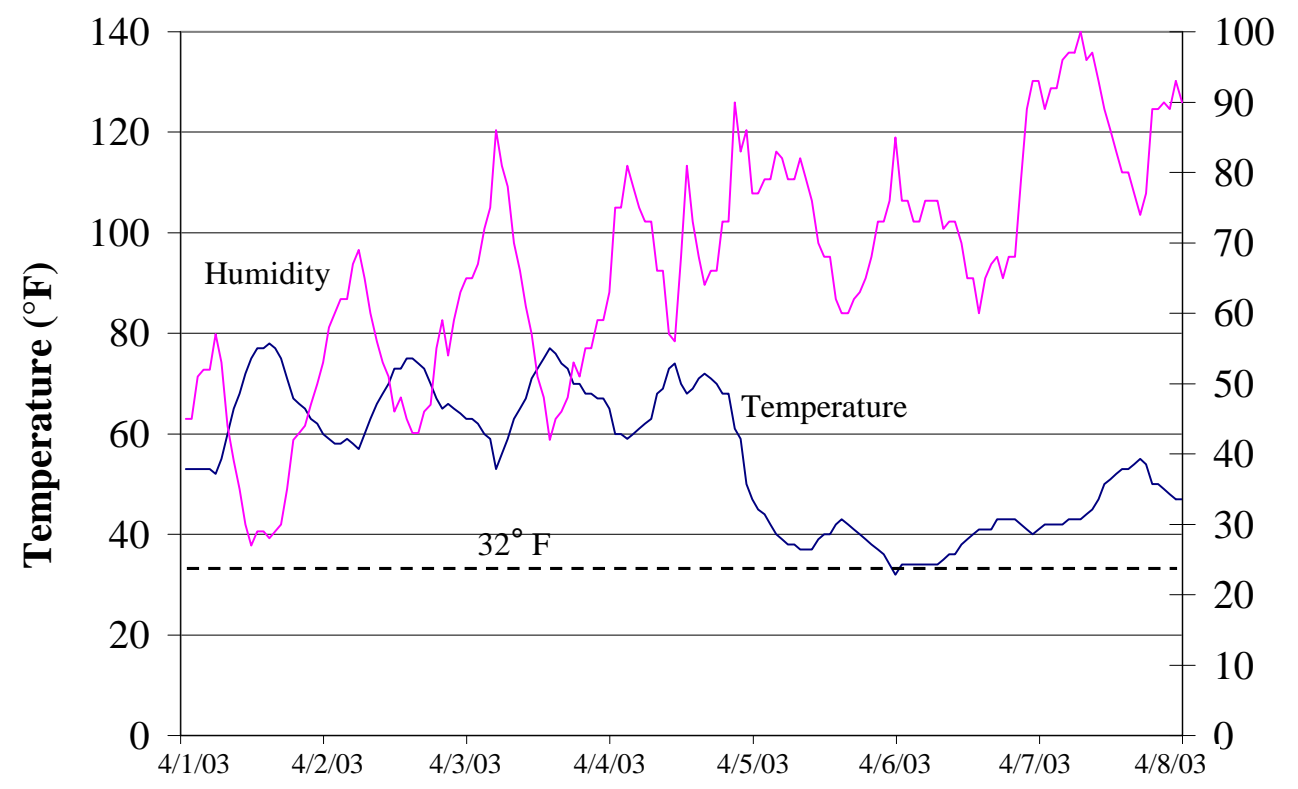

先

Date

b) Eastbound

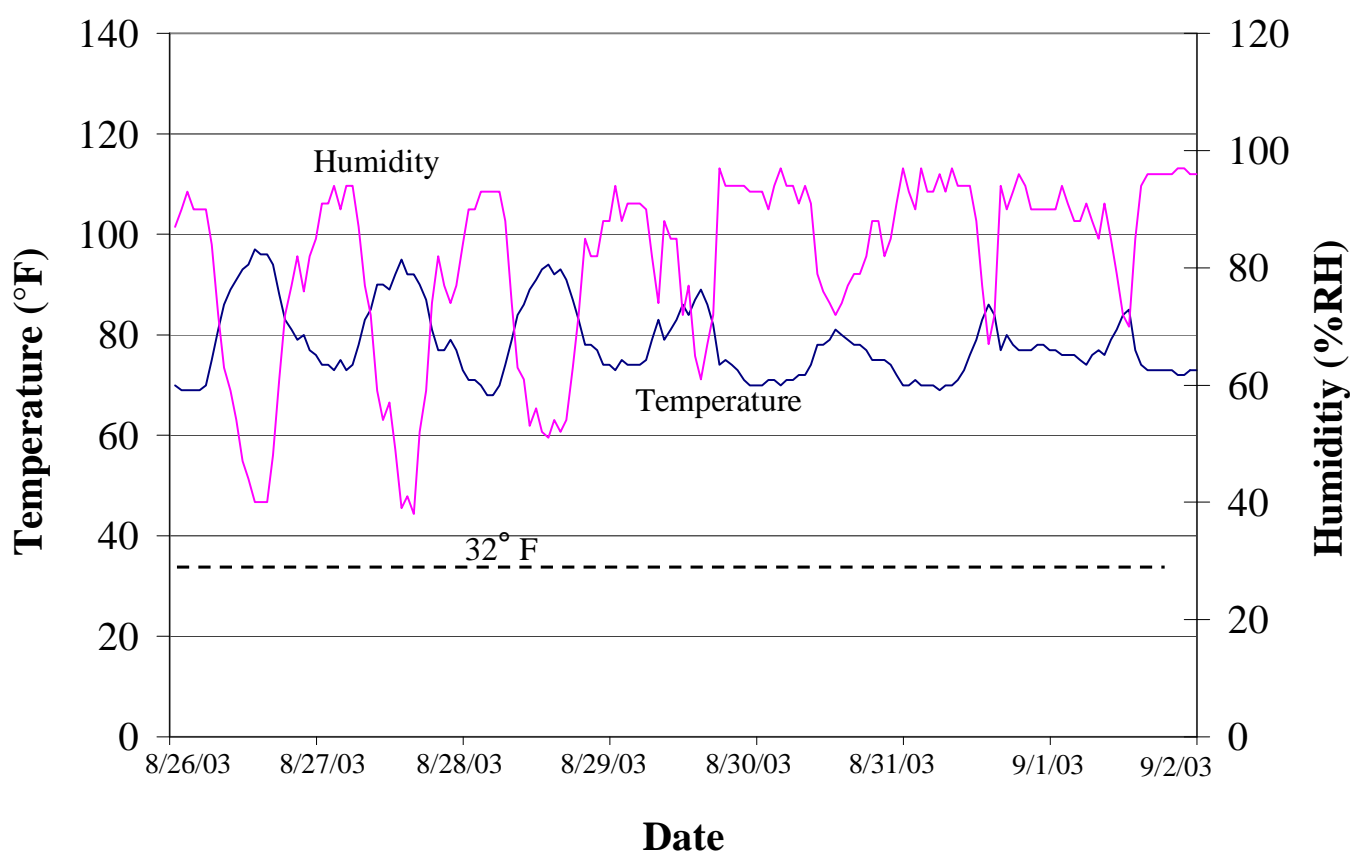

b) Westbound

Figure 2.18: Temperature and humidity data, Span $F$ 
Span K (EB)

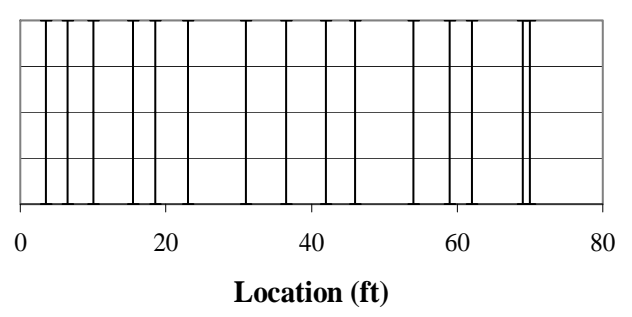

Span K (WB)

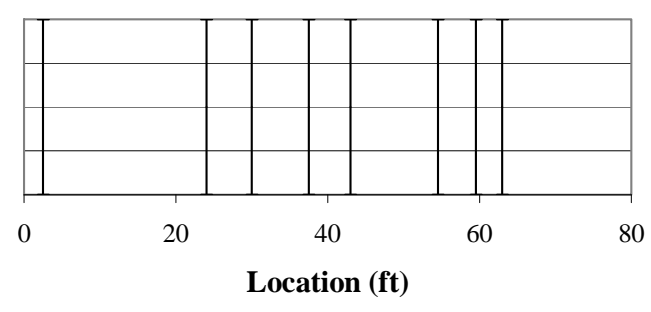

Figure 2.19: Span K crack pattern, eastbound and westbound 


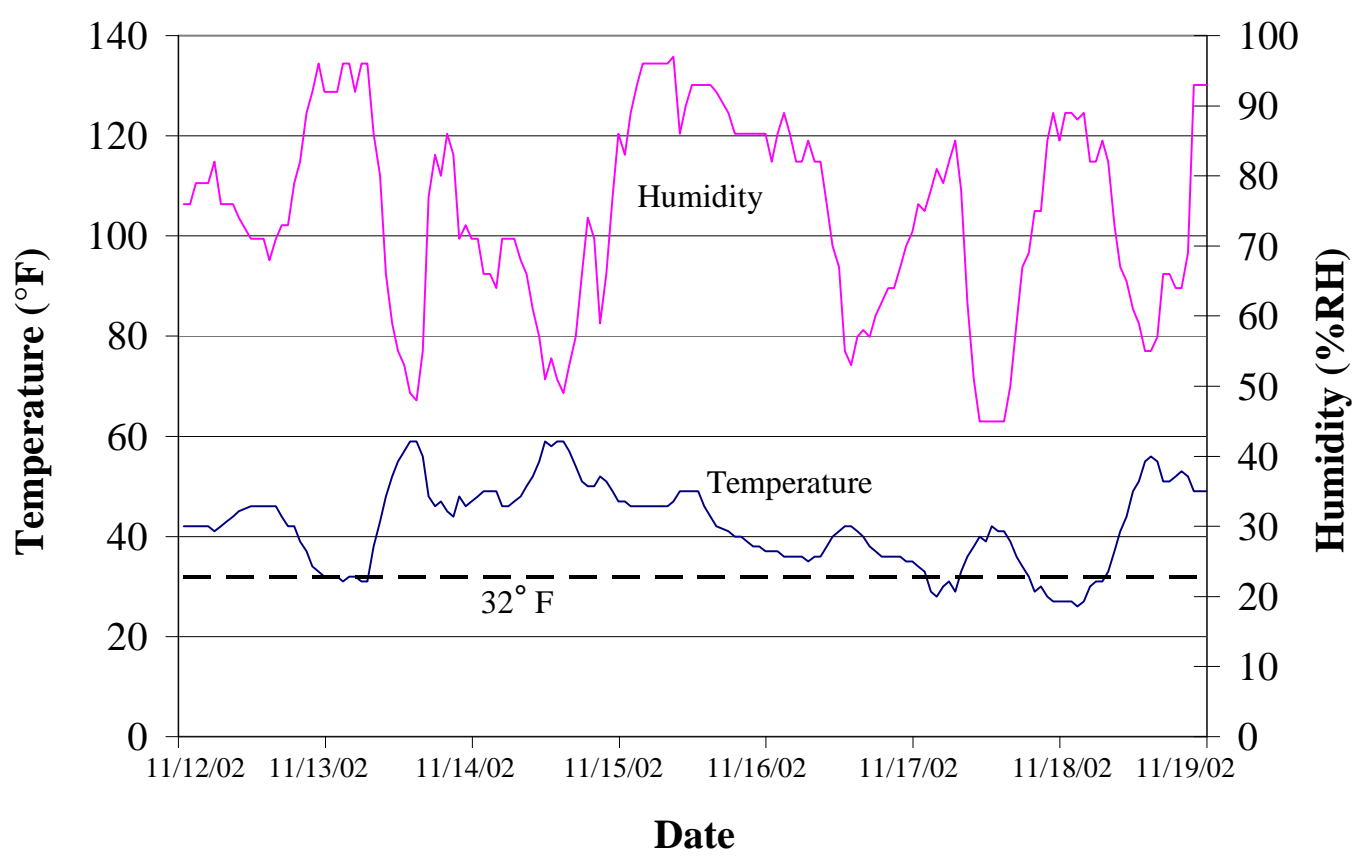

b) Eastbound

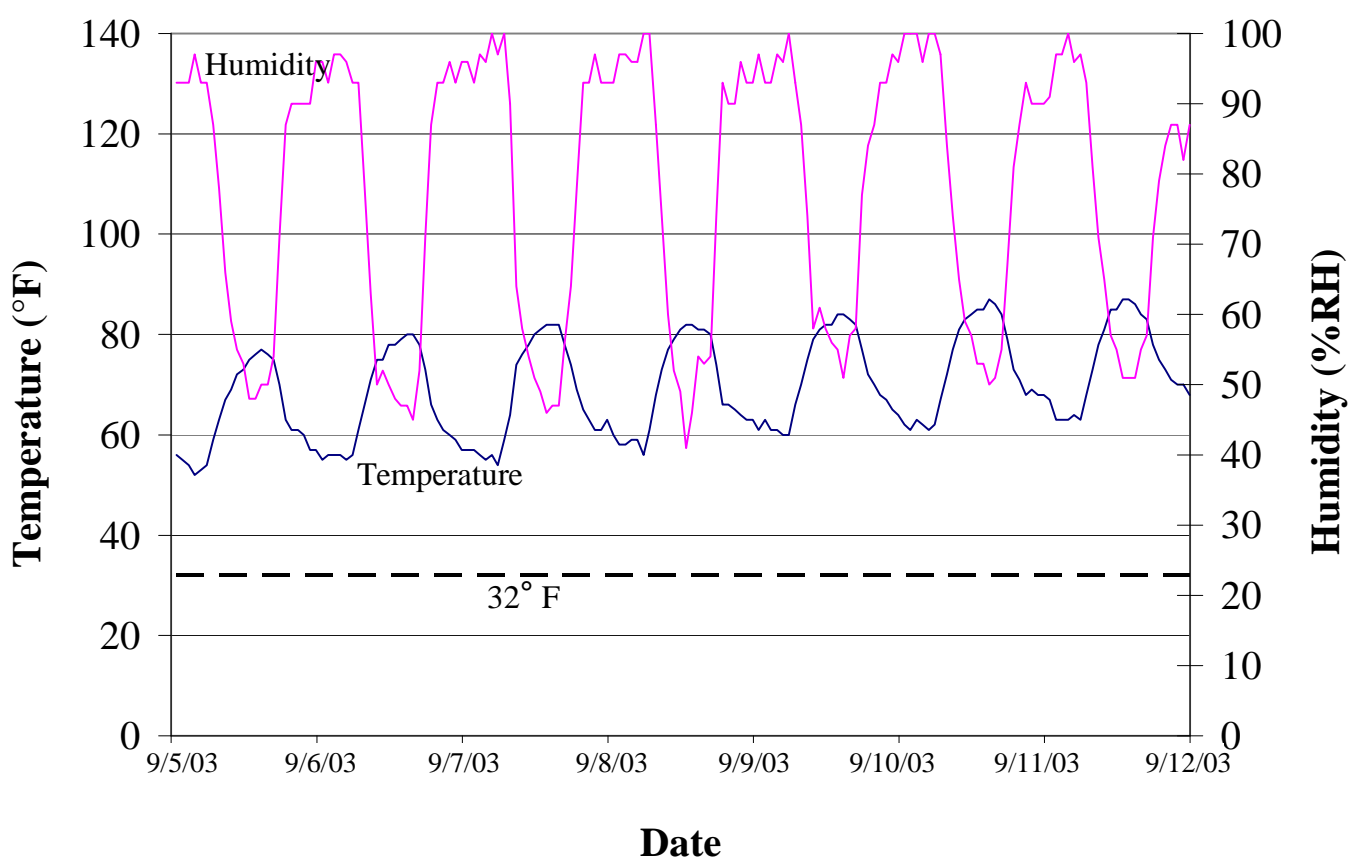

b) Westbound

Figure 2.20: Temperature and humidity data, Span K 


\subsection{Summary}

Based on a quantitative and qualitative investigation of the bridge deck cracking pattern of the US-50 bridge, the following trends were observed:

1. Significantly more cracking was observed in the eastbound span than the westbound span.

2. Little cracking was observed in regions adjacent to expansion joints.

3. Cracks in negative moment regions of the bridge were generally more closely spaced than in positive moment regions.

4. Cracks in negative moment regions of the bridge were generally finer (0.010 to 0.013 in.) than cracks in positive moment regions (0.016 to 0.020 in.).

An investigation of the design and construction of the bridge revealed three major factors that appear to have significantly influenced the bridge deck cracking behavior:

\section{Deck Reinforcement:}

An inadequate reinforcement ratio and bar spacing is present in the positive moment regions of the bridge, likely contributing to the extensive cracking and increased crack widths in these regions. The negative moment regions contain an increased reinforcement ratio and decreased bar spacing which led to decreased crack widths in the regions.

\section{Bridge Geometry:}

Regions adjacent to expansion joints exhibited the least cracking due to decreased restraint. The most cracking occurred in positive moment regions not adjacent to expansion joints due to high tensile stresses caused by high levels of restrained shrinkage. Negative moment regions not adjacent to expansions joints likely also experienced high tensile forces but less cracking due to increased reinforcement. 


\section{Weather:}

The difference in cracking performance of the eastbound and westbound structures can be attributed to the weather during construction. Detrimental effects caused by the low temperatures during the construction of the eastbound structure include a high temperature differential between the deck and the steel girders during casting, a retarded development of tensile strength in the deck, and improper and ineffective wet curing. Other weather conditions that contributed to deck cracking include low humidities and high wind speeds during casting. The most severe cracking was exhibited by eastbound Spans D-G which experienced this combination of environmental factors. The difference in performance between the eastbound and westbound structures illustrates the importance of weather conditions during construction.

\section{$\underline{2.6 \text { Conclusions }}$}

Based on an analysis of the structure and its construction, it was determined that poor weather conditions during construction and inadequate deck reinforcement caused the significant bridge deck cracking of the US-50 bridge. The deck reinforcement ratio and bar spacings in the positive moment regions of the bridge were below those recommended to control deck cracking (Frosch et al. 2003, 2006) which resulted in considerable deck cracking and wide cracks. Deck cracking of the eastbound structure was significantly worse than the westbound structure due to poor weather conditions at the time of casting. While a 7 day minimum wet cure was required at the time of construction, low temperatures at the time of casting made proper wet curing difficult if not impossible. Low temperatures also led to increased deck cracking by causing a slow development of concrete strength and a high temperature differential between the concrete deck and the steel girders during hydration. 


\section{CHAPTER 3 \\ CURING INVESTIGATION}

\subsection{Introduction}

Laboratory specimens were constructed to investigate the influence of both the wetcure duration and concrete mix on the shrinkage of concrete. The primary objectives of this phase of the research were to determine whether the current INDOT-required 7 day wet cure is adequate and to compare the performance of INDOT Class C concrete used in bridge decks to the performance of a lower-cement-content mix. A secondary objective was to evaluate the capability of sensors to quantitatively measure the quality and duration of the wet curing.

\subsection{Specimen Design}

The laboratory specimens were designed to represent an interior section of a fullscale bridge deck. The size selected was 24 in. by 24 in. by 8 in., with the 8 in. dimension representing the thickness of a typical bridge deck (Figure 3.1). The other dimensions were selected to provide sufficient surface area to shrink similarly to a bridge deck while still allowing for ease of handing in the laboratory. The specimens were designed to allow for free shrinkage and therefore contained no reinforcing steel or other form of restraint. 


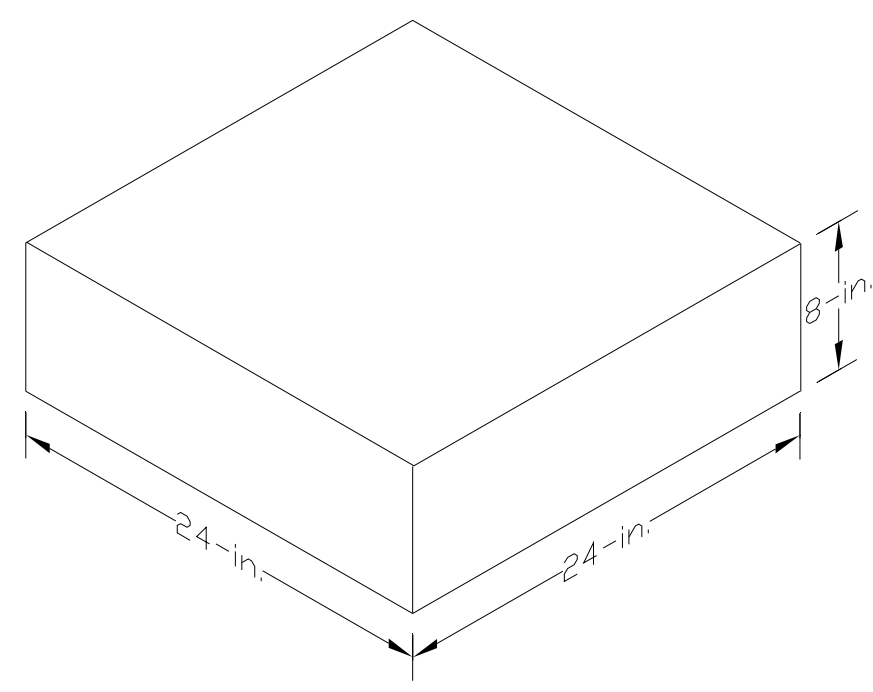

Figure 3.1: Specimen dimensions

\subsubsection{Specimen Variables}

Three test variables were evaluated, including the duration of wet cure, wet curing procedure, and concrete mix. Details of the specimens are provided in Table 3.1.

\section{o Curing Duration}

The specimens were continuously wet cured for different durations, varying from 1 to 28 days. Following wet curing, the specimens were placed in a humidity-controlled room and permitted to shrink freely.

\section{O Curing Procedure}

While the majority of the specimens were continuously wet cured, two variable curing procedures were implemented to investigate the effect of improper curing regimens. The first procedure consisted of alternating periods of wet curing and drying (Figure 3.2). The second procedure consisted of initially wet curing the specimens but, rather than rewetting the burlap as needed, allowing it to slowly dry out (Figure 3.3). This procedure simulated an improper curing regimen which may occur during construction. 
0 Concrete Mix

Two mixes were selected and included an INDOT Class C concrete mix, typically used in bridge deck construction, as well as a concrete mix designed with a lower cement content. This alternate mix was designed using recommendations provided in a previous JTRP study (Frosch et al. 2003) to produce lower shrinkage. The concrete was designed to achieve a minimum strength of 4000 psi as required for bridge deck construction.

Table 3.1: Wet cure specimens

\begin{tabular}{|c|c|c|}
\hline \multirow{2}{*}{$\begin{array}{c}\text { Wet Cure } \\
\text { Duration (days) }\end{array}$} & \multicolumn{2}{|c|}{ Specimen } \\
\cline { 2 - 3 } & INDOT Class C & Low Shrinkage Mix \\
\hline 1 & C-1 & LS-1 \\
\hline 3 & C-3 & LS-3 \\
\hline 5 & C-5 & LS-5 \\
\hline 7 & C-7 & LS-7 \\
\hline 10 & C-10 & LS-10 \\
\hline 14 & C-14 & LS-14 \\
\hline 21 & C-21 & LS-21 \\
\hline 28 & C-28 & LS-28 \\
\hline Variable 1 & C-V1 & LS-V1 \\
\hline Variable 2 & C-V2 & LS-V2 \\
\hline
\end{tabular}




\begin{tabular}{|c|c|c|c|c|c|c|c|c|c|}
\hline \multicolumn{2}{|c|}{$\frac{\text { Day } 1}{\text { Wet cure }}$} & \multicolumn{3}{|c|}{$\begin{array}{l}\frac{\text { Day } 4}{\text { Resume }} \\
\text { wet cure }\end{array}$} & \multicolumn{5}{|c|}{$\begin{array}{l}\frac{\text { Day } 8}{\text { Resume }} \\
\text { wet cure }\end{array}$} \\
\hline & & \multicolumn{3}{|c|}{1} & \multicolumn{5}{|c|}{1} \\
\hline 1 & 2 & 3 & 4 & 5 & 6 & 7 & 8 & 9 & 10 \\
\hline & $\begin{array}{c}1 \\
\text { Dav }\end{array}$ & & & & $\begin{array}{c}1 \\
\text { Dav } 6\end{array}$ & & & & $\begin{array}{c}1 \\
\text { Dav } 10\end{array}$ \\
\hline & $\begin{array}{l}\text { Begi } \\
\text { dryin } \\
\text { perio }\end{array}$ & & & & $\begin{array}{l}\text { Begin } \\
\text { drying } \\
\text { perioc }\end{array}$ & & & & $\begin{array}{l}\text { Begin } \\
\text { ermanen } \\
\text { drying } \\
\text { period }\end{array}$ \\
\hline
\end{tabular}

Figure 3.2: Variable Cure 1 timeline

Day 1

Wet cure

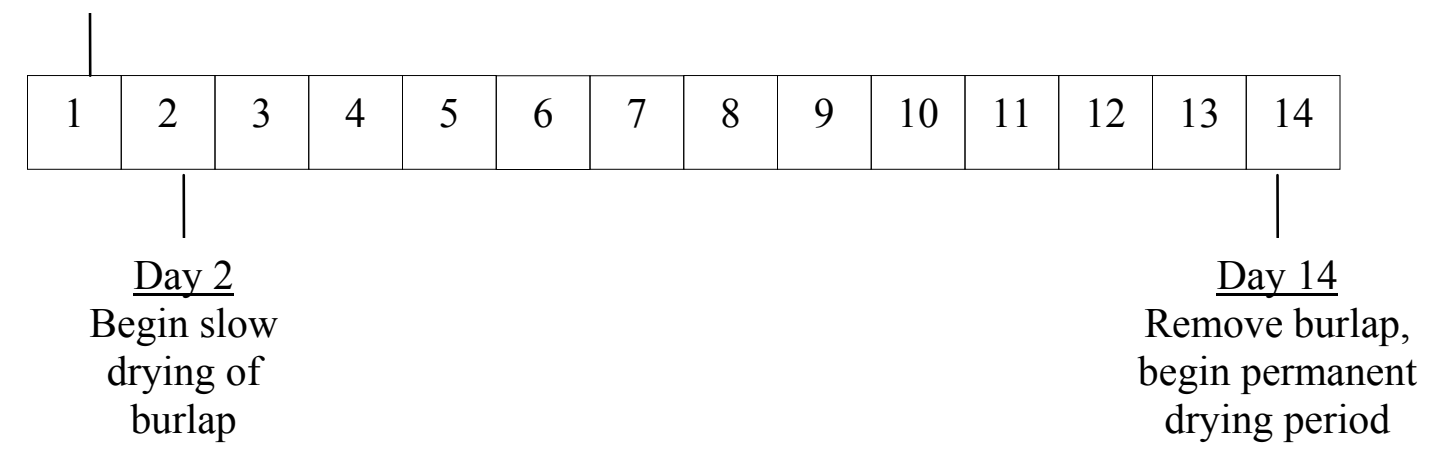

Figure 3.3: Variable Cure 2 timeline 


\section{$\underline{3.3}$ Instrumentation}

Instrumentation of the curing specimens was designed to serve two purposes. The first was to measure the shrinkage of the specimens. The second was to investigate the effectiveness of the sensors to serve as a measurement device that can monitor the quality and duration of the curing procedure. Instrumentation included embedment strain gages, humidity gages, and thermocouples.

\subsubsection{Strain Gages}

Vishay Micro-Measurements EGP-5-350 embedment strain gages were placed in the specimens to measure concrete shrinkage strains. These gages consisted of a 4 in. gage length inside of a 5 in. outer body. In addition to providing protection for the gage inside, the outer body's deformations allow the concrete to securely attach to the gage, ensuring maximum strain sensitivity. The engineering data for the strain gages is provided in Table 3.2 .

Table 3.2: Embedment strain gages details

\begin{tabular}{|c|c|}
\hline Gage Type & EGP-5-350 \\
\hline Resistance in Ohms at $24^{\circ} \mathrm{C}$ & $350+/-0.8 \%$ \\
\hline Gage Factor at $24^{\circ} \mathrm{C}$ & $2.06+/-1.0 \%$ \\
\hline Temperature Range & $+25^{\circ}$ to $+125^{\circ} \mathrm{F}$ \\
\hline Self-Temperature Compensation & Yes \\
\hline Strain Limits & $0.5 \%$ \\
\hline
\end{tabular}

The gages were oriented in the specimens such that longitudinal shrinkage strains could be measured. This alignment is shown in Figure 3.4. To install the gages at the same position in all specimens, they were hung from above the forms using wire to provide correct alignment at the center of the specimens (Figure 3.5). 

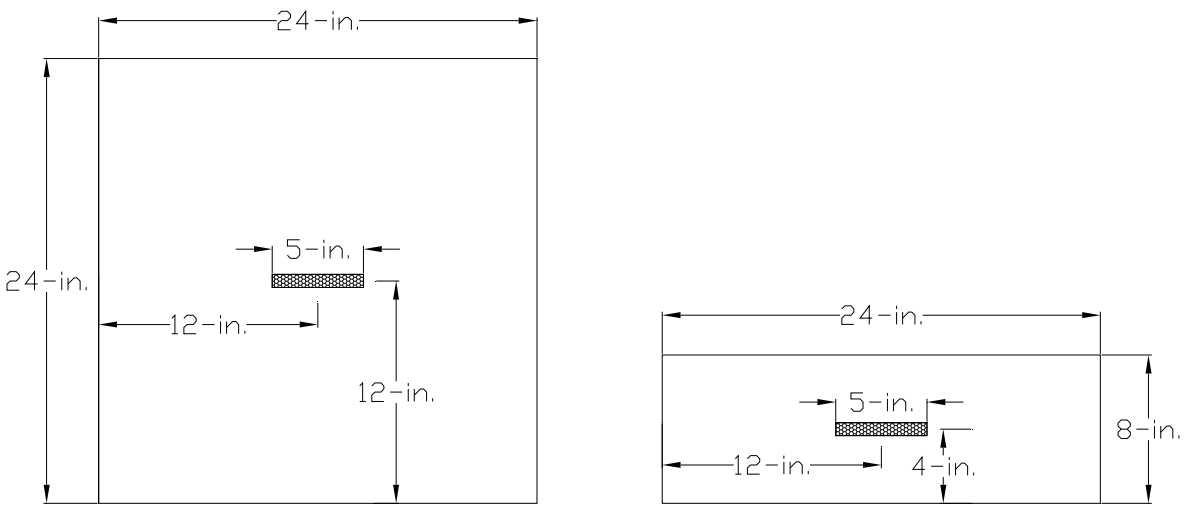

Figure 3.4: Alignment of embedment strain gages

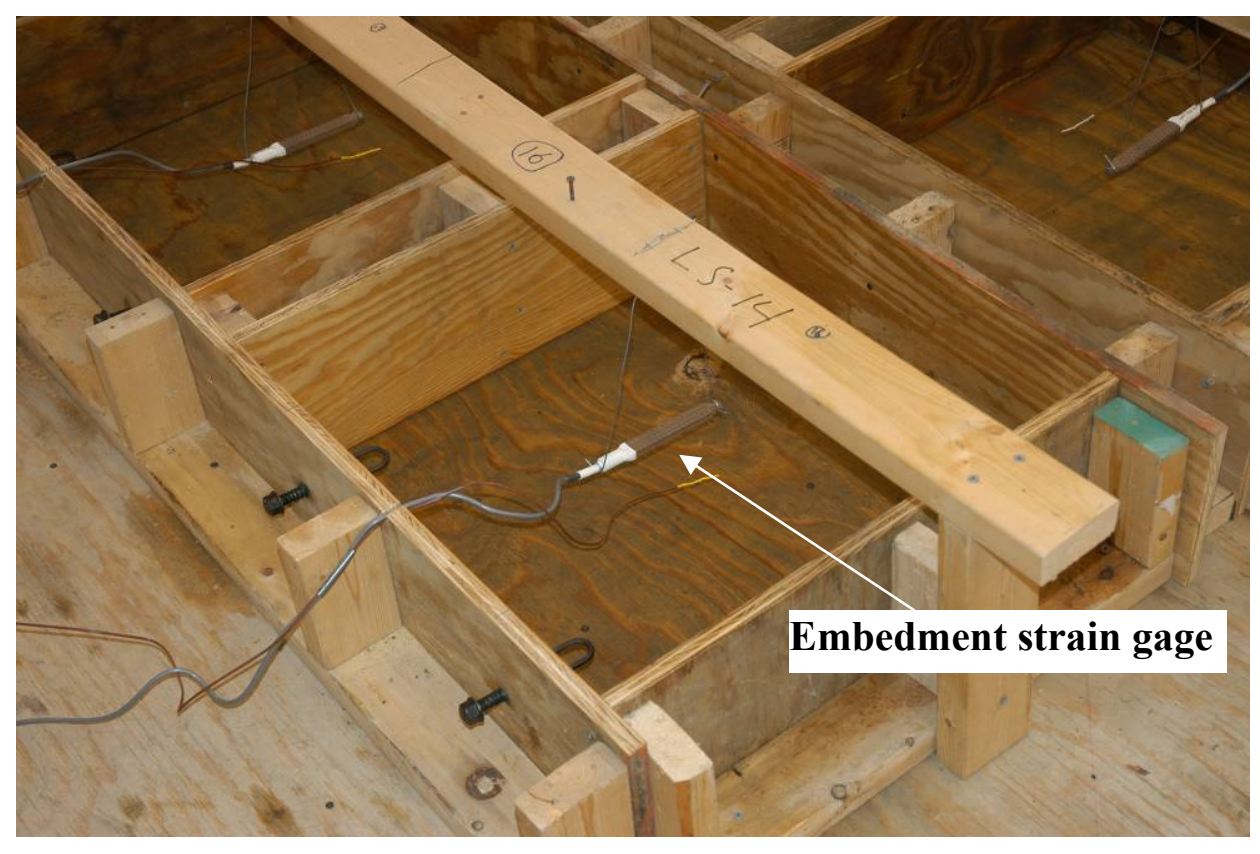

Figure 3.5: Concrete formwork and embedment strain gage 


\subsubsection{Relative Humidity Sensors}

Relative humidity sensors were installed in selected specimens to investigate whether a correlation can be observed between the internal relative humidity of the concrete and the curing procedure. A number of humidity sensors were considered including the Sensiron SHT7x Humidity and Temperature Sensor, the Ohmic Instruments UPS-600 Humidity Sensor, and the Ohmic Instruments IC-HC-610 Humidity Sensor. The Ohmic Instruments IC-HC-610 Humidity Sensor was selected for a number of reasons. First, the sensor can measure a wide range of humidities and is accurate up to about $95 \%$ RH. Second, the sensor is a capacitive sensor and has a linear DC voltage output, making it easy to implement in the field using common data collection systems. Finally, it is relatively inexpensive, making it a good candidate for field implementation.

When placed in concrete, the humidity sensor must be protected from the concrete, water, and other materials which would interfere with the accuracy of or damage the sensor. A method to protect the humidity sensor, developed in previous research (Grasley and Lange 2004), was implemented which involved placing the sensor inside a small plastic tube. One end of the tube was sealed with electrician's tape and Star Brite Liquid Electrical Tape waterproofing sealant. The other end was covered by a Gore-Tex patch and attached with Super Glue Cyanoacrylate adhesive. Gore-Tex was used because it allows water vapor to reach the sensor while protecting it from liquids or other materials that could damage the sensor.

Humidity sensors were not placed in all of the shrinkage specimens because they were being evaluated solely as a monitoring device. Therefore, humidity sensors were placed in the four specimens that underwent variable curing to determine if irregular curing practices could be observed through analysis of the data from the sensor only. Humidity sensors were also placed in the 7-day cure specimens to provide a relative frame of reference. The 7-day cure specimens were selected as the control, as this is the standard wet curing duration required by INDOT.

The humidity gages were placed near the center of the specimens. The alignment of the gages did not matter, but they were placed as close to the center of the specimens as possible to eliminate edge effects without interfering with the embedment strain gages. 


\subsubsection{Thermocouples}

Thermocouples were installed in the curing specimens to determine if there was a correlation between the internal temperature of the concrete and the curing procedure. The thermocouples were made of Type $\mathrm{T}$ thermocouple wire from Omega Engineering, Inc. One copper wire and one constantan wire were soldered together and covered with shrink wrap for protection. The thermocouples measure temperature relative to a Campbell Scientific 107-L Temperature Probe which uses a thermistor to measure the ambient air temperature. The details of the probe are provided in Table 3.3.

The thermocouples were placed within the specimen relatively close to the center. Space was provided to eliminate interference with the embedment strain gages and humidity sensors.

Table 3.3: Temperature probe details

\begin{tabular}{|c|c|}
\hline Sensor Type & $\begin{array}{c}\text { Campbell Scientific 107-L } \\
\text { Temperature Probe }\end{array}$ \\
\hline Temperature Measurement Range & $-35^{\circ}$ to $+50^{\circ} \mathrm{C}$ \\
\hline Temperature Survival Range & $-50^{\circ}$ to $+100^{\circ} \mathrm{C}$ \\
\hline Accuracy (at $0^{\circ}$ to $+50^{\circ} \mathrm{C}$ ) & $+/-0.20^{\circ} \mathrm{C}$ \\
\hline
\end{tabular}




\section{$\underline{\text { 3.4 Materials }}$}

Two types of concrete were used for this study. The first was an INDOT Class C mix obtained from Irving Materials (IMI), a local supplier. INDOT Class C is the type of concrete typically used in bridge decks across the State of Indiana. The mix design is provided in Table 3.4. The second type of concrete, which was also obtained from IMI, was a lower shrinkage mix and was designed as previously discussed to exhibit lower shrinkage relative to that typically observed for Class $\mathrm{C}$ concrete. This mix was designed to reduce shrinkage primarily through a reduction in cement content which also reduced water demand. In addition, fly ash was included to assist in the reduction of shrinkage. Crushed stone aggregate (3/4 in.), consistent with the Class C Concrete, was selected. However, sand content was increased to reduce void space. The mix was designed with a target concrete compressive strength of 4500 psi and 6\% air. The low shrinkage mix design is also provided in Table 3.4.

Table 3.4: Concrete mix proportions (amount per cubic yard)

\begin{tabular}{|c|c|c|}
\hline Material & INDOT Class C & $\begin{array}{c}\text { Low Shrinkage } \\
\text { Mix }\end{array}$ \\
\hline Portland Cement (Type I) & $658 \mathrm{lbs}$ & $440 \mathrm{lbs}$ \\
\hline Fly Ash (Class C) & 0 & $100 \mathrm{lbs}$ \\
\hline Water & $273 \mathrm{lbs}$ & $220 \mathrm{lbs}$ \\
\hline \#8 Stone & $1796 \mathrm{lbs}$ & $1816 \mathrm{lbs}$ \\
\hline \#23 Sand & $1222 \mathrm{lbs}$ & $1398 \mathrm{lbs}$ \\
\hline Micro Air & $4.0 \mathrm{oz}$ & $3.3 \mathrm{oz}$ \\
\hline Glenium 3030 & $13.3 \mathrm{oz}$ & $11.0 \mathrm{oz}$ \\
\hline Target air content & $6 \%$ & $7 \%$ \\
\hline Slump & $6 \mathrm{in}$. & $4 \mathrm{in}$. \\
\hline Air Content & $6.8 \%$ & $4.8 \%$ \\
\hline
\end{tabular}


Standard 6-in. by 12-in. cylinder specimens were cast along with the curing specimens at the time of the concrete pour. The cylinders were continuously wet cured until the time of testing, which occurred at 7, 14, 21, and 28 days. The strength gain for both types of concrete is shown in Figure 3.6. Despite the lower cement content, the lower shrinkage mix achieved a strength similar to the Class $\mathrm{C}$ mix.

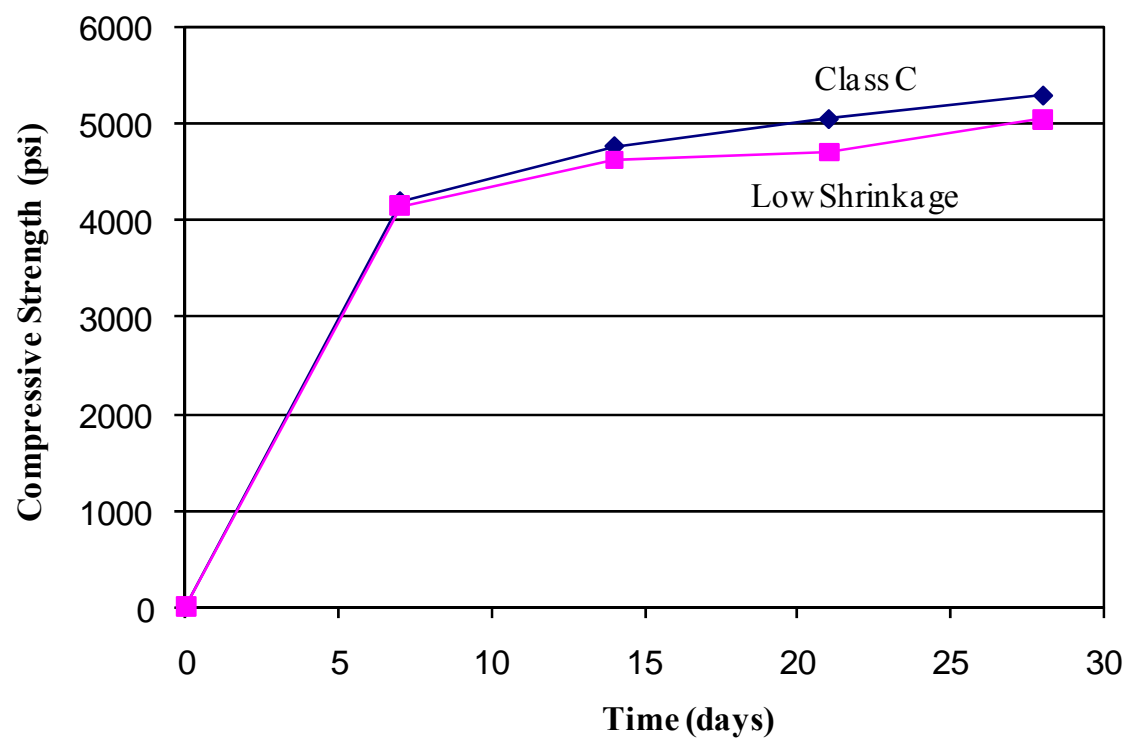

Figure 3.6: Strength gain curve 


\subsection{Specimen Construction}

\subsubsection{Formwork}

The concrete formwork (Figure 3.7) was designed so that all specimens could be cast at approximately the same time. Simultaneous casting was required to minimize potential variations in the concrete mix as well as environmental conditions such as temperature and humidity.

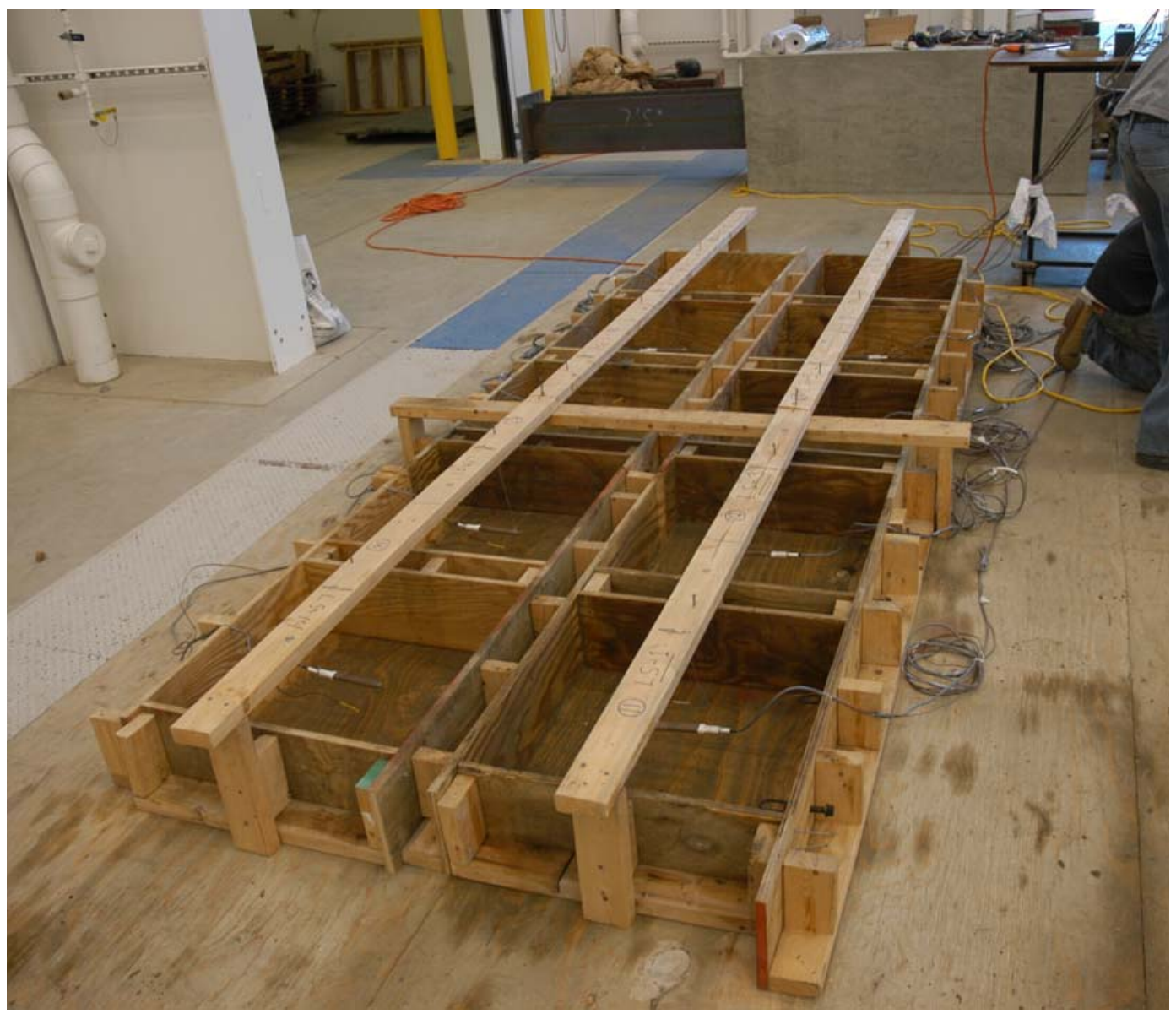

Figure 3.7: Specimen formwork 


\subsubsection{Testing Frames}

In addition to the formwork, testing frames were constructed to hold the specimens throughout the duration of the test. These frames, as shown in Figure 3.8, were built to hold two specimens each so that the specimens that were subjected to the same wet curing procedure could be stored together. The specimens were placed in the frames vertically and positioned so that the embedment gages measured strains in the vertical direction. This alignment was selected to minimize restraint and provide a uniform exposure surface to eliminate the potential for differential shrinkage across the depth of the specimen.

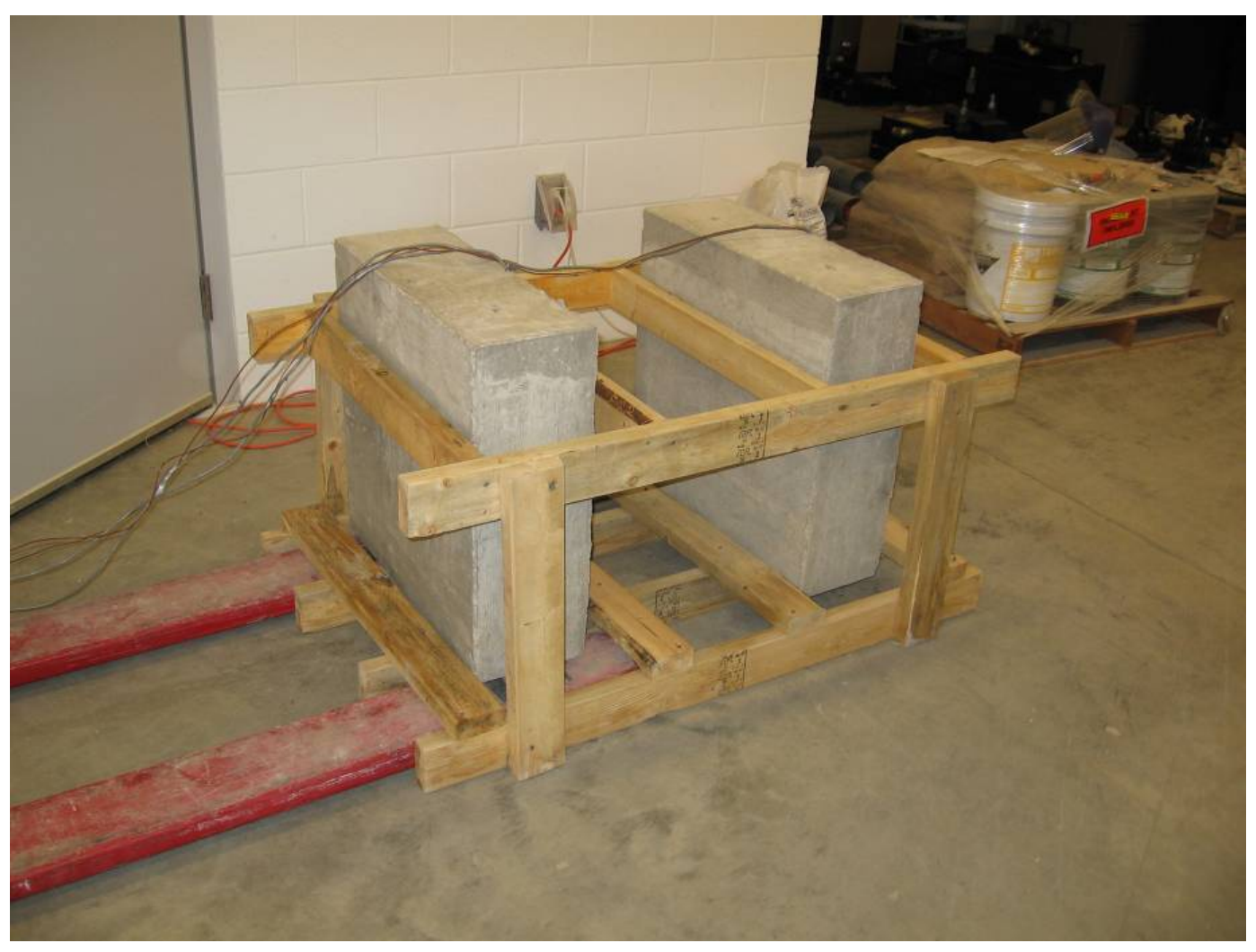

Figure 3.8: Testing frame 


\subsubsection{Casting}

The shrinkage specimens were cast on August 13, 2007. The Class C concrete specimens were cast first and finishing was completed at approximately 2:15 PM. The low shrinkage specimens were cast immediately afterwards and were finished at approximately 3:10 PM. A complete timeline of the casting operation is shown in Figure 3.9.

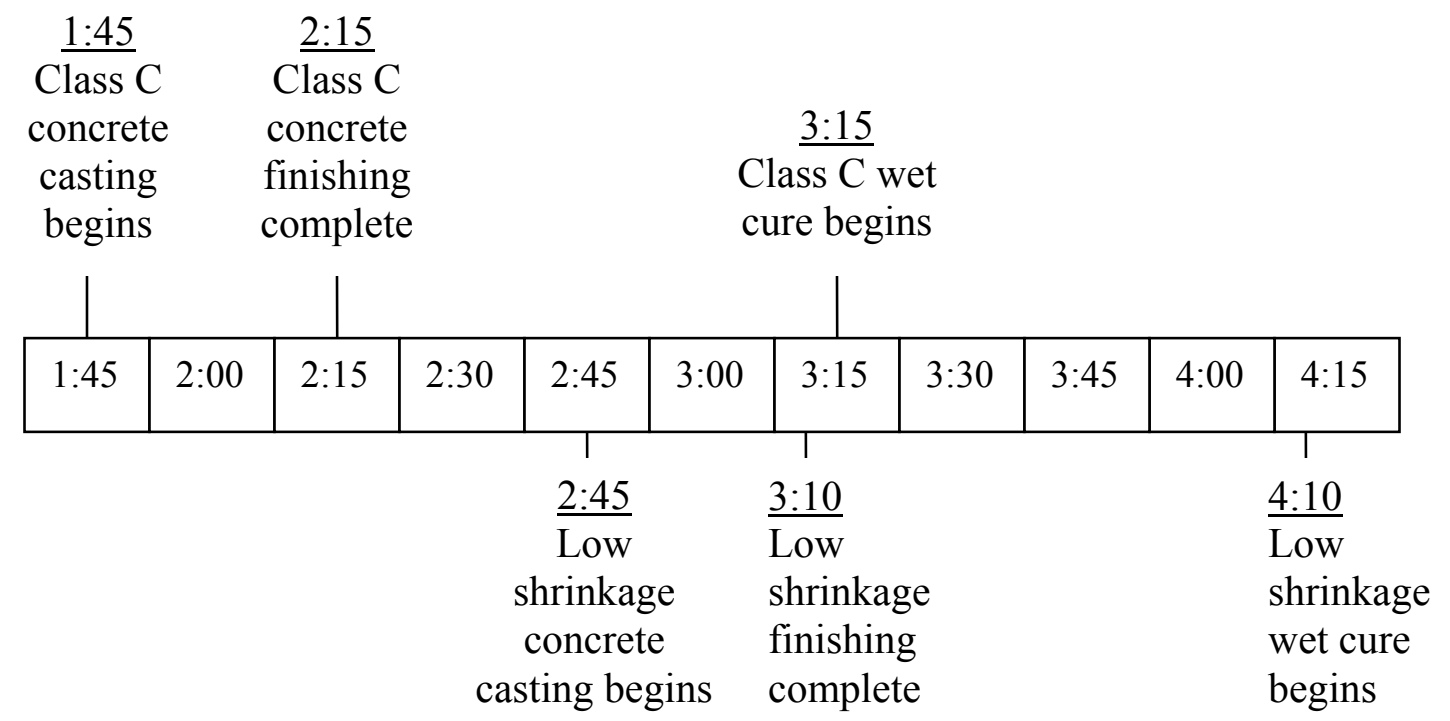

Note: All times are P.M. on August 13, 2007

Figure 3.9: Concrete casting timeline 
The concrete was delivered to the formwork directly from the truck using the truck's chute and subsequently vibrated. During vibration, the sensors were inserted by hand and properly aligned (Figure 3.10). The specimens were hand screeded and finished using a float. Approximately one hour after finishing, they were covered with wet burlap and plastic sheeting to initiate the wet curing process.

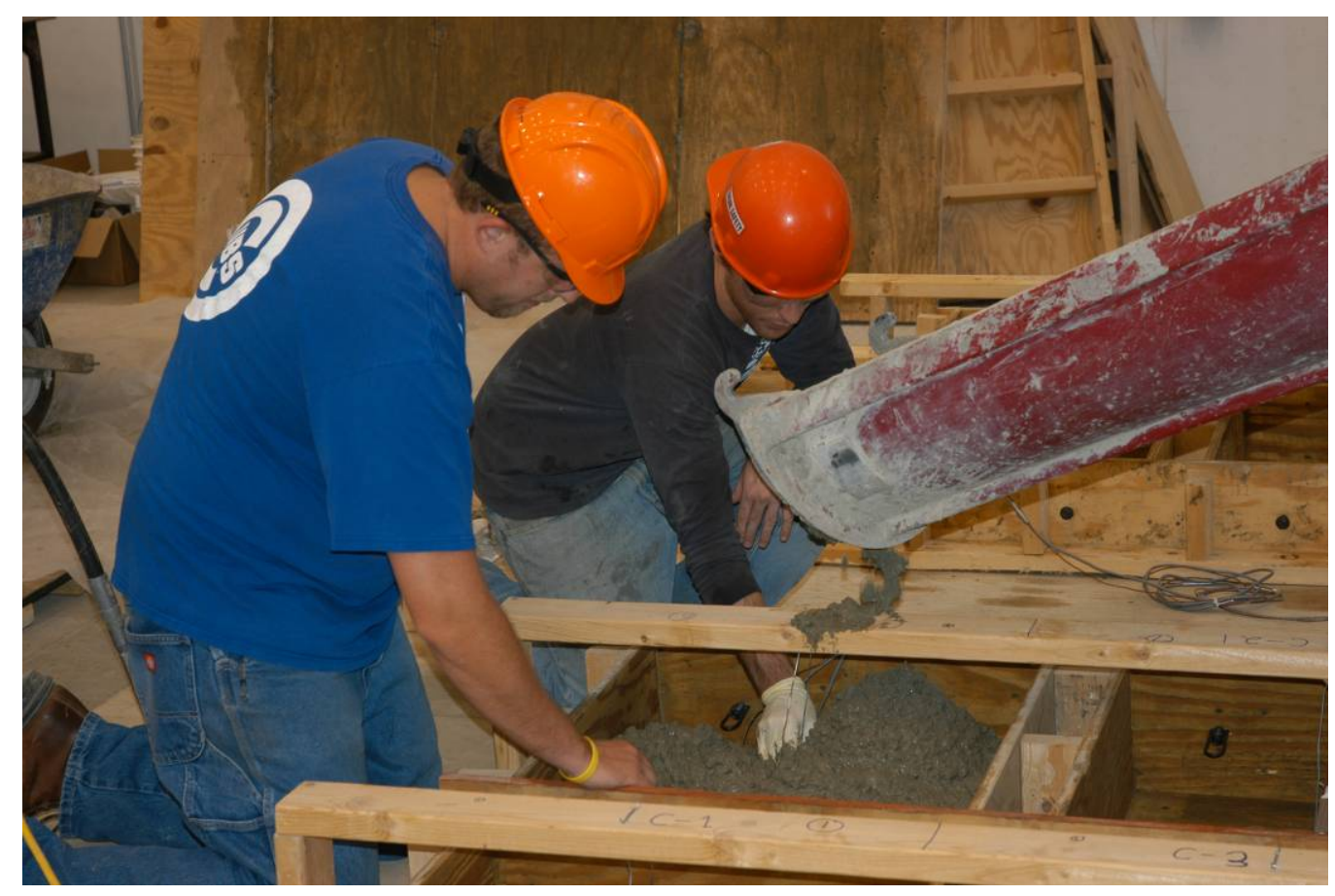

Figure 3.10: Aligning of concrete embedment gages 


\section{$\underline{3.6}$ Test Procedure}

After the specimens were cast, varying curing duration and procedures were implemented to investigate their effect on shrinkage.

\subsubsection{Curing Procedure}

Twenty total specimens were constructed, ten of INDOT Class C concrete and ten of the low-shrinkage concrete. All twenty specimens were wet cured for the first 24 hours in the concrete formwork. Wet curing was accomplished by placing wet burlap over the specimens and re-wetting the burlap as needed. After 24 hours, the formwork was removed and the specimens were placed vertically in testing frames and re-covered with wet burlap, continuing the wet cure. When wet curing was finished according to the testing schedule, the burlap was removed, and the specimens were placed in a humidity-controlled room, with the relative humidity set at $50 \%$.

As designed, the first eight sets of specimens were subjected to continuous wet curing of varying durations as provided in Table 3.1. The final two sets of specimens were subjected to variable wet curing. Timelines of these procedures are presented in Figure 3.2 and Figure 3.3.

At 28 days, the last set of specimens was placed in the humidity-controlled room (Figure 3.11) and permitted to cure over an extended period of time. Humidity was monitored to maintain $50 \% \mathrm{RH}$ throughout the duration of testing. 


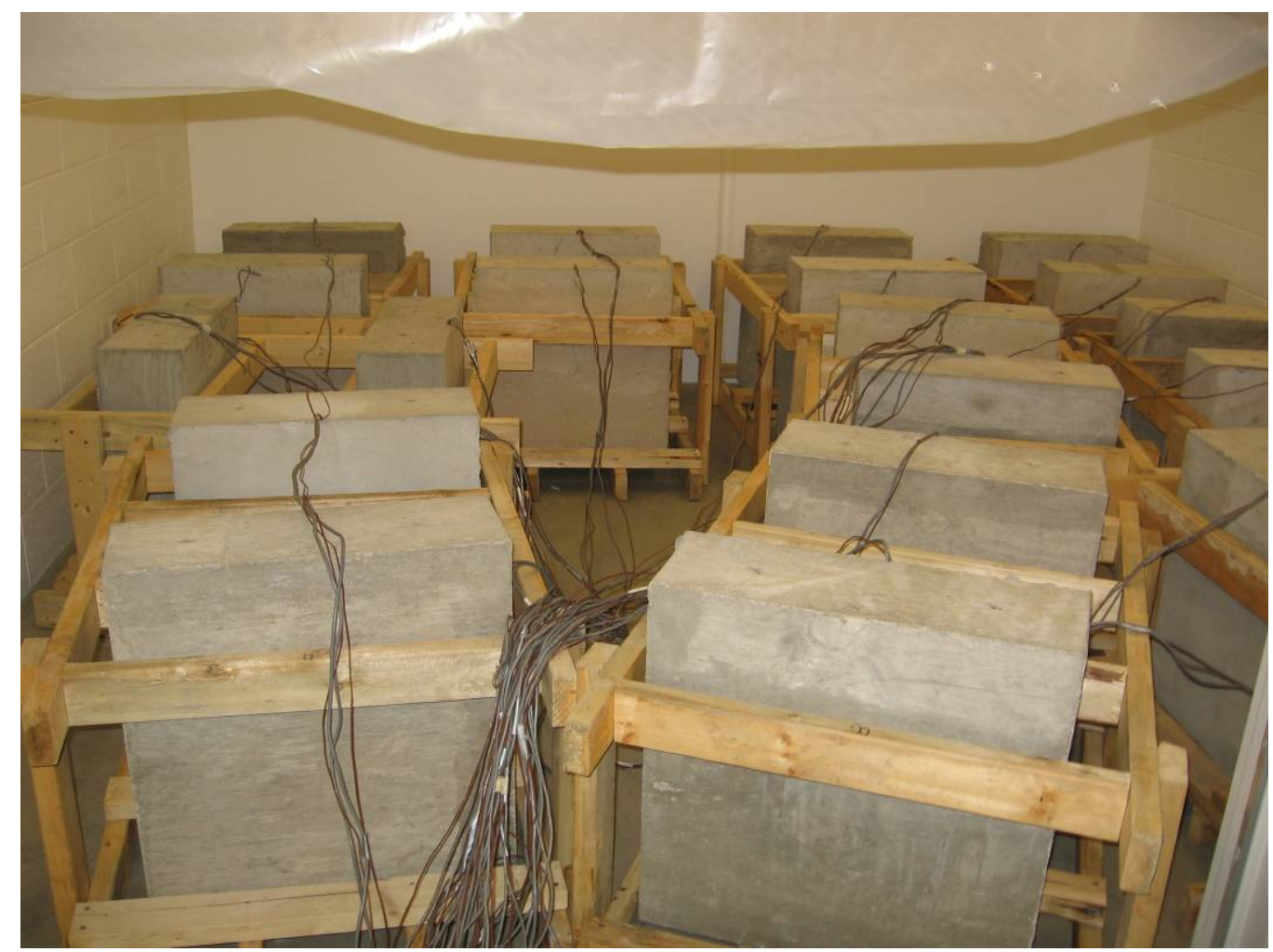

Figure 3.11: Humidity-controlled room

\subsubsection{Data Collection}

A Campbell Scientific CR10X Datalogger was used to collect data during the test. Four AM16/32 Multiplexers were connected to the CR10X Datalogger to increase the number of sensors that could be used. The CR10X Datalogger was programmed by connecting it to the laboratory laptop and using MultiLogger software. The system began collecting data prior to the concrete pour to ensure that the program was running properly and to zero the strain gages. The thermocouples and humidity gages did not require zeroing, as they directly read temperature and humidity, respectively. During the first two weeks after the concrete was cast, the CR10X collected data every 15 minutes. Data was downloaded and examined approximately once every day to ensure that the gages were reading correctly and that the system was operating properly. After the first two weeks, the CR10X was reprogrammed to collect data once every hour. 


\subsubsection{Strain Gages}

Strains were calculated using the following relationship:

$$
\begin{gathered}
\varepsilon=\frac{\left(4 \times 10^{6}\right) V_{r}}{G F\left(1000-2 V_{r}\right)} \\
V_{r}=\left(\frac{V_{\text {out }}}{V_{\text {ex }}}\right)-\left(\frac{V_{\text {out } 0}}{V_{\text {ex }}}\right)
\end{gathered}
$$

where: $\quad V_{\text {out }}=$ Voltage Output $(\mathrm{mV})$

$$
\mathrm{V}_{\text {out } 0}=\text { Voltage Output at zero strain }(\mathrm{mV})
$$$$
\mathrm{V}_{\mathrm{ex}}=\text { Excitation Voltage }(\mathrm{V})
$$$$
\mathrm{GF}=\text { Gage Factor }=2.06
$$

\subsubsection{Humidity Sensors}

The humidity was measured by exciting the sensor with 5 Volts and measuring the output voltage. These values were then related to relative humidity using the following relationship:

$$
V_{\text {out }}=V_{\text {excite }} *(0.0062 *(\text { SensorRH })+0.16)
$$

where: $\quad V_{\text {out }}=$ Voltage Output

$$
\mathrm{V}_{\text {excite }}=\text { Excitation Voltage }(\text { Voltage Input })=5 \mathrm{~V}
$$

Sensor RH = Relative Humidity (\%)

\subsubsection{Thermocouples}

The Campbell Scientific 107-L Temperature Probe measured the ambient temperature at the location of the datalogger. Temperatures relative to the temperature probe were then measured by the thermocouples located in the specimens. No subsequent calculations were required. 


\section{$\underline{3.7 \text { Results }}$}

Shrinkage and temperature data measured during testing revealed important information about the effect of curing duration and procedure. The data was analyzed to determine the general shrinkage behavior and investigate how varying curing duration, curing procedure, and concrete mix proportions affect bridge deck shrinkage. Furthermore, the data was evaluated to determine whether the embedded sensors have potential for use as curing measurement devices.

\subsubsection{Shrinkage Behavior}

A consistent shrinkage behavior can be observed in all specimens despite the varying durations of wet cure. For all specimens, an initial swelling was observed, likely due to thermal expansion during hydration, as elevated temperatures caused an expansion of the concrete. This relationship is evident in comparing the internal temperature of the specimens with their early age shrinkage (Figure 3.12).

Following the initial swelling, significant shrinkage lasting approximately two days was observed. It is likely that some of these strains are due to early age autogeneous shrinkage along with a small amount of unavoidable plastic and drying shrinkage. However, a majority of this strain is likely due to thermal volumetric change. As the internal temperature dropped after the peak hydration temperature was reached, the overall volume of the concrete decreased.

The scatter of strains measured at their peak (corresponding approximately to peak hydration temperature) is commonly observed in this type of gage. Until the gage adheres fully to the concrete, variations in strain are common. It is assumed that the gages became fully adhered at the peak strain. Therefore, all shrinkage plots were zeroed at the time of the peak strain which occurred at approximately 12 hours after casting. Early age strain plots for all continuously wet cured specimens are presented in Figure 3.13. 


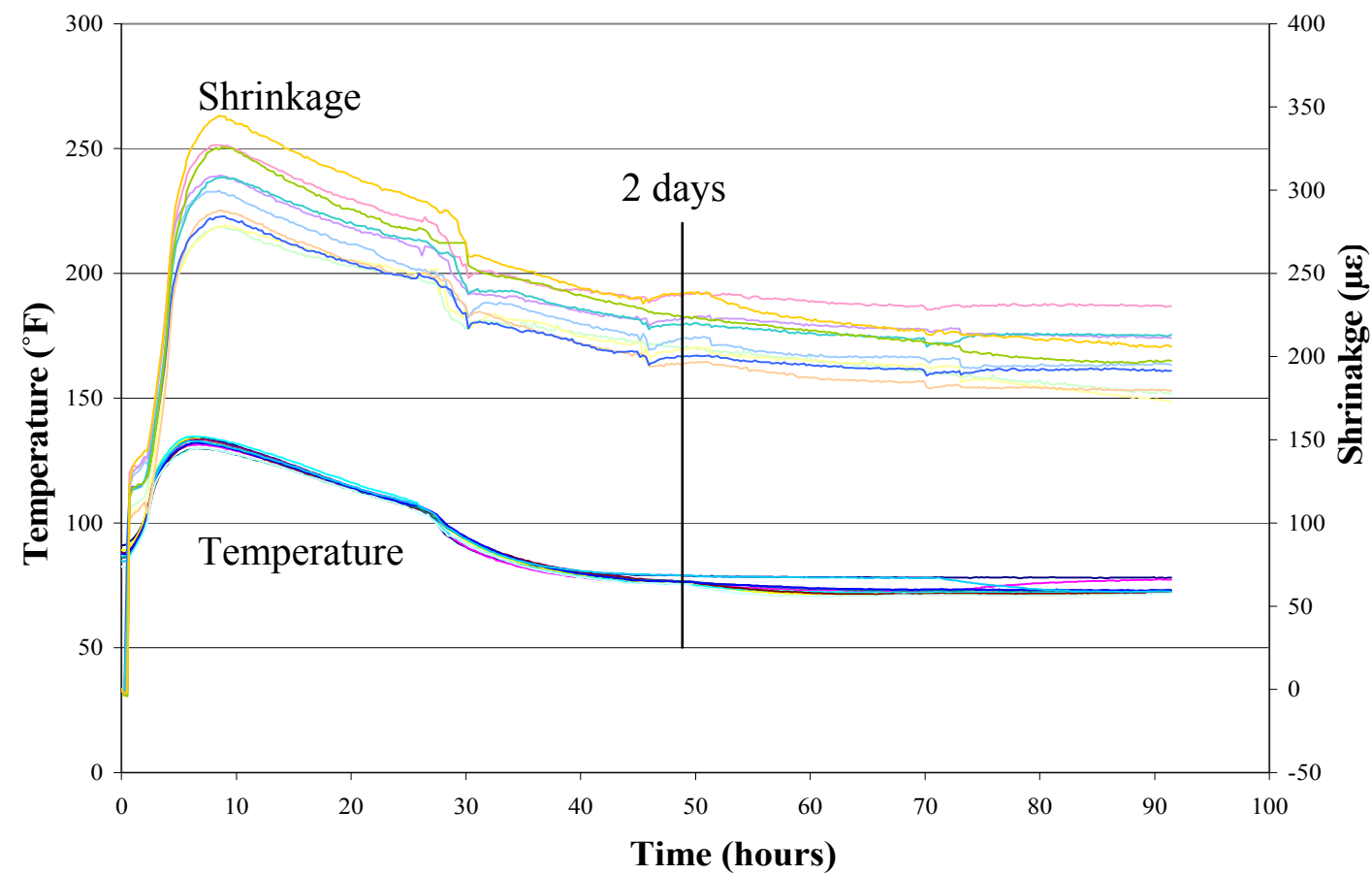

a) Class $\mathbf{C}$ concrete

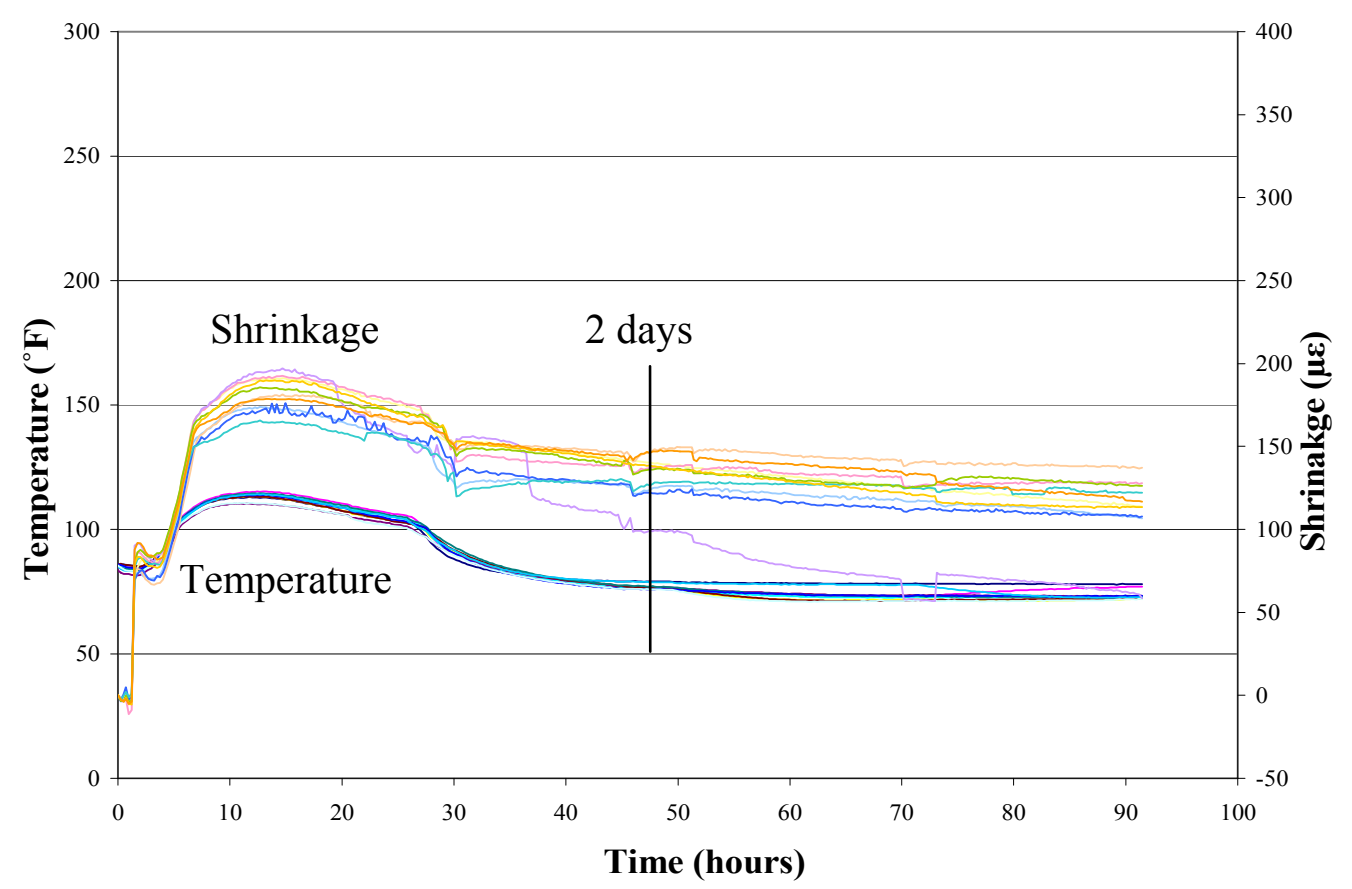

b) Low shrinkage concrete

Figure 3.12: Early age shrinkage and temperature 


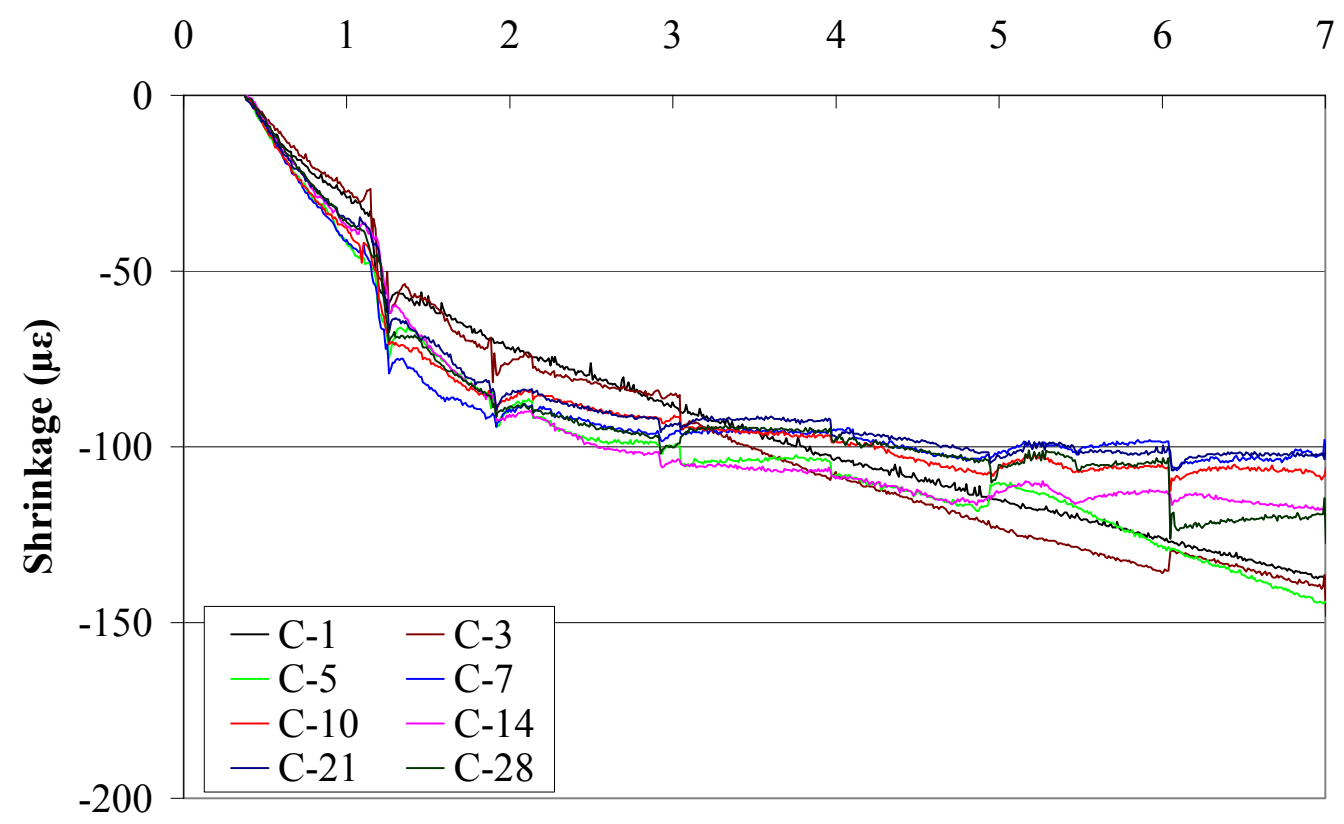

Time (days)

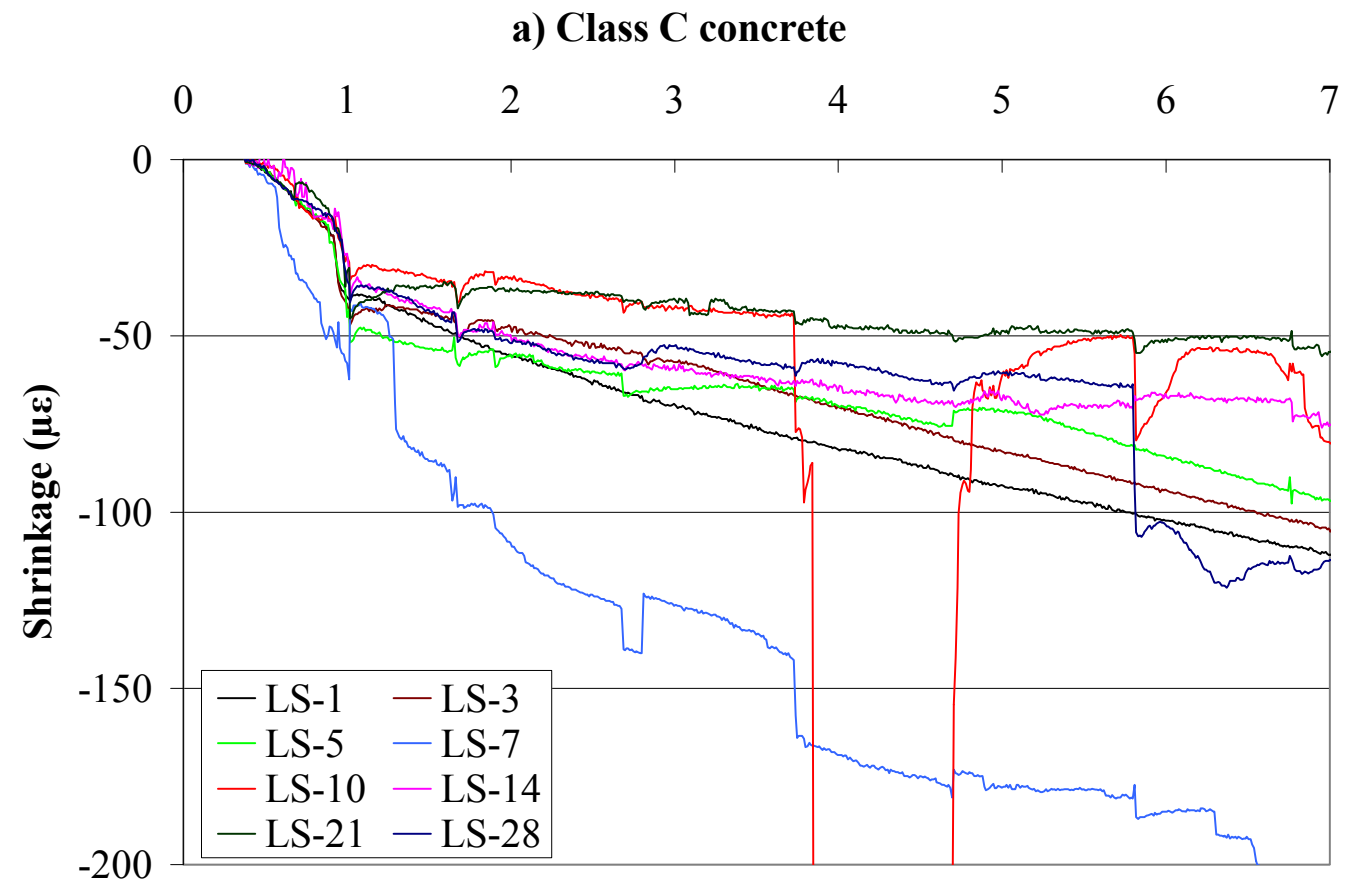

Time (days)

b) Low shrinkage concrete

Figure 3.13: Early age shrinkage behavior 
The peak temperature was $133.5^{\circ} \mathrm{F}$ for the Class $\mathrm{C}$ concrete and $105.0^{\circ} \mathrm{F}$ for the low shrinkage mix. The lower peak hydration temperature exhibited by the low shrinkage mix, due to the decreased cement content, lead to less thermal swelling and subsequent thermal contraction. Measured shrinkage after 48 hours, which is largely the amount of thermal shrinkage, is provided in Table 3.5. The average thermal shrinkage was $-89.1 \mu \varepsilon$ for the Class C concrete and $-50.9 \mu \varepsilon$ for the low shrinkage mix (excluding Specimen LS-7 which experienced a gage malfunction).

Gage malfunction, characterized by sharp jumps in measured strain, occurred frequently in all specimens but was extreme in specimens C-28, LS-7, LS-10, LS-21, and LS-28. These jumps occurred during the period of wet cure, indicating that the cause was likely the high water content of the concrete during the periods. During drying, the jumps were much less frequent and severe. Because of these malfunctions, shrinkage data during wet curing for the above specimens cannot be considered accurate. However, general trends during wet curing can be observed and trusted. In addition, shrinkage data during drying is likely to be accurate.

Following the initial high-rate of shrinkage, the shrinkage leveled off during wet curing. During this time, the internal temperatures of the specimens leveled off as well. Relatively low shrinkage strains were measured from Day 2 through the end of the wet cure duration. Shrinkage strains measured from 48 hours through the end of the specified wet cure duration are presented in Table 3.6. This shrinkage behavior is clearly visible in the strains measured for Specimen C-7, which is shown in Figure 3.14. During the first 12 hours, there is a rapid expansion due to the thermal effects of hydration. Between 12 and 48 hours, a rapid volumetric shrinkage due to cooling after peak hydration is observed, as well as some minor effects of drying shrinkage. After approximately 48 hours, the shrinkage levels off. This period extends until the end of wet cure, at which point drying shrinkage is initiated. The rate of shrinkage is initially fairly rapid and decreases over time. A similar shrinkage pattern was observed in the other continuous wet cure specimens. Shrinkage behavior of all specimens through 240 days is presented in Figure 3.15. 
Table 3.5: Shrinkage at 48 hours

\begin{tabular}{|c|c|c|}
\hline \multirow{2}{*}{$\begin{array}{c}\text { Curing } \\
\text { Duration } \\
\text { (days) }\end{array}$} & Class C & Low shrinkage \\
\cline { 2 - 3 } & -78.0 & -61.7 \\
\hline 1 & -81.3 & -52.2 \\
\hline 3 & -96.6 & -59.7 \\
\hline 5 & -92.0 & -122.0 \\
\hline 7 & -87.4 & -38.0 \\
\hline 10 & -96.8 & -55.9 \\
\hline 14 & -88.1 & -37.8 \\
\hline 21 & -92.8 & -56.7 \\
\hline 28 & -89.1 & $-50.9 *$ \\
\hline Average & & \\
\hline
\end{tabular}

*Excludes Specimen LS-7

Table 3.6: Shrinkage from 48 hours through the end of wet cure

\begin{tabular}{|c|c|c|}
\hline \multirow{2}{*}{$\begin{array}{c}\text { Curing } \\
\text { Duration } \\
\text { (days) }\end{array}$} & Strain $(\mu \varepsilon)$ \\
\cline { 2 - 3 } & - & Low shrinkage \\
\hline 1 & -3.9 & -5.3 \\
\hline 3 & -14.2 & -11.9 \\
\hline 5 & -6.0 & -102.4 \\
\hline 7 & -24.4 & -47.4 \\
\hline 10 & -24.2 & -29.3 \\
\hline 14 & 0.0 & -61.3 \\
\hline 21 & -19.7 & -18.4 \\
\hline 28 & -13.2 & $-31.0^{*}$ \\
\hline Average & & \\
\hline
\end{tabular}

*Excludes Specimen LS-7 


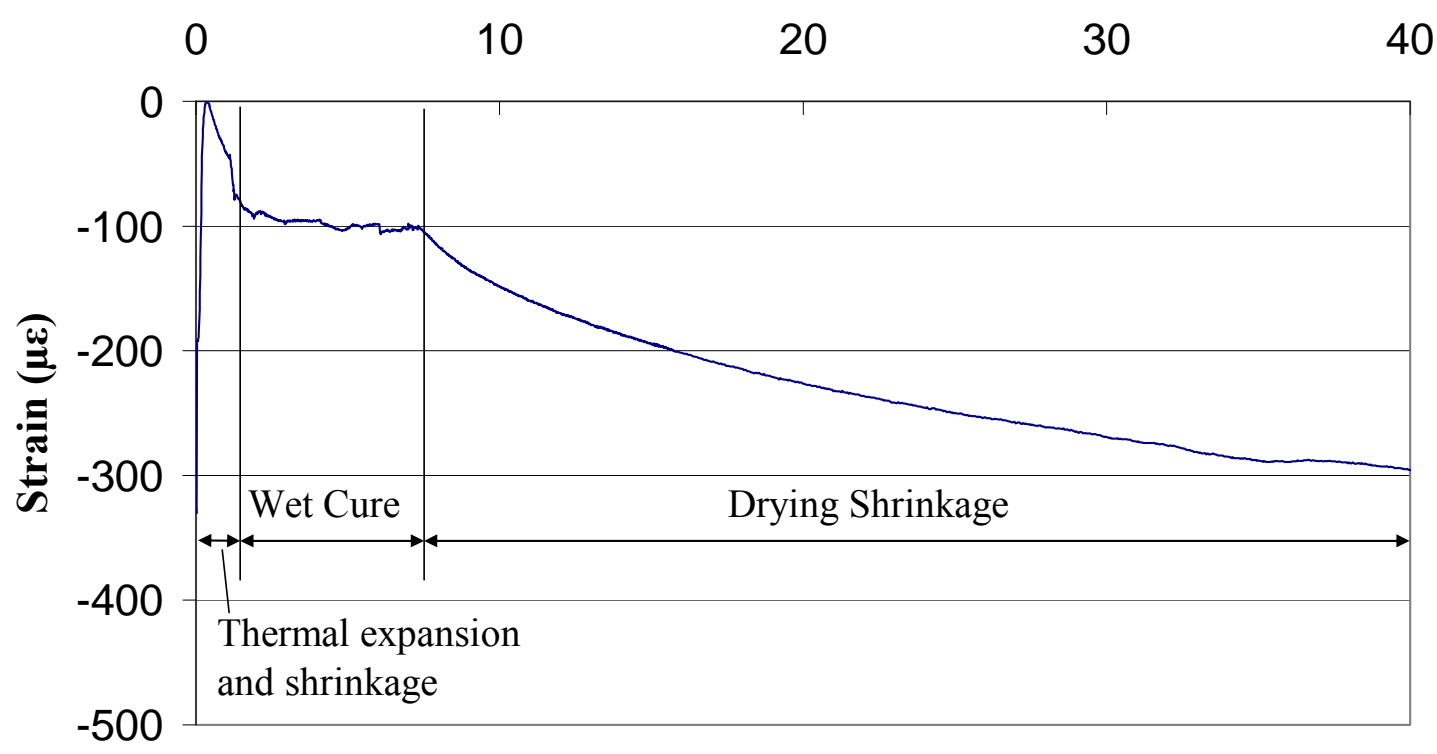

Time (days)

Figure 3.14: Early age shrinkage behavior (Specimen C-7) 


$\begin{array}{llllll}0 & 50 & 100 & 150 & 200 & 250\end{array}$

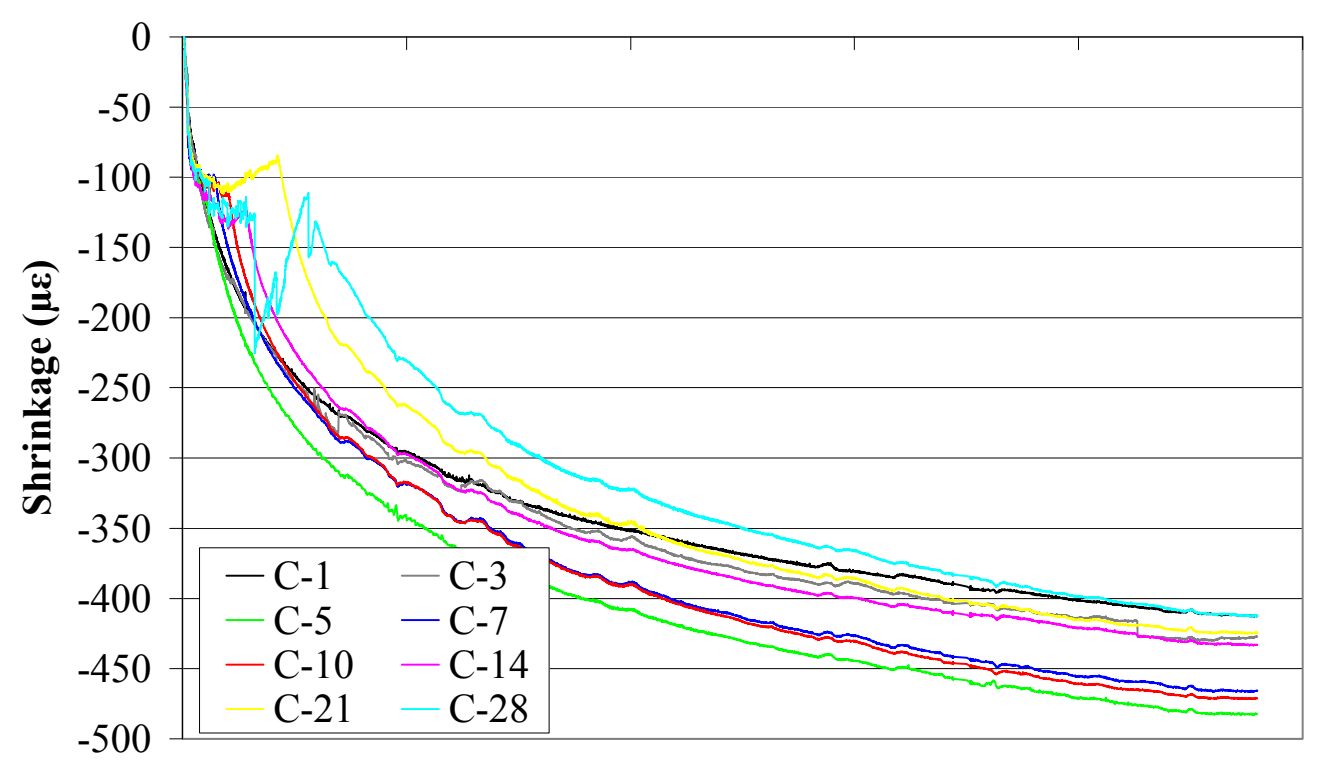

Time (days)

a) Class $\mathbf{C}$ concrete

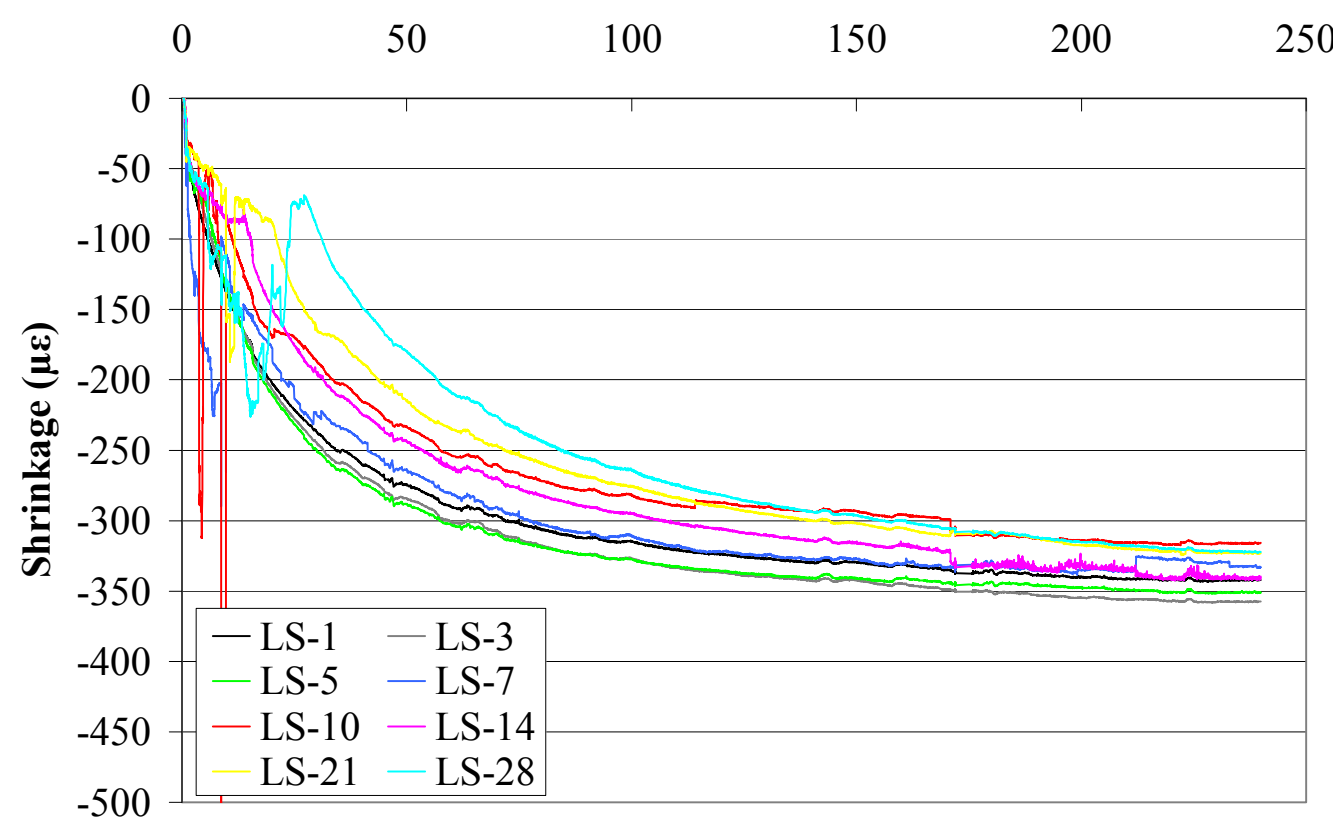

Time (days)

b) Low shrinkage concrete

Figure 3.15: Shrinkage behavior through 240 days 
The general shrinkage behavior can also be observed in plots of the rate of shrinkage. The rate of shrinkage was determined by computing the slope of the shrinkage and averaging the slopes over a 6-hour period. Figure 3.16 provides a plot comparing the rate of shrinkage of Specimen C-1 and C-7. The initial rate of shrinkage of both specimens is very high but decreased rapidly, reaching a slope of approximately $-20 \mu \varepsilon /$ day at 24 hours. At this point, the rate of shrinkage of Specimen C-1 slowly decreased, reaching a rate of approximately $-9 \mu \varepsilon /$ day after 7 days of drying (Day 8 ). The rate of shrinkage of Specimen C-7 continued to decrease rapidly, finally reaching a rate of shrinkage of zero at approximately 90 hours. Throughout the duration of wet cure, the rate of shrinkage of Specimen C-7 varies, but remains within a range of -7.5 to $+4 \mu \varepsilon /$ day, indicating very little shrinkage occurred during this period. At Day 7, Specimen C-7 exhibited rapid shrinkage, reaching a maximum rate of shrinkage of $-22.3 \mu \varepsilon /$ day shortly after the end of wet curing. During drying, Specimen C-7 exhibited behavior similar to C-1, shrinking at a rate of approximately $-7.5 \mu \varepsilon /$ day after 7 days of drying (Day 14).

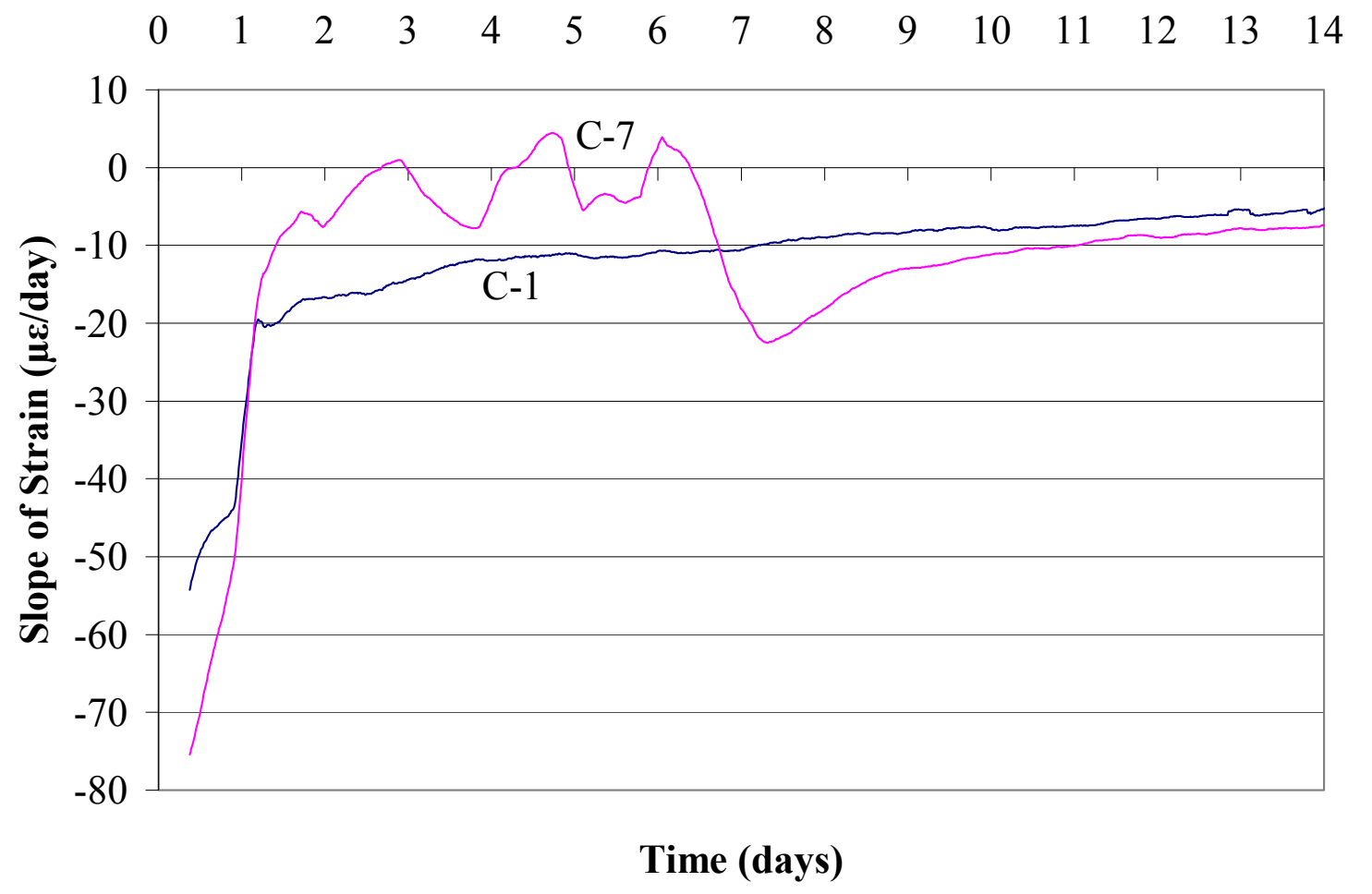

Figure 3.16: Rate of shrinkage, $\mathrm{C}-1$ and $\mathrm{C}-7$ 


\subsubsection{Effect of Curing Duration}

Continuous wet curing was very effective in delaying the onset of drying shrinkage. After the initial thermal shrinkage, shrinkage strains were minimal until the end of the wet curing period. Shrinkage strains from Day 2 through the end of the wet curing period are shown in Table 3.6. The strains during this period were small as well as similar regardless of the duration of wet cure. It is clear that increasing the duration of wet cure delayed the onset of drying shrinkage.

To compare the drying shrinkage behavior of the specimens, the strain plots were zeroed at the end of the specified wet curing duration. Figure 3.17 presents the shrinkage behavior of each specimen in the 210 days following the end of wet curing. Shrinkage values at 210 days after the end of wet cure are shown in Table 3.7.

Some correlation can be seen between wet curing duration and shrinkage measured at 210 days after the end of wet cure. Figure 3.18 presents shrinkage for all continuously cured specimens at 210 days after the end of wet cure. There is a general trend demonstrating that longer curing duration leads to a decrease in shrinkage at 210 days after the end of wet cure. In the case of the Class $C$ concrete, the 1 day wet cure specimens exhibited the most shrinkage while the 28 day wet cure specimens exhibited the least.

Similarly, specimen LS-1 exhibited the most shrinkage at 210 days after the end of wet curing among the low shrinkage mix specimens, followed by Specimen LS-3 and Specimen LS-5. The rest of the low shrinkage specimens did not follow this trend but measured similar strains averaging $-240.4 \mu \varepsilon$. 


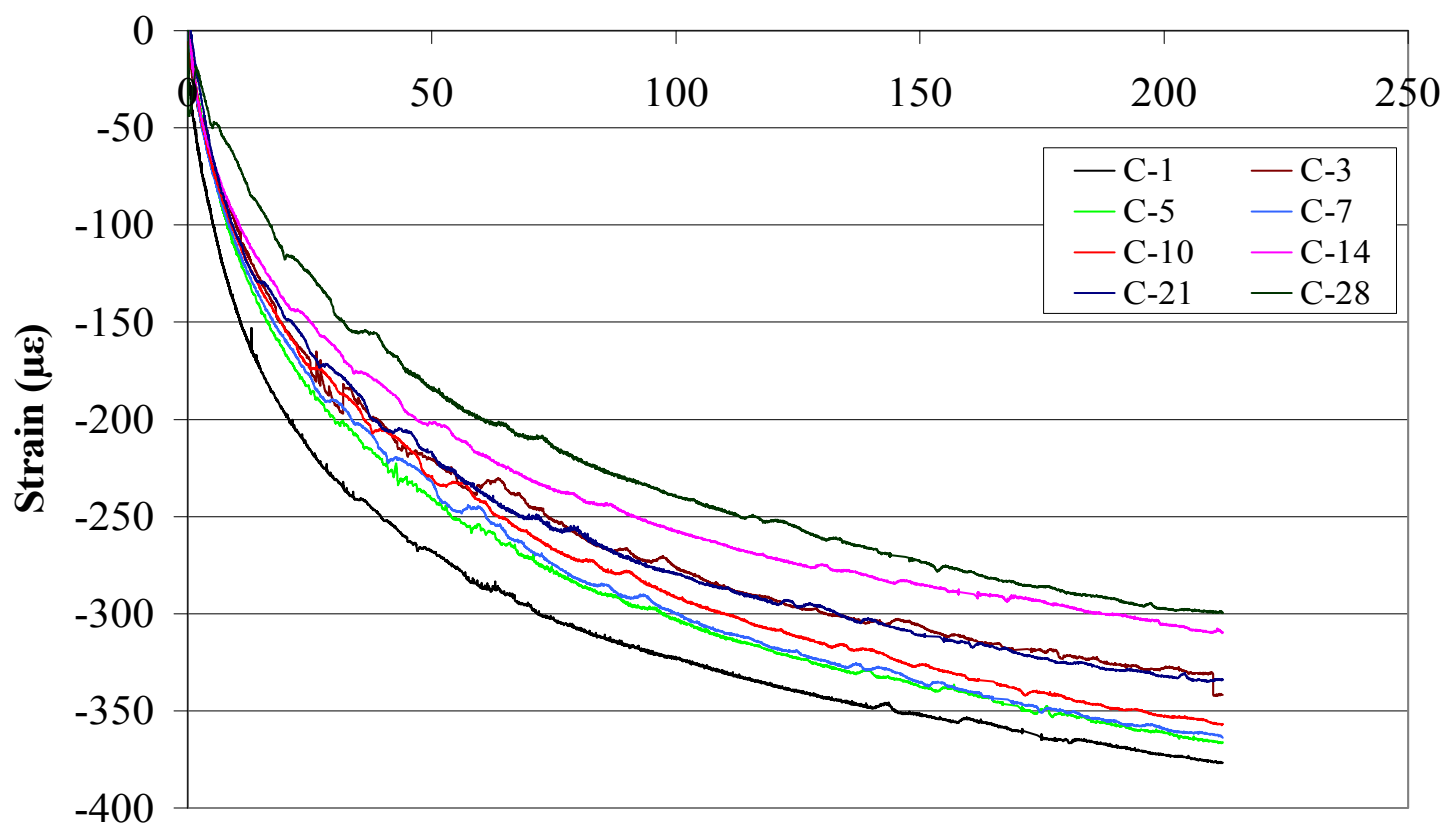

Time (days)

a) Class $\mathbf{C}$ concrete

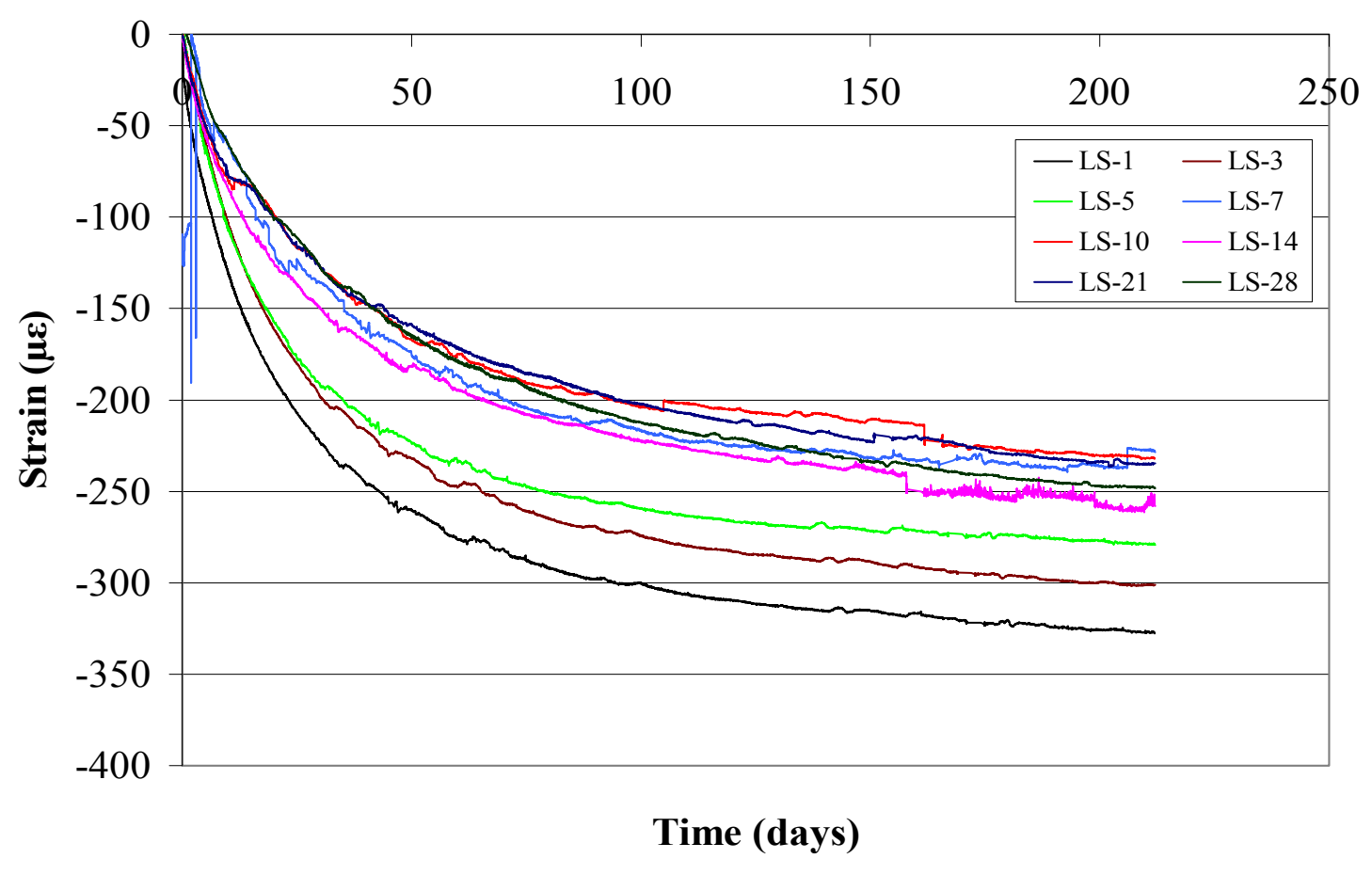

b) Low shrinkage concrete

Figure 3.17: Shrinkage behavior after the end of wet curing 
Table 3.7: Shrinkage at 210 days after the end of wet cure

\begin{tabular}{|c|c|c|}
\hline \multirow{2}{*}{$\begin{array}{c}\text { Curing } \\
\text { Duration } \\
\text { (days) }\end{array}$} & Class C & Low shrinkage \\
\cline { 2 - 3 } & & \\
\hline 1 & -376.7 & -327.6 \\
\hline 3 & -331.1 & -301.1 \\
\hline 5 & -366.4 & -279.2 \\
\hline 7 & -362.3 & -228.6 \\
\hline 10 & -356.6 & -232.1 \\
\hline 14 & -309.1 & -258.0 \\
\hline 21 & -333.9 & -234.8 \\
\hline 28 & -299.3 & -248.3 \\
\hline
\end{tabular}




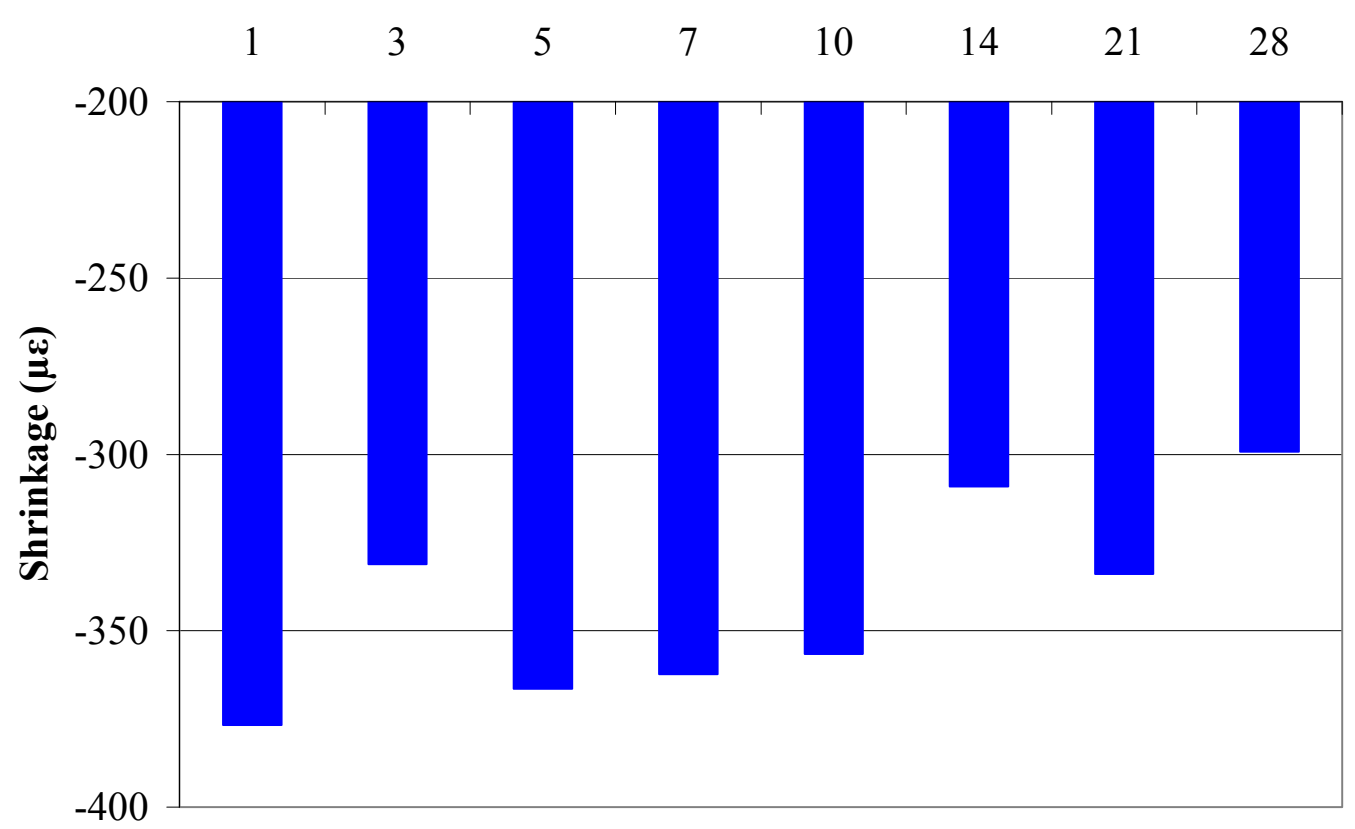

Wet curing duration (days)

Class $\mathbf{C}$ concrete

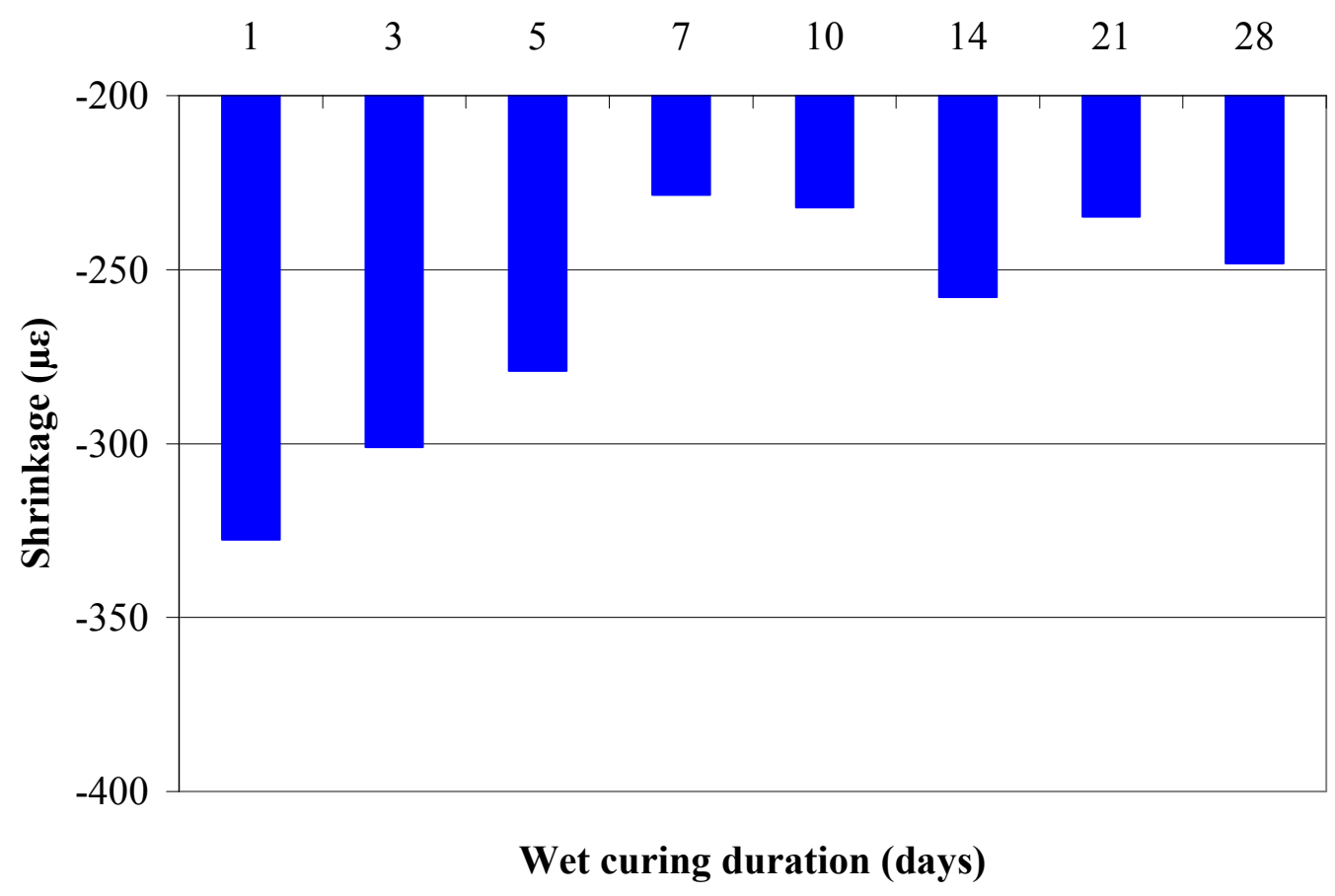

a) Low shrinkage mix

Figure 3.18: Shrinkage at 210 days after the end of wet cure 


\subsubsection{Effect of Curing Procedure}

Two variable curing procedures were implemented in addition to the continuous curing procedure to determine their effect on concrete shrinkage. These variable curing procedures are shown in Figure 3.2 and Figure 3.3.

The Variable Cure 1 procedure consisted of alternating wet cure periods with periods of drying. This cycling lasted for a total of 9 days; therefore, Variable Cure 1 specimens were compared to C-10 and LS-10 specimens (no 9 day continuous wet cure was implemented). Early age shrinkage plots for both Class $\mathrm{C}$ concrete and the low shrinkage mix are shown in Figure 3.19 and Figure 3.20. A summary of shrinkage at 10 and 240 days can be found in Table 3.8 .

Specimen C-V1 demonstrated more shrinkage than Specimen C-10, as was expected. This difference was due to the periods of drying during which the specimen began to shrink at a rapid rate. Shrinkage of Specimen C-V1 decreased during periods of wet-curing and increased during periods of drying. At 10 days, Specimen C-V1 had experienced $62.8 \mu \varepsilon$ more shrinkage than Specimen C-10. At 240 days, Specimen C-V1 continued to show a higher amount of shrinkage than Specimen C-10. However, the difference in shrinkage strains had decreased to $30.6 \mu \varepsilon$. This demonstrates that, despite exhibiting more early-age shrinkage due to drying periods, Specimens C-10 and C-V1 would likely experience a similar ultimate shrinkage.

The low shrinkage specimens (LS-V1 and LS-10) exhibited a different behavior. As in the case of the Class C specimens, Specimen LS-V1 experienced more rapid shrinkage during the first 10 days during the alternating wet curing and drying periods. After 10 days, Specimen LS-V1 had experienced $45.8 \mu \varepsilon$ more shrinkage than Specimen LS-10. At 240 days, this shrinkage difference had increased to $61.0 \mu \varepsilon$. However, this data cannot be fully trusted due to gage malfunction in Specimen LS-10. 


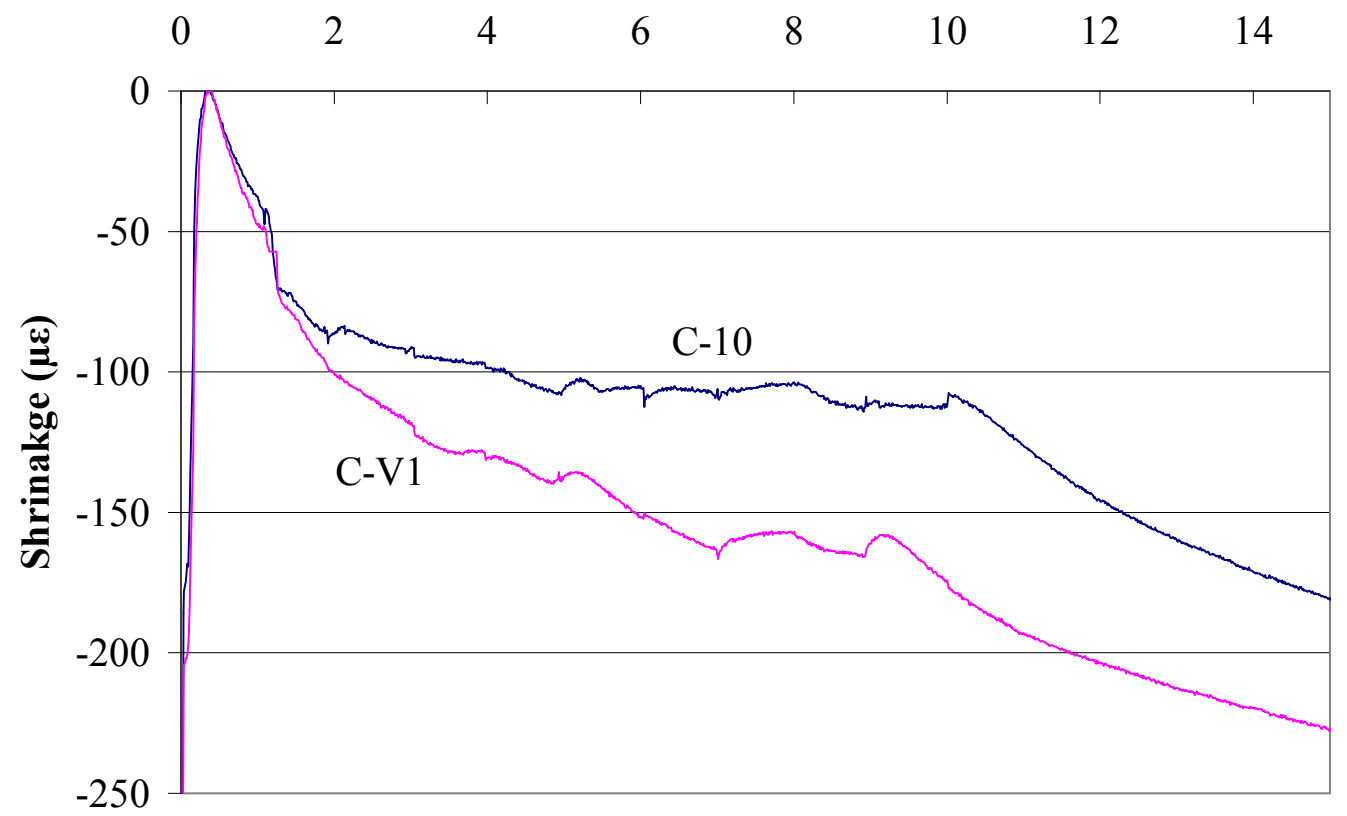

Time (days)

a) Early age

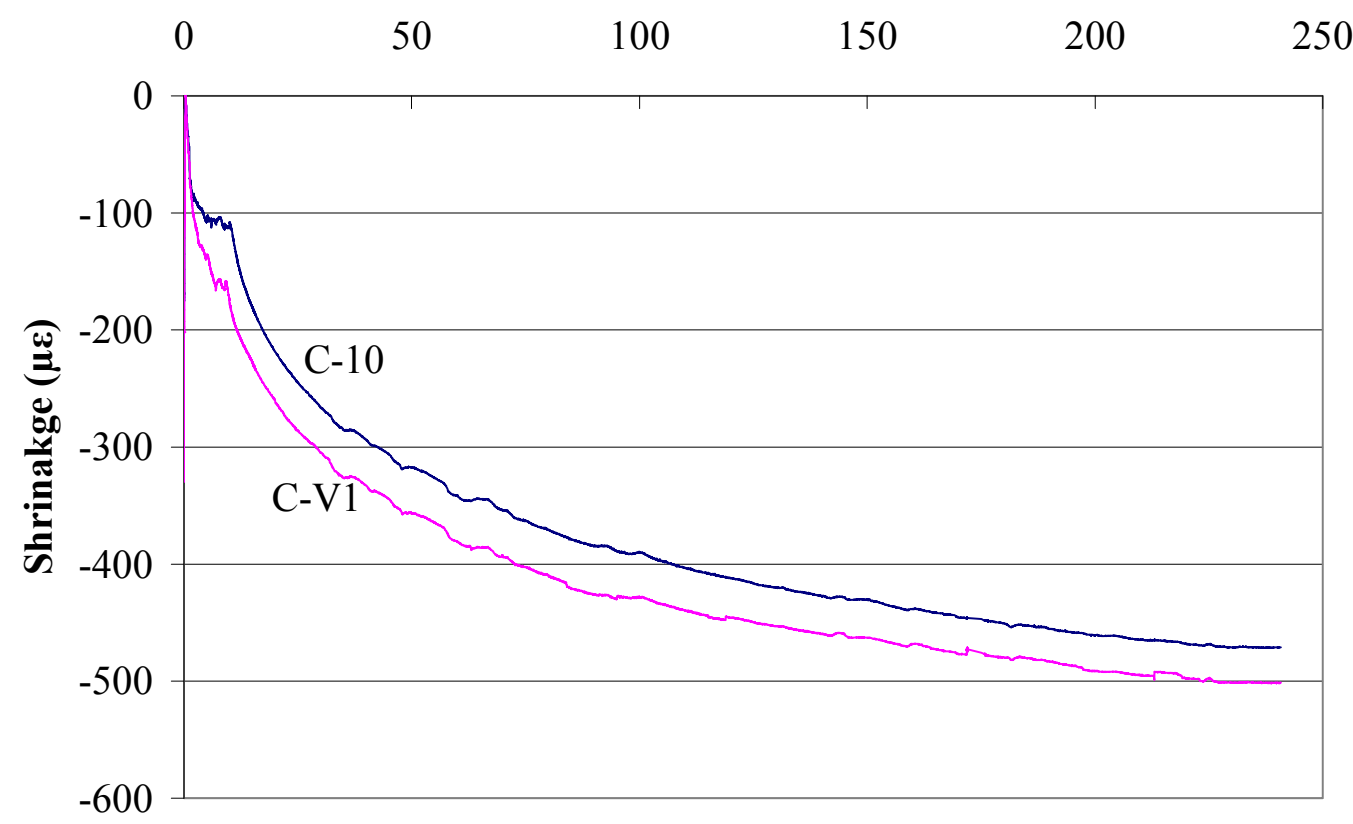

Time (days)

b) Total shrinkage

Figure 3.19: Variable Cure 1, Class C concrete 


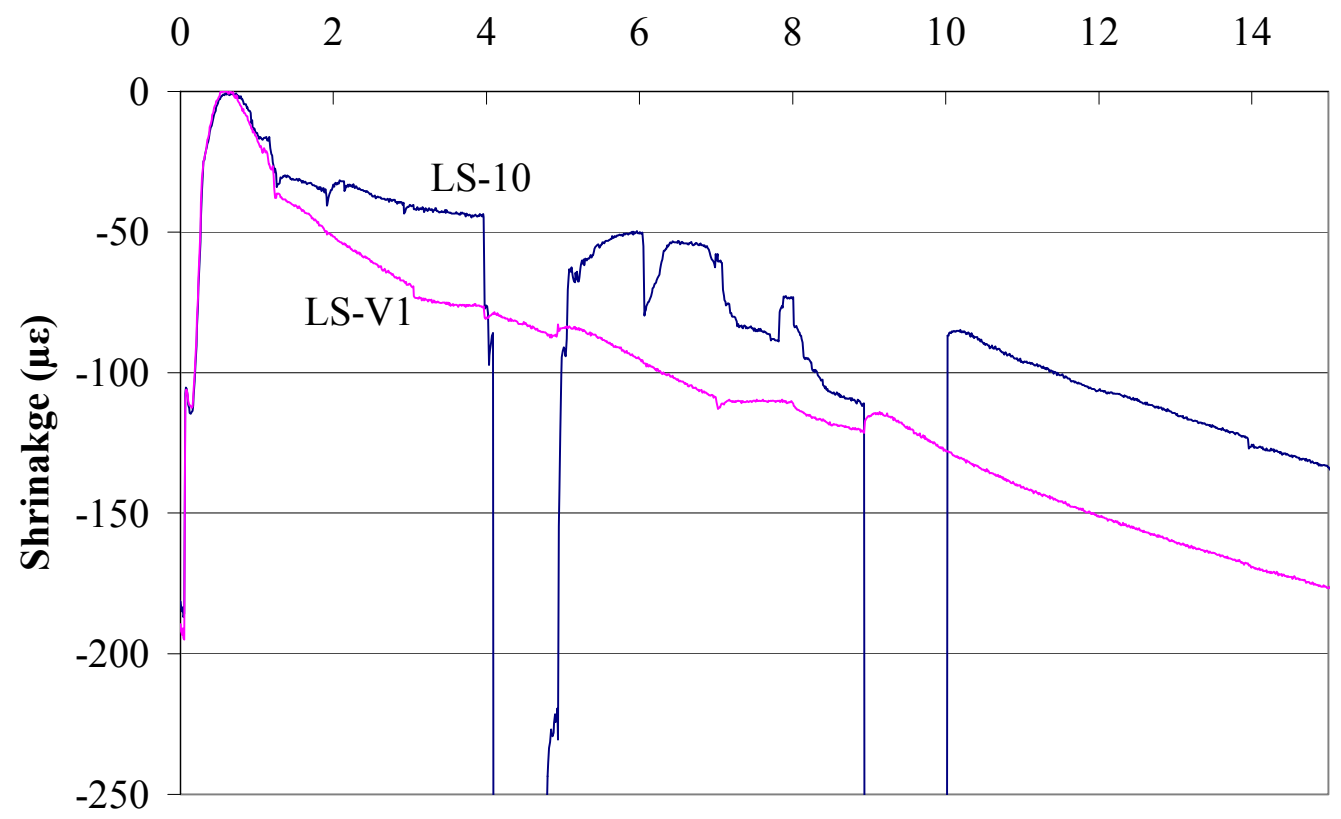

Time (days)

a) Early age

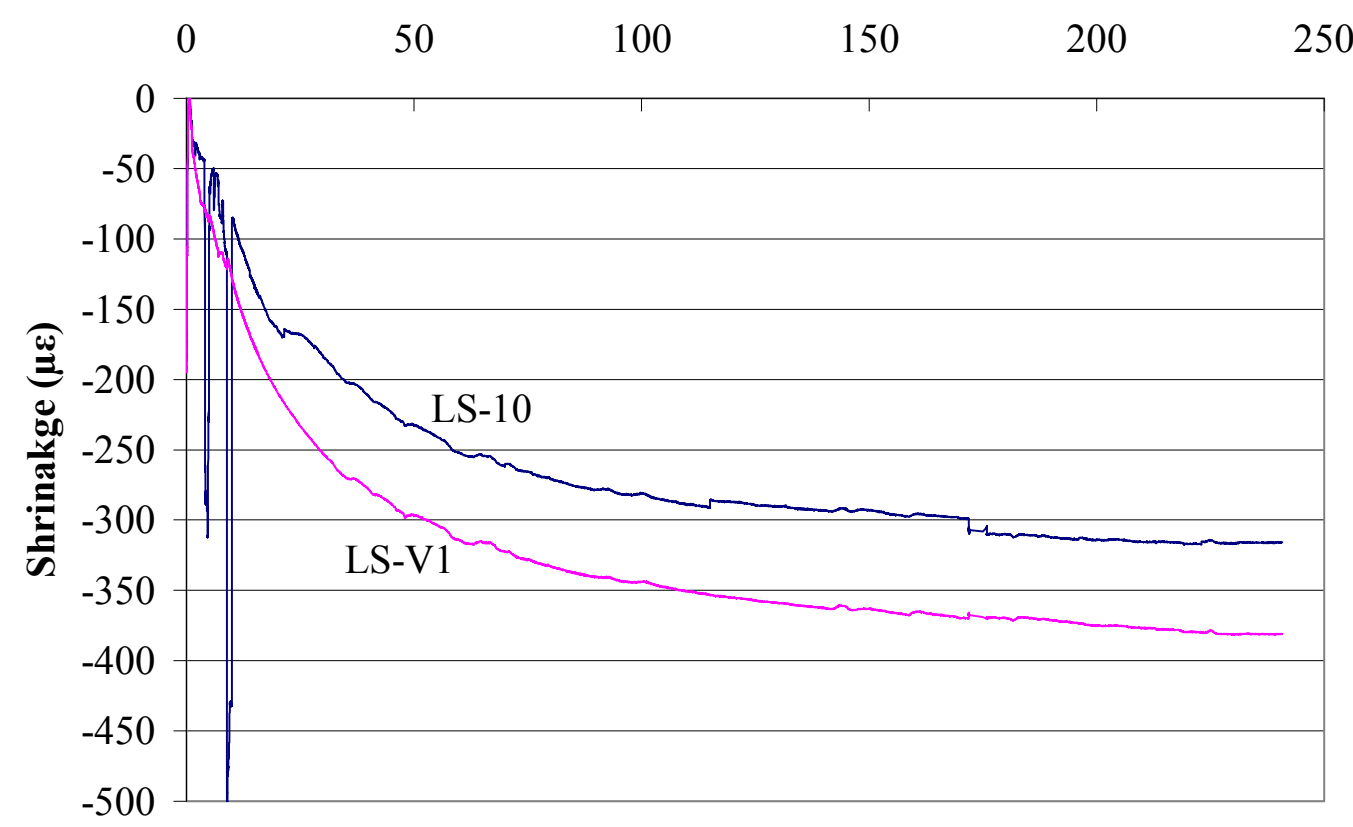

Time (days)

b) Total shrinkage

Figure 3.20: Variable Cure 1, Low shrinkage mix 
Table 3.8: Variable Cure 1 shrinkage

\begin{tabular}{|c|c|c|c|c|}
\hline \multirow{2}{*}{$\begin{array}{c}\text { Curing } \\
\text { Duration }\end{array}$} & \multicolumn{2}{|c|}{ Strain at 10 days $(\boldsymbol{\mu} \varepsilon)$} & \multicolumn{2}{c|}{ Strain at 240 days $(\boldsymbol{\mu \varepsilon})$} \\
\cline { 2 - 5 } & Class C & $\begin{array}{c}\text { Low } \\
\text { shrinkage }\end{array}$ & Class C & $\begin{array}{c}\text { Low } \\
\text { shrinkage }\end{array}$ \\
\hline Variable 1 & -174.6 & -131.2 & -491.5 & -375.2 \\
\hline 10 day wet cure & -111.8 & -85.4 & -461.0 & -314.2 \\
\hline
\end{tabular}

The Variable Cure 2 procedure involved an initial wetting of burlap, as was performed with all continuous wet curing specimens. However, the burlap was not rewetted as needed, and instead allowed to dry for a period of 14 days before removal; therefore, Variable Cure 2 specimens were compared to C-14 and LS-14 specimens. Early age shrinkage plots for these specimens can be seen in Figure 3.21 and Figure 3.22. A summary of shrinkage after 14 days and shrinkage at 240 days can be found in Table 3.9.

After 48 hours, following the expansion and shrinkage due to thermal effects, higher shrinkage could already be observed in Specimen C-V2 than Specimen C-14. From Day 2 through Day 14, the variable curing procedure produced a steady shrinkage in Specimen C-V2 while Specimen C-14 underwent much reduced shrinkage during the wet curing period. At Day 14, Specimen C-V2 exhibited $81.6 \mu \varepsilon$ more shrinkage than Specimen C-14. By Day 240, this shrinkage difference had decreased to $50.9 \mu \varepsilon$, indicating a convergence in shrinkage strains.

The low shrinkage concrete specimens exhibited a different early age behavior as Specimen LS-14 demonstrated more shrinkage than Specimen LS-V2 after 48 hours. Through 14 days, Specimen LS-14 underwent very little shrinkage, while Specimen LS-V2 demonstrated higher shrinkage. After 14 days, Specimen C-V2 exhibited $41.5 \mu \varepsilon$ more shrinkage than Specimen C-14. By Day 240, this shrinkage difference had decreased to $12.7 \mu \varepsilon$. 


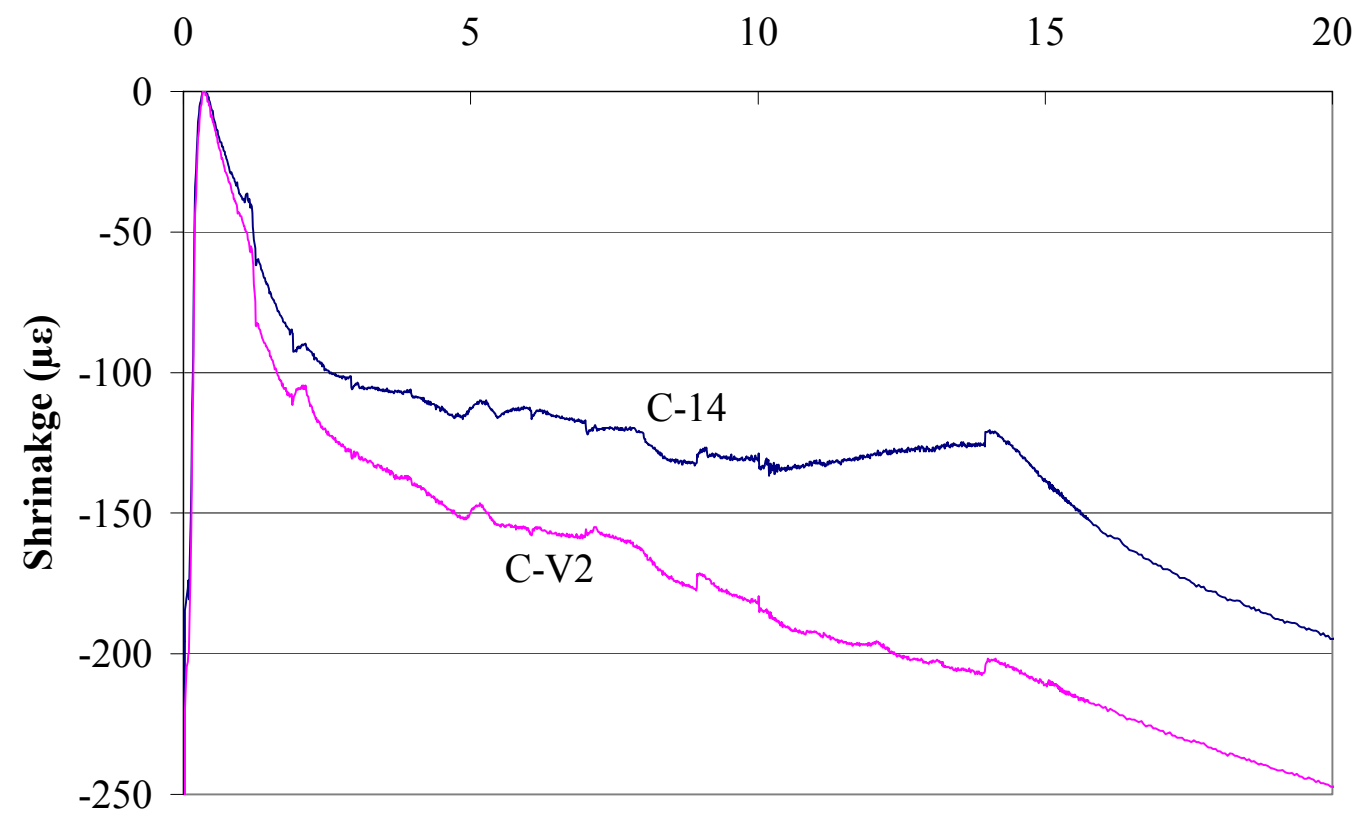

Time (days)

a) Early age

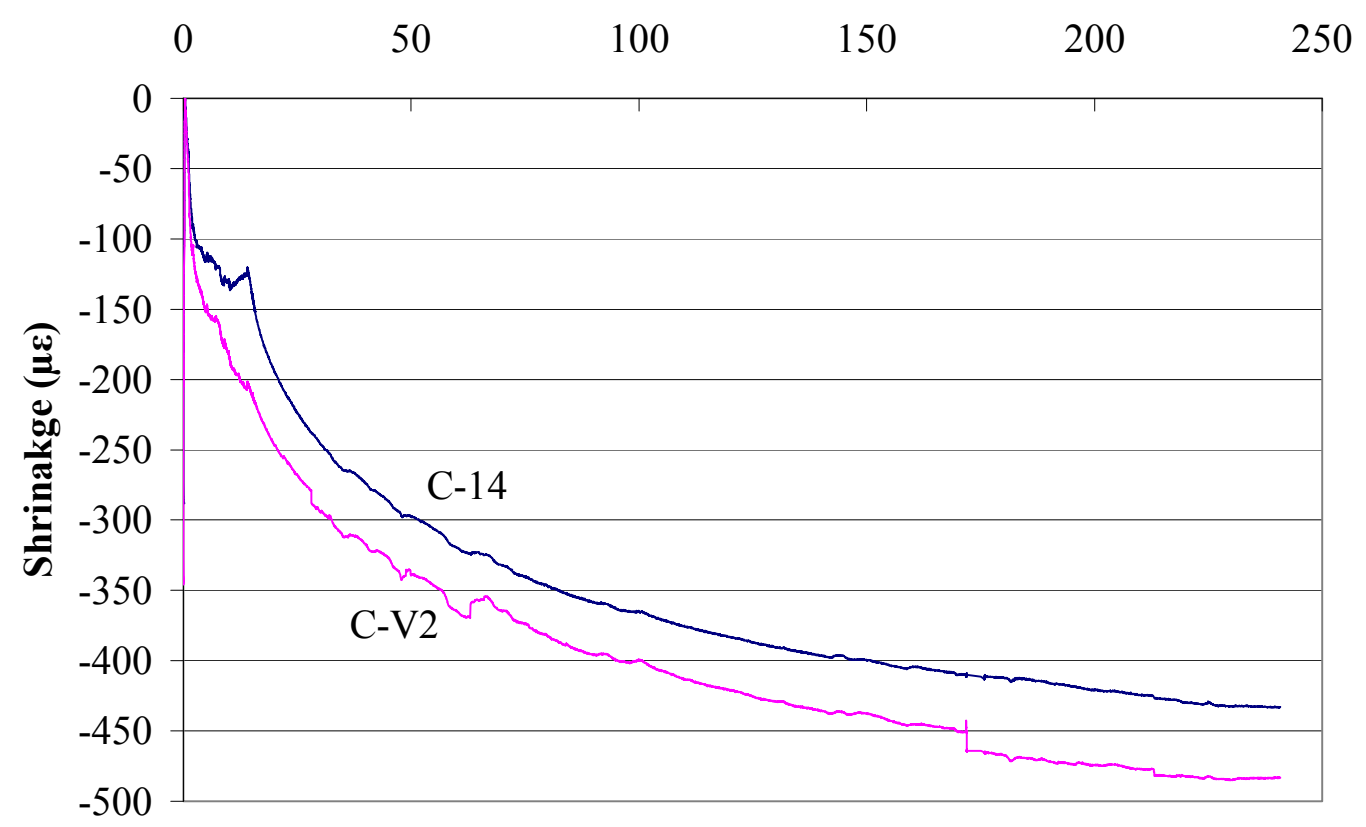

Time (days)

b) Total shrinkage

Figure 3.21: Variable Cure 2, Class $\mathrm{C}$ concrete 


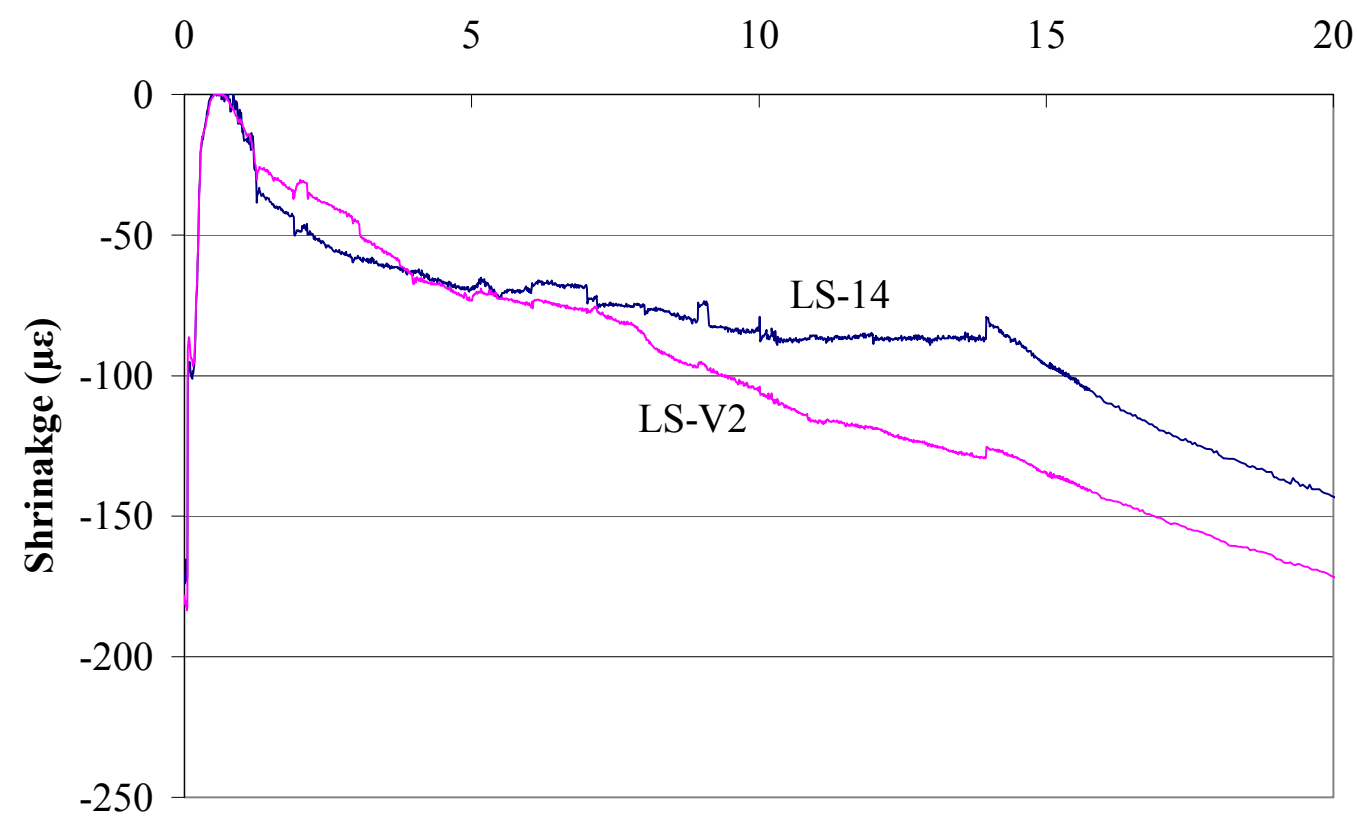

Time (days)

a) Early age

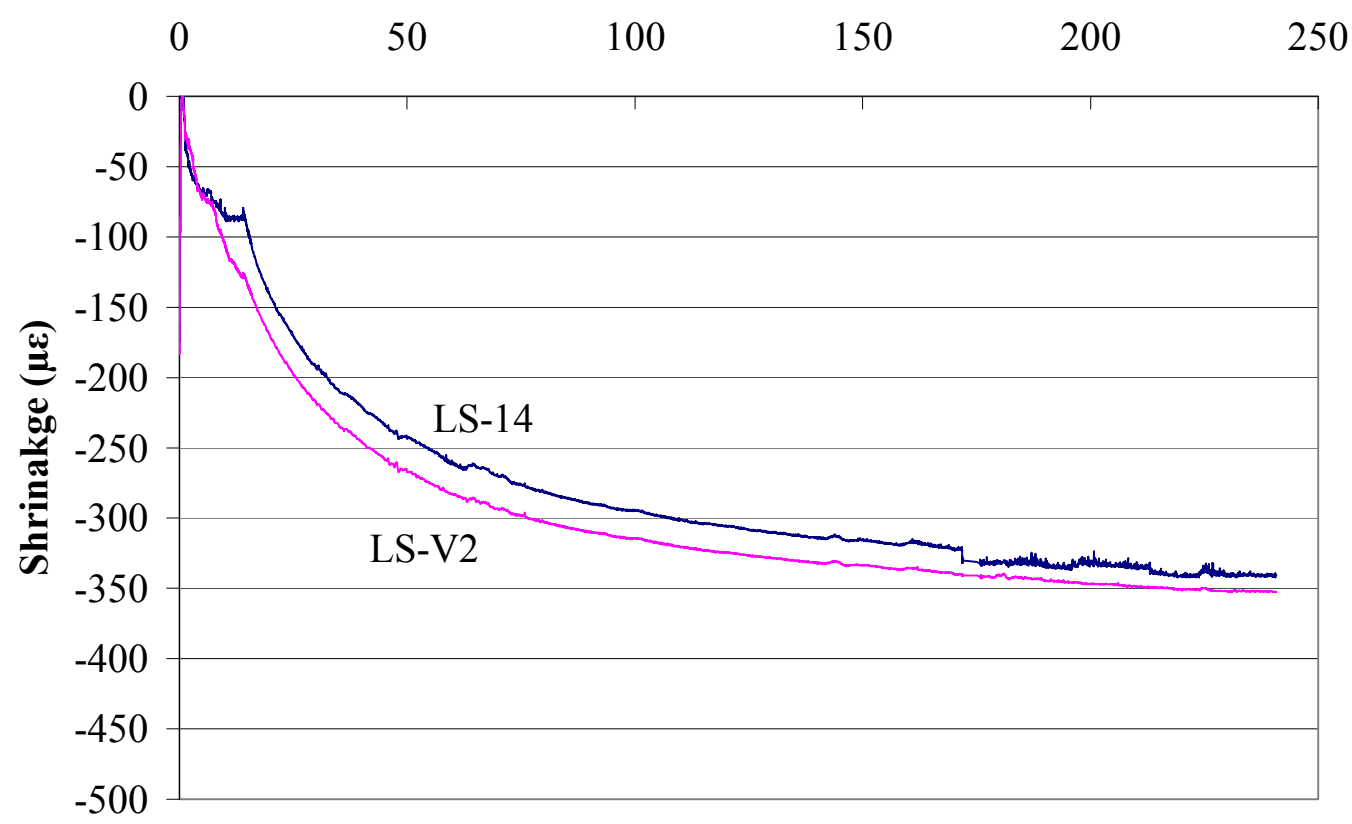

Time (days)

b) Total shrinkage

Figure 3.22: Variable Cure 2, Low shrinkage mix 
Table 3.9: Variable Cure 2 shrinkage

\begin{tabular}{|c|c|c|c|c|}
\hline \multirow{2}{*}{$\begin{array}{c}\text { Curing } \\
\text { Duration }\end{array}$} & \multicolumn{2}{|c|}{ Strain at 14 days $(\boldsymbol{\mu} \varepsilon)$} & \multicolumn{2}{c|}{ Strain at 240 days $(\boldsymbol{\mu \varepsilon})$} \\
\cline { 2 - 5 } & Class C & $\begin{array}{c}\text { Low } \\
\text { shrinkage }\end{array}$ & Class C & $\begin{array}{c}\text { Low } \\
\text { shrinkage }\end{array}$ \\
\hline Variable 2 & -202.6 & -126.6 & -484.0 & -352.5 \\
\hline 14 day wet cure & -121.0 & -85.1 & -433.1 & -339.8 \\
\hline
\end{tabular}

\subsubsection{Effect of Concrete Mix}

The same set of curing durations and procedures was applied to both INDOT Class $\mathrm{C}$ and low shrinkage concrete specimens to determine the influence of the concrete mix on free shrinkage. A full set of plots comparing each pair of specimens is presented in Figure 3.23 .

Several differences in behavior were noted. As previously discussed, initial swelling due to the heat of hydration was less in the low shrinkage specimens. At 48 days, an average of $38.2 \mu \varepsilon$ less shrinkage was measured in the low shrinkage specimens than the Class $\mathrm{C}$ specimens. The internal temperature during heat of hydration was also lower in the low shrinkage mix, with an average peak temperature $105.0^{\circ} \mathrm{F}$ compared to $133.5^{\circ} \mathrm{F}$ in the Class $\mathrm{C}$ specimens. This reduction in temperature can be beneficial, as it will decrease the differential temperature between the deck and the girders, especially in a steel superstructure. In addition, it will decrease the thermal shrinkage as the internal temperature of the concrete drops from its peak to the ambient temperature.

The Class $\mathrm{C}$ concrete mix exhibited higher average shrinkage strains for all cases considered, including thermal shrinkage, shrinkage after the end of wet cure, and total shrinkage. A summary of shrinkage values, measured at 240 days, and the difference in shrinkage at this time is presented in Table 3.10. A bar graph presenting shrinkage at 240 days is presented in Figure 3.24. An average of $109.7 \mu \varepsilon$ less shrinkage was measured in the low shrinkage specimens than the Class C specimens at 240 days. This corresponds with an an approximate $25 \%$ reduction in total shrinkage. 
In addition, the shrinkage of the low shrinkage specimens was observed to have leveled off more significantly than the Class C specimens at 240 days. The Class C specimens averaged $-11.1 \mu \varepsilon$ of shrinkage from Day 200 through Day 240, while the low shrinkage specimens average $-4.1 \mu \varepsilon$ of shrinkage over the same period. Complete shrinkage data from Day 200 through Day 240 is presented in Table 3.11. This result indicates that, while the low shrinkage specimens had already undergone most of their ultimate shrinkage by Day 240, it appears that the Class C specimens will continue to shrink and produce significantly higher ultimate shrinkage strains. 


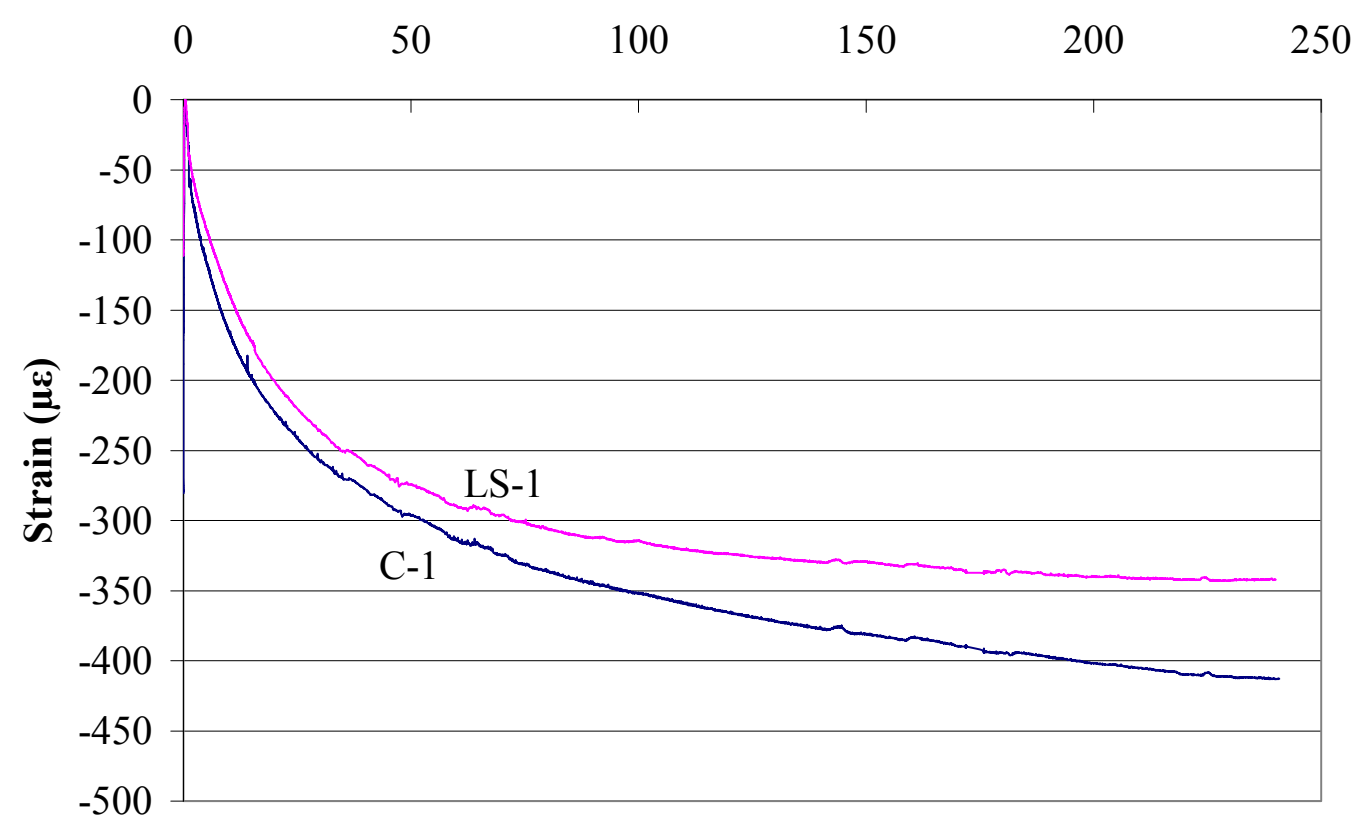

Time (days)

a) 1 day wet cure

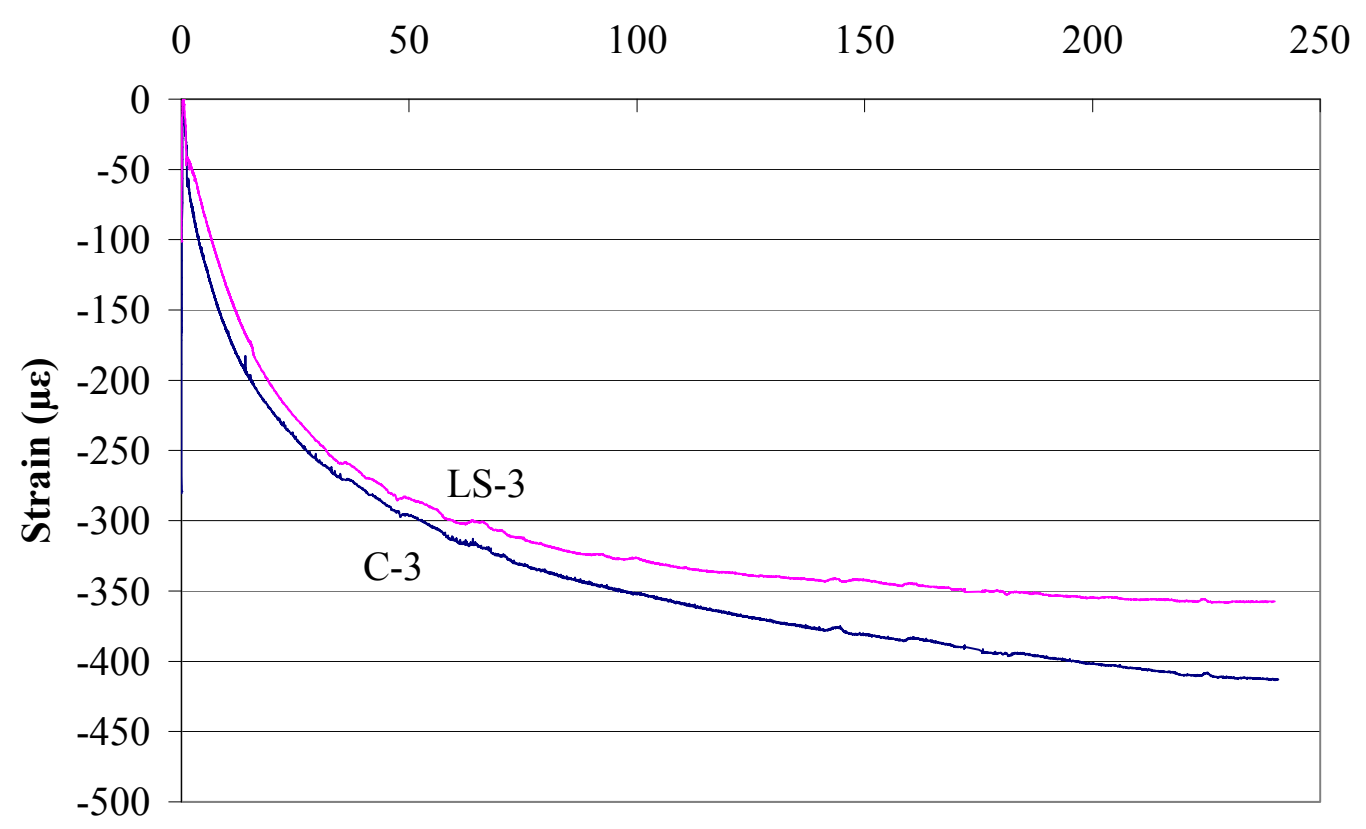

Time (days)

b) 3 day wet cure

Figure 3.23: Influence of concrete mix on shrinkage 


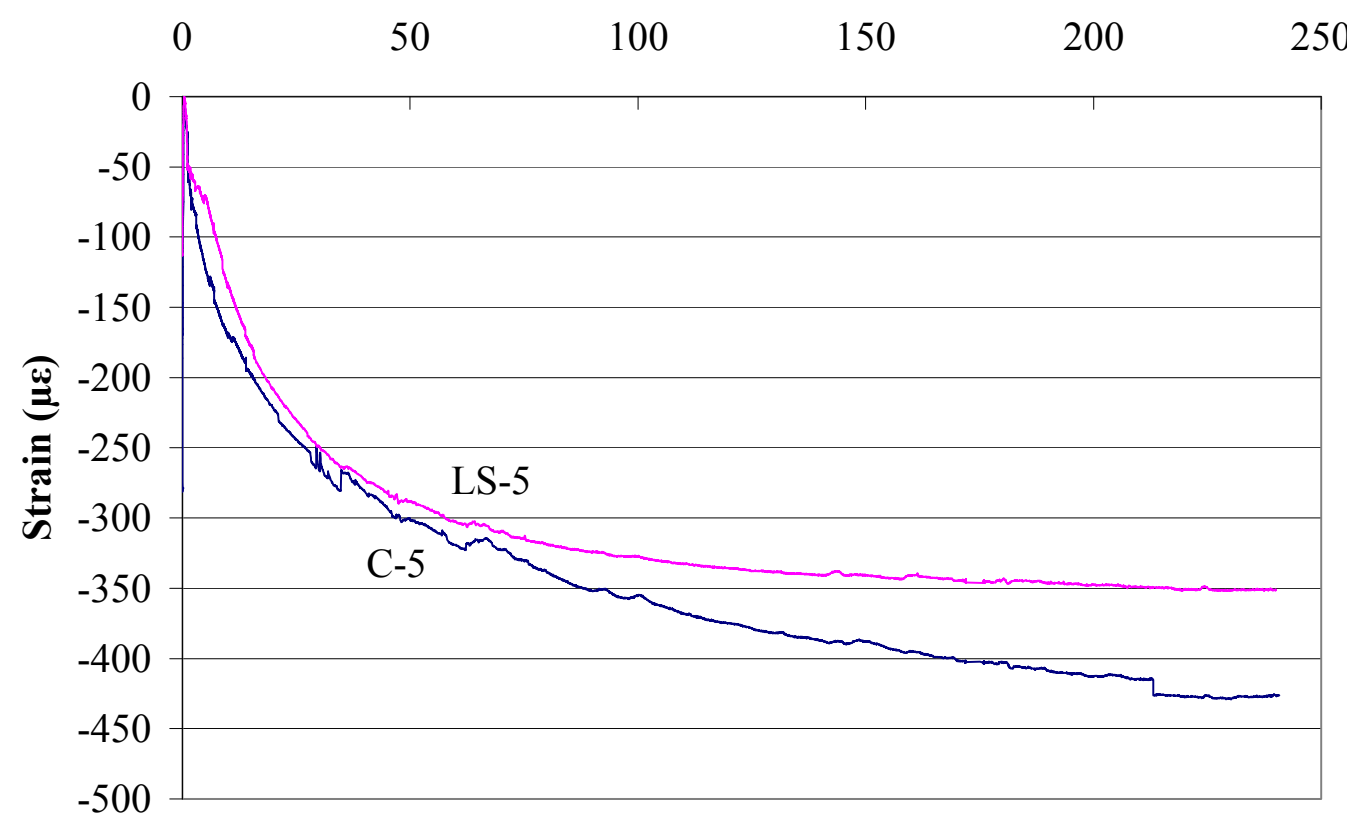

Time (days)

c) 5 day wet cure

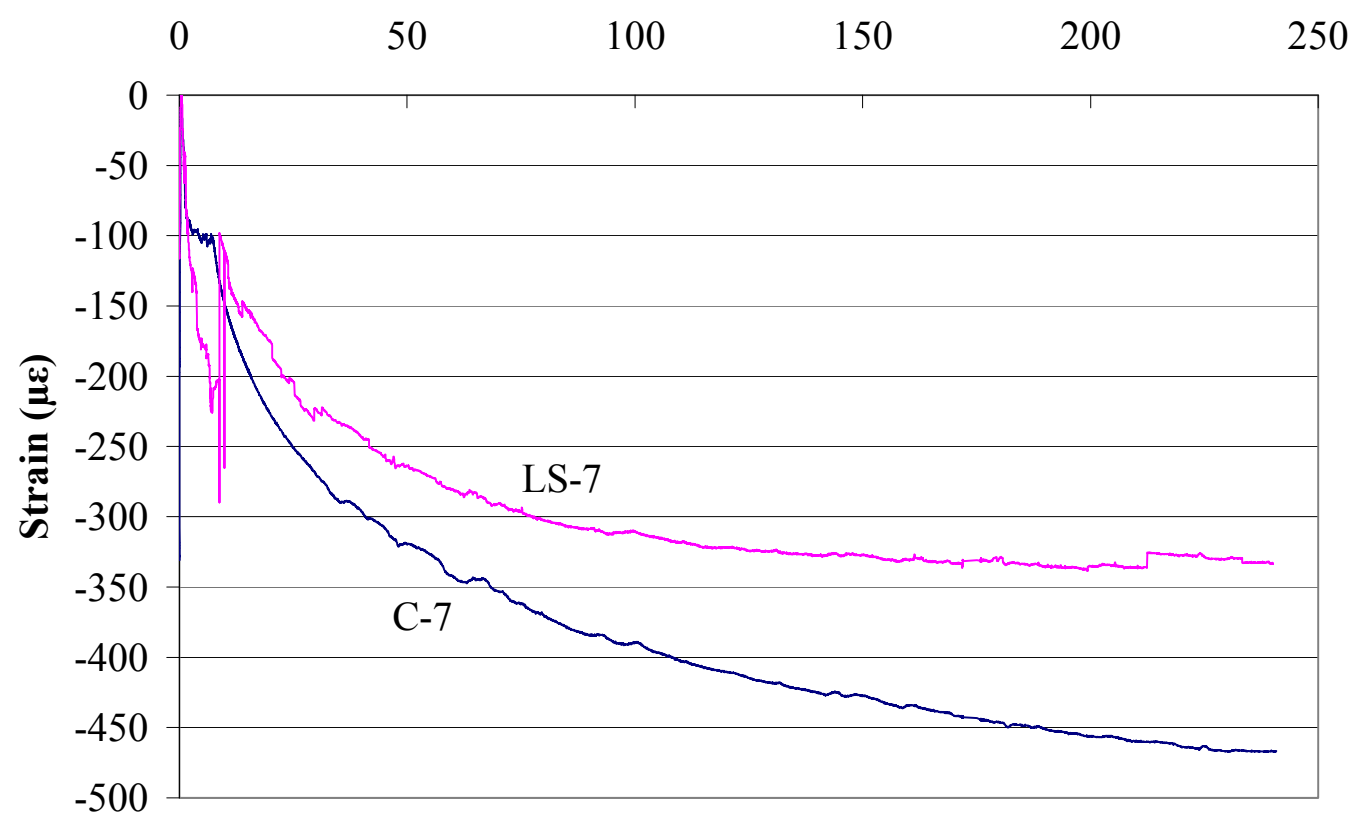

Time (days)

d) 7 day wet cure

Figure 3.23 (continued): Influence of concrete mix on shrinkage 


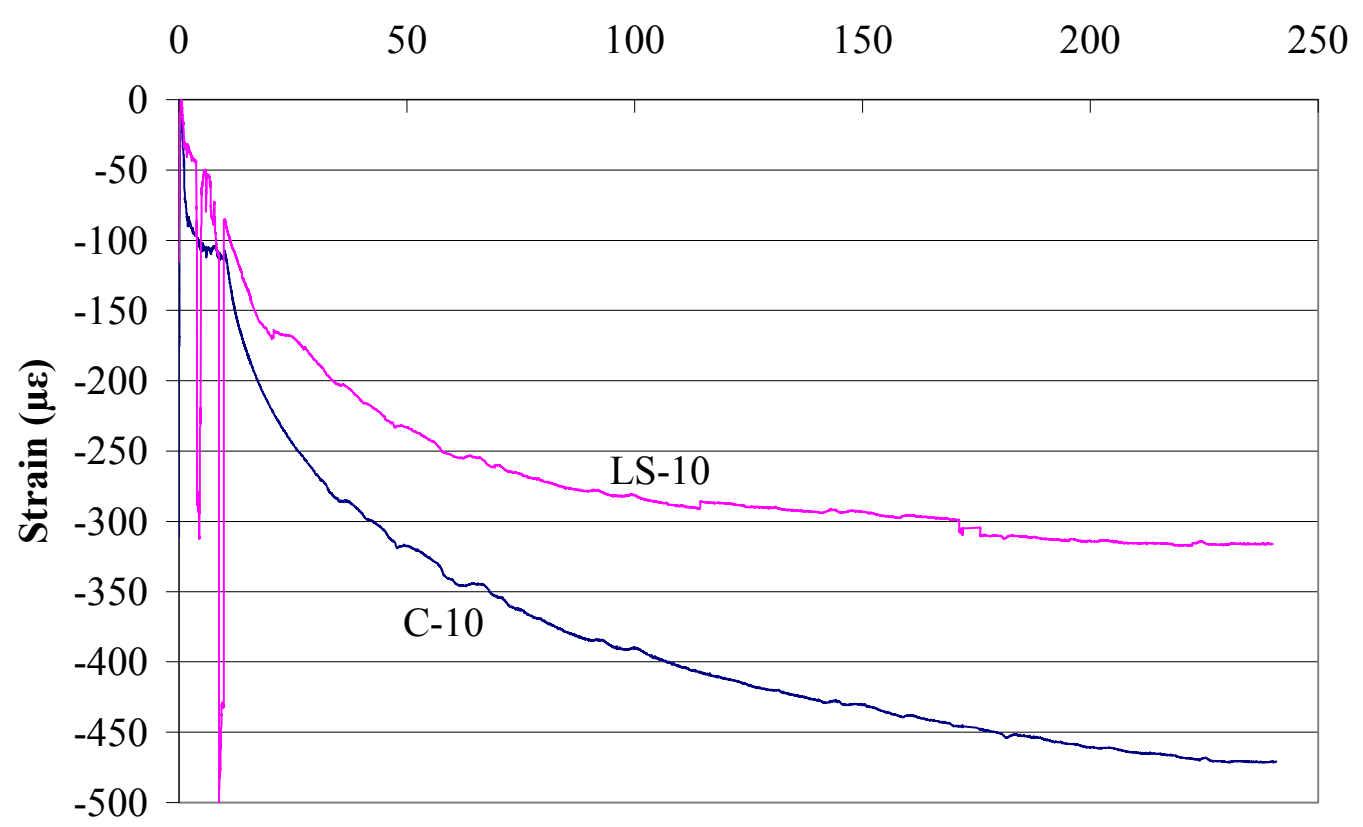

Time (days)

e) 10 day wet cure

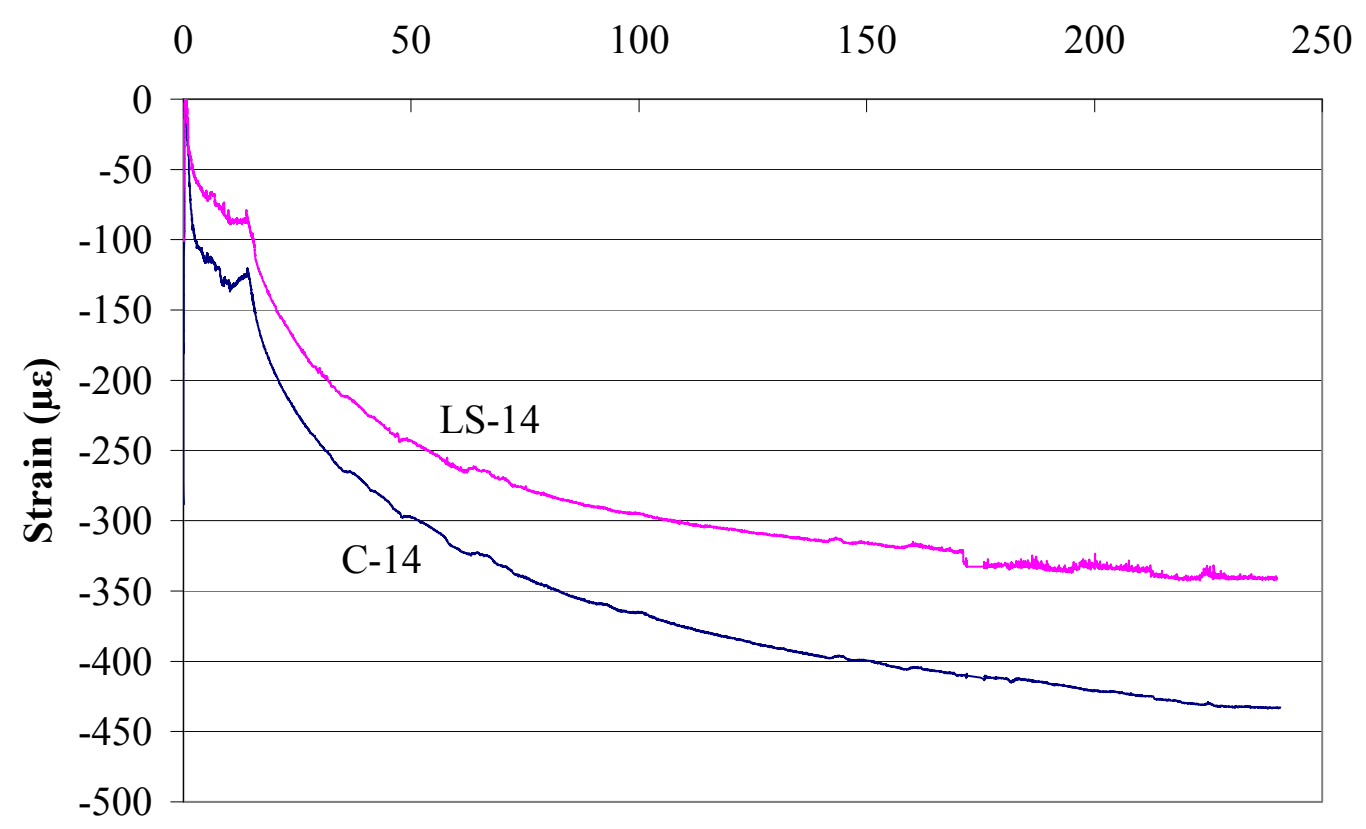

Time (days)

f) 14 day wet cure

Figure 3.23 (continued): Influence of concrete mix on shrinkage 


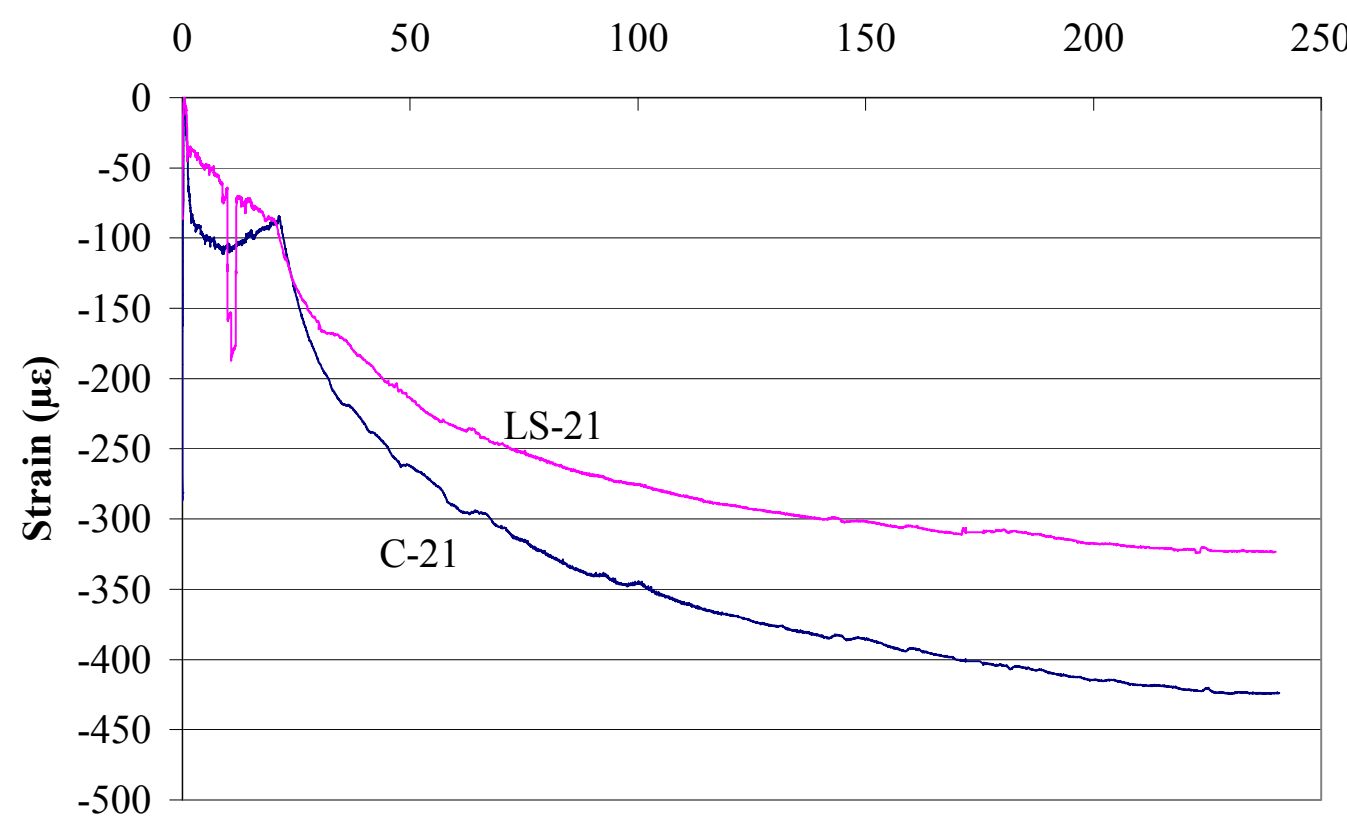

Time (days)

g) 21 day wet cure

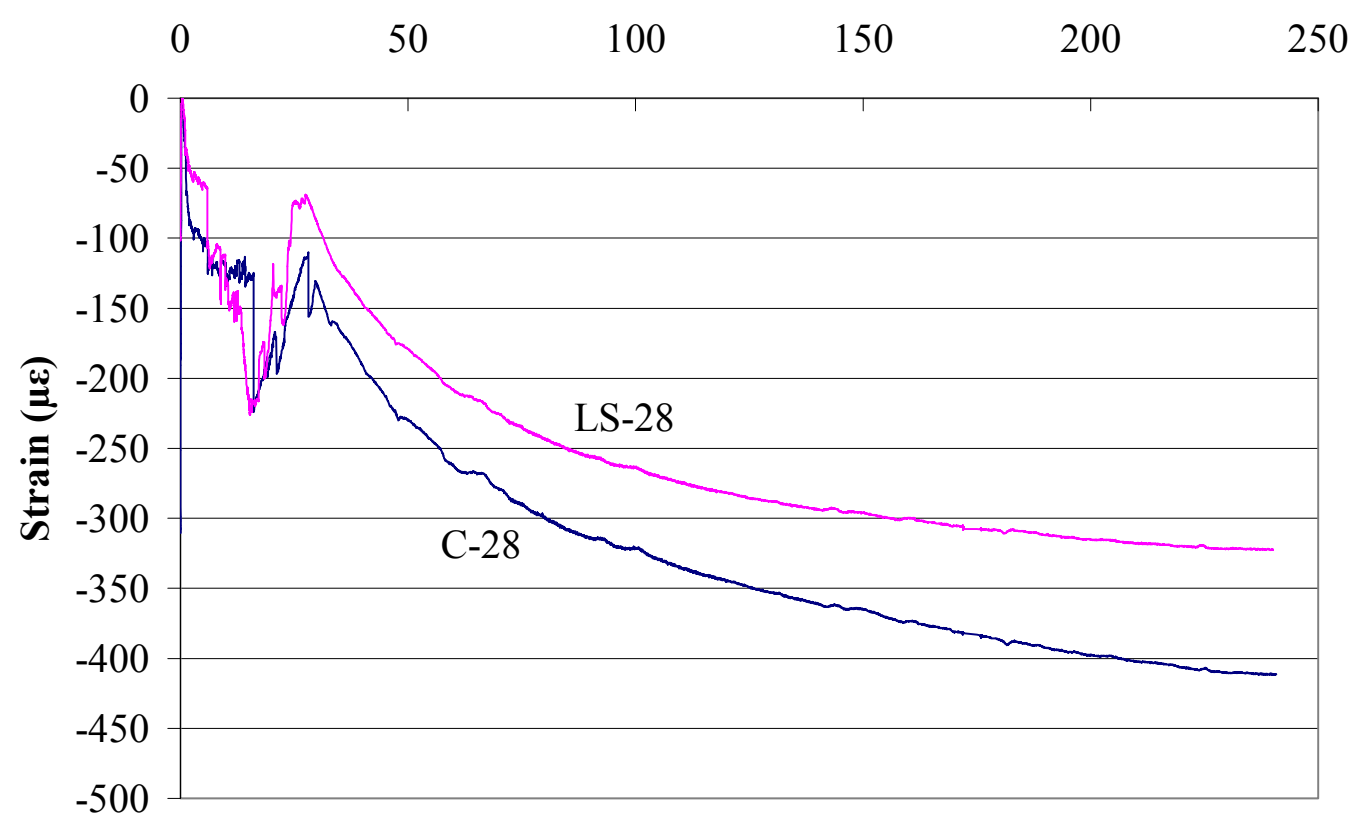

Time (days)

h) 28 day wet cure

Figure 3.23 (continued): Influence of concrete mix on shrinkage 


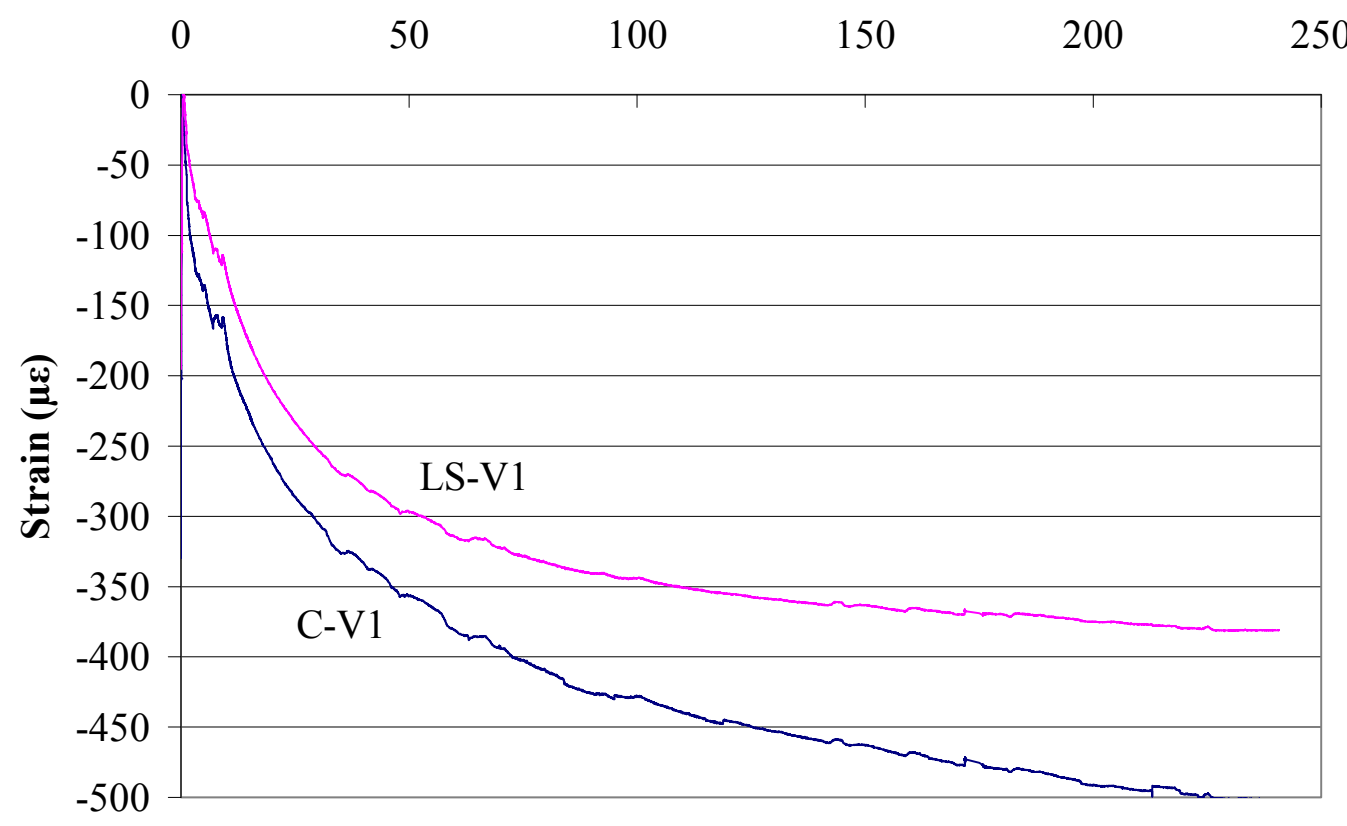

Time (days)

i) Variable Cure 1

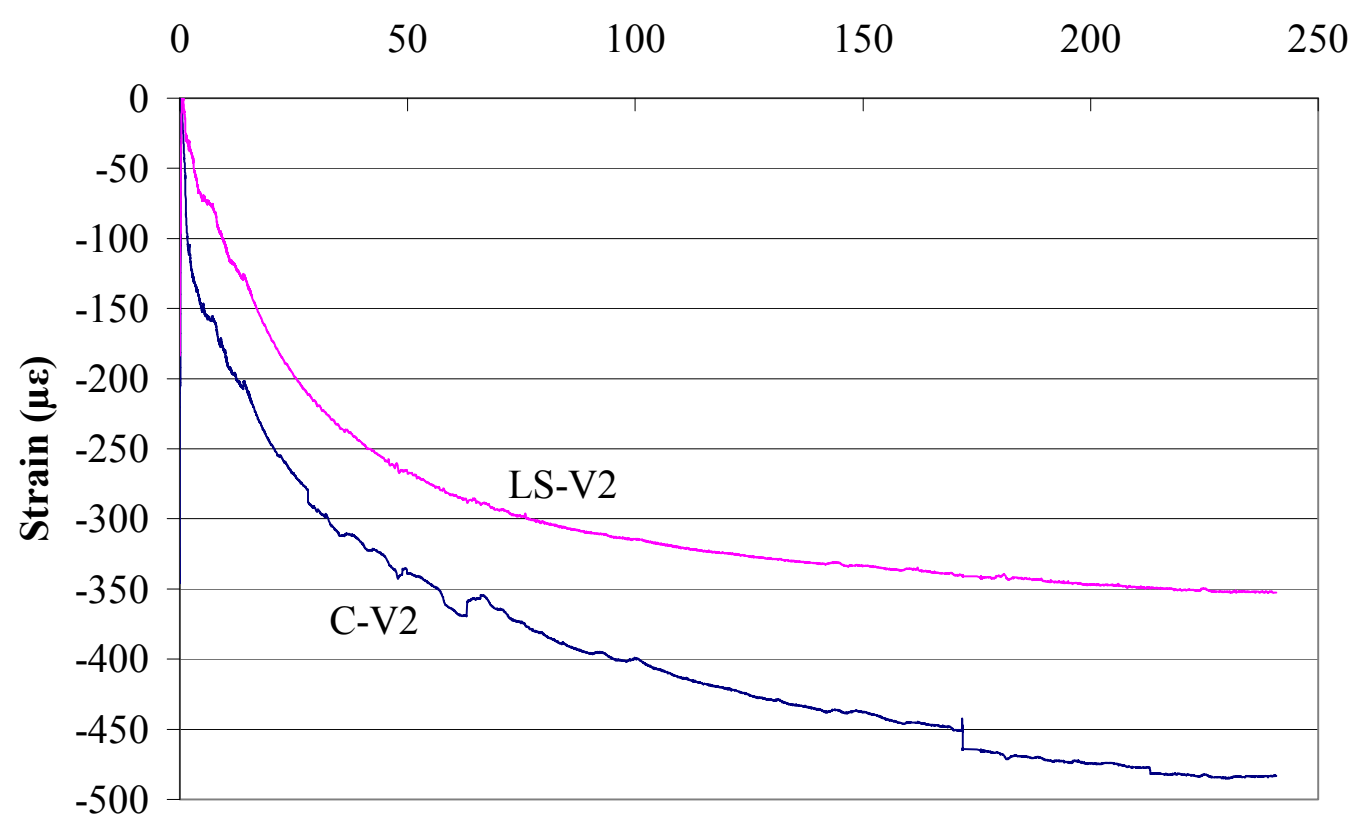

Time (days)

j) Variable Cure 2

Figure 3.23 (continued): Influence of concrete mix on shrinkage 
Table 3.10: Shrinkage at 240 days

\begin{tabular}{|c|c|c|c|}
\hline \multirow{2}{*}{$\begin{array}{c}\text { Curing Duration } \\
\text { (days) }\end{array}$} & Class C & Low shrinkage & Difference \\
\cline { 2 - 4 } & -412.4 & -342.1 & -70.3 \\
\hline 1 & -427.3 & -357.3 & -70.0 \\
\hline 3 & -482.4 & -351.1 & -131.4 \\
\hline 5 & -465.6 & -333.3 & -132.4 \\
\hline 7 & -471.1 & -315.8 & -155.3 \\
\hline 10 & -433.1 & -339.8 & -93.3 \\
\hline 14 & -424.8 & -323.1 & -101.7 \\
\hline 21 & -412.4 & -322.5 & -89.9 \\
\hline 28 & -501.9 & -381.0 & -120.9 \\
\hline Variable 1 & -484.0 & -352.5 & -131.5 \\
\hline Variable 2 & -451.5 & -341.9 & -109.7 \\
\hline Average & & & \\
\hline
\end{tabular}

Table 3.11: Shrinkage from Day 200 through Day 240

\begin{tabular}{|c|c|c|}
\hline $\begin{array}{c}\text { Curing Duration } \\
\text { (days) }\end{array}$ & \multicolumn{2}{|c|}{ Strain $(\boldsymbol{\mu \varepsilon})$} \\
\cline { 2 - 3 } & Class C & Low shrinkage \\
\hline 1 & -11.2 & -2.2 \\
\hline 3 & -13.1 & -2.8 \\
\hline 5 & -11.6 & -3.6 \\
\hline 7 & -10.4 & 1.8 \\
\hline 10 & -10.2 & -1.6 \\
\hline 14 & -11.8 & -8.9 \\
\hline 21 & -9.6 & -5.3 \\
\hline 28 & -13.8 & -7.1 \\
\hline Variable 1 & -10.4 & -5.8 \\
\hline Variable 2 & -8.7 & -5.7 \\
\hline Average & -11.1 & -4.1 \\
\hline
\end{tabular}




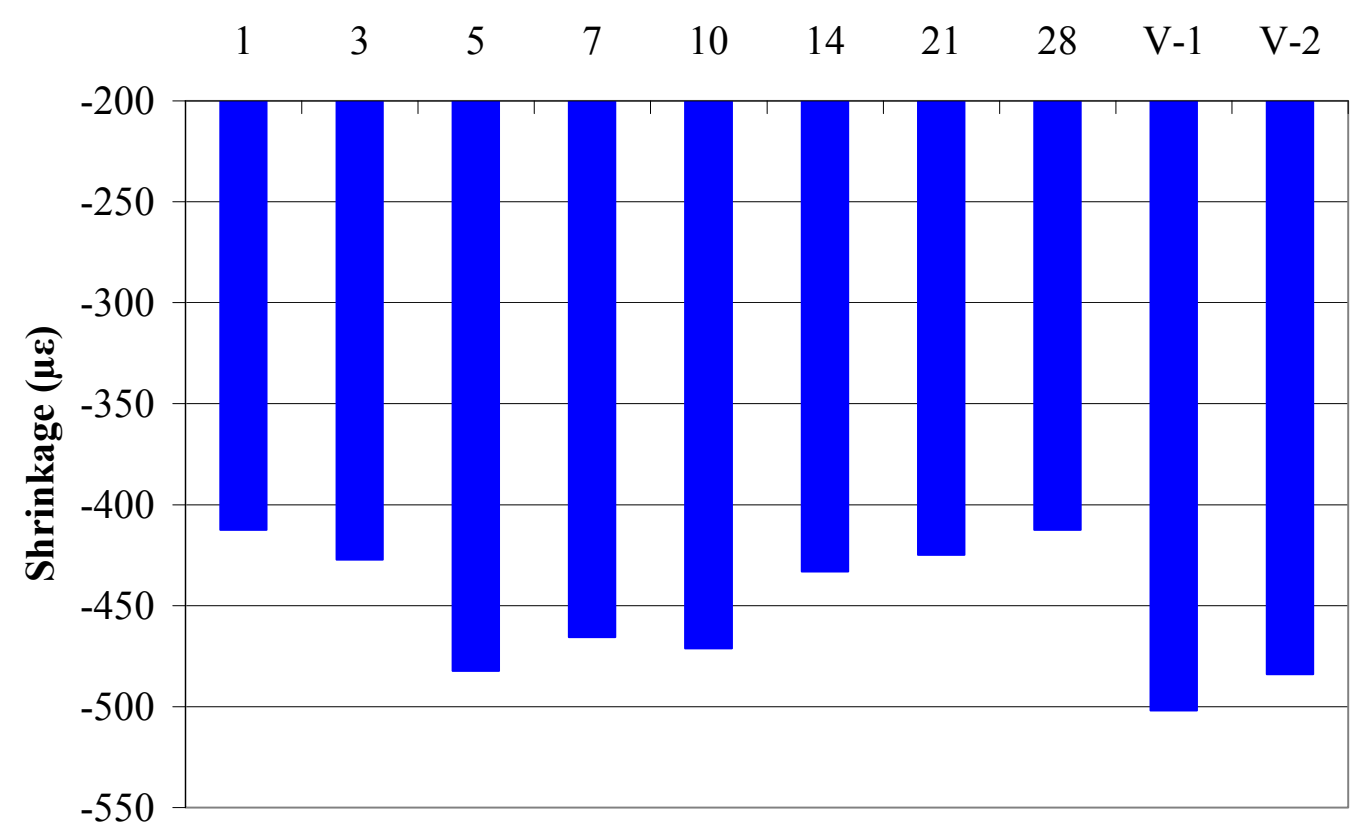

Wet curing duration (days)

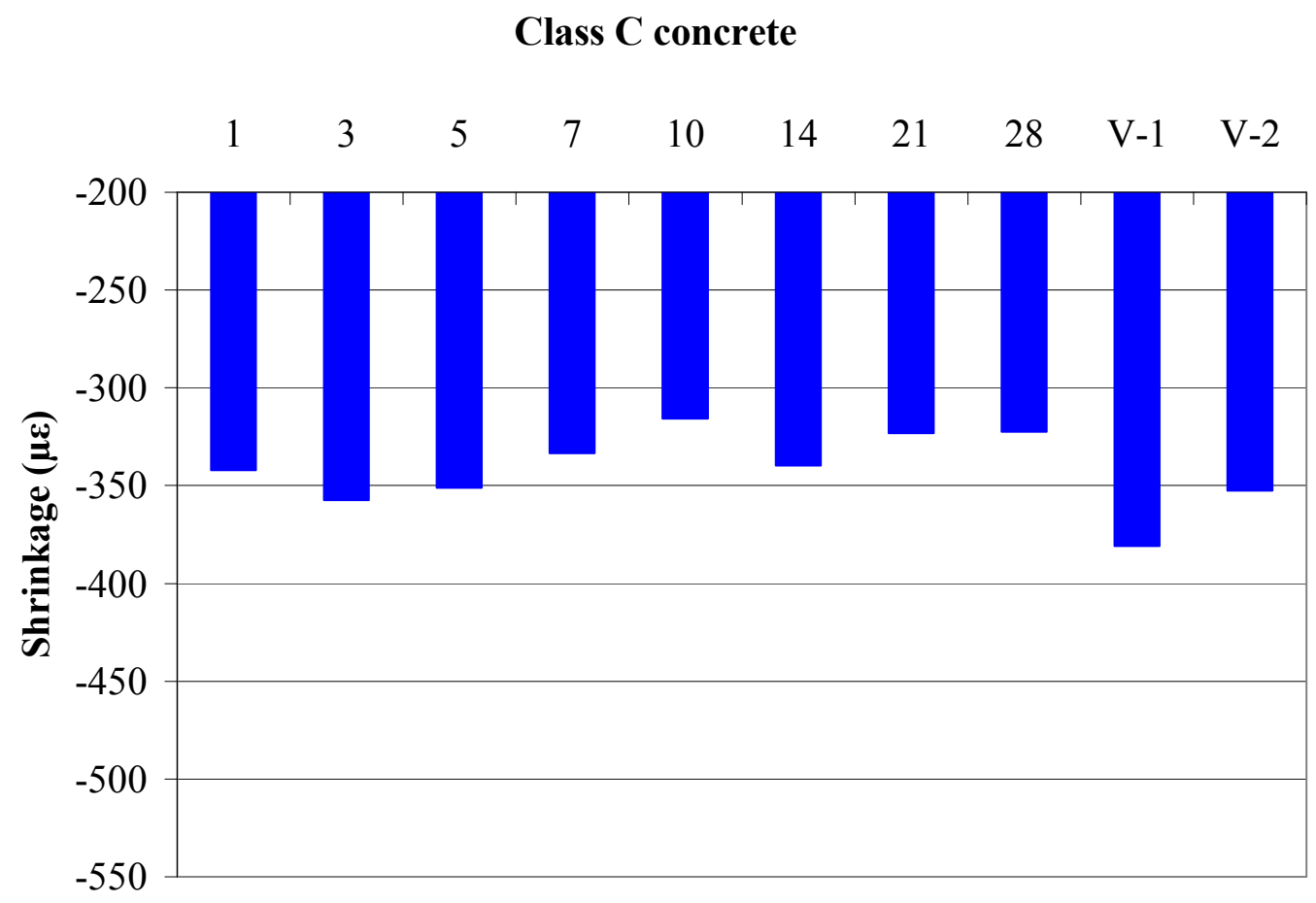

Wet curing duration (days)

Low shrinkage mix

Figure 3.24: Shrinkage at 240 days 


\subsubsection{Curing Measurement Device}

Three types of sensors were installed in the variable curing specimens to evaluate whether any of them could be used as a curing measurement device. Embedment strain gages and thermocouples were placed in all specimens while humidity sensors were placed in the variable curing and the 7 day wet cure specimens.

\subsubsection{Embedment Strain Gages}

The embedment strain gages demonstrated some potential to monitor the curing procedures. Comparing the strains of the variable cure specimens to those of the continuously wet cured specimens demonstrated the differences in behavior. Increased shrinkage was evident in the variable cure specimens when compared to the corresponding continuous wet cure specimens. In addition, the rate of shrinkage changed considerably during periods of wet curing.

All specimens exhibited a similar general behavior. During wet curing, the rate of shrinkage varied but was approximately zero (Figure 3.25). At the end of wet curing, there was an initial rapid shrinkage which eventually leveled off at approximately 5 days after the end of wet curing. For the Class $\mathrm{C}$ specimens, the maximum rate of shrinkage was approximately $-22.5 \mu \varepsilon$ /day which occurred at approximately 6 hours after the end of wet curing. The low shrinkage specimens demonstrated more variation but had an average maximum shrinkage rate of approximately $-13 \mu \varepsilon /$ day 6 hours after the end of wet curing. The specimens also exhibited a similar rate of shrinkage behavior after the end of wet cure regardless of curing duration. Figure 3.26, which presents shrinkage behavior of the Class C specimens zeroed at 24 hours before the end of wet cure, demonstrates the consistent shrinkage behavior of all specimens. 


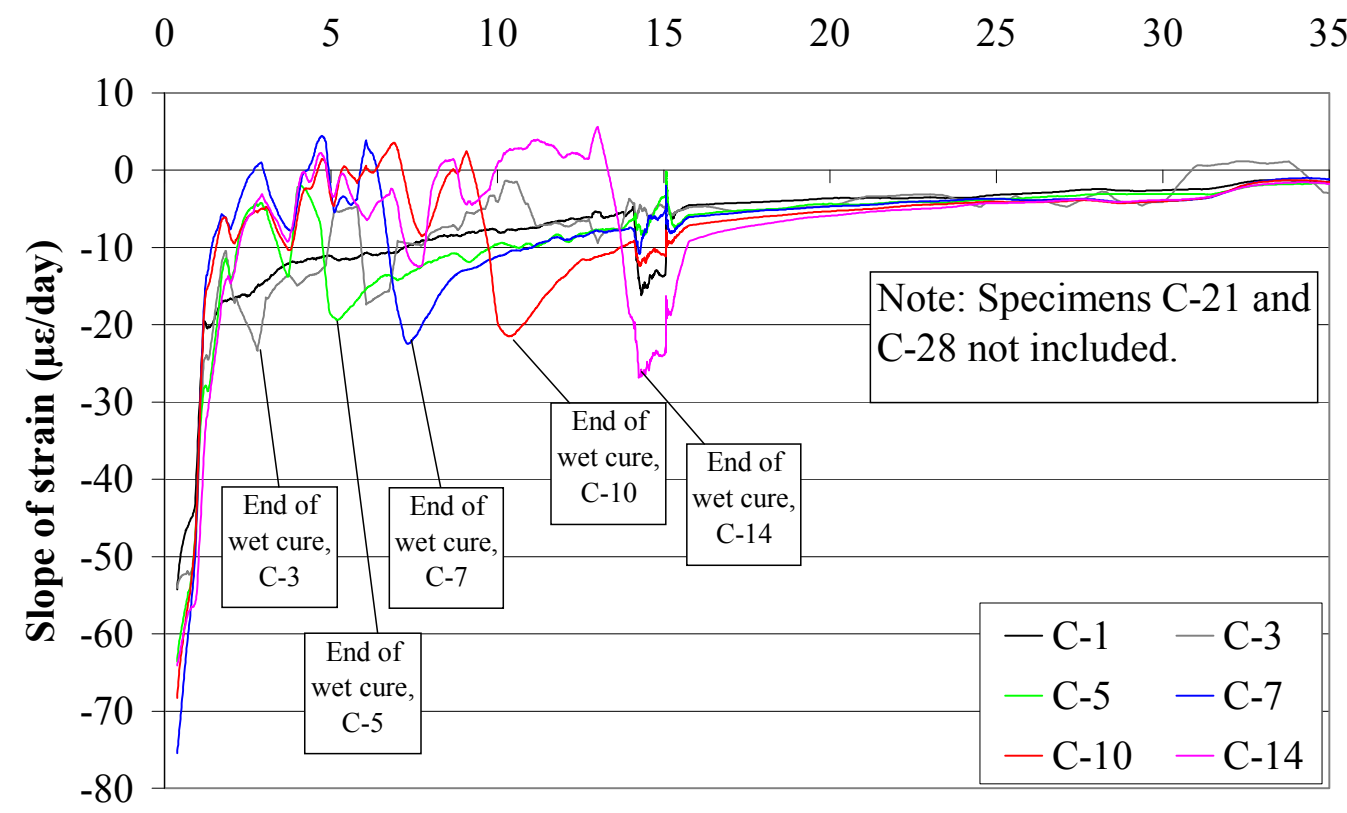

Time (days)

\section{Class $\mathbf{C}$ concrete}

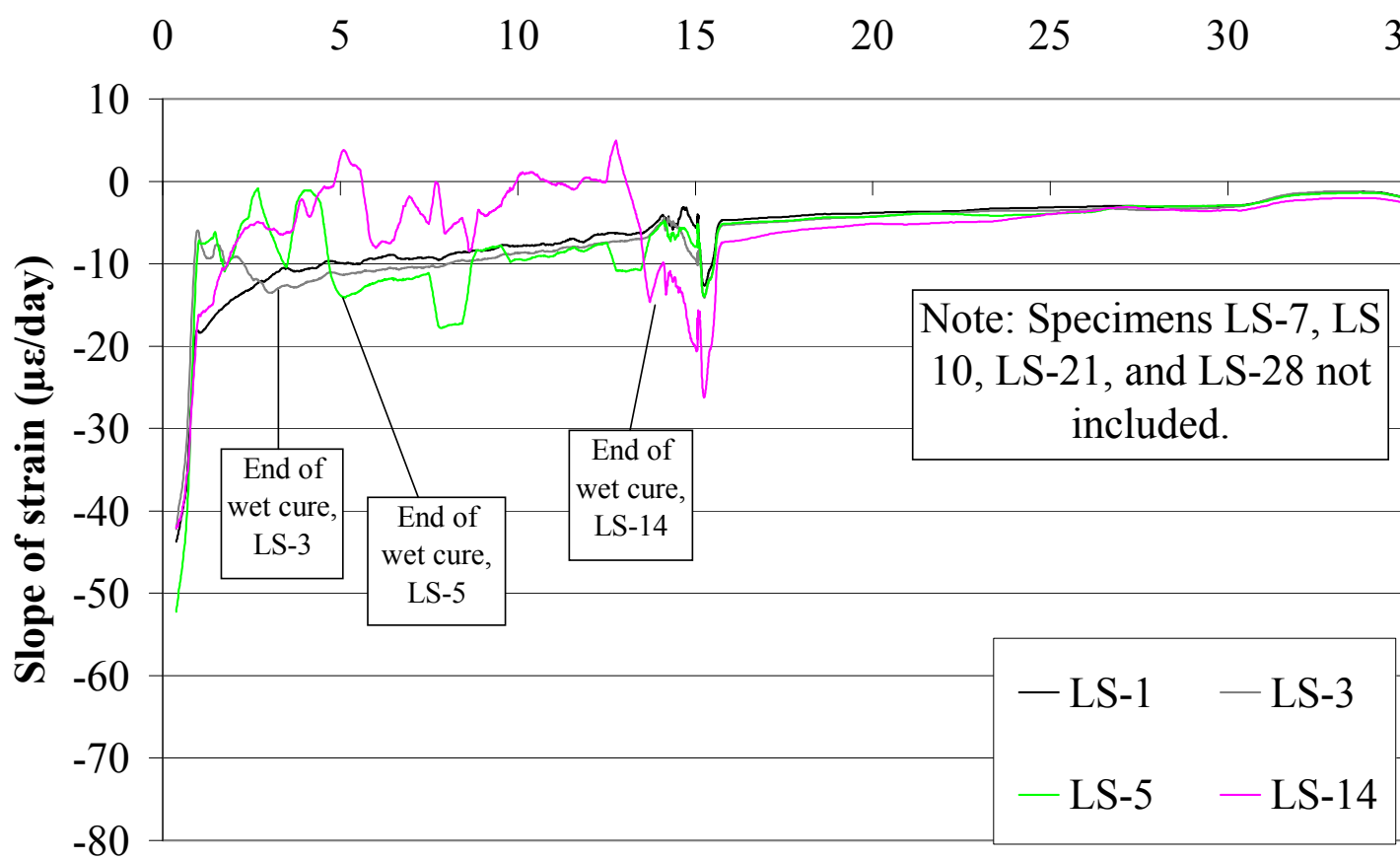

Time (days)

Low shrinkage mix

Figure 3.25: Rate of shrinkage 


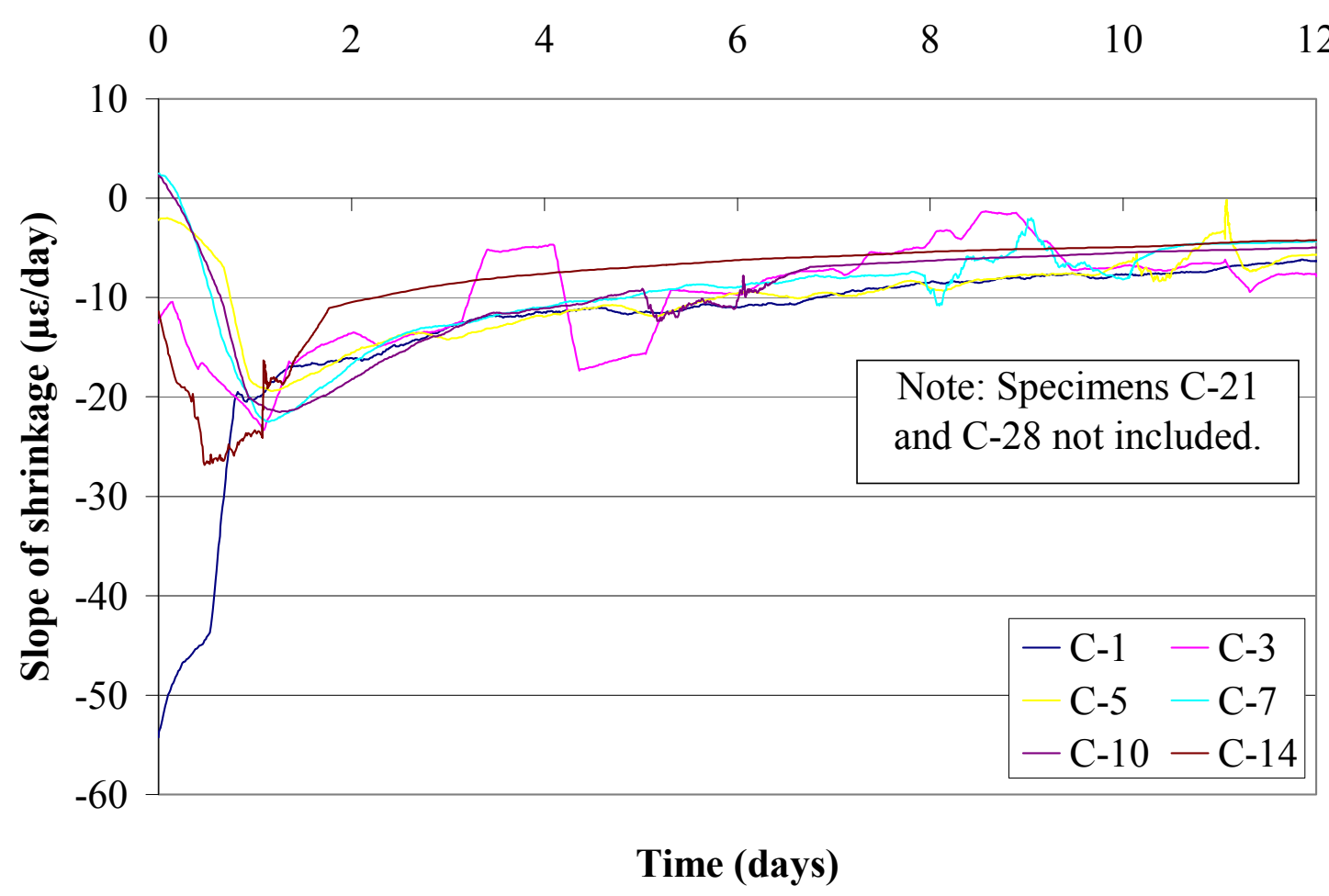

Figure 3.26: Rate of shrinkage (zeroed 1 day before end of wet cure)

The variable cure specimens were implemented to investigate whether the curing measurement devices could effectively monitor irregular curing procedures. Figure 3.27 and Figure 3.28 present the early age slope of shrinkage of all variable cure specimens. The Variable Cure 1 specimens, which underwent alternating wet curing and drying periods, exhibited a higher rate of shrinkage during drying periods. When wet curing was resumed, the rate of shrinkage decreased dramatically and returned to approximately zero. The Variable Cure 2 specimens, which were initially wet cured but not rewet, showed a higher rate of shrinkage than the 14 day wet cure specimens during the first 14 days. 


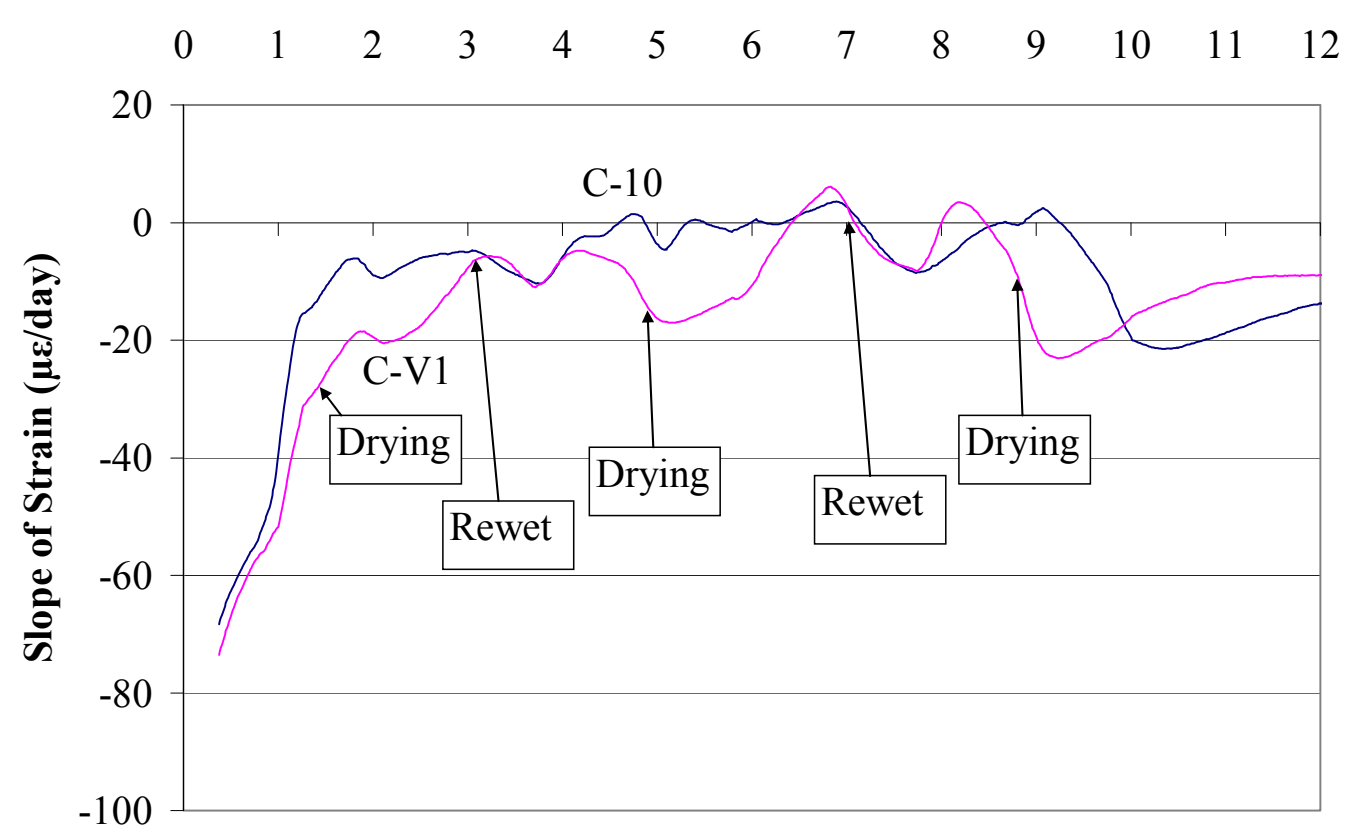

Time (days)

\section{Class $\mathbf{C}$ concrete}

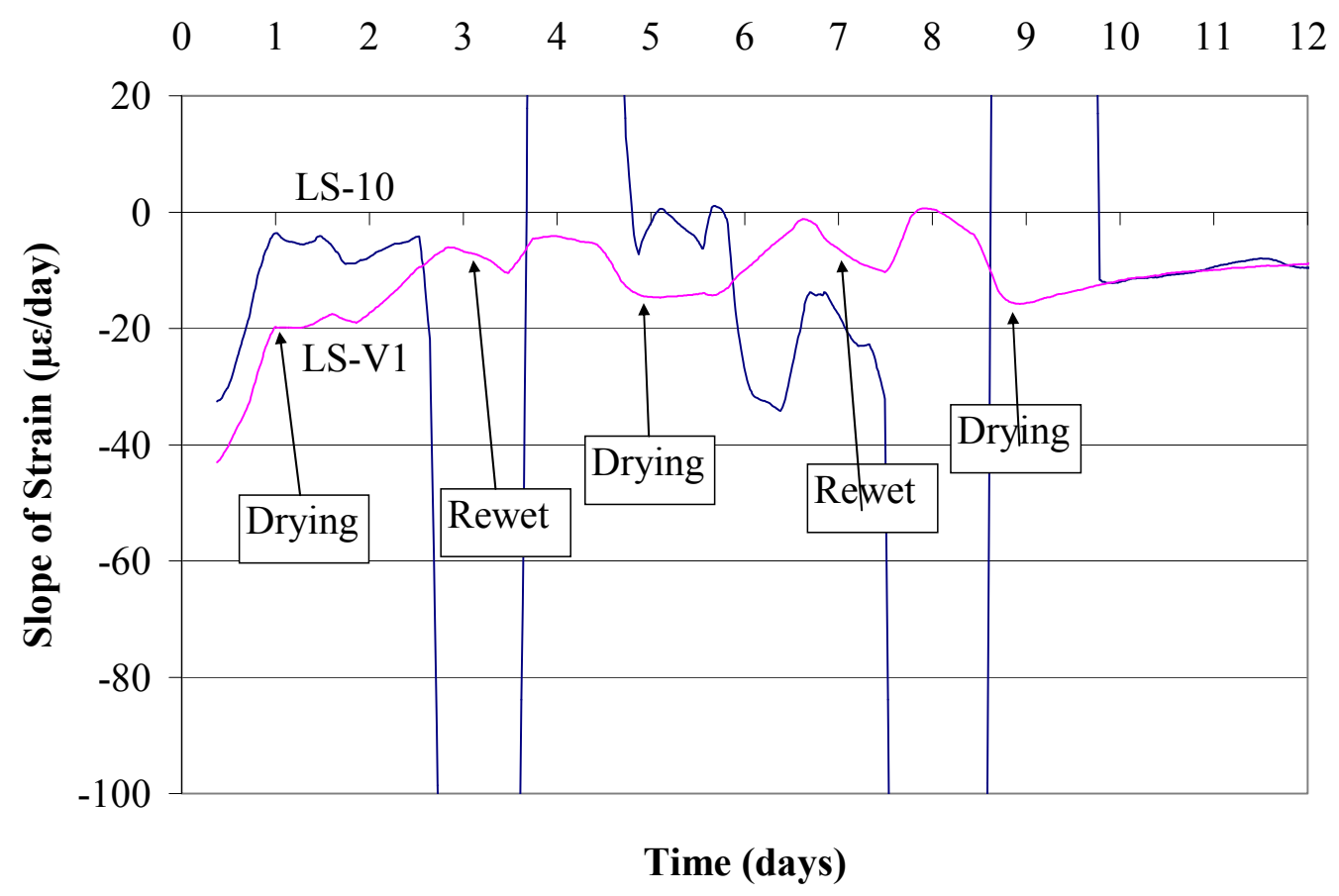

b) Low shrinkage mix

Figure 3.27: Rate of shrinkage, Variable Cure 1 

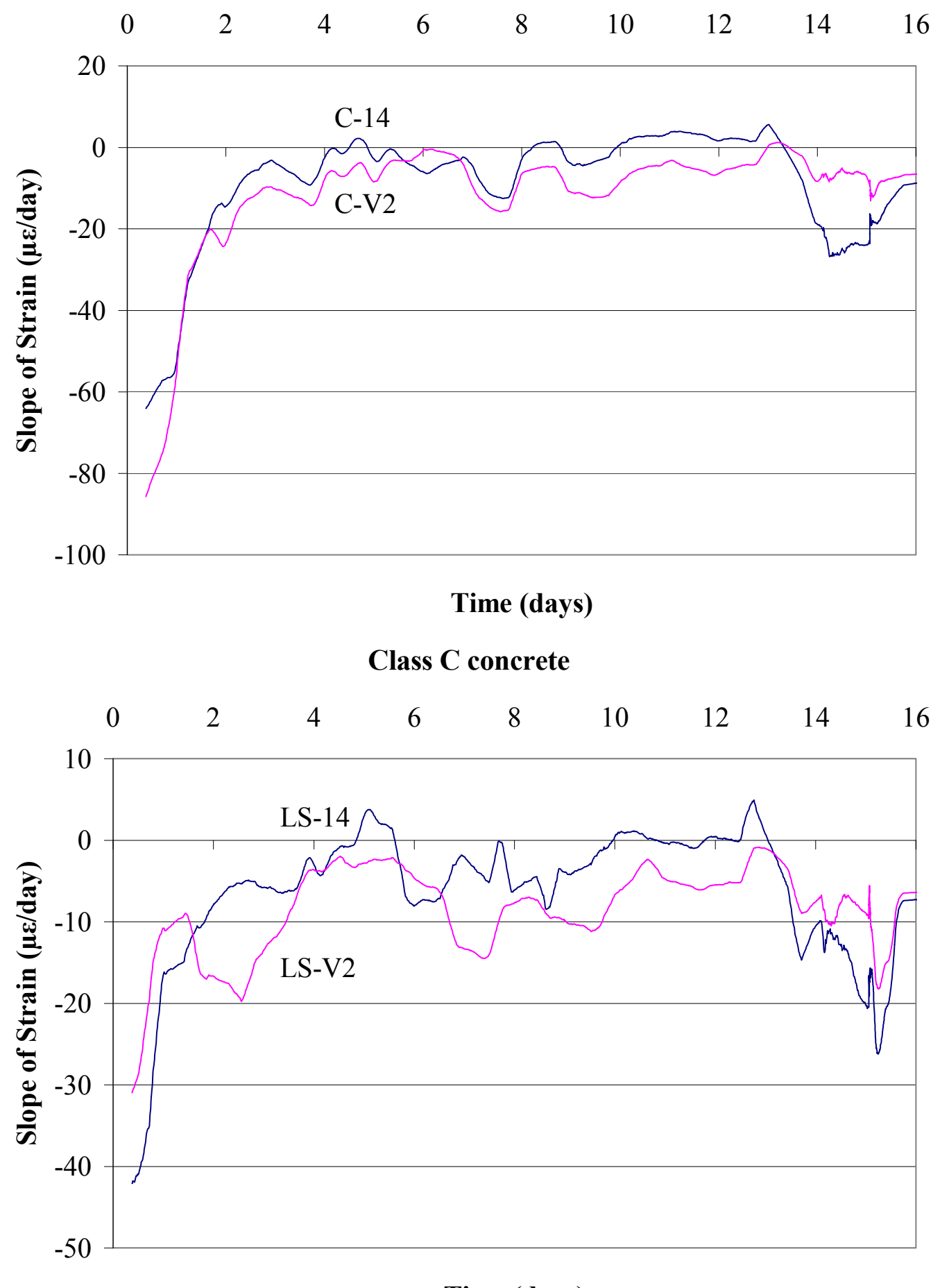

Time (days)

b) Low shrinkage mix

Figure 3.28: Rate of shrinkage, Variable Cure 2 


\subsubsection{Relative Humidity Sensors}

Considering previous research regarding humidity sensors in concrete (Grasley and Lange 2004), it was expected that the internal humidity would provide a correlation to the curing procedure. However, the data collected from the humidity sensors yielded no beneficial data. This is likely due to an error in the fabrication of the sensor protection system or a sensor malfunction due to $100 \% \mathrm{RH}$.

The humidity gages were tested relative to an ambient humidity gage and were shown to be accurate prior to the casting. The ambient humidity in the laboratory was approximately $52 \%$, which was read accurately by the sensors immediately prior to placing the concrete. When the specimens were wet-curing, it was expected that the internal relative humidity would be close to $100 \%$. Due to inaccuracies in the sensor at humidities above $95 \%$, the sensor was not expected to provide accurate measurements. Rather, it would only indicate humidities above $95 \%$. Indeed, the sensors read humidities as high as $132 \%$, a reading that indicated a high relative humidity of greater than $95 \%$. Once the wet curing period ended and the specimen began to dry out, it was expected that the sensor would indicate a decreasing internal relative humidity. However, the sensors continued to indicate very high humidities, well above $100 \%$, for a considerable number of days beyond the end of wet curing. In fact, the first humidity gage to read below $100 \%$ relative humidity was in Specimen LS-V1, occurring at approximately 51 days. All other specimens continued to read relative humidities about $100 \%$ even after 160 days.

It appears that the humidity gages underwent an event during or shortly after placement of the concrete that affected all future readings. One possible explanation is that the GoreTex patch detached during the pour and allowed liquids or solids to damage the sensor. Another possible reason for the failure of the sensors is that the concrete hardened around the GoreTex patch, blocking moisture vapors from flowing through the patch. The high humidity air would then be trapped within the plastic protection case, producing very high humidity readings even as the concrete around it was drying out. Future research is recommended on the use of humidity sensors as a humidity monitoring device. 


\subsubsection{Thermocouples}

The data collected from the thermocouples demonstrated some potential insight regarding the curing procedure based on the difference between the ambient temperature and the temperature of the water used to wet cure.

During the first day of wet curing, all of the specimens had very high internal temperatures due to the heat of hydration. After 32 hours, the temperature of all of the specimens dropped to approximately $78^{\circ} \mathrm{F}$. At this time, the burlap had been removed from Specimens C-1, LS-1, C-V1, and LS-V1, and they remained at this temperature, approximately matching the ambient temperature. The internal temperature of the other specimens continued to drop until reaching approximately $72^{\circ} \mathrm{F}$. This temperature was maintained whenever the wet burlap was covering the specimens. When the burlap was removed, the temperature rose to approximately $78^{\circ} \mathrm{F}$. The internal temperatures for all specimens are provided in Figure 3.29. A jump in internal temperature, from $72^{\circ}$ to $78^{\circ} \mathrm{F}$ can be seen at the end of each wet cure duration.

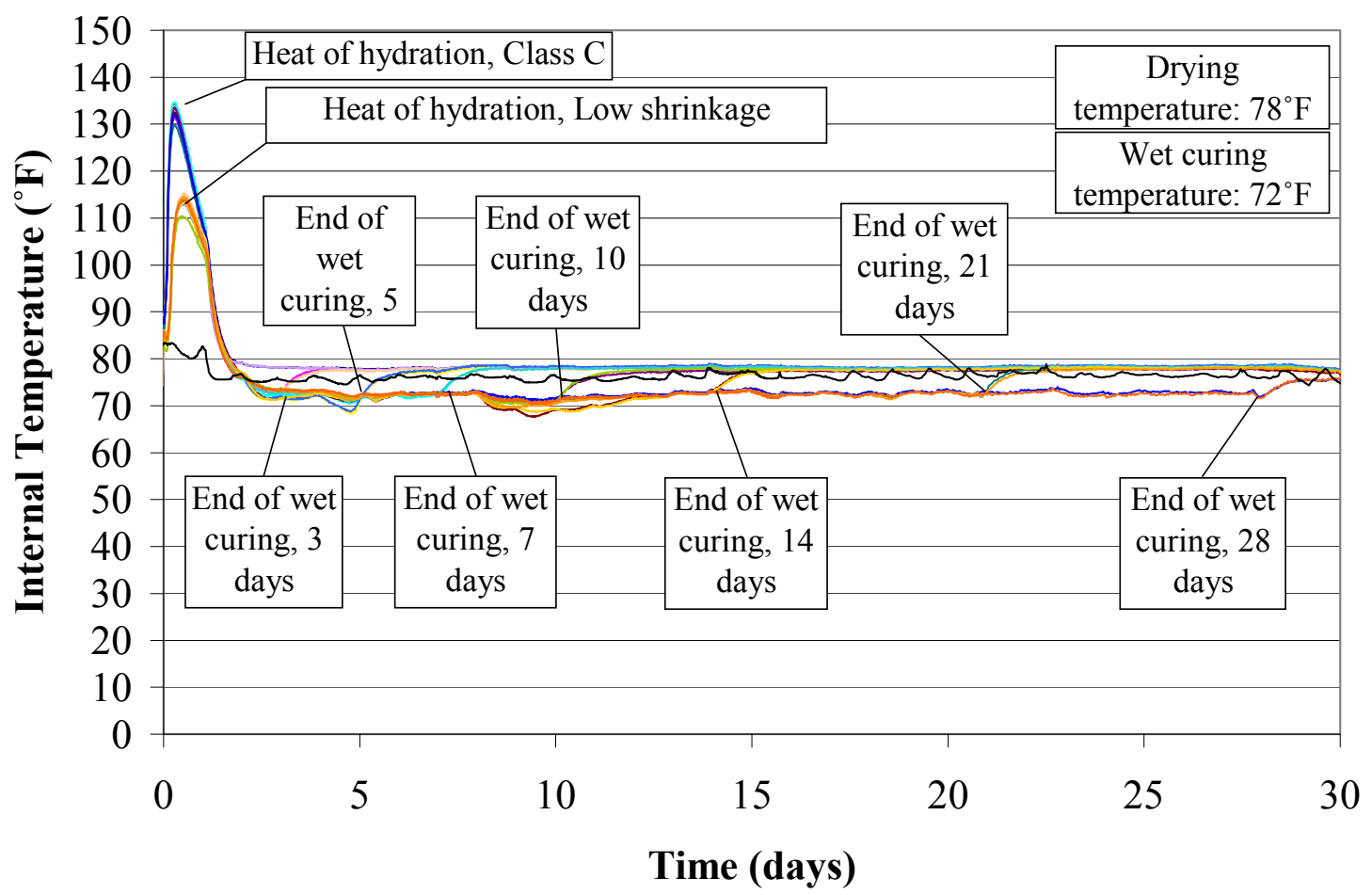

Figure 3.29: Internal temperature, continuously wet cured specimens 
When analyzing the internal temperature change in the Variable Cure-1 specimens (Figure 3.30), which underwent periods of wet cure followed by drying periods, the thermal behavior can be clearly seen. Periods of wet curing can be observed from Day 3 to Day 5 and Day 7 to Day 9 during which the temperature drops to between $70^{\circ} \mathrm{F}$ and $72^{\circ} \mathrm{F}$. Periods of drying can be observed from Day 1 to Day 3, Day 5 to Day 7, and after Day 9, when the temperature of the specimens rises to approximately $78^{\circ} \mathrm{F}$.

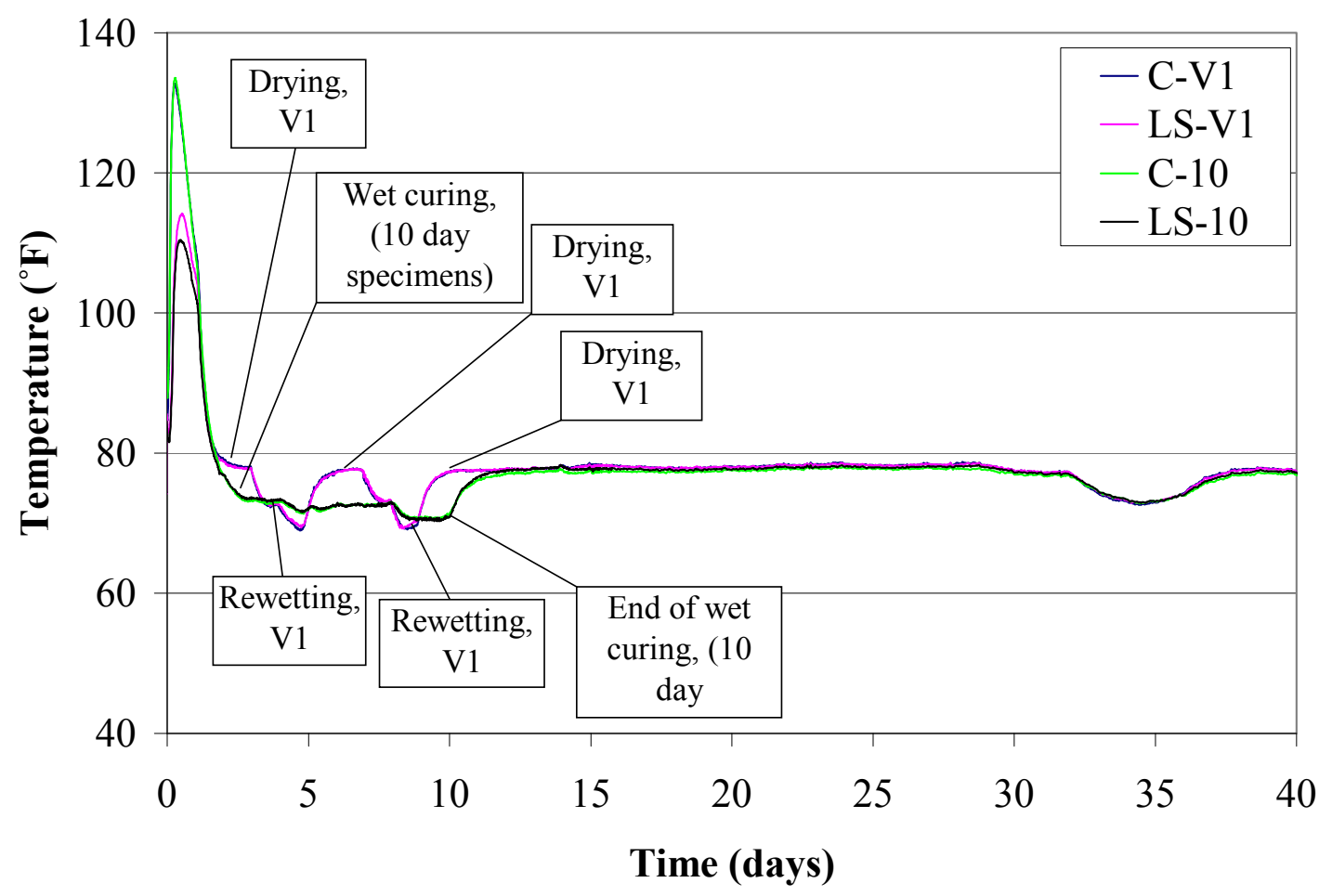

Figure 3.30: Internal temperature, Variable Cure 1 specimens

There is less of a correlation between Variable Cure Procedure 2 and internal temperature. As shown in Figure 3.31, the internal temperature of the specimens remains low despite the improper curing regimen. The presence of the burlap likely depressed the temperature of Specimens C-V2 and LS-V2 despite not being rewet. However, at 
approximately Day 8, there is a drop in the internal temperature of Specimens C-14 and LS-14 which is not observed in Specimens C-V2 and LS-V2. This temperature change is likely due to a decrease in the water temperature used during rewetting, demonstrating the lack of rewetting of the variable cure specimens.

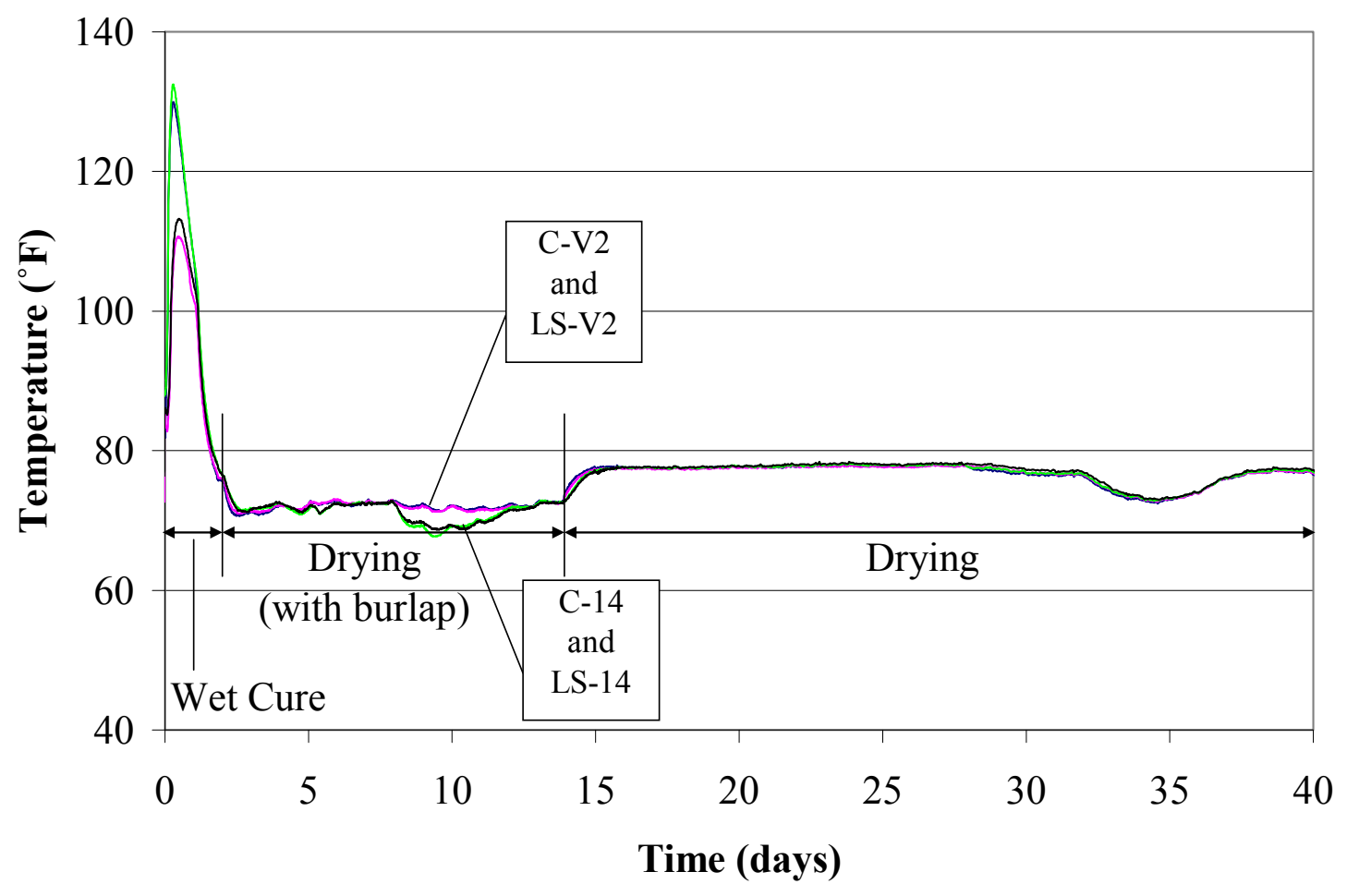

Figure 3.31: Internal temperature, Variable Cure 2 specimens 


\section{$\underline{\text { 3.8 Long Term Results }}$}

Specimens were monitored beyond 240 days to evaluate the long term shrinkage behavior of concrete at Day 550. The measurements were compared between the corresponding specimens to evaluate and identify how the effects of different curing durations, curing procedures, and concrete mixes affect the long term shrinkage of the concrete deck.

\subsubsection{Shrinkage Behavior}

The long term shrinkage behavior confirms the trend that was observed at approximately 240 days, when the shrinkage started to level off. After approximately 260 days, the rate of shrinkage had decreased almost completely. From this point onward, small strain fluctuations of around $\pm 50 \mu \varepsilon$ were noticed. As shown in Figure 3. and Figure 3.33, this trend is observed for both Class $\mathrm{C}$ and low shrinkage specimens. 


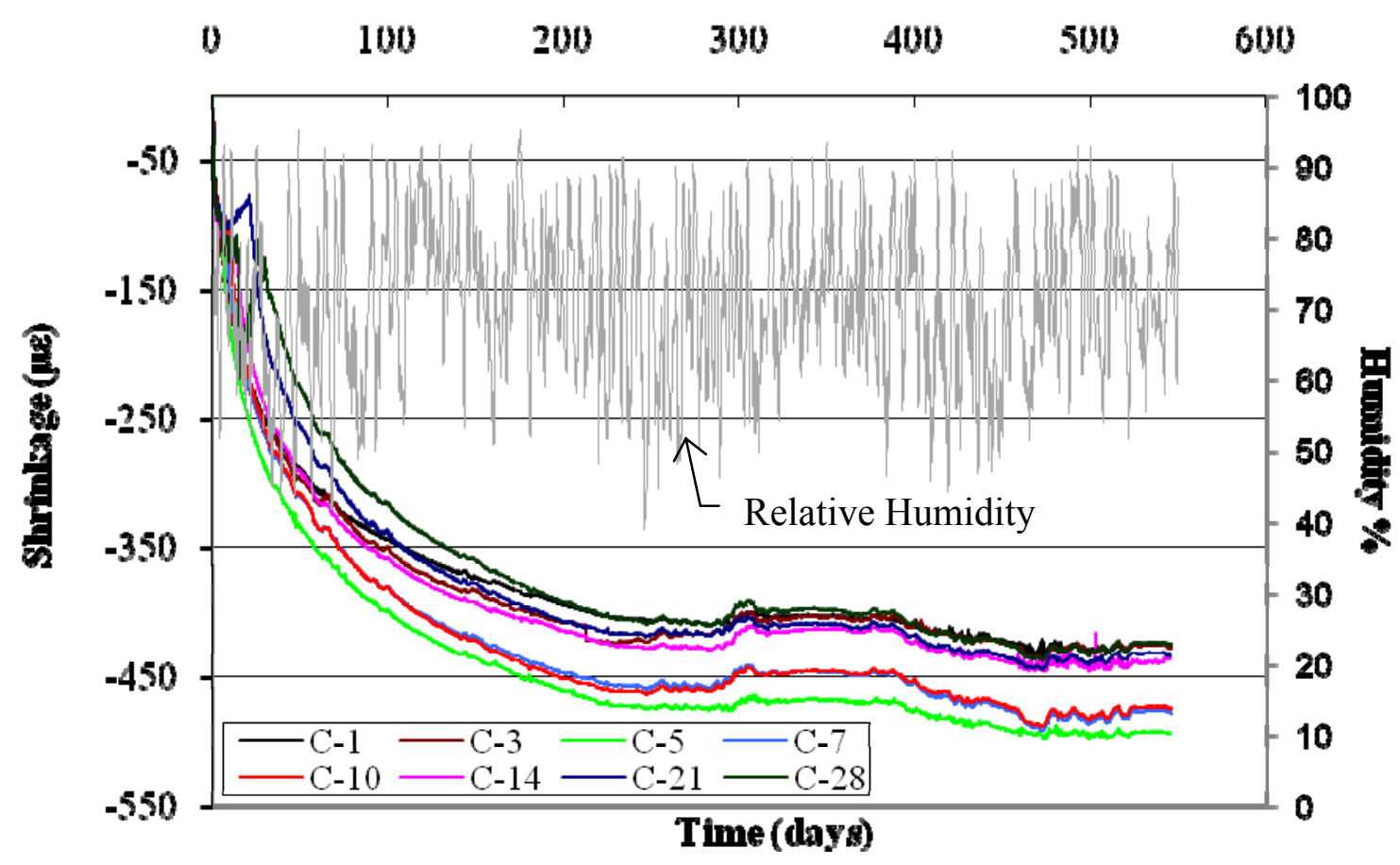

a) Relative humidity comparison

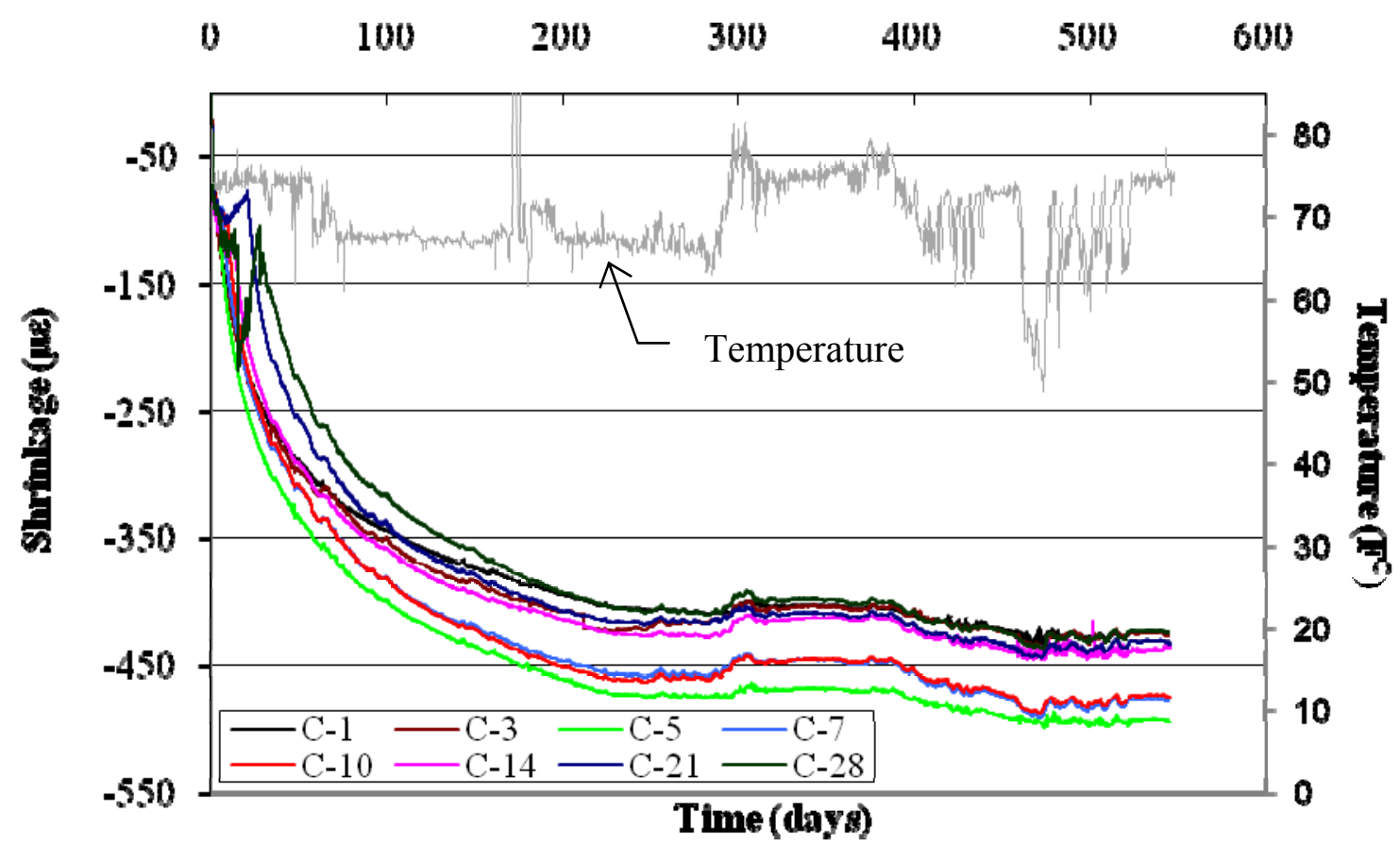

b) Temperature comparison

Figure 3.32 : Shrinkage behavior through 545 days (Class $C$ concrete) 


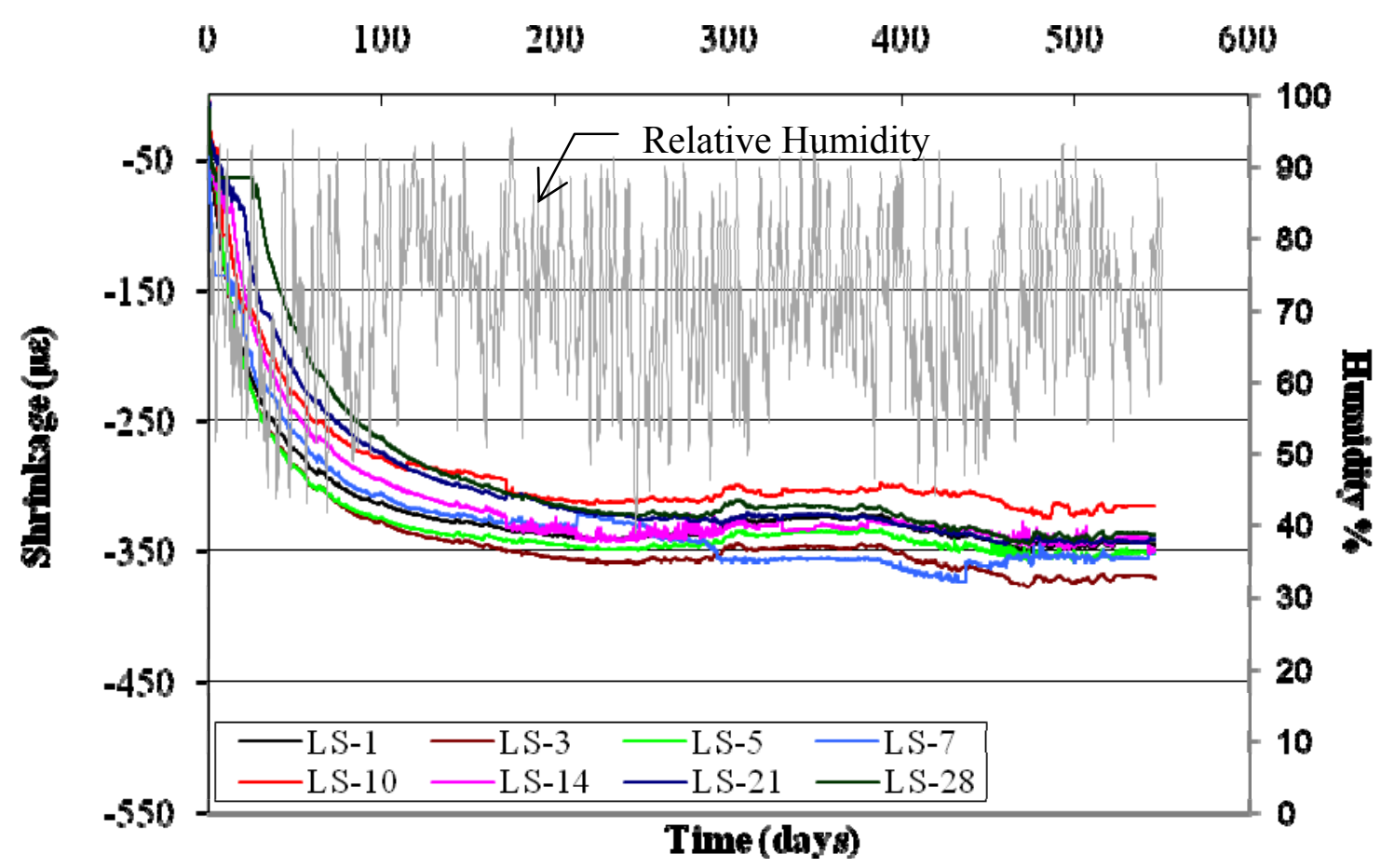

c) Relative humidity comparison

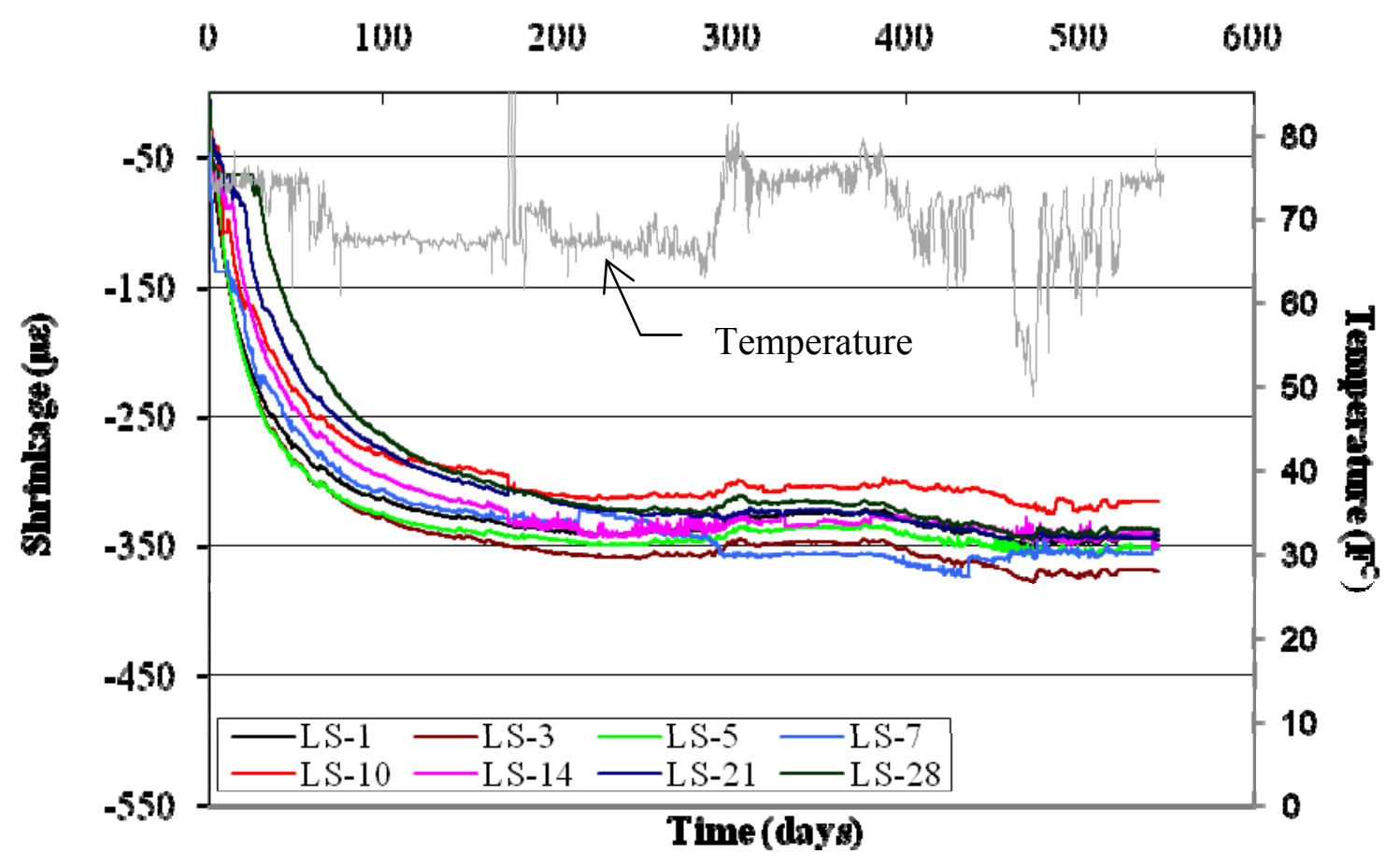

d) Temperature comparison

Figure 3.33: Shrinkage behavior through 545 days (Low shrinkage concrete) 
The small strain variations that occurred after 260 days are primarily due to temperature and humidity changes during this period of time. Unfortunately, the temperature of the specimens during this period is undefined since the embedded thermocouples stopped recording data after 210 days. The room temperature and ambient relative humidity was used to evaluate the shrinkage behavior as illustrated in Figure 3.32 and Figure 3.33. Considering that concrete undergoes volume changes when subjected to temperature variations, the shrinkage plateau observed between Days 300 and 390 is likely caused by the response of the concrete to the corresponding increases in temperature and humidity.

Around Day 300, a small increase of about $+15 \mu \varepsilon$ was likely caused by a higher temperature strain rate than the shrinkage strain rate. When the temperature decreased at approximately Day 390, the concrete exhibited a strain reduction of $-30 \mu \varepsilon$ that includes the thermal effects and the shrinkage strain increase. Throughout this time interval, the strain was also influenced by the fluctuations in ambient humidity.

The slope of strain or rate of shrinkage provides a clear interpretation of the long term shrinkage behavior. A comparison of the rate of shrinkage for Specimen C-1 and C-7 is shown in Figure 3.34. The plot reveals a similar overall behavior for the specimens. They both reached zero around Day 260 and oscillated afterwards between $\pm 2 \mu \varepsilon /$ day until the last day recorded. These values demonstrate, once again, that the shrinkage essentially leveled off after 260 days. 


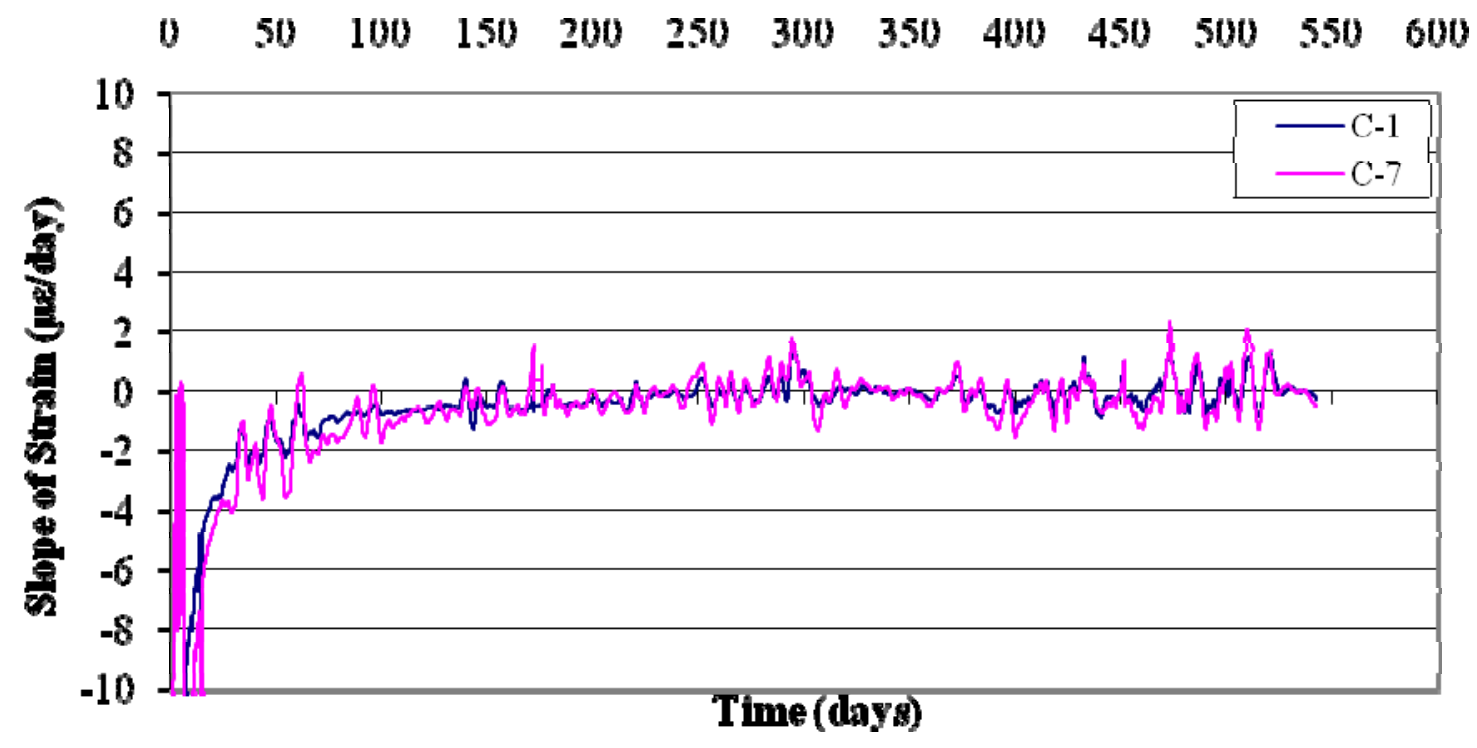

Figure 3.34: Rate of shrinkage, $\mathrm{C}-1$ and $\mathrm{C}-7$

\subsubsection{Effect of Curing Duration}

The same effect of curing duration on the shrinkage of the specimens was observed in comparing the results on Day 210 and Day 518. This similarity is due to the shrinkage rate behavior, which remained closed to zero after 260 days (Figure 3.). Figure 3.35 provides evidence of the behavior after the end of wet curing of specimens with different curing durations. The shrinkage strains at 518 days after the end of wet curing are listed in Table 3.12. In general, specimens with shorter curing durations underwent more shrinkage than specimens with longer durations with a few exceptions as shown in Figure 3.36. For instance, the shrinkage strain of Specimen C-1 was of $-406.9 \mu \varepsilon$ while a lower value of $-318.7 \mu \varepsilon$ was obtained for Specimen C-28. When comparing the order of the specimens with respect to their shrinkage values at Day 210 (Figure 3.18) and Day 518, it can be observed that only LS-7 changes its position due to a shrinkage increase of $32 \mu \varepsilon$. The reduction in shrinkage obtained from the increased curing duration is not a short term phenomenon. These results indicate the reduction remains for the life of the concrete and for the mixes tested, a difference of approximately $100 \mu \varepsilon$ was observed in extending the curing duration from 1 day to 28 days which is approximately a $25 \%$ shrinkage decrease. 


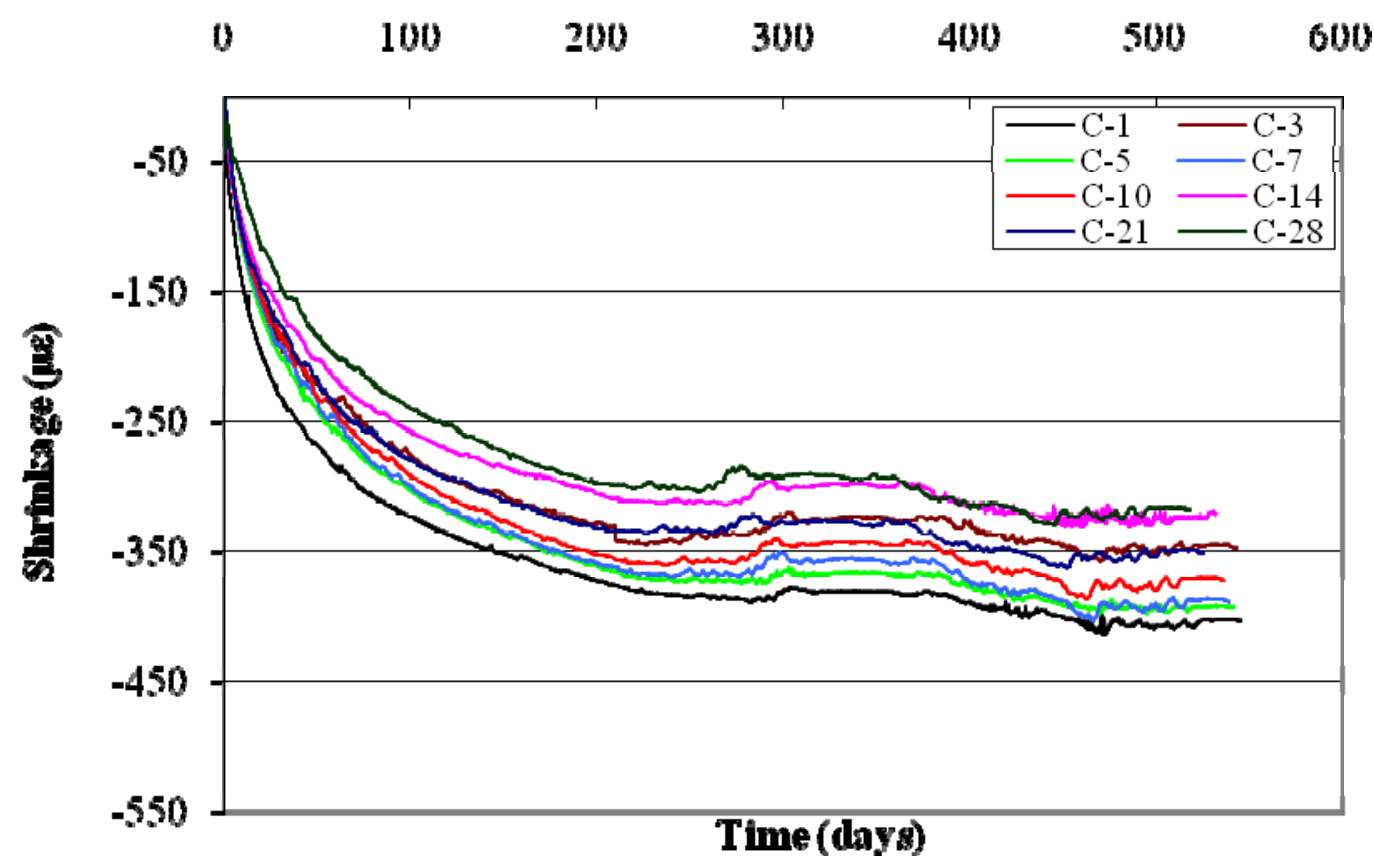

a) Class $\mathbf{C}$ concrete

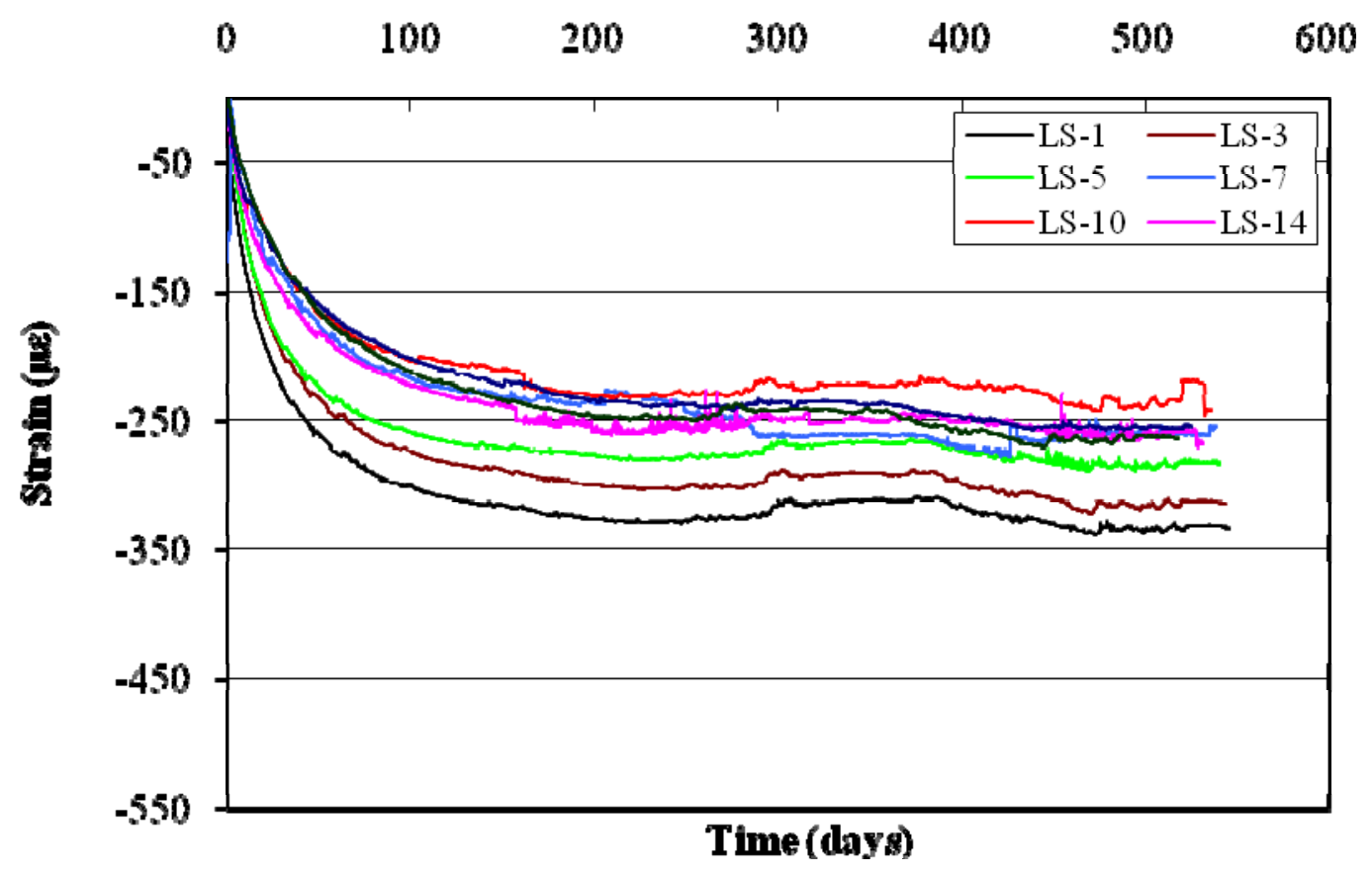

a) Low shrinkage concrete

Figure 3.35: Shrinkage at 518 days after the end of wet cure 
Table 3.12: Shrinkage at 518 days after the end of wet cure

\begin{tabular}{|c|c|c|}
\hline \multirow{2}{*}{$\begin{array}{c}\text { Curing } \\
\text { Duration } \\
\text { (days) }\end{array}$} & \multicolumn{2}{|c|}{ Strain $(\boldsymbol{\mu \varepsilon})$} \\
\cline { 2 - 3 } & Class C & $\begin{array}{c}\text { Low } \\
\text { shrinkage }\end{array}$ \\
\hline 1 & -406.9 & -332.8 \\
\hline 3 & -348.5 & -315.9 \\
\hline 5 & -393.4 & -284.8 \\
\hline 7 & -387.0 & -260.3 \\
\hline 10 & -371.5 & -234.1 \\
\hline 14 & -324.8 & -258.1 \\
\hline 21 & -349.3 & -256.3 \\
\hline 28 & -318.7 & -264.1 \\
\hline
\end{tabular}



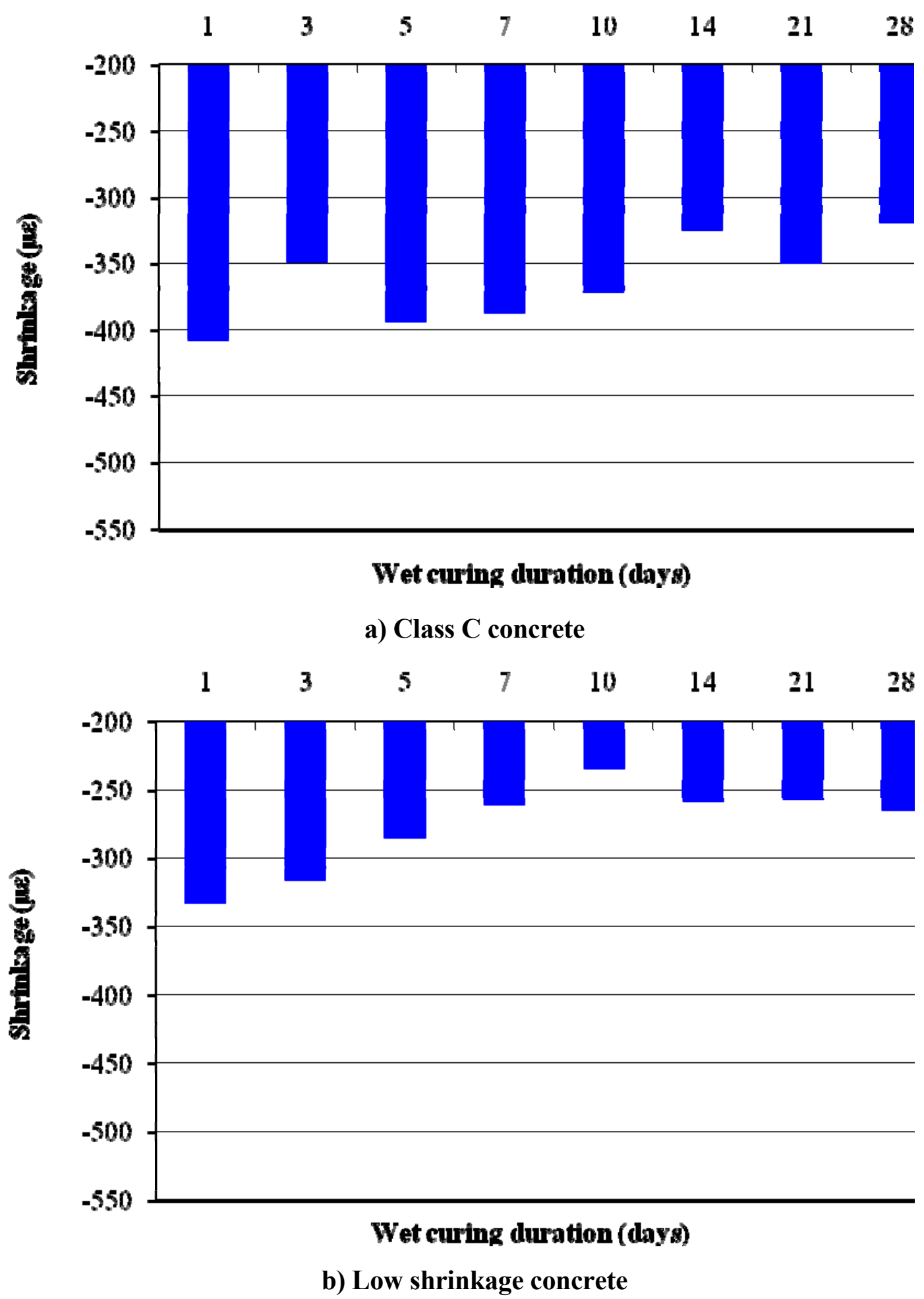

Figure 3.36: Shrinkage at 518 days after the end of wet cure 


\subsubsection{Effect of Curing Procedure}

Two variable curing specimens were considered to determine how the curing procedure employed affects long term shrinkage. As previously discussed, Variable Cure 1 involved a procedure of alternating wet curing periods which lasted 9 days while Variable Cure 2 provided an initial wetting of burlap followed by a dry period prior to removal of the burlap at 14 days. Table 3.13 compares the shrinkage strains for Variable Cure 1 and Specimen C-10 at 10 and 545 days. As shown in Figure 3., analysis of the results at 240 days had indicated that the shrinkage difference between Specimens C-10 and C-V1 decreased from $-62.8 \mu \varepsilon$ at 10 days to $-30.6 \mu \varepsilon$ at 240 days. At 545 days, the difference increased to $-41.6 \mu \varepsilon$. As a result, the expected convergence of strains did not occur; instead, an increase of $11.0 \mu \varepsilon$ was revealed. The difference between Specimens LS-10 and LS-V1 also increased in this period.

The difference in strains between Variable Cure 2 and Specimen C-14 was also evaluated. Table 3.14 presents the data for this case and Figure 3. reveals the trend for the different days. The estimated difference between C-V2 and C-14 decreased from $81.6 \mu \varepsilon$ at 14 days to $-38.7 \mu \varepsilon$ at 545 days. Although this difference reduction implies a future convergence, it is difficult to extrapolate this trend because the strains had already leveled off as illustrated in the overall shrinkage behavior. The difference calculated from LS-V2 and LS-14 increased $3.4 \mu \varepsilon$, describing a constant behavior from Day 240 to Day 545. 
Table 3.13: Variable Cure 1 shrinkage

\begin{tabular}{|c|c|c|c|c|}
\hline \multirow{2}{*}{$\begin{array}{c}\text { Curing } \\
\text { Duration }\end{array}$} & \multicolumn{2}{|c|}{ Strain at 10 days $(\boldsymbol{\mu \varepsilon})$} & \multicolumn{2}{c|}{ Strain at 545 days $(\boldsymbol{\mu \varepsilon})$} \\
\cline { 2 - 5 } & Class C & Low shrinkage & Class C & Low shrinkage \\
\hline Variable Cure 1 & -174.6 & -131.2 & -516.2 & -390.2 \\
\hline 10 day wet cure & -111.8 & -85.4 & -474.6 & -315.8 \\
\hline Difference & -62.8 & -45.8 & -41.6 & -74.4 \\
\hline
\end{tabular}

Table 3.14: Variable Cure 2 shrinkage

\begin{tabular}{|c|c|c|c|c|}
\hline \multirow{2}{*}{$\begin{array}{c}\text { Curing } \\
\text { Duration }\end{array}$} & \multicolumn{2}{|c|}{ Strain at 14 days $(\boldsymbol{\mu \varepsilon})$} & \multicolumn{2}{c|}{ Strain at 545 days $(\boldsymbol{\mu \varepsilon})$} \\
\cline { 2 - 5 } & Class C & Low shrinkage & Class C & Low shrinkage \\
\hline Variable Cure 2 & -202.6 & -126.6 & -474.7 & -366.4 \\
\hline 14 day wet cure & -121.0 & -85.1 & -436.1 & -350.4 \\
\hline Difference & -81.6 & -41.5 & -38.7 & -16.1 \\
\hline
\end{tabular}

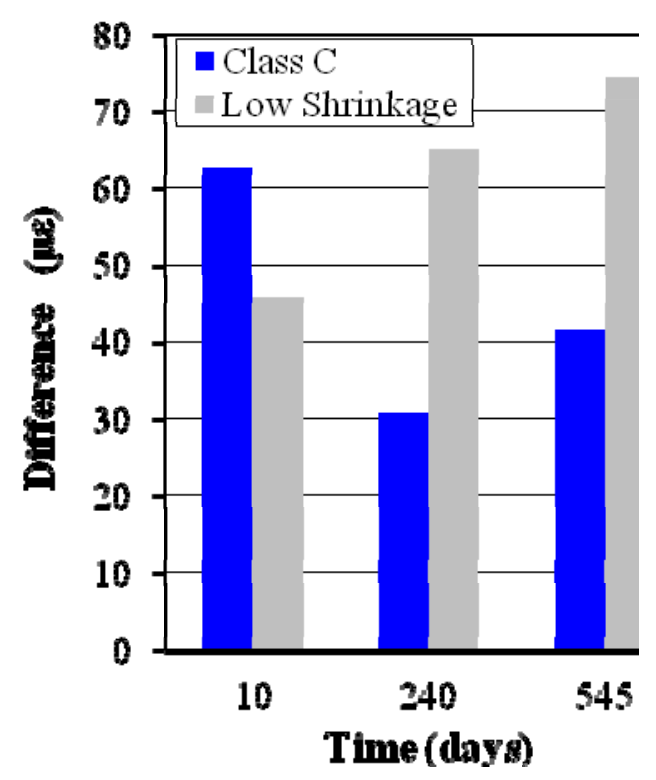

a) 10 Day wet cure - Variable 1

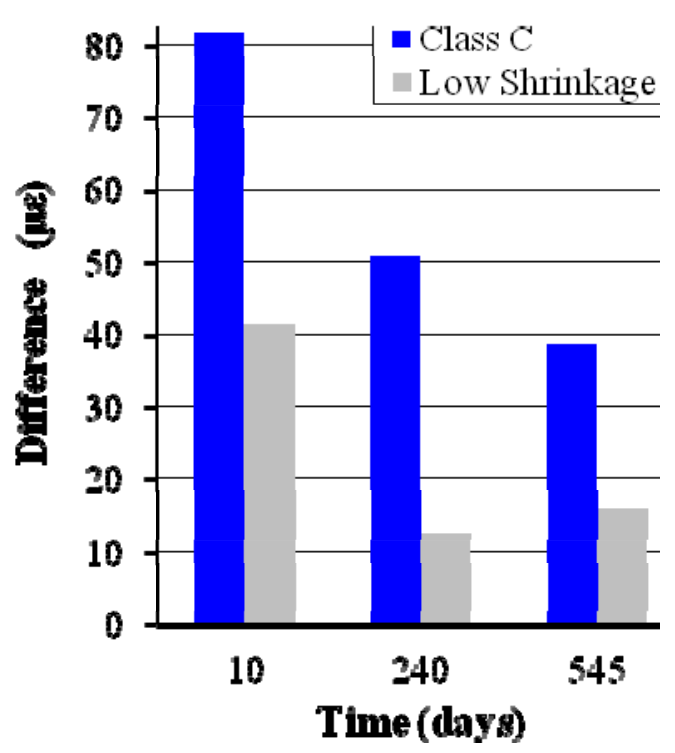

b) 14 Day wet cure - Variable 2

Figure 3.37: Shrinkage Difference 


\subsubsection{Effect of Concrete Mix}

Measurements from both INDOT Class C and low shrinkage concrete specimens were analyzed at 545 days to evaluate how the concrete mix design contributes to long term shrinkage. Figure 3.38 indicates the total shrinkage exhibited by both concrete mixes at 545 days. Higher strains were noted in Class $\mathrm{C}$ specimens than the low shrinkage concrete specimens. The average difference was calculated to be $106.2 \mu \varepsilon$ or $23 \%$ of Class C average strain according to Table 3.15 .

Again, the shrinkage of both mixes appeared to have leveled off considerably at 240 days according to shrinkage variations between Day 545 and Day 240 shown in Table 3.16. Class $\mathrm{C}$ specimens averaged $-6.8 \mu \varepsilon$ from Day 240 through Day 545 while the low shrinkage specimens average $-10.3 \mu \varepsilon$ over the same period of time. This result indicates that both concrete mixes had already undergone most of their shrinkage by Day 240 . 


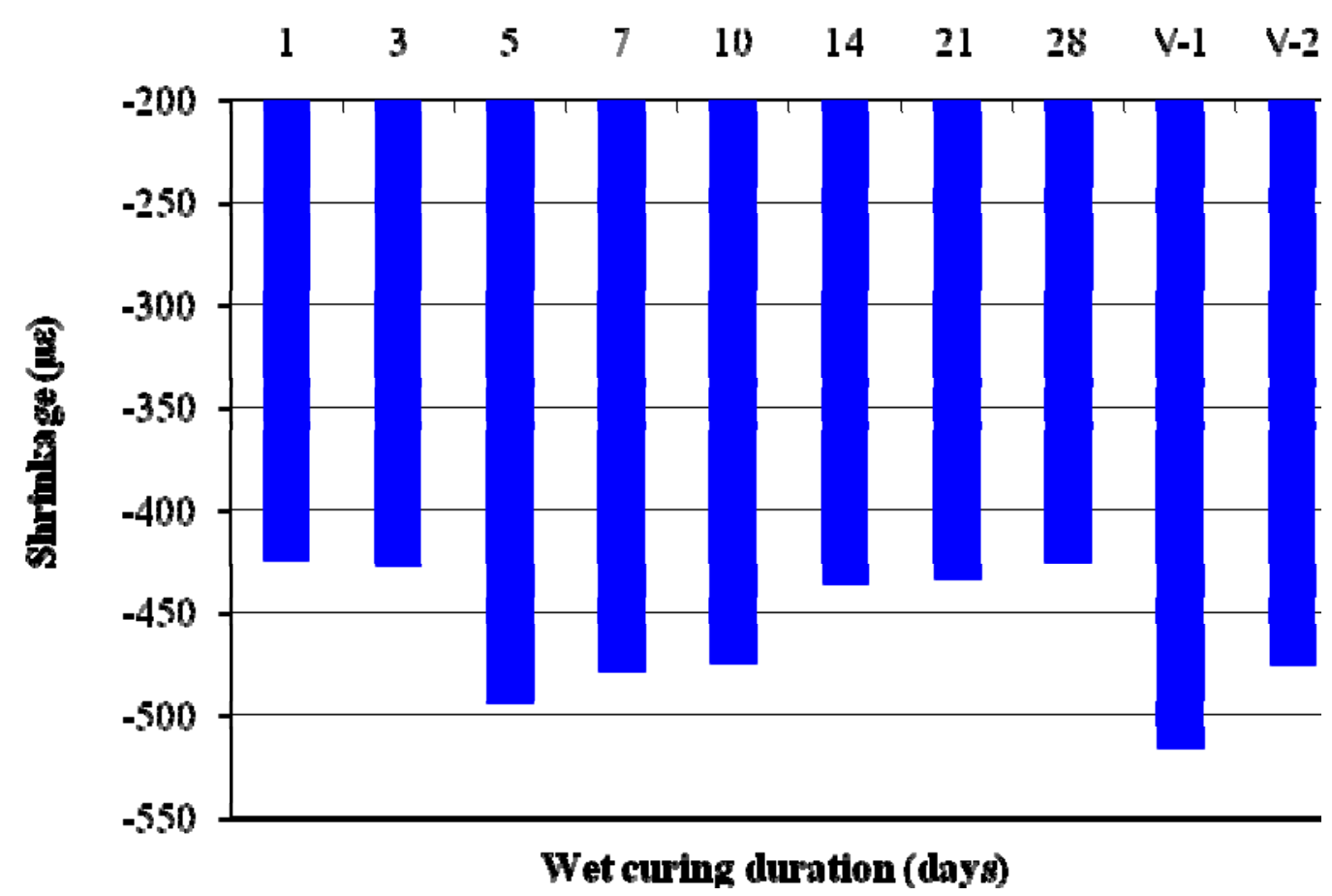

a) Class $\mathbf{C}$ concrete

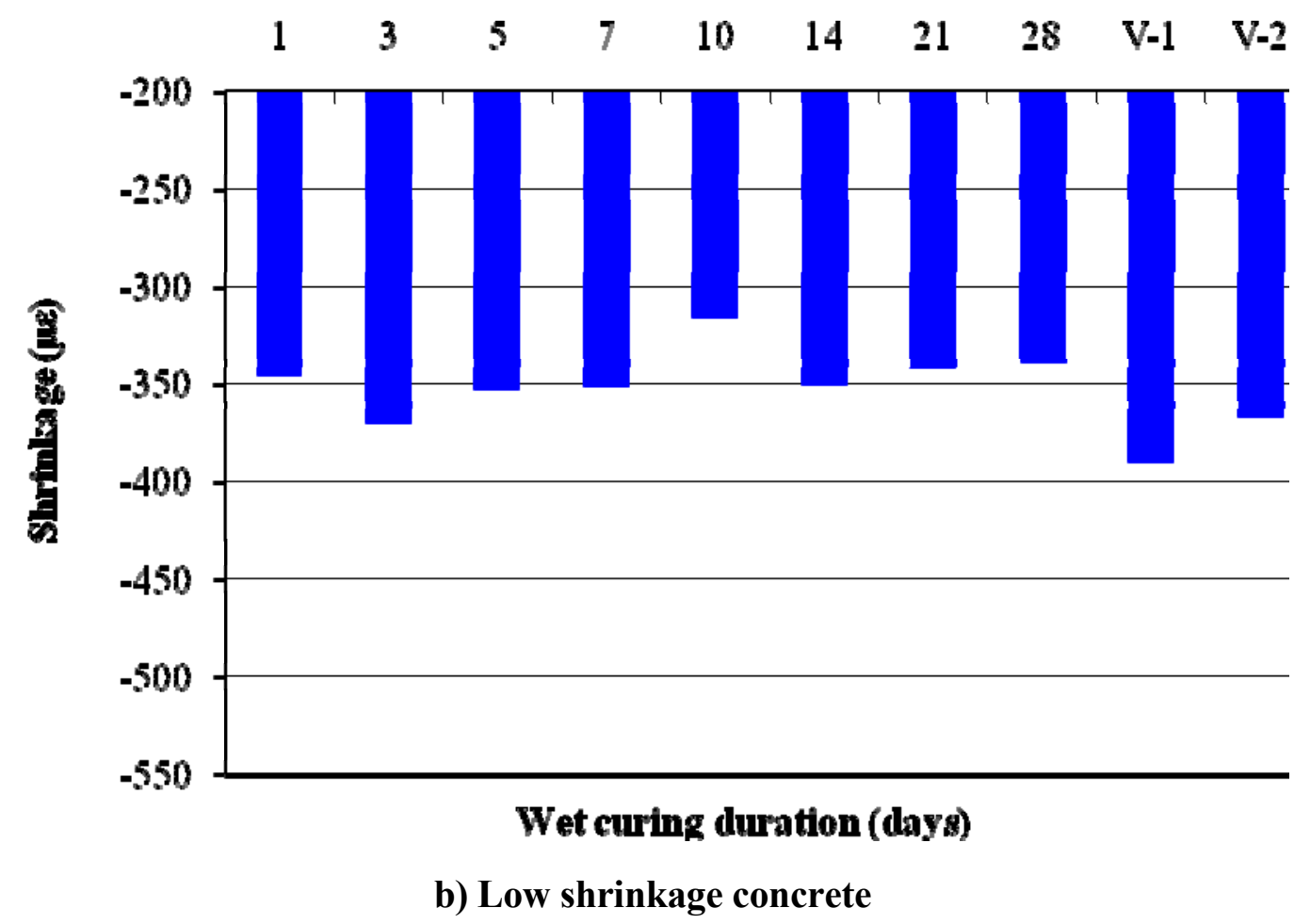

Figure 3.38: Total shrinkage at 545 days 
Table 3.15: Shrinkage at 545 days

\begin{tabular}{|c|c|c|c|}
\hline \multirow{2}{*}{$\begin{array}{c}\text { Curing } \\
\text { Duration } \\
\text { (days) }\end{array}$} & Class C & $\begin{array}{c}\text { Low } \\
\text { shrinkage }\end{array}$ & Difference \\
\cline { 2 - 4 } & -424.5 & -345.5 & -79.0 \\
\hline 1 & -426.8 & -369.7 & -57.0 \\
\hline 3 & -494.3 & -352.9 & -141.4 \\
\hline 5 & -478.1 & -351.0 & -127.1 \\
\hline 7 & -474.6 & -315.8 & -159.8 \\
\hline 10 & -436.1 & -350.4 & -86.7 \\
\hline 14 & -433.1 & -341.5 & -92.6 \\
\hline 21 & -425.2 & -338.5 & -87.7 \\
\hline 28 & -516.2 & -390.2 & -126.0 \\
\hline Variable 1 & -474.7 & -366.4 & -108.3 \\
\hline Variable 2 & -458.3 & -352.2 & -106.2 \\
\hline Average & & & \\
\hline
\end{tabular}

Table 3.16: Shrinkage from Day 240 through Day 545

\begin{tabular}{|c|c|c|}
\hline \multirow{2}{*}{$\begin{array}{c}\text { Curing } \\
\text { Duration } \\
\text { (days) }\end{array}$} & \multicolumn{2}{|c|}{ Strain $(\boldsymbol{\mu \varepsilon})$} \\
\cline { 2 - 3 } & Class C & $\begin{array}{c}\text { Low } \\
\text { shrinkage }\end{array}$ \\
\hline 1 & -12.1 & -3.4 \\
\hline 3 & 0.5 & -12.4 \\
\hline 5 & -11.9 & -1.8 \\
\hline 7 & -12.5 & -17.7 \\
\hline 10 & -3.5 & 0.0 \\
\hline 14 & -3.0 & -10.6 \\
\hline 21 & -8.3 & -18.4 \\
\hline 28 & -12.8 & -16.0 \\
\hline Variable 1 & -14.3 & -9.2 \\
\hline Variable 2 & 9.3 & -13.9 \\
\hline Average & -6.8 & -10.3 \\
\hline
\end{tabular}




\subsection{Summary}

A laboratory investigation was conducted to investigate the effect of curing duration, curing procedure, and concrete mix design on shrinkage. A series of varying wet curing durations and procedures were applied to concrete specimens constructed from both INDOT Class $\mathrm{C}$ concrete and a low cement content concrete mix. The shrinkage behavior exhibited by the specimens revealed the following trends:

1. All specimens experienced thermal expansion during the first 12 hours after casting and a rapid thermal shrinkage lasting until approximately 48 hours after casting.

2. The Class $\mathrm{C}$ concrete specimens experienced a higher peak hydration temperature, higher thermal expansion, and higher thermal shrinkage than the low cement content concrete specimens.

3. Little shrinkage was observed in all specimens from 48 hours after casting through the end of continuous wet curing.

4. Similar behavior at the end of wet cure was observed in all specimens regardless of wet curing duration. The initial rate of shrinkage was high $(-22.5$ $\mu \varepsilon$ /day for Class $\mathrm{C},-13 \mu \varepsilon /$ day for the low shrinkage mix). At 7 days after the end of wet cure, the rate of shrinkage had leveled off $(-9 \mu \varepsilon /$ day for Class $\mathrm{C}$ concrete, $-4 \mu \varepsilon /$ day for the low shrinkage mix).

5. Increased wet curing duration generally produced less shrinkage at both 210 and 518 days after the end of wet cure.

6. The Class $\mathrm{C}$ concrete specimens exhibited more drying shrinkage than the low cement content concrete specimens regardless of wet curing duration or procedure.

7. Improper curing procedures, including cycles of wet curing and drying and curing without rewetting the burlap, produced more shrinkage than continuous wet curing. 
8. All specimens were still shrinking 210 days after the end of wet cure. The majority of shrinkage was measured by 260 days with a very low rate observed following this time period.

9. The Class $\mathrm{C}$ concrete specimens exhibited a higher rate of shrinkage at both 210 and 518 days after the end of wet cure than low cement content concrete specimens.

Three sensors were evaluated as potential curing measurement devices, including embedment strain gages, humidity sensors, and thermocouples. An analysis of the data from these sensors produced the following results:

1. Embedment strain gages demonstrated potential for use as a curing measurement device. Because the rate of shrinkage during the period of wet cure varied but was approximately zero, shrinkage lasting more than a few hours indicates drying, and therefore improper wet curing.

2. The humidity gages did not function properly in the test, likely due to an inadequate protection system. Future testing relating internal relative humidity of the concrete to the curing procedure should be conducted.

3. Thermocouples, measuring the internal temperature of the specimens relative to the ambient temperature, demonstrated some potential for use as a curing measurement device. During wet cure, the internal temperature of the concrete was lower than the ambient temperature, due to water temperatures lower than the ambient air temperature. During drying, the internal temperature of the concrete closely matched the ambient air temperature. Wet curing could be monitoring by comparing the internal temperature of the concrete, the temperature of the water used for wet curing, and the ambient air temperature. 


\section{$\underline{3.10 \text { Conclusions }}$}

Continuous wet curing is very effective in delaying the onset of drying shrinkage. Restrained shrinkage cracking can be reduced by increasing the duration of wet curing, allowing the concrete to develop increased tensile strength prior to the onset of drying shrinkage. Increasing the duration of wet cure duration also decreased the shrinkage at 210 days after the end of wet cure, although it was unclear at that time whether a decrease in ultimate shrinkage would result. Continued monitoring to 518 days after the end of wet cure indicated that the magnitude of the difference essentially was maintained and confirmed the importance of wet curing duration. Continuous wet curing is crucial, as improper curing procedures produced an increase in shrinkage during early age when tensile strength is low. Shrinkage can be greatly reduced by using a low cement content concrete mix. This mix decreased the heat of hydration, thermal shrinkage, and ultimate shrinkage (by approximately 25\%) without significantly decreasing compressive strength and will likely lead to decreased restrained shrinkage cracking. 


\section{CHAPTER 4 \\ CRACK REPAIR INVESTIGATION}

\subsection{Introduction}

While design and construction procedures can be implemented to minimize bridge deck cracking, the elimination of cracking all together is not possible. More importantly, recently developed design and construction procedures will only control the cracking of newly constructed bridges. Therefore, there is a need to develop an effective crack repair method. Proper repair of bridge deck cracking can provide significant functional and economic benefits.

A testing program was designed to evaluate the ability of various crack repair techniques to prevent chloride penetration and withstand structural loading. Specimens were designed to represent interior bridge deck sections. Full depth cracks were then introduced and subsequently repaired with different commercially available products. After the repair, the specimen was restressed to simulate traffic loading. Finally, a macrocell corrosion test was initiated to investigate the capability of the various products to prevent chloride penetration and steel corrosion. Based on the results, the effectiveness of the various products evaluated was assessed.

\section{$\underline{4.2}$ Specimen Design}

The crack repair specimens were designed to represent an interior section of a bridge deck. An 8 in. thickness was selected as it corresponds with the bridge thickness typically used. The specimen length was chosen as 24 in. to allow for adequate development of cracks. Finally, the width of the specimens was selected as 8 in. to allow for easy handling in the laboratory. The reinforcing steel had an overall length of 52 in., 
with 14 in. of length extending beyond the concrete. This extension was required to allow the specimens to be loaded through the reinforcement. Details of the specimen are provided in Figure 4.1. The longitudinal steel consisted of two mats of \#4 bars spaced at 5 in. The specimens were designed with a top and bottom cover of 2 in.
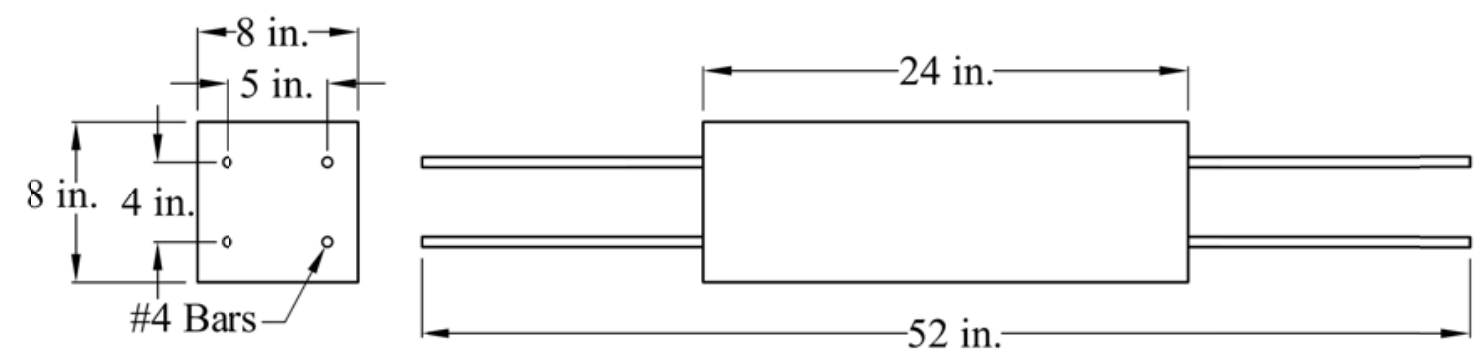

Figure 4.1: Specimen geometry

\subsubsection{Reinforcement}

The specimens were designed with two mats of longitudinal steel, corresponding to a typical reinforcement layout in a bridge deck. No. 4 bars were spaced at 5 in. (Figure 4.1). Although the exact reinforcement layout was not important for this test, this bar size and spacing is typical for bridge decks and is within the recommended limits provided by NCHRP Report 380 (\#4 bars spaced at no more than 6 in.) and other research programs (Radabaugh 2001, French et al. 1999). The reinforcement was designed with a top and bottom cover of 2 in.

\subsubsection{Crack Widths}

For the specimens to represent field conditions as closely as possible, they were designed such that full depth cracks could be initiated and opened to realistic values. Crack widths of 0.004 in. and greater have been shown to allow chloride penetration, but deck cracks can commonly reach widths of 0.025 in. Therefore, the specimens were designed to have cracks within a range of 0.016 in. to 0.020 in. This crack width was observed on the US-50 Bridge and is common on bridge decks. 


\subsubsection{Specimen Variables}

The primary variable considered in this test was the type of crack repair. Based on a review of crack repair technologies, it was determined that the most promising repair techniques were gravity feed and overlay repairs. It was desired to test a variety of products. Therefore, both epoxies and methacrylates were selected for inclusion in the study as gravity feed repair products to investigate the importance of bond strength in crack repair products. In addition, a non-structural waterproofing sealer was included as a gravity feed repair product to investigate the importance of bond strength in crack repair products. While a waterproofer can effectively seal the crack, it has very low bond strength and would likely fail during restressing. Finally, two overlay crack repair systems were selected. A summary of the repair techniques is presented in Figure 4.2. Each product was applied to a set of three specimens to reduce the probability of irregular specimens or other factors affecting the test results.

A second variable considered was the effect of crack width on corrosion of the reinforcement. For this test, three sets of specimens were left un-repaired. Target crack widths were 0.010 to $0.013 \mathrm{in}$., 0.016 to $0.020 \mathrm{in}$., and 0.035 to $0.040 \mathrm{in}$. The set with crack widths in the range of 0.016 to 0.020 in. also served as the control specimens for the repaired specimens. Again, three specimens were constructed for each target crack width.

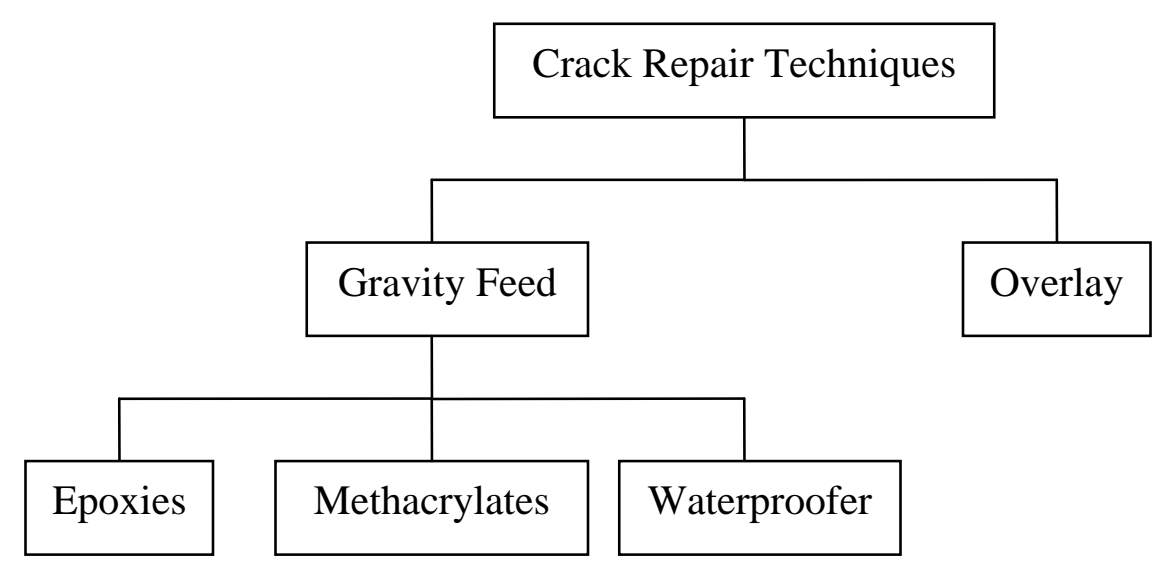

Figure 4.2: Crack repair techniques 


\section{$\underline{4.3 \text { Materials }}$}

\subsubsection{Concrete}

The concrete used to construct the specimens was INDOT Class C concrete, obtained from Irving Materials (IMI), to represent a bridge deck constructed in Indiana. Mix proportions are provided in Table 4.1.

Table 4.1: Concrete Mix Proportions

\begin{tabular}{|c|c|}
\hline Material & $\begin{array}{c}\text { Quantity (per cubic } \\
\text { yard) }\end{array}$ \\
\hline Portland Cement (Type I) & $655 \mathrm{lbs}$ \\
\hline Water & $235 \mathrm{lbs}$ \\
\hline \#8 Stone & $1785 \mathrm{lbs}$ \\
\hline \#23 Sand & $1262 \mathrm{lbs}$ \\
\hline Micro Air & $3.3 \mathrm{oz}$ \\
\hline Glenium 3030 & $20.0 \mathrm{oz}$ \\
\hline Slump & $4 \mathrm{in}$. \\
\hline Air Content & $6.8 \%$ \\
\hline
\end{tabular}

Standard 6 by 12 in. cylinder specimens were cast along with the specimens at the time of the concrete casting. The cylinders were continuously wet cured until the time of testing, which occurred at $7,14,21$, and 28 days. The strength gain curve is shown in Figure 4.3. 


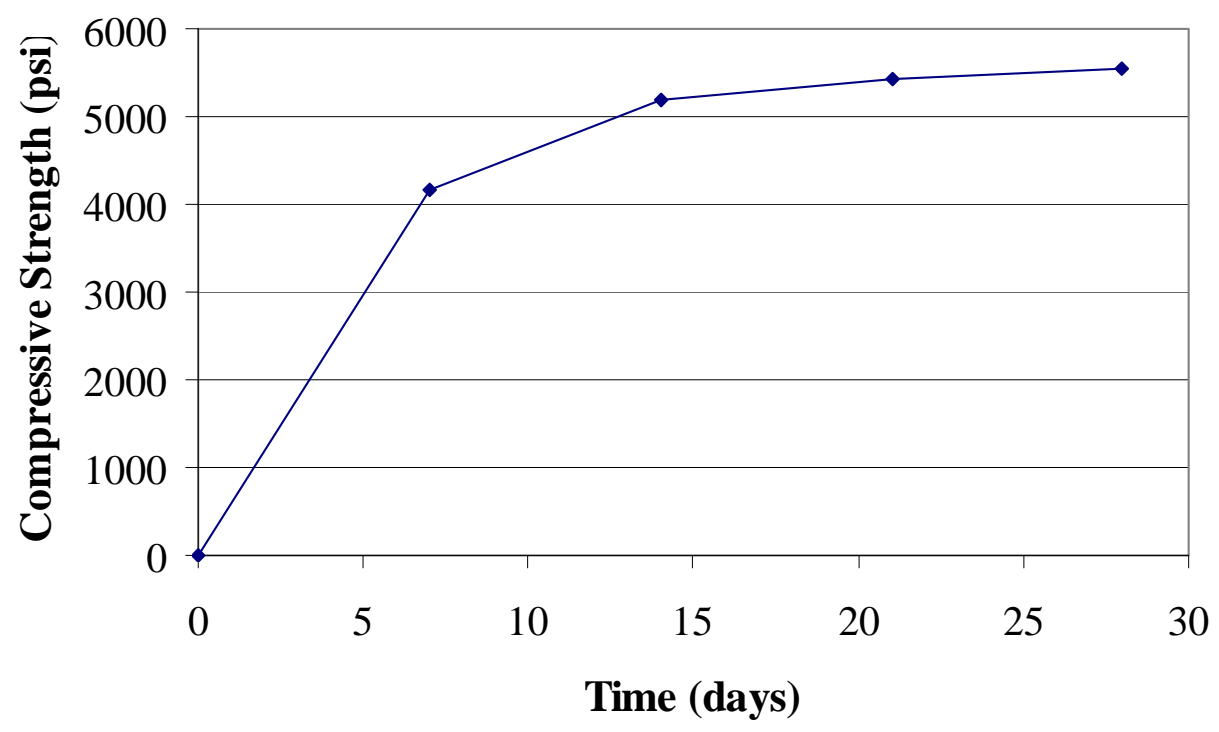

Figure 4.3: Strength gain curve

\subsubsection{Reinforcement}

No. 4 steel reinforcing bars were used in all specimens. The bars were obtained from the same heat of steel and conformed to ASTM A615 Grade 60. Strength tests were not performed on the reinforcing steel as the intent of the study was corrosion of the reinforcement.

It should be noted that epoxy coated reinforcement was not used in the test. While epoxy coated reinforcing bars are commonly implemented in bridge decks, the purpose of the testing program was to evaluate the effectiveness of the repair products in terms of sealing cracks and minimizing corrosion. Therefore, black reinforcement was used. This testing procedure provides a relative measure of performance of the crack repair techniques.

\subsubsection{Crack Repair Products}

A variety of crack repair products was selected based on industry research and recommendations from previous studies (Pincheira and Dorshorst 2005). The selected 
products are provided in Table 4.2 and Table 4.3. Manufacturer-provided data sheets for all products can be found in Appendix A.

Table 4.2: Gravity feed repair products

\begin{tabular}{|l|l|l|}
\hline Product Name & Manufacturer & Repair Type \\
\hline SikaPronto 19 TF & SIKA Corp. & Methacrylate \\
\hline Sikadur 55 SLV & SIKA Corp. & Epoxy \\
\hline MARK-127 & Poly-Carb & Epoxy \\
\hline MARK-135 Safe-T-Seal & Poly-Carb & Epoxy \\
\hline Epoxeal GS Structural & BASF & Epoxy \\
\hline Degadeck Crack Sealer Plus & BASF & Methacrylate \\
\hline Enviroseal & BASF & Waterproofer \\
\hline Dural 335 & Euclid / Tamms & Epoxy \\
\hline Dural 50 & Euclid / Tamms & Epoxy \\
\hline Dural 50 LM & Euclid / Tamms & Epoxy \\
\hline SurePoxy HMSLV & Kaufman Products & Epoxy \\
\hline FX-770 HM LV & Fox Industries & Epoxy \\
\hline FX-821 MMA & Fox Industries & Methacrylate \\
\hline Bridge Seal & Unitex Chemicals & Epoxy \\
\hline
\end{tabular}

Table 4.3: Overlay repair products

\begin{tabular}{|l|l|l|}
\hline Product Name & Company & Repair Type \\
\hline Mark-163 FlexoGrid & Poly-Carb & Epoxy Overlay \\
\hline Pro-Poxy Type III D.O.T. & Unitex Chemicals & Epoxy Overlay \\
\hline
\end{tabular}




\subsection{Specimen Construction}

Formwork was constructed so that all specimens could be cast at the same time. The reinforcing steel was placed in the formwork by drilling holes in the end forms and sliding the steel through. This method allowed for accurate placement of the reinforcement. Details of the formwork are shown in Figure 4.4.

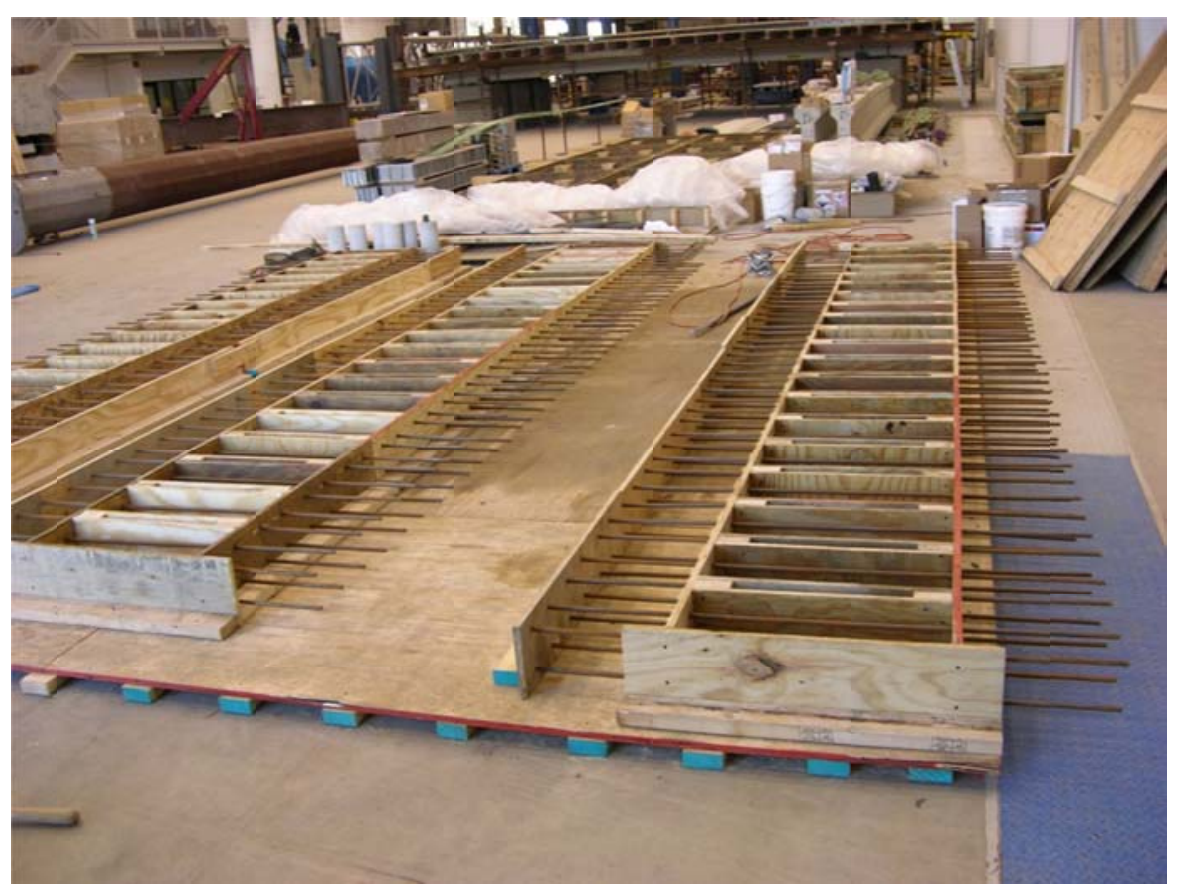

Figure 4.4: Formwork

The specimens were cast on November 7, 2007. The concrete was delivered to the formwork directly from the concrete truck. The specimens were hand screeded and finished using a float. Approximately one hour after finishing, they were covered with wet burlap and plastic sheeting to initiate the wet cure. The specimens were wet cured for the INDOT-required 7 days, after which the formwork was stripped and the specimens were air cured for 7 more days before cracking was initiated. 


\subsection{Specimen Preparation}

Before the macrocell corrosion test could be initiated, the specimens underwent a series of preparation stages. First, cracks were introduced into the specimens through direct tension. The cracks were then repaired using various commercially available products. After repair, the specimens were restresssed to simulate structural traffic loads.

\subsubsection{Cracking Procedure}

A loading system was designed to produce uniform tension in the specimens. An overview of this system is provided in Figure 4.5. Two steel beams were tensioned to the laboratory strong floor using a hydraulic ram, and tensioning rods were placed through holes drilled in the beam webs. These rods were then attached to the reinforcing steel, which extended 14 in. outside of the specimens, using angled mechanical wedges designed to fit \#4 reinforcing bars (obtained from Howlett Machine Works). Specially designed grip plates with angled holes were used to hold the wedges and allow them to grip the reinforcing steel during tensioning. This system was designed to ensure that equal tension was introduced into all reinforcing bars, producing a full depth crack. A detail of this connection system is shown in Figure 4.6.

Load was applied using a hydraulic ram through the use of a hand pump. First cracking occurred at a tensile force between 30 and 35 kips, or an approximate concrete tensile stress of 500 psi. Between one and three additional cracks occurred shortly after first cracking, but typically the stressing resulted in a total of three transverse cracks. The force was then increased to produce yielding of the steel reinforcement. Yielding was required to prevent the crack from closing upon release of the tensile force.

Specimens were stressed to reach a desired crack width rather than a specific stress, and therefore there was some variation in the amount of tensile force applied. In addition, specimens that had only two cracks required less force than those with three or four cracks, but generally the cracks reached an adequate width at approximately 60 kips (an approximate steel stress of $75 \mathrm{ksi}$ ). Figure 4.7 shows a typical specimen with three full depth transverse cracks. To simulate field conditions, cracks were generally opened to 
widths between 0.016 and 0.020 in. A typical specimen crack, with a width of approximately 0.020 in. is shown in Figure 4.8. Crack widths varied from 0.013 to 0.025 in.

Nine specimens, which were left unrepaired, were stressed to achieve varying crack widths to investigate the influence of crack width on reinforcement corrosion. Three specimens were loaded to produce crack widths between 0.010 and 0.013 in., three specimens were loaded to produce cracks widths between 0.016 and 0.020 in (same crack widths as repaired specimens), and three specimens were loaded to produce crack widths between 0.030 and 0.040 in.

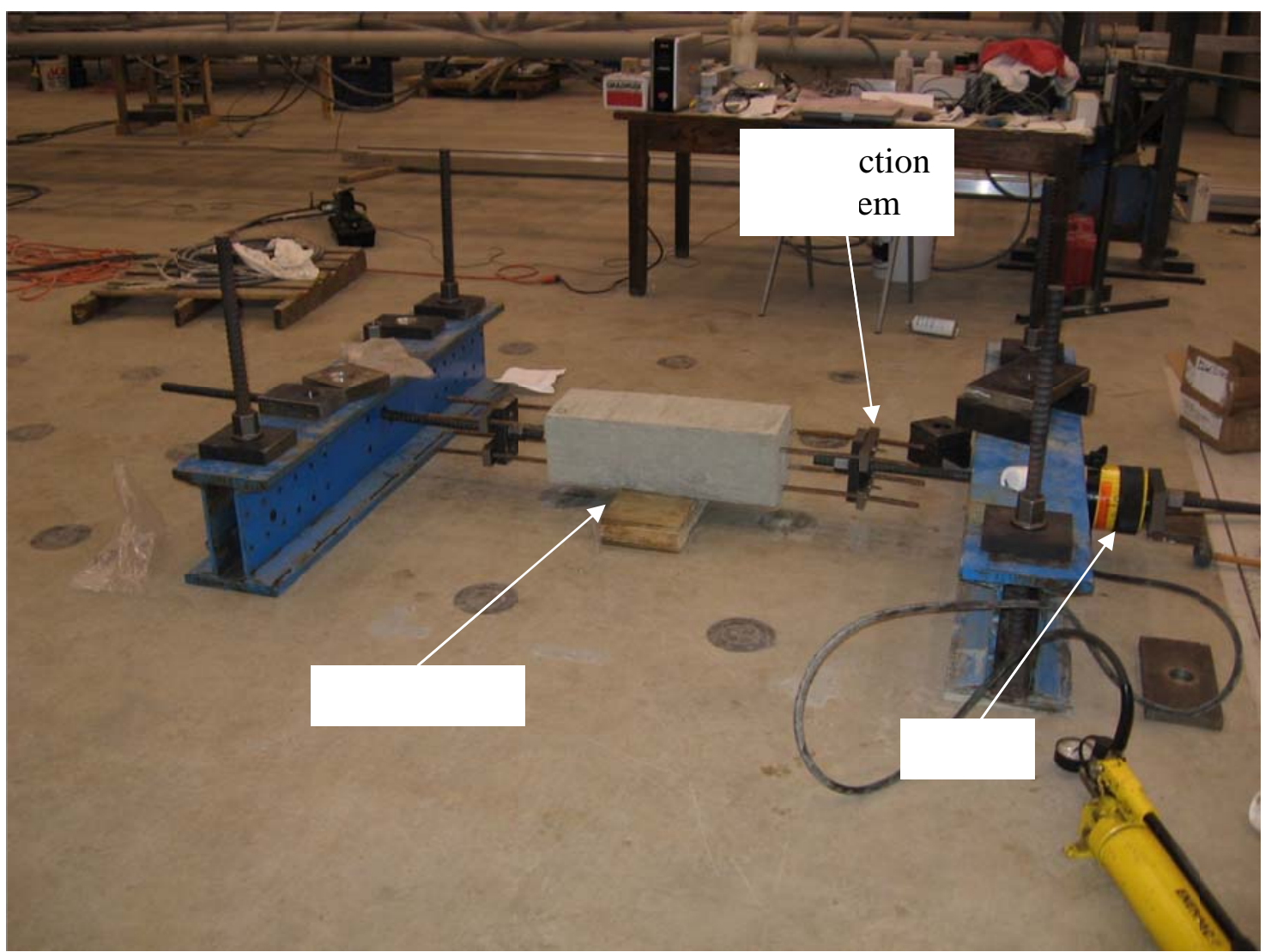

Figure 4.5: Laboratory cracking setup 


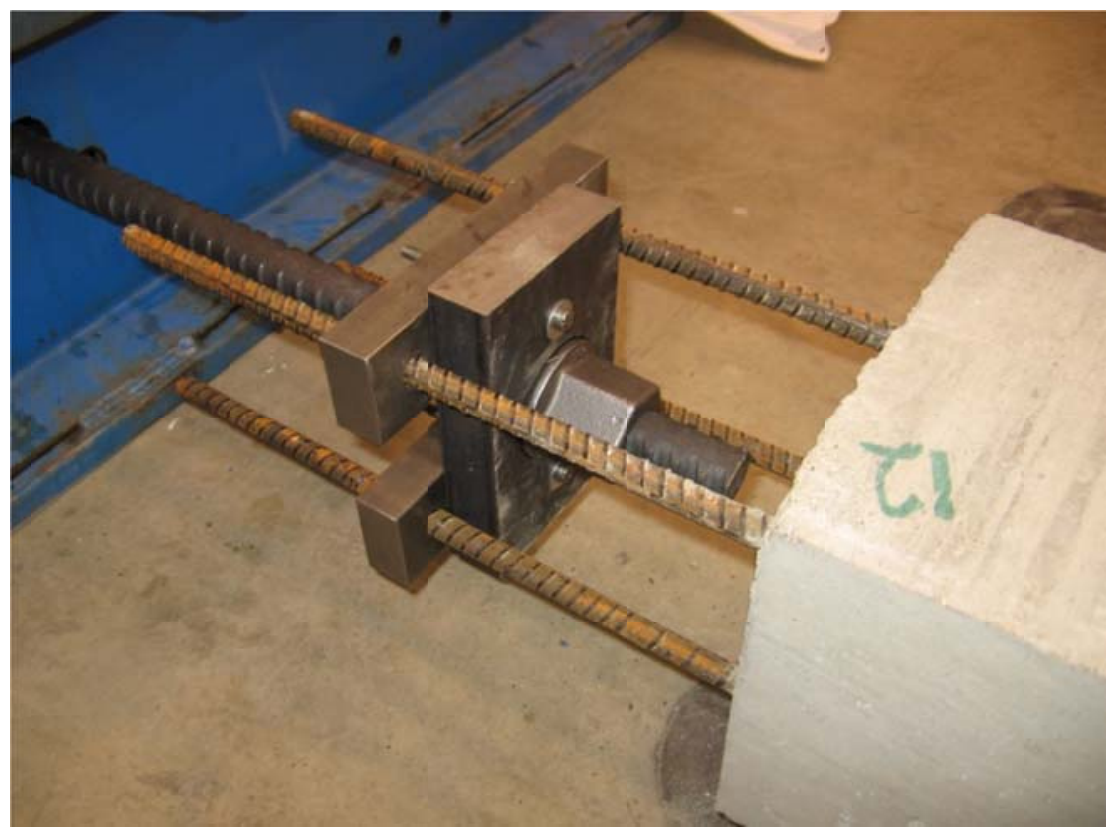

Figure 4.6: Steel grip plates

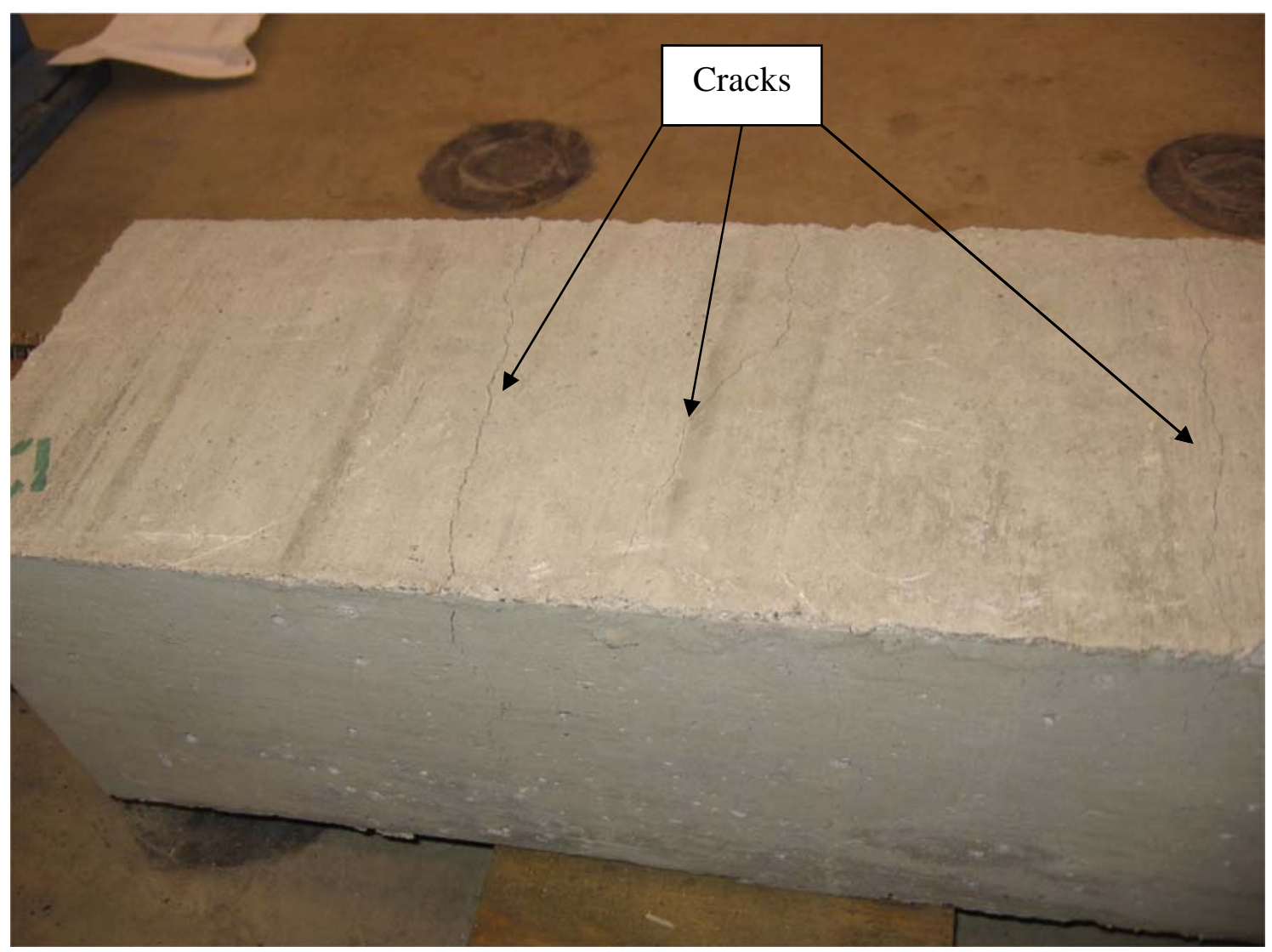

Figure 4.7: Typical cracked specimen 


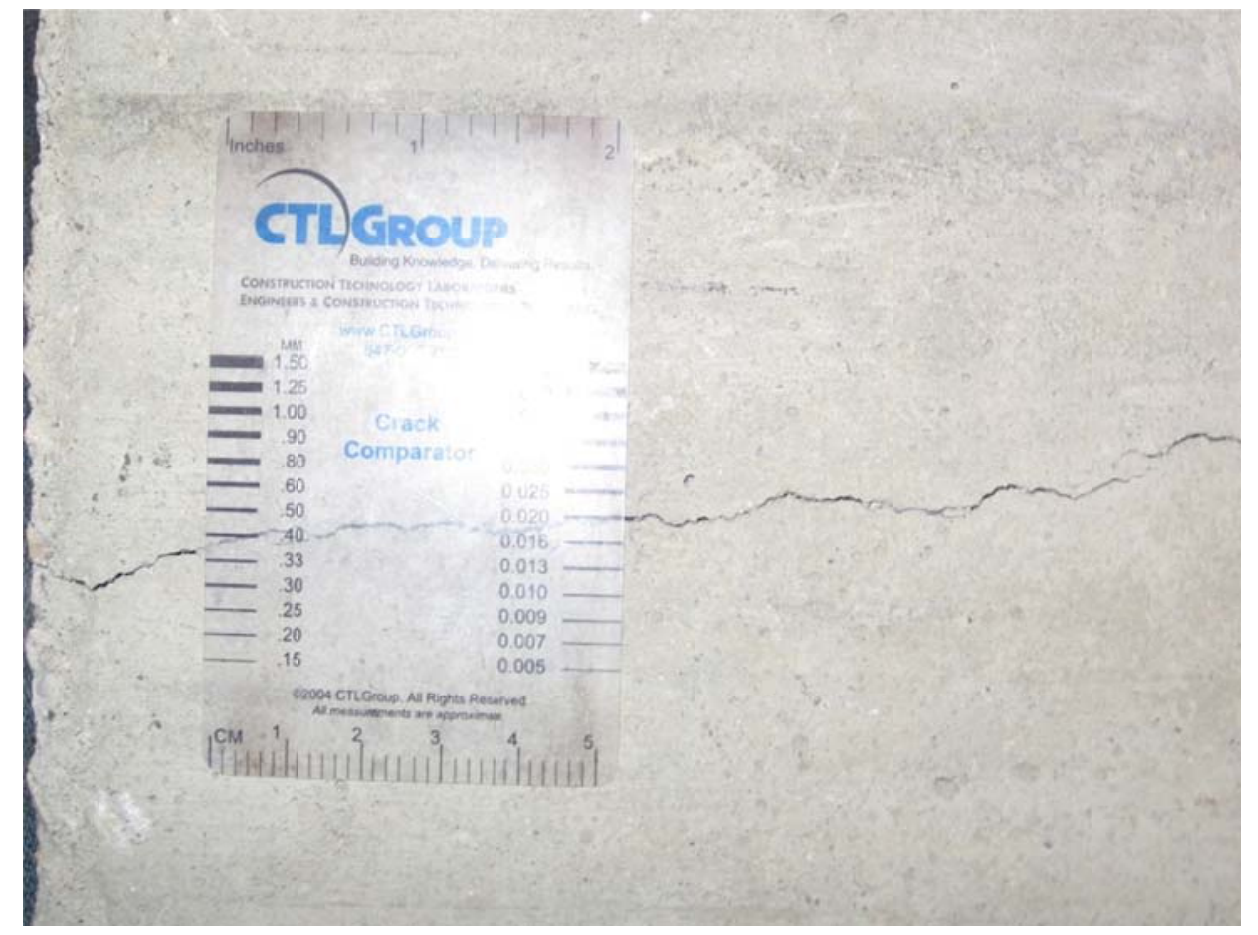

Figure 4.8: Specimen crack with crack comparator

\subsubsection{Crack Repair Application}

Four types of products were used to repair the cracked specimens, including epoxy, methacrylate, and waterproofing gravity repair products, as well as epoxy overlay systems. Each repair product was applied to a group of three specimens. An effort was made to distribute specimens with two or four cracks or varying crack widths throughout the groups to reduce the probability of an irregular specimen affecting the test. Specimen details are provided in Table 4.4 while Table 4.5 provides detailed information including the number of cracks and crack widths. 


\subsubsection{Gravity Feed Repair Products}

Gravity feed products included both epoxies and methacrylates. A non-structural waterproofing product was also applied using the gravity technique. A consistent application process was used for all gravity feed products to compare their relative ease of application. The specimens were cleaned by air-blasting to remove any debris from the surface and from the opening of the cracks. The products were then prepared by mixing the two part epoxies and two part methyl methacrylates in a bucket using a mixing paddle attached to an electric drill. Mixing procedures varied slightly based on manufacturer guidelines but generally involved steady medium-speed mixing for approximately three to five minutes. A pretreatment stripe, such as the one shown in Figure 4.9, was then applied to all cracks. Pretreatement was re-applied as needed when the repair product had fully penetrated the crack, a common practice in field application, but did not exceed three reapplications as this was considered unrealistic for field application. The top surface of the specimens was then flooded with the repair product and spread evenly with a paint roller. The product was permitted to set for three to five minutes based on the manufacturer recommendations and any excess was removed with a squeegee.

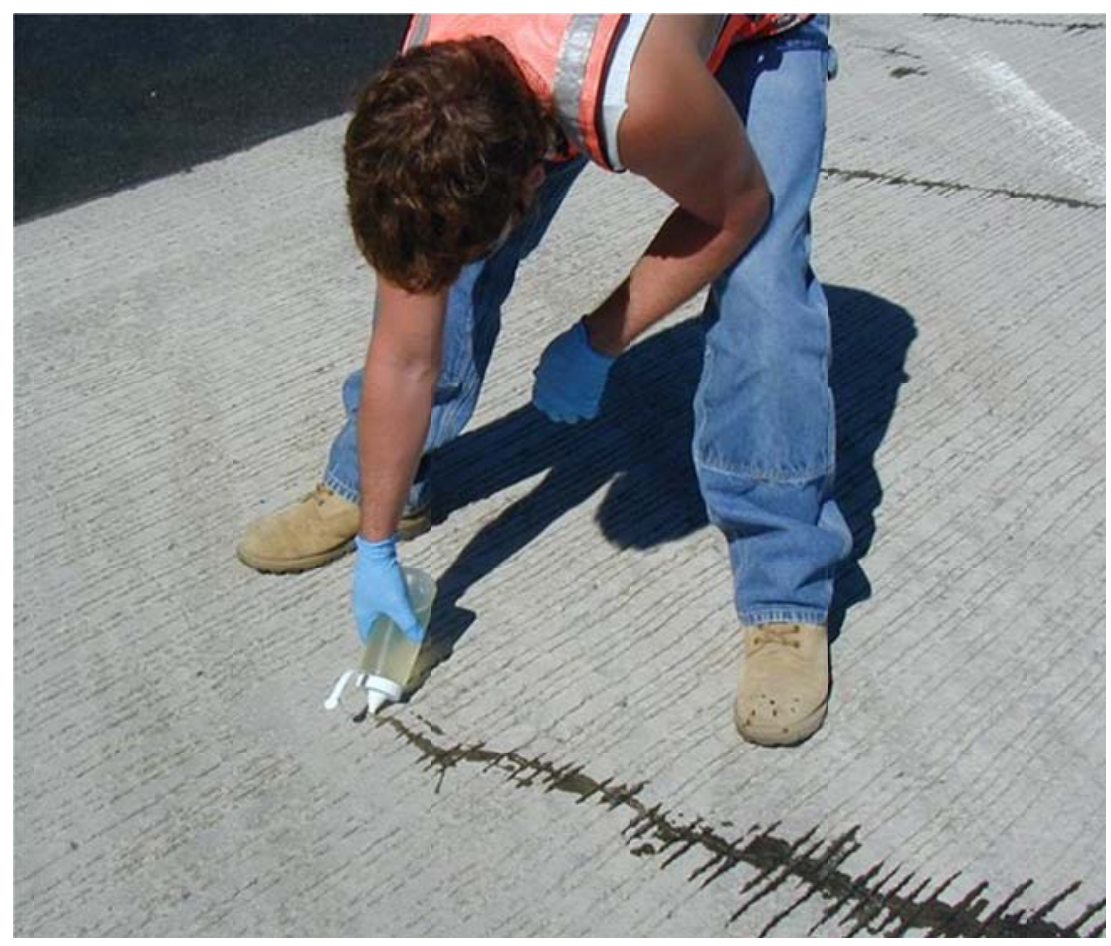

Figure 4.9: Field application of a pretreatment stripe 
There was a clear difference between epoxy products and methacrylate products in their ability to fill cracks. Methacrylate products had a much lower viscosity and filled all cracks quickly, requiring multiple pretreatment applications. This performance indicates higher crack penetration depths and a more adequate crack repair. Multiple pretreatments of each crack is a labor-intensive process and may be unrealistic for field applications. However, the presence of SIP forms may prevent leaking of crack repair product through the deck, reducing the number of pretreatements required while allowing the product to more adequately repair the crack. Epoxy repair products had a higher viscosity and therefore required fewer pretreatment stripes. However, the product may not have fully penetrated the crack, especially in the case of finer cracks. Overall, the methacrylate products were easier to handle and apply but concerns exist about the need for multiple pretreatment applications.

\subsubsection{Overlay Repair Products}

The two overlay repair products were applied using a similar procedure with some small differences based on manufacturer recommendations. First, the specimens were cleaned of debris with an air hose. The product was then mixed in the same manner as the gravity feed products and spread evenly across the entire surface of the specimens without a pre-stripe application. After setting for approximately three to five minutes, an aggregate material was spread across the surface. One overlay used a glacial gravel aggregate while the other called for silica sand. After setting for approximately fifteen minutes, the excess aggregate was brushed off. This procedure was repeated to apply a second layer for both overlay repair products. 
Table 4.4: Specimen Details

\begin{tabular}{|c|c|c|c|}
\hline $\begin{array}{c}\text { Specimen } \\
\text { Set } \\
\end{array}$ & Manufacturer & Product Name & Repair Type \\
\hline 1 & \multirow{3}{*}{ BASF } & Epoxeal GS Structural & Epoxy \\
\hline 2 & & $\begin{array}{c}\text { Degadeck Crack Sealer } \\
\text { Plus }\end{array}$ & Methacrylate \\
\hline 3 & & Enviroseal & Waterproofer \\
\hline 4 & \multirow{3}{*}{ Euclid / Tamms } & Dural 335 & Epoxy \\
\hline 5 & & Dural 50 & Epoxy \\
\hline 6 & & Dural 50 LM & Epoxy \\
\hline 7 & \multirow{2}{*}{ Fox Industries } & FX-770 HM LV & Epoxy \\
\hline 8 & & FX-821 MMA & Methacrylate \\
\hline 9 & Kaufman Products & SurePoxy HMSLV & Epoxy \\
\hline 10 & \multirow{3}{*}{ Poly-Carb } & MARK 127 & Epoxy \\
\hline 11 & & MARK 135 Safe-T-Seal & Epoxy \\
\hline 12 & & MARK 163 FlexoGrid & $\begin{array}{l}\text { Epoxy } \\
\text { Overlay }\end{array}$ \\
\hline 13 & \multirow{2}{*}{ SikaCorp. } & SikaPronto 19 TF & Methacrylate \\
\hline 14 & & Sikadur 55 SLV & Epoxy \\
\hline 15 & \multirow{2}{*}{ Unitex Chemicals } & Bridge Seal & Epoxy \\
\hline 16 & & Pro-Poxy Type III D.O.T. & $\begin{array}{l}\text { Epoxy } \\
\text { Overlay }\end{array}$ \\
\hline 17 & \multicolumn{2}{|c|}{ Small Cracks (0.010 to 0.013 in.) } & None \\
\hline 18 & \multicolumn{2}{|c|}{ Medium Cracks (0.016 to 0.020 in.) } & None \\
\hline 19 & \multicolumn{2}{|c|}{ Large Cracks (0.035 to 0.040 in.) } & None \\
\hline 20 & \multicolumn{2}{|c|}{ No Cracks } & None \\
\hline
\end{tabular}


Table 4.5: Specimen Cracking Details

\begin{tabular}{|c|c|c|c|c|c|}
\hline Product Name & $\begin{array}{c}\text { Specimen } \\
\text { ID }\end{array}$ & $\begin{array}{c}\text { Crack 1 } \\
\text { width (in.) }\end{array}$ & $\begin{array}{c}\text { Crack } 2 \\
\text { width (in.) }\end{array}$ & $\begin{array}{c}\text { Crack } 3 \\
\text { width (in.) }\end{array}$ & $\begin{array}{c}\text { Crack } 4 \\
\text { width (in.) }\end{array}$ \\
\hline \multirow{3}{*}{$\begin{array}{l}\text { Poly-Carb } \\
\text { Mark } 163\end{array}$} & M163-1 & 0.016 & 0.025 & 0.013 & - \\
\hline & M163-2 & 0.016 & 0.016 & 0.013 & - \\
\hline & M163-3 & 0.02 & 0.02 & - & - \\
\hline \multirow{3}{*}{$\begin{array}{l}\text { Poly-Carb } \\
\text { Mark } 127\end{array}$} & M127-1 & 0.02 & 0.025 & - & - \\
\hline & M127-2 & 0.016 & 0.016 & 0.016 & - \\
\hline & M127-3 & 0.025 & 0.016 & - & - \\
\hline \multirow{3}{*}{$\begin{array}{l}\text { Poly-Carb } \\
\text { Mark } 135\end{array}$} & M135-1 & 0.01 & 0.02 & 0.016 & - \\
\hline & M135-2 & 0.02 & 0.016 & 0.01 & - \\
\hline & M135-3 & 0.013 & 0.02 & 0.013 & - \\
\hline \multirow{3}{*}{$\begin{array}{l}\text { Tammes } \\
\text { Dural } 50\end{array}$} & D50-1 & 0.016 & 0.02 & 0.013 & - \\
\hline & D50-2 & 0.016 & 0.016 & 0.016 & - \\
\hline & D50-3 & 0.025 & 0.016 & 0.016 & - \\
\hline \multirow{3}{*}{$\begin{array}{c}\text { Tammes } \\
\text { Dural } 335\end{array}$} & D335-1 & 0.013 & 0.016 & 0.02 & - \\
\hline & D335-2 & 0.013 & 0.016 & 0.016 & - \\
\hline & D335-3 & 0.025 & 0.016 & 0.016 & - \\
\hline \multirow{3}{*}{$\begin{array}{c}\text { Tammes } \\
\text { Dural } 50 \text { LM }\end{array}$} & D50LM-1 & 0.025 & 0.02 & 0.016 & - \\
\hline & D50LM -2 & 0.013 & 0.016 & 0.016 & - \\
\hline & D50LM -3 & 0.02 & 0.02 & 0.02 & - \\
\hline \multirow{3}{*}{$\begin{array}{c}\text { Fox } \\
\text { FX } 770-H M L V\end{array}$} & FX770-1 & 0.025 & 0.013 & 0.016 & - \\
\hline & FX770-2 & 0.013 & 0.013 & 0.016 & - \\
\hline & FX770-3 & 0.016 & 0.025 & - & - \\
\hline \multirow{3}{*}{$\begin{array}{c}\text { Sika } \\
\text { Sikadur } 55 \text { SLV }\end{array}$} & 55SLV-1 & 0.016 & 0.016 & 0.016 & - \\
\hline & 55SLV-2 & 0.025 & 0.025 & - & - \\
\hline & $55 S L V-3$ & 0.013 & 0.02 & 0.025 & - \\
\hline \multirow{3}{*}{$\begin{array}{l}\text { Kaufman } \\
\text { HMSLV }\end{array}$} & HMSLV-1 & 0.025 & 0.02 & - & - \\
\hline & HMSLV-2 & 0.016 & 0.016 & 0.013 & - \\
\hline & HMSLV-3 & 0.02 & 0.02 & 0.016 & - \\
\hline \multirow{3}{*}{$\begin{array}{c}\text { Unitex } \\
\text { Pro-Poxy Type } \\
\text { III D.O.T }\end{array}$} & T3DOT-1 & 0.025 & 0.016 & 0.02 & - \\
\hline & T3DOT-2 & 0.016 & 0.016 & 0.016 & - \\
\hline & T3DOT-3 & 0.013 & 0.016 & 0.01 & 0.013 \\
\hline \multirow{3}{*}{$\begin{array}{c}\text { Unitex } \\
\text { Bridge Seal }\end{array}$} & BSeal-1 & 0.01 & 0.02 & 0.016 & - \\
\hline & BSeal-2 & 0.02 & 0.016 & 0.013 & - \\
\hline & BSeal-3 & 0.025 & 0.016 & 0.013 & - \\
\hline
\end{tabular}




\begin{tabular}{|c|c|c|c|c|c|}
\hline \multirow{3}{*}{$\begin{array}{c}\text { Sika } \\
\text { Pronto } 19\end{array}$} & P19-1 & 0.02 & 0.016 & 0.016 & - \\
\hline & P19-2 & 0.016 & 0.02 & 0.016 & - \\
\hline & P19-3 & 0.025 & 0.02 & - & - \\
\hline \multirow{3}{*}{$\begin{array}{c}\text { Fox } \\
\text { FX-821 }\end{array}$} & FX821-1 & 0.013 & 0.016 & 0.013 & - \\
\hline & FX821-2 & 0.02 & 0.016 & 0.02 & - \\
\hline & FX821-3 & 0.025 & 0.02 & - & - \\
\hline \multirow{3}{*}{$\begin{array}{c}\text { BASF } \\
\text { Epoxesl GS } \\
\text { Structural }\end{array}$} & EGSS-1 & 0.02 & 0.025 & 0.025 & - \\
\hline & EGSS-2 & 0.02 & 0.016 & - & - \\
\hline & EGSS-3 & 0.02 & 0.016 & - & - \\
\hline \multirow{3}{*}{$\begin{array}{c}\text { BASF } \\
\text { DegaDeck }\end{array}$} & DDeck-1 & 0.016 & 0.02 & - & - \\
\hline & DDeck-2 & 0.02 & 0.02 & 0.016 & - \\
\hline & DDeck-3 & 0.02 & 0.025 & - & - \\
\hline \multirow{3}{*}{$\begin{array}{c}\text { BASF } \\
\text { Enviroseal }\end{array}$} & ES-1 & 0.02 & 0.016 & 0.02 & - \\
\hline & ES-2 & 0.013 & 0.013 & 0.02 & - \\
\hline & ES-3 & 0.016 & 0.02 & - & - \\
\hline \multirow{3}{*}{$\begin{array}{c}\text { No Repair } \\
\text { Small Cracks }\end{array}$} & NR S-1 & 0.013 & 0.013 & 0.01 & - \\
\hline & NR S-2 & 0.013 & 0.01 & 0.01 & - \\
\hline & NR S-3 & 0.013 & 0.013 & 0.01 & - \\
\hline \multirow{3}{*}{$\begin{array}{c}\text { No Repair } \\
\text { Medium Cracks }\end{array}$} & NR M-1 & 0.02 & 0.016 & - & - \\
\hline & NR M-2 & 0.02 & 0.025 & 0.016 & - \\
\hline & NR M-3 & 0.016 & 0.016 & 0.02 & - \\
\hline \multirow{3}{*}{$\begin{array}{c}\text { No Repair } \\
\text { Large Cracks }\end{array}$} & NR L-1 & 0.04 & 0.04 & - & - \\
\hline & NR L-2 & 0.04 & 0.045 & - & - \\
\hline & NR L-3 & 0.03 & 0.03 & 0.04 & 0.03 \\
\hline
\end{tabular}

Note: “-” denotes no crack

\subsubsection{Restressing}

After the cracked specimens were repaired, tensile stresses were reintroduced to simulate subsequent traffic loading after repairs. The bond strength and flexibility of the repair products were the major factors in determining whether the product could withstand loading.

The specimens were restressed using the same cracking setup used to initiate the original cracks. All specimens were loaded to $32 \mathrm{kips}$, which placed a stress of 500 psi into the concrete. This stress level was approximately identical to that which produced first 
cracking in the specimens. This load also represented a stress of approximately $40 \mathrm{ksi}$, or 2/3 of the yield strength of the reinforcement, a stress considered the maximum service load stress that a bridge deck will be subjected to (ACI 318-05).

Because the bond strength of the repair products was higher than the tensile strength of the concrete, stresses greater than the tensile strength would likely cause the initiation of new cracking of the concrete rather than re-cracking at the repair site. However, failure of a gravity feed crack repair can occur despite a high bond strength if the bond area is extremely small due to inadequate depth of penetration. During restressing, repair product failure was observed in only a small number of specimens that were repaired with an epoxy gravity feed product but was generally not specific to a particular product. Overall, the gravity feed repair products were able to withstand the forces reintroduced into the specimens.

All specimens repaired with an overlay product cracked above the location of the original crack during restressing. Because a pretreatment procedure was not applied to fill the cracks prior to the overlay application, there was a very low cross sectional area at those locations to resist the tensile force.

\subsection{Testing Procedure}

Once the specimens were repaired and restressed, a macrocell corrosion test was initiated to evaluate the effectiveness of each product in terms of repairing cracks to resist reinforcement corrosion. Macrocell action occurs when a metal undergoing active corrosion is electrically connected to another undergoing a lower rate of corrosion or not corroding at all. This action generally occurs due to a difference in materials or environmental conditions between the two regions. In the case of reinforced concrete, a macrocell can be created between two mats of reinforcement connected by transverse reinforcement or construction devices such as slab bolsters or chairs. The actively corroding region, usually the top mat of steel, becomes the anode while the bottom mat becomes the cathode. An electron flow occurs between the two mats, which can be monitored by measuring the voltage drop across a resistor connecting the anode and the cathode. Corrosion is initiated by the presence of salt solution. 


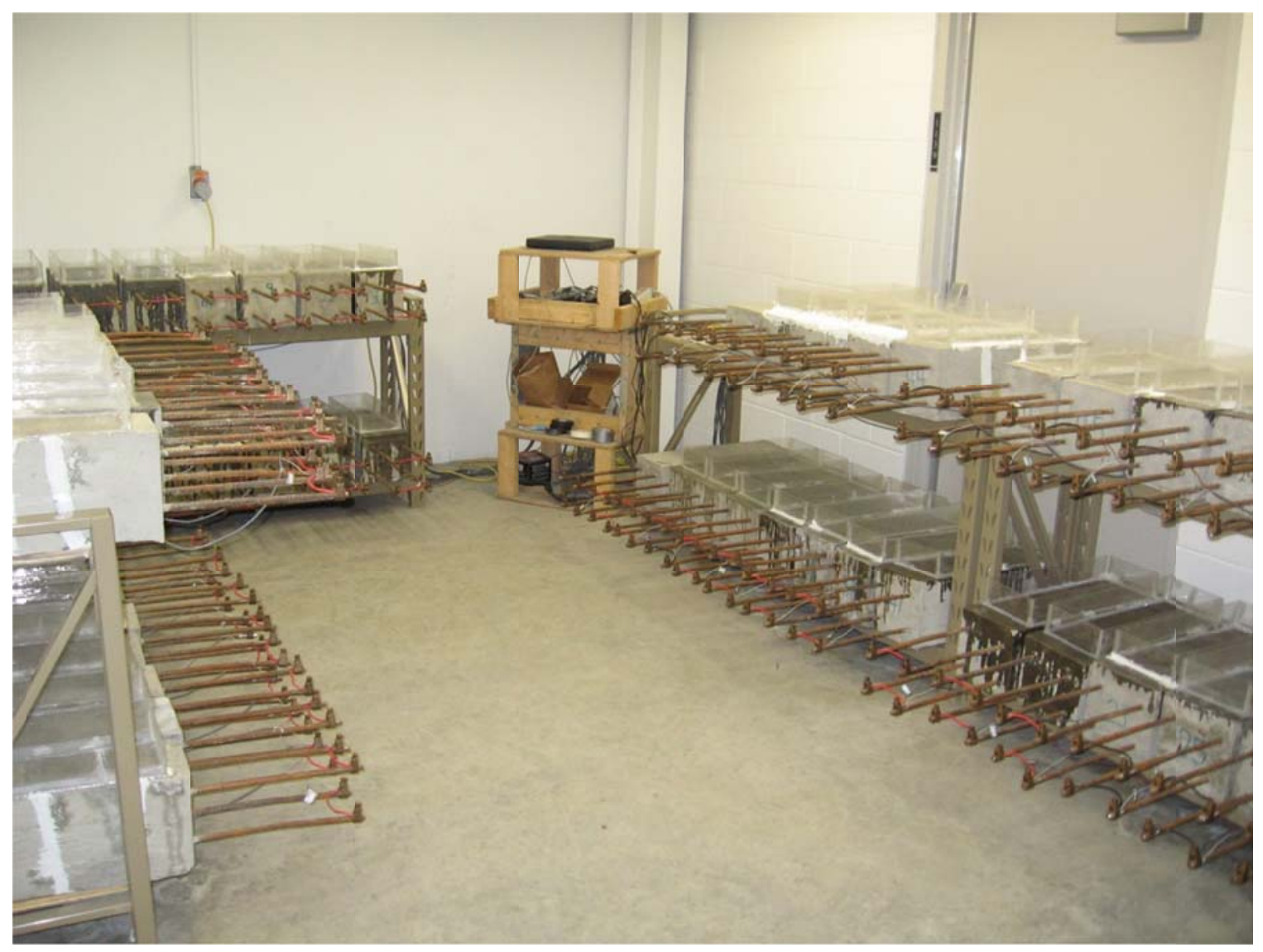

Figure 4.10: Crack repair specimens

\subsubsection{Test Setup}

The macrocell test setup was based on ASTM G109-92, Test Method for Determining the Effects of Chemical Admixtures on the Corrosion of Embedded Steel Reinforcement in Concrete Exposed to Chloride Environments. The two bars in the top mat were electrically connected with 6 gage wire (Figure 4.11). Similarly, the two bars in the bottom mat were electrically connected. The two mats were then electrically connected across a 100-ohm resistor. The voltage drop across this resistor was measured using a Campbell Scientific CR10X Datalogger connected to two Campbell Scientific AM16/32 Multiplexers. A schematic of the electrical circuit is presented in Figure 4.12. 


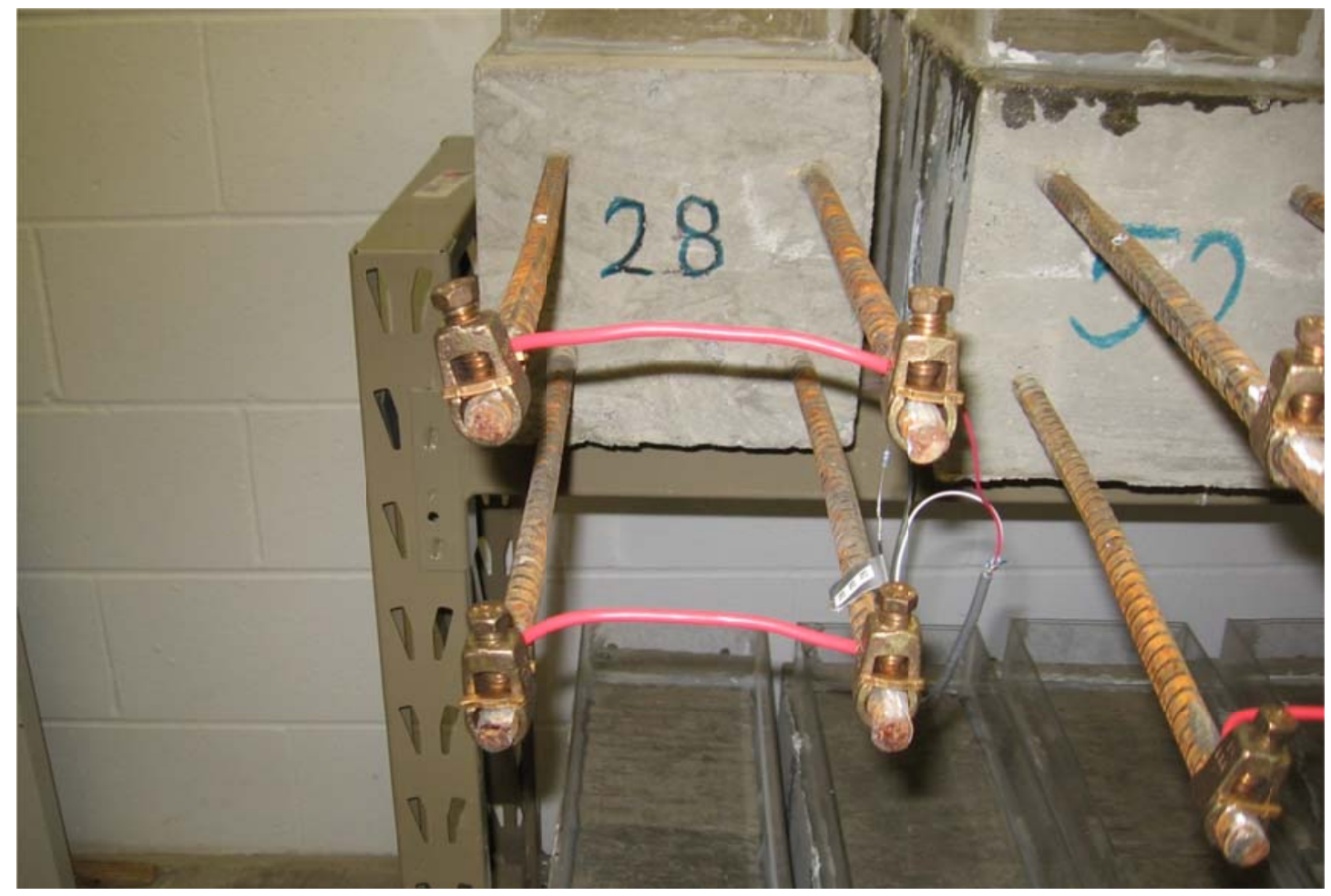

Figure 4.11: Macrocell corrosion test electrical connections

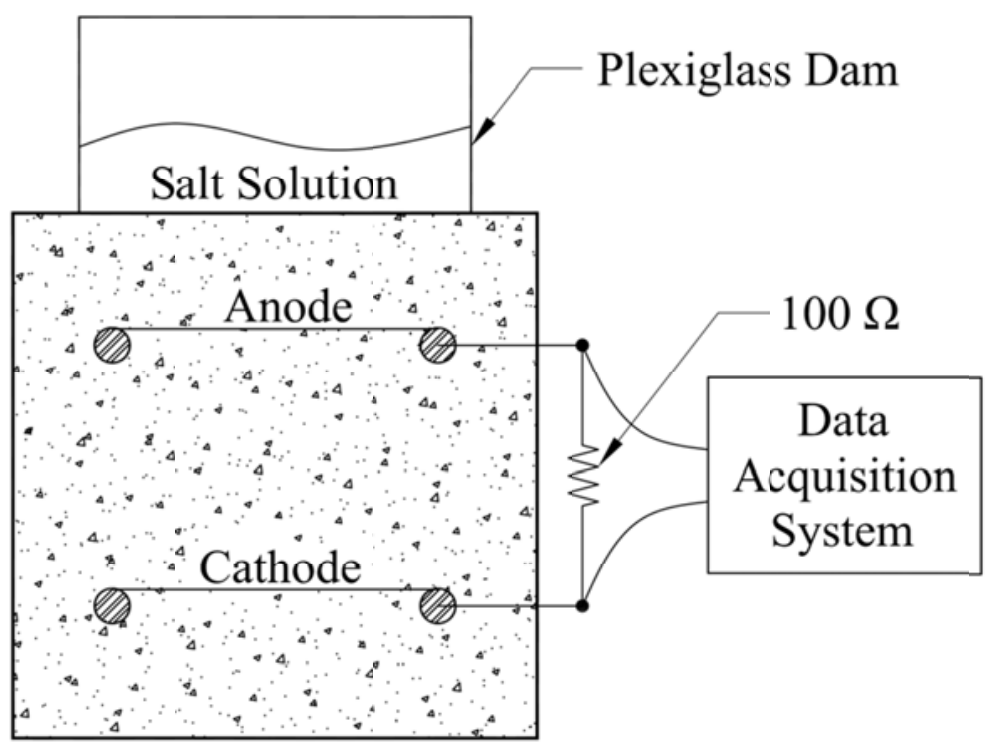

Figure 4.12: Macrocell electrical circuit 
A plexiglass dam was placed on the top of each specimen and sealed using silicone (Figure 4.13). Corrosion was then initiated by pooling $3 \%$ by weight salt solution on the top of the specimens. A densimeter was used to prepare the salt solution. In addition, silicone was used to seal the cracks on the sides and bottom of the specimens to prevent leakage.

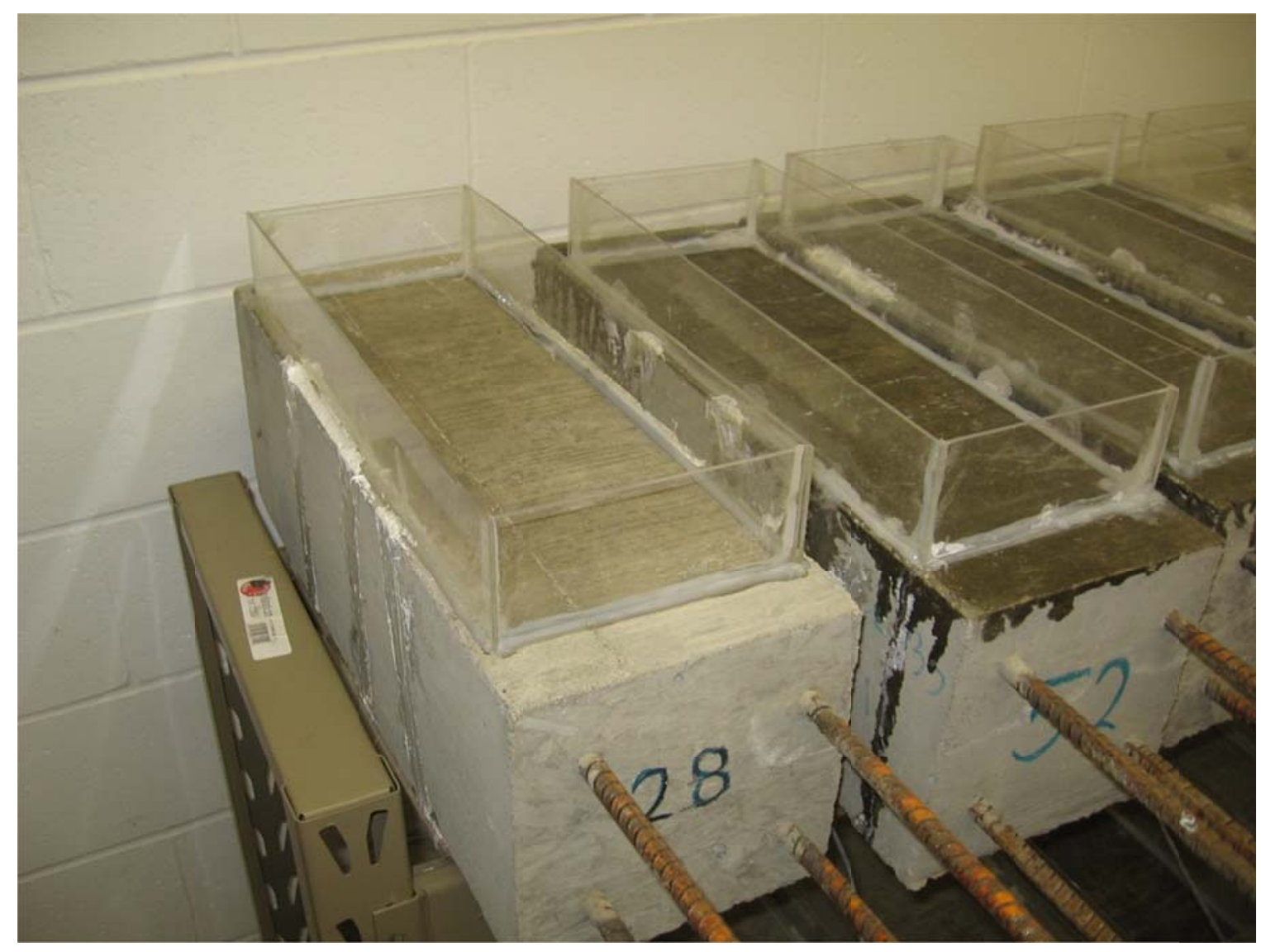

Figure 4.13: Plexiglass dams

\subsubsection{Test Procedure}

\subsubsection{Macrocell Corrosion Test}

During the macrocell corrosion test, alternating wet and dry periods were completed every 14 days. Therefore, a full cycle was completed every 28 days. As shown in Figure 4.13, the dams were filled with a $3 \%$ by weight salt solution ensuring a corrosive environment during the wet period. At the beginning of the dry period, a vacuum was used 
to remove the salt solution from the specimens. Data were recorded every six hours and downloaded monthly to ensure that all channels were working properly. The test began on April 18, 2008 and ended approximately one year later at the end of the last dry period on April 6, 2009.

\subsubsection{Visual Examination}

Once the macrocell test was completed, the top corners of the specimens were removed as shown in Figure 4.14 to extract the steel reinforcement and assess the degree of corrosion presented on the bar, especially at the location of cracks. Photographs of each specimen were taken shortly after the removal of the reinforcement to document the corrosion at that time and to permit future reevaluations. The degree of corrosion on each bar was visually examined and ranked from zero, when no corrosion was detected to 10 , for severe corrosion. Specimens and their reinforcement were laid out according to their repair product number to allow further comparisons between the different crack repair techniques applied as shown in Figure 4.15.

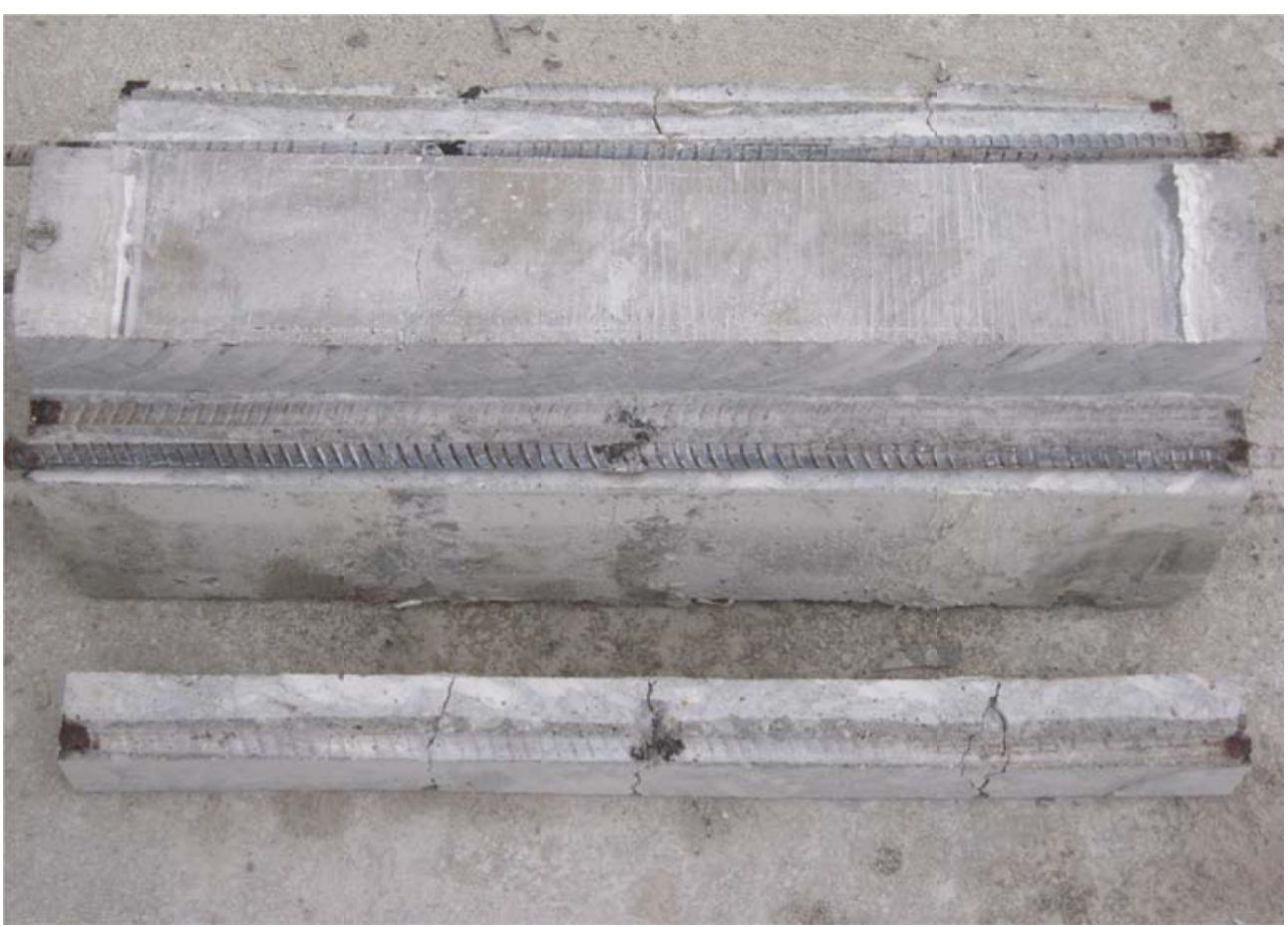

Figure 4.14: Specimens after macrocell test 


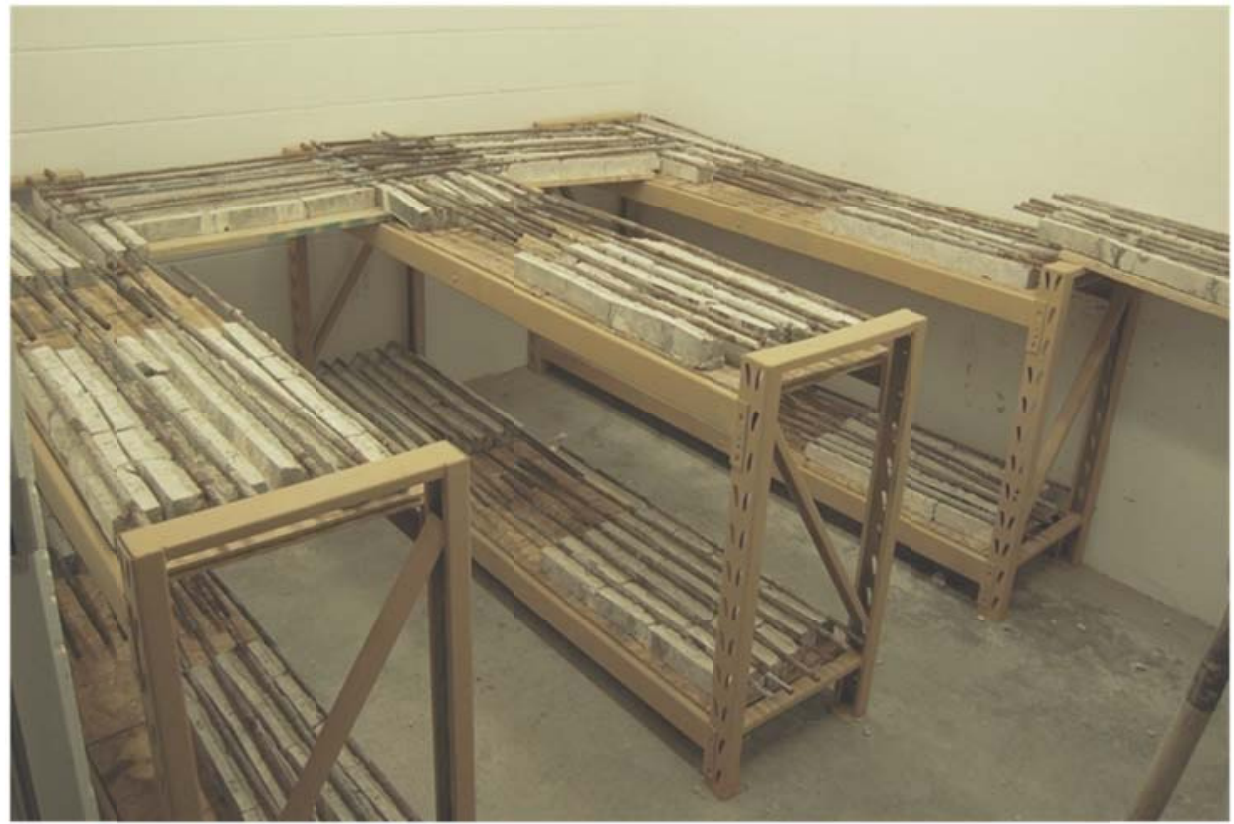

Figure 4.15: Reinforcement after macrocell test 


\section{$\underline{4.7 \text { Test Results }}$}

During application and restressing, some general observations were made. The epoxyies and methacrylates exhibited different behavior during the crack repair application. The methacrylates were easier to handle due to their lower viscosity. However, they required more pretreatement stripe applications to fully repair the crack, which may be unrealistic in field applications. Conversely, the epoxies were harder to handle but required fewer pretreatement stripes which is beneficial for field application but may indicate a decreased depth of penetration. Based solely on ease of application, methacrylates exhibited a better performance than the epoxies.

Restressing of the specimens also demonstrated some important information about the repair products. All specimens repaired with an overlay system were recracked at the location of the original crack during restressing. Therefore, an overlay system alone is not adequate to repair bridge deck cracking. When an overlay system is implemented, a gravity feed repair system should first be applied to fill the cracks to prevent re-cracking in the overlay at the location of the deck cracks. In addition, restressing produced a small number of failures in the epoxy gravity feed repairs. This failure was not observed in specimens repaired with methacrylates.

It should also be noted that many of the specimens were shown to be inadequately repaired based on leaking. Upon filling the plexiglass dams with salt solution, many of the specimens leaked from the sides and bottom of the cracks, indicating the salt water had penetrated through the depth of the crack despite the repair. The leaking was not specific to one repair technique or repair product.

The total corrosion of the reinforcement embedded in each specimen was determined from the potential difference recorded across the resistor during the macrocell test. Based on Ohm's law $(V=I \cdot R)$, the current was calculated using the resistor's measured resistance and the voltage drop. Total corrosion was subsequently obtained by integrating over the test duration the computed electric current. Upon conclusion of the test, the rebar was extracted from the specimens to visually determine the degree of corrosion present on the bars. Correlations between these observations and 
measurements from the test were made. Furthermore, the effectiveness of the repair products was evaluated. Finally, the influence of crack widths on the corrosion of the reinforcement was investigated.

\subsubsection{Corrosion Measurement}

The behavior exhibited by the electric current throughout the test was approximately the same for all specimens although the magnitude of the values varied. Typical behavior is illustrated in Figure 4.16 as provided by Specimen 10 while the results for all specimens are provided in Appendix B. For the first 14 days (end of the first dry cycle), the measurements were essentially zero, since no salt solution had been pooled in the dams. An increase was observed shortly after the beginning of the wet cycle in all specimens, indicating that during this cycle, the bar experienced some corrosion. From Day 30 to 50, data were not recorded due to a malfunction of the datalogger; therefore, the values before and after the gap were connected by a straight

line as shown. From Day 50 to approximately Day 70, the rate of corrosion increased significantly and remained fairly constant until Day 170. 


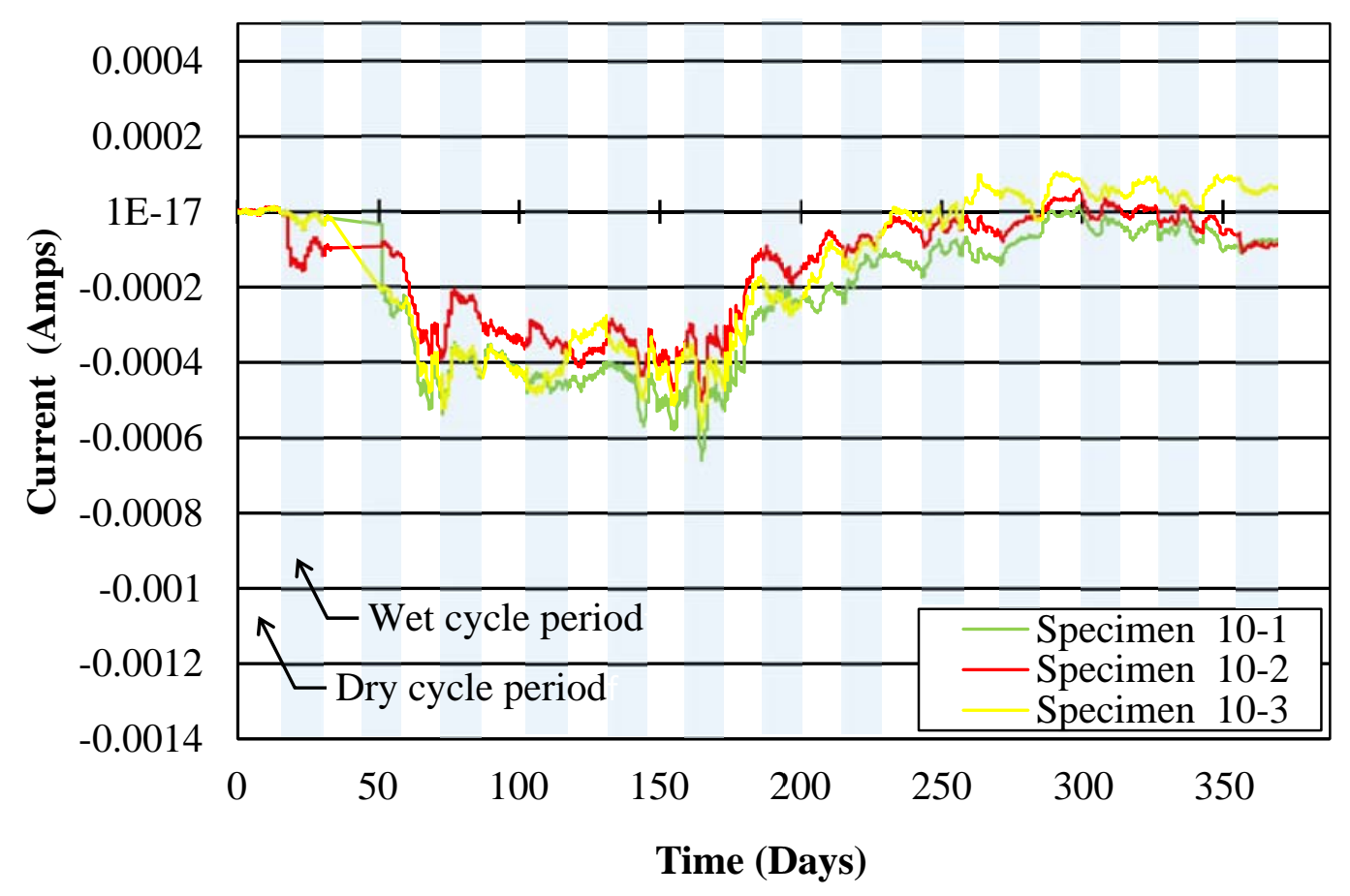

Figure 4.16: Typical current behavior through 360 days

Around Day 170, at the beginning of the dry cycle, the electric current exhibited a sudden decrease which lasted about 15 days. This reduction was observed for almost all specimens. During this time period, the bars were wire brushed to remove corrosion that had occurred on exposed areas that were not embedded in concrete. This corrosion caused an increase in the electric current measured before Day 170 that was essentially reduced after brushing the bars. Figure 4.17 shows the rust on the protruding bars. After Day 185 through the end of the test, an effort was made to prevent corrosion on the exposed areas of the bar by oiling and brushing the exposed reinforcement periodically.

Subsequent to the abrupt reduction, a steady decrease was experienced by almost all specimens. When 300 days was reached, the measured values were close to zero and continued oscillating around zero for the remainder of the test. A common trend between all wet or dry cycle periods was not noticeable. In fact, the electrical current increased or decreased regardless of the cycle considered. 


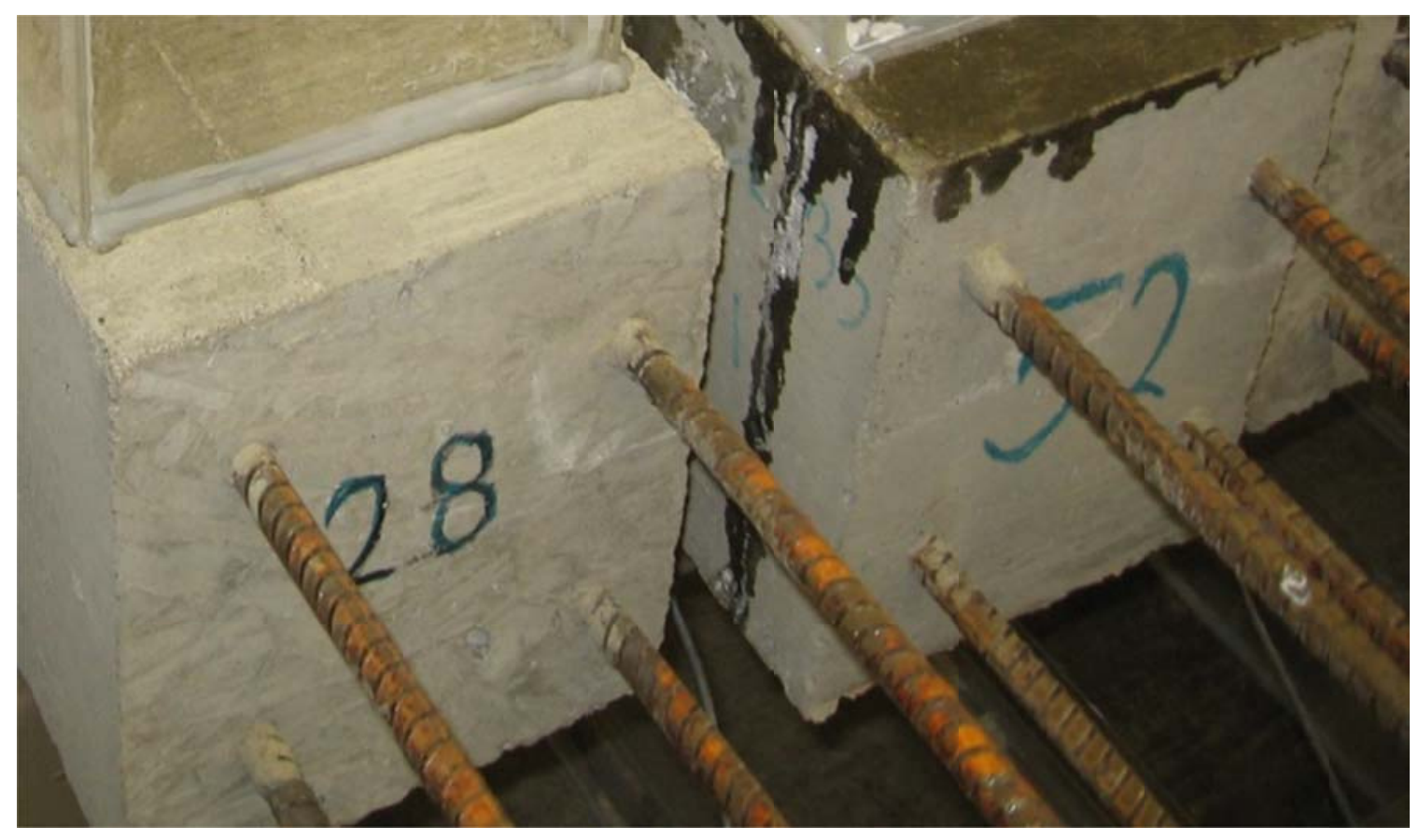

Figure 4.17: Corrosion on exposed bars during test

The presence of corrosion on the exposed surface of the bars considerably affected the results obtained from the macrocell corrosion test. The contribution of the exposed surface to the corrosion current can be estimated from Figure 4.18. This figure shows the results of two control specimens that were not cracked or subjected to wet cycles. As shown, corrosion was measured for both specimens. Corrosion was presumably caused by leaking and splattering of salt solution on adjacent specimens. While this exposure was not desirable for a control, it turns out that this was actually beneficial as it provided excellent data regarding the influence of the exposed reinforcement. 


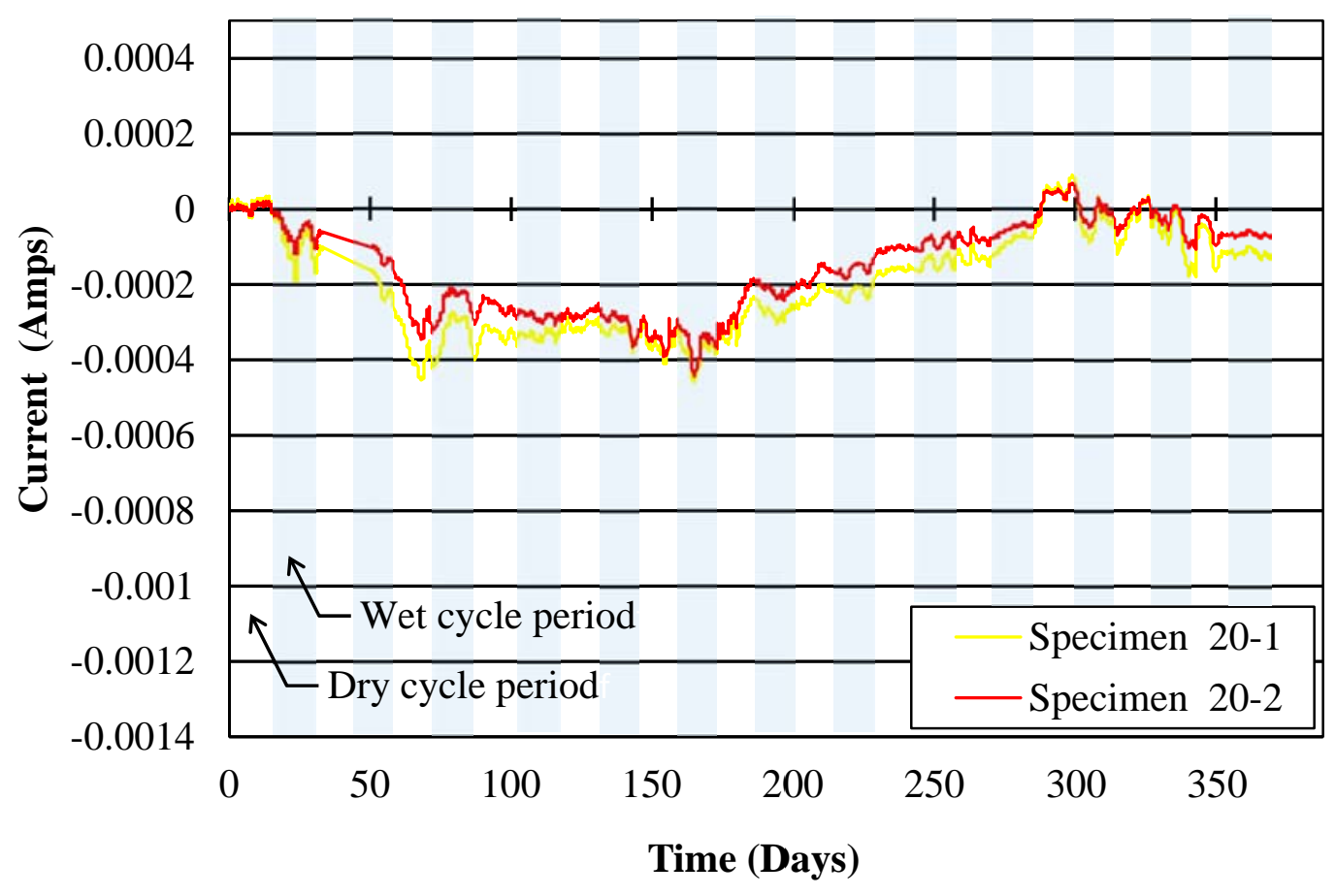

Figure 4.18: Control specimens

Based on the electric current, corrosion was calculated for the entire test duration. The electrical current is the slope or rate of change of corrosion. Therefore, the total corrosion can be calculated by integrating the current over time. Corrosion of the three duplicate specimens of each repair product is plotted in Figure 4.19a to Figure 4.37a. Generally, a gradual increase from Day 50 to 200 was noticed before it leveled off through the duration of the test.

\subsubsection{Visual Examination}

Upon conclusion of the macrocell corrosion test, a visual assessment was performed to evaluate the degree of corrosion exhibited on the bars. Photographs were taken once the top corners of the specimens were removed. Evidence of the corrosion present on the bars is shown in Figure $4.19 \mathrm{~b}$ to Figure $4.37 \mathrm{~b}$ for a representative specimen of each repair product. 


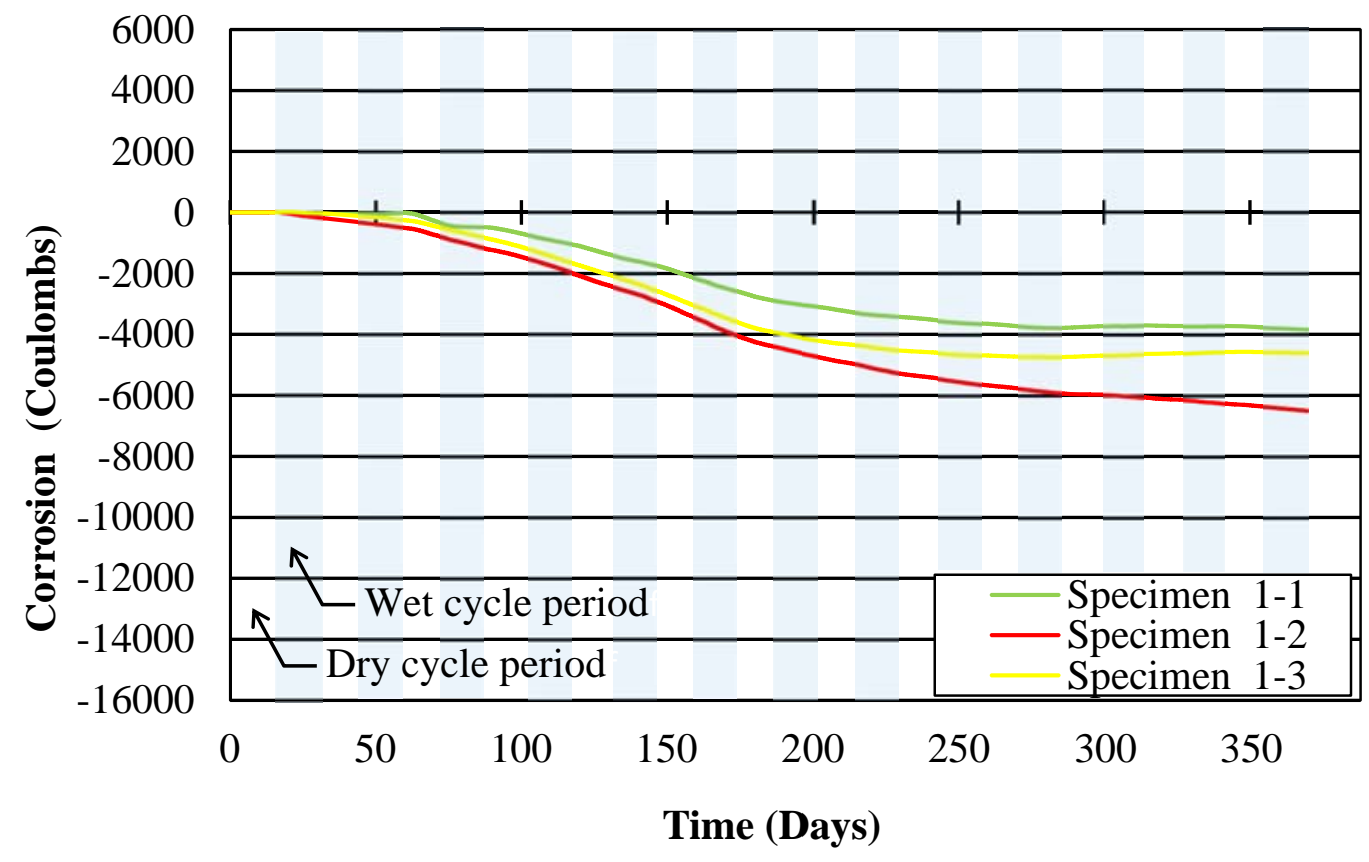

a) Corrosion through 360 days

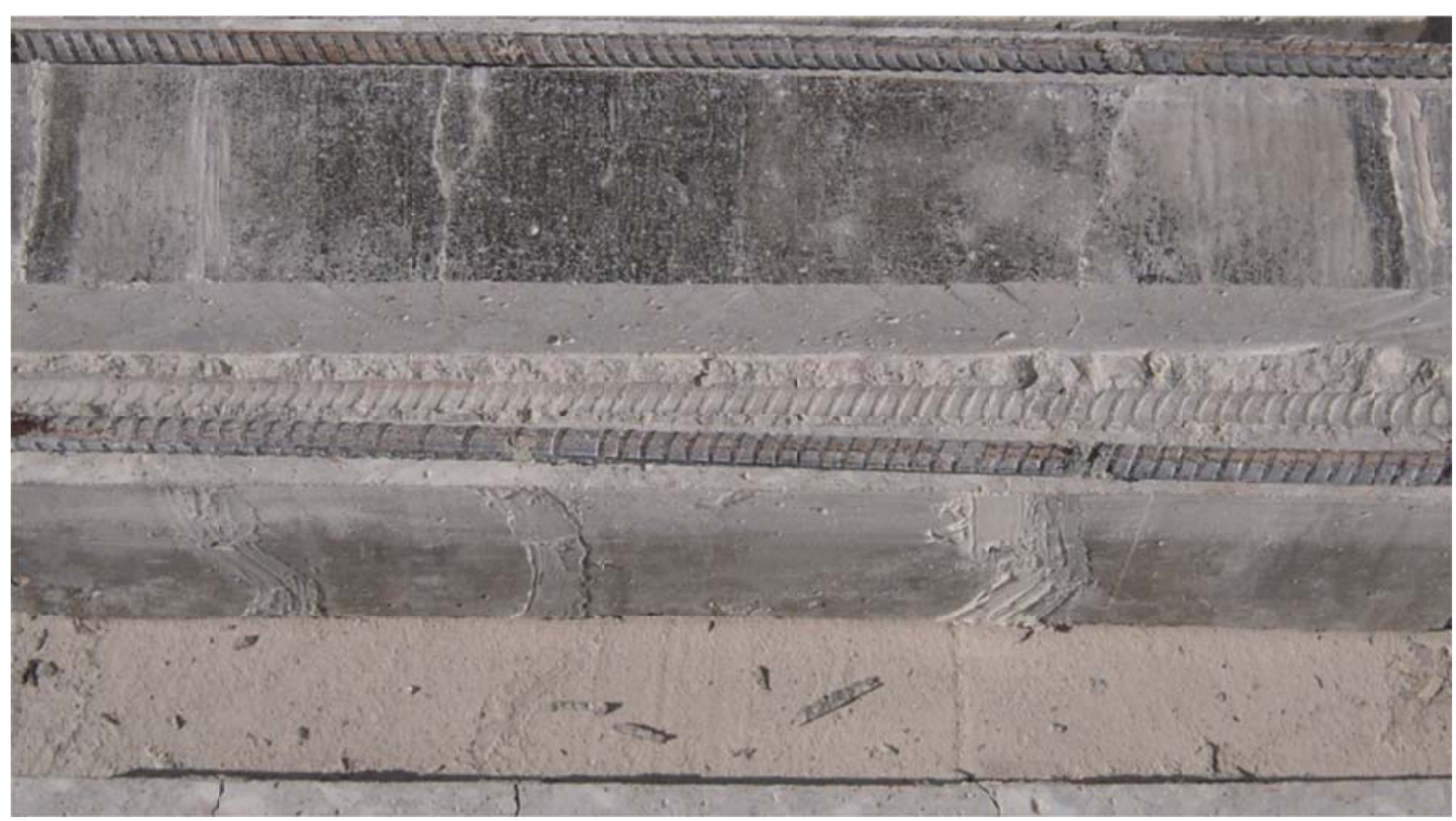

b) Corrosion on top bars

Figure 4.19: BASF - Epoxeal (Epoxy) 


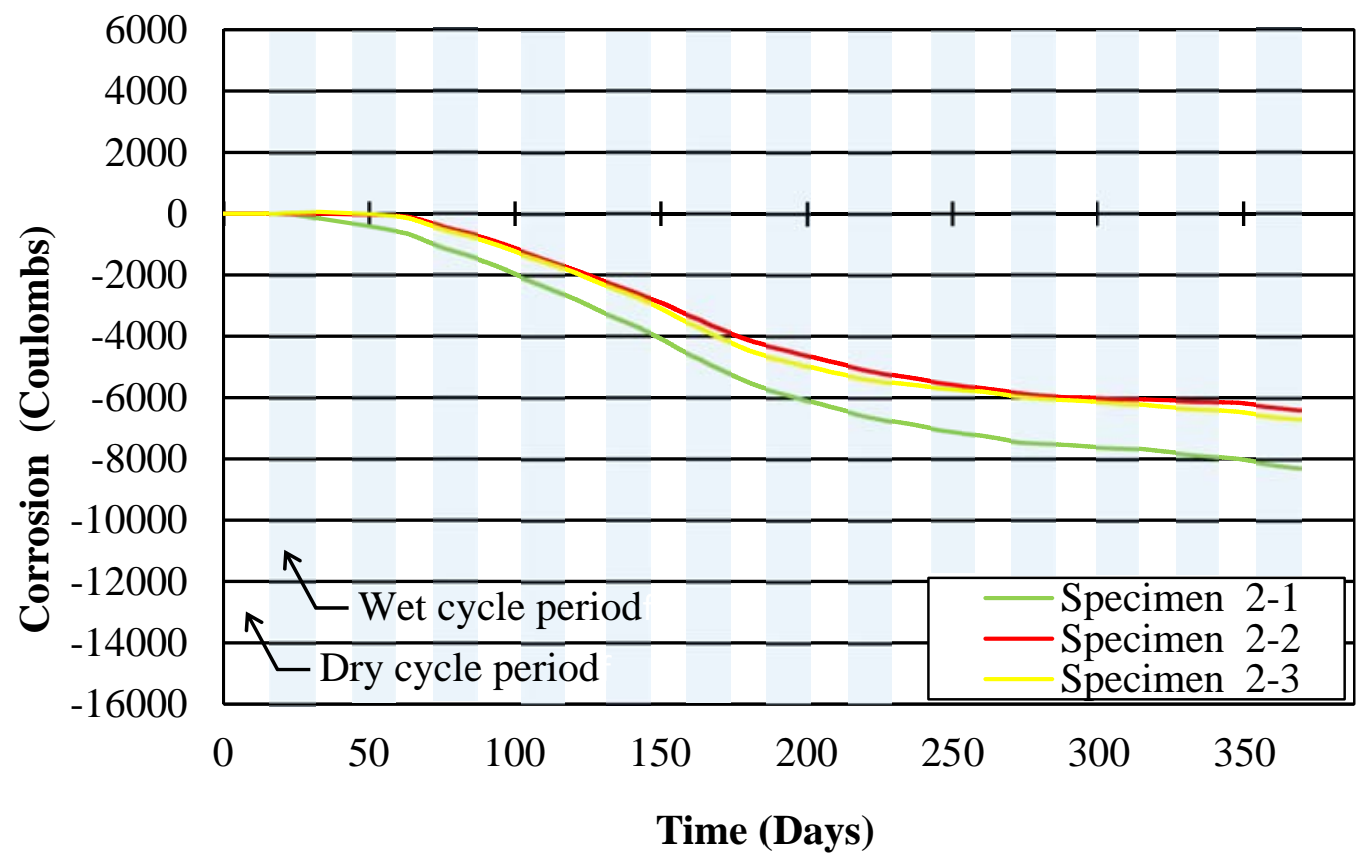

a) Corrosion through 360 days

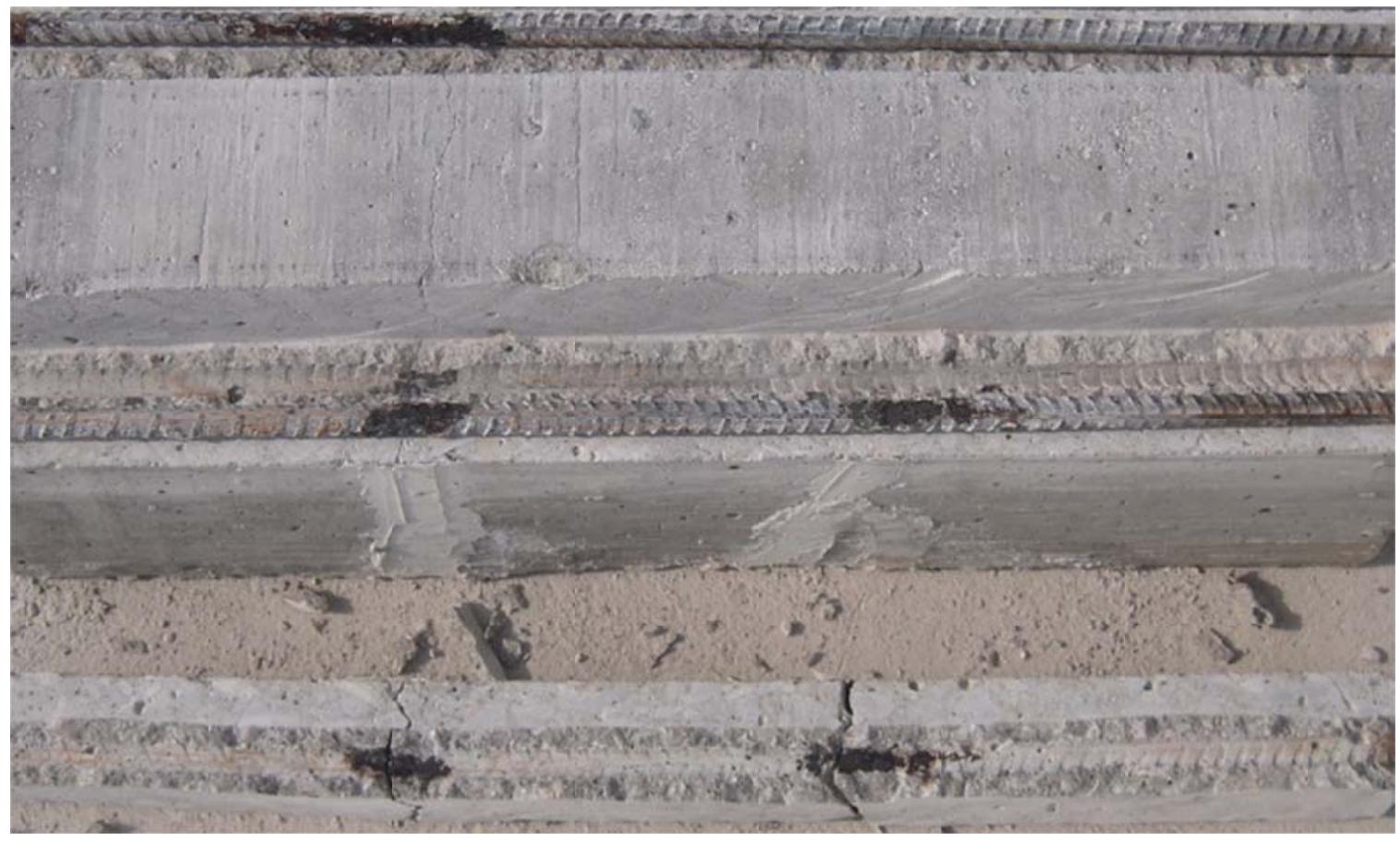

b) Corrosion on top bars

Figure 4.20: BASF - Degadeck (Methacrylate) 


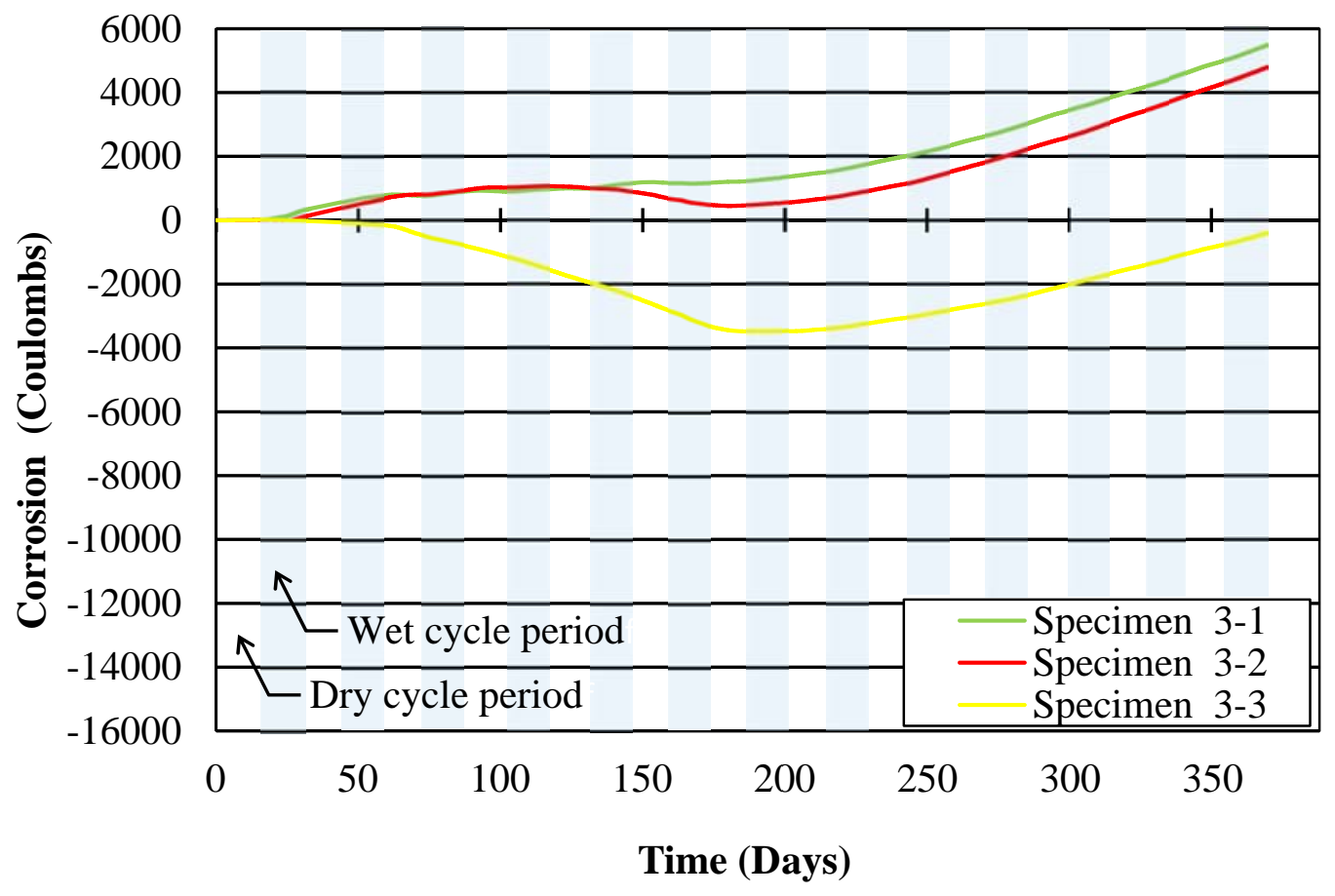

a) Corrosion through 360 days

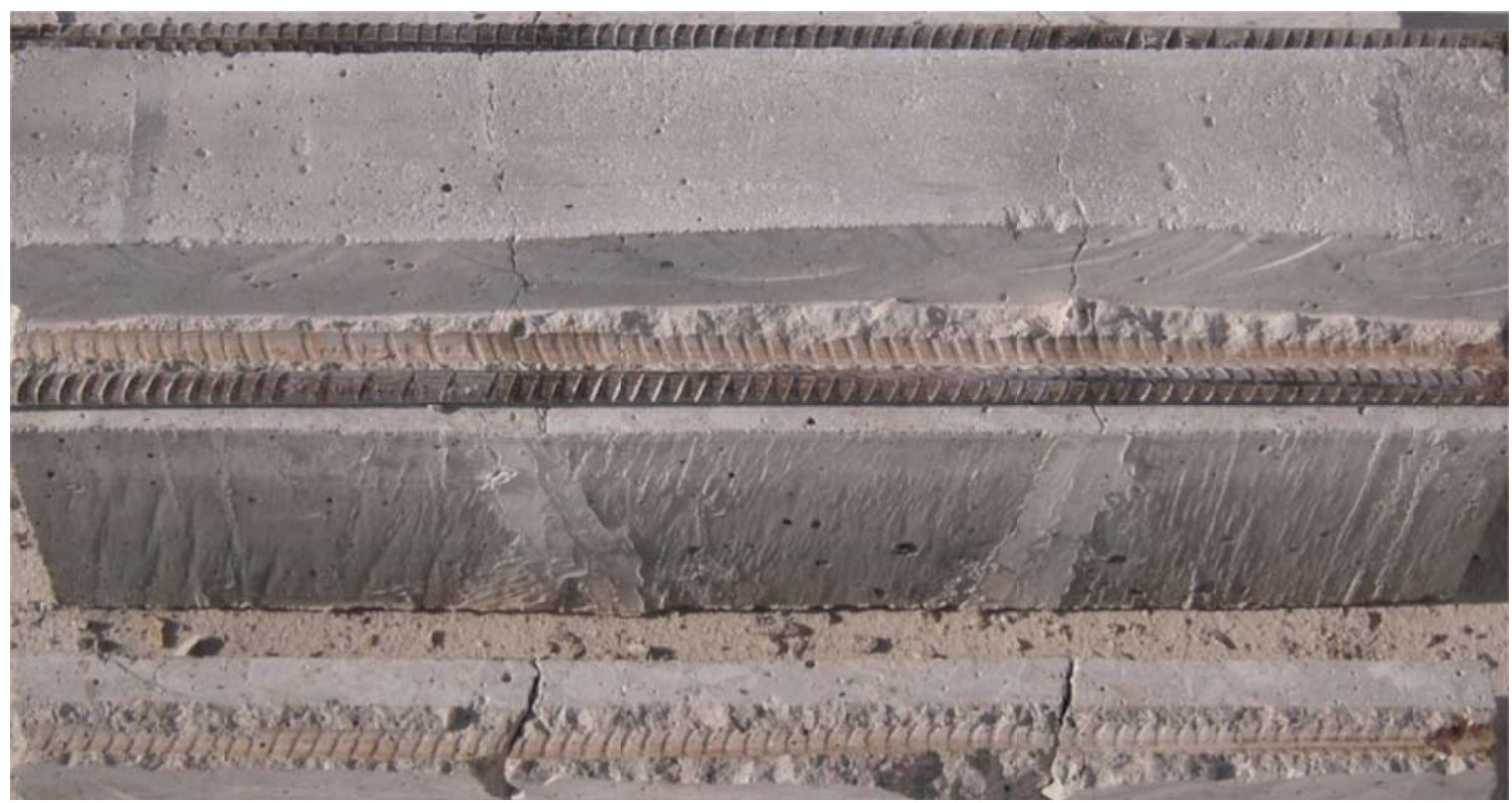

b) Corrosion on top bars

Figure 4.21: BASF - Enviroseal (Waterproofer) 


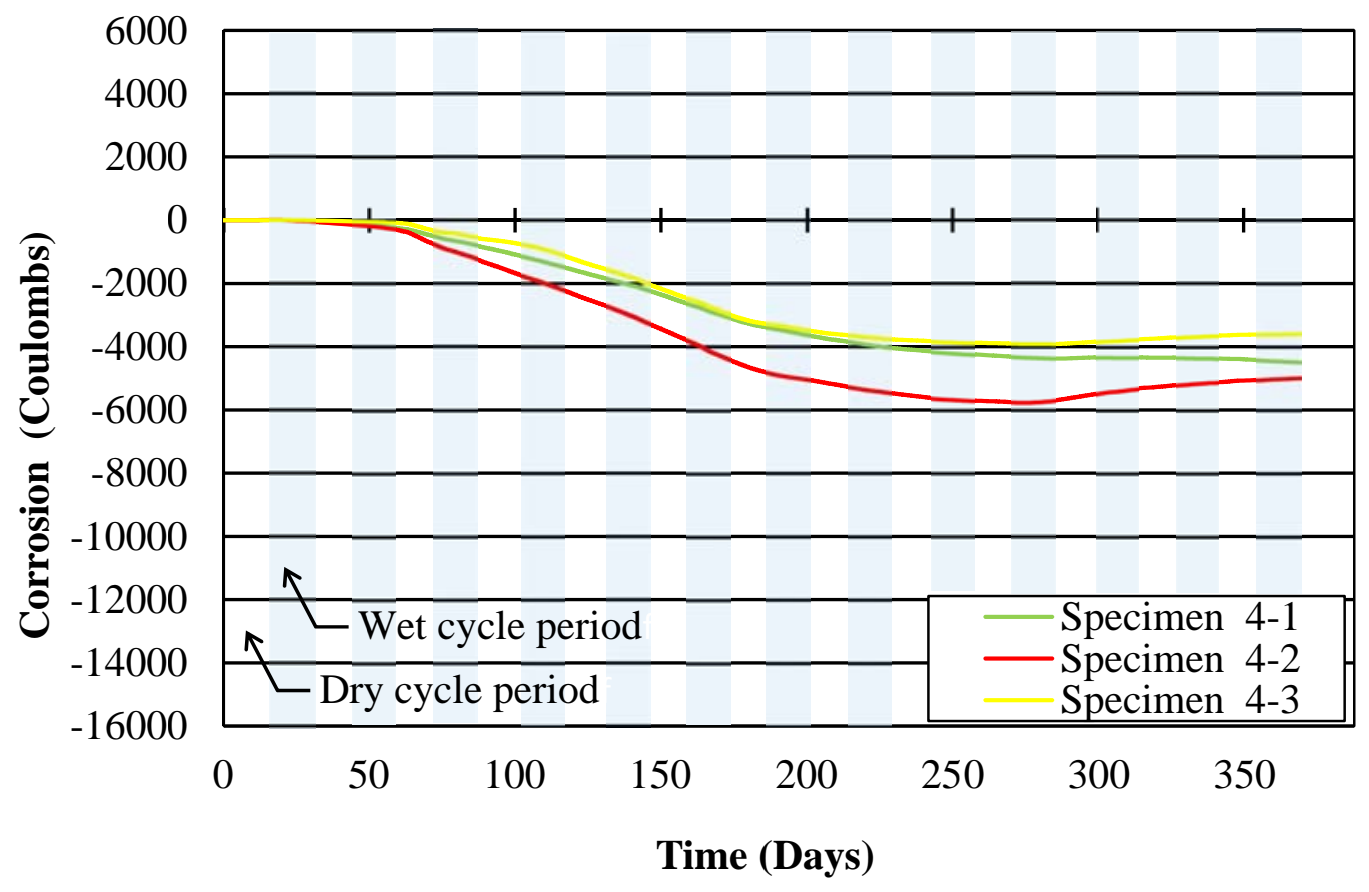

a) Corrosion through 360 days

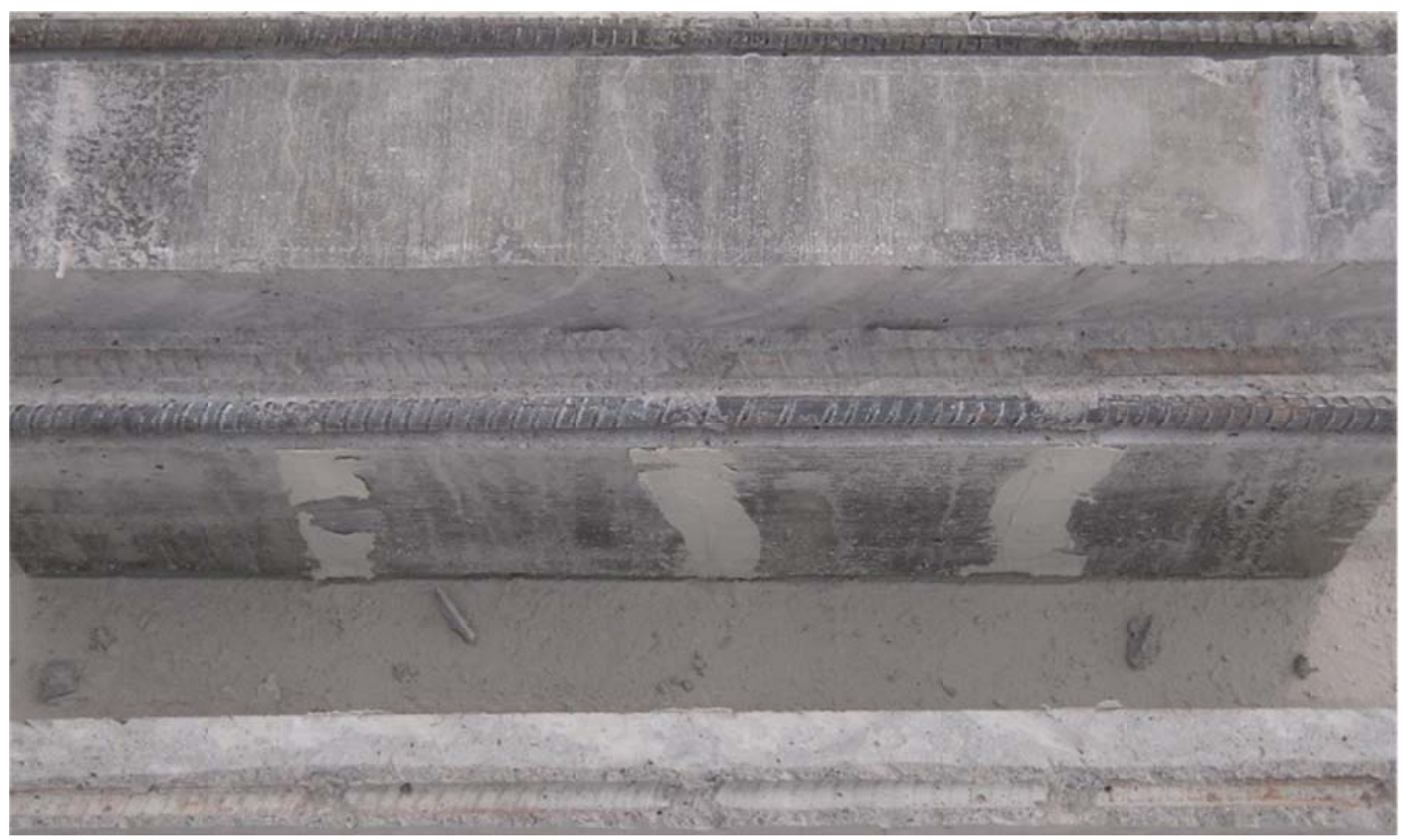

b) Corrosion on top bars

Figure 4.22: Euclid/Tamms - Dural 335 (Epoxy) 


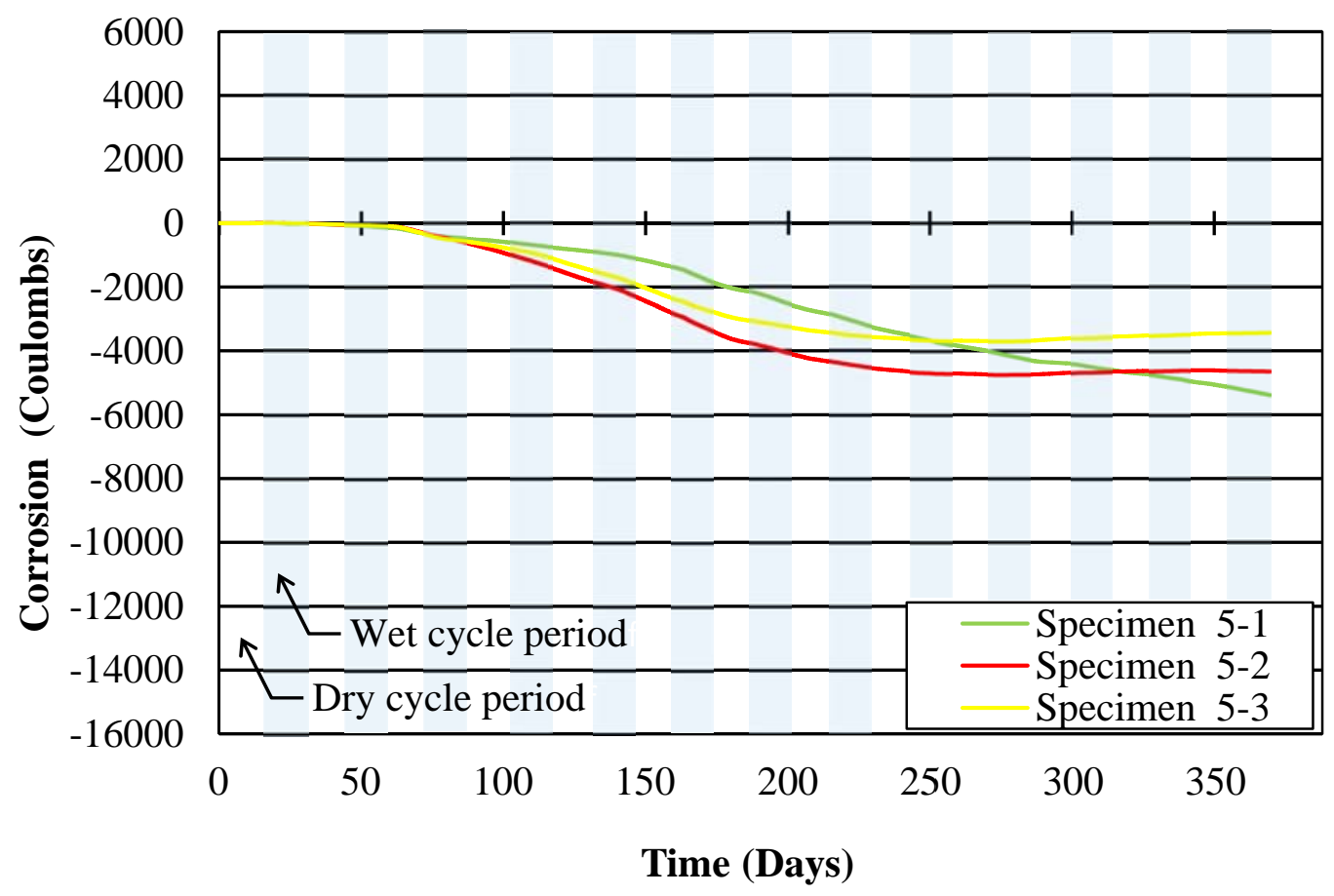

a) Corrosion through 360 days

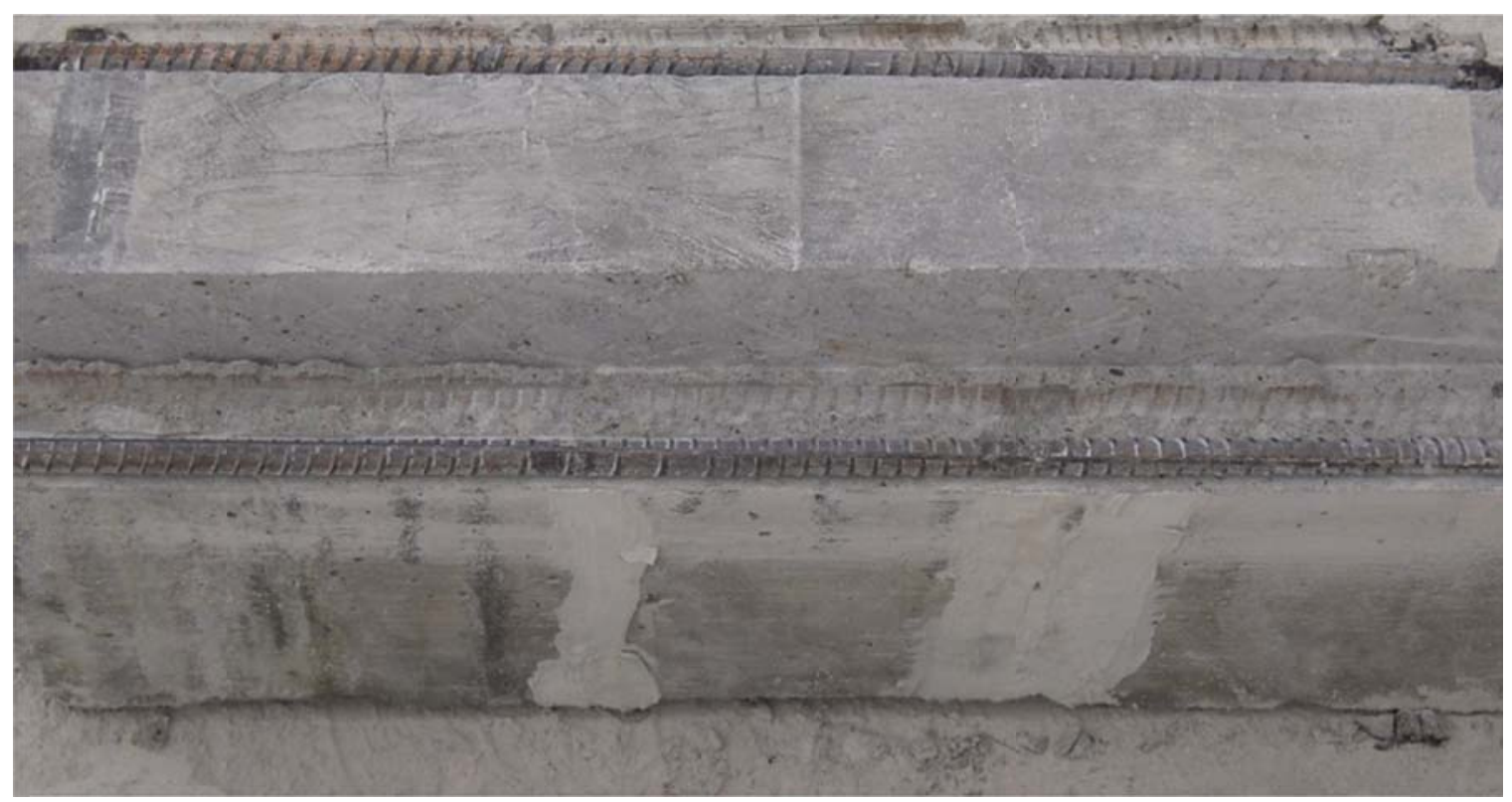

b) Corrosion on top bars

Figure 4.23: Euclid/Tamms - Dural 50 (Epoxy) 


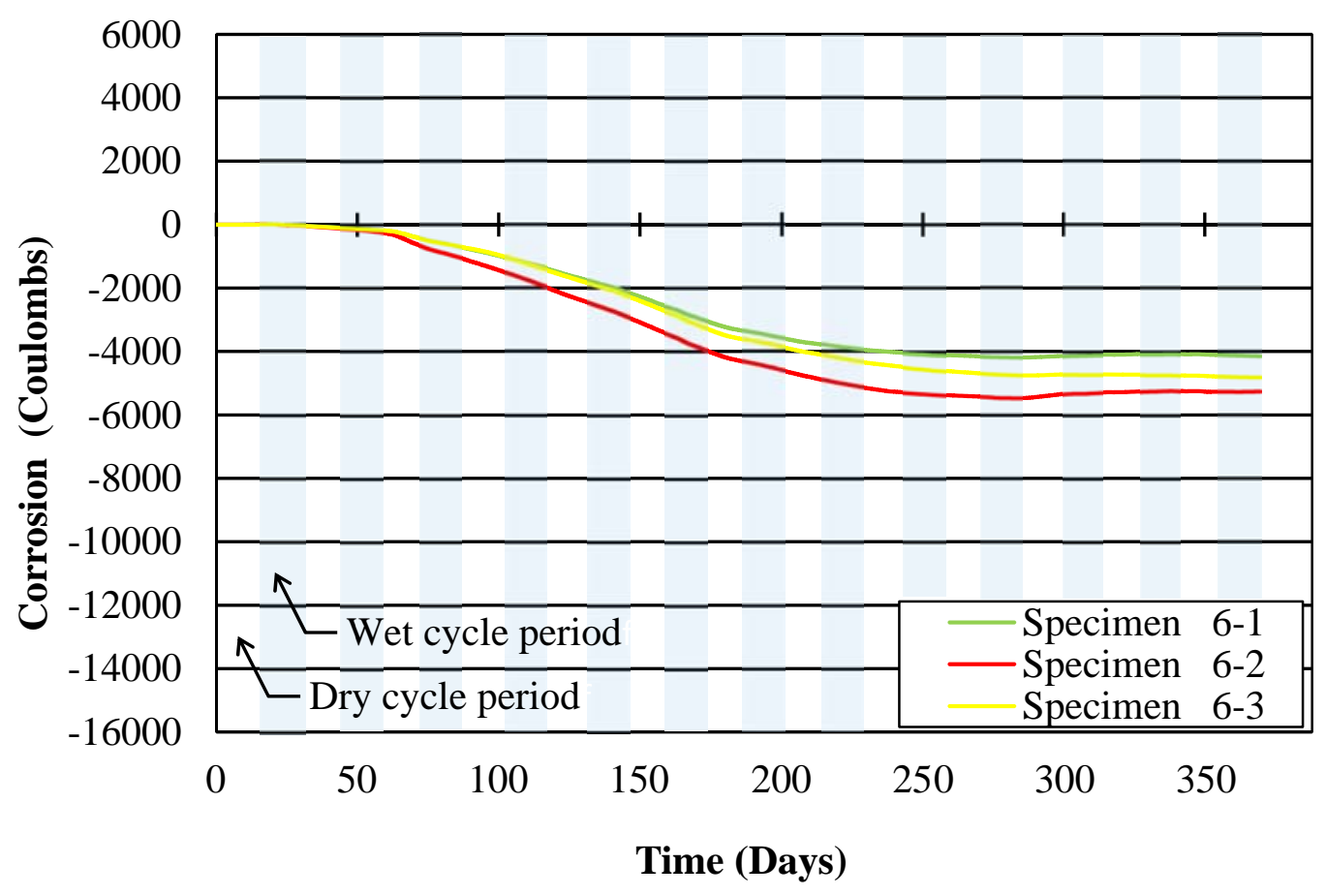

a) Corrosion through 360 days

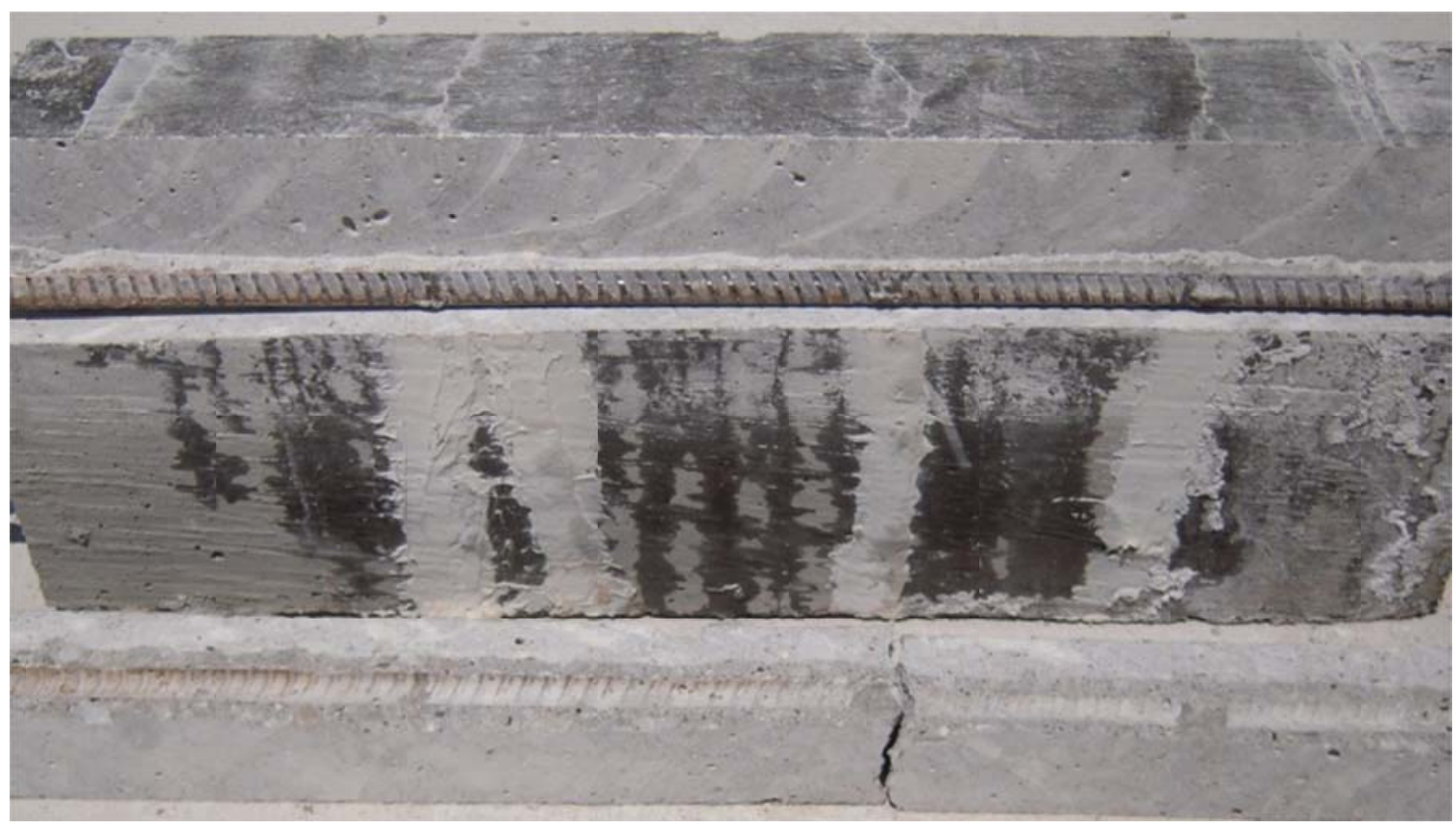

b) Corrosion on top bars

Figure 4.24: Euclid/Tamms - Dural 50 LM (Epoxy) 


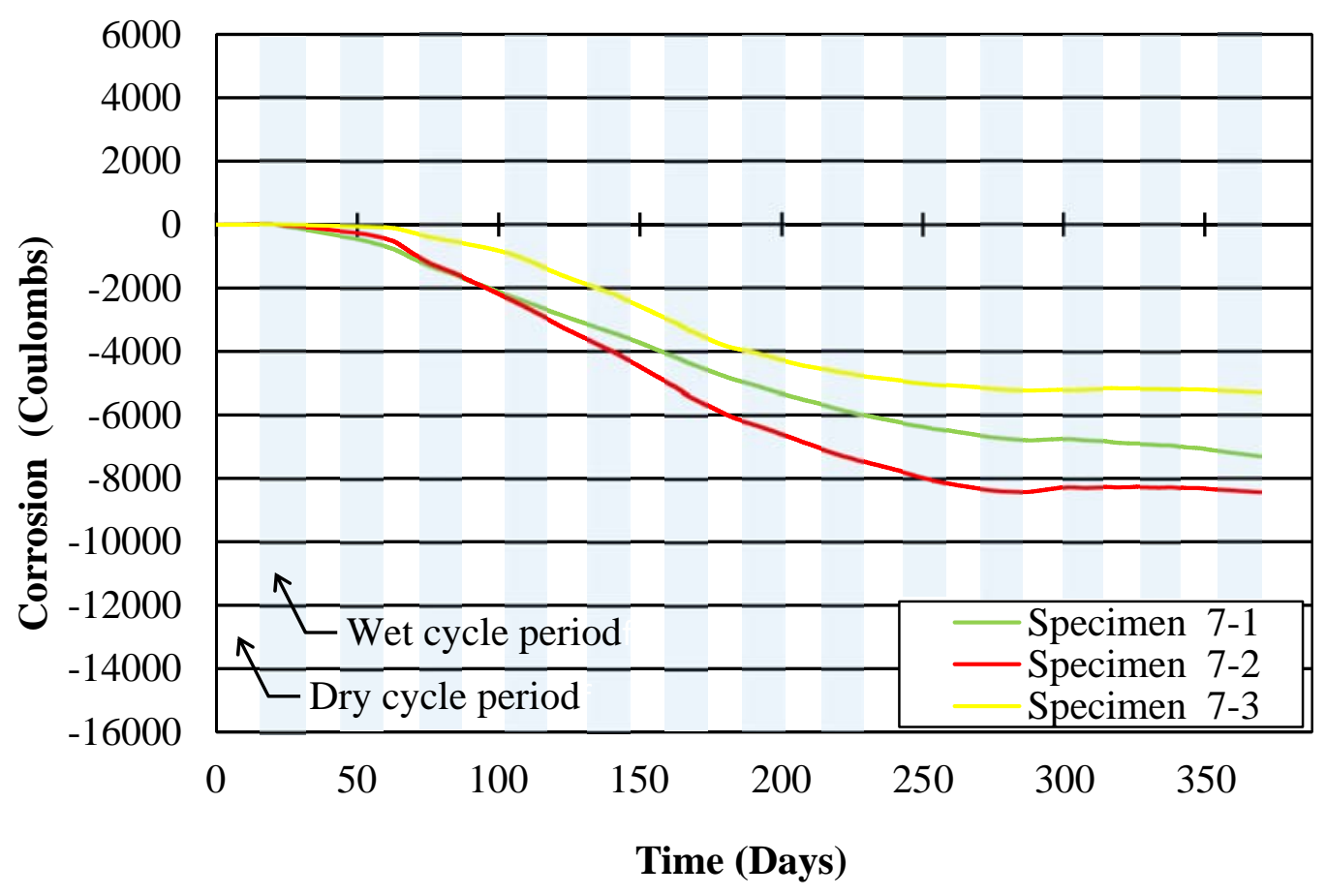

a) Corrosion through 360 days

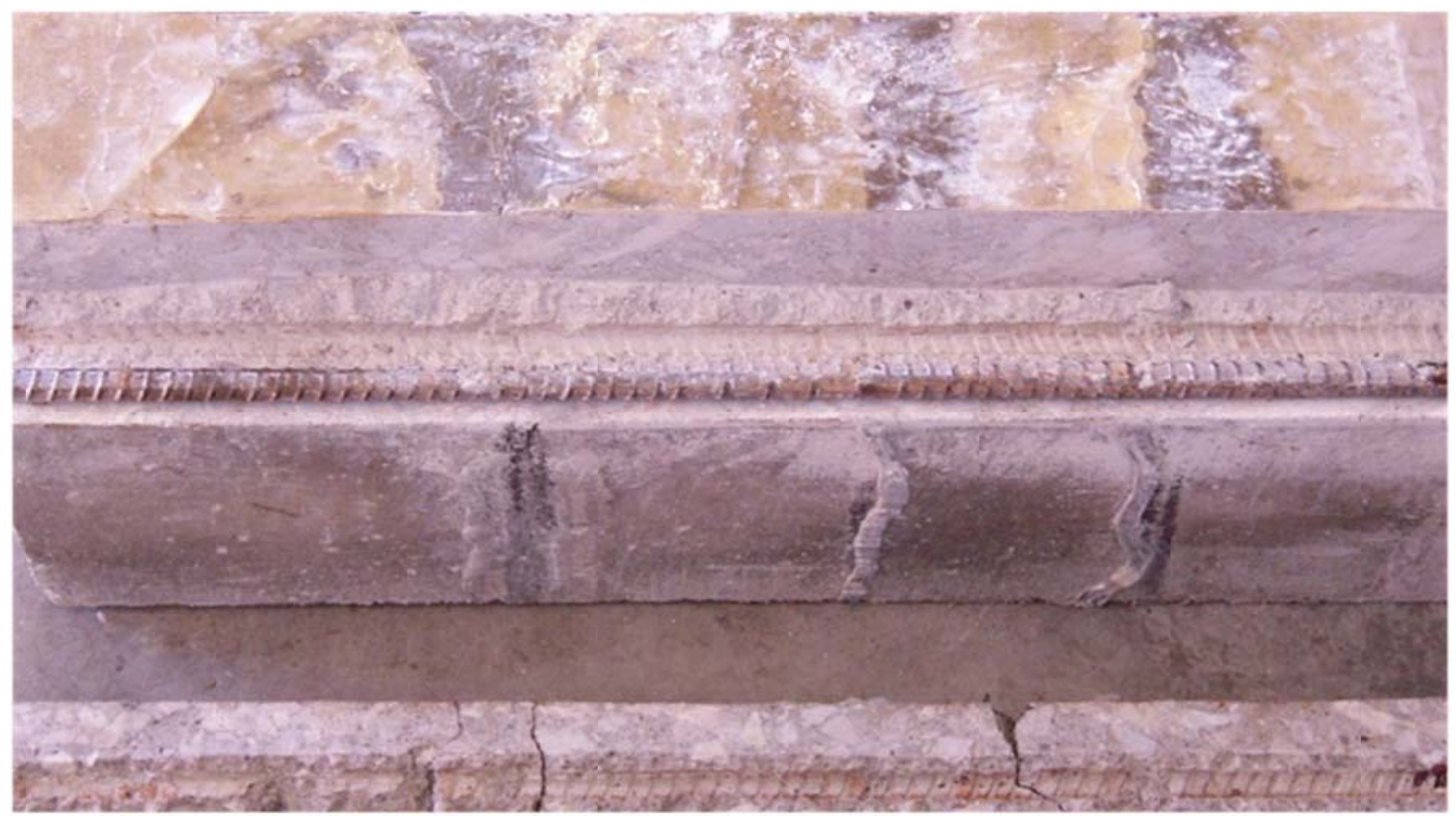

b) Corrosion on top bars

Figure 4.25: Fox Industries - FX 770 HM LV (Epoxy) 


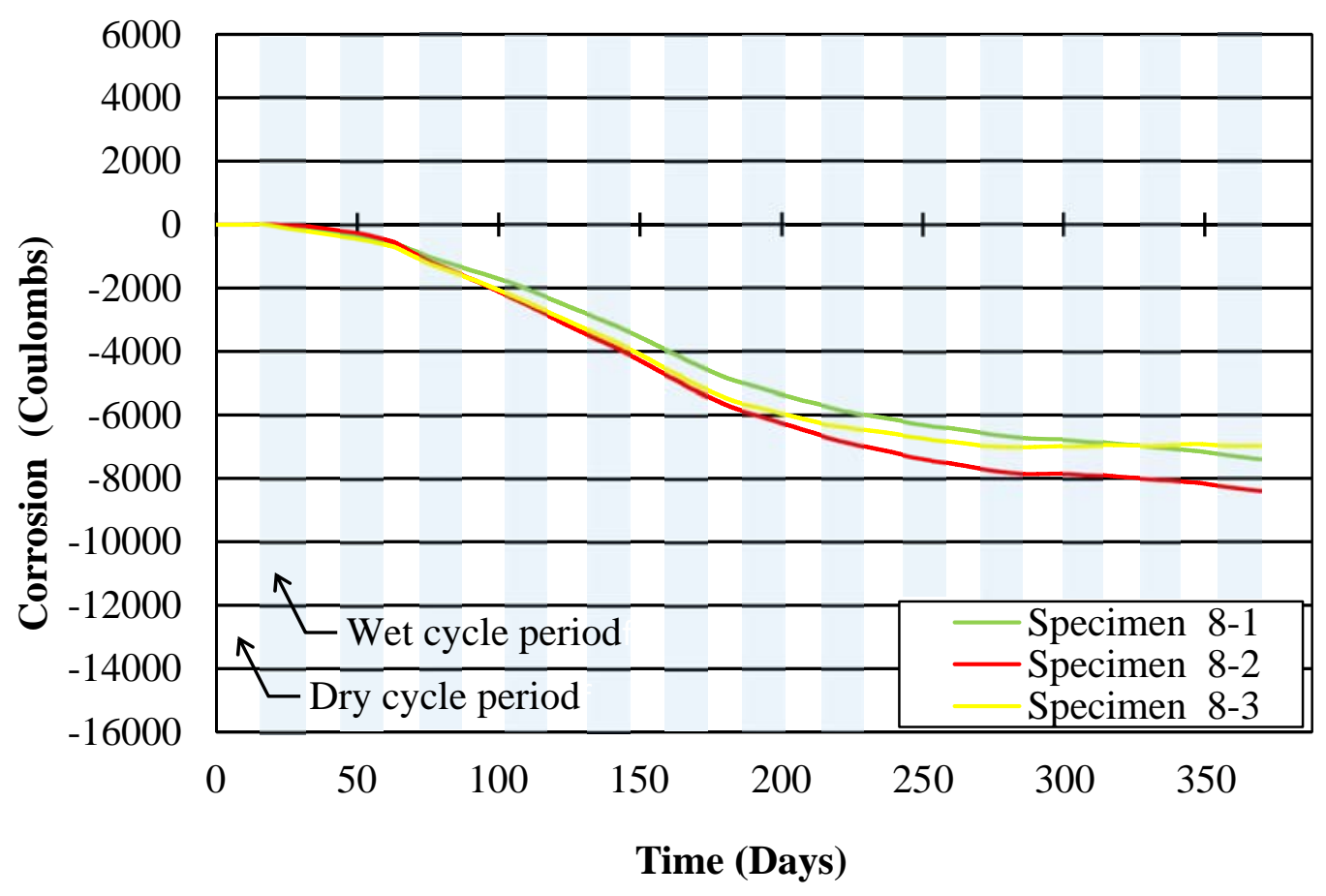

a) Corrosion through 360 days

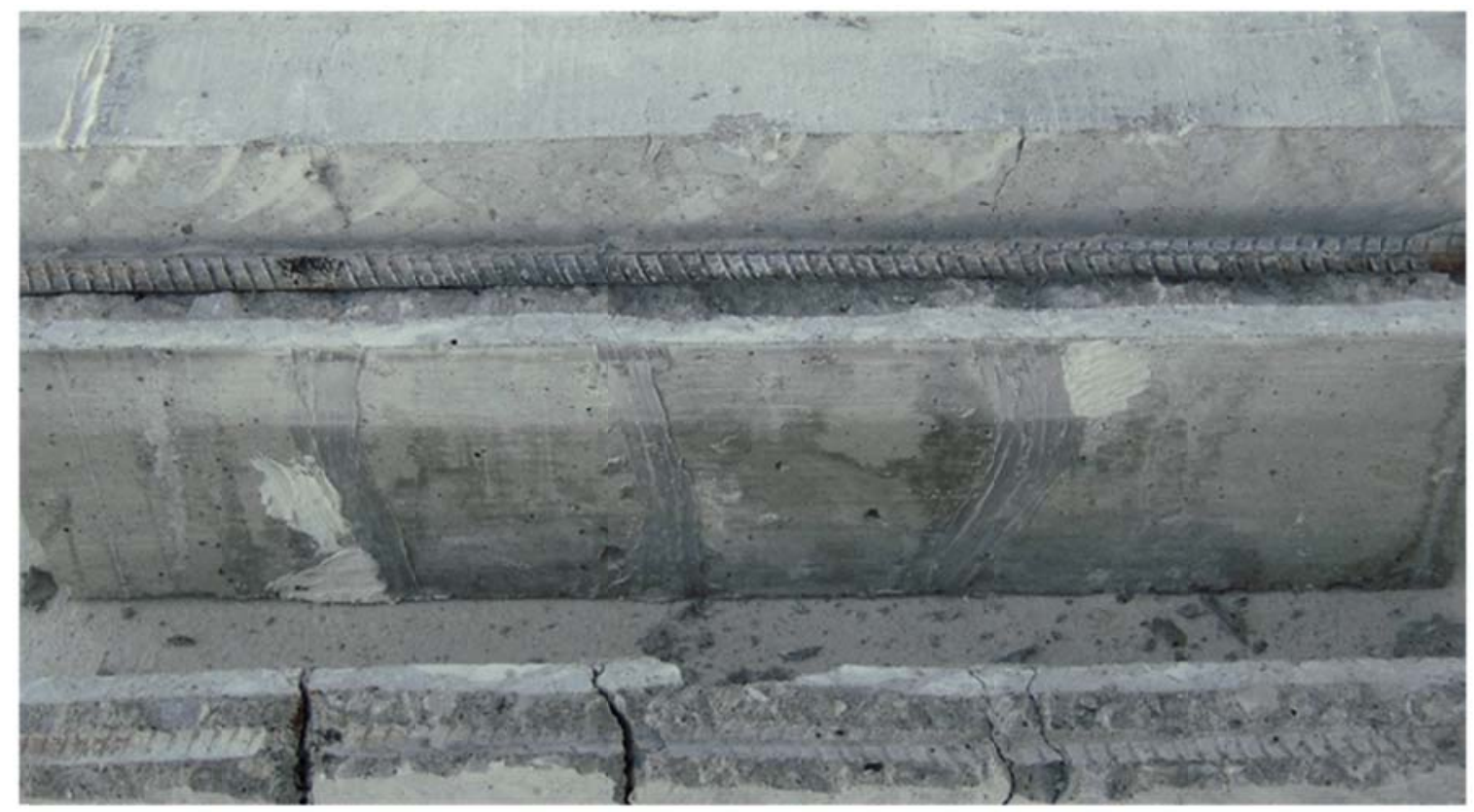

b) Corrosion on top bars

Figure 4.26: Fox Industries - FX 821 MMA (Methacrylate) 


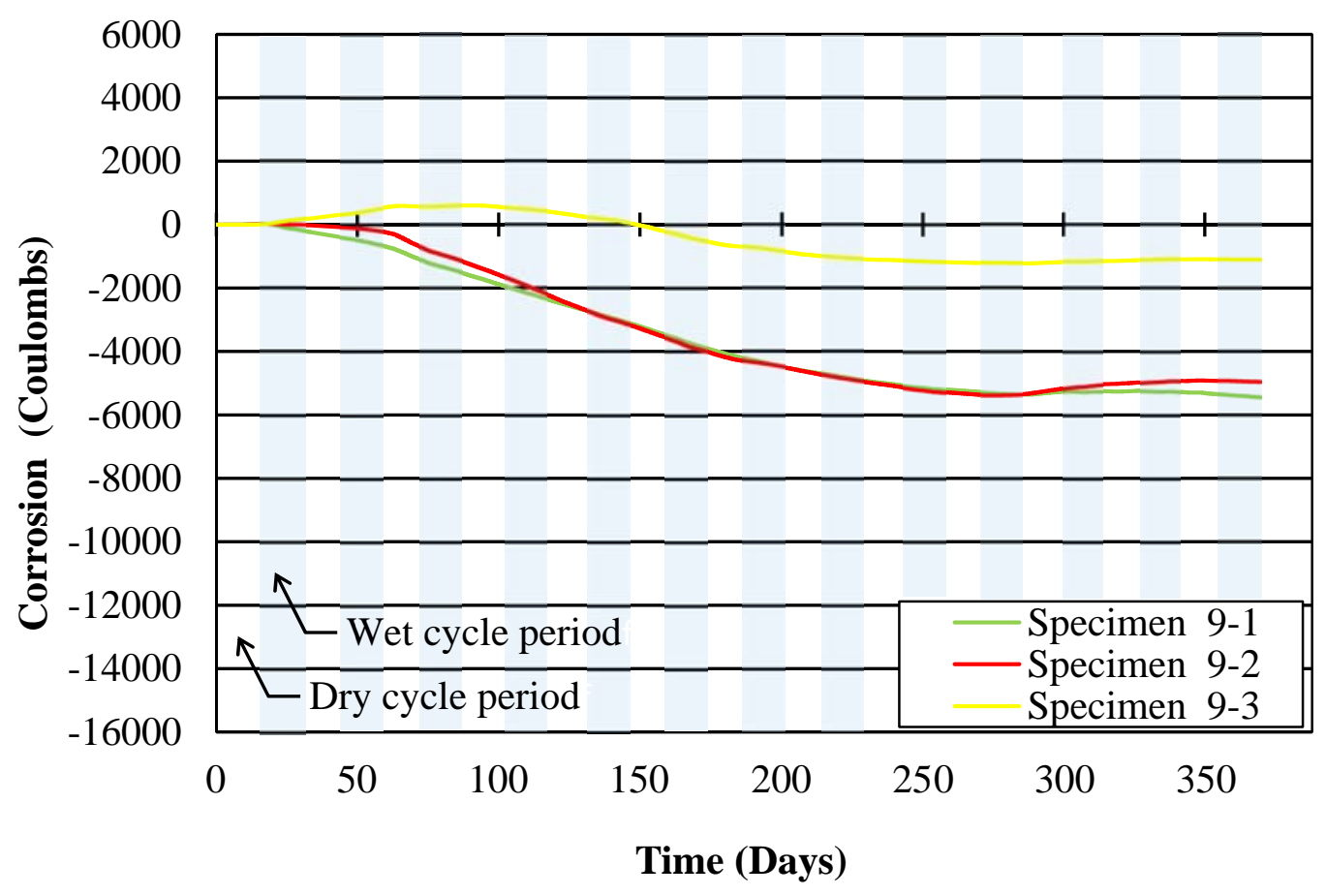

a) Corrosion through 360 days

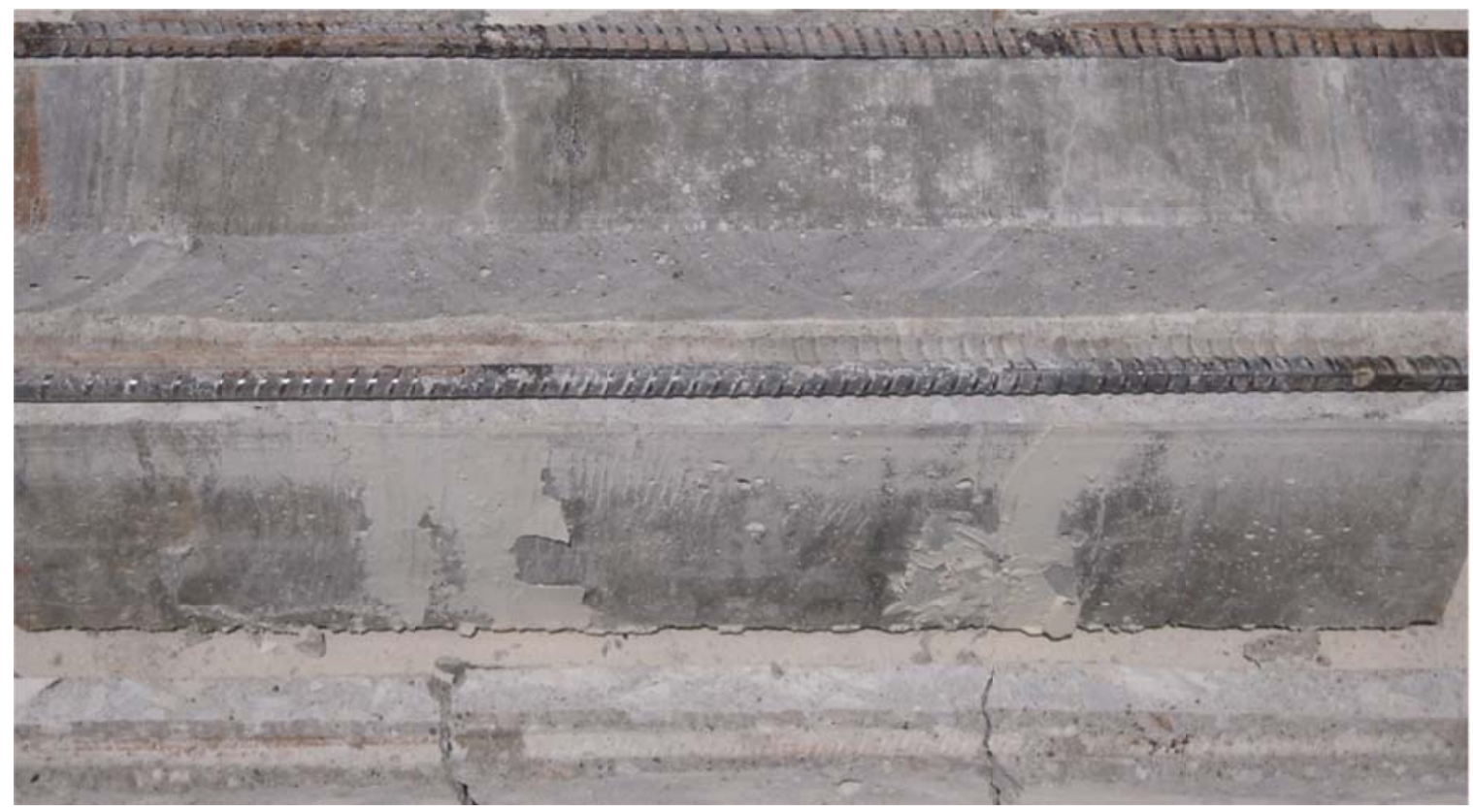

b) Corrosion on top bars

Figure 4.27: Kaufman Products - SurePoxy HMSLV (Epoxy) 


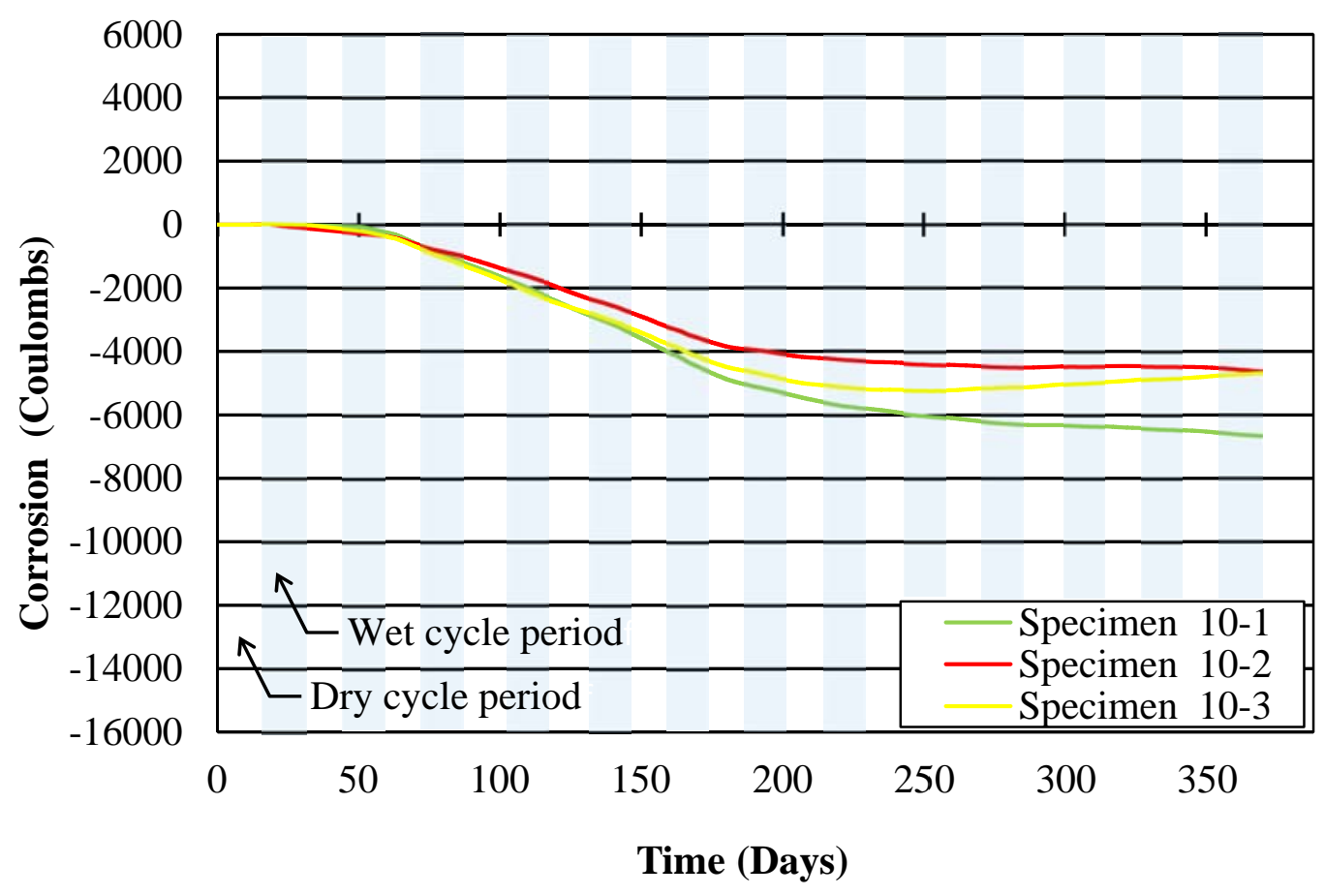

a) Corrosion through 360 days

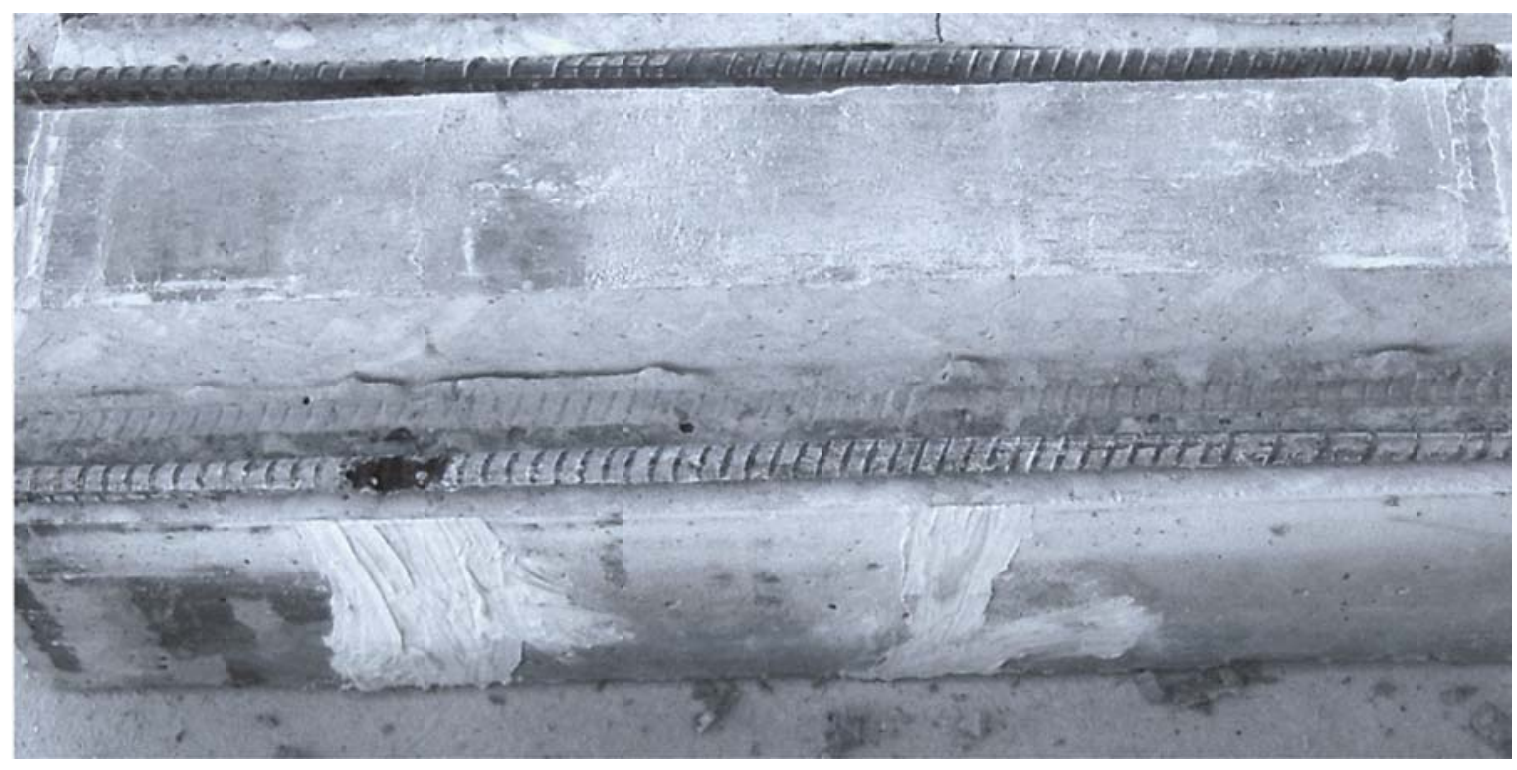

b) Corrosion on top bars

Figure 4.28: PolyCarb - MARK 127 (Epoxy) 


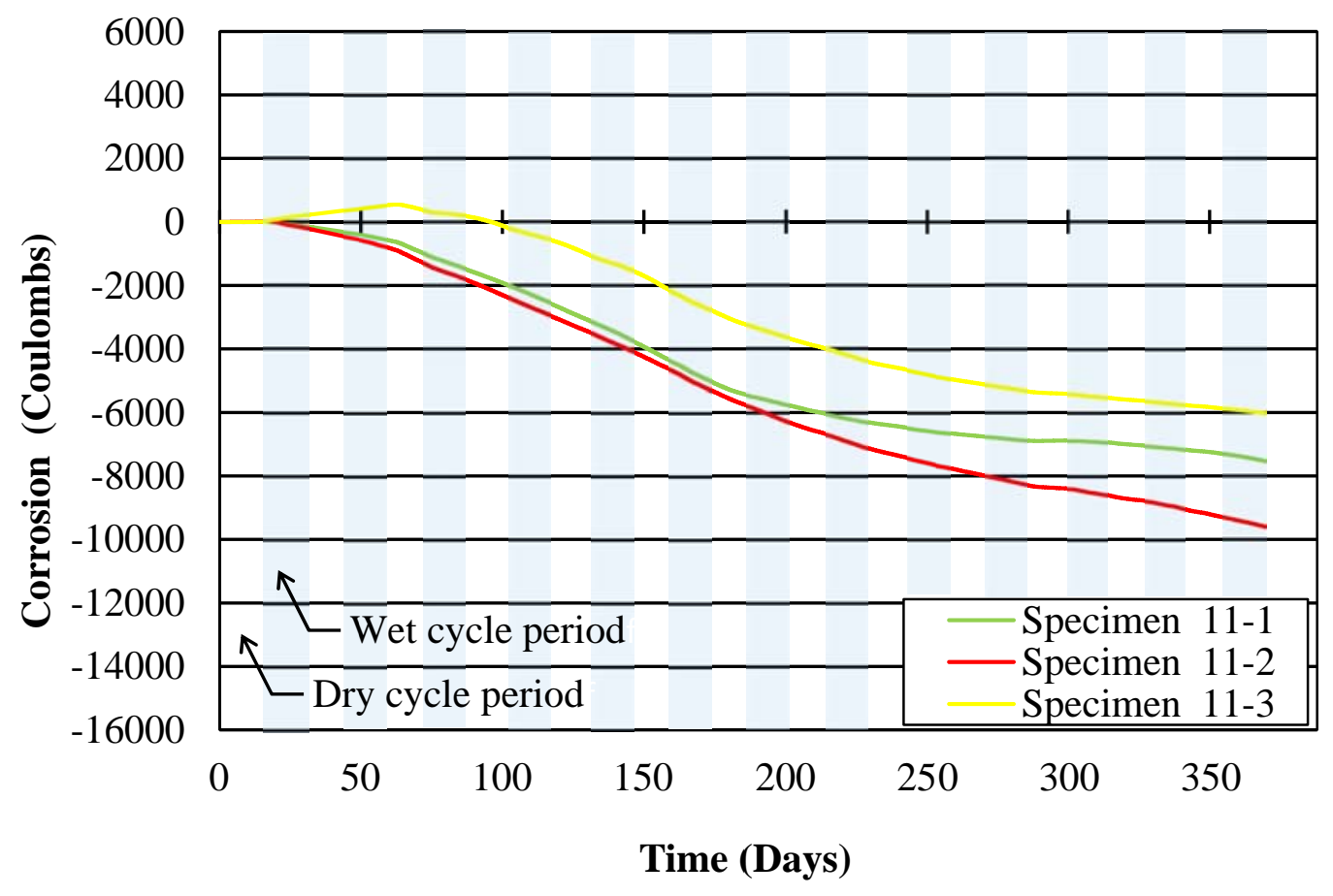

a) Corrosion through 360 days

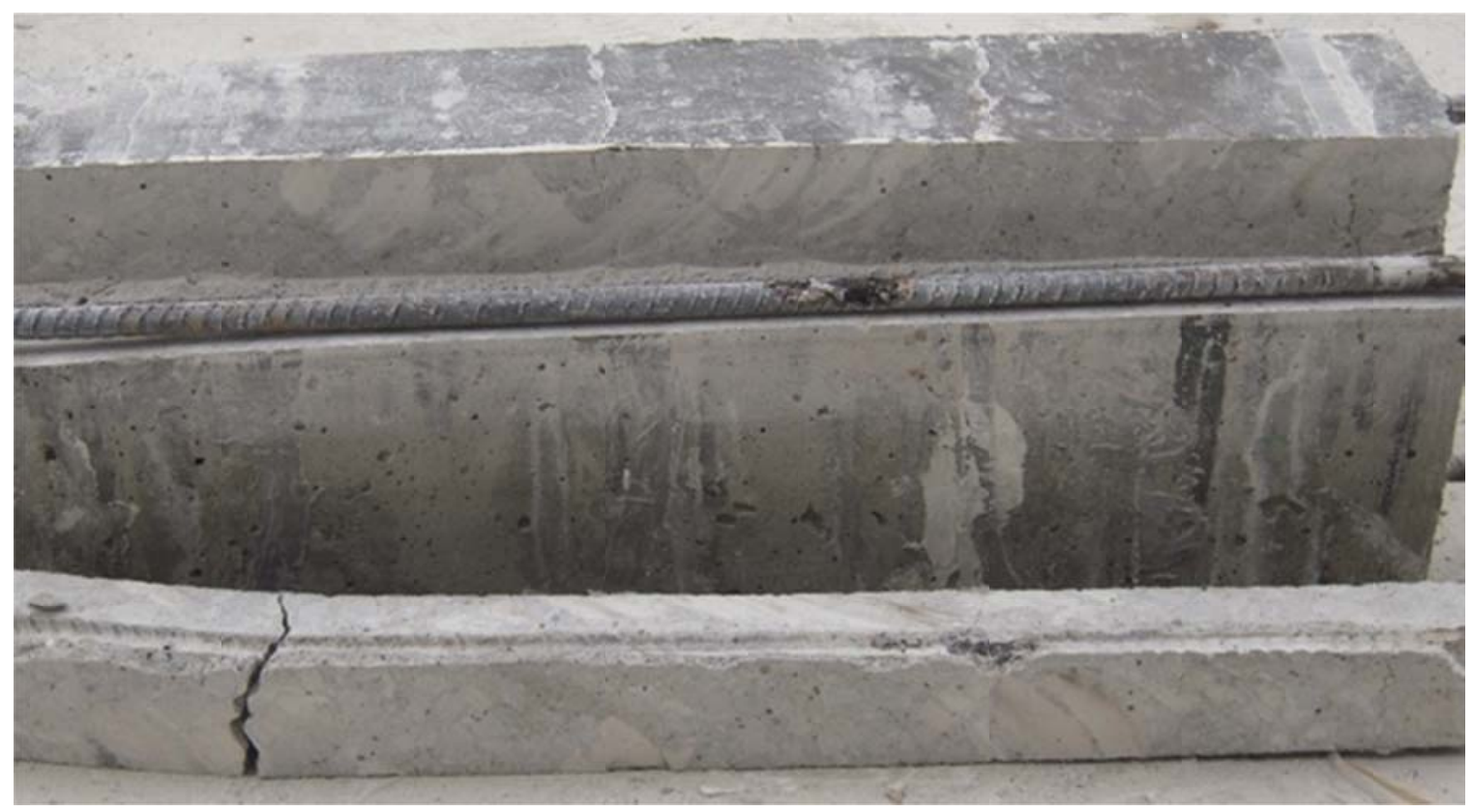

b) Corrosion on top bars

Figure 4.29: PolyCarb - MARK 135 Safe-T-Seal (Epoxy) 


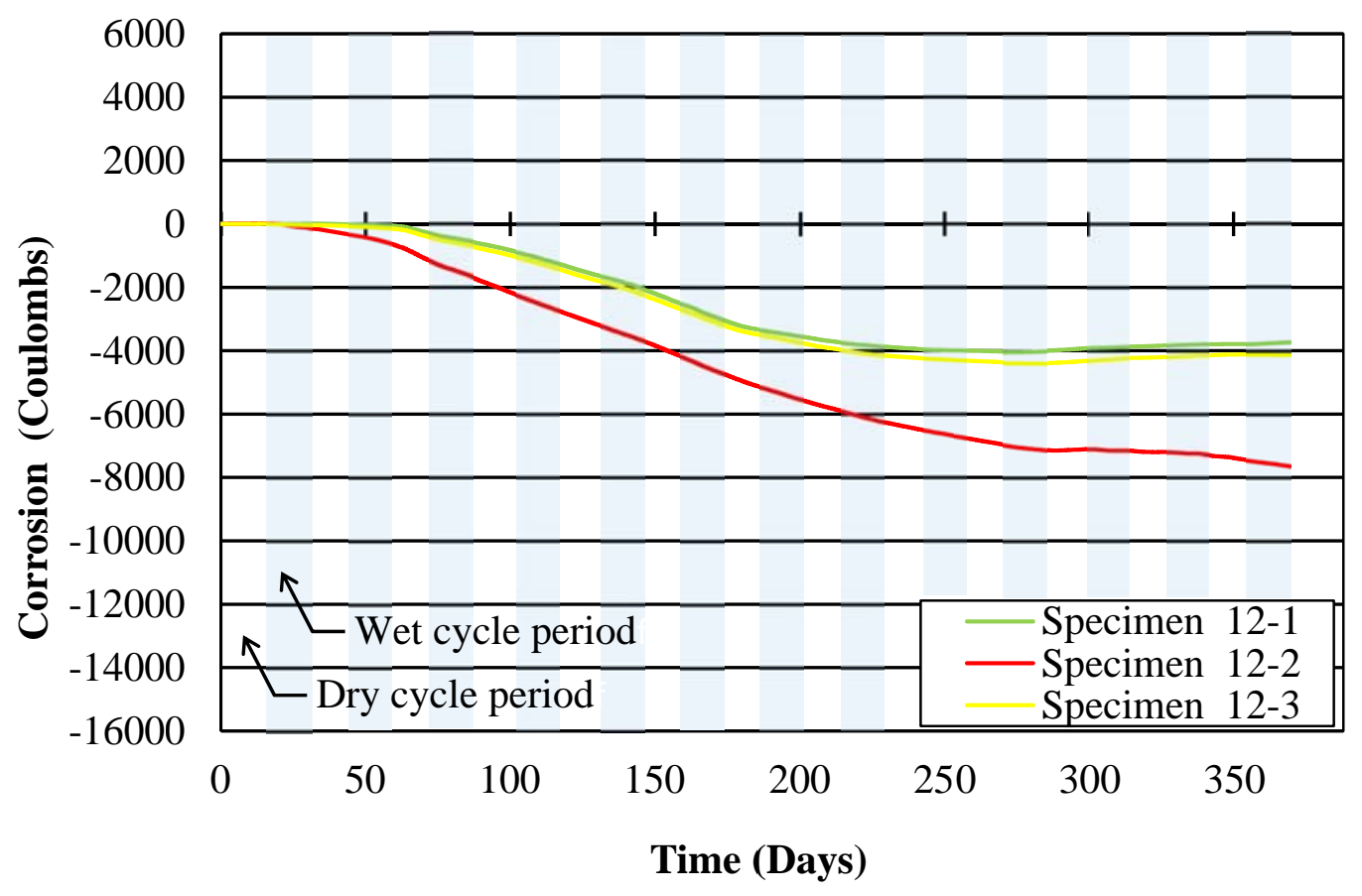

a) Corrosion through 360 days

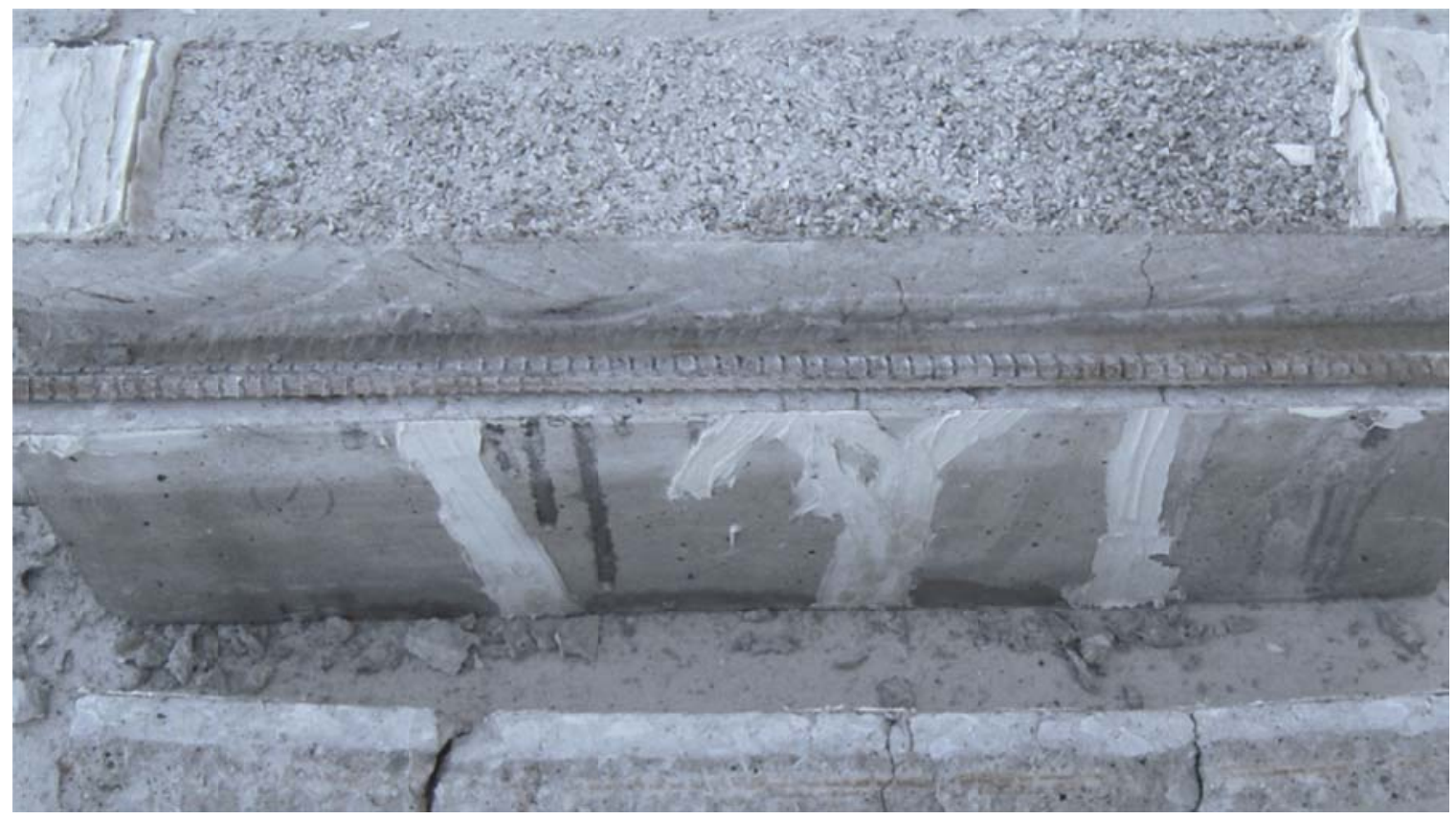

b) Corrosion on top bars

Figure 4.30: PolyCarb - MARK 163 FlexoGrid (Epoxy Overlay) 


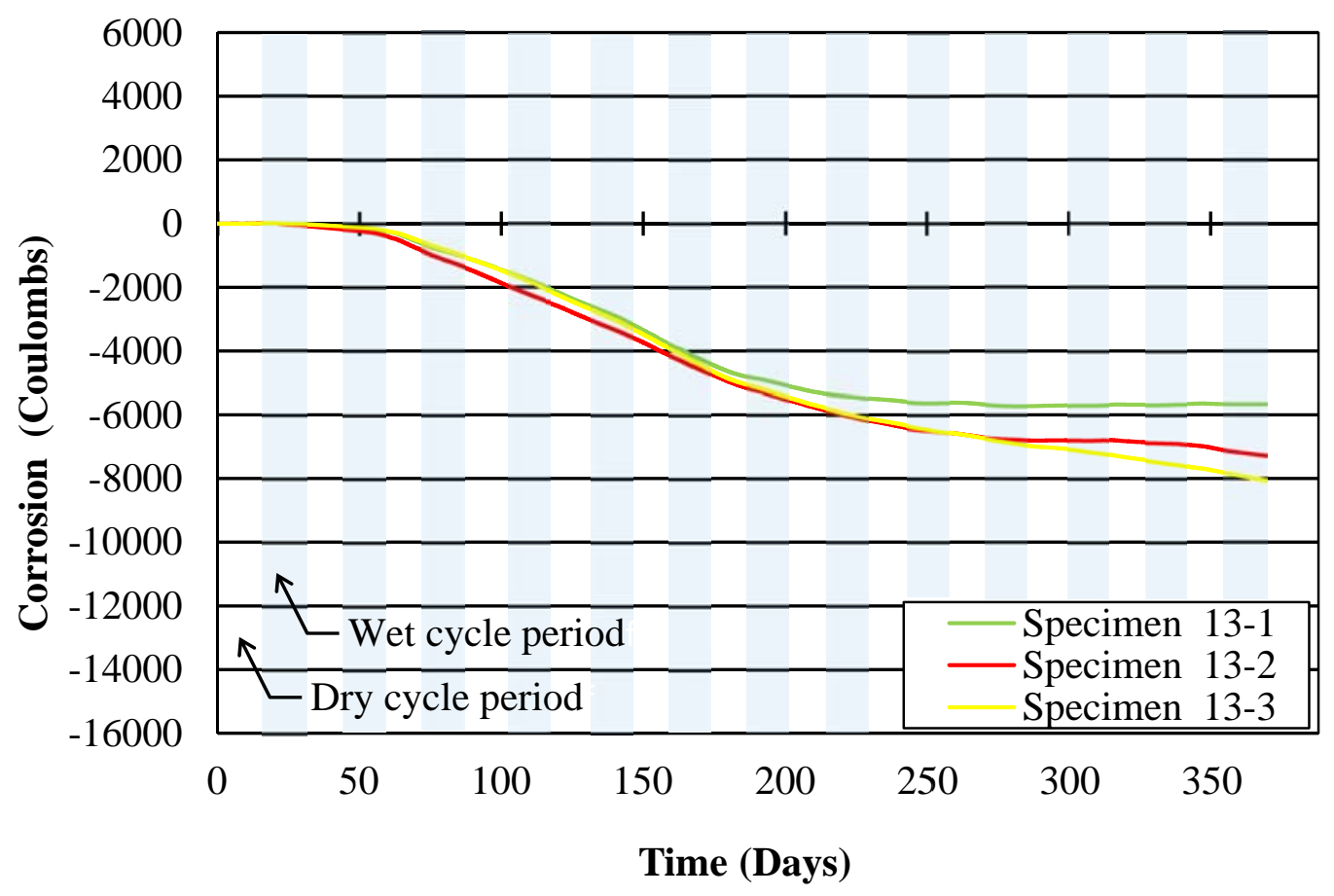

a) Corrosion through 360 days

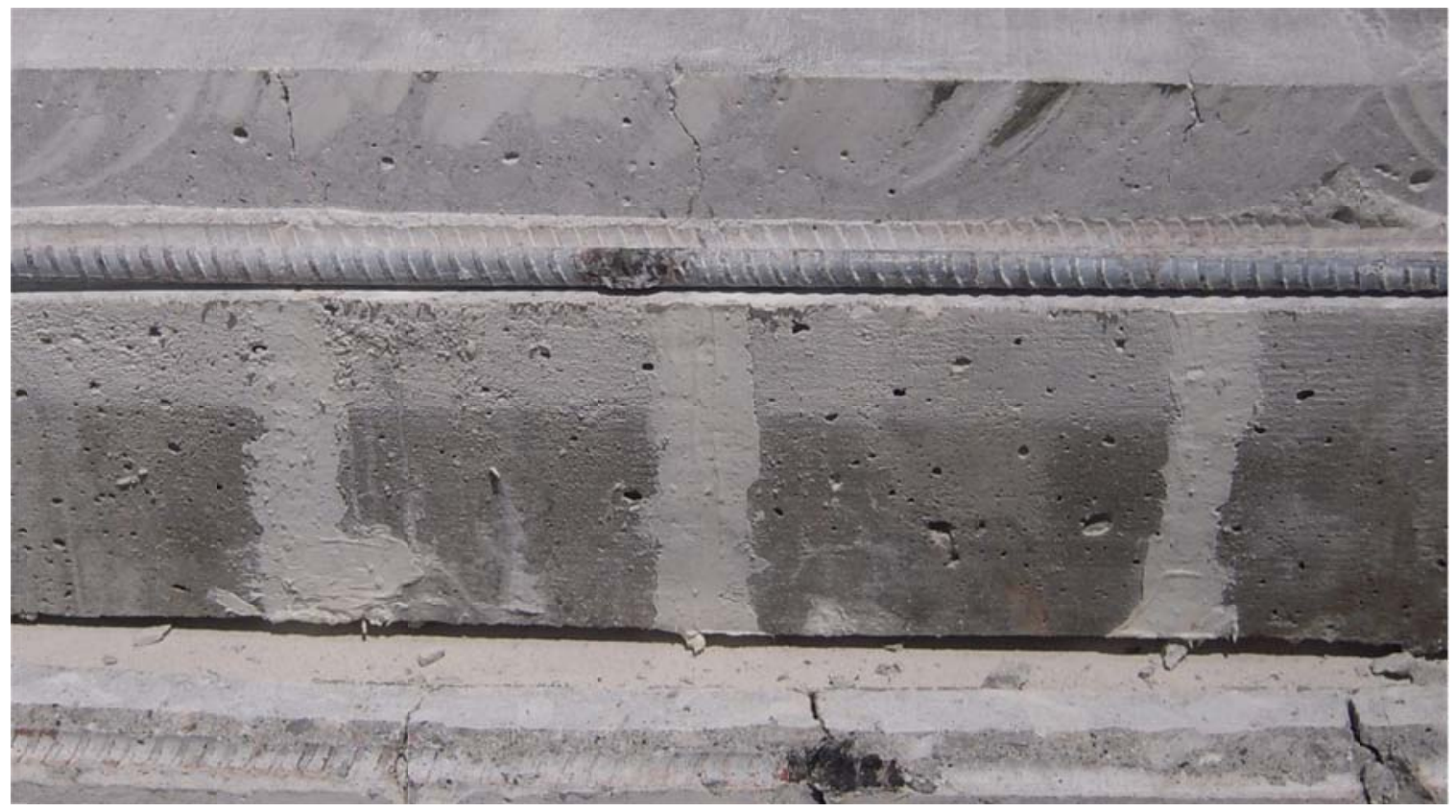

b) Corrosion on top bars

Figure 4.31: SikaCorp. - SikaPronto 19 (Methacrylate) 


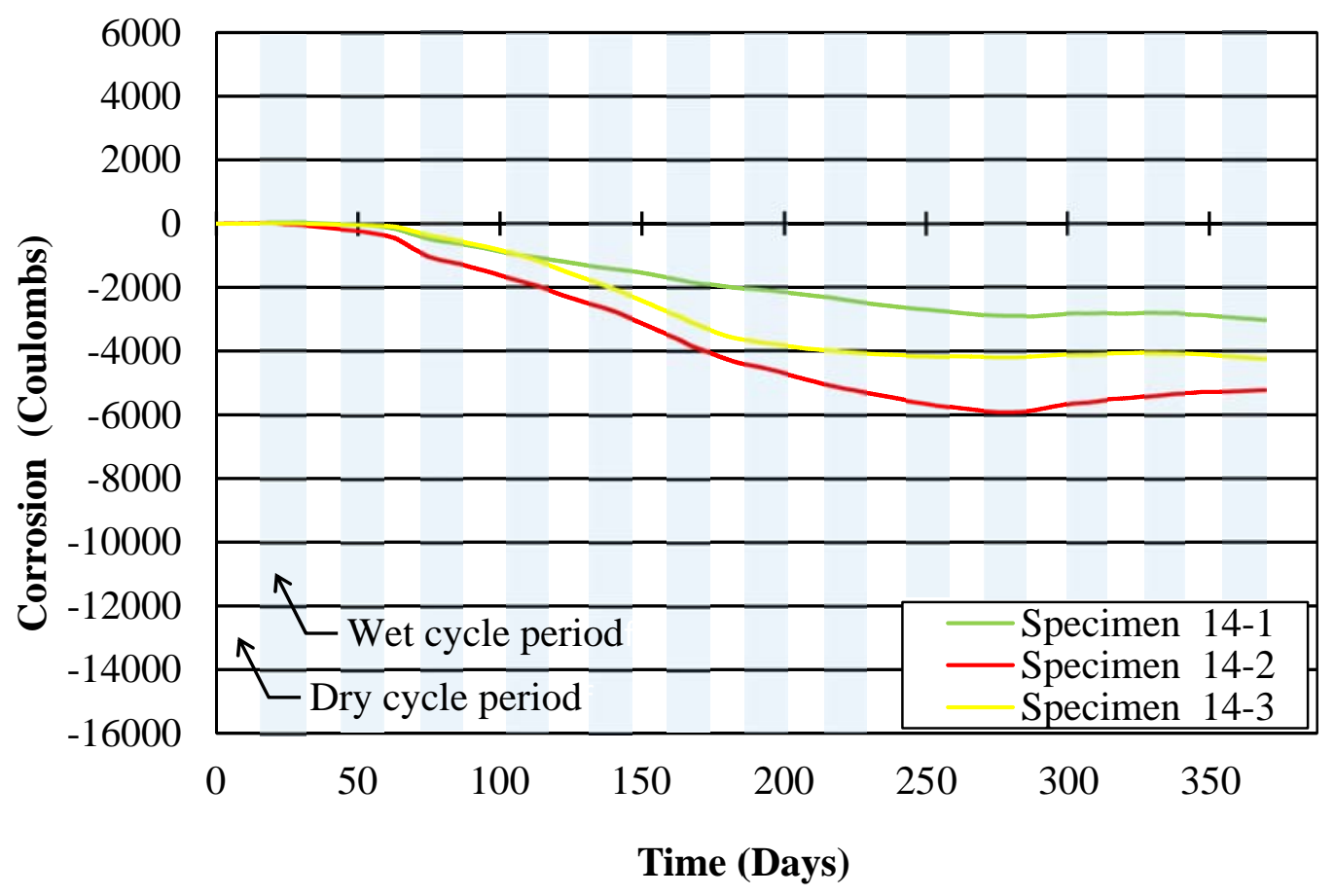

a) Corrosion through 360 days

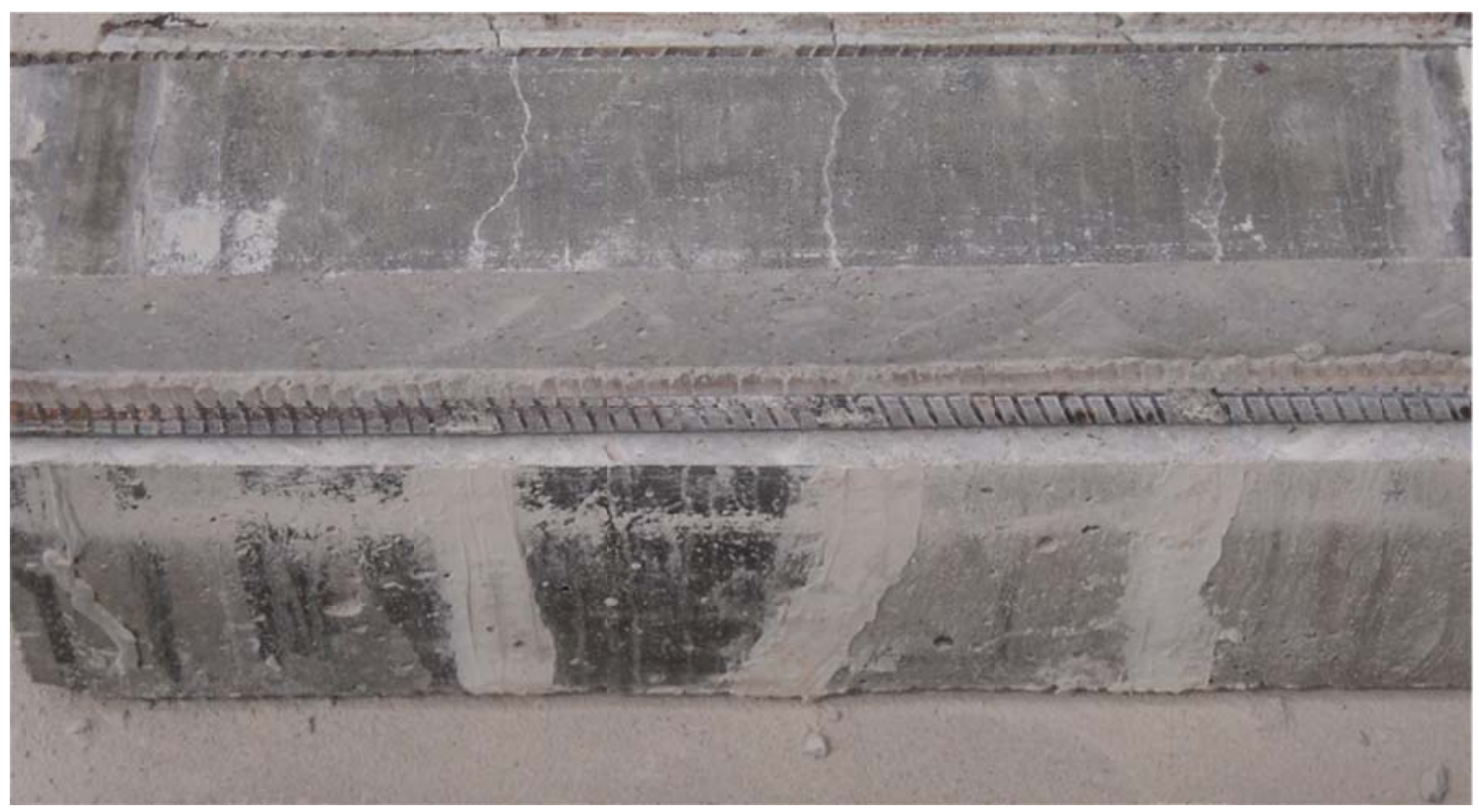

b) Corrosion on top bars

Figure 4.32: SikaCorp. - Sikadur 55 SLV (Epoxy) 


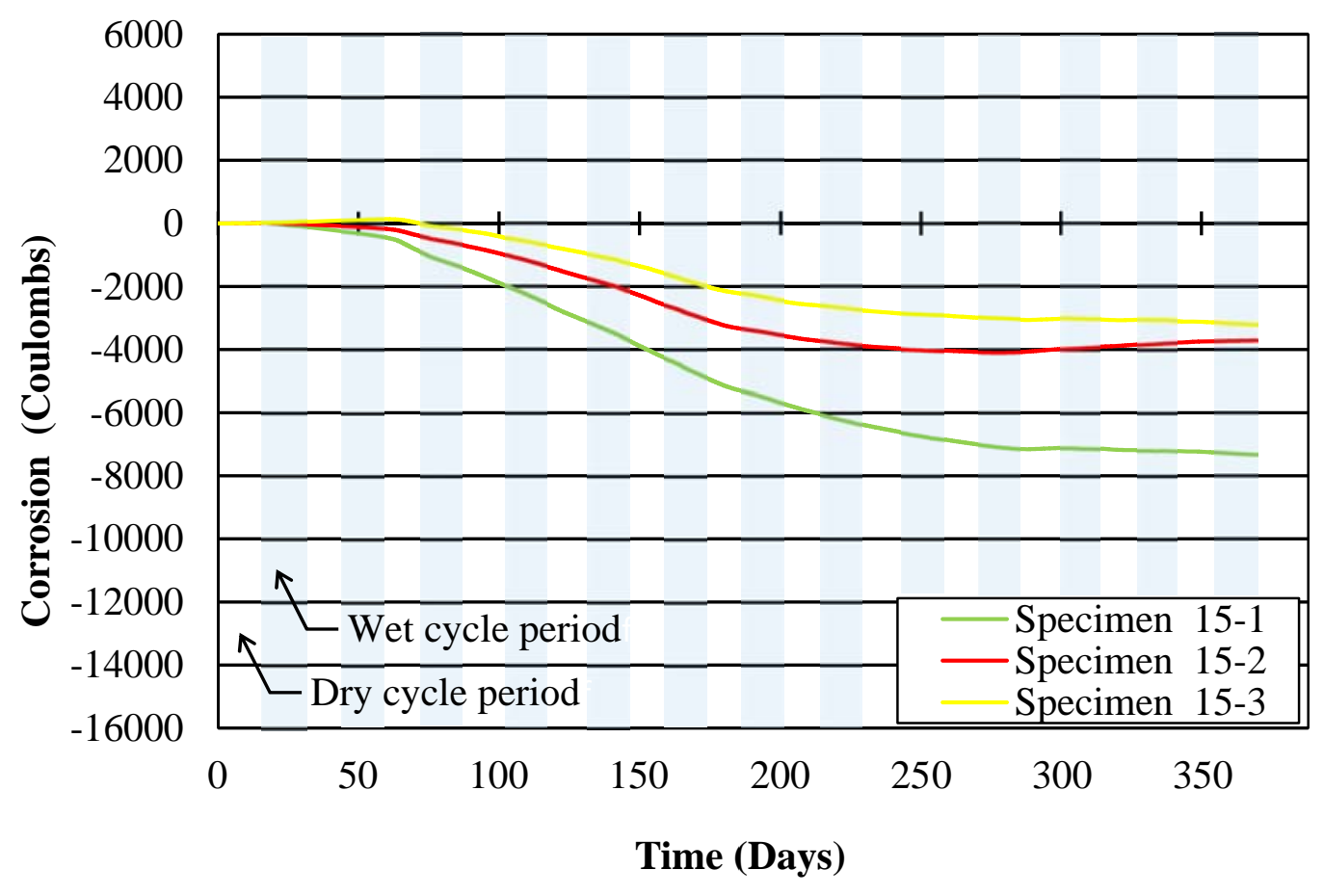

a) Corrosion through 360 days

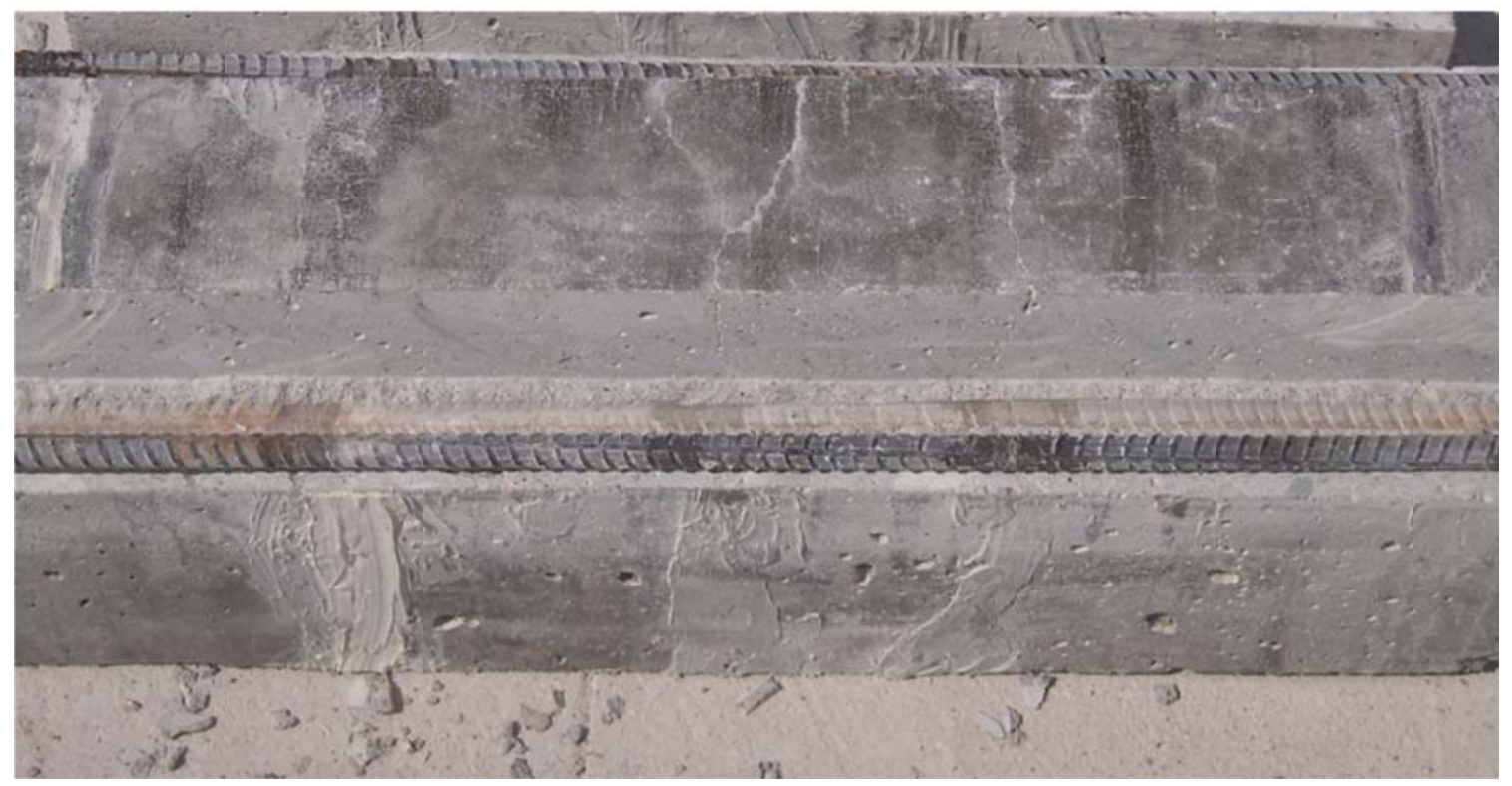

b) Corrosion on top bars

Figure 4.33: Unitex Chemicals - Bridge Seal (Epoxy) 


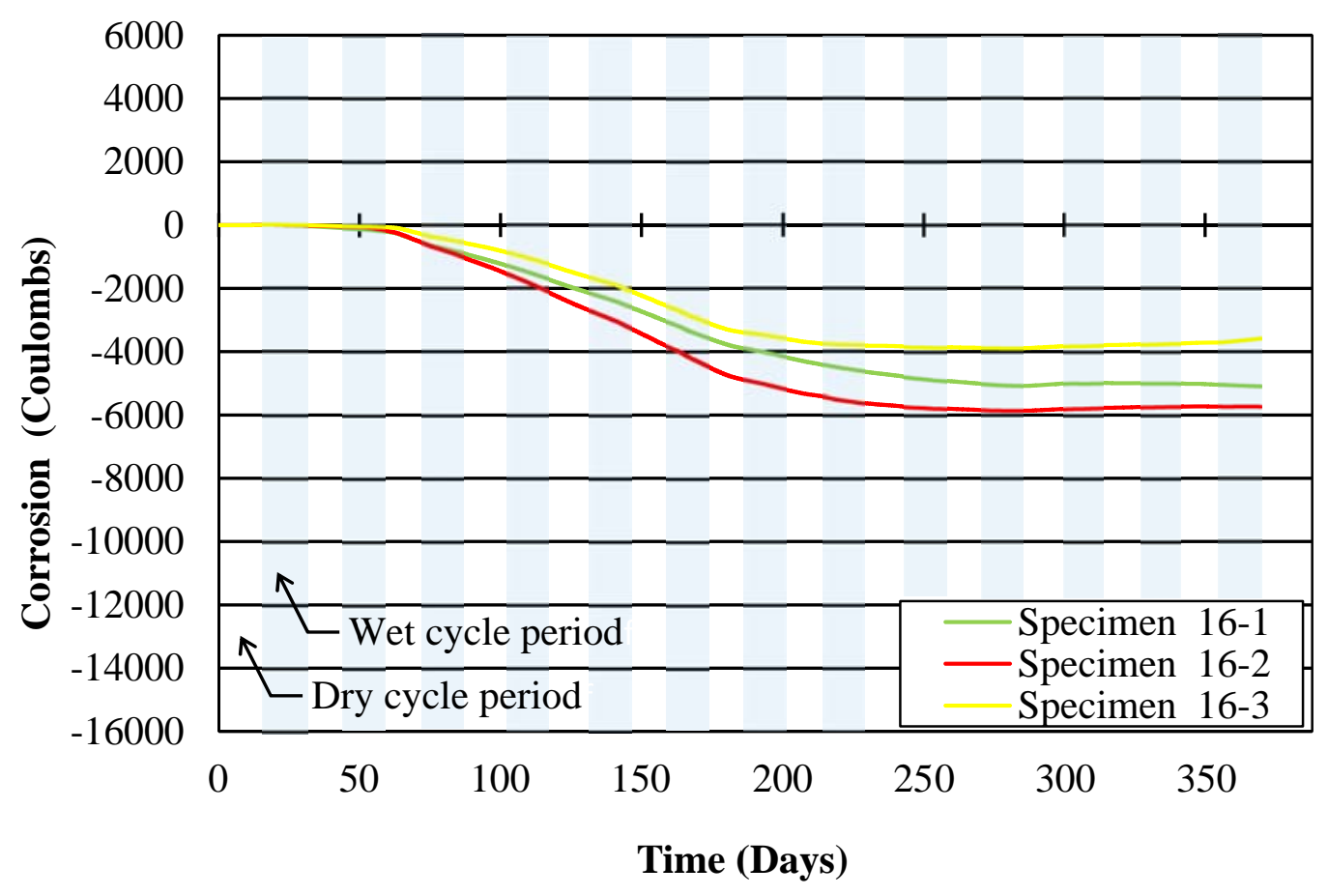

a) Corrosion through 360 days

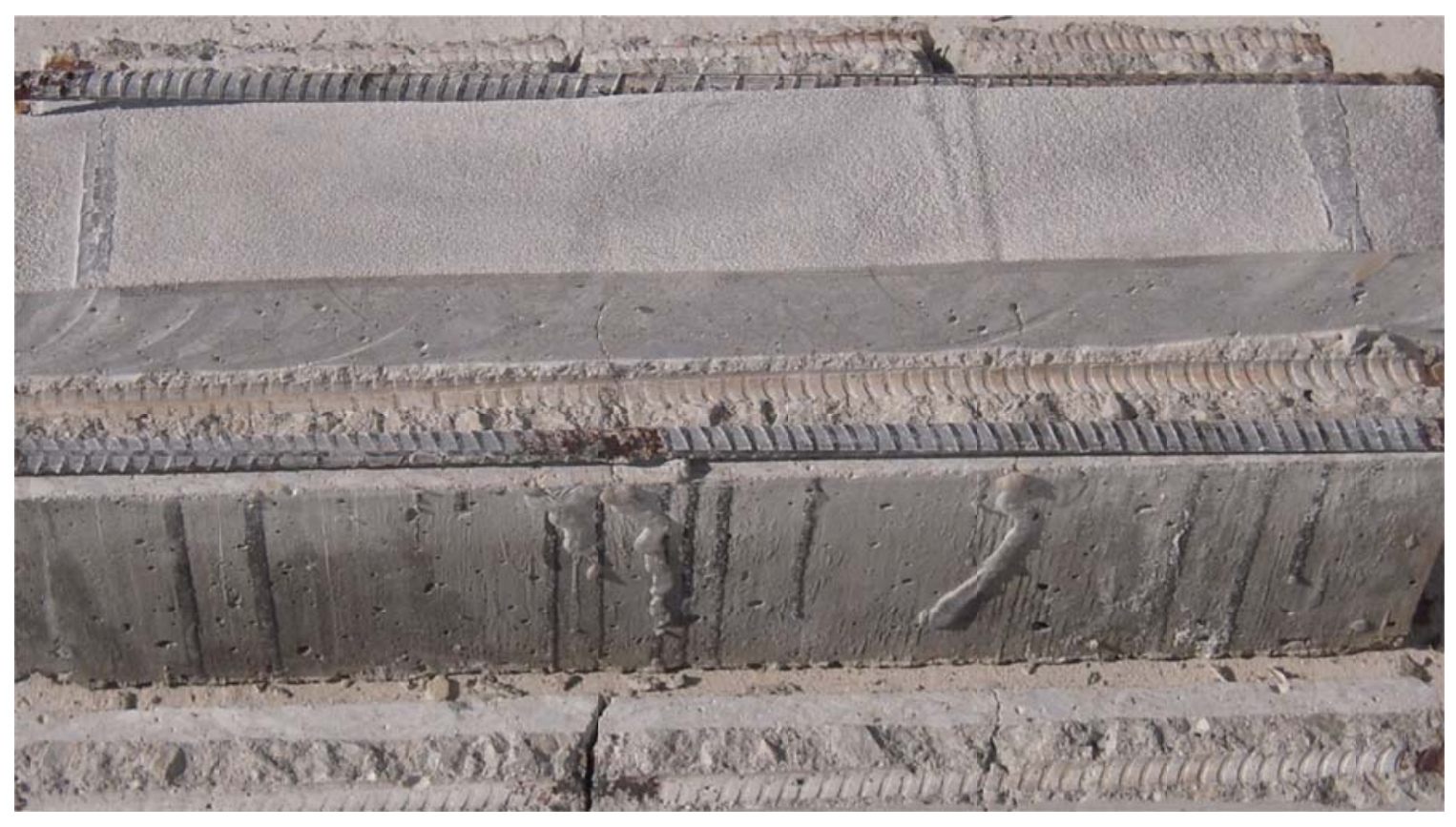

b) Corrosion on top bars

Figure 4.34: Unitex Chemicals - ProPoxy Type III D.O.T. (Epoxy Overlay) 


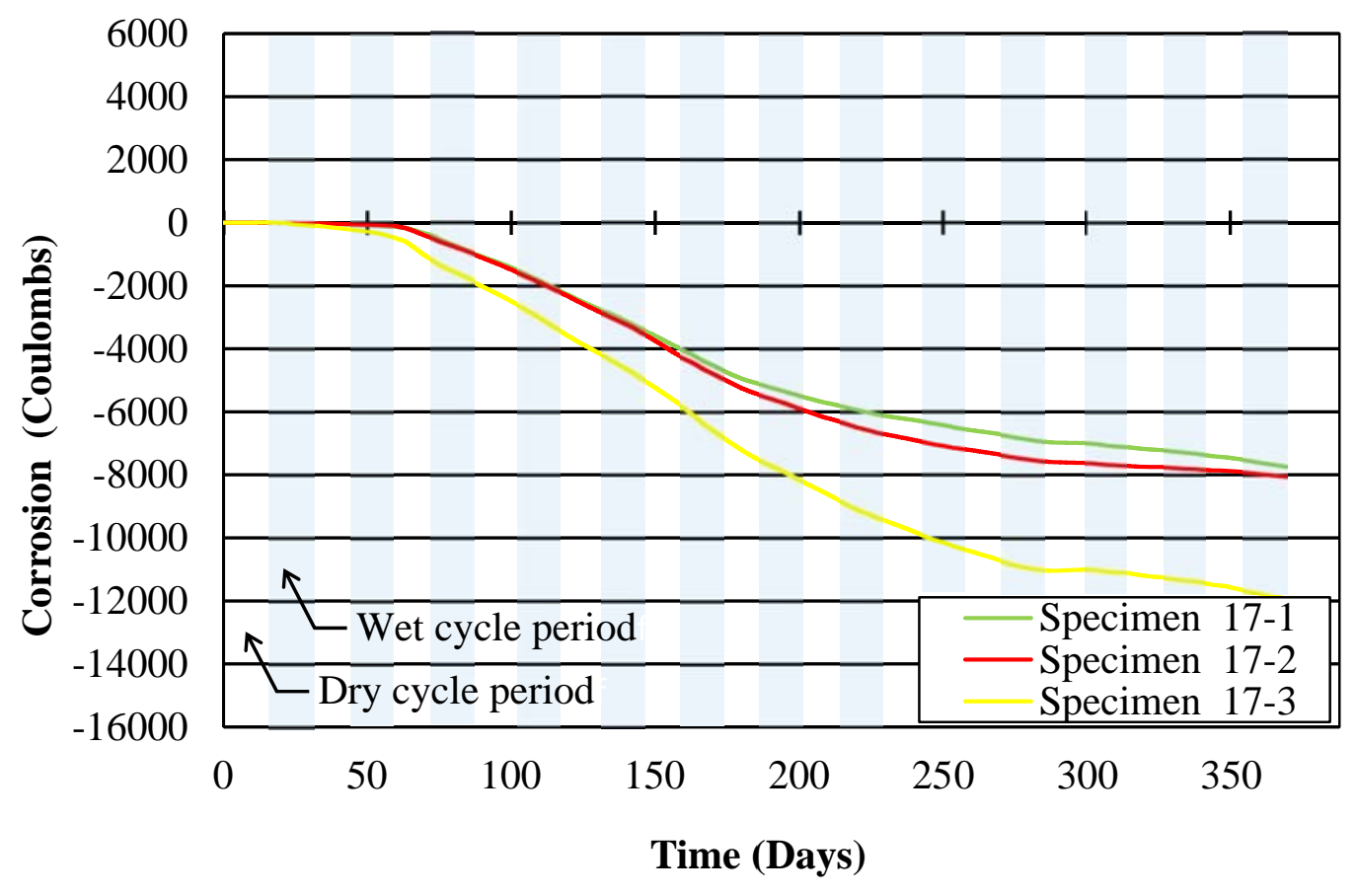

a) Corrosion through 360 days

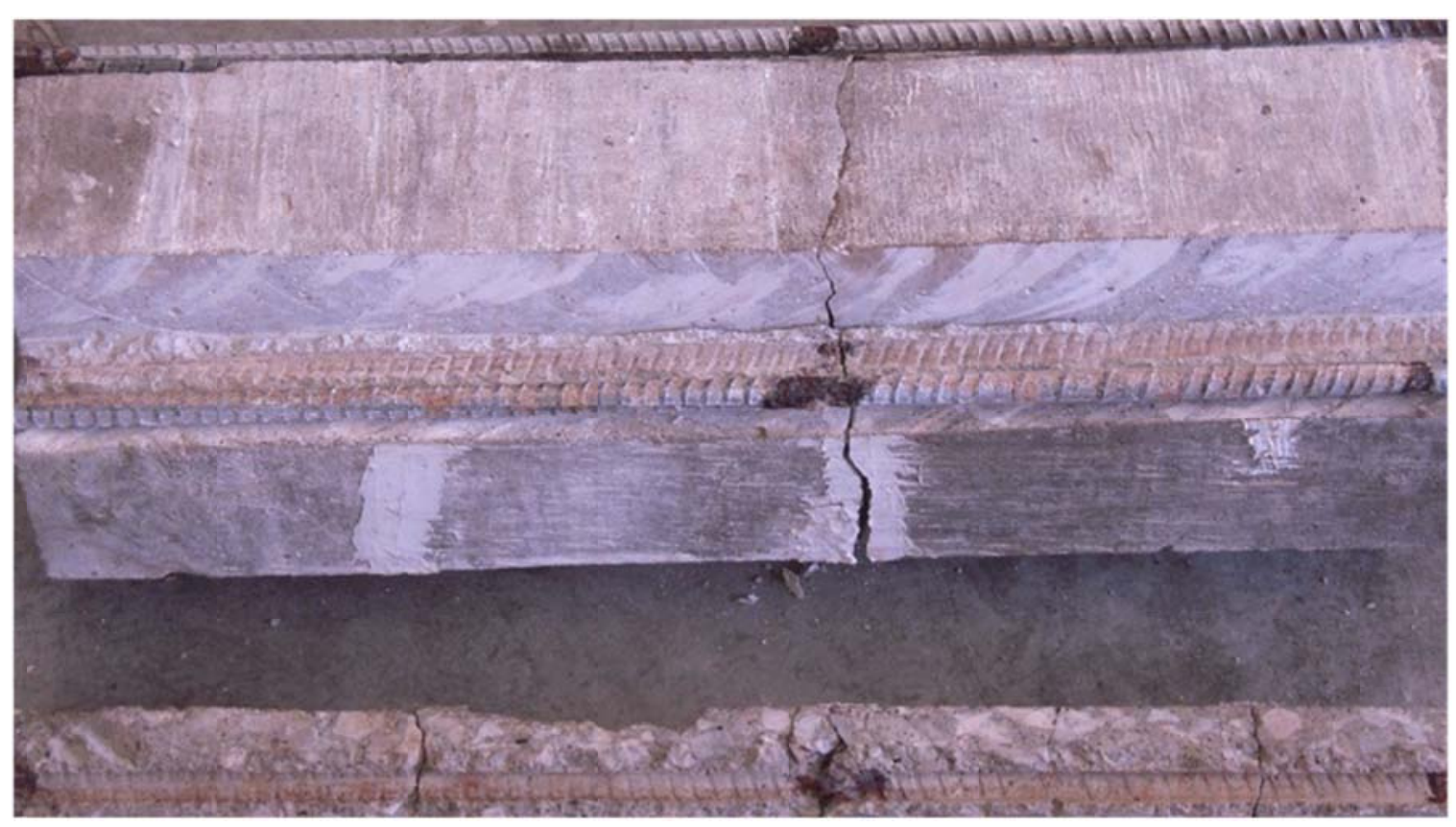

b) Corrosion on top bars

Figure 4.35: No Repair 1 - Small Cracks 


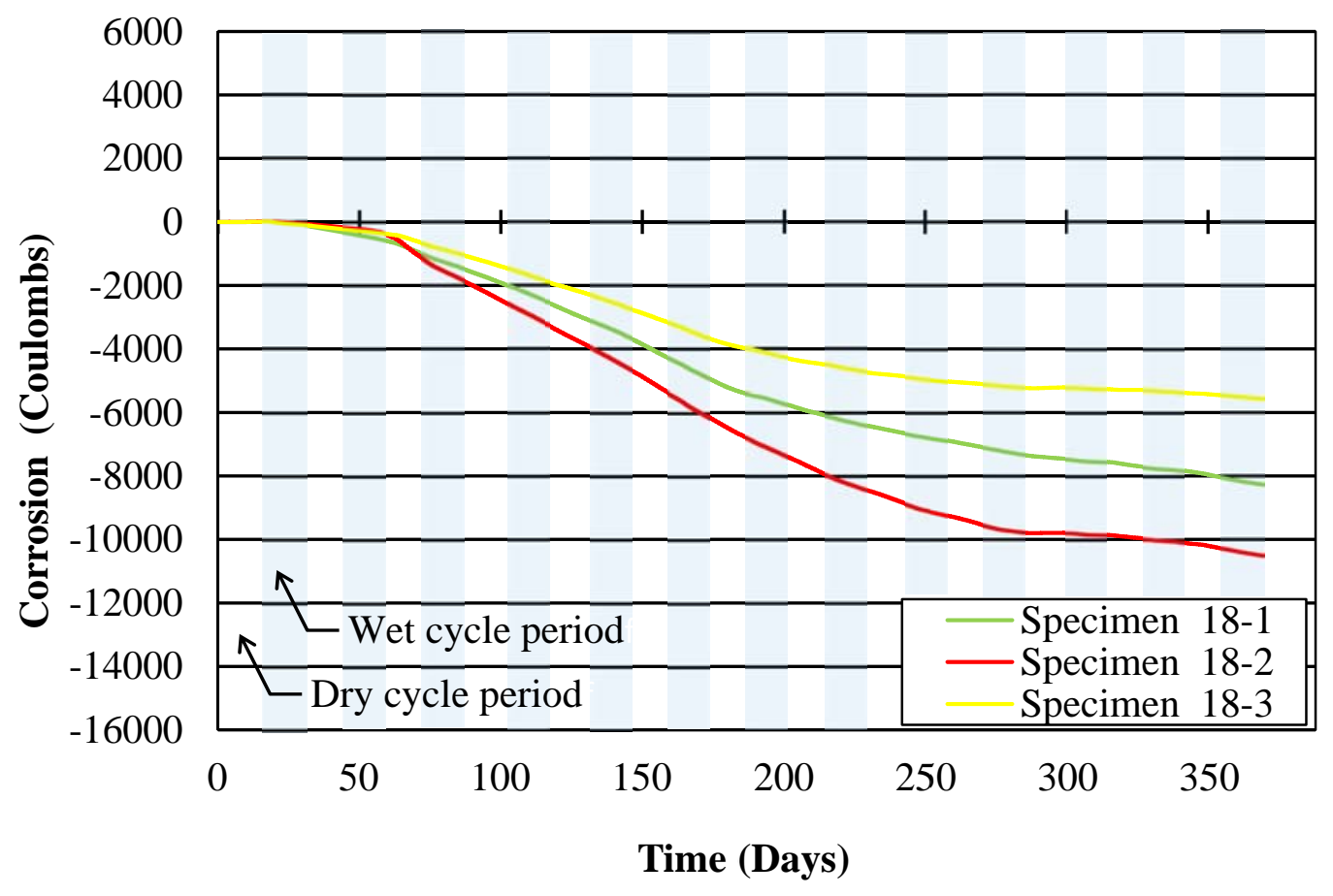

a) Corrosion through 360 days

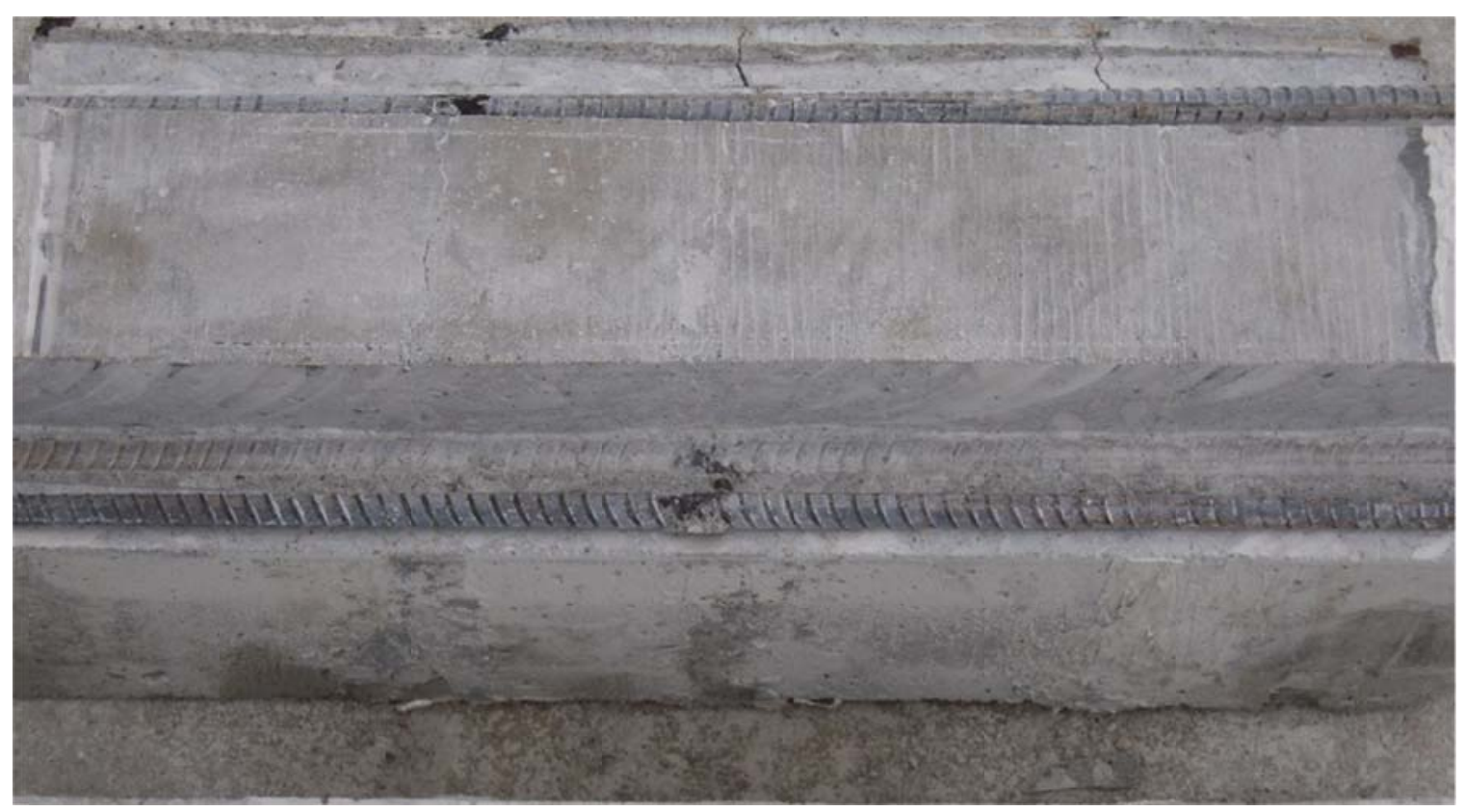

b) Corrosion on top bars

Figure 4.36: No Repair 2 - Medium Cracks 


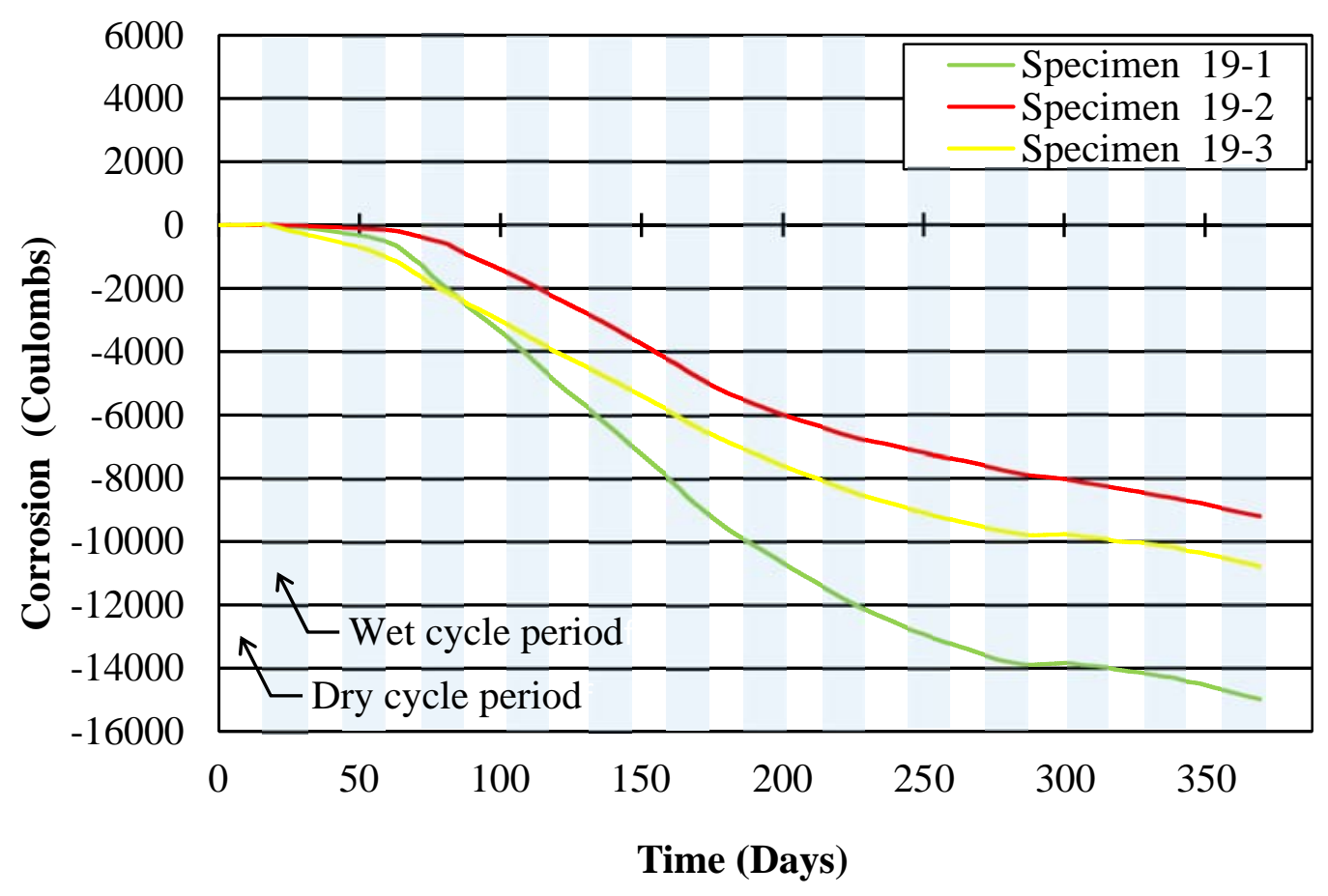

a) Corrosion through 360 days

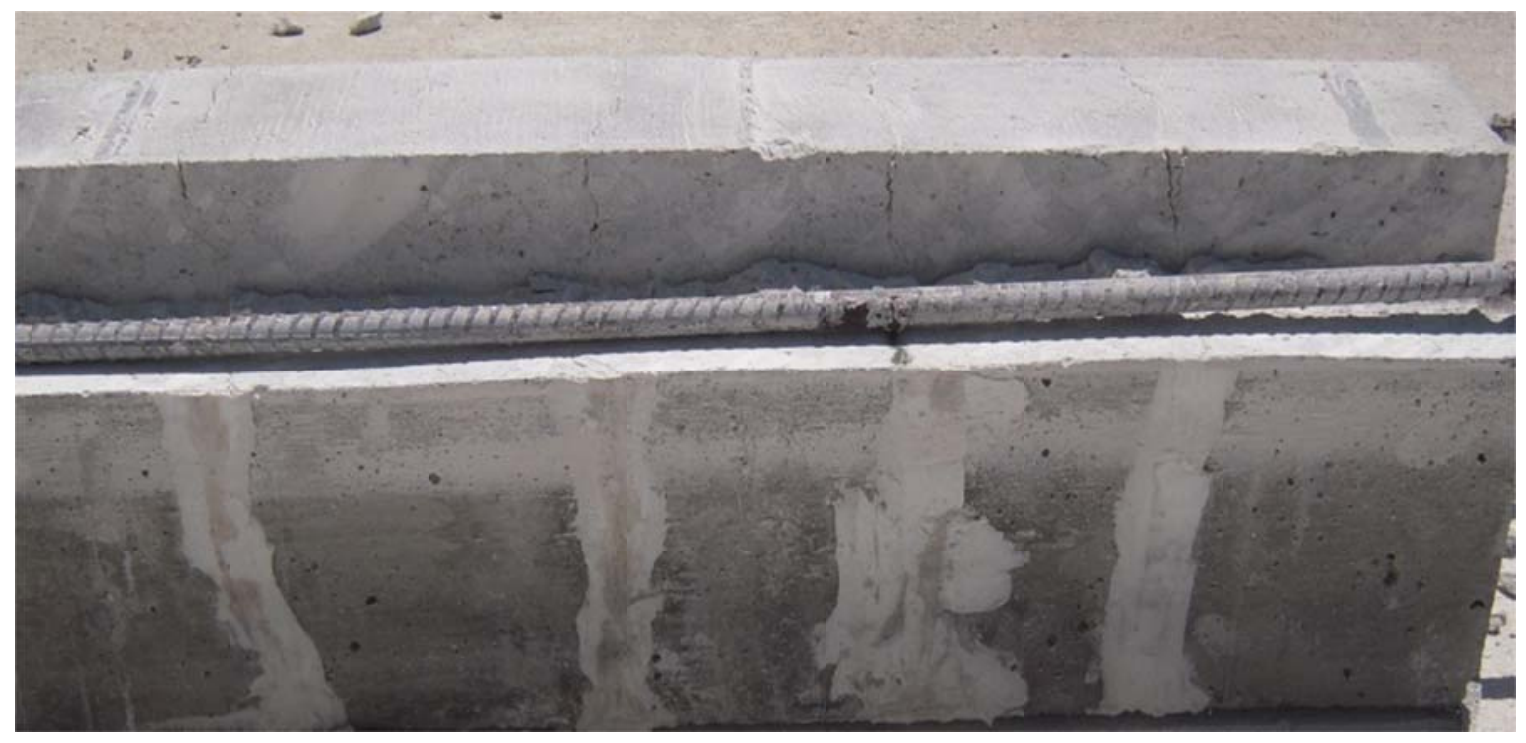

b) Corrosion on top bars

Figure 4.37: No Repair 3 - Large Cracks 


\subsection{Analysis of Results}

\subsubsection{Corrosion Measurement}

The total corrosion calculated for each repair product was plotted in order from best to worst to identify any relative differences as shown in Figure 4.38. This value was computed by averaging the total corrosion of the three specimens of each repair product. The specimens with abnormal corrosion measurements were not considered in the average (Specimen 3-1, 3-2, 9-3 and 12-2). It can be observed that the total corrosion measured was similar for the first 11 products, with the exception of the first product (Enviroseal). In considering the next products (12-16), a jump is noted which seems to indicate significantly less performance. Overall, this data can be interpreted as producing two main groups with total corrosion values around -4500 (Group 1) and -7500 (Group 2) coulombs. It is important to consider this trend because a small amount of corrosion such as that observed on the exposed bars can cause major variations in the ranking within these groups.

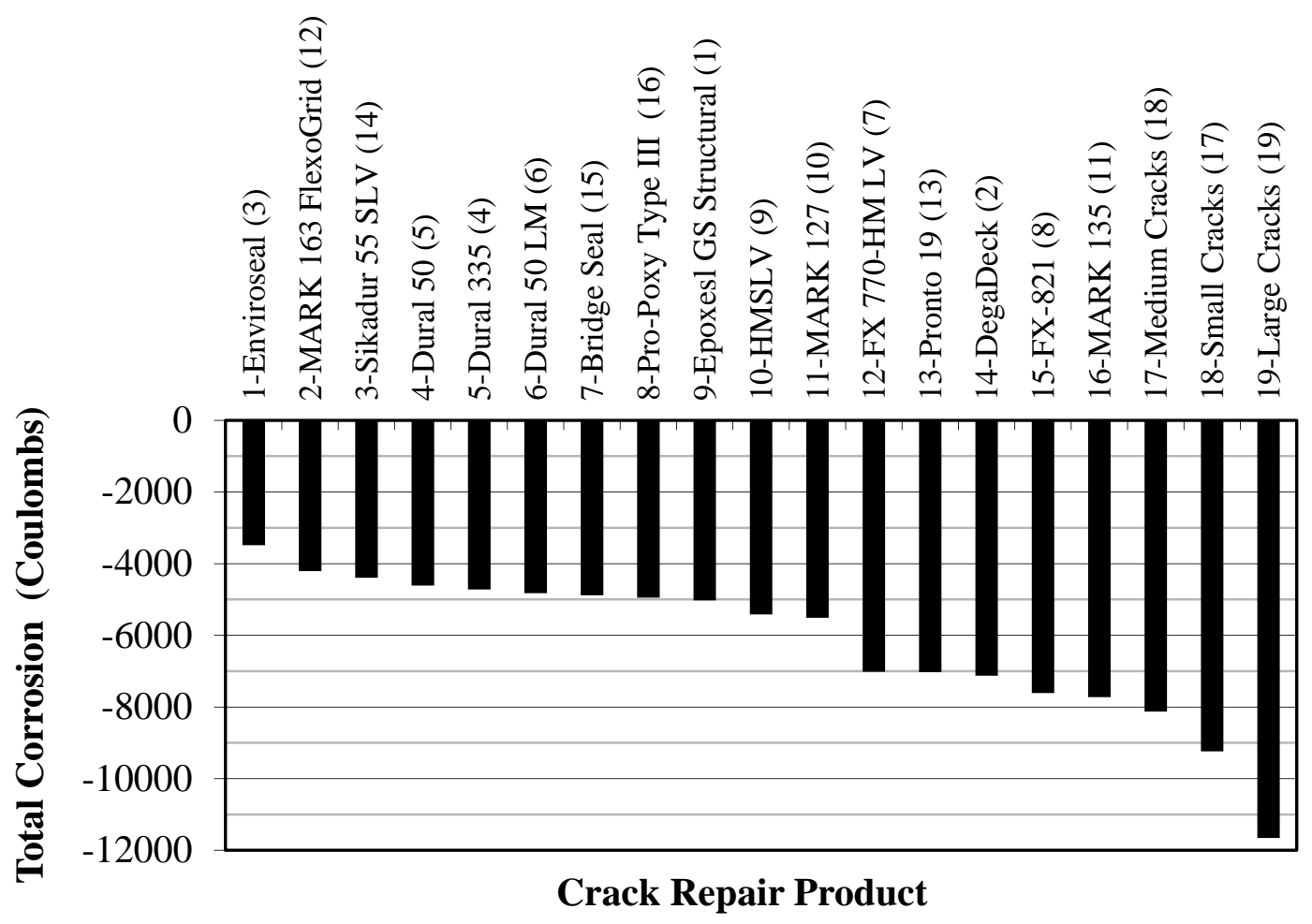

Figure 4.38: Total corrosion of repair products 
The first product (Enviroseal), which is a waterproofer, was the only repair type that displayed abnormal behavior as shown in Figure 4.21a. As shown, after approximately 200 days, the corrosion began reducing and in fact went positive. This unusual performance was explained after examining the bars embedded at the bottom of the specimens. Figure 4.39 provides evidence of the severe degree of corrosion on the bottom bars. These bars were far more corroded than the top bars. The corrosion on the bottom mat is likely due to leaks in the specimen's dam. It appears that the salt solution penetrated and reached the bottom steel layer of the specimen from the sides or bottom surface where the waterproofer was not applied. The electrochemical process was then reversed since the bottom mat was corroding faster than the top mat supporting that the measured corrosion was of a positive sign.

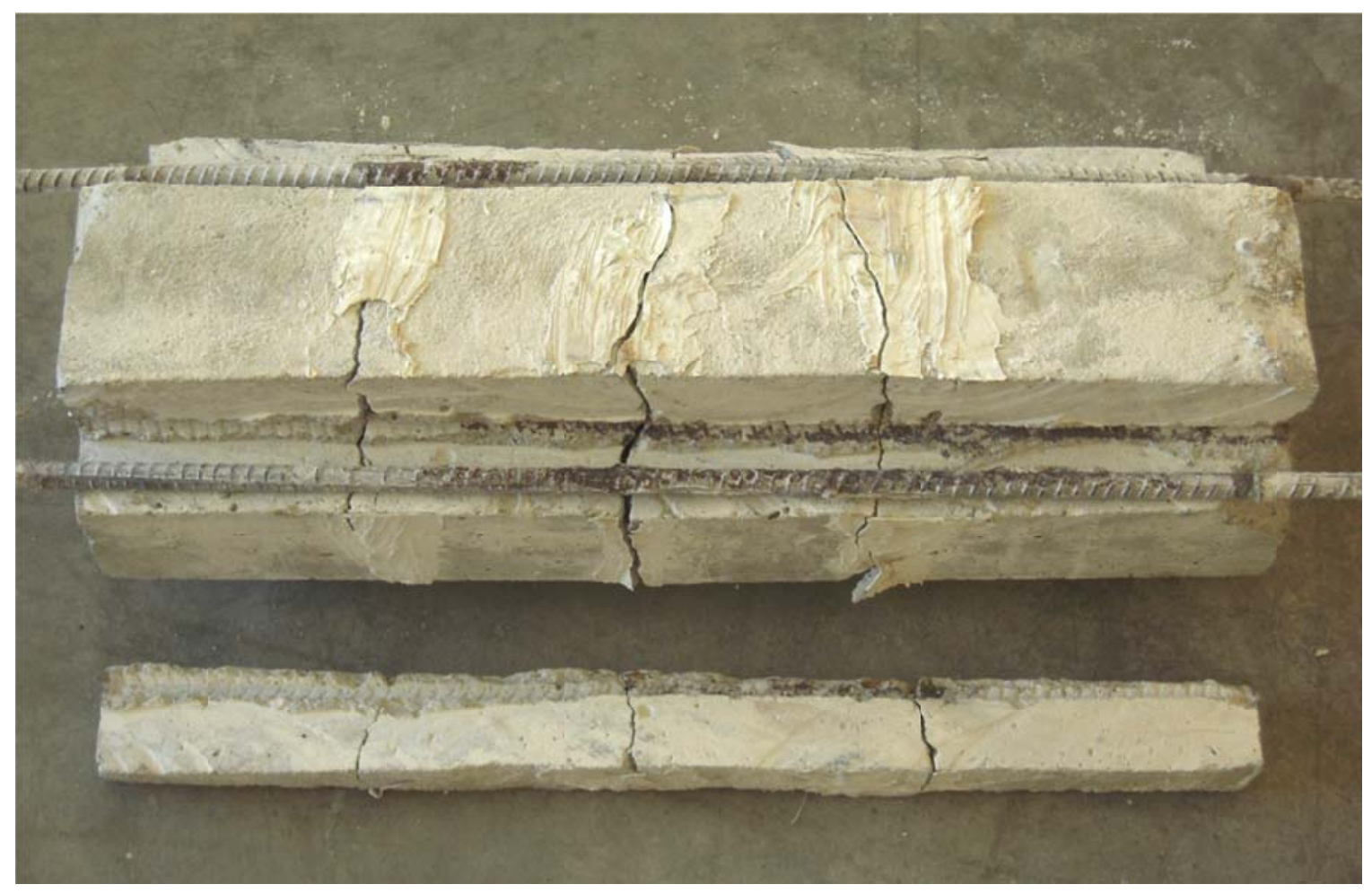

Figure 4.39: Corrosion on bottom bars, Enviroseal (Waterproofer) 
The repair products were ranked in accordance to the total corrosion measured at the end of the test as previously illustrated in Figure 4.38 and as indicated in Table 4.6, where 1 indicates best performance. As noted, while Enviroseal ranks 1 as shown in Figure 4.38, it should be excluded as the total corrosion measured is not respective of its actual behavior since the values provided were influenced by corrosion of the bottom bars. While there appears to be benefits of this product, the results cannot be properly assessed due to the different corrosion mechanism that occurred. Therefore, the results of Enviroseal are provided at the bottom of the table. 
Table 4.6: Corrosion measurement ranking

\begin{tabular}{|c|c|c|c|c|c|}
\hline & $\begin{array}{c}\text { Corrosion } \\
\text { Measurement } \\
\text { Ranking }\end{array}$ & Product & Manufacturer & Repair Type & $\begin{array}{c}\text { Total } \\
\text { Corrosion } \\
\text { (Coulombs) }\end{array}$ \\
\hline \multirow{9}{*}{ 官 } & 1 & $\begin{array}{l}\text { MARK } 163 \\
\text { FlexoGrid }\end{array}$ & Poly-Carb & $\begin{array}{l}\text { Epoxy } \\
\text { Overlay }\end{array}$ & -4209 \\
\hline & 2 & Sikadur 55 SLV & SikaCorp & Epoxy & -4396 \\
\hline & 3 & Dural 50 & Euclid / Tamms & Eроху & -4614 \\
\hline & 4 & Dural 335 & Euclid / Tamms & Ероху & -4722 \\
\hline & 5 & Dural 50 LM & Euclid / Tamms & Ероху & -4826 \\
\hline & 6 & Bridge Seal & Unitex & Epoxy & -4883 \\
\hline & 7 & $\begin{array}{l}\text { Pro-Poxy Type } \\
\text { III D.O.T }\end{array}$ & Unitex & $\begin{array}{l}\text { Epoxy } \\
\text { Overlay }\end{array}$ & -4949 \\
\hline & 8 & $\begin{array}{c}\text { Epoxesl GS } \\
\text { Structural }\end{array}$ & BASF & Epoxy & -5024 \\
\hline & 9 & HMSLV & $\begin{array}{l}\text { Kaufman } \\
\text { Products }\end{array}$ & Epoxy & -5415 \\
\hline & 10 & MARK 127 & Poly-Carb & Ероху & -5510 \\
\hline \multirow{5}{*}{ 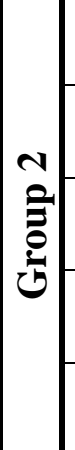 } & 11 & FX 770-HM LV & Fox Industries & Epoxy & -7015 \\
\hline & 12 & Pronto 19 & SikaCorp & Methacrylate & -7030 \\
\hline & 13 & DegaDeck & BASF & Methacrylate & -7128 \\
\hline & 14 & FX-821 & Fox Industries & Methacrylate & -7609 \\
\hline & 15 & MARK 135 & Poly-Carb & Ероху & -7725 \\
\hline & 16 & \multicolumn{2}{|c|}{ Medium Cracks (0.016 to 0.020 in.) } & None & -8126 \\
\hline & 17 & \multicolumn{2}{|c|}{ Small Cracks ( 0.010 to 0.013 in.) } & None & -9236 \\
\hline & 18 & \multicolumn{2}{|c|}{ Large Cracks ( 0.035 to 0.040 in.) } & None & -11657 \\
\hline & Not Ranked & Enviroseal & BASF & Waterproofer & $-3487 *$ \\
\hline
\end{tabular}

*Corrosion on bottom bars 


\subsubsection{Visual Examination}

The measured electric current cannot be entirely attributed to corrosion of the reinforcement inside the concrete. As previously discussed, a considerable amount of the recorded voltage difference was caused by corrosion of the exposed reinforcement. For this reason, it is important to correlate the results obtained from currents measured in the macrocell test with a visual assessment that was performed once the test concluded.

The top mat of the specimens was extracted to evaluate the extent of corrosion. Upon opening the specimens, it was found that corrosion was concentrated at the location of cracks as shown in Figure 4.40. Extensive pitting was evident in many specimens at these locations. In general, corrosion was not observed in regions of uncracked concrete. The degree of corrosion exhibited on the bars at crack locations was quantified in the range from 0 to 10, with 10 being noted as severe corrosion and the worst case of all corrosion rated in any bar. Parameters such as the reduction of the cross section area, the size of the affected region as well as the color observed were considered when evaluating the level of corrosion.

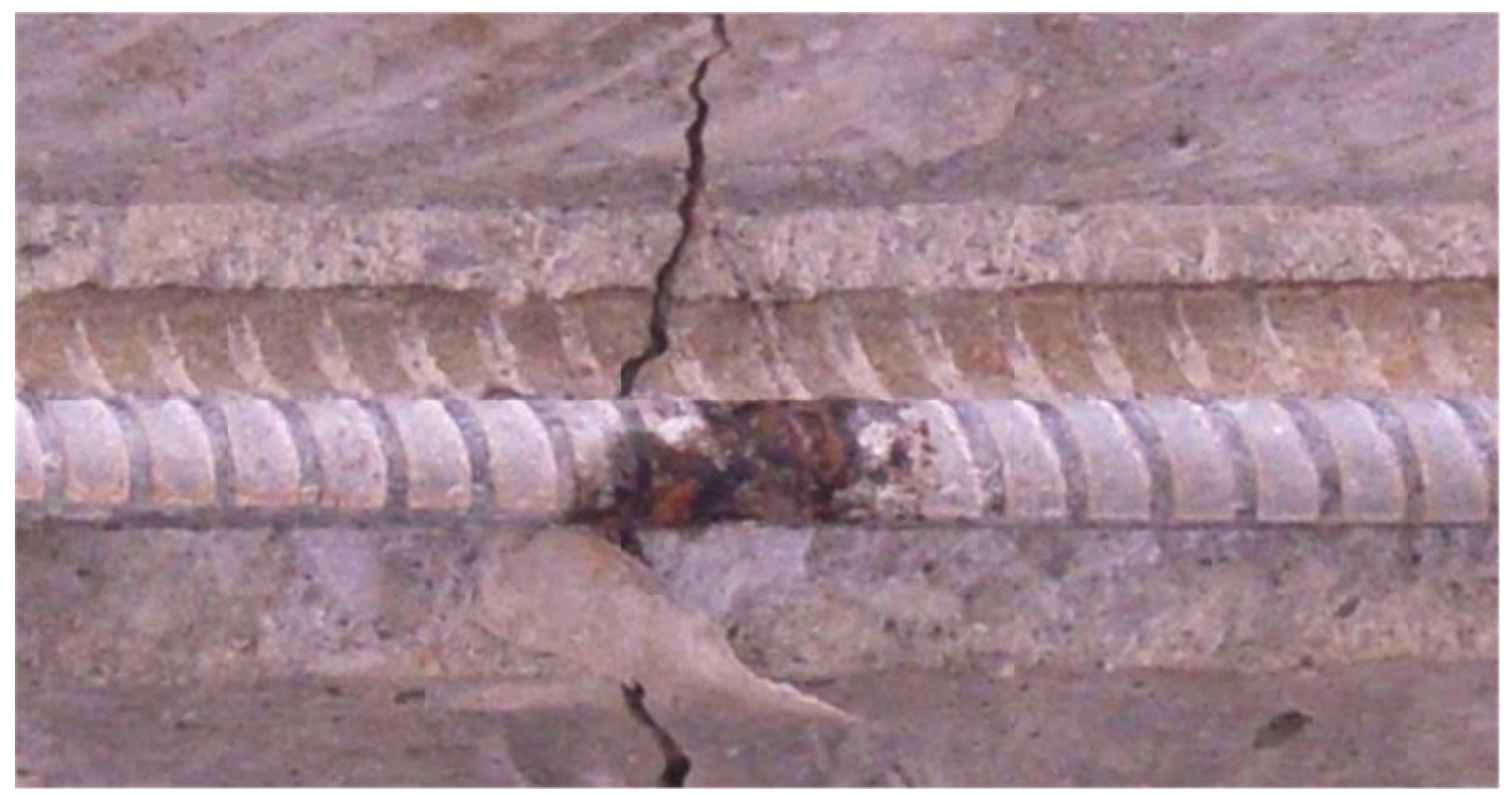

Figure 4.40: Corrosion on top bar at crack location 
For each specimen, an average corrosion value was calculated by summing the corrosion values assigned at each crack and dividing them by the number of times a crack intersected each of the top bars. Complete details are provided in Appendix C. Subsequently, an average was computed for the three duplicate specimens available for each repair product to further rank its performance as presented in Figure 4.41 and Table 4.7. All repair products were ranked in descending order, where a rank of 1 indicates the best performance according to the visual assessment. As illustrated in Figure 4.41, the average of the repair products increases gradually throughout the ranking except for the average of DegaDeck. The specimens for this product exhibited a significant amount of corrosion as shown in Figure 4.40.

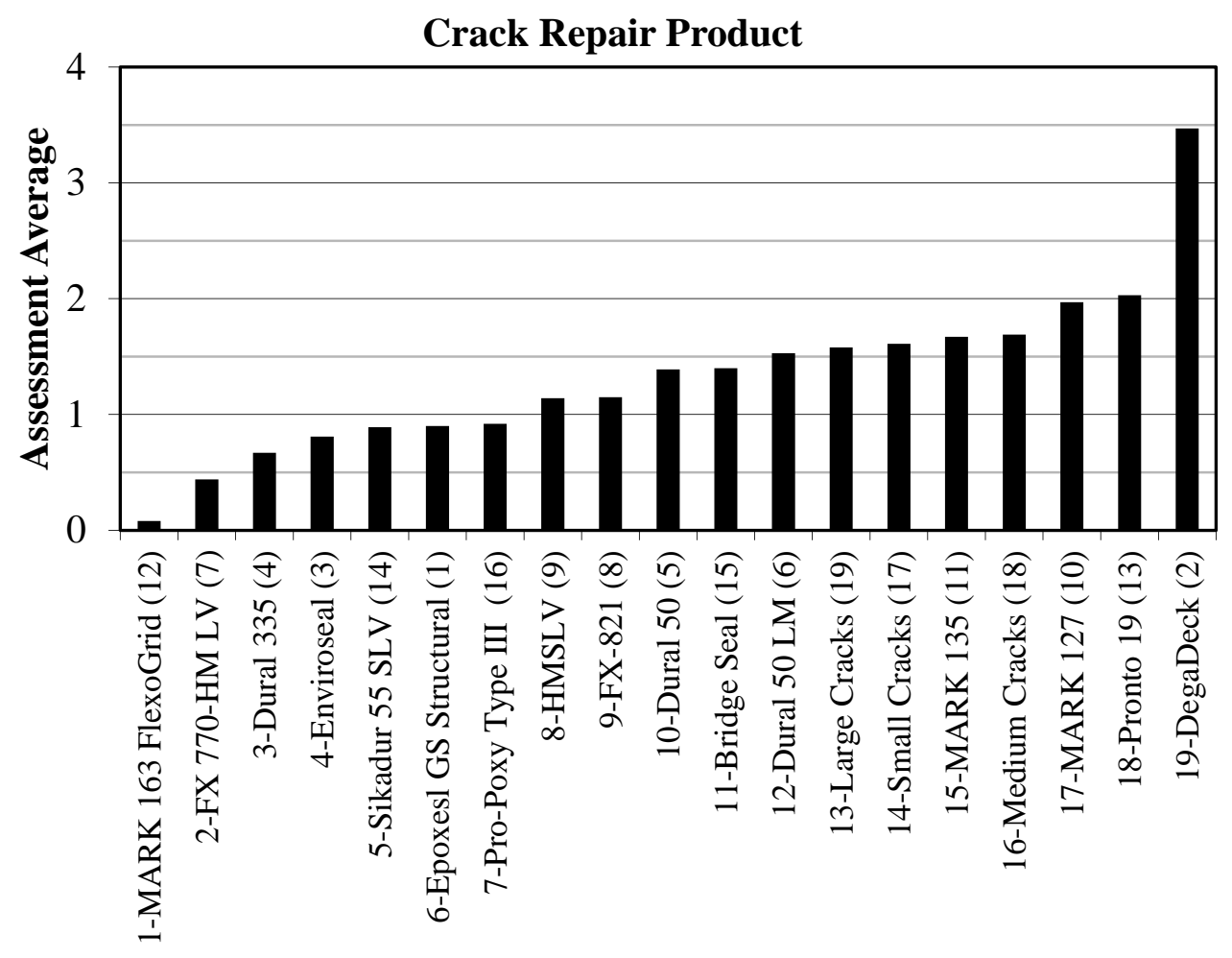

Figure 4.41: Assessment Average of repair products 
Table 4.7: Visual examination ranking

\begin{tabular}{|c|c|c|c|c|}
\hline $\begin{array}{c}\text { Visual } \\
\text { Examination } \\
\text { Ranking }\end{array}$ & Product & Manufacturer & Repair Type & $\begin{array}{c}\text { Assessment } \\
\text { Average }\end{array}$ \\
\hline 1 & $\begin{array}{l}\text { MARK } 163 \\
\text { FlexoGrid }\end{array}$ & Poly-Carb & $\begin{array}{c}\text { Epoxy } \\
\text { Overlay }\end{array}$ & 0.08 \\
\hline 2 & FX 770-HM LV & Fox Industries & Epoxy & 0.44 \\
\hline 3 & Dural 335 & Euclid / Tamms & Epoxy & 0.67 \\
\hline 4 & Sikadur 55 SLV & SikaCorp & Epoxy & 0.89 \\
\hline 5 & $\begin{array}{c}\text { Epoxesl GS } \\
\text { Structural }\end{array}$ & BASF & Epoxy & 0.90 \\
\hline 6 & $\begin{array}{c}\text { Pro-Poxy Type III } \\
\text { D.O.T }\end{array}$ & Unitex & $\begin{array}{l}\text { Epoxy } \\
\text { Overlay }\end{array}$ & 0.92 \\
\hline 7 & HMSLV & $\begin{array}{l}\text { Kaufman } \\
\text { Products }\end{array}$ & Epoxy & 1.14 \\
\hline 8 & FX-821 & Fox Industries & Methacrylate & 1.15 \\
\hline 9 & Dural 50 & Euclid / Tamms & Epoxy & 1.39 \\
\hline 10 & Bridge Seal & Unitex & Epoxy & 1.40 \\
\hline 11 & Dural 50 LM & Euclid / Tamms & Epoxy & 1.53 \\
\hline 12 & \multicolumn{2}{|c|}{ Large Cracks ( 0.035 to 0.040 in.) } & None & 1.58 \\
\hline 13 & \multicolumn{2}{|c|}{ Small Cracks ( 0.010 to 0.013 in.) } & None & 1.61 \\
\hline 14 & MARK 135 & Poly-Carb & Epoxy & 1.67 \\
\hline 15 & \multicolumn{2}{|c|}{ Medium Cracks ( 0.016 to 0.020 in.) } & None & 1.69 \\
\hline 16 & MARK 127 & Poly-Carb & Epoxy & 1.97 \\
\hline 17 & Pronto 19 & SikaCorp & Methacrylate & 2.03 \\
\hline 18 & DegaDeck & BASF & Methacrylate & 3.47 \\
\hline Not Ranked & Enviroseal & BASF & Waterproofer & $0.81^{*}$ \\
\hline
\end{tabular}

*Corrosion on bottom bars 


\subsubsection{Correlation of Results (Corrosion Measurement and Visual Examination)}

A direct correlation between the corrosion measurement and the values determined from the visual assessment was not evident. It is felt that this discrepancy was caused primarily because of the corrosion present on the exposed bars, which affected the corrosion current. Therefore, the rankings provided by the visual assessment are considered more reliable than the corrosion measurements. Although the rankings provided by the corrosion measurement and the visual assessment are different as shown in Table 4.6 and Table 4.7, it is of importance to indicate that some similarities exist in the ranking positions.

From the visual assessment, three of the top five repair products also ranked in the top five based on the current measurements. Thus, the performance of these three products is supported by the results of both methods. Similarly, eight of the top ten products according to visual observation are also ranked within the top ten based on the current measurements. These eight products are listed in Table 4.8.

It is important to indicate that Pincheira et al. (2005) recommended five crack sealers, two of which are included in Table 4.8 (Sikadur 55 SLV, Dural 335). From the remaining three, two were not considered in this investigation (Sikadur 52 and Denedeck Crack Sealer) and the last product recommended (Degadeck Crack Sealer) exhibited a deficient performance in the current investigation. The support of Sikadur 55 SLV and Dural 335 from two independent studies considering different testing methods is significant.

Table 4.8: Best performance (Corrosion Measurement and Visual Examination)

\begin{tabular}{|c|c|c|}
\hline Product & Manufacturer & Repair Type \\
\hline MARK 163 FlexoGrid & Poly-Carb & Epoxy Overlay \\
\hline Dural 335 & Euclid / Tamms & Epoxy \\
\hline Sikadur 55 SLV & SikaCorp & Epoxy \\
\hline Epoxesl GS Structural & BASF & Epoxy \\
\hline Pro-Poxy Type III D.O.T & Unitex & Epoxy Overlay \\
\hline HMSLV & Kaufman Products & Epoxy \\
\hline Dural 50 & Euclid / Tamms & Epoxy \\
\hline Bridge Seal & Unitex & Epoxy \\
\hline
\end{tabular}


From the visual examination ranking (Table 4.7), it is observed that four repair specimens are ranked below the specimens with large and small cracks that were not repaired. Similarly, three repaired specimens are ranked below all specimens with no repair product applied and different crack widths. This ranking indicates that the performance of these specimens was not improved by the repair technique.

\subsubsection{Repair Type Performance}

The rankings from Table 4.7 were compared to identify whether certain repair types yielded better performance. From the rankings, no evident trends associated with product type were noticed. For example, the ranking for epoxy repairs ranged from $2^{\text {nd }}$ place for FX 770-HMLV to $17^{\text {th }}$ place for Mark 127.

Although no clear trend was noticeable, an overall evaluation of the performance of each repair type can be drawn from the product ranking. From Table 4.7, it can be observed that the epoxies performed the best. The top eight places show specimens repaired with these types. It should be noted, however, that the performance for this type varied significantly between different products even within the same company of epoxies.

The worst performance was demonstrated by the methacrylates. While only three products were tested, two out of three of these products were ranked last with the best ranked ninth. Based on the results of this study, methacrylates are not recommended. The best repair product for each repair type is presented in Table 4.9. Since some repair types only had one product represented, this table should not be considered as indicating best performance of all products commonly available. 
Table 4.9: Best product performance for each repair type

\begin{tabular}{|c|c|l|c|c|}
\hline Repair Type & Product & Manufacturer & $\begin{array}{c}\text { Visual } \\
\text { Examination } \\
\text { Ranking }\end{array}$ & $\begin{array}{c}\text { Corrosion } \\
\text { Measurement } \\
\text { Ranking }\end{array}$ \\
\hline $\begin{array}{c}\text { Epoxy } \\
\text { Overlay }\end{array}$ & $\begin{array}{c}\text { MARK 163 } \\
\text { FlexoGrid }\end{array}$ & Poly-Carb & 1 & 1 \\
\hline Epoxy & FX 770-HM LV & Fox Industries & 2 & 11 \\
\hline Methacrylate & FX-821 & Fox Industries & 8 & 14 \\
\hline
\end{tabular}

\subsubsection{Influence of Crack Widths}

Specimens with varying crack widths were constructed to evaluate the influence of crack width on corrosion. Three crack widths were considered, small ( 0.010 to 0.013 in.), medium (0.016 to 0.020 in.), and large (0.035 to 0.040 in.). Considering Table 4.7, these specimens rank in the bottom six, demonstrating significant corrosion as expected. Based on the visual assessment, specimens with large cracks exhibited the least amount of corrosion, followed by specimens with small cracks, and then specimens with medium cracks. Similarly, from the current measurement ranking, no logical order was observed between the specimens; specimens with medium cracks had the least amount of corrosion and large cracks presented the most amount of corrosion as shown in Table 4.6. Hence, from these results, no direct correlation between crack width and corrosion could be determined. Photographs and corrosion measurements of these three specimens are shown in Figure 4.35, Figure 4.36, and Figure 4.37 for small, medium, and large cracks, respectively. Considering crack widths greater than 0.010 in., it appears that crack width does not significantly influence corrosion. Different results may be expected for smaller crack widths. This finding is consistent with the debate summarized in Darwin et al. (1985) about the influence of crack width and cover on corrosion. In this paper, Manning and Beeby agreed that there in not a clear relationship between the crack width and amount of corrosion. 


\subsubsection{Properties of Repair Products}

Different technical specifications are provided for each of the repair products depending on type and technique. Among the tested products, Enviroseal (waterproofer) is the only product whose properties are not adequate for structural repair. This product is a penetrating sealer that protects against moisture intrusion, freeze and thaw cycles, and chloride intrusion. This product was intended to be a control to evaluate the influence of product strength. Unfortunately, due to the different corrosion mechanism, comparisons could not be made.

A comparison between the conclusions presented by Hoffman (2008) and this study and those from a technical report (Johnson et al. 2009) about the performance of crack sealers was conducted. From Hoffman (2008), it was determined that methacylates provided better penetration depths than epoxies. Similarly, Johnson et al. (2009) concluded that generally HMWM products penetrate better into the crack and that epoxy products usually develop higher bond strength. In addition, the following properties for crack sealers were recommended: viscosity less than $500 \mathrm{cP}$ (or $25 \mathrm{cP}$ for HMWM sealers), tensile strength more than 1160 psi, and tensile elongation larger than 10 percent. The repair products evaluated in this study were reviewed to determine if they satisfy the specifications recommended above. From Figure 4.42, it can be observed that all products with data available satisfy the viscosity recommendations. The tensile strength is adequate for all products except for Dural $50 \mathrm{LM}$ as illustrated in Figure 4.43. Finally, the tensile elongation is satisfied only by six repair products as shown in Figure 4.44. From these figures, no trend was evident between the recommended properties and product ranking. Therefore, it is important that the performance of individual products be considered and their results cannot be generalized considering simply these three material properties. 
Visual examination ranking

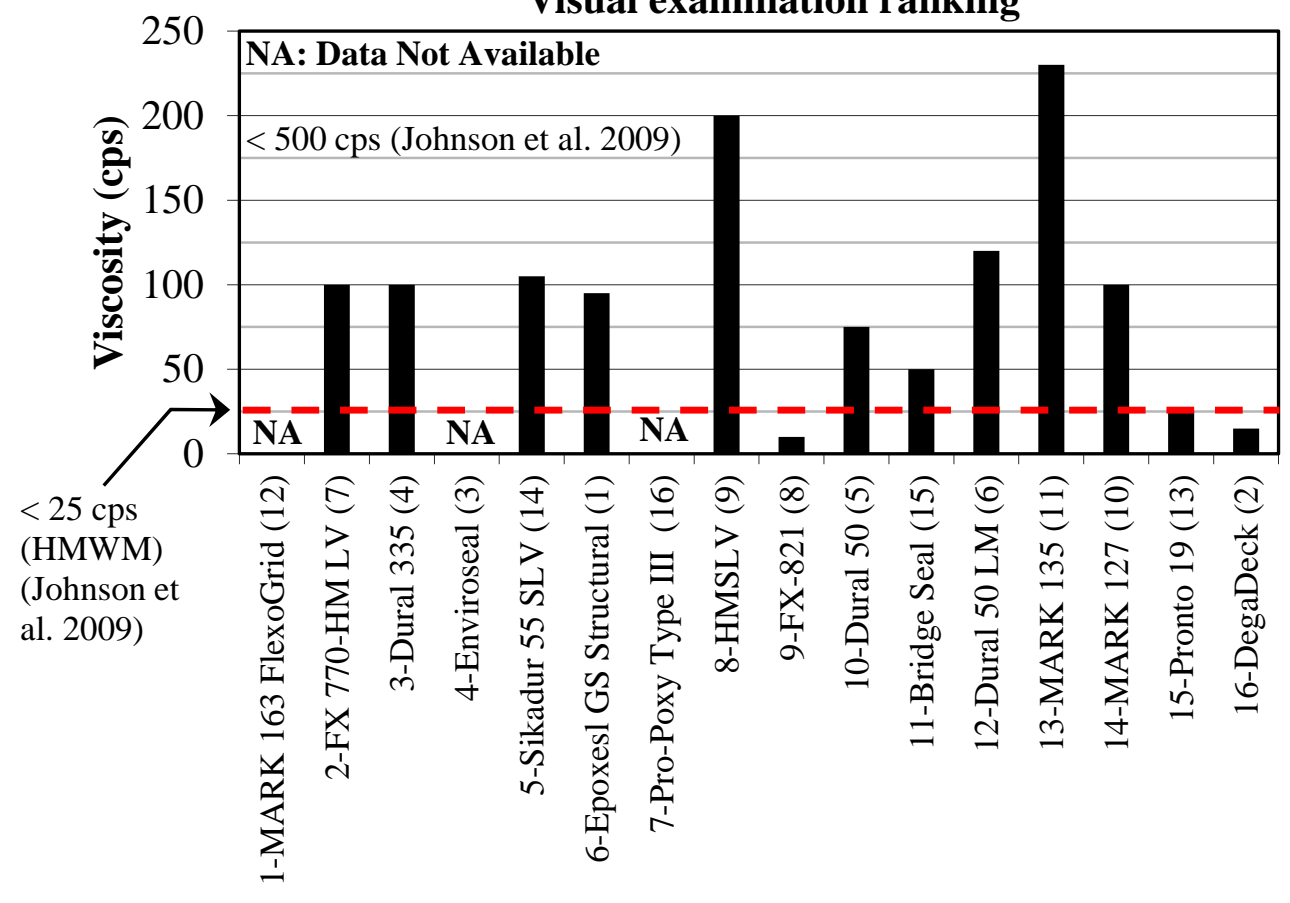

Figure 4.42: Viscosity vs. Assessment Ranking

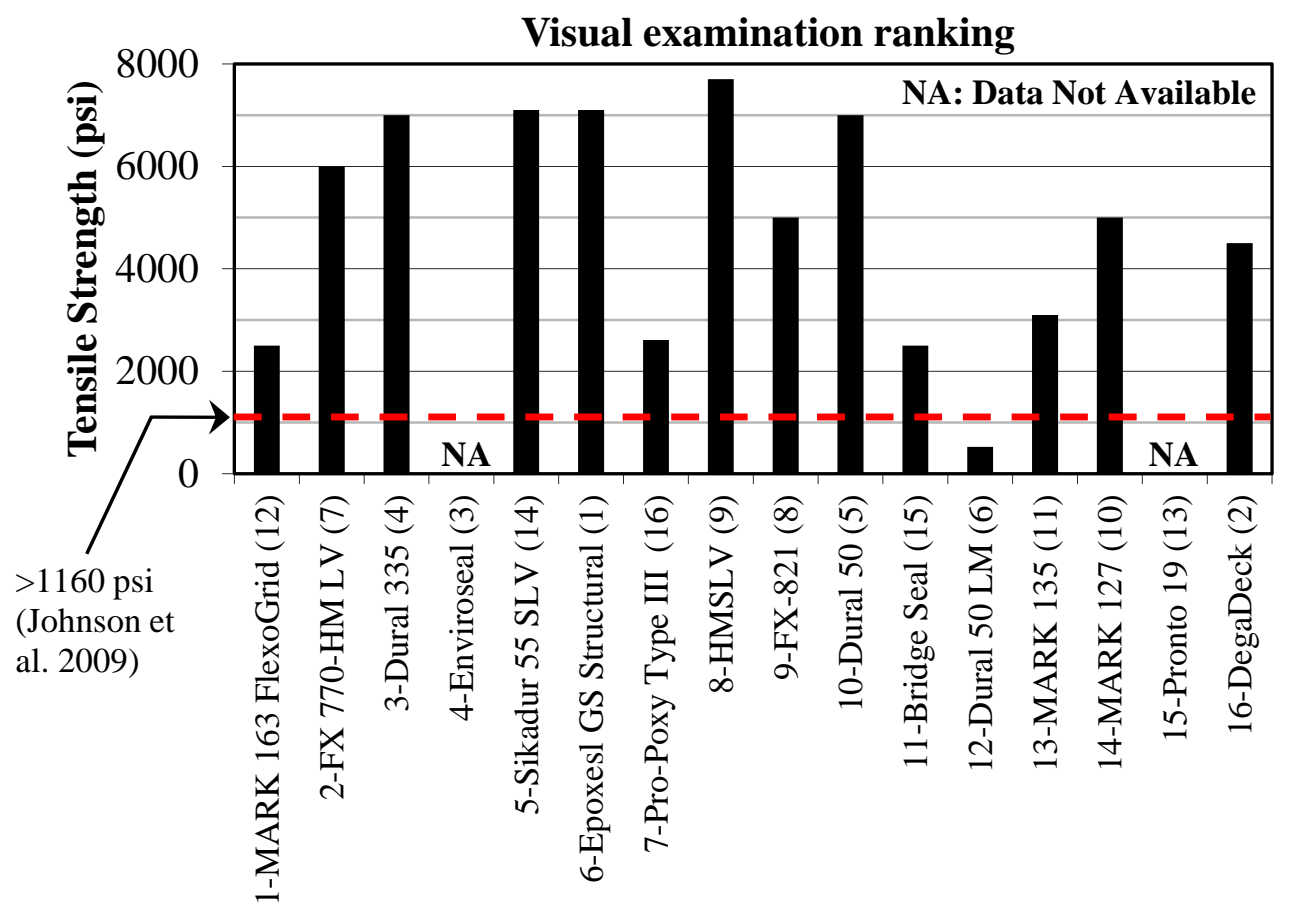

Figure 4.43: Tensile Strength vs. Assessment Ranking 


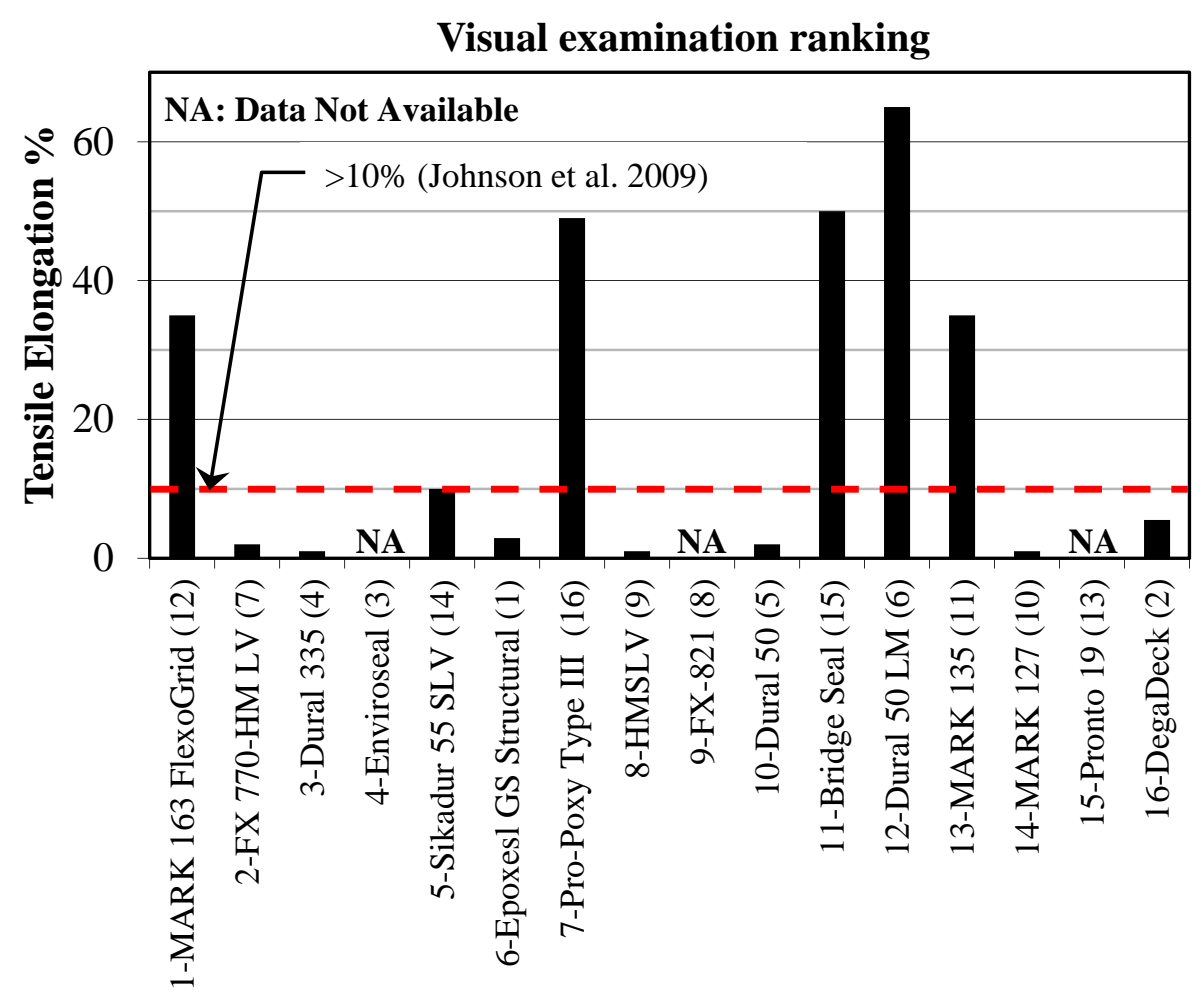

Figure 4.44: Tensile Elongation vs. Assessment Ranking

\section{$\underline{4.9 \text { Conclusions }}$}

Considering only the performance of the repair products during application and restressing, the following conclusions were made:

1. The ability of gravity feed crack repair products to fill cracks was improved by applying a pretreatment stripe to all cracks.

2. A standard application procedure is needed, as there is some variation in manufacturer-supplied guidelines. Consistent surface preparation, mixing times, pretreatment application, and finishing are necessary for optimal crack repair performance.

3. Among gravity feed repair products, methacrylates were easier to handle than epoxies due to their lower viscosity but required more pretreatment applications. 
4. Some failure was observed in the epoxy gravity feed products upon reloading, while all methacrylate gravity feed products withstood the applied loads.

5. All overlays were cracked upon reloading at the location of the original crack.

6. Leaking was observed in some specimens, indicating an inadequate crack repair. The leaking was not specific to a certain repair technique or product.

The following conclusions about the crack sealing performance after application are based on the investigation conducted here.

1. In general, epoxies provided the best performance in preventing corrosion. However, significant variation among products was observed indicating that the type of material alone is not indicative of performance. This variation is likely due to the different physical properties of the materials. Table 4.8 provides a list of top performing products evaluated in this study.

2. Based on the results, methacrylates should not be considered as an effective solution to repair cracks due to their poor performance.

3. No correlation was evident between the corrosion exhibited by the following crack widths: small ( 0.010 to 0.013 in), medium (0.016 to 0.020 in), and large (0.035 to 0.040 in). For these widths, corrosion does not appear to be significantly influenced by crack widths. 


\section{CHAPTER 5 \\ CRACK CONTROL INVESTIGATION}

\subsection{Specimen Design}

Once a concrete bridge deck cracks, the reinforcement is responsible for controlling crack widths below specified limits to prevent the penetration of deleterious agents and ensure the durability of the deck. Laboratory specimens were constructed to evaluate the reinforcement required to optimally control crack widths. Test variables such as the amount, diameter, and spacing of the reinforcement were investigated to determine their specific contribution in controlling cracking. Moreover, design recommendations from previous studies and the behavior of restrained reinforced concrete decks were evaluated.

\subsection{Specimen Design}

The laboratory specimens were designed to represent a composite section of a concrete deck and steel superstructure of a full scale bridge deck. The specimen is restrained through connection with the steel girder as illustrated in Figure 5.1. A steel girder was selected as this superstructure provides maximum restraint of the deck (Radabaugh 2001). Six concrete deck specimens with various reinforcement designs were considered. A crack was pre-formed at midspan to simulate transverse deck cracking and evaluate crack growth and stresses on the reinforcement at this location. 


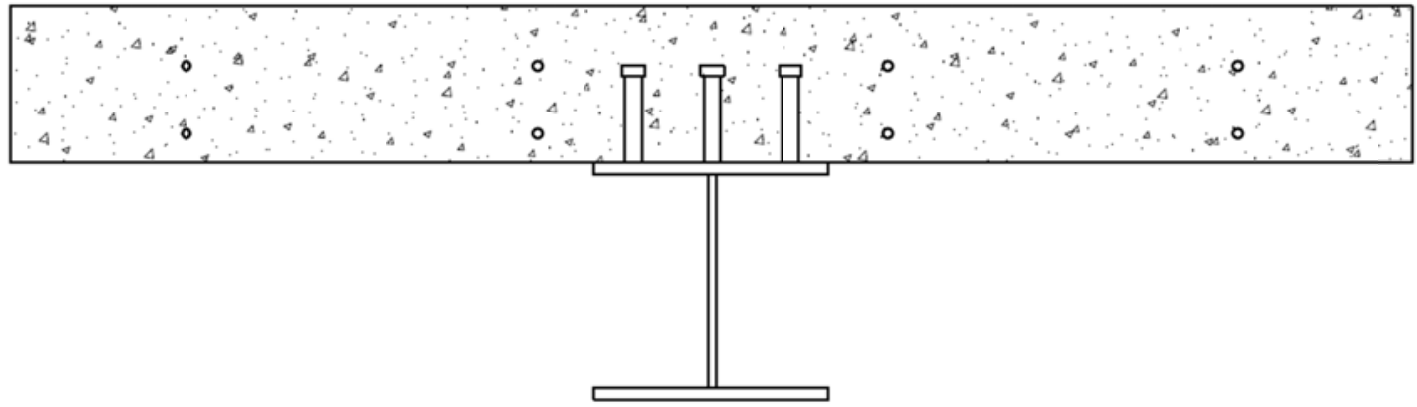

Figure 5.1: Specimen composite section

The concrete deck was designed with a thickness of 8 in. to represent a typical section of a bridge deck. A width of $6 \mathrm{ft}$ was selected to consider a reasonable girder spacing, but on the smaller size range such that greater levels of restraint are provided. As six specimens were to be constructed, a length of $12 \mathrm{ft}$ was determined based on size limitations in the lab. The specimen dimensions are shown in Figure 5.2.

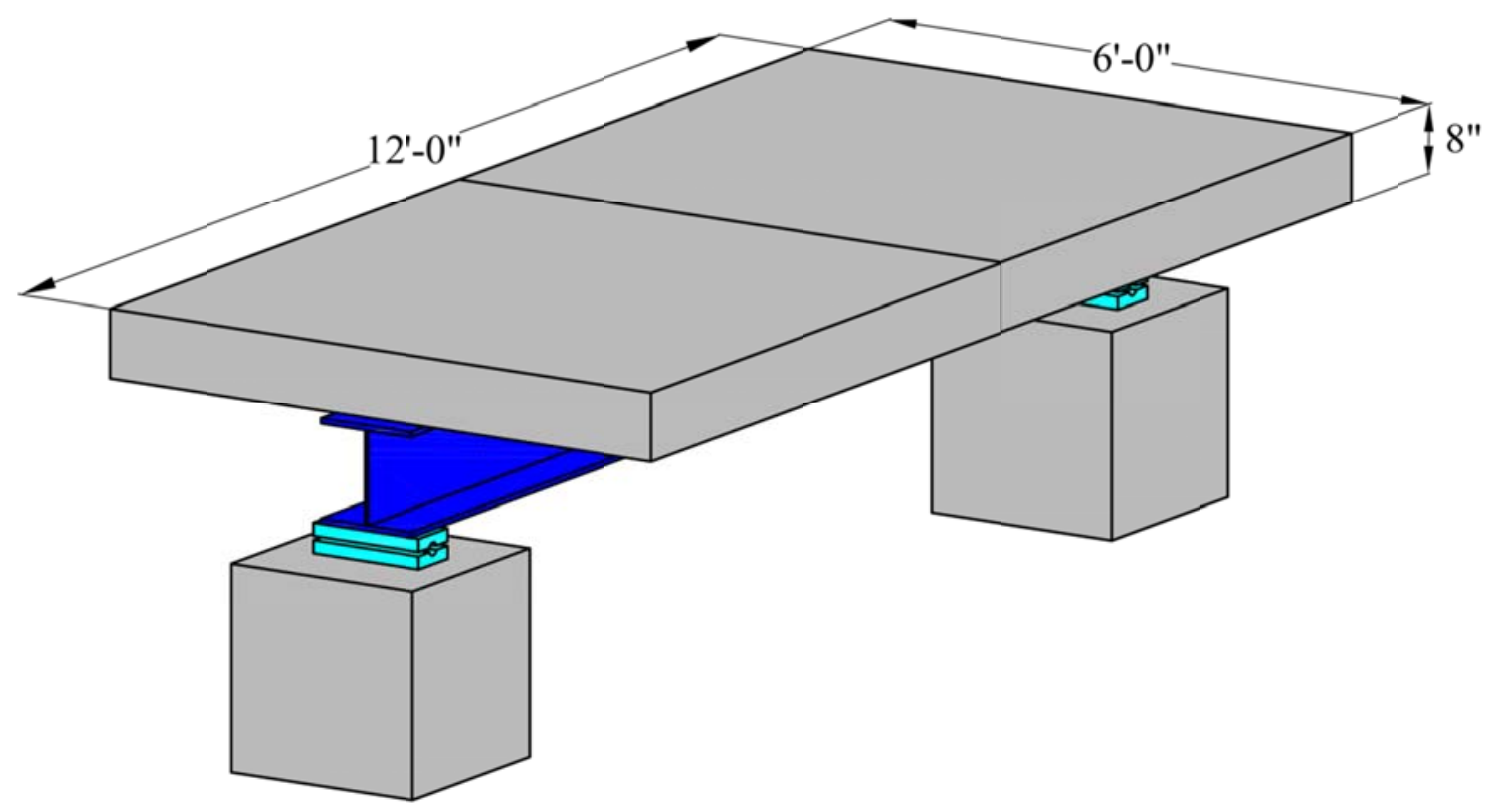

Figure 5.2: Concrete deck specimen 
For the steel girders, a flange width of 12 in. was considered as it corresponds to the flange width used on a bridge located on I-65 over SR 25 which has been previously studied in regards to transverse deck cracking (Radabaugh 2001). The smallest girder section (W12x65) was selected for easy handling and its low moment of inertia, which allowed the measurement of deflections on a relatively short span. The shear stud spacing along the length of the girder was 12 in. consistent with SR 18 over I-65 which has also been studied in regards to transverse deck cracking. This stud arrangement has been used in the field and it is also considered to provide significant restraint. Along the width of the girder, shear studs were spaced every 4 in. The shear studs had a diameter of 7/8 in. and a height of 5 in. as shown in Figure 5.3.

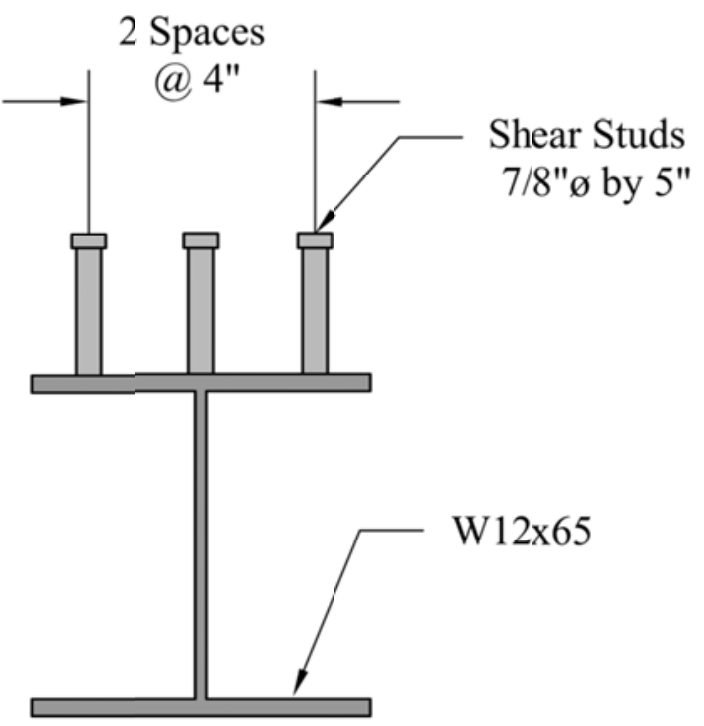

a) Cross section

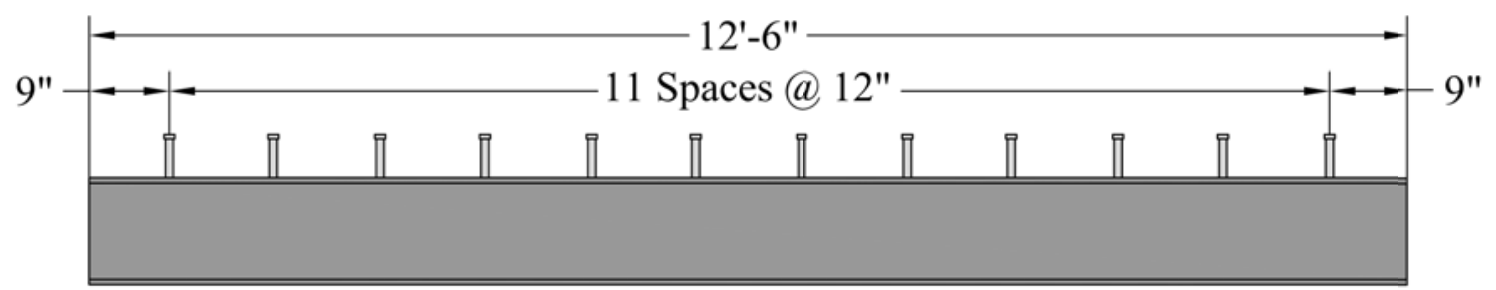

b) Elevation

Figure 5.3: Shear stud spacing 
To simulate transverse deck cracking and guarantee the formation of a crack in each specimen, a crack was introduced at midspan. An 8 in. by $6 \mathrm{ft}$ plexiglass sheet was used to pre-form the crack. A thickness of 0.25 in. was selected to prevent it from warping during concrete casting.

Figure 5.4 illustrates the pre-formed crack in the deck. The transverse reinforcement (\#4 bar) was spaced every 12 in. in all the specimens.

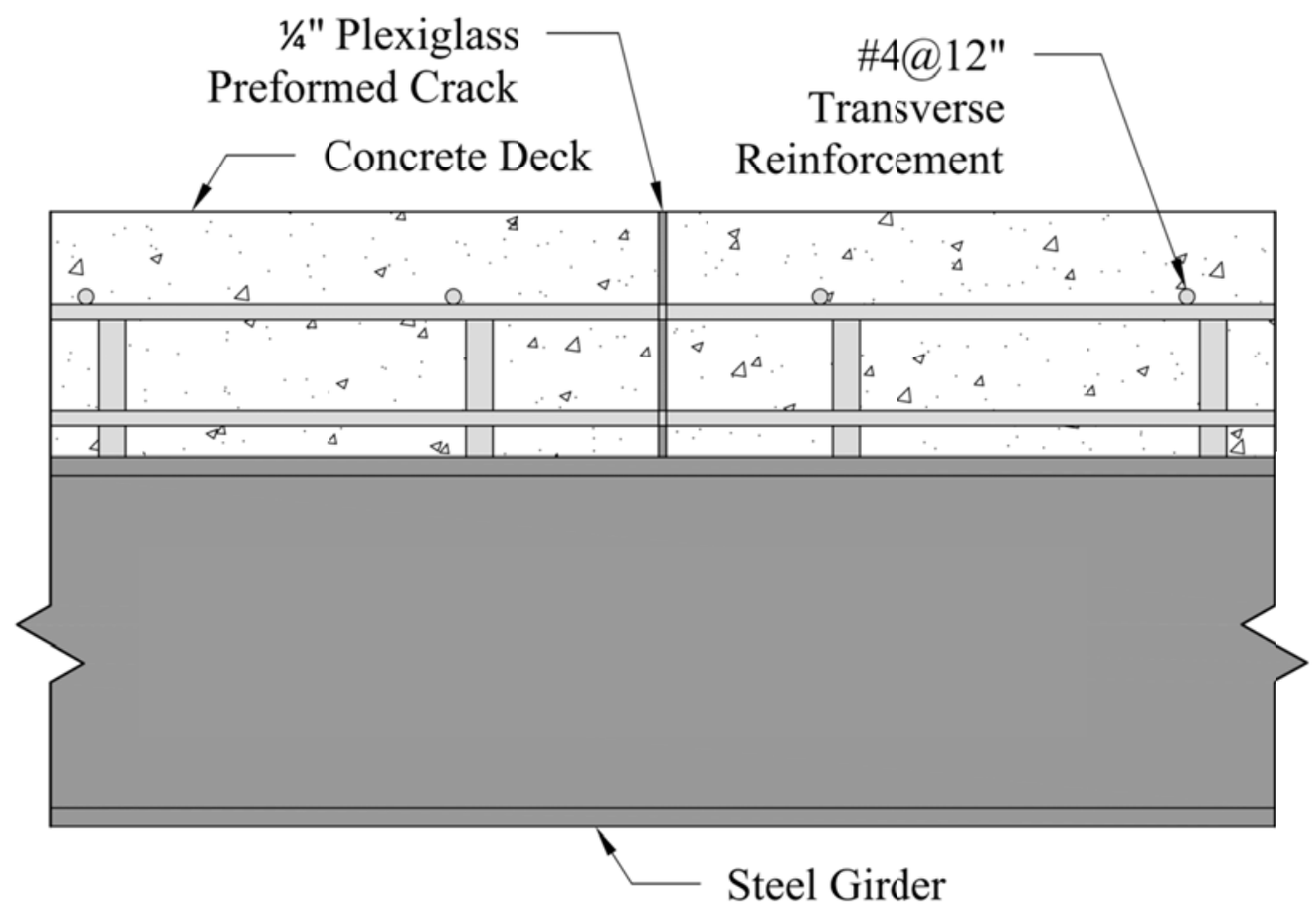

Figure 5.4: Preformed crack location 


\subsection{Specimen Variables}

Three test variables were evaluated which include the reinforcement amount, bar spacing, and bar diameter to assess their influence on the control of restrained shrinkage cracking. The longitudinal reinforcement design was different for each of the specimens considered. The amount, spacing, and diameter of the reinforcement were varied to evaluate the performance of different reinforcement designs when controlling cracking. Table 5.1 presents the test variables used in the concrete deck specimens.

Table 5.1: Test variables

\begin{tabular}{|c|c|c|}
\hline \multirow{2}{*}{ Spacing (in.) } & \multicolumn{2}{|c|}{ Reinforcement Ratio, $\boldsymbol{\rho}_{\mathbf{g}}(\mathbf{\%})$} \\
\cline { 2 - 3 } & $\mathbf{\# 4} \mathbf{~ b a r}$ & $\mathbf{\# 5}$ bar \\
\hline 4 & 1.25 & - \\
\hline 8 & 0.63 & 0.97 \\
\hline 12 & 0.42 & 0.65 \\
\hline 18 & 0.27 & - \\
\hline
\end{tabular}

Details of the test specimens are shown in Table 5.2. The reinforcement layout of each specimen is illustrated in Figure 5.5.

Table 5.2: Specimen description

\begin{tabular}{|c|c|c|c|}
\hline Specimen & $\begin{array}{c}\text { Spacing } \\
\text { (in.) }\end{array}$ & Bar Size & $\begin{array}{c}\text { Reinforcement } \\
\text { Ratio, } \boldsymbol{\rho}_{\mathbf{g}}(\mathbf{\%})\end{array}$ \\
\hline 1 & 18 & $\# 4$ & 0.27 \\
\hline 2 & 4 & $\# 4$ & 1.25 \\
\hline 3 & 12 & $\# 5$ & 0.65 \\
\hline 4 & 12 & $\# 4$ & 0.42 \\
\hline 5 & 8 & $\# 5$ & 0.97 \\
\hline 6 & 8 & $\# 4$ & 0.63 \\
\hline
\end{tabular}




\section{$\underline{\text { Reinforcement Amount }}$}

The influence of the amount of reinforcement was investigated. By varying the bar spacing and diameter, various amounts of reinforcement ranging from $0.27 \%$ to $1.25 \%$ were evaluated. A ratio of $0.27 \%$ represents a minimum amount of reinforcement expected to be used in a bridge deck as provided by \#4 at 18”. No.4 bars are the smallest size typically used while 18” is consistent with the maximum spacing provided by AASHTO. A ratio of $0.63 \%$ was included to investigate a reinforcement level recommended in previous studies (Frosch et al. 2003, 2006) based on the expression $\rho_{g}=6 \sqrt{f_{c}^{\prime}} / f_{y}$ as well as the minimum recommended by ACI $224 \mathrm{R}-01$ (0.6\%). The maximum value of $1.25 \%$ was selected to essentially double the recommended amount of 0.63\%.

\section{Reinforcement Spacing}

The longitudinal reinforcement of the specimens was spaced at 4, 8, 12, and 18 in. to determine the influence of the bar spacing on the control of cracks. To specifically evaluate the influence of spacing, two specimens were designed with approximately the same reinforcement ratio $(0.63 \%$ and $0.65 \%)$ but were reinforced using different bar sizes.

\section{$\underline{\text { Reinforcement Diameter }}$}

The bar diameter was varied to evaluate its influence on crack control. Two bar diameters were used, \#4 and \#5. These diameters were considered since they are commonly used in bridge decks. Bar diameter was varied for the same bar spacing as well as for the same reinforcement amount (0.63\% and $0.65 \%)$ such that its influence could be assessed. 


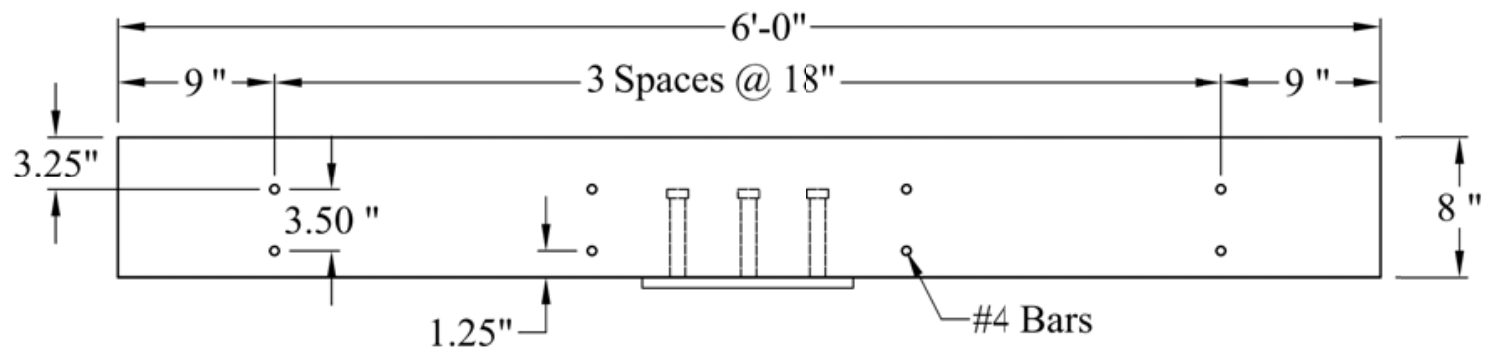

a) Specimen 1

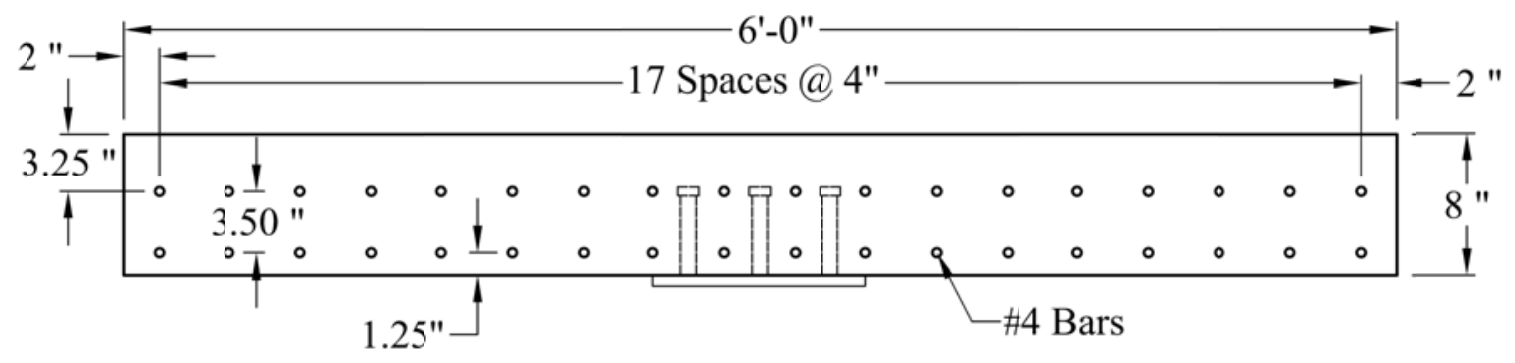

b) Specimen 2

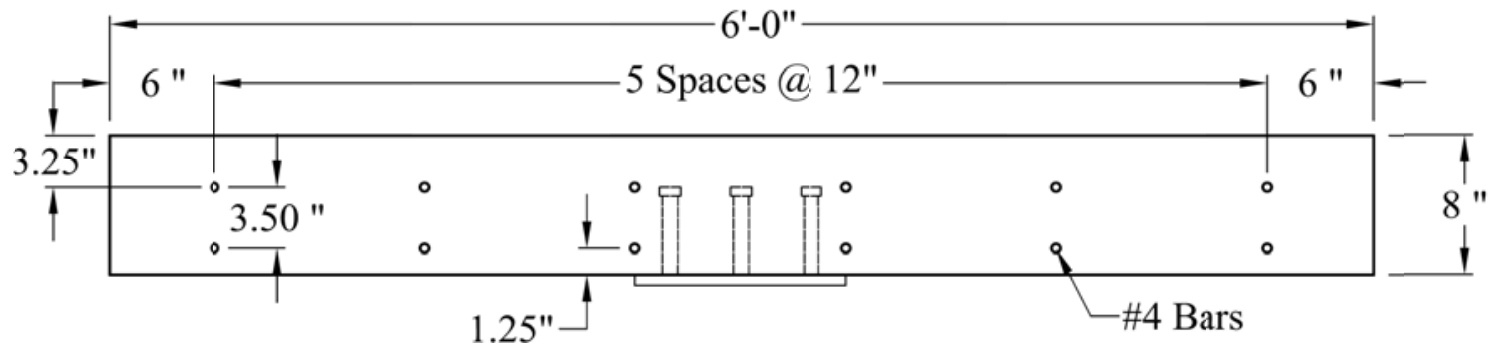

c) Specimen 3

Figure 5.5: Specimen reinforcement layout 


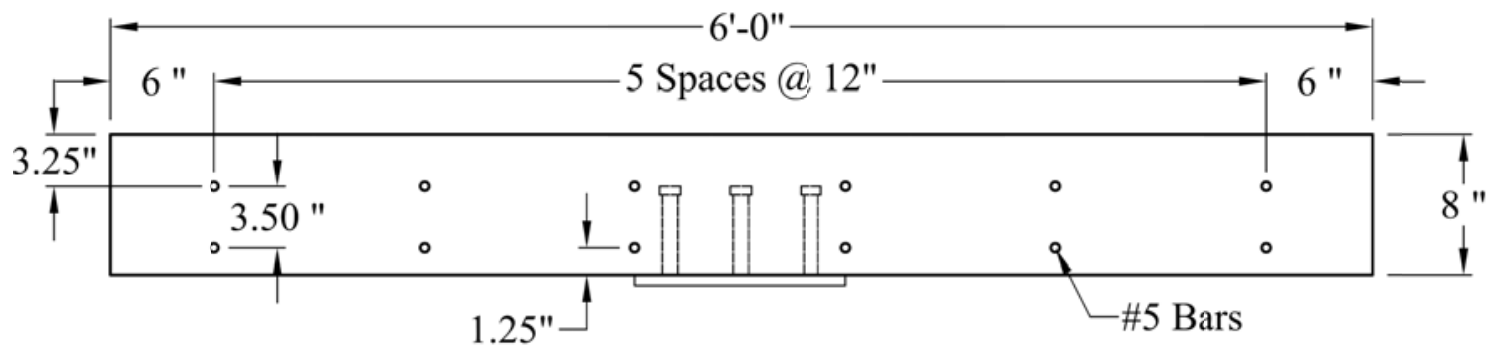

d) Specimen 4

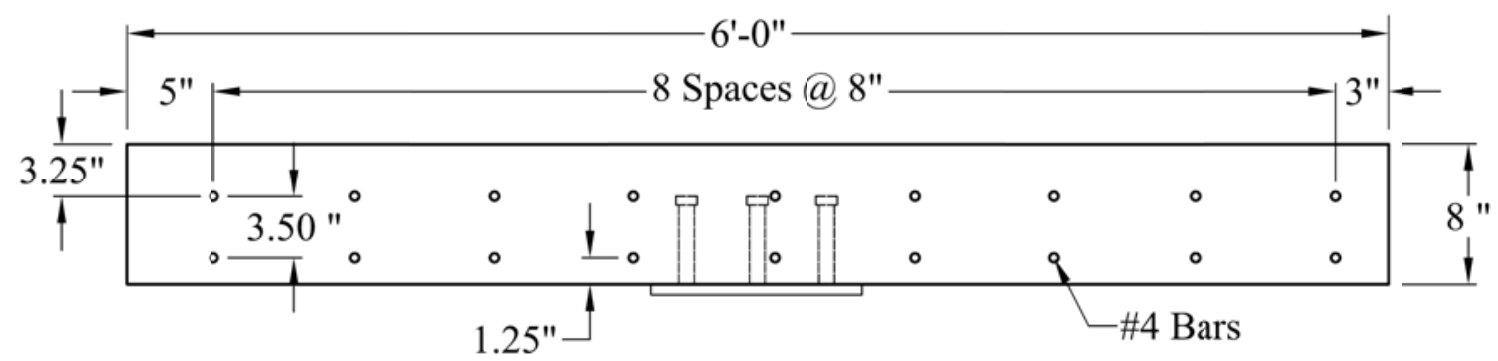

e) Specimen 5

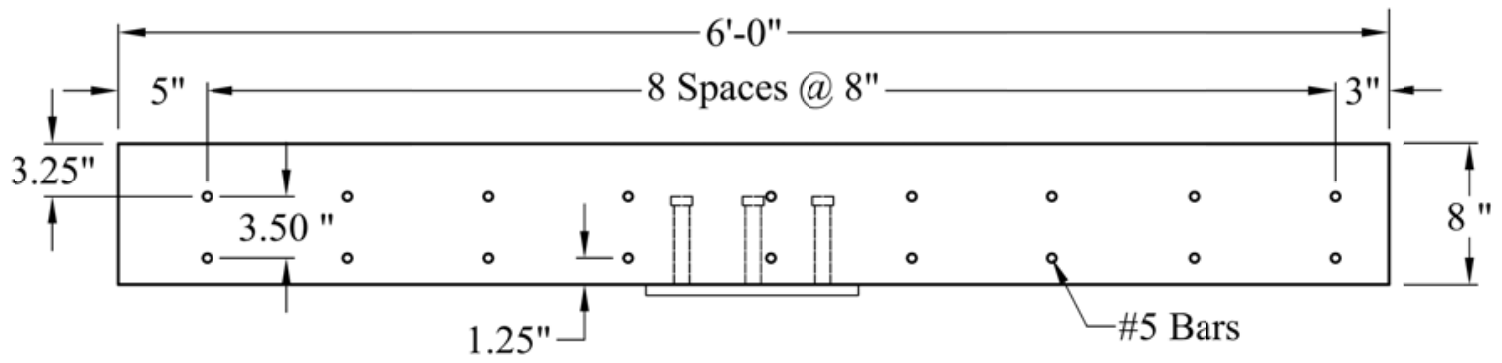

f) Specimen 6

Figure 5.5 (continued): Specimen reinforcement layout 


\subsection{Specimen Construction}

The six specimens were constructed simultaneously in the Bowen Laboratory to enable testing with the same concrete mix as well as the same environmental conditions to eliminate the influence of these parameters. Several phases are considered for the construction of the specimens.

\subsubsection{Pin and Roller Connections}

Once support blocks ( $2 \mathrm{ft}$ cubes) were placed at the location of the specimens, roller and pin connections were used to provide for simple support of the girder. For the roller, a steel bar was placed between the surfaces of the two plates. The pin was made by placing a round steel bar in the rounded grooves of two steel plates. The length of the plates was 14 in. to extend beyond the width of the flange. Figure 5.6 shows both connections in detail. The bottom plate of both connections was leveled with a surveyor's level before fixing the elevation and location of the plates with hydrostone.

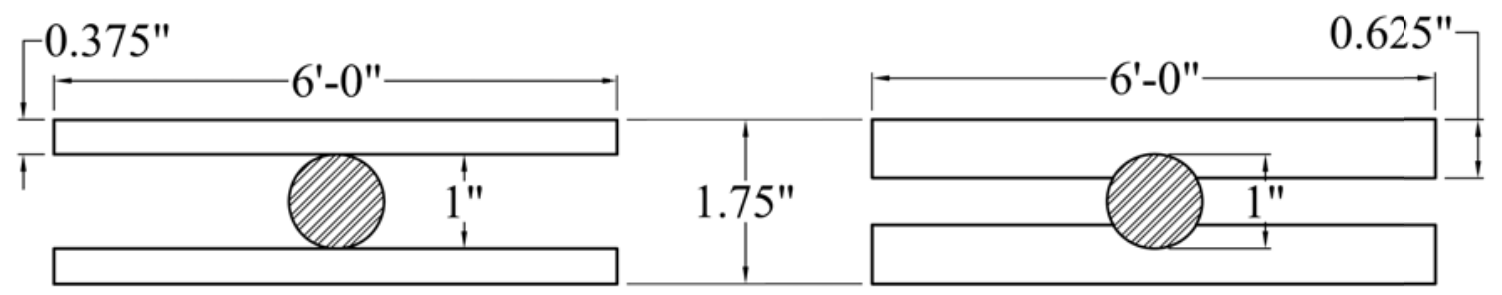

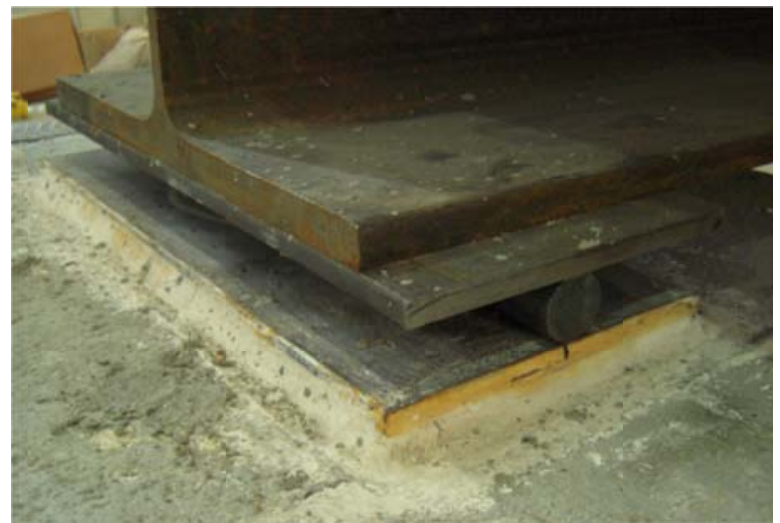

a) Roller connection

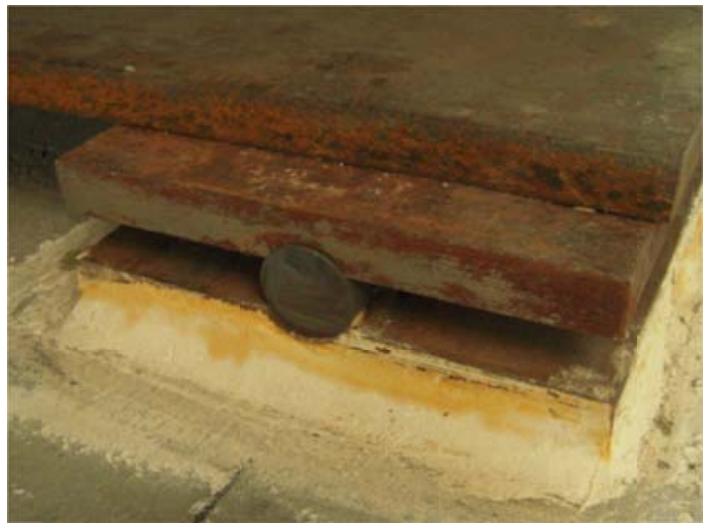

b) Pin connection

Figure 5.6: Connection between steel girder and support 


\subsubsection{Steel Girders}

The girders were fabricated and delivered by Indiana Steel Fabricating Inc. They were lifted and set on the supports using an overhead crane. Construction of the formwork began after girders were set.

\subsubsection{Formwork}

The formwork design considered three sets of two specimens each as shown in Figure 5.7 and Figure 5.8. This design permitted a better distribution of forces and a reduction of formwork materials. The formwork was built with $3 / 4$ in. Grade B-B plyform, and $2 \times 4$ in. lumber for support elements as well as $4 \times 4$ in. lumber for the shoring posts. Wedges were used to obtain the required height of the shores. The formwork was constructed to provide almost complete support of the concrete load when casting. The steel girder supported only the tributary load over its top flange.

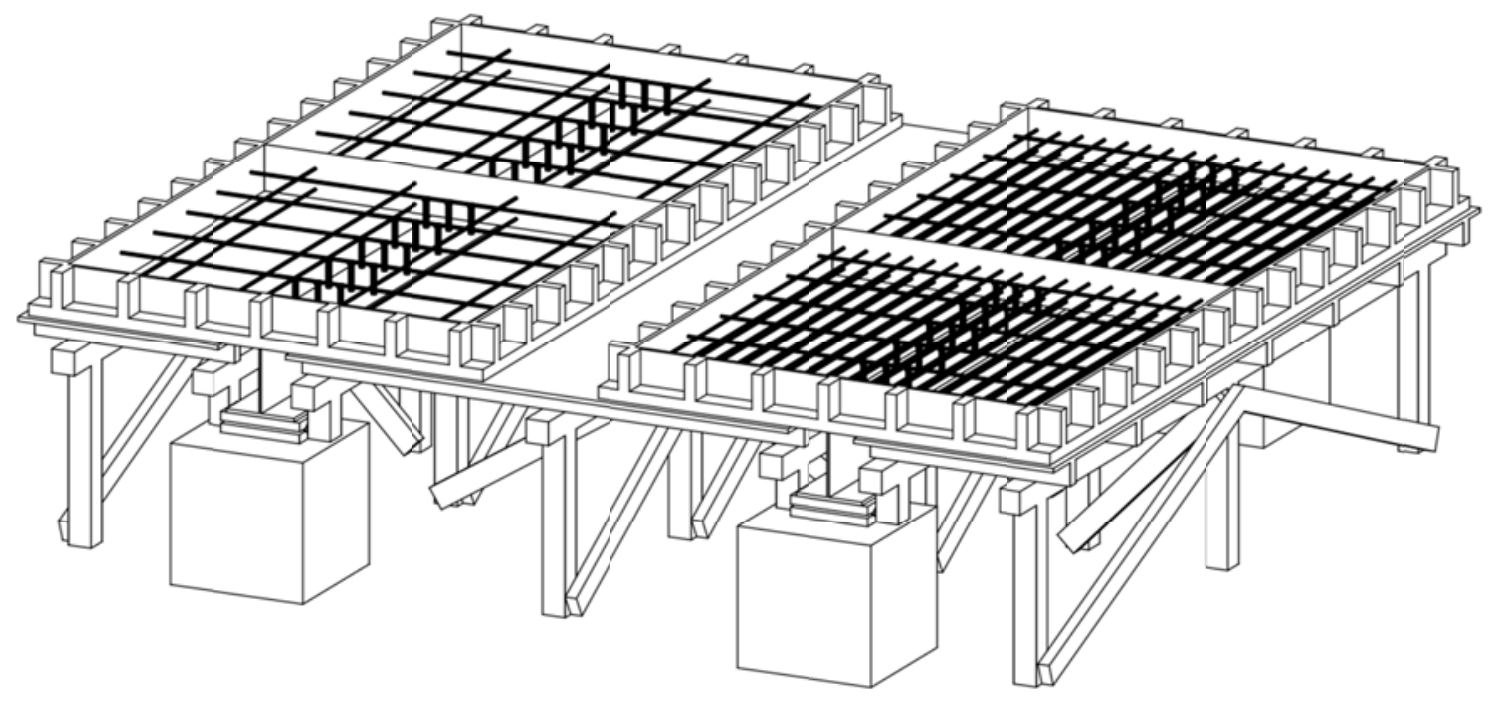

Figure 5.7: Specimen formwork 


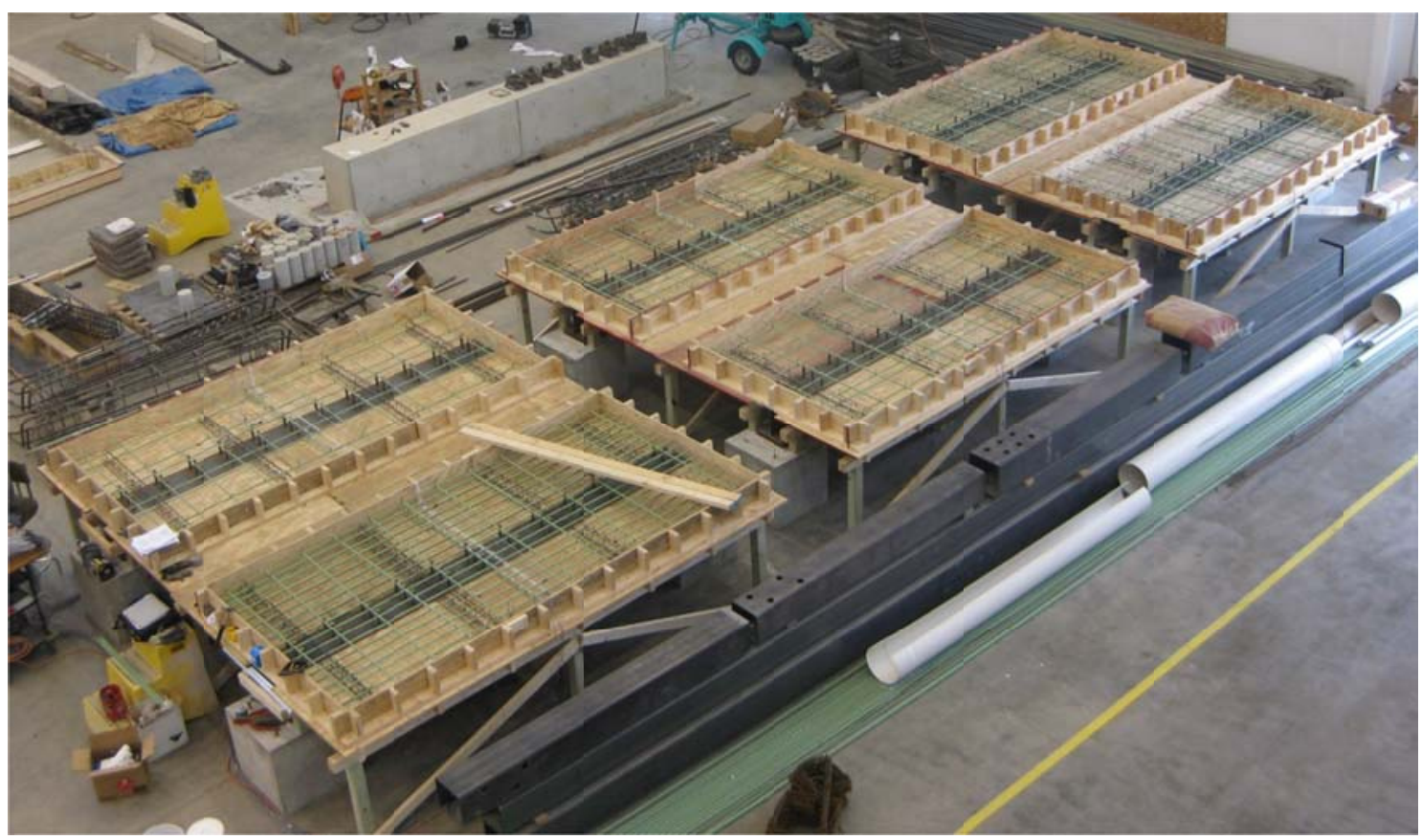

Figure 5.8: Specimen formwork

\subsubsection{Reinforcing Steel}

After completion of the formwork, the plexiglass was drilled considering the different reinforcement designs. The sheets were placed vertically at midspan so that the bottom and top reinforcing steel could be inserted through the holes. The bottom reinforcement layer was set on 1 in. chairs and the top layer on 3 in. chairs placed on top of the bottom reinforcement. The bars were then tied to the chairs to prevent movement when casting the concrete. The top transverse reinforcement was placed every 12 in. in all specimens and tied to the longitudinal top layer. Finally, the plexiglass sheets were sealed to the forms to restrain movement when casting and avoid leakage between the two sections of concrete. Figure 5.9 shows the reinforcing steel and plexiglass sheet for Specimen 1 (\#4 at 18”). 


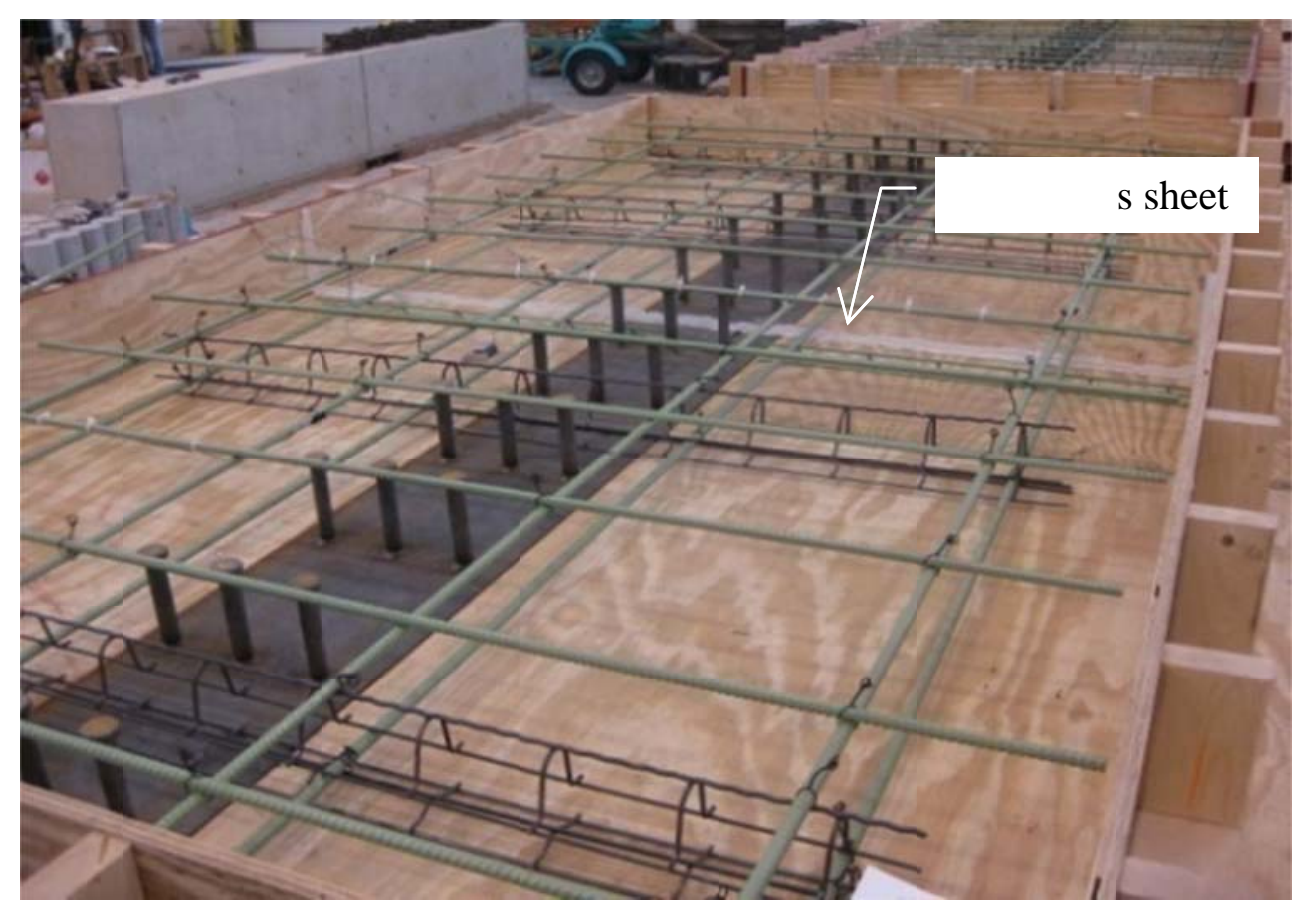

Figure 5.9: Reinforcing steel and plexiglass sheet

\subsubsection{Deck Casting}

The specimens were cast on the same day on Tuesday, August 25, 2009. Two trucks were required to deliver a total of $12 \mathrm{yd}^{3}$ of concrete. The concrete was specified as INDOT Class C. Casting of the specimens began at 2:10 PM and finished at 3:50 PM. Specimens 1-3 (Table 5.2) were cast with concrete from the first truck and Specimens 4-6 from the second truck. As shown in Figure 5.10, the laboratory concrete bucket was used to cast the specimens. Special attention was given when placing the concrete on the strain gages to avoid damage. After the concrete was placed, a magnesium screed and bull float were used to screed and finish the specimens. For ease of handling, lifting inserts were embedded in the slab approximately 30 minutes after casting. At the same time, linear potentiometers were inserted into the concrete over the pre-formed crack to measure crack growth over the test duration. 


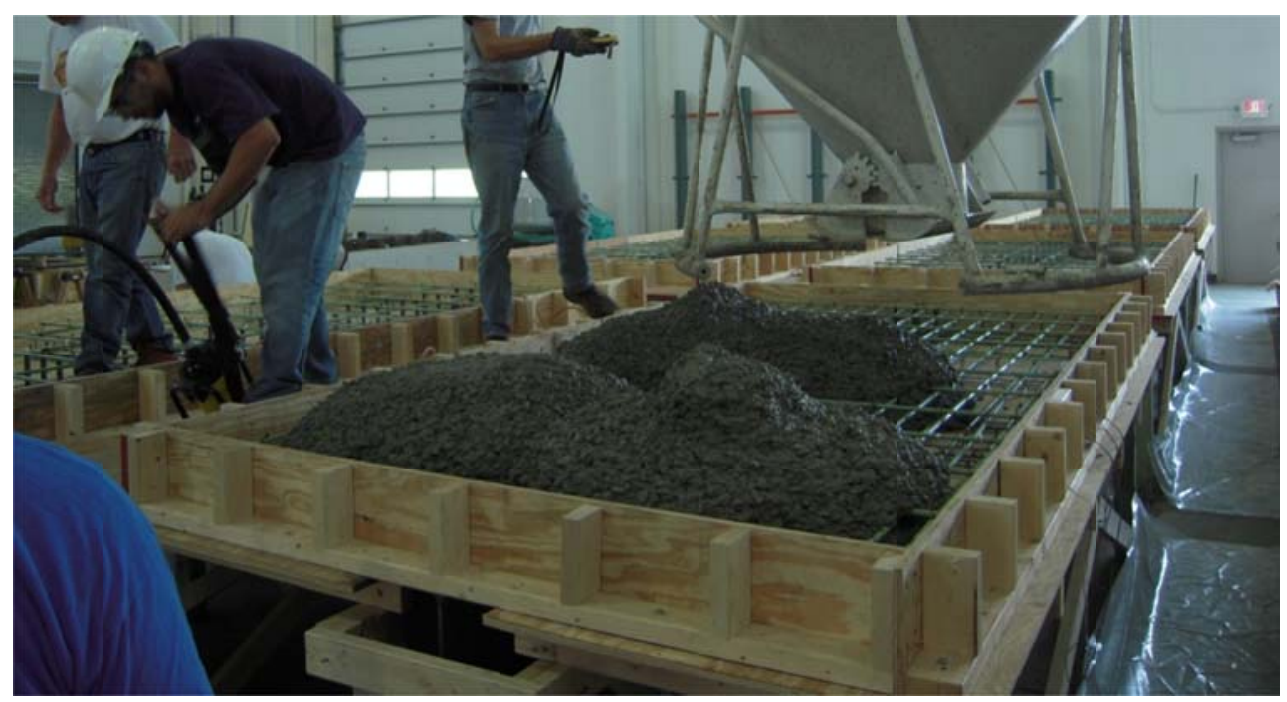

Figure 5.10: Casting of specimens

Wet burlap and plastic sheeting were used to cover the specimens approximately one hour after finishing the deck (Figure 5.11). The specimens were cured for 3 days. After 4 days, the formwork was removed to transfer the loads to the concrete deck and girder. The wet curing duration was limited to three days to exacerbate early age shrinkage for the specimens. Figure 5.12 presents the timeline of events described above.

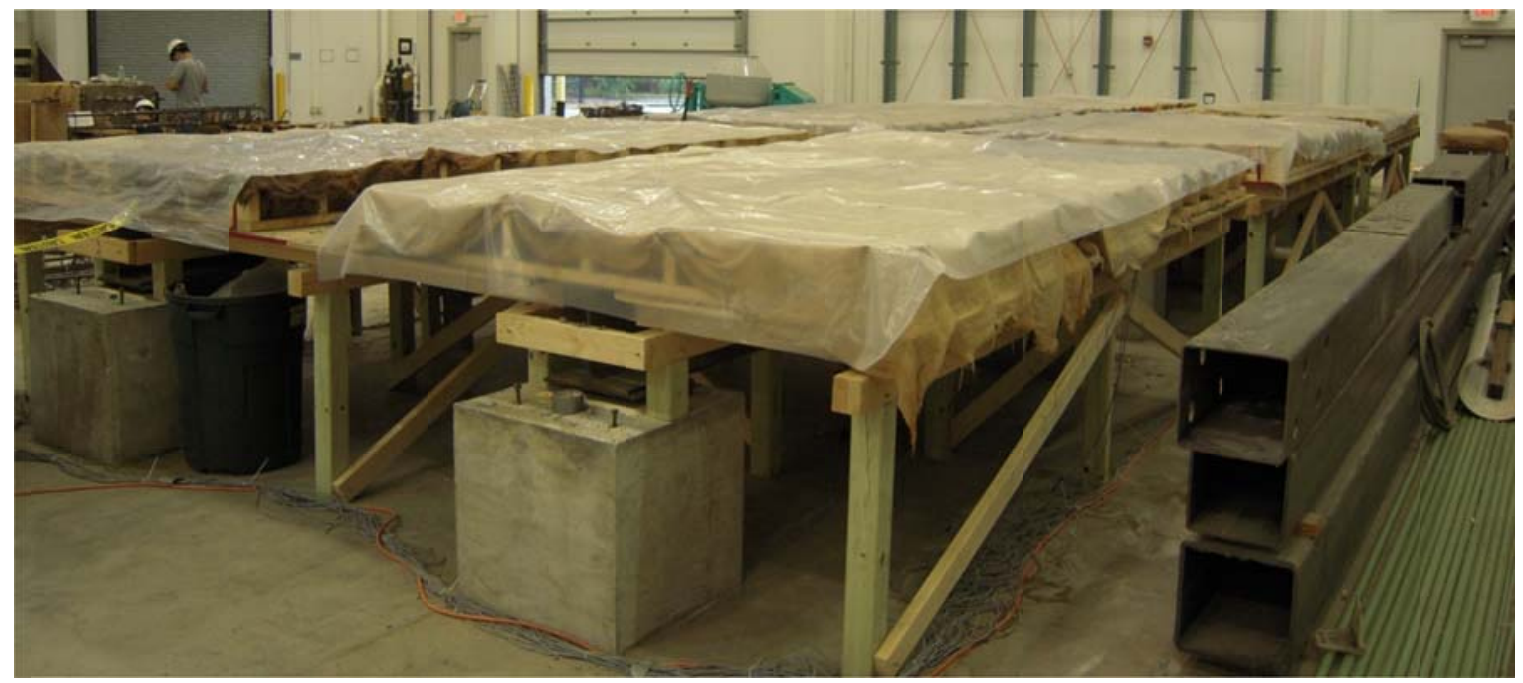

Figure 5.11: Curing of specimens 


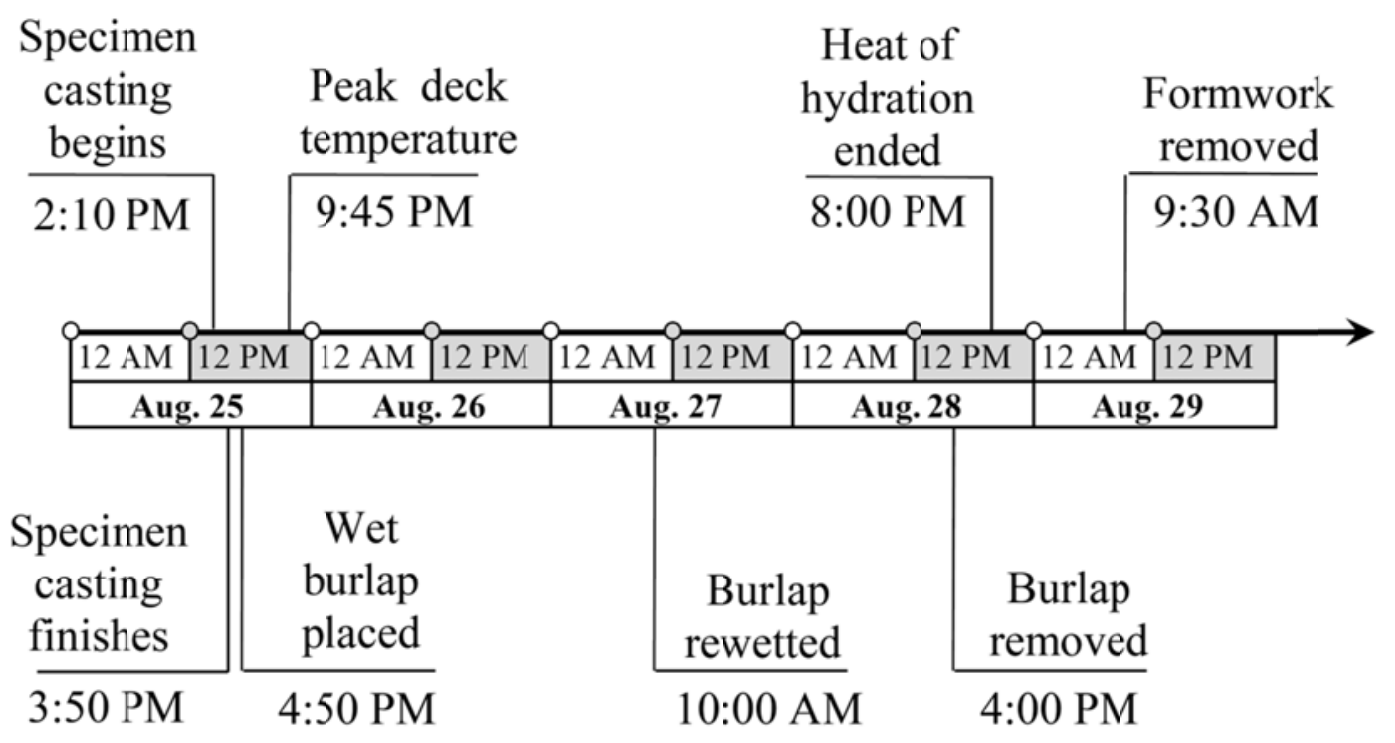

Figure 5.12: Timeline between casting and formwork removal

\subsection{Materials}

\subsubsection{Concrete}

The same type of concrete typically used in Indiana bridge decks (INDOT Class C) was supplied by Irving Materials (IMI) for construction of the decks. Class C concrete has a design compressive strength of 4000 psi and a maximum aggregate size of $3 / 4$ in. The design weights are provided in Table 5.3. Two trucks were required to deliver the $12 \mathrm{yd}^{3}$ of concrete for the specimens. To obtain a desirable slump of 6 in., 6 and 3 gallons of water were added to the concrete from the first and second truck, respectively. The batched weights were the same as the design mix weights. 
Table 5.3: Concrete mix design (per cubic yard)

\begin{tabular}{|c|c|}
\hline Material & INDOT Class C \\
\hline Portland Cement (Type I) & $658 \mathrm{lbs}$ \\
\hline Fly Ash (Class C) & none \\
\hline Water & $245 \mathrm{lbs}$ \\
\hline \#8 Stone & $1800 \mathrm{lbs}$ \\
\hline \#23 Sand & $1200 \mathrm{lbs}$ \\
\hline Micro Air & $3.95 \mathrm{oz}$ \\
\hline Glenium 3030 & $13.2 \mathrm{oz}$ \\
\hline Slump & $6 \mathrm{in}$. \\
\hline
\end{tabular}

Standard 6 in. by 12 in. cylinders were cast at the same time as the deck specimens. These samples were also cured for 3 days. Cylinders for both concretes $\left(1^{\text {st }}\right.$ and $2^{\text {nd }}$ truck) were obtained and tested at $7,14,21,28$, and 56 days. On these days, compressive and split cylinder tests were performed according to ASTM C39 and ASTM C496. Figure 5.13 and Figure 5.14 illustrate the strength gain curve of the concrete for both tests considered. It can be observed that the concrete strength from the $2^{\text {nd }}$ truck is somewhat lower than the $1^{\text {st }}$ truck; however, the strengths are generally comparable. 


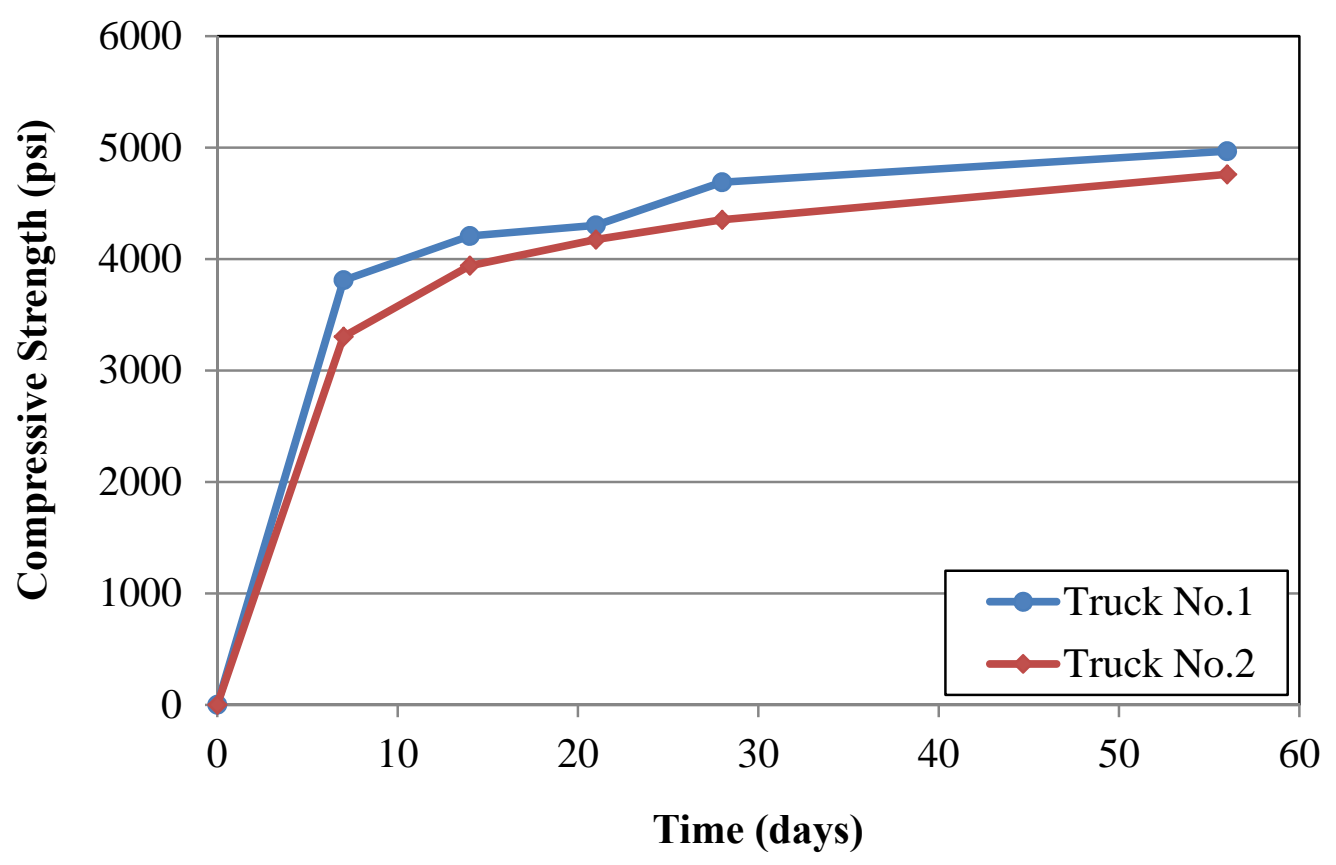

Figure 5.13: Strength gain curve for concrete (compressive cylinder test)

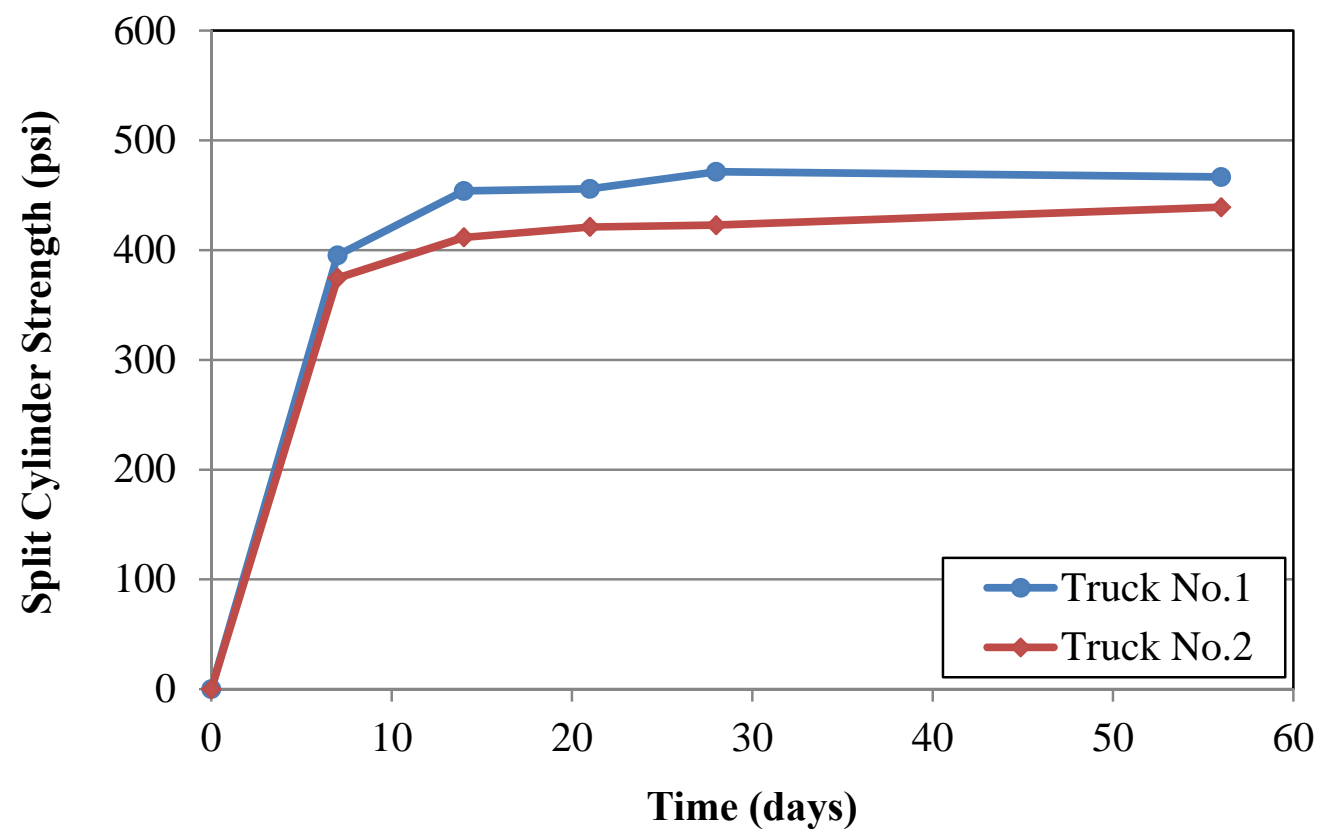

Figure 5.14: Strength gain curve for concrete (split cylinder test) 


\subsubsection{Reinforcing Steel}

The specimens were constructed using \#4 and \#5 bars. Both bars were specified as ASTM A615 Grade 60. A universal testing machine was used to obtain the stressstrain relationship for these bars. Figure 5.15 and Figure 5.16 show the tensile strength of the \#4 and \#5 bars, respectively. Table 5.4 indicates the yield and ultimate stress of both bars. Strain gages were also used to verify the extensometer measurements. Both measurements were identical except in the vicinity of the yield plateau. It is likely that strain concentrations, at the strain gage, caused these small variations.

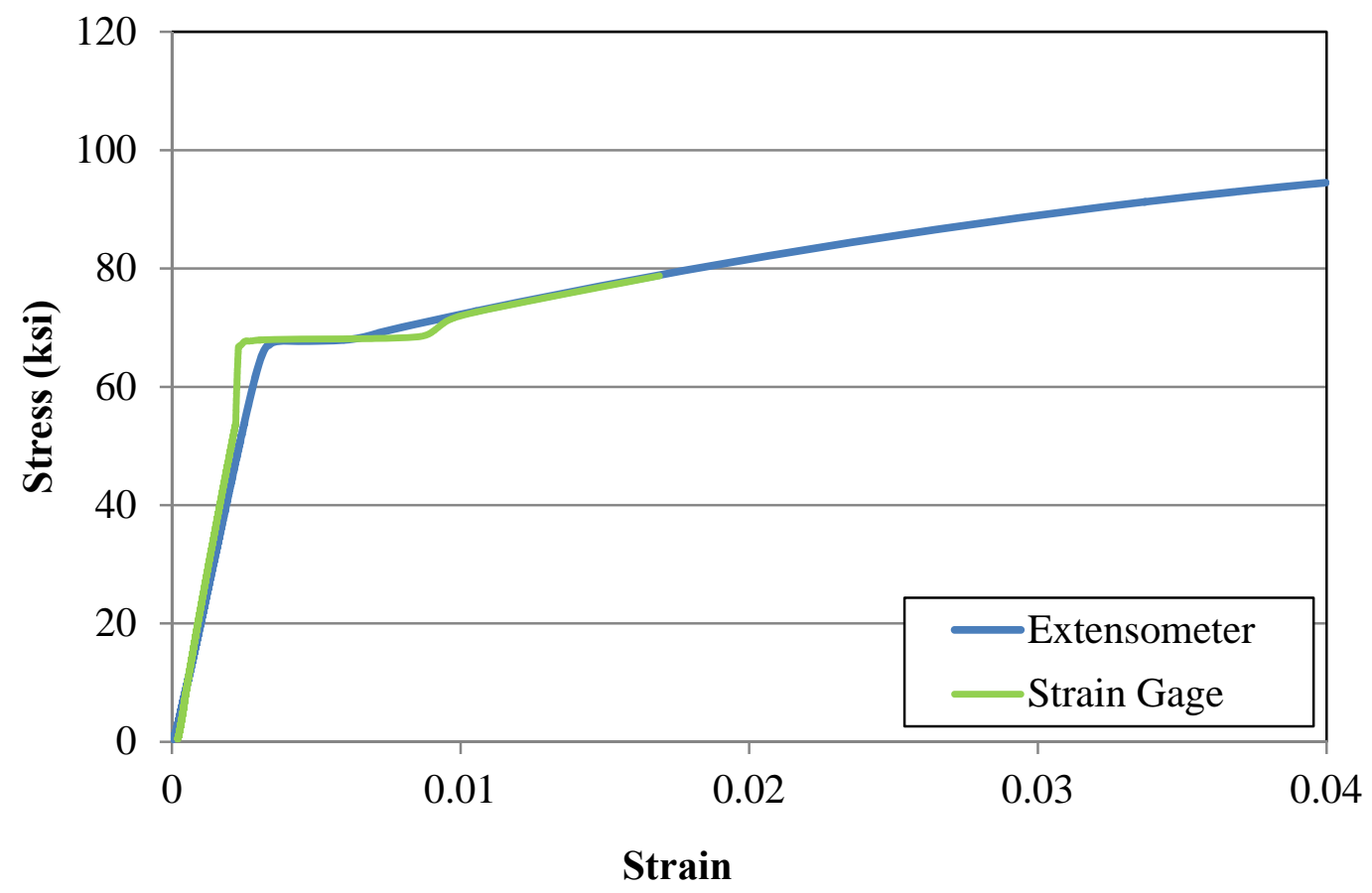

Figure 5.15: Reinforcement tensile strength (\#4 bar) 


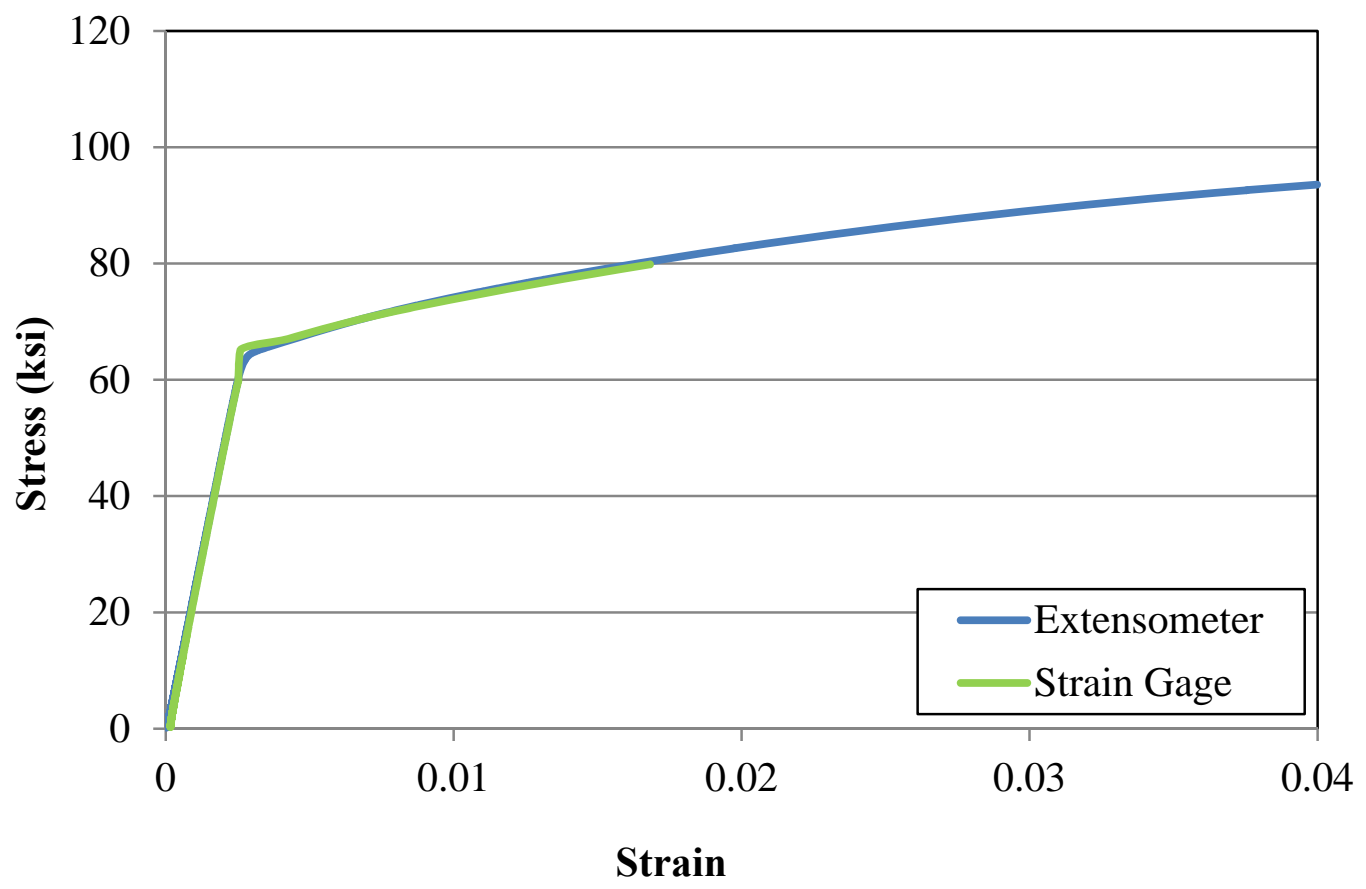

Figure 5.16: Reinforcement tensile strength (\#5 bar)

Table 5.4: Yield and ultimate stress

\begin{tabular}{|c|c|c|}
\hline Bar Size & $\mathbf{f}_{\mathbf{y}}(\mathbf{k s i})$ & $\mathbf{f}_{\mathbf{u}}(\mathbf{k s i})$ \\
\hline$\# 4$ & 68 & 98 \\
\hline$\# 5$ & 64 & 97 \\
\hline
\end{tabular}

\subsubsection{Steel Girder}

A W12x65 steel shape was used to construct the concrete deck specimens. The stud shear connectors were installed in the steel fabrication shop. The steel girders correspond to ASTM A572 Grade 50. 


\subsection{Instrumentation}

Instrumentation was installed to evaluate the behavior of the specimens and in particular the deck subjected to restrained shrinkage and thermal volumetric changes. For this purpose, linear potentiometers, strain gages, and thermocouples were installed at different locations throughout the specimens. All specimens had the same instrumentation layout except for Specimens 1 and 2 which included an additional strain gage at the bottom flange of the girder. The location of the instrumentation in each specimen is shown in Figure 5.17 to Figure 5.22. The gages in the deck are illustrated in the plan view while the gages on the girder are illustrated in the elevation view. All instrumentation is identified as follows: (Specimen)-(Gage Type)-(Deck/Girder)-(Gage \#) 


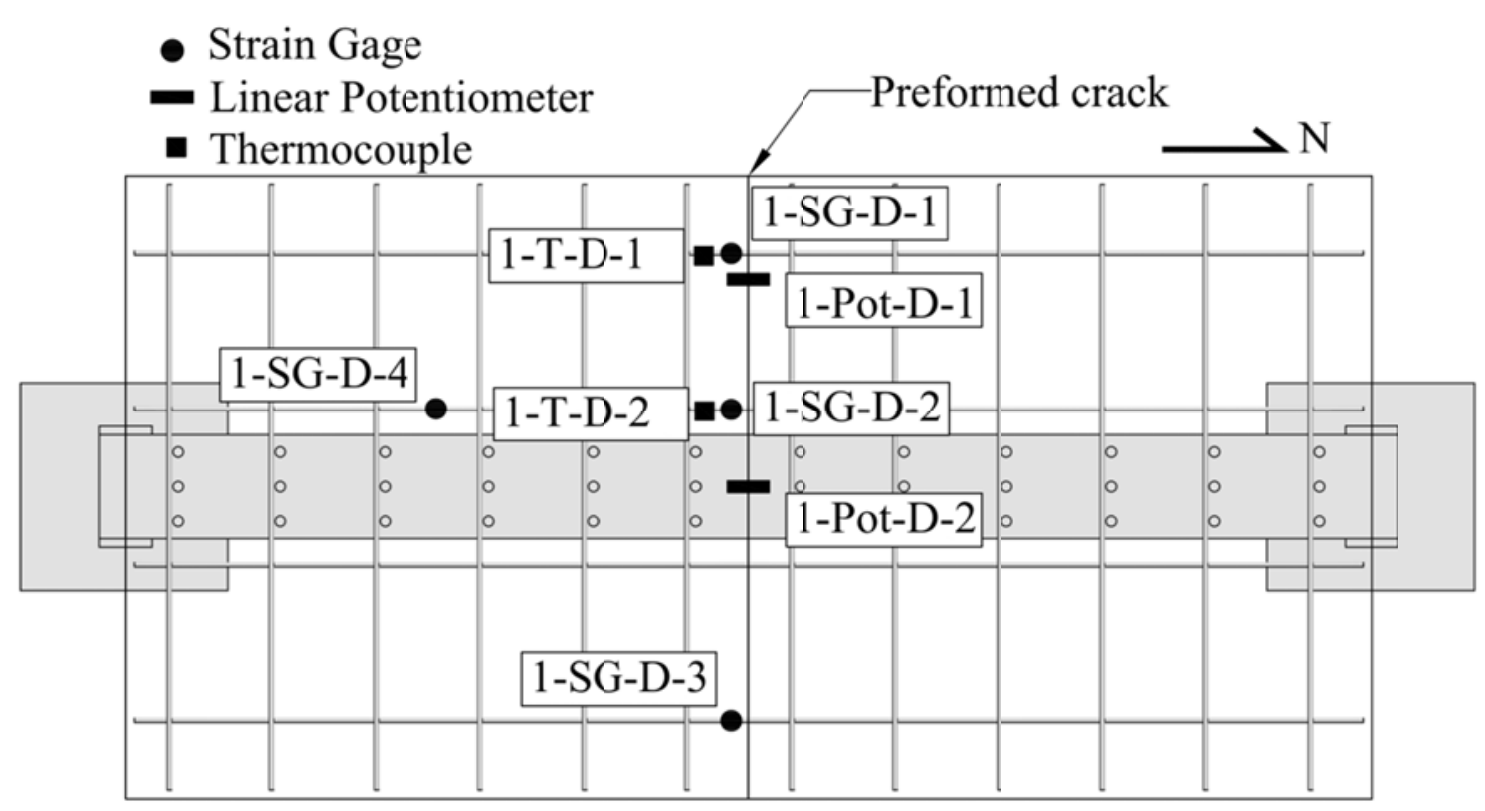

a) Plan view of deck gages

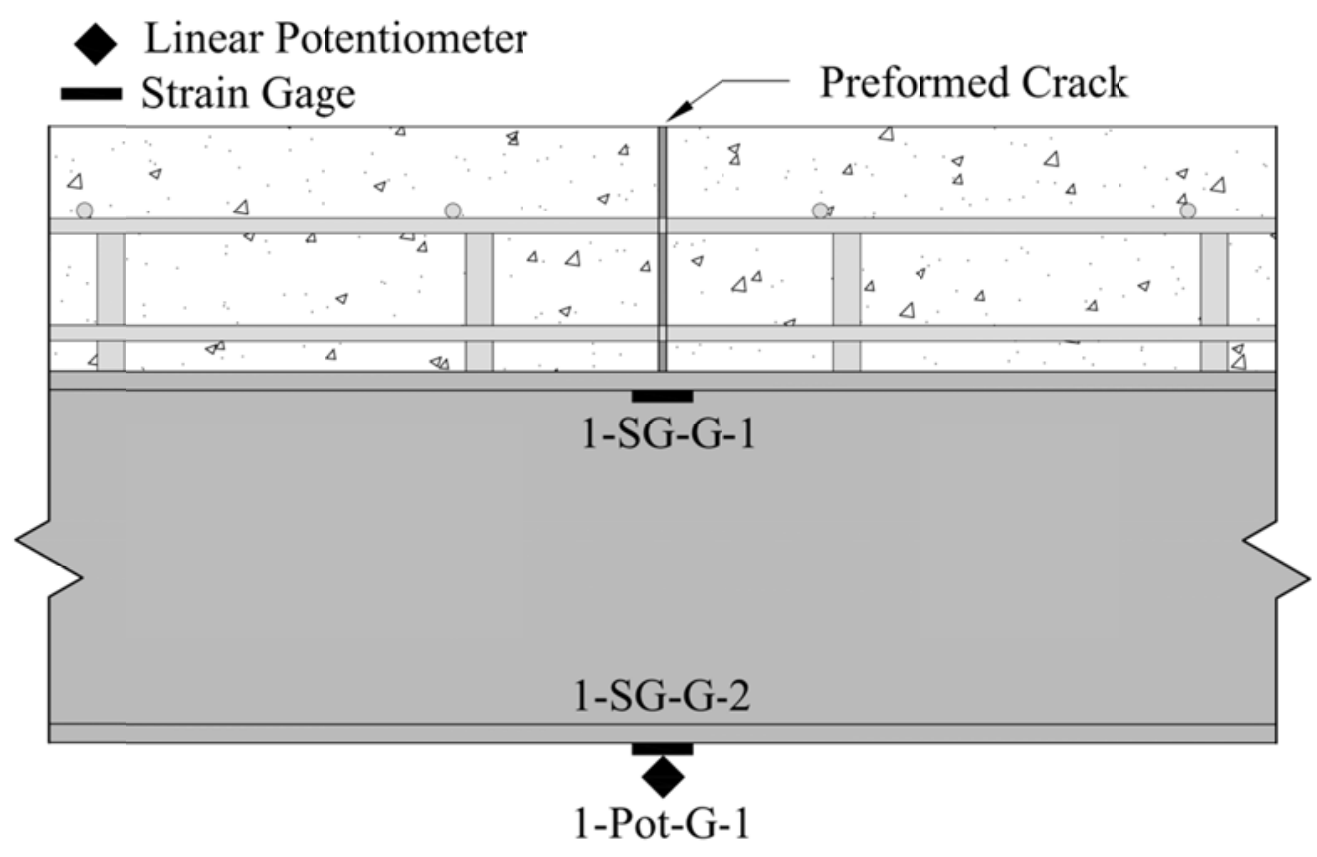

b) Elevation view of girder gages

Figure 5.17: Instrumentation layout, Specimen 1 


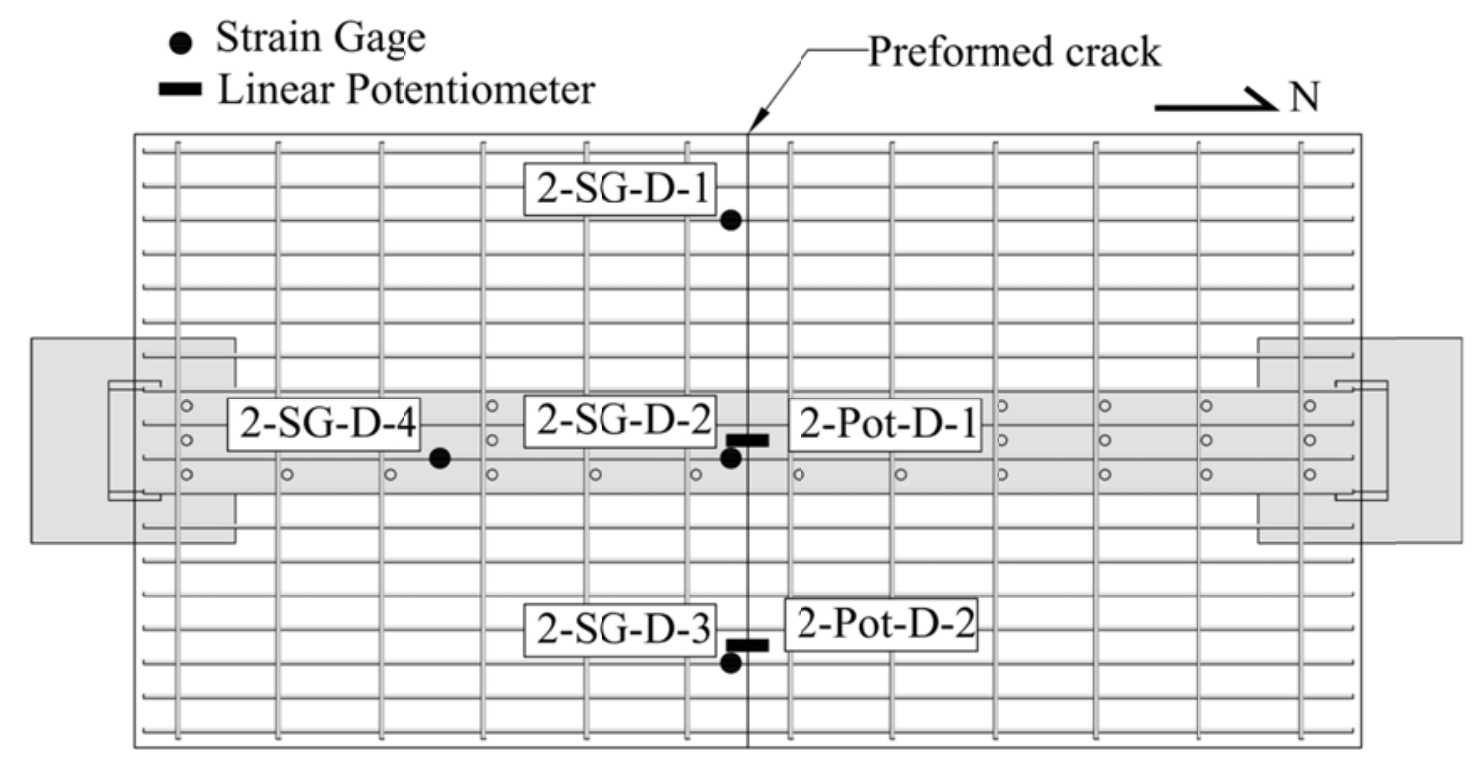

a) Plan view of deck gages

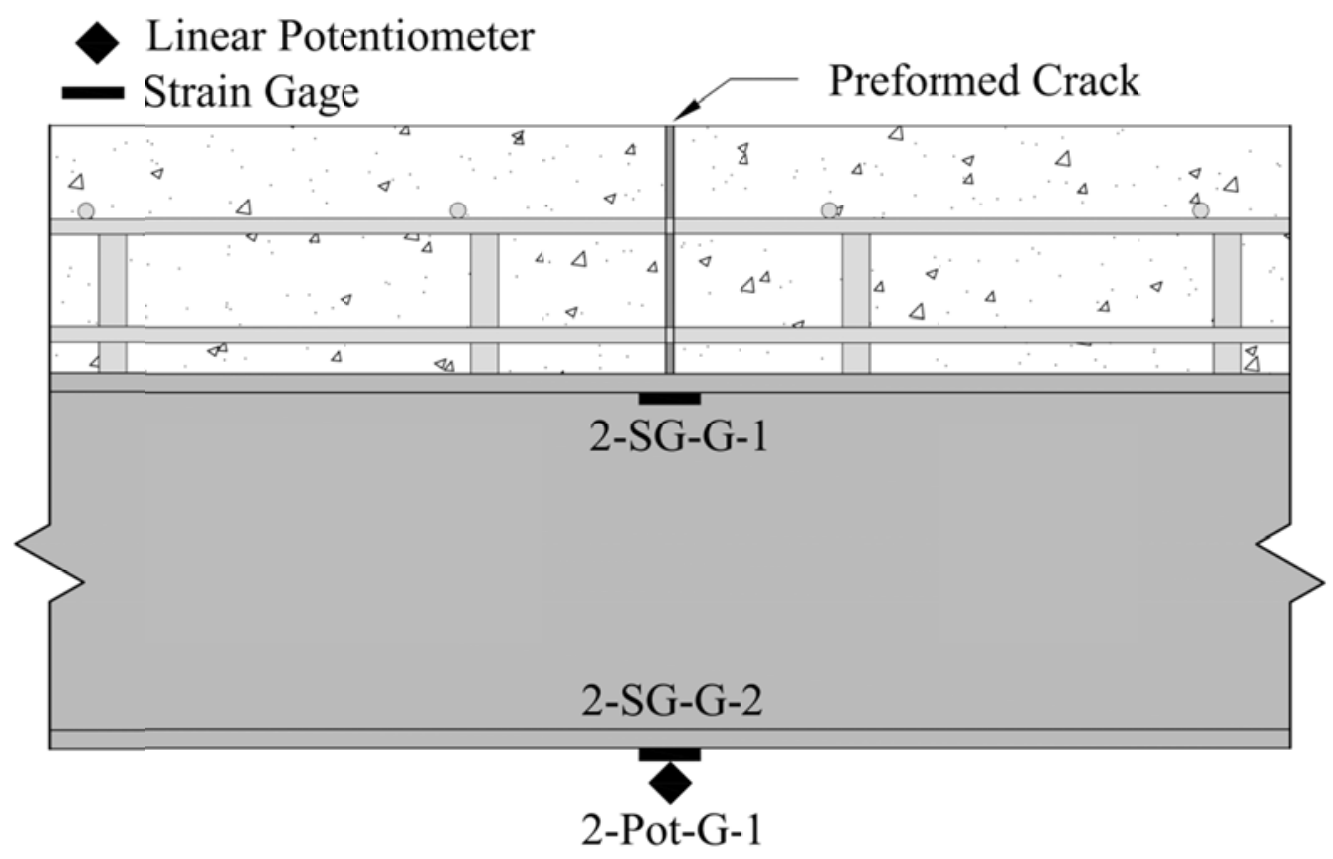

b) Elevation view of girder gages

Figure 5.18: Instrumentation layout, Specimen 2 


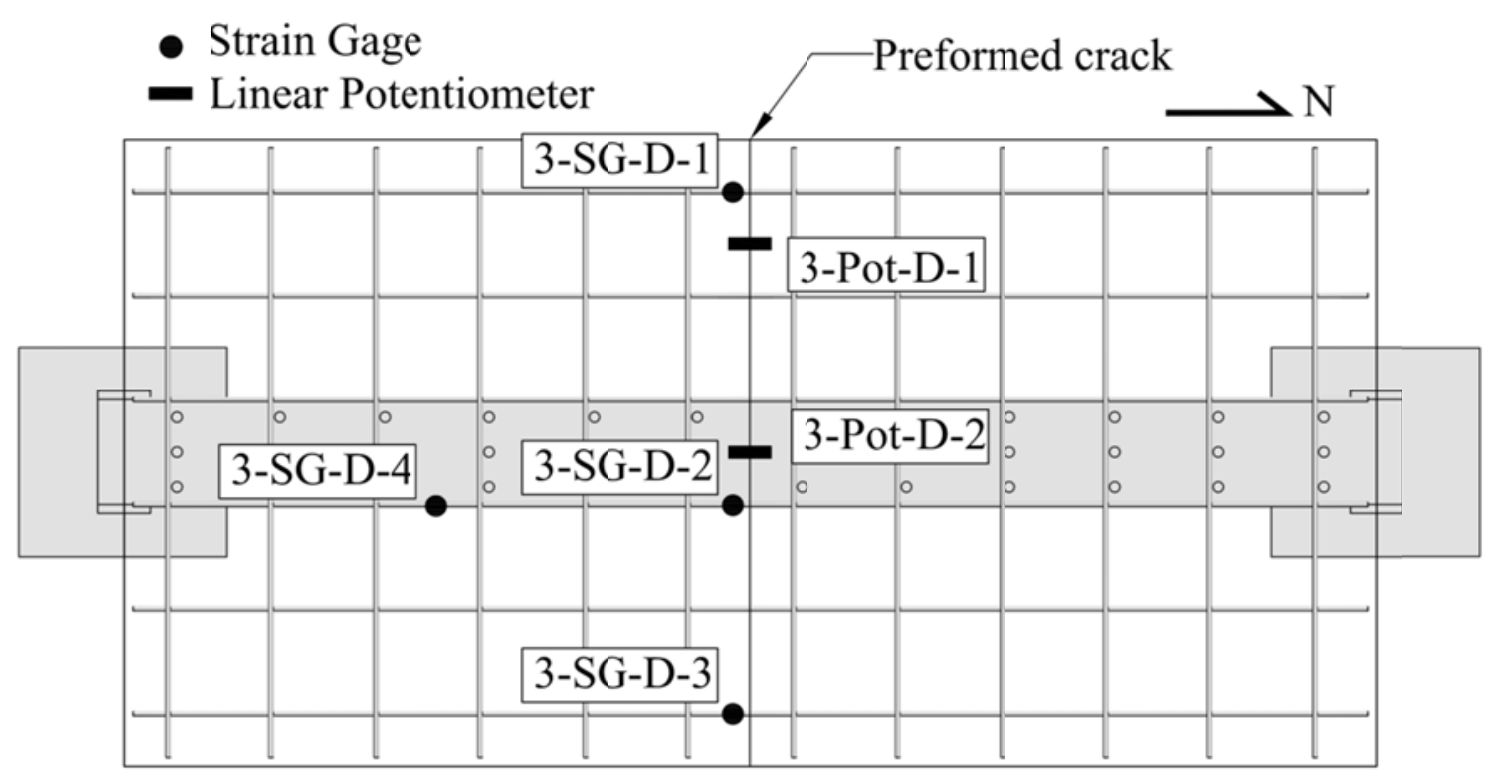

a) Plan view of deck gages

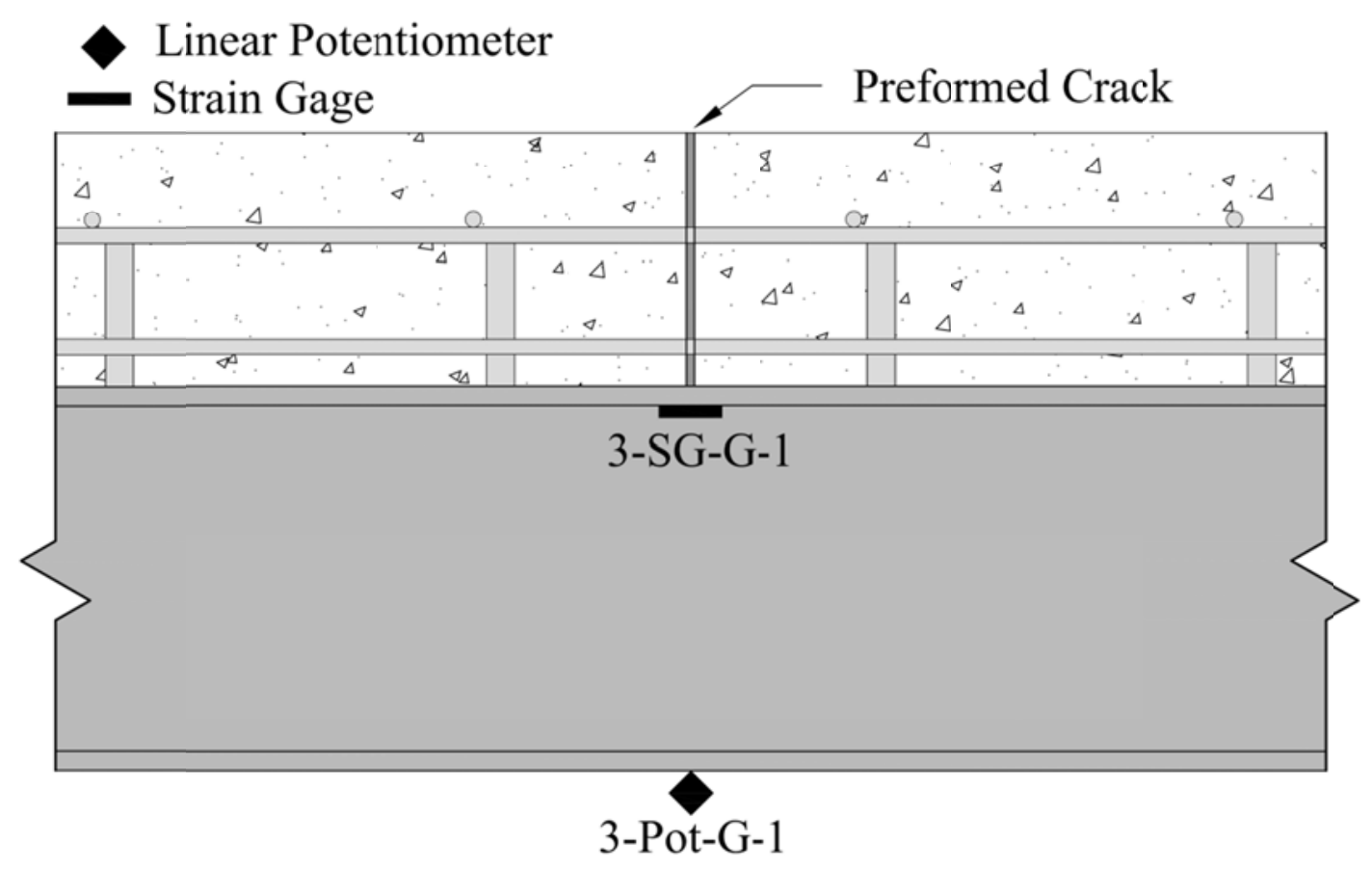

b) Elevation view of girder gages

Figure 5.19: Instrumentation layout, Specimen 3 


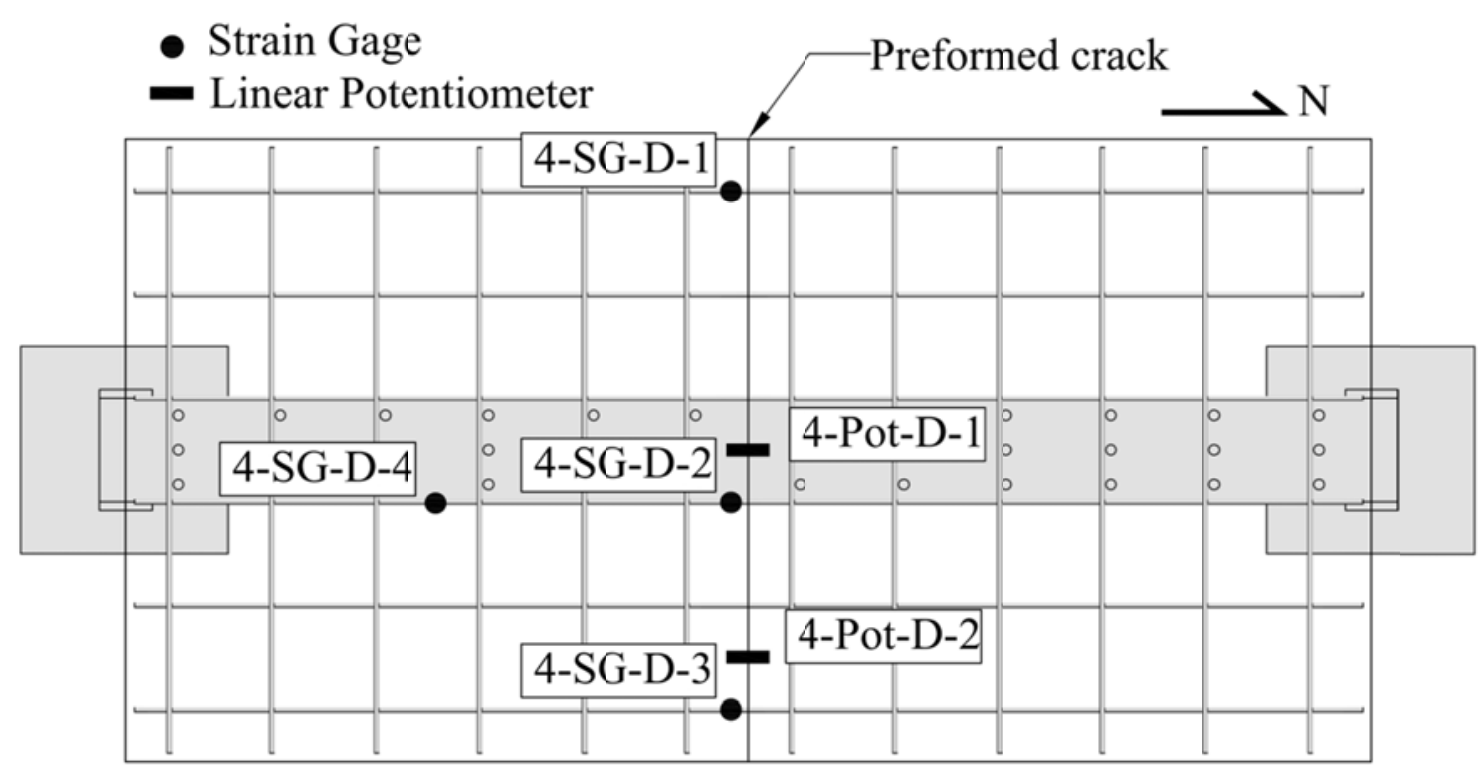

a) Plan view of deck gages

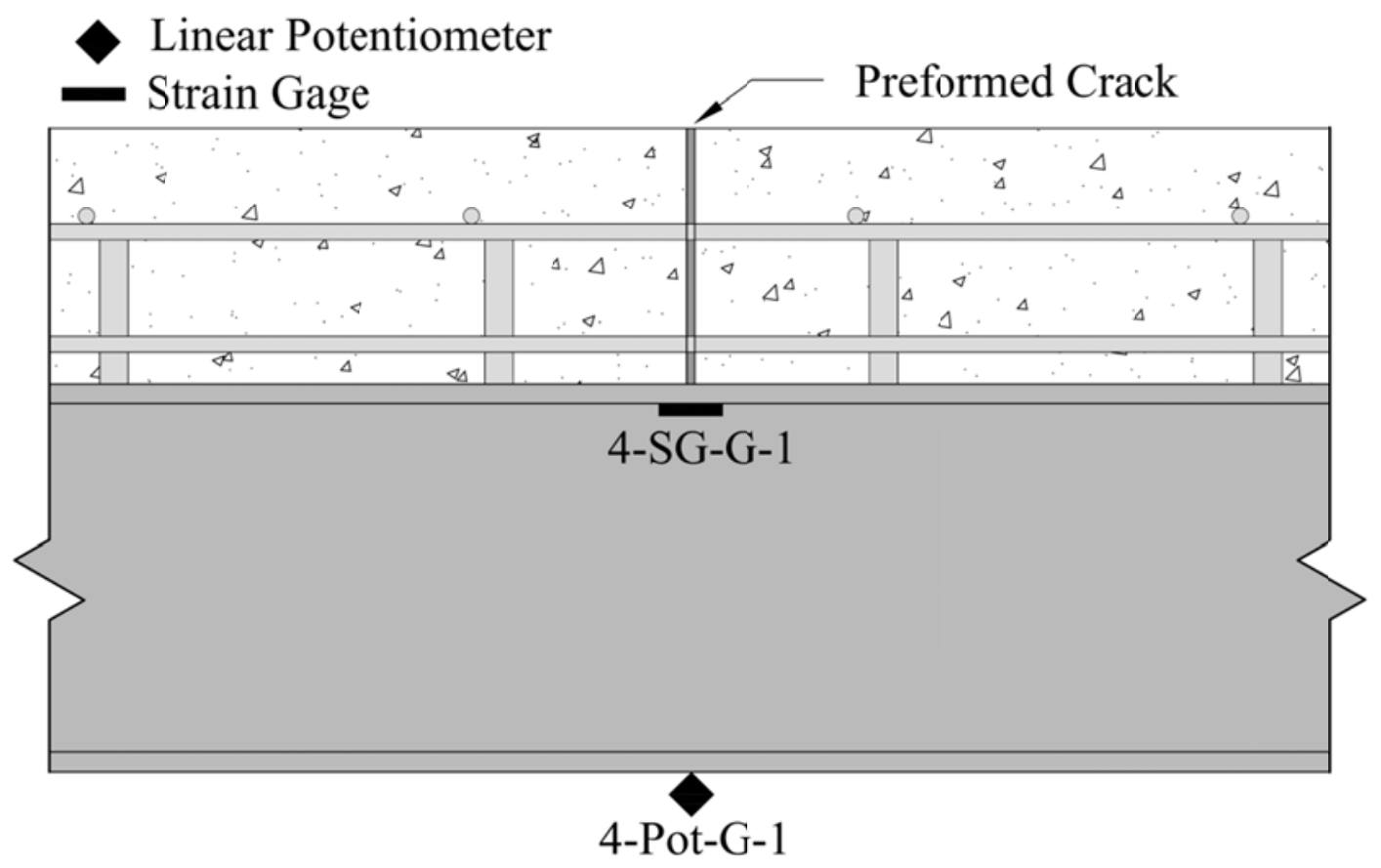

b) Elevation view of girder gages

Figure 5.20: Instrumentation layout, Specimen 4 


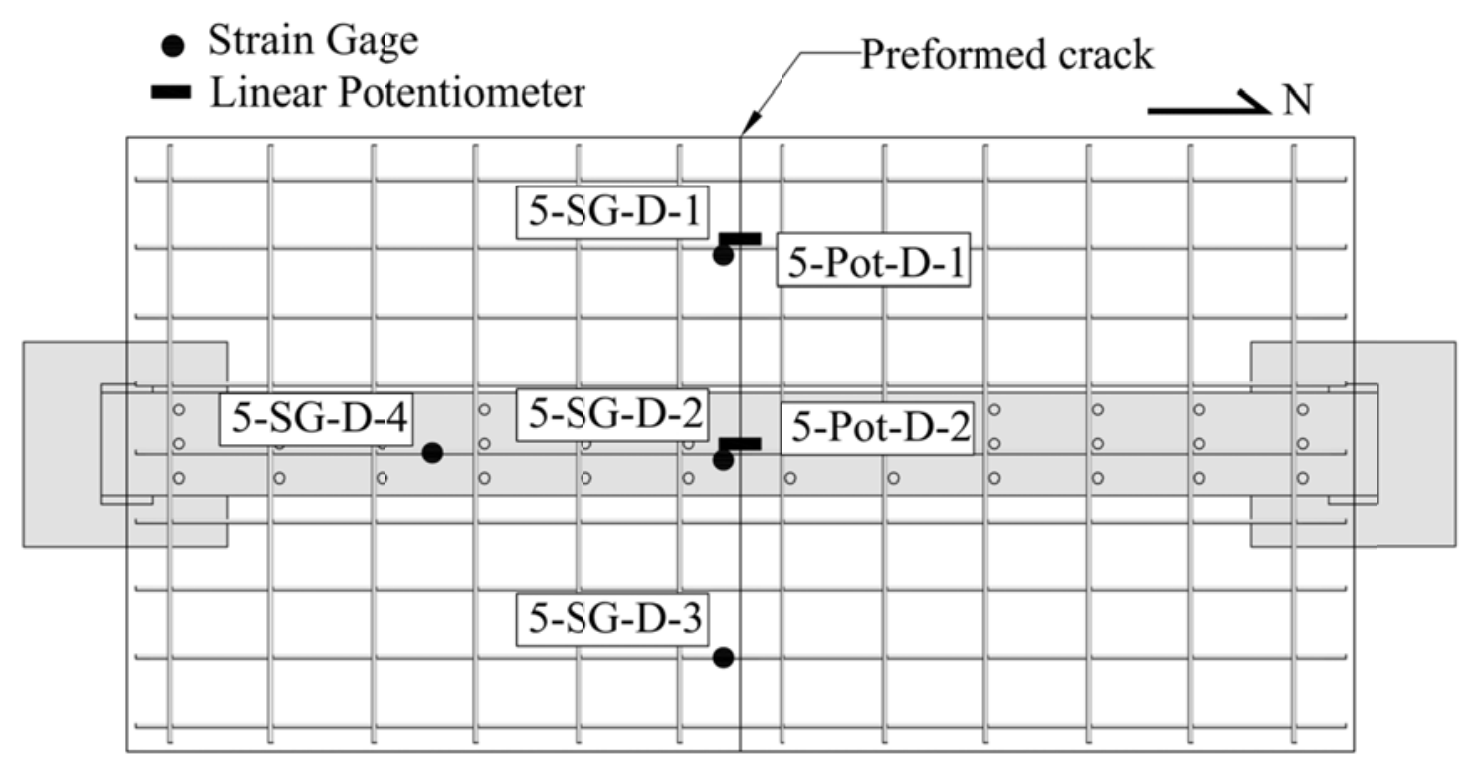

a) Plan view of deck gages

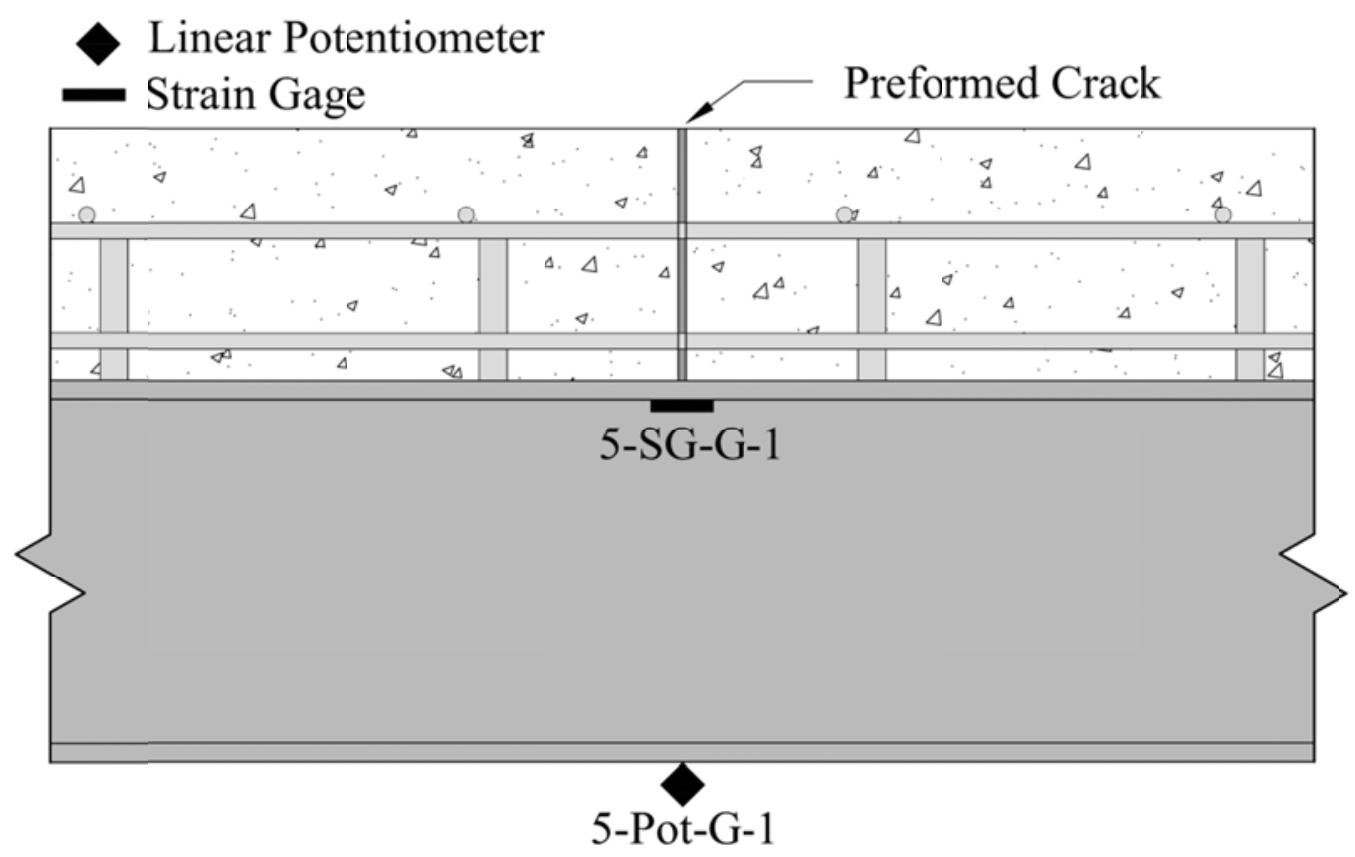

b) Elevation view of girder gages

Figure 5.21: Instrumentation layout, Specimen 5 


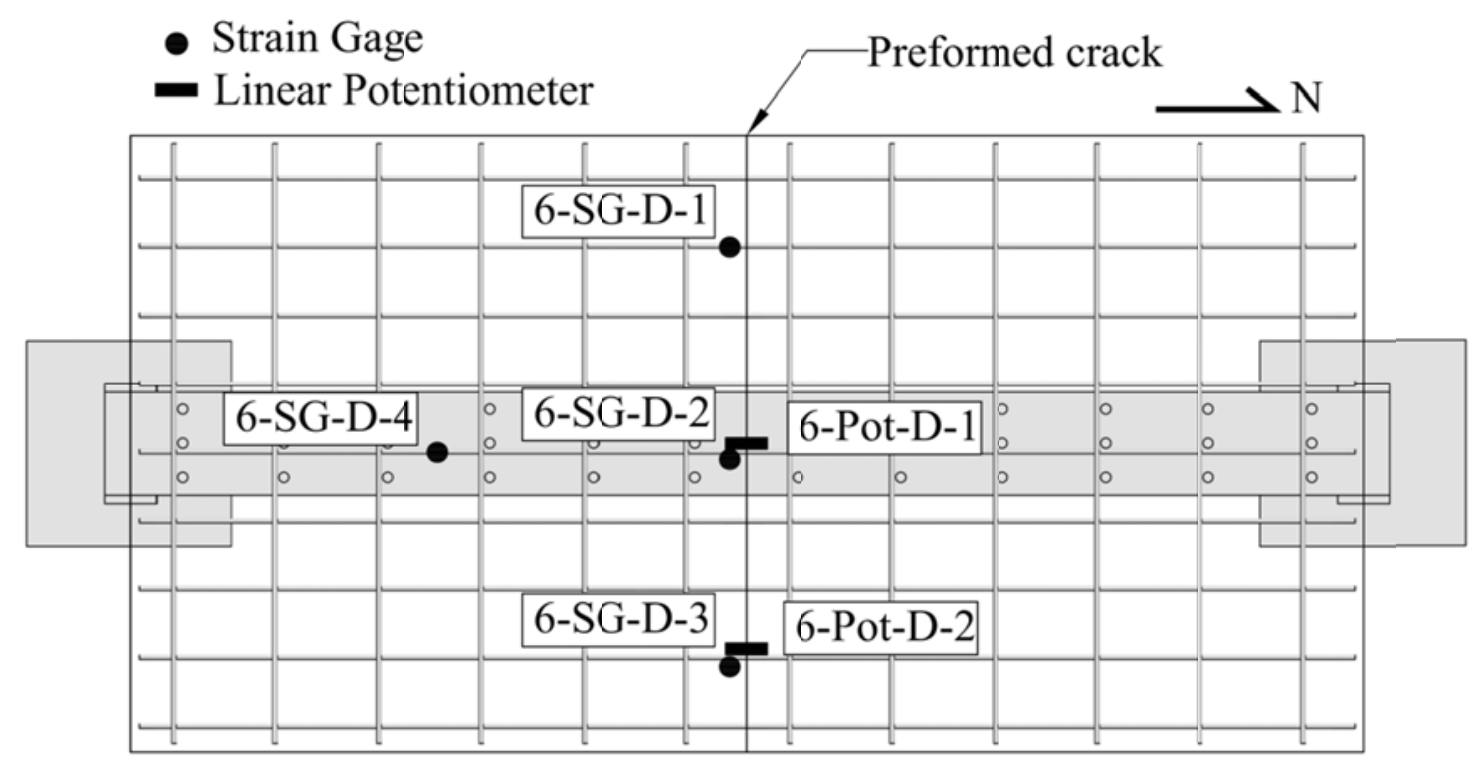

a) Plan view of deck gages

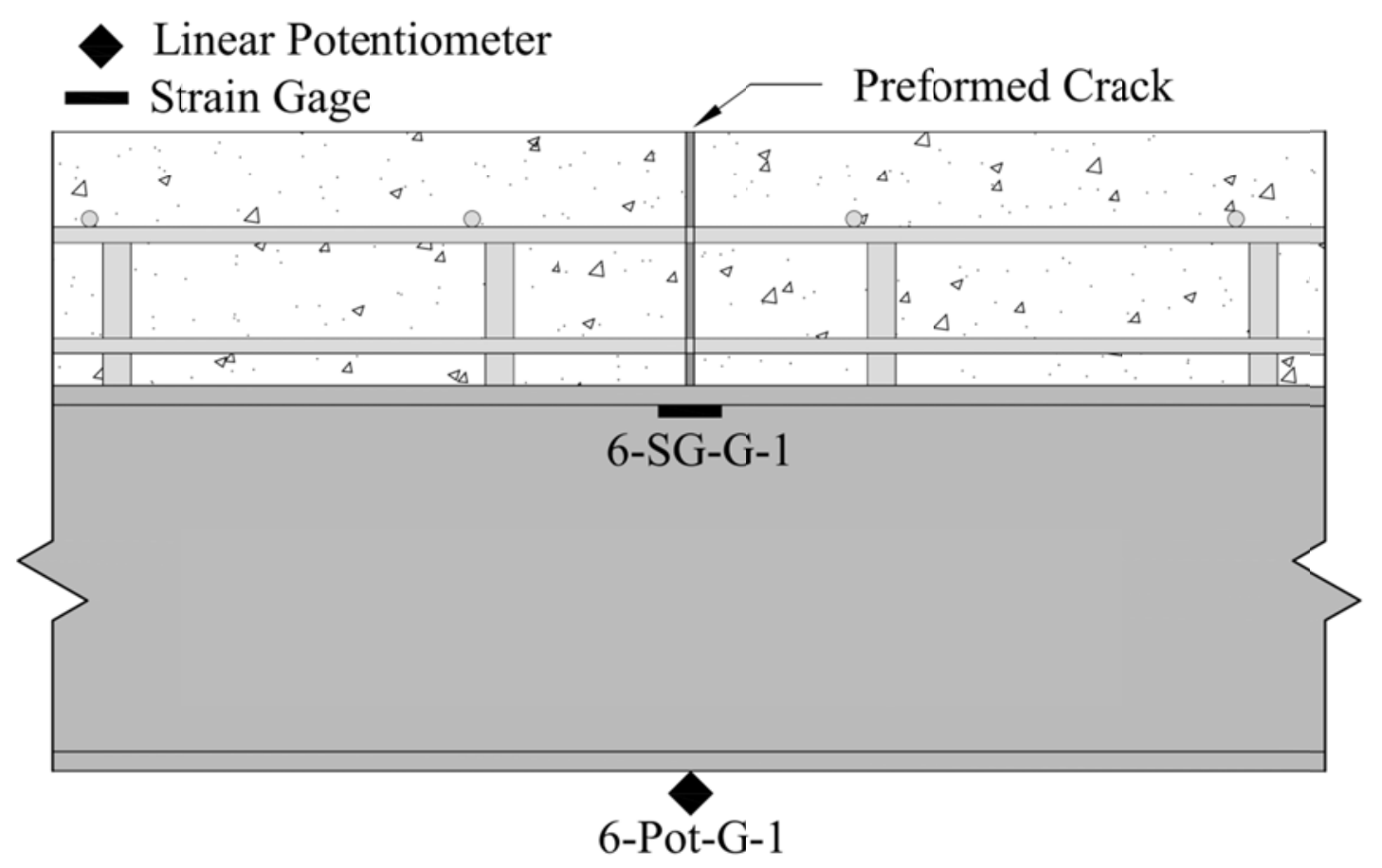

b) Elevation view of girder gages

Figure 5.22: Instrumentation layout, Specimen 6 


\subsubsection{Strain Gages}

Strain gages were installed on the top reinforcement to measure strains near the pre-formed crack and at the quarterspan of the deck. In addition, gages were installed on the girder flanges to determine the stain gradient through the depth of the girder. A CEA06-250UW-350/P2 strain gage from Vishay Micro Measurements was used at these locations. The strain gage details are listed in Table 5.5. To ensure protection of the gages, M-Coat B and M-Coat F were used on the reinforcement while M-COAT B was used on the girder gages. The strain gages and protective coating were applied according to Vishay Micro Measurements installation procedures. Figure 5.23 shows the strain gages located on the top longitudinal reinforcement at midspan, adjacent to the simulated crack.

Table 5.5: Strain gage specifications

\begin{tabular}{|c|c|}
\hline Gage Type & CEA-06-250UW-350/P2 \\
\hline Resistance in Ohms at $24^{\circ} \mathrm{C}$ & $350 \pm 0.3 \%$ \\
\hline Gage Factor at $24^{\circ} \mathrm{C}$ & $2.07 \pm 1.0 \%$ \\
\hline Temperature Range & $-100^{\circ}$ to $+350^{\circ} \mathrm{F}\left[-75^{\circ}\right.$ to $\left.+175^{\circ} \mathrm{C}\right]$ \\
\hline Strain Range & $\pm 3.0 \%$ \\
\hline Gage Length & 0.250 \\
\hline
\end{tabular}




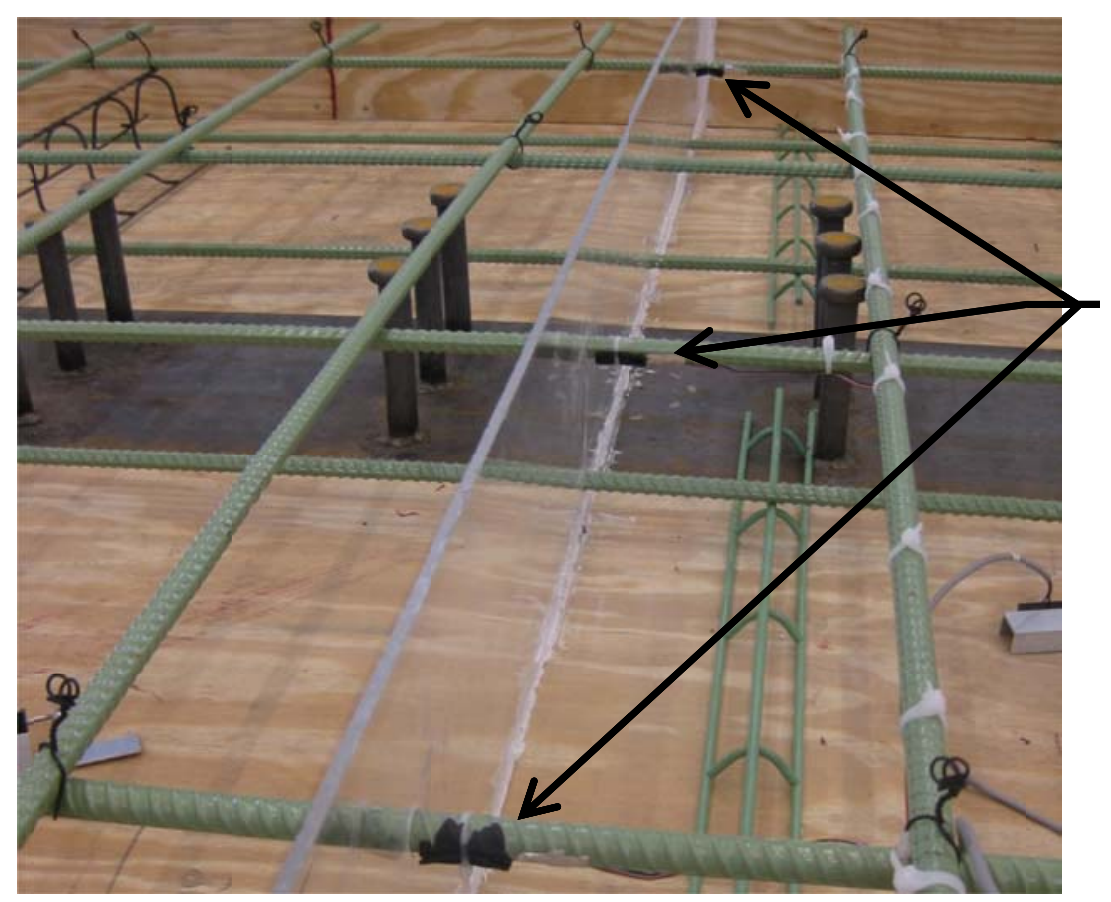

Figure 5.23: Strain gages at midspan

\subsubsection{Linear Potentiometers}

Linear potentiometers were installed on the test specimens to measure crack growth as well as girder deflections at midspan throughout the duration of the test. The potentiometers were obtained from ETI Systems and were specified as LCP12A-12-1K with an electrical stroke of 0.5 in. The potentiometers were calibrated using an Instron Extensiometer High Magnitude Calibrator up to a precision of ten thousandths (0.0001) of an inch. The calibration data was recorded in the System 7000 StrainSmart software for each potentiometer. The deck potentiometers were attached to aluminum sections to facilitate embedment of the gage in concrete. Similarly, the potentiometers located under the girders where mounted to aluminum sections and then attached to a stand allowing measurement of deflections. For the deck potentiometers, the aluminum sections were coated to avoid any chemical reaction between the concrete and aluminum. Figure 5.24 shows the potentiometers at both locations. 


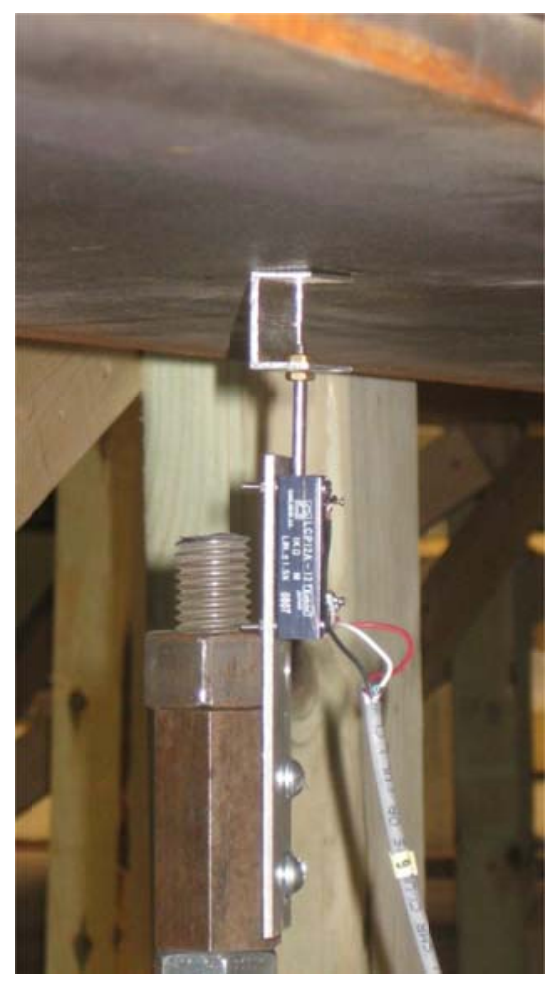

a) Deflection measurements

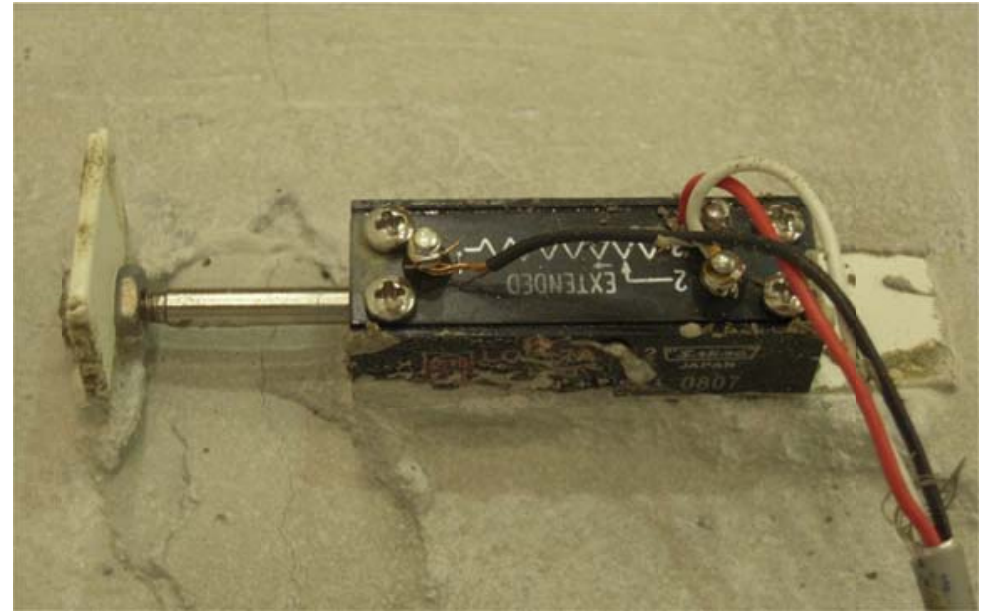

b) Crack growth measurements

Figure 5.24: Girder and deck potentiometers

\subsubsection{Thermocouples}

Thermocouples were installed to record the ambient temperature and the concrete temperature in Specimen 1. Thermocouples were made of Type $\mathrm{T}$ thermocouple wire from Omega Engineering Inc. A silicone was applied on the thermocouples to ensure their protection when casting the deck specimen. In Specimen 1, two thermocouples were placed as close as possible to the strain gages (1-SG-D-1 and 1-SG-D-2) to evaluate the influence of temperature on the gage measurements. In addition, a thermocouple was placed next to the System 7000 to measure the ambient temperature. The copper and constantan wires were connected to the System 7000 such that the temperatures were continuously monitored. 


\subsection{Data Collection}

A Vishay Micro-Measurements System 7000 was used to collect data during the test. A laptop computer and StrainSmart software were used to acquire, reduce, and store the data from the gages. Prior to casting, data were collected to ensure proper functioning of the system. The potentiometers and strain gages were zeroed 1 hour prior to casting of the specimens. Zeroing of the thermocouples was not required since they measure the actual temperature. The data were scanned every 10 seconds and recorded every 5 minutes. In general, data were downloaded and examined weekly.

The width of the pre-formed cracks was also measured using a crack measuring microscope (Bausch \& Lomb). For each specimen, cracks were measured approximately at the center and $1 \mathrm{ft}$ from both edges of the deck. Measurements were made at the same location each time.

\subsection{Results}

All gages installed remained functional after casting. The gage measurements are presented in this section. Gages were zeroed at 5 days, after curing of the specimens and formwork removal. At Day 5, the heat of hydration had dissipated. As shown in Figure 5.25, at 5 days, the gages read essentially zero. By zeroing all gages at this time, the shrinkage behavior of all specimens can be assessed without any slight variations caused by formwork removal. From the data, the general behavior of the gage measurements was evaluated. These measurements included strains in the longitudinal reinforcement and girder, crack width displacements, and girder deflections. The test results allow comparison of the various parameters to assess their effectiveness in controlling crack widths. 


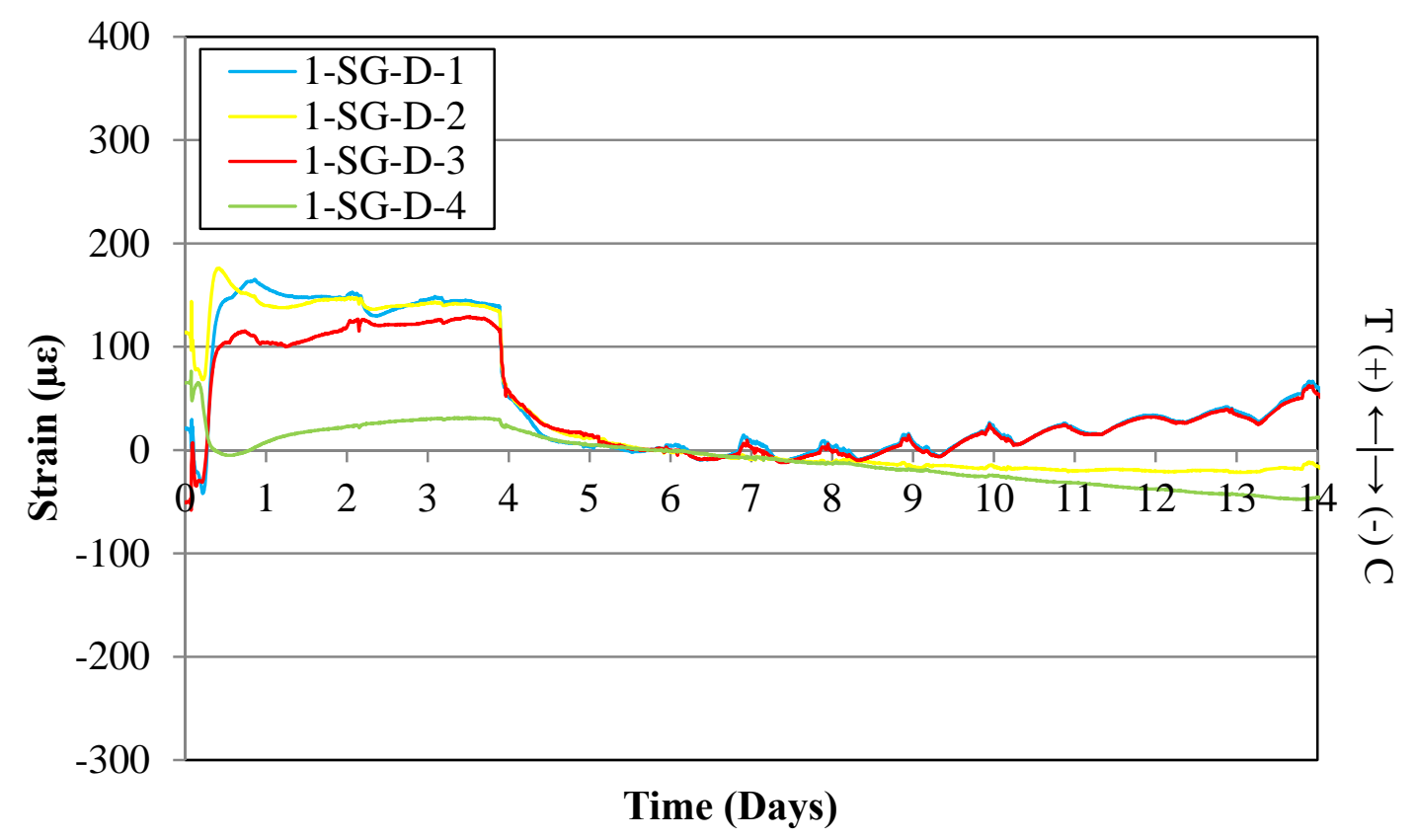

Figure 5.25: Typical early age strain behavior (Specimen 1)

\subsubsection{Thermocouples}

During the test, three thermocouples were used to obtain the ambient temperature and the temperature in the concrete deck (Specimen 1) near two strain gages placed on the longitudinal reinforcement. Only Specimen 1 was installed with thermocouples to provide a typical temperature trend to be used for all specimens. Figure 5.26 presents the temperature during the first 10 days. As shown, the ambient temperature exhibited sudden variations due to temporary opening of the overhead door which was located near the specimens. In addition, the difference between the deck and ambient temperature caused by the heat of hydration can be observed during the first four days. A peak temperature of $135^{\circ} \mathrm{F}$ was reached 8 hours after casting of the decks. Both embedded thermocouples measured approximately the same temperature. The deck and ambient temperatures were essentially the same after 4 days until the end of the test as shown in Figure 5.27. Again, sudden variations in air temperature recorded by the ambient gage are evident due to opening of the overhead doors. 


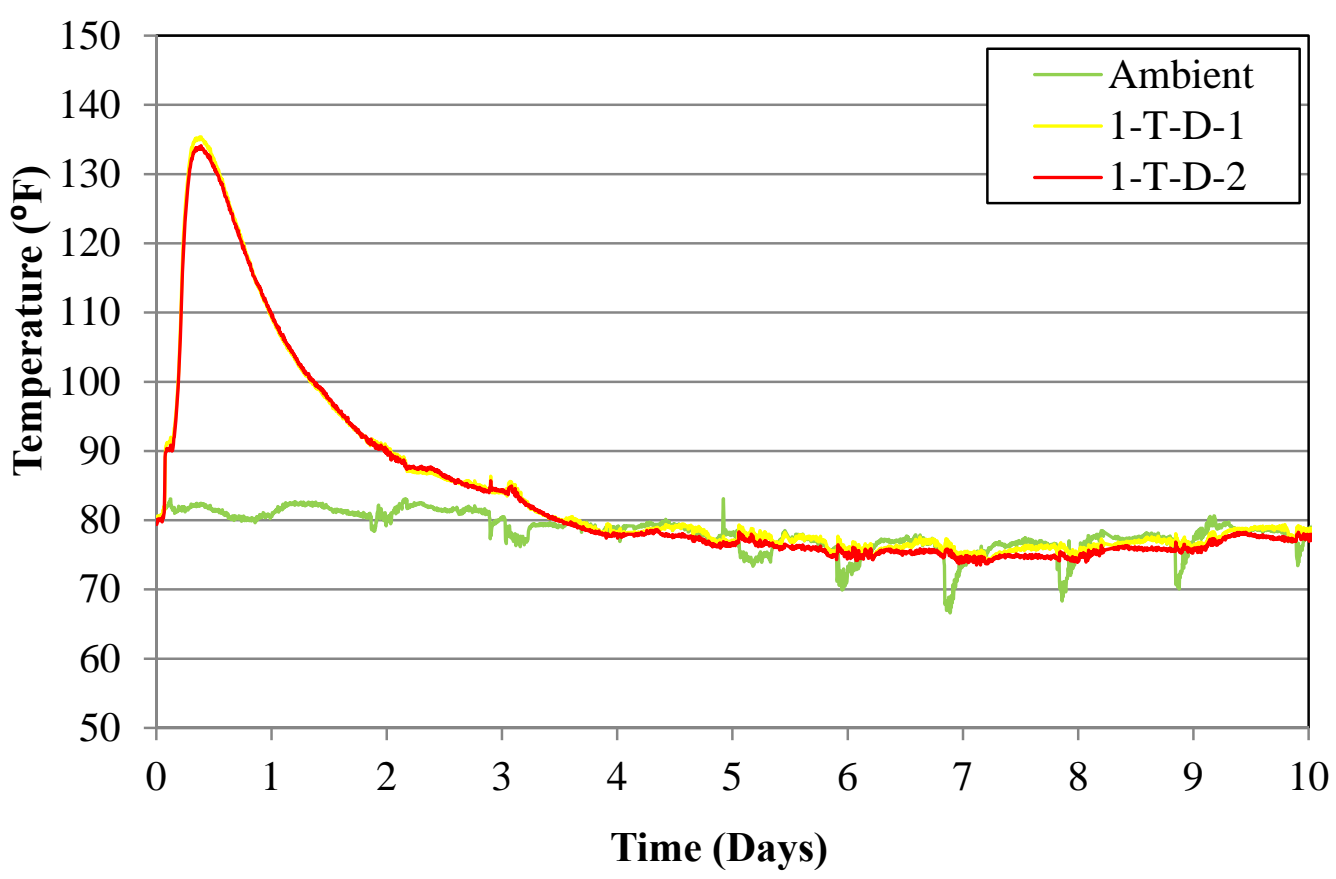

Figure 5.26: Ambient and deck temperature (first week)

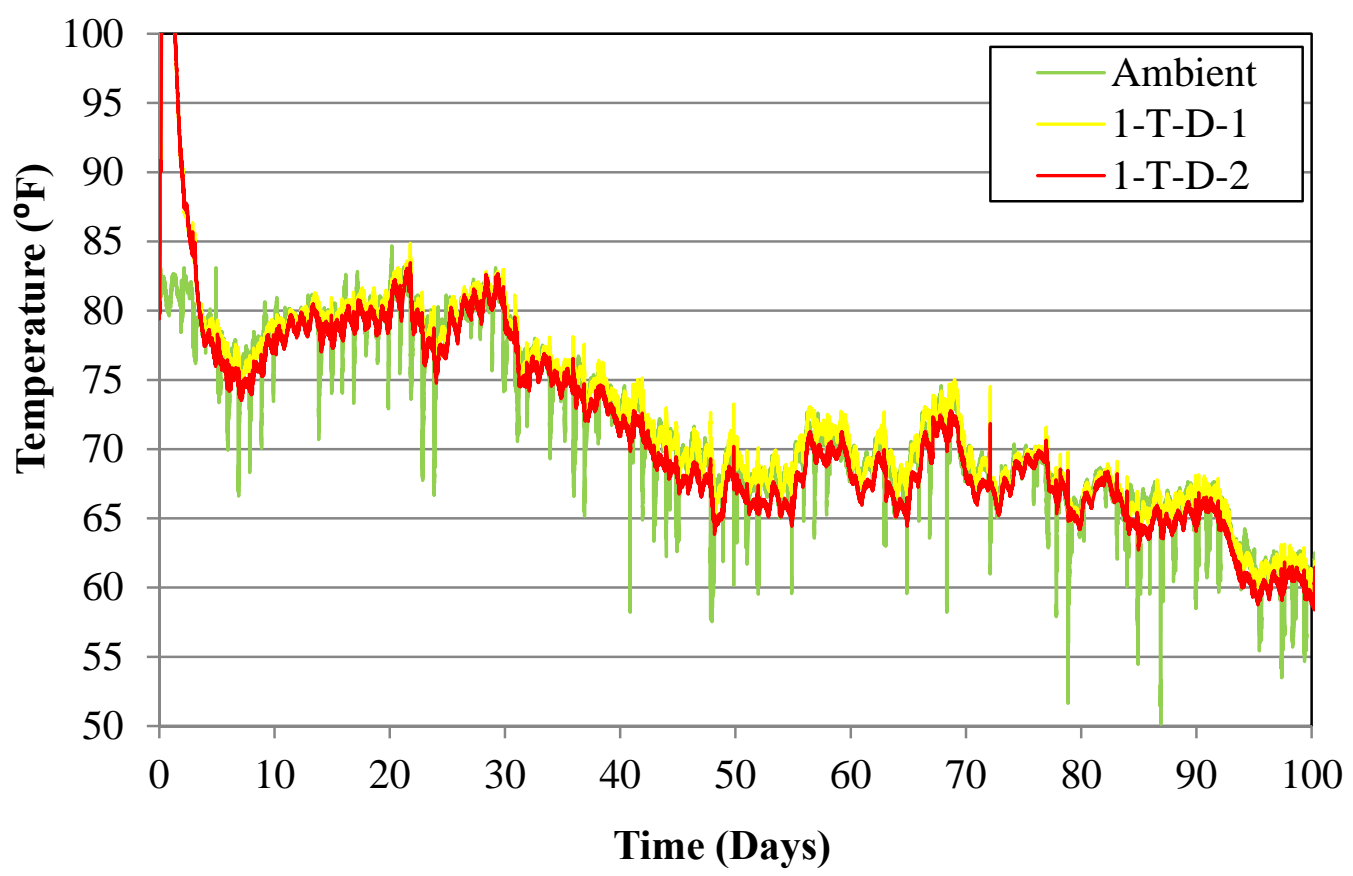

Figure 5.27: Ambient and deck temperature 


\subsubsection{Reinforcement Strain Gages}

In all specimens, Gages 1-3 measured strains near the crack location while Gage 4 measured strains at the quarterspan of the deck (Section 5.6). Overall, the strain behavior for Gages 1 and 3 was essentially the same in all specimens. A rapid increase was exhibited after initial set (Figure 5.25), approximately 6 hours after casting, in response to the thermal expansion of the concrete during hydration. At the peak temperature, the maximum strain was reached. Then, the strains decreased slightly as the temperature declined. Throughout the curing duration, from Day 1 to Day 4, strains were fairly constant except in a few gages where the strain increased because of early shrinkage. On Day 4, a sudden decrease of strain was observed because of removal of the shores as load was transferred from the formwork to the deck/girder system. Approximately by Day 7, it appears that the lowest strains were attained. Following this day, shrinkage effects became evident and tensile strains began to rise. As exhibited in Figure 5.28, a gradual increase continued for approximately 30 days. It should be noted that the gages were zeroed at 5 days as discussed earlier. From this point onward, the stain rate decreased as the shrinkage rate declined. By the end of the test, strains were increasing at a much lower rate.

The strain behavior for Gage 2 varied with respect to Gages 1 and 3, also located at midspan. This variation is due to the proximity of the instrumented reinforcement to the steel girder and shear studs. In the first week, the strain behavior was similar to that observed for Gages 1 and 3. Approximately around Day 7, Gage 2 started to develop compressive strains. After a variable time period between the specimens, the strains began to increase because of the ongoing shrinkage. At the end of the test, all specimens with the exception of Specimen 2 indicated tensile strains. These strain values were lower than those obtained from Gages 1 and 3 because of the additional restraint provided by the girder. 
Strain gage 4 was located at quarterspan to evaluate the compressive strains induced by concrete shrinkage. In the first week, the trend was similar to the gages at midspan but the strains were smaller in magnitude. Following the first week, compressive strains increased steadily for 20 days (Figure 5.28). After this point, the compressive strains continued increasing at a lower rate. As evident, strains at the location of the crack (Gages 1-3) were tensile while strain in between the crack and end of the specimen at the quarterspan (Gage 4) was compressive. 


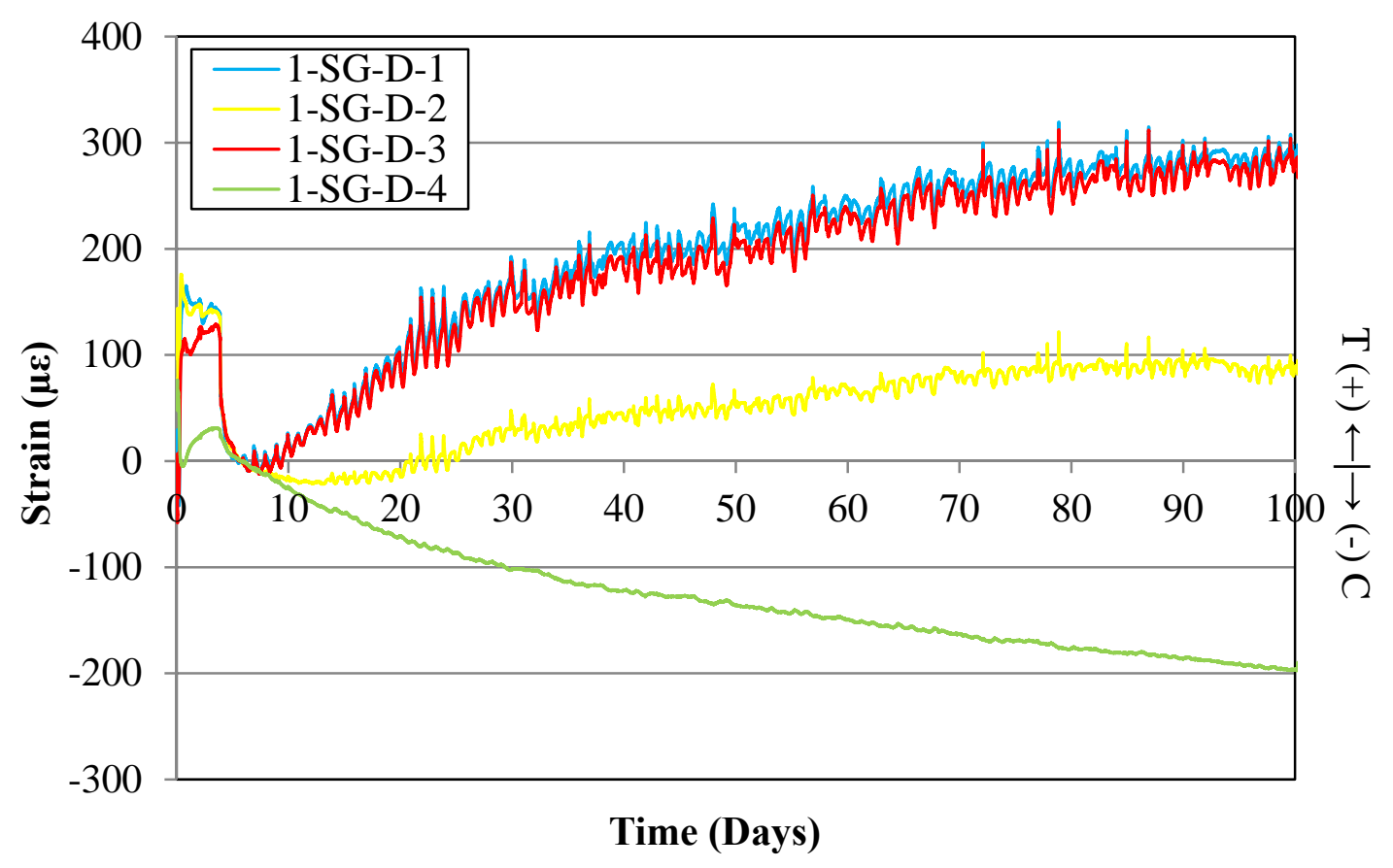

a) Specimen 1 (\#4@18”)

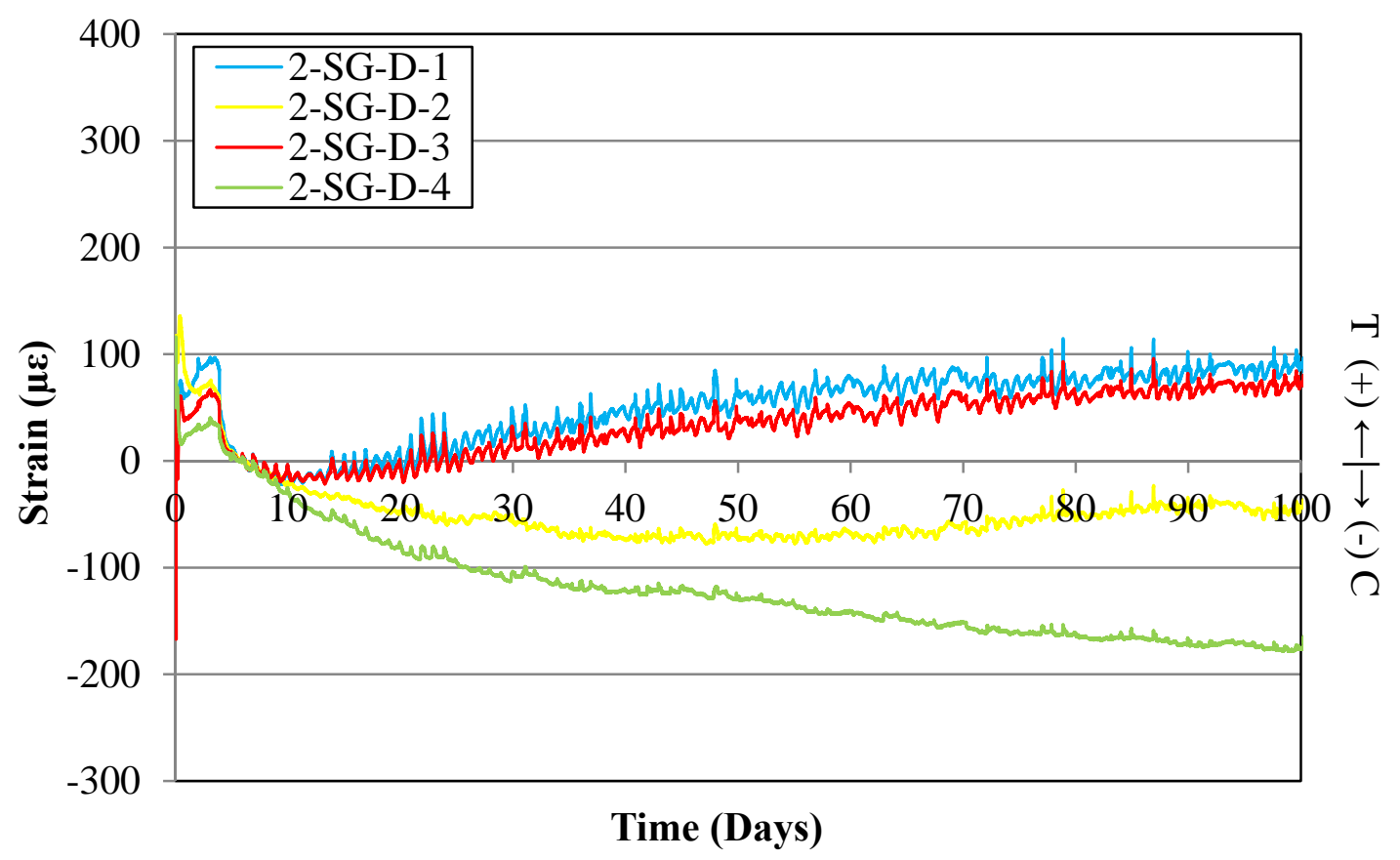

b) Specimen 2 (\#4@4")

Figure 5.28: Top longitudinal reinforcing steel strain 


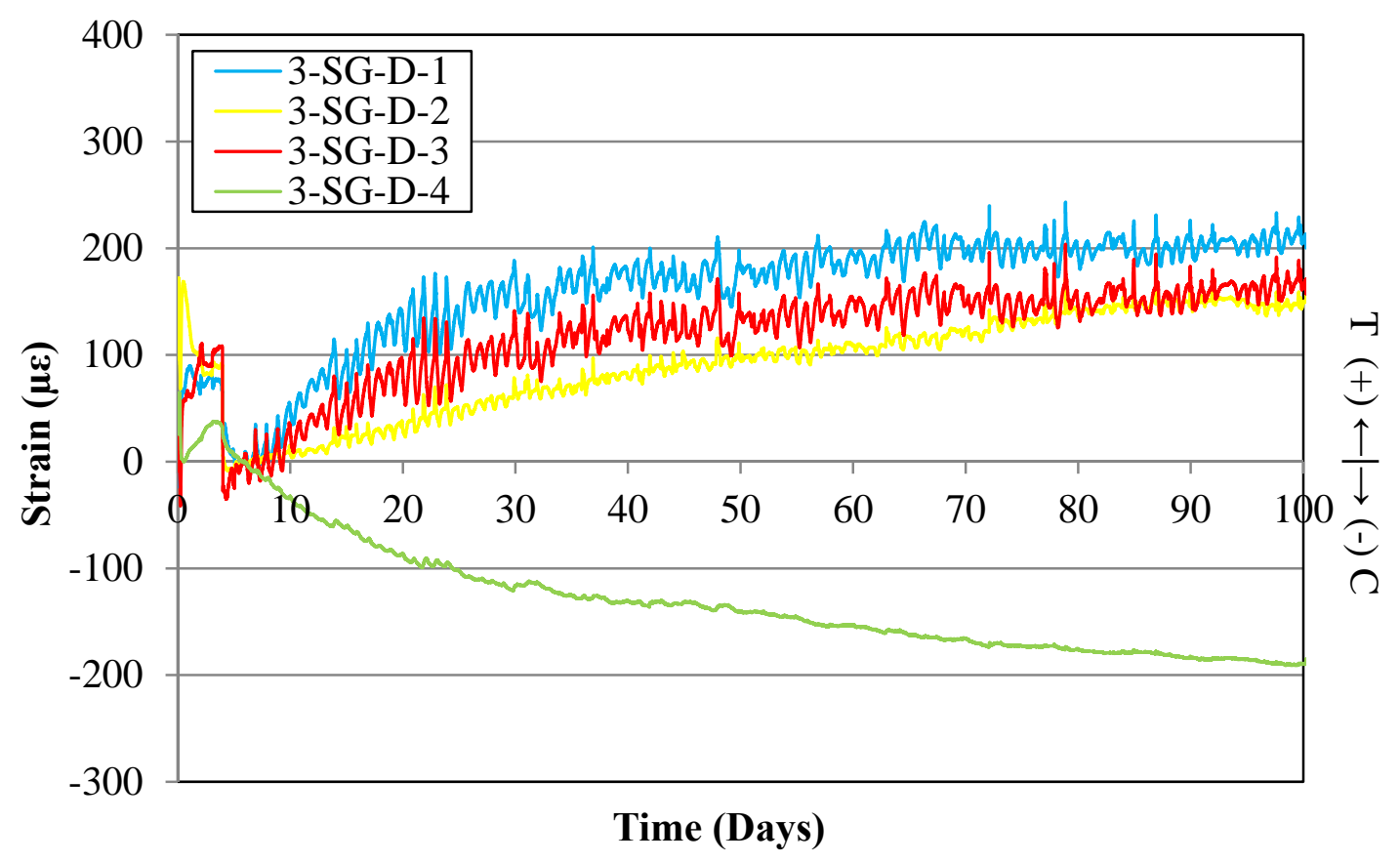

c) Specimen 3 (\#5@12")

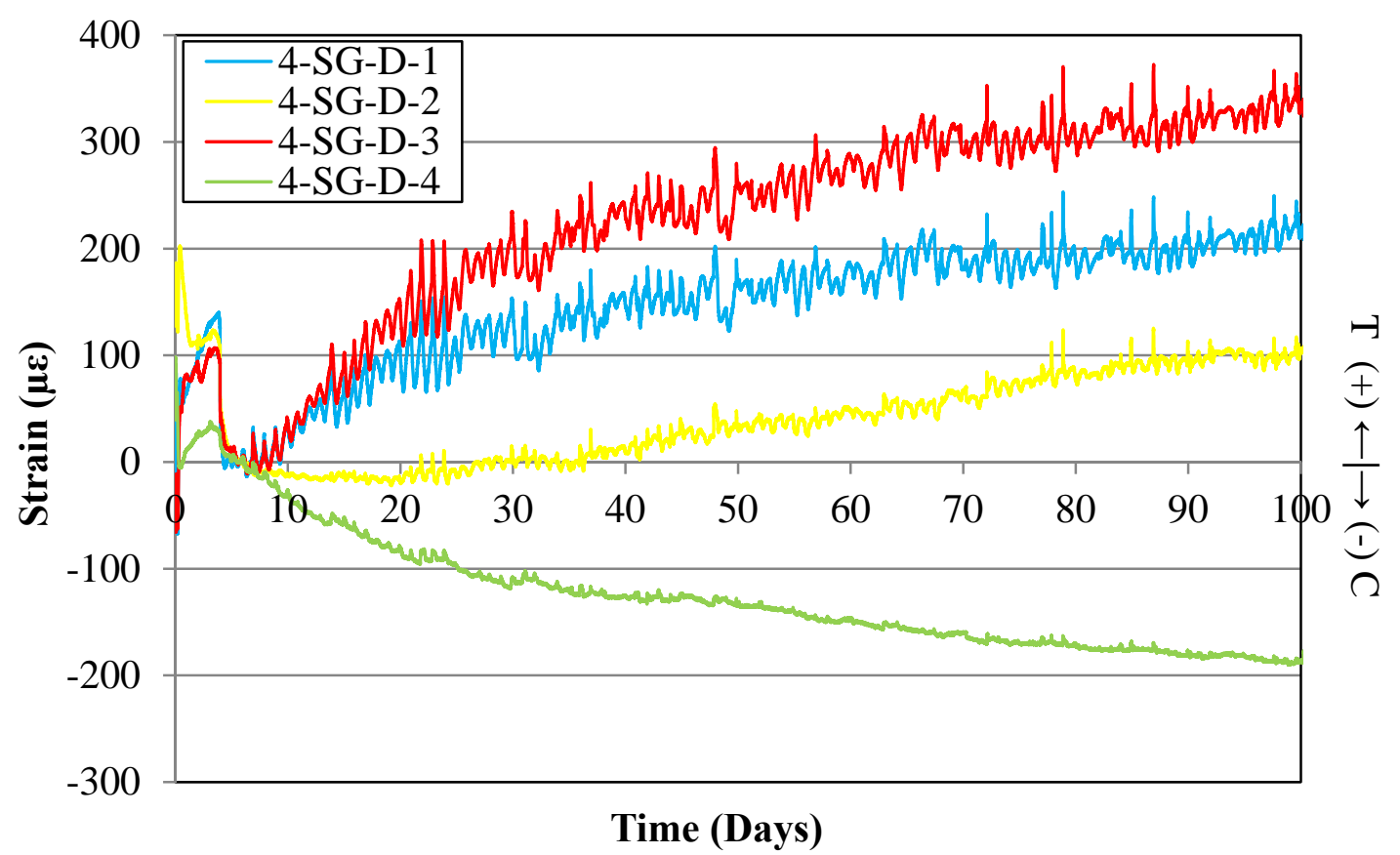

d) Specimen 4 (\#4 @ 12")

Figure 5.28 (continued): Top longitudinal reinforcing steel strain 


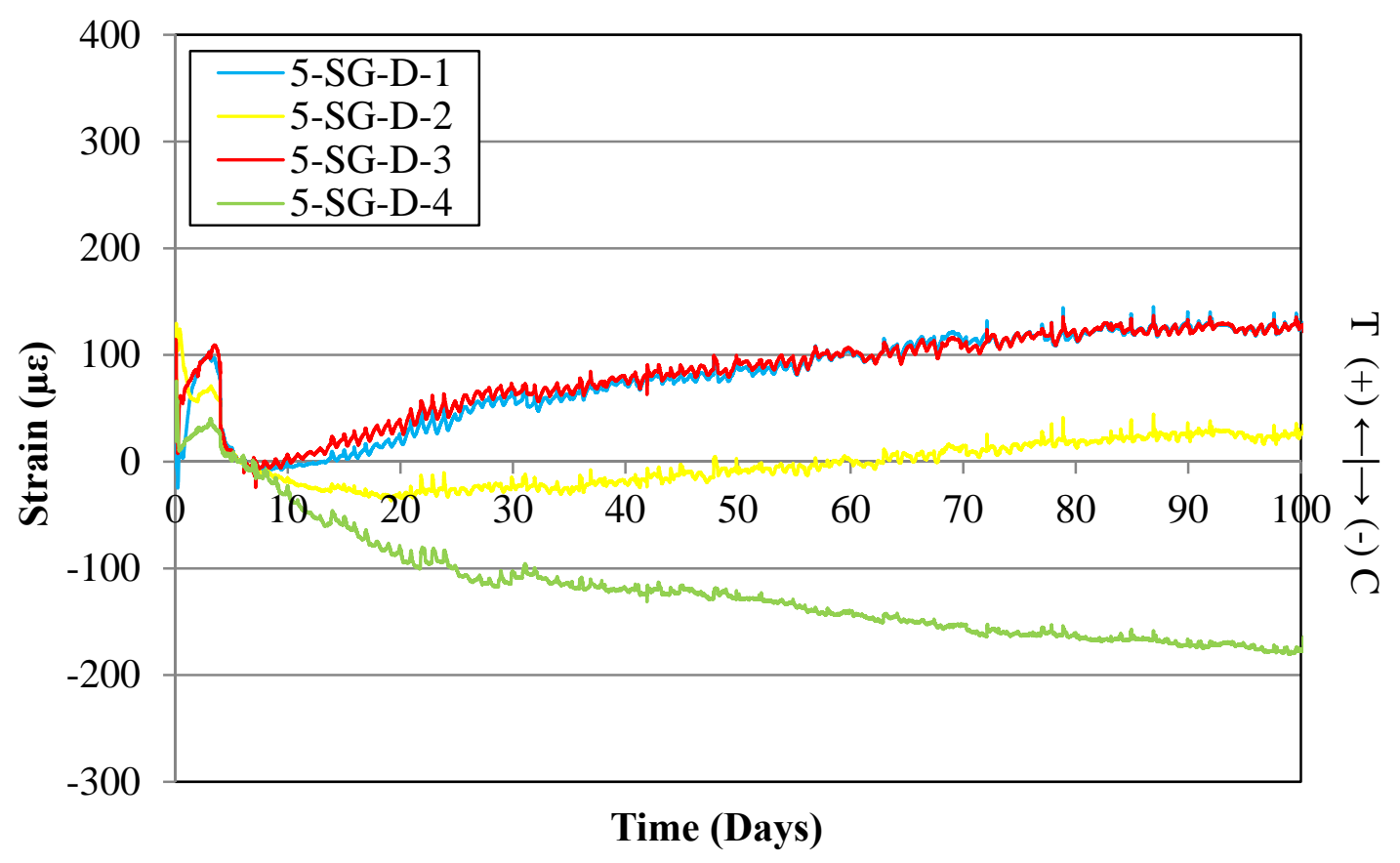

e) Specimen 5 (\#5@8”)

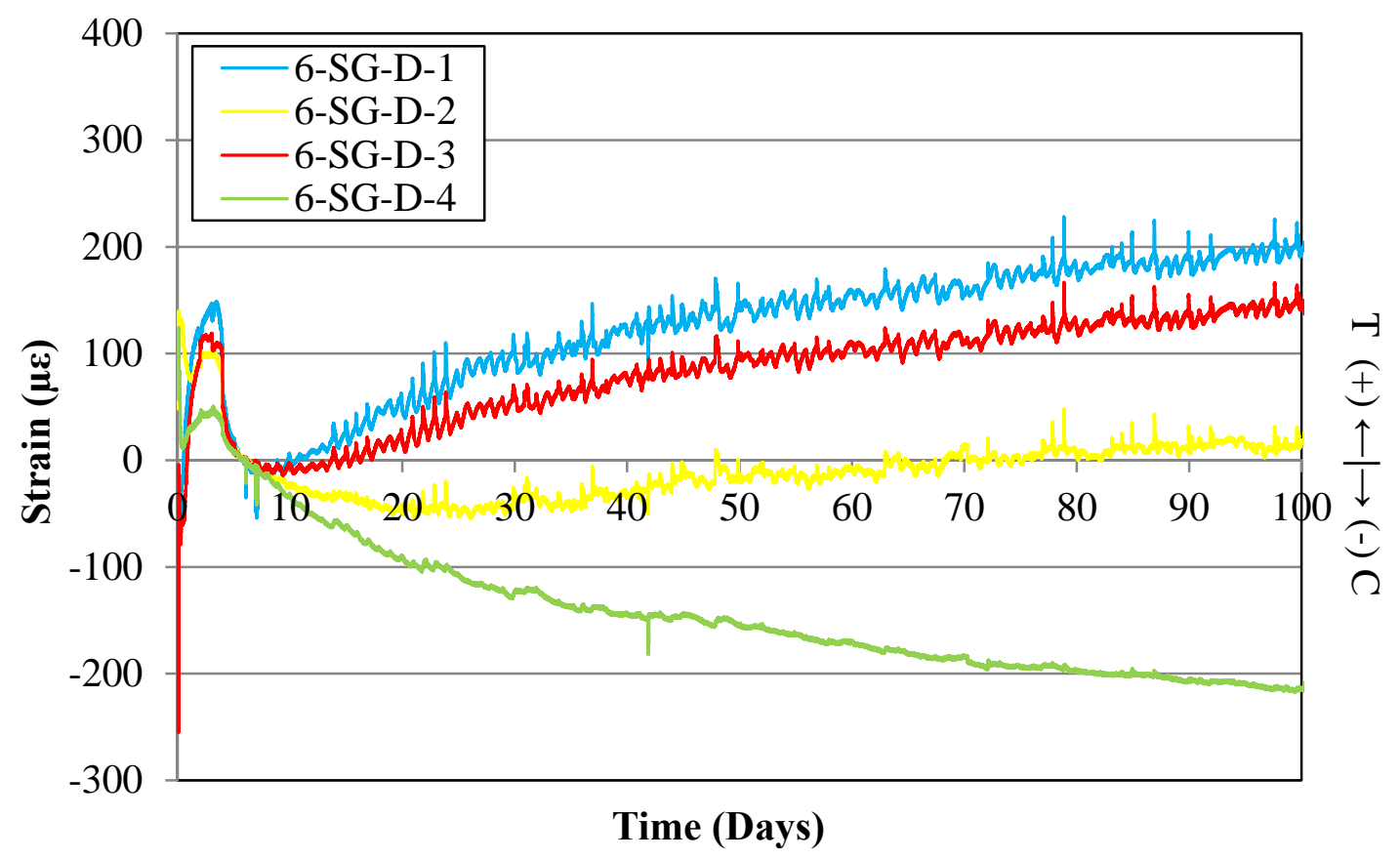

f) Specimen 6 (\#4 @ 8")

Figure 5.28 (continued): Top longitudinal reinforcing steel strain 


\subsubsection{Girder Strain Gages}

The behavior of the girder was similar in all specimens with only variations in the magnitude of the response. In general, compressive strains were obtained on the top flange gages and tensile strains on gages located at the bottom flange because of the positive moment caused by deck shrinkage and gravity loads. Gages were zeroed at 5 days as discussed earlier.

After casting, the top flanges exhibited a decrease in strain due to the heat of hydration (Figure 5.29). The minimum was reached at the peak temperature. Following this point, the strains increased for approximately 4 days as the temperature declined. Once curing had discontinued and the formwork was removed, the top flanges experienced a significant increase in strains for the first 30 days prior to a decrease in the compressive strain rate. Compressive strains revealed a steady increase for the remainder of the test.

The bottom flanges in Specimens 1 and 2 experienced the opposite behavior of the top flanges in the first 30 days. Tensile strains were fairly constant from this day to the end of the test. After 100 days, compressive strains in the top flange were greater than tensile strains in the bottom flange. 


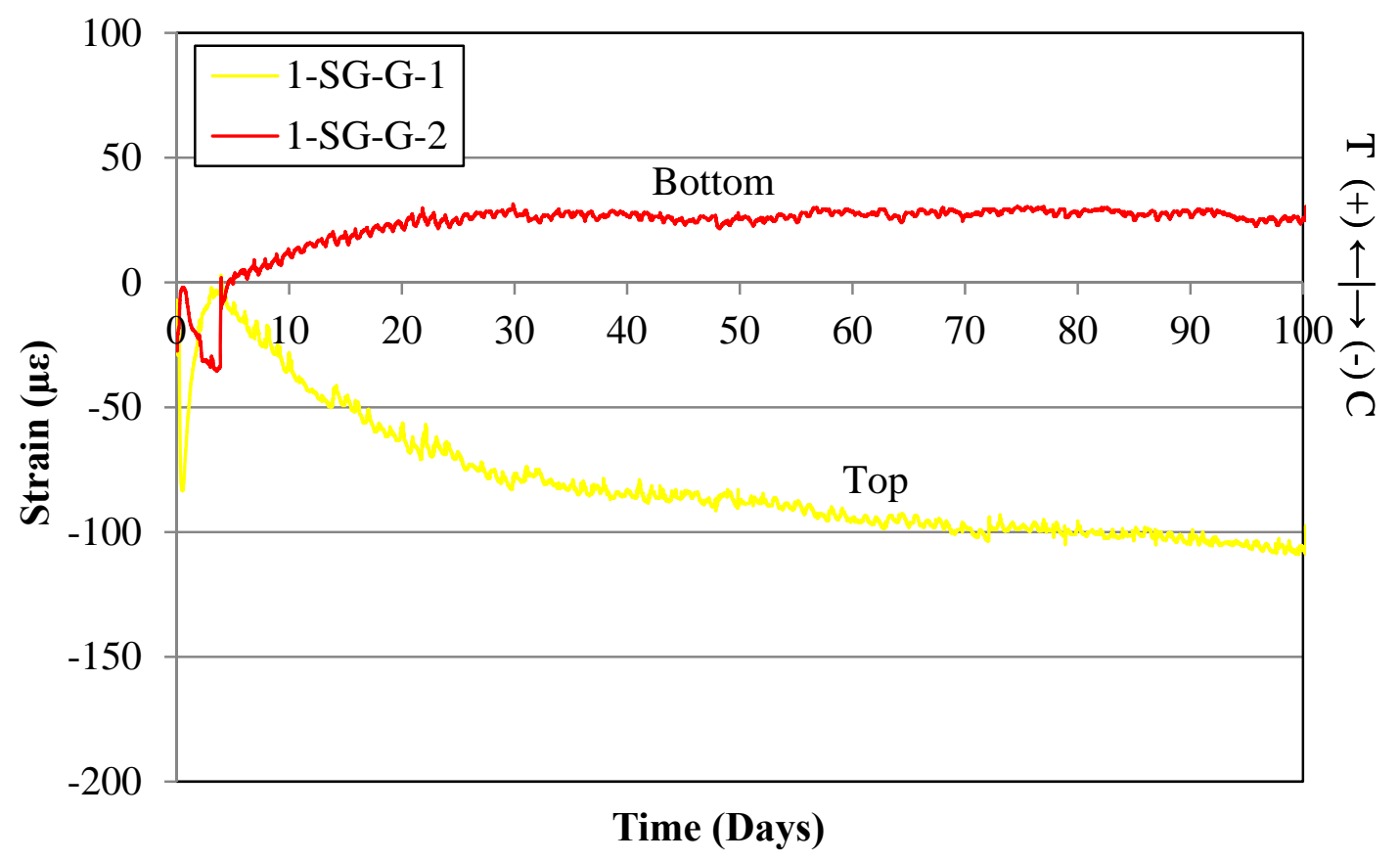

a) Specimen 1 (\#4@18”)

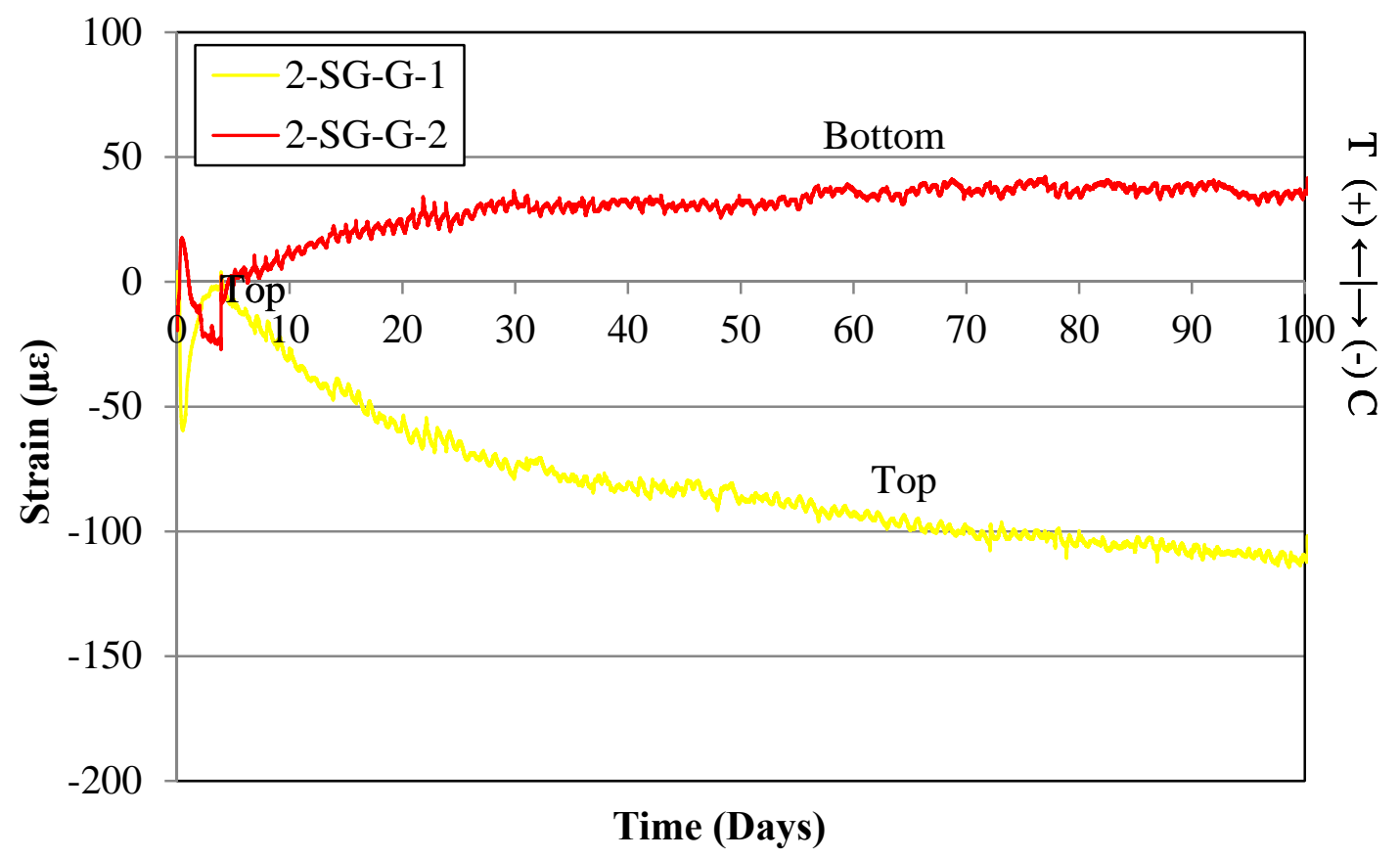

b) Specimen 2 (\#4@4")

Figure 5.29: Longitudinal girder strain at midspan 


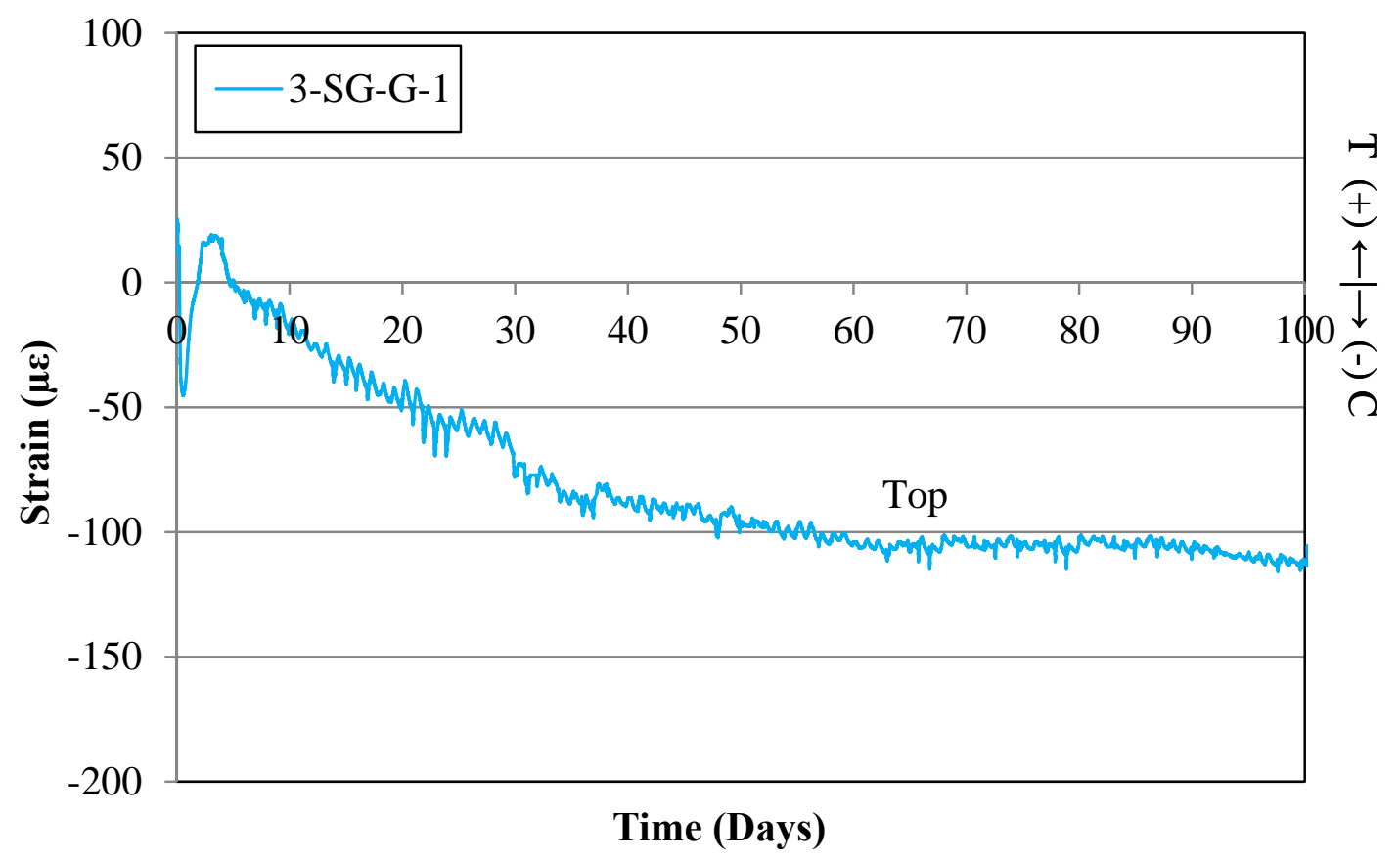

c) Specimen 3 (\#5@12")

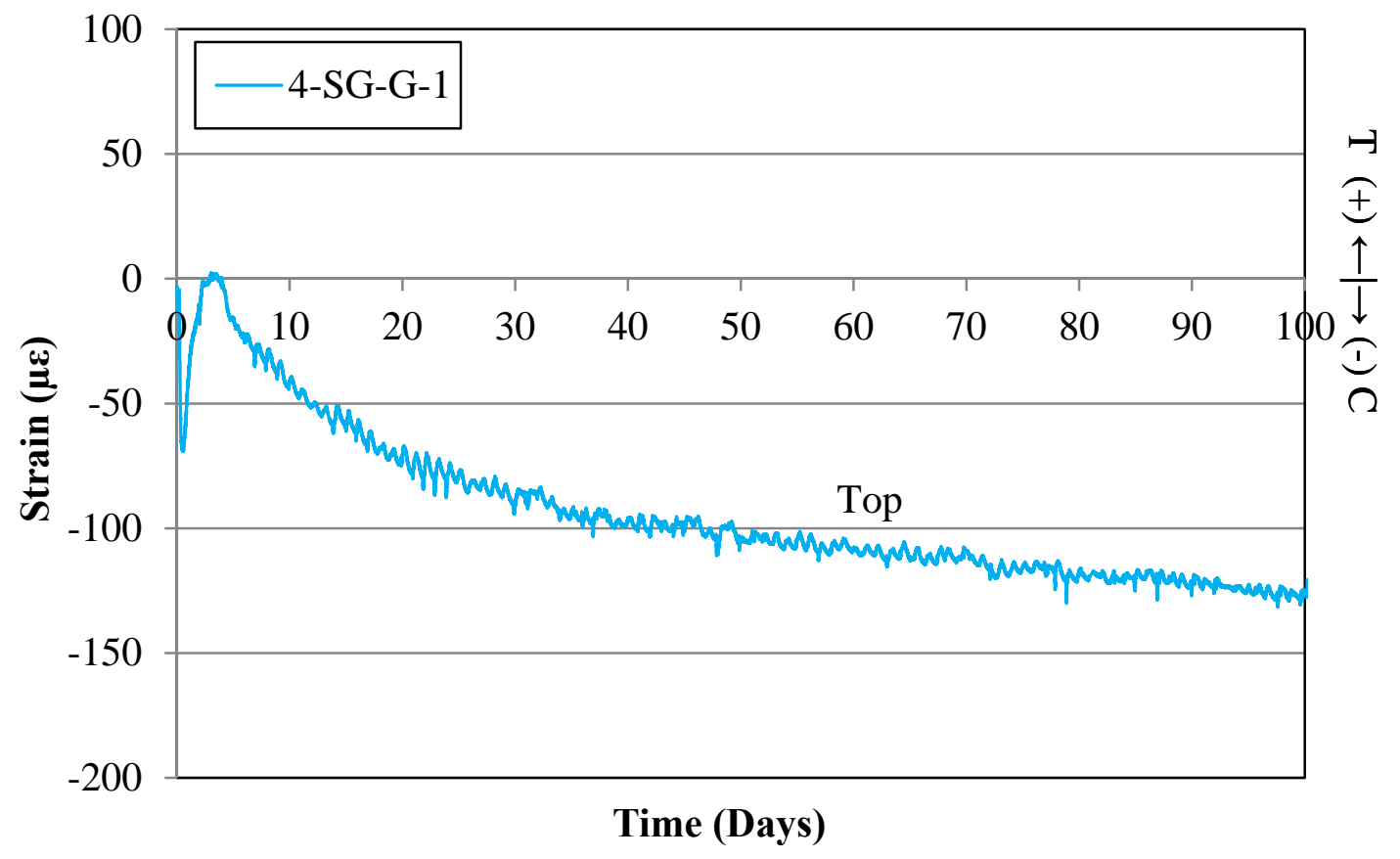

d) Specimen 4 (\#4@12”)

Figure 5.29 (continued): Longitudinal girder strain at midspan 


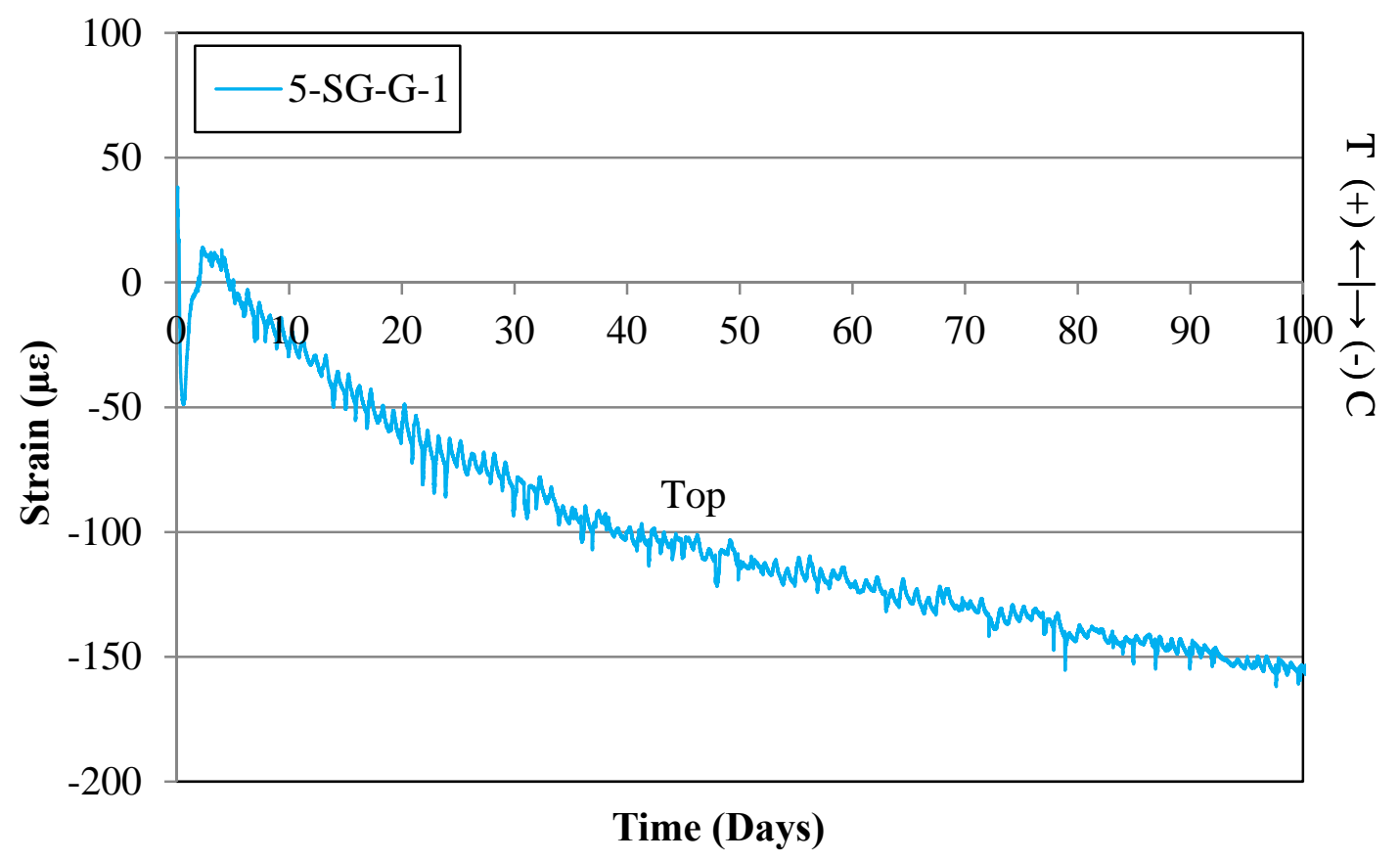

e) Specimen 5 (\#5@8”)

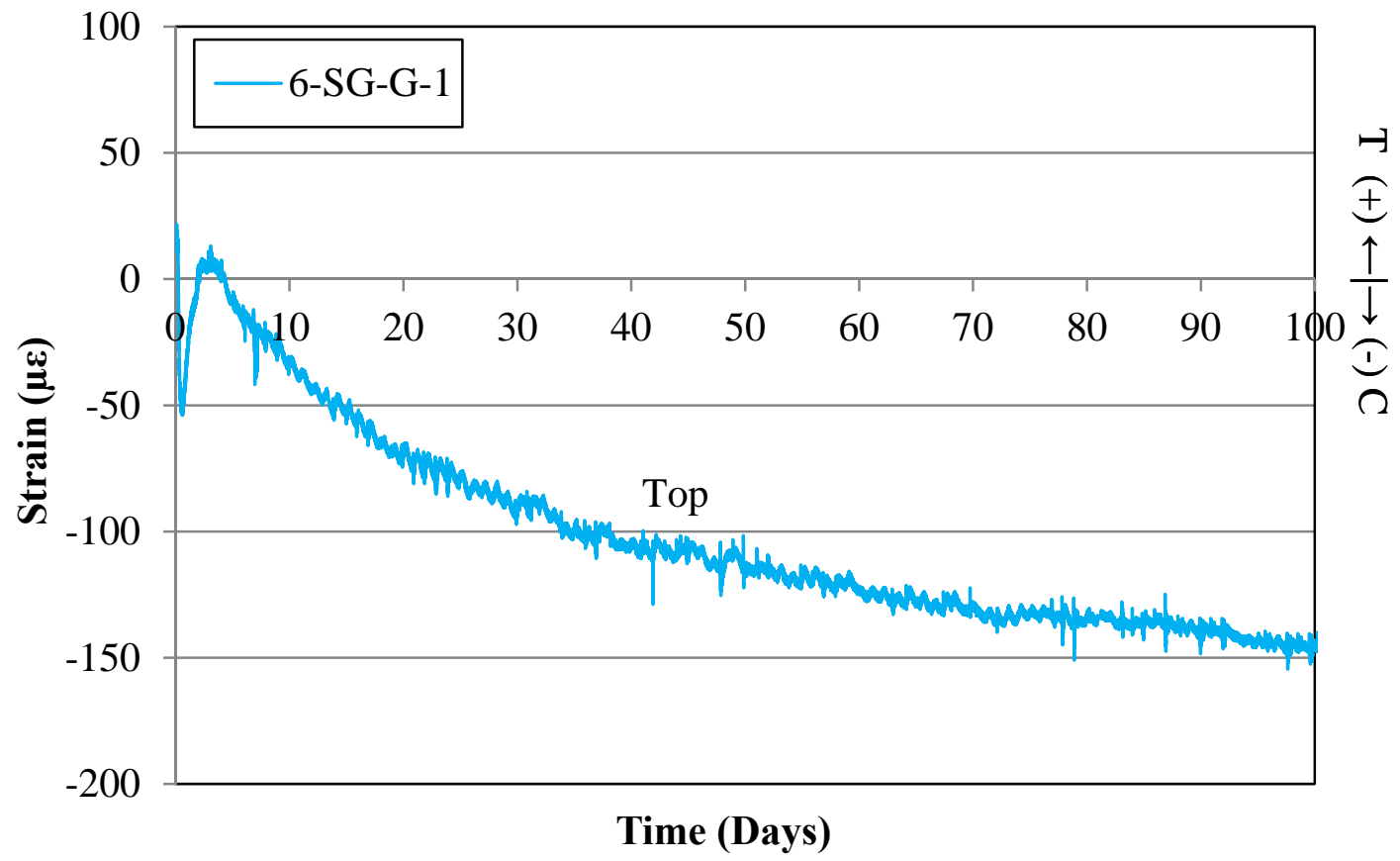

f) Specimen 6 (\#4@8”)

Figure 5.29 (continued): Longitudinal girder strain at midspan 


\subsubsection{Deck Potentiometers}

Linear potentiometers located in the deck recorded crack displacements over time. Daily temperature cycles caused the displacement measurements to fluctuate as shown in Figure 5.30. However, the magnitude of the fluctuations was significantly different in comparing the six specimens. Large fluctuations are evident in Specimens 1-3 while much smaller fluctuations are evident in Specimens 4-6. It should be noted that positive values indicate opening of the crack. Consequently, negative values such as evident in Specimen 2 are questionable. As previously discussed, the potentiometers were also zeroed at 5 days.

In general, as more clearly illustrated by Specimens 4-6, a sharp increase was revealed shortly after the embedment of the potentiometers. The maximum displacement was reached at the peak temperature and remained fairly constant throughout the curing duration. Once the wet burlap was removed, displacements declined slightly and increased afterwards, when the formwork was removed. The displacement started to increase because of the drying shrinkage experienced by the deck at approximately Day 7. This increase was significant up to Day 30, after this point, the shrinkage rate decreased and the displacement increased rather slowly until the end of the test. 


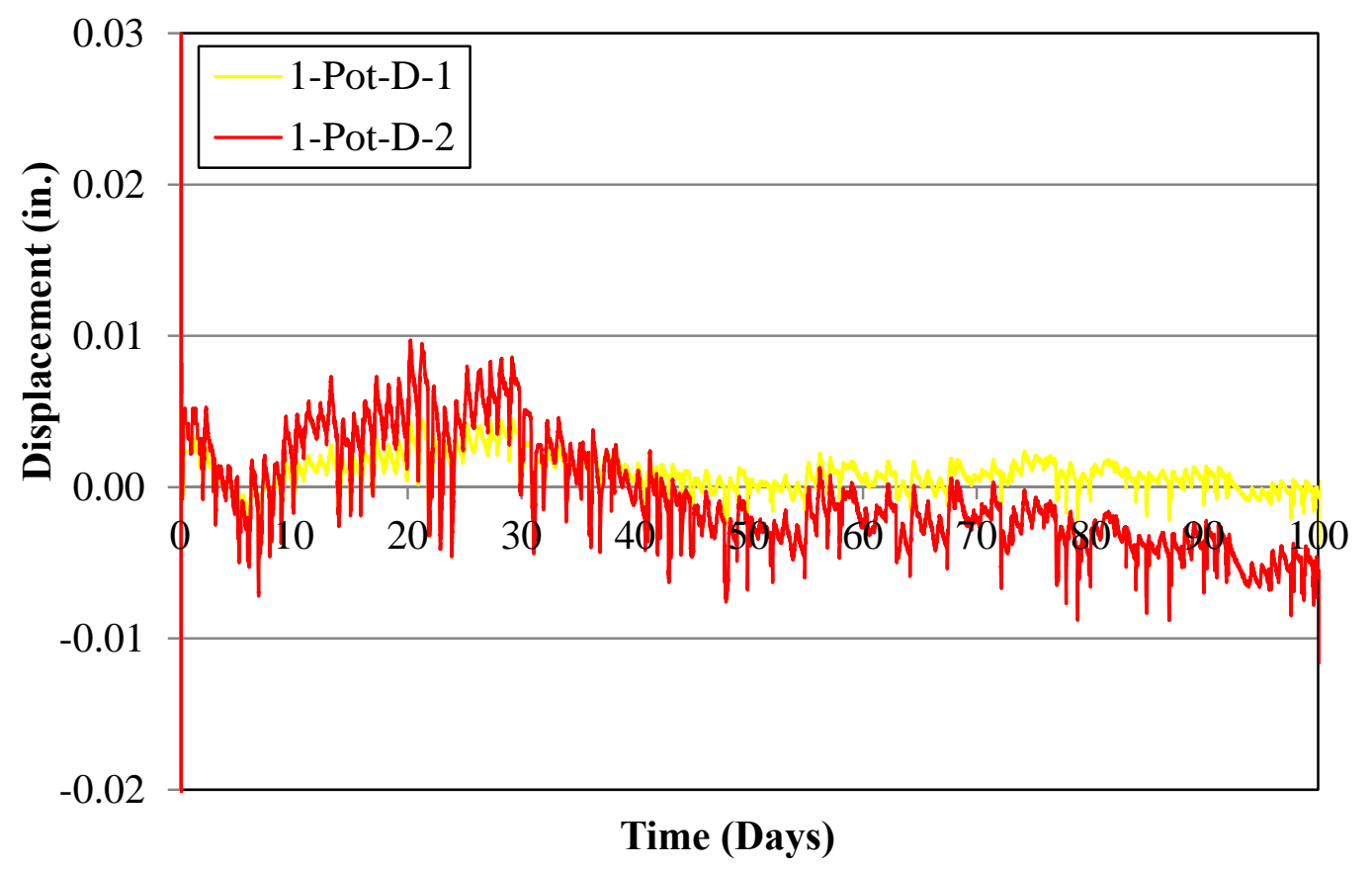

a) Specimen 1 (\#4@18”)

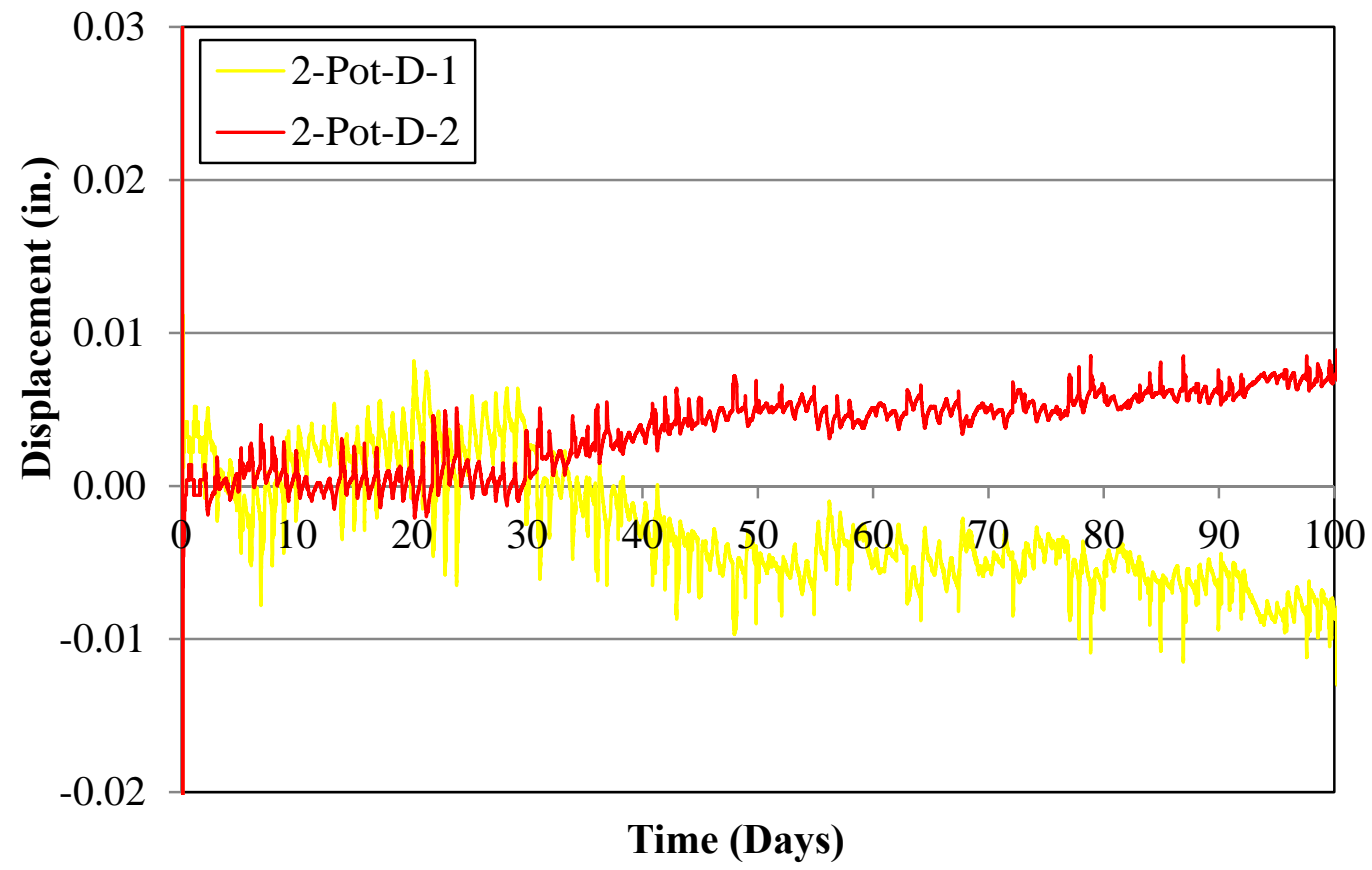

b) Specimen 2 (\#4@4”)

Figure 5.30: Crack width displacement 


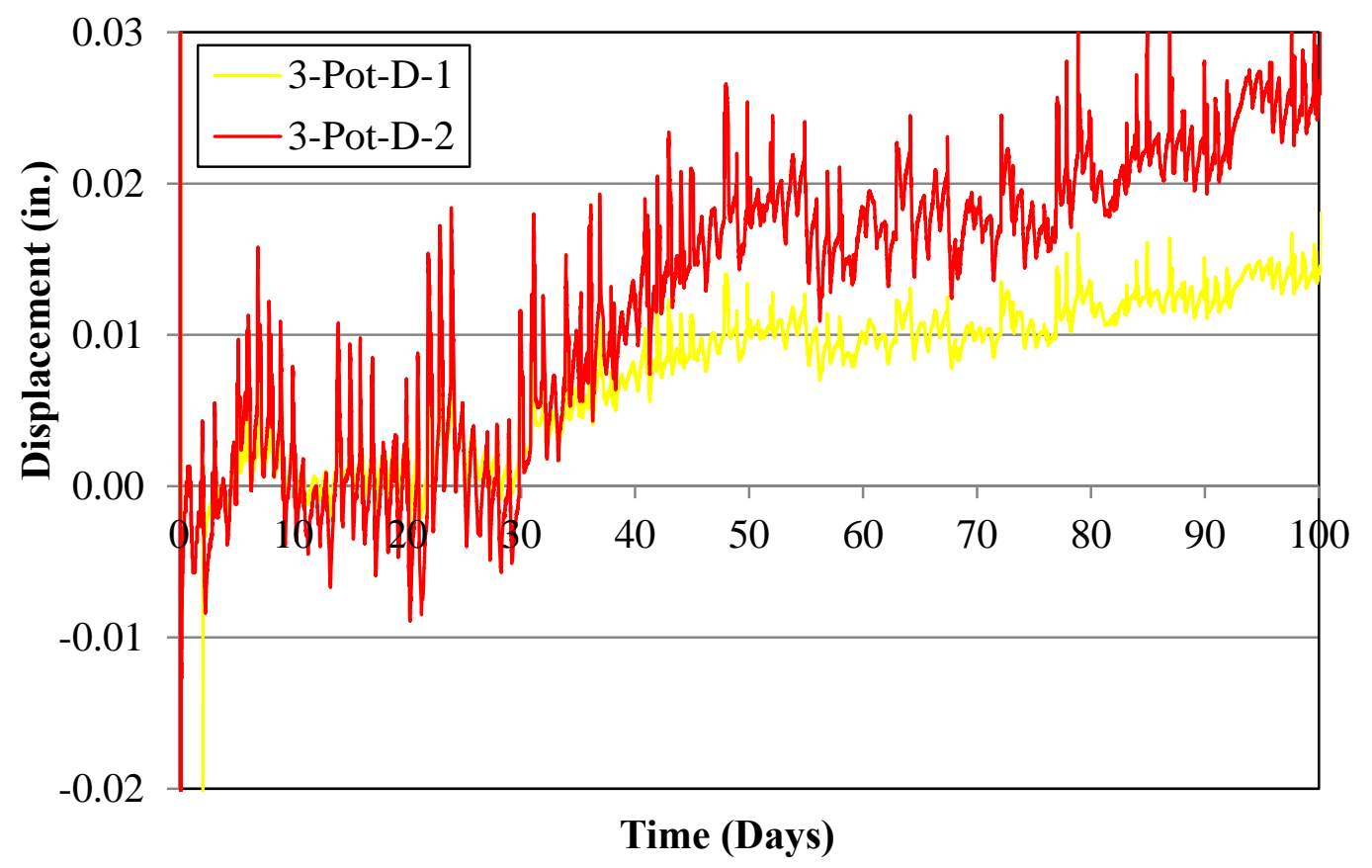

c) Specimen 3 (\#5@12")

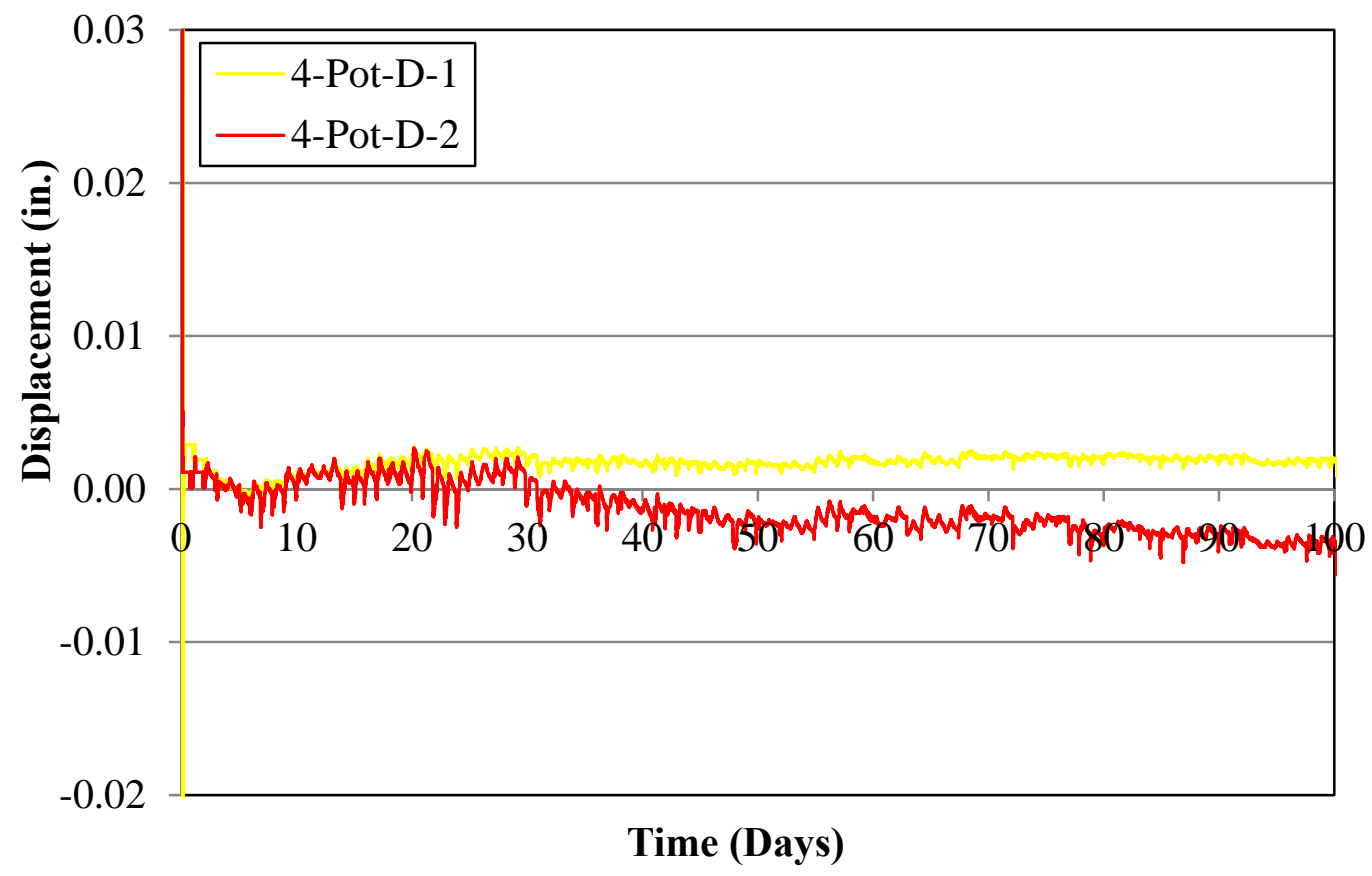

d) Specimen 4 (\#4 @ 12")

Figure 5.30 (continued): Crack width displacement 


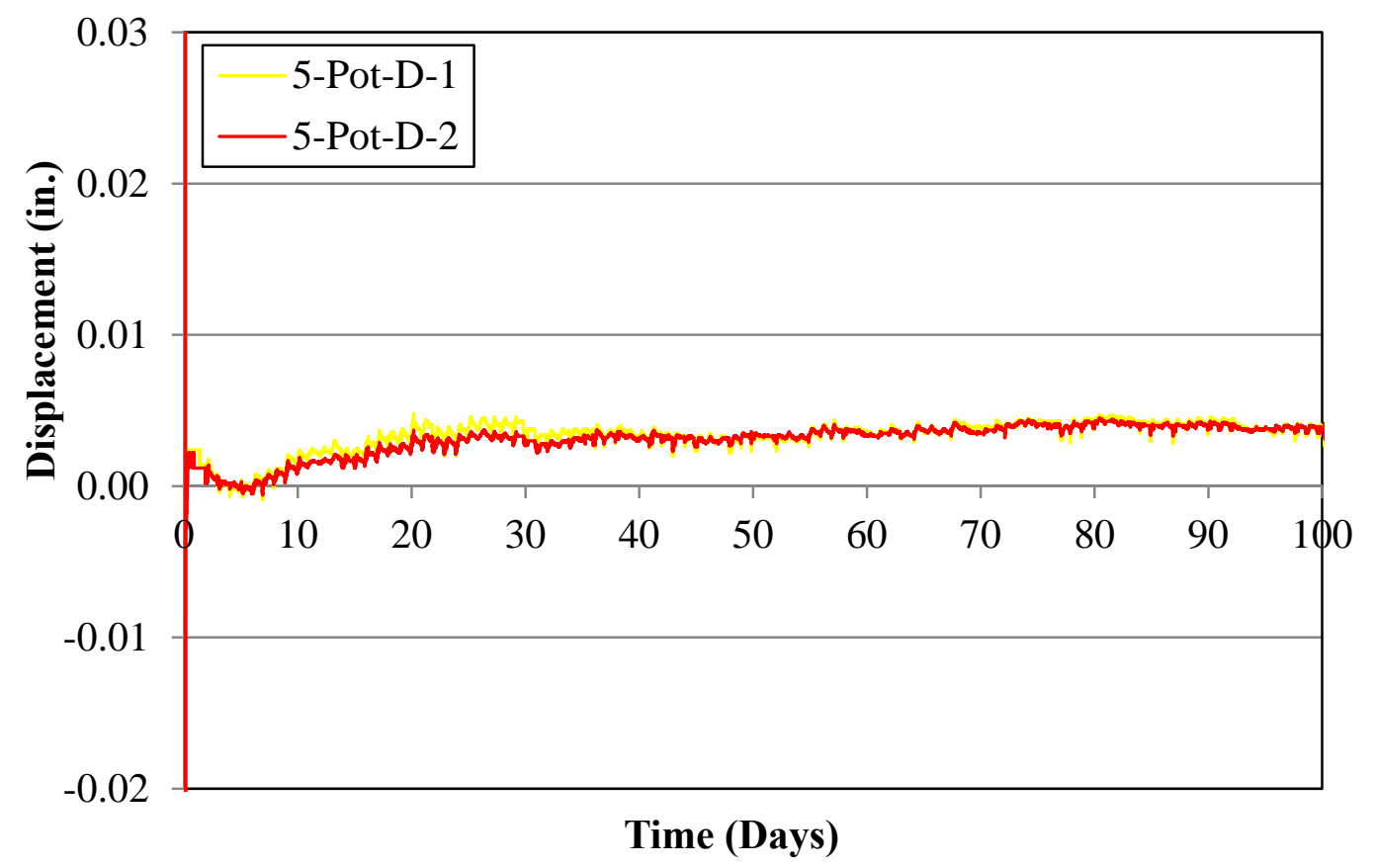

e) Specimen 5 (\#5@8”)

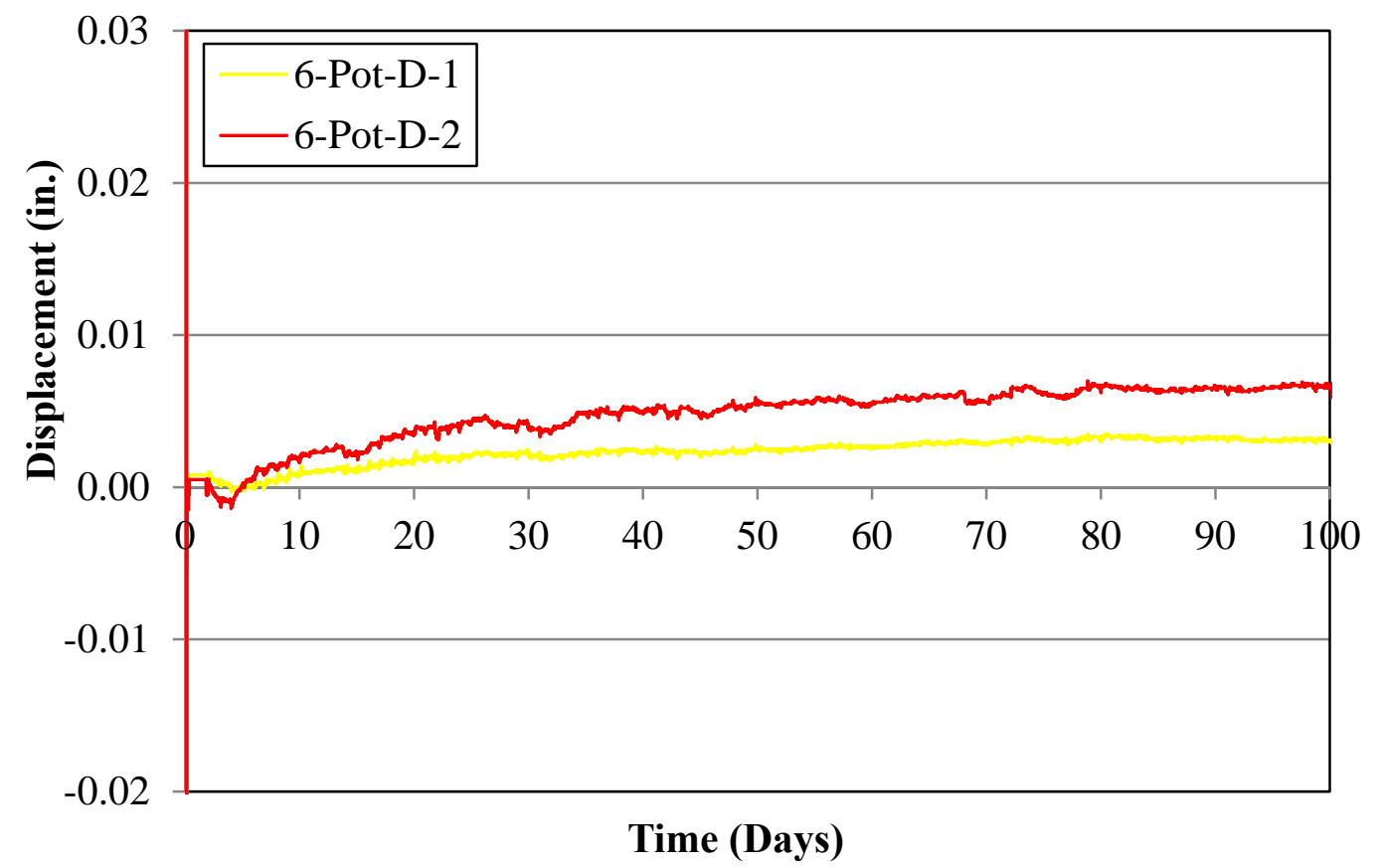

f) Specimen 6 (\#4 @ 8")

Figure 5.30 (continued): Crack width displacement 


\subsubsection{Girder Potentiometers}

Linear potentiometers were located under the girders at midspan to measure deflections caused by restrained shrinkage of the deck in combination with composite action between the deck and steel girder. Overall, the displacement trends were similar. All gages indicated downward deflections after removal of the formwork until the end of the test as shown in Figure 5.31. Again, gages were zeroed at 5 days to evaluate deflection due to shrinkage.

During casting, small downward deflections were measured resulting from the small portion of the concrete load supported by the girders. Afterwards, the specimens experienced an upward deflection due to the rise of temperature until the maximum deck temperature was obtained. Then, the deflection decreased as the temperature declined. After the heat of hydration dissipated, the displacements remained stable while the specimens were cured. Once the wet burlap was removed, the displacement slightly increased prior to the significant instantaneous downward deflection caused by formwork removal. Through the remainder of the test, the rate of downward deflections decreased as the rate of the drying shrinkage of the concrete declined. 


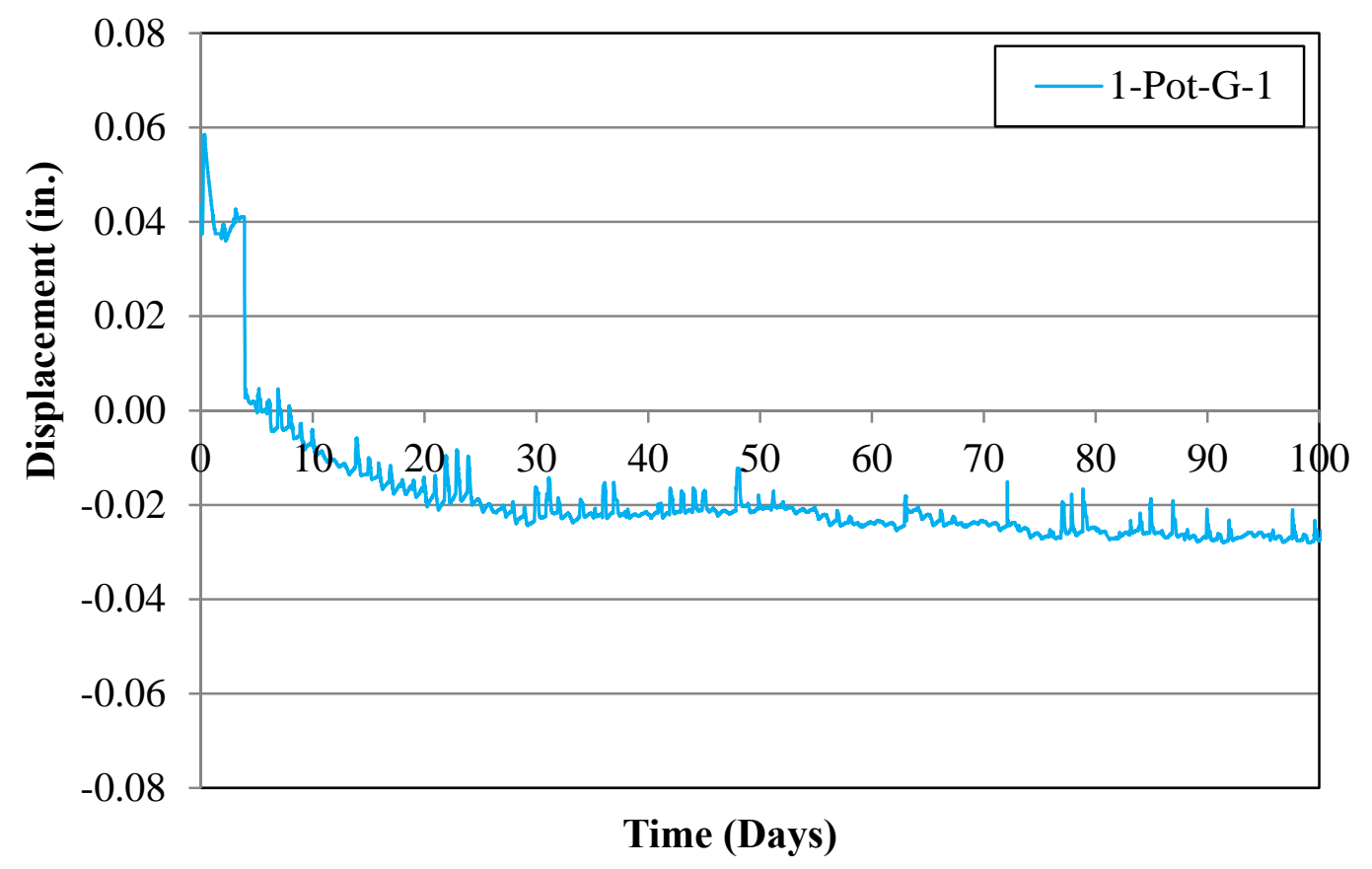

a) Specimen 1 (\#4 @ 18”)

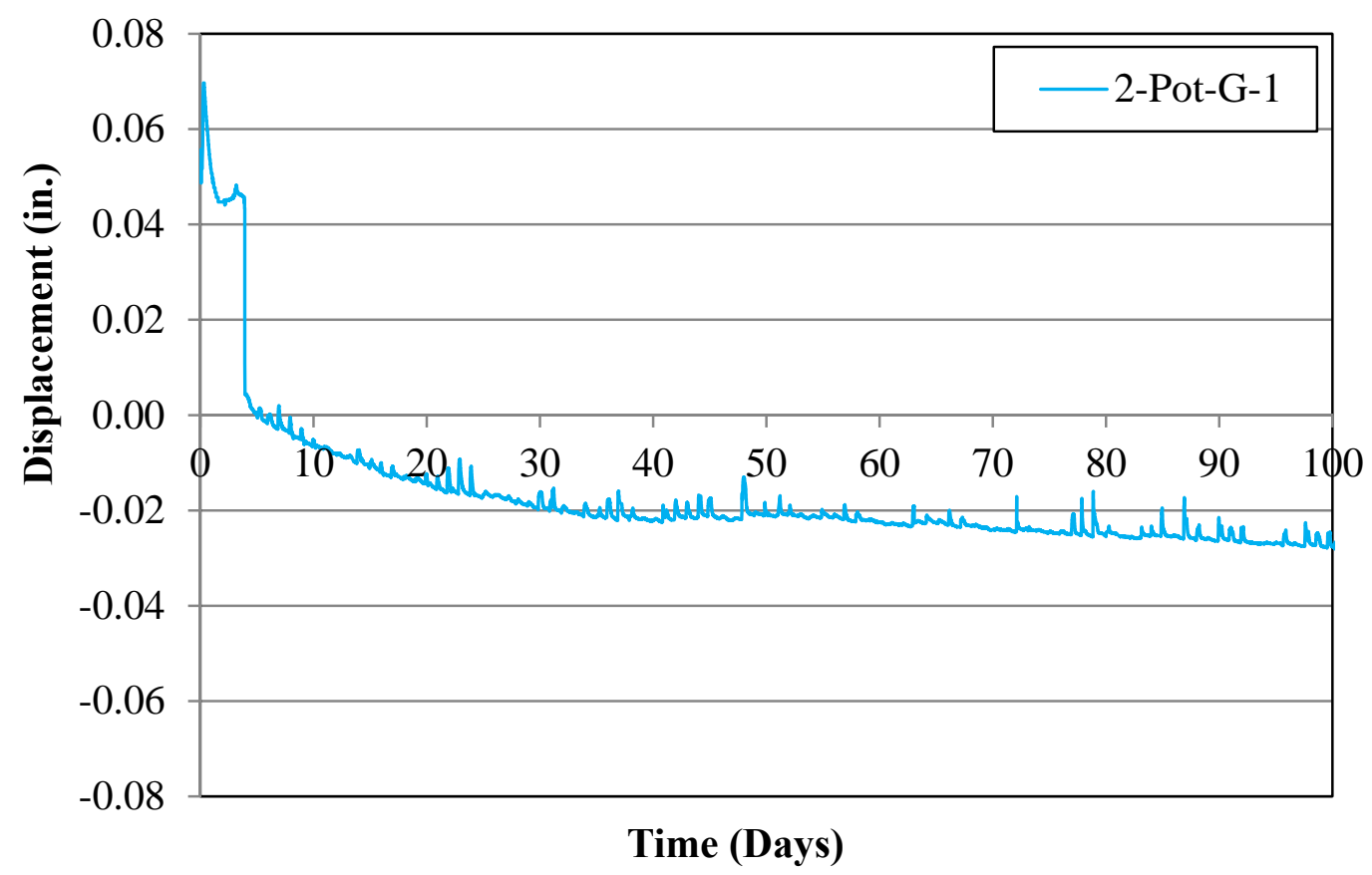

b) Specimen 2 (\#4@4”)

Figure 5.31: Girder deflection at midspan 


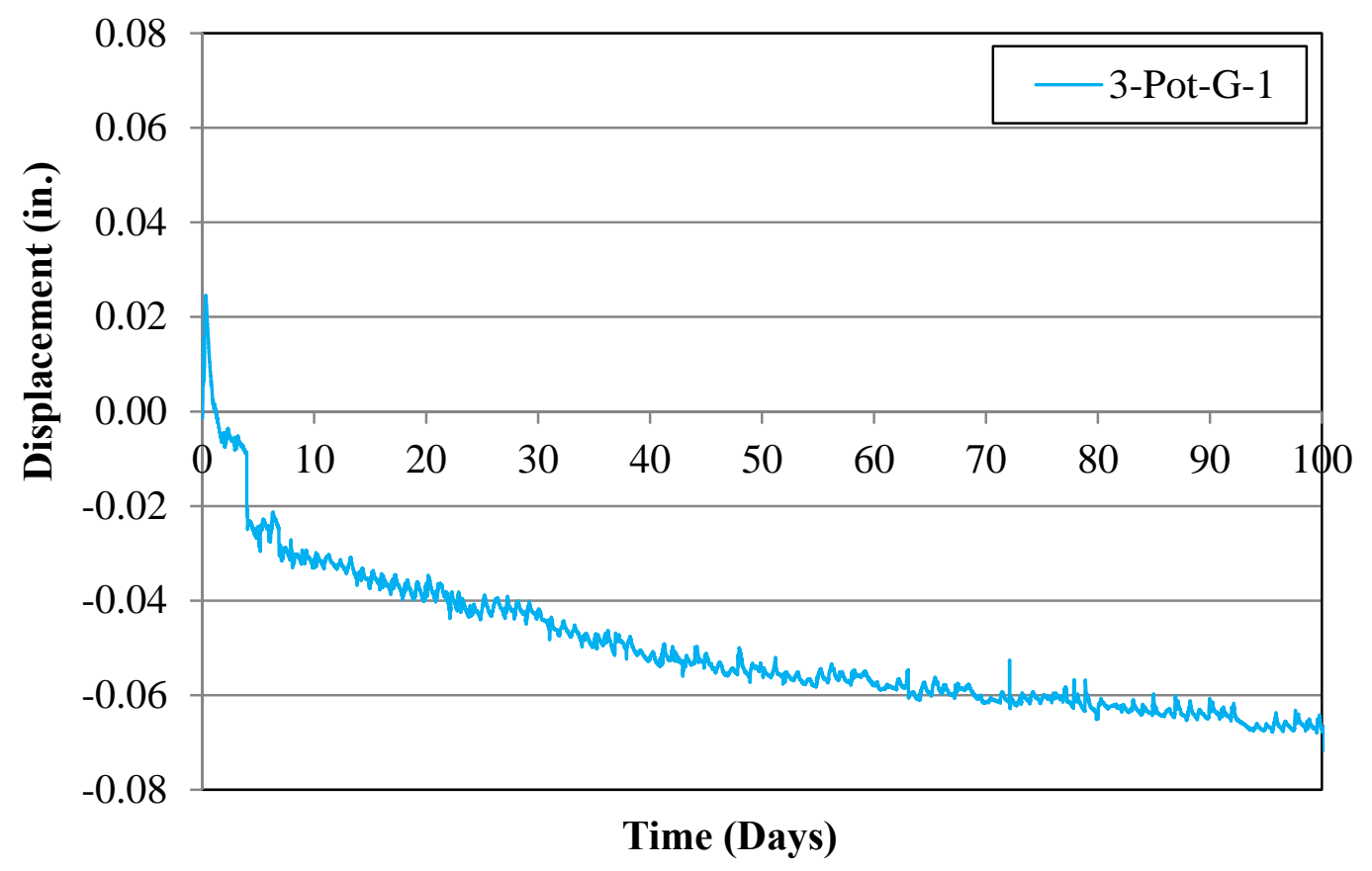

c) Specimen 3 (\#5 @ 12”)

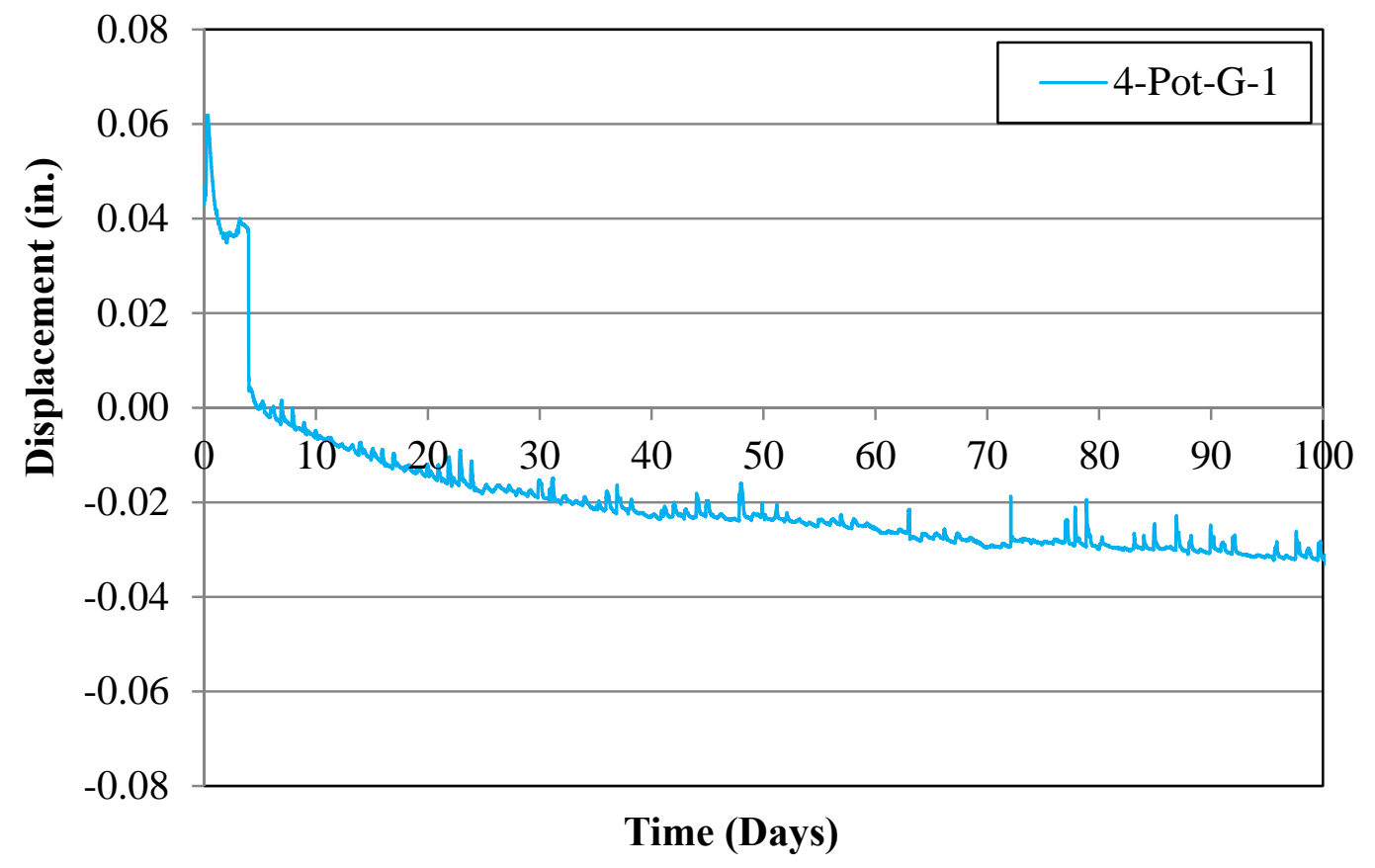

d) Specimen 4 (\#4 @ 12”)

Figure 5.31 (continued): Girder deflection at midspan 


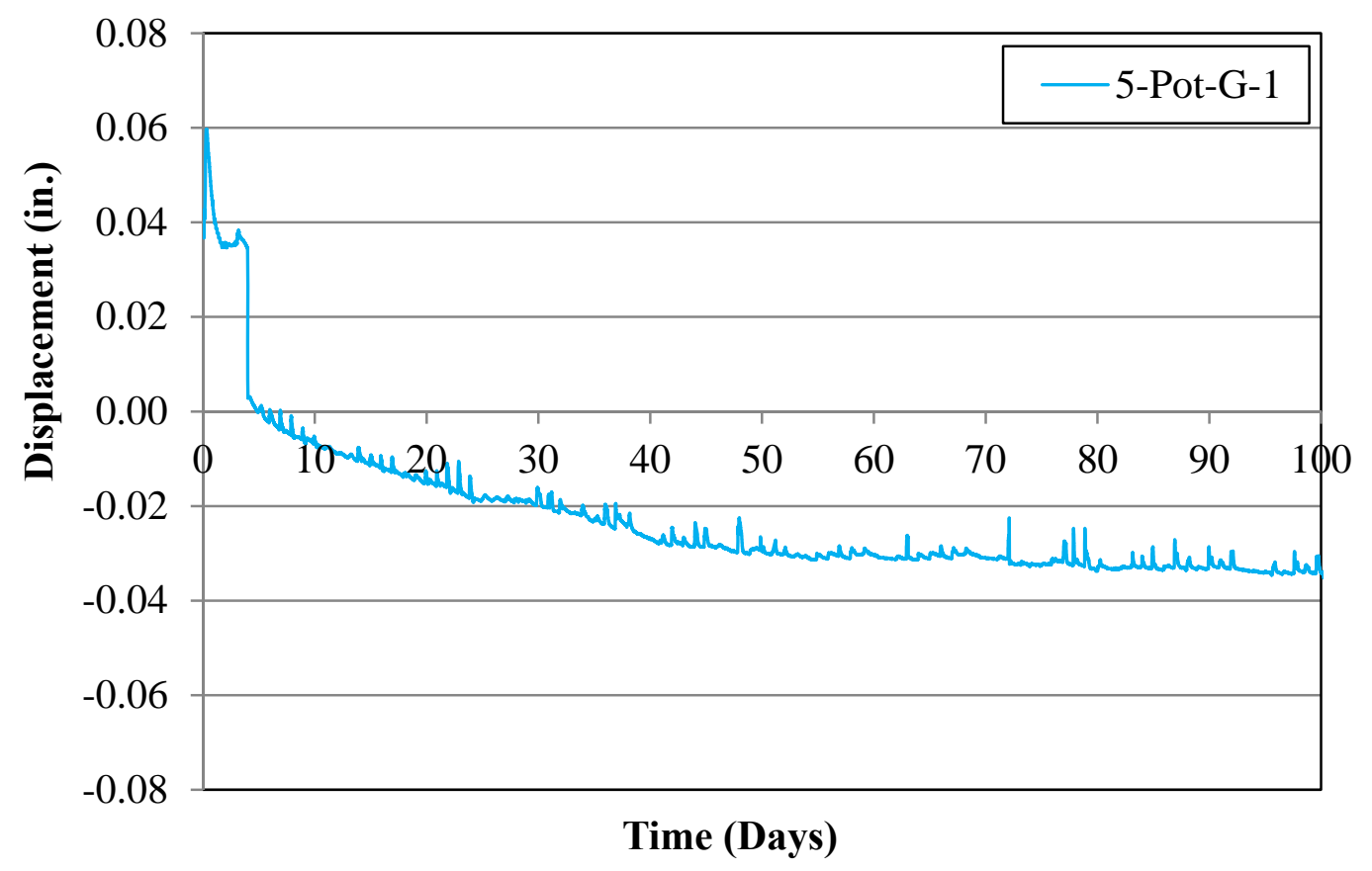

e) Specimen 5 (\#5 @ 8”)

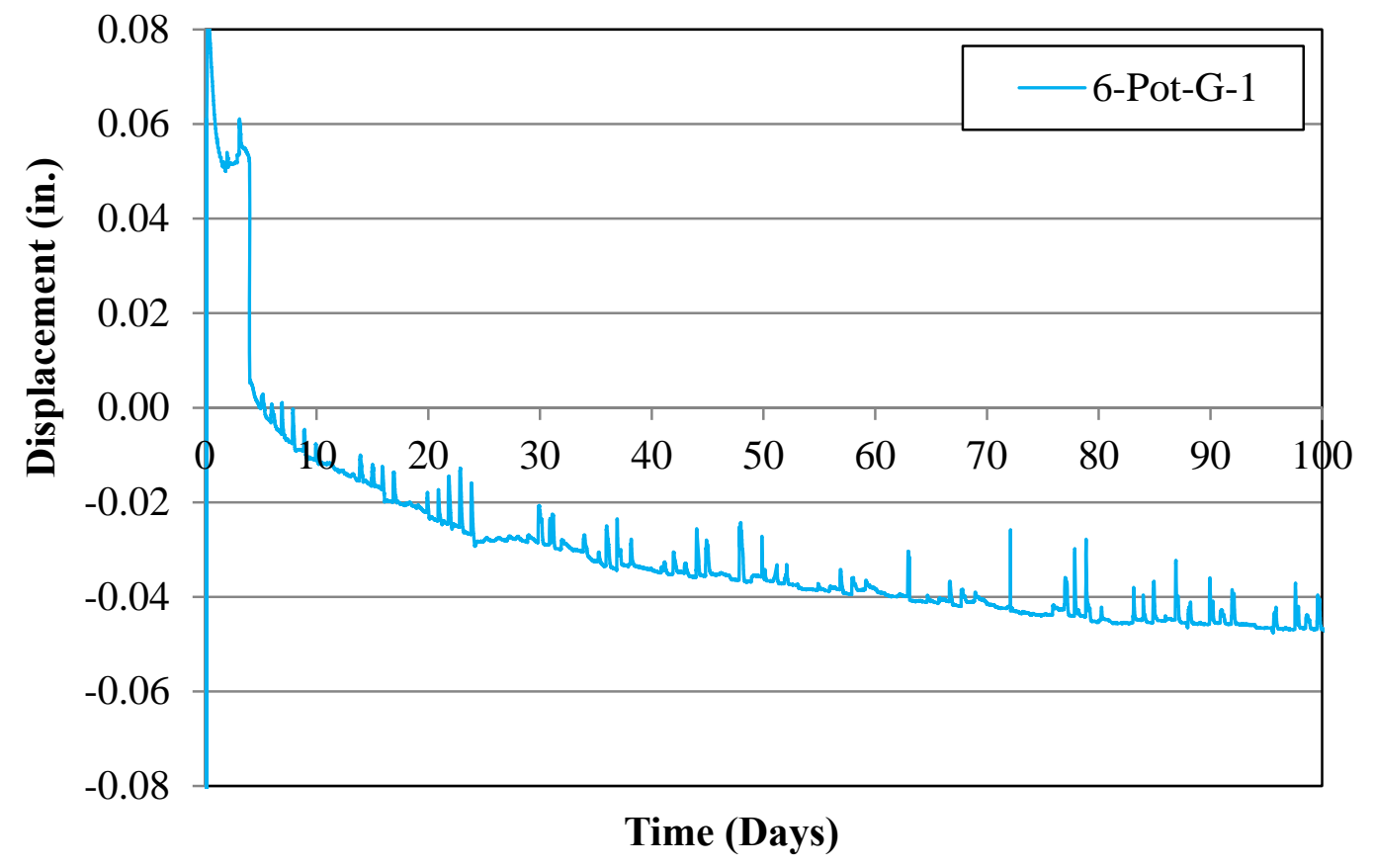

f) Specimen 6 (\#4 @ 8”)

Figure 5.31 (continued): Girder deflection at midspan 


\subsubsection{Crack Widths}

The width of the pre-formed crack was measured twice during the test. Measurements were made at three different locations, close to the sides and at the center of the deck as explained in Section 5.7. The maximum and average widths are presented in Table 5.6 and Table 5.7 for the different reinforcement layouts.

Table 5.6: Crack width at Day 70

\begin{tabular}{|c|c|c|c|c|c|}
\hline \multirow{2}{*}{ Specimen } & \multirow{2}{*}{$\boldsymbol{\rho}_{\mathbf{g}}(\mathbf{\%})$} & \multirow{2}{*}{ Spacing (in.) } & \multirow{2}{*}{$\begin{array}{c}\text { Bar } \\
\text { Size }\end{array}$} & \multicolumn{2}{|c|}{ Crack Width (in.) } \\
\cline { 5 - 6 } & & & Average & Max. \\
\hline 1 & 0.27 & 18 & $\# 4$ & 0.007 & 0.008 \\
\hline 2 & 1.25 & 4 & $\# 4$ & 0.005 & 0.005 \\
\hline 3 & 0.65 & 12 & $\# 5$ & 0.006 & 0.007 \\
\hline 4 & 0.42 & 12 & $\# 4$ & 0.006 & 0.007 \\
\hline 5 & 0.97 & 8 & $\# 5$ & 0.005 & 0.006 \\
\hline 6 & 0.63 & 8 & $\# 4$ & 0.006 & 0.007 \\
\hline
\end{tabular}

Table 5.7: Crack Width at Day 100

\begin{tabular}{|c|c|c|c|c|c|}
\hline \multirow{2}{*}{ Specimen } & \multirow{2}{*}{$\boldsymbol{\rho}_{\mathbf{g}}(\mathbf{\%})$} & \multirow{2}{*}{ Spacing (in.) } & \multirow{2}{*}{$\begin{array}{c}\text { Bar } \\
\text { Size }\end{array}$} & \multicolumn{2}{|c|}{ Crack Width (in.) } \\
\cline { 5 - 6 } & & & Average & Max. \\
\hline 1 & 0.27 & 18 & $\# 4$ & 0.008 & 0.009 \\
\hline 2 & 1.25 & 4 & $\# 4$ & 0.005 & 0.005 \\
\hline 3 & 0.65 & 12 & $\# 5$ & 0.006 & 0.007 \\
\hline 4 & 0.42 & 12 & $\# 4$ & 0.007 & 0.008 \\
\hline 5 & 0.97 & 8 & $\# 5$ & 0.006 & 0.007 \\
\hline 6 & 0.63 & 8 & $\# 4$ & 0.006 & 0.007 \\
\hline
\end{tabular}




\subsection{Analysis of Results}

The results were used to evaluate the performance of different reinforcement designs in controlling crack widths. Parameters such as the reinforcement ratio, spacing, and bar diameter were considered in the evaluation. Crack openings were also assessed to provide a correlation between the reinforcement parameters and crack widths.

\subsubsection{Reinforcement Ratio}

The strains obtained near the crack (Gages S-D-1 and S-D-3) were averaged and plotted for specimens with $\# 4$ bars as shown in Figure 5.32. It should be noted that tensile strains in the reinforcement are directly related to crack width as the strains are measured at the location of the crack. This figure also presents the shrinkage strains (zeroed at Day 5) obtained from a concrete free-shrinkage test (Hoffman 2008) of INDOT Class $\mathrm{C}$ concrete where the specimen was wet cured for 5 days. The shrinkage strains of the concrete were plotted as tensile for comparison purposes.

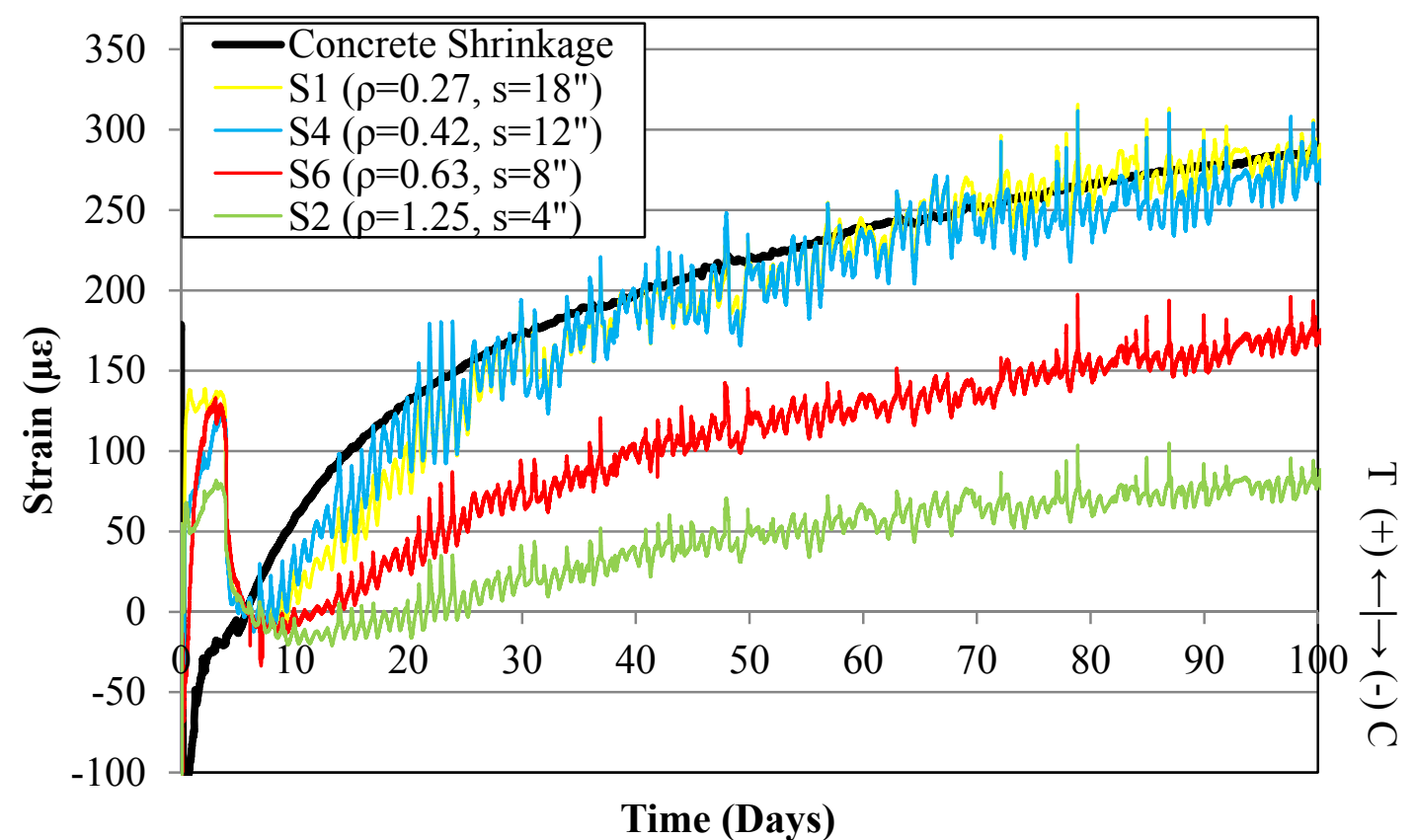

Figure 5.32: Reinforcement strain, \#4 bar 
A small decrease in strain was observed when the reinforcement amount rose from $0.27 \%$ to $0.42 \%$. This small variation indicates that the steel contribution was not significant for reinforcement ratios lower than $0.42 \%$. In comparing the free-shrinkage strains of Class $\mathrm{C}$ concrete, similar trends and magnitudes are observed. This similarity demonstrates that for ratios lower than $0.42 \%$, the reinforcement is not providing significant resistance against shrinkage and therefore crack growth. From $0.42 \%$ to $0.63 \%$, the strains decreased from 272 to $171 \mu \varepsilon$ at Day 100 when zeroed at Day 5. This significant variation reveals an effective contribution of the steel in reducing strains. In addition, an increase in the amount of steel from $0.63 \%$ to $1.25 \%$ produced a reduction of $86 \mu \varepsilon$. Although, the influence of the reinforcement ratio was not as effective as going from $0.42 \%$ to $0.63 \%$, it was still substantial. A strain reduction of $40 \%$ from the freeshrinkage was achieved with $0.63 \%$ reinforcement while a reduction of $72 \%$ was achieved with $1.25 \%$ reinforcement.

Specimens with identical bar spacings and different reinforcement ratios were compared to further evaluate the influence of the reinforcement ratio on the strains developed at midspan. Figure 5.33 and Figure 5.34 plot strains for specimens with 8 and 12 in. bar spacings, respectively. The difference in strains between both specimens confirms the significant influence of the reinforcement ratio on the developed strains independent of bar spacing. 


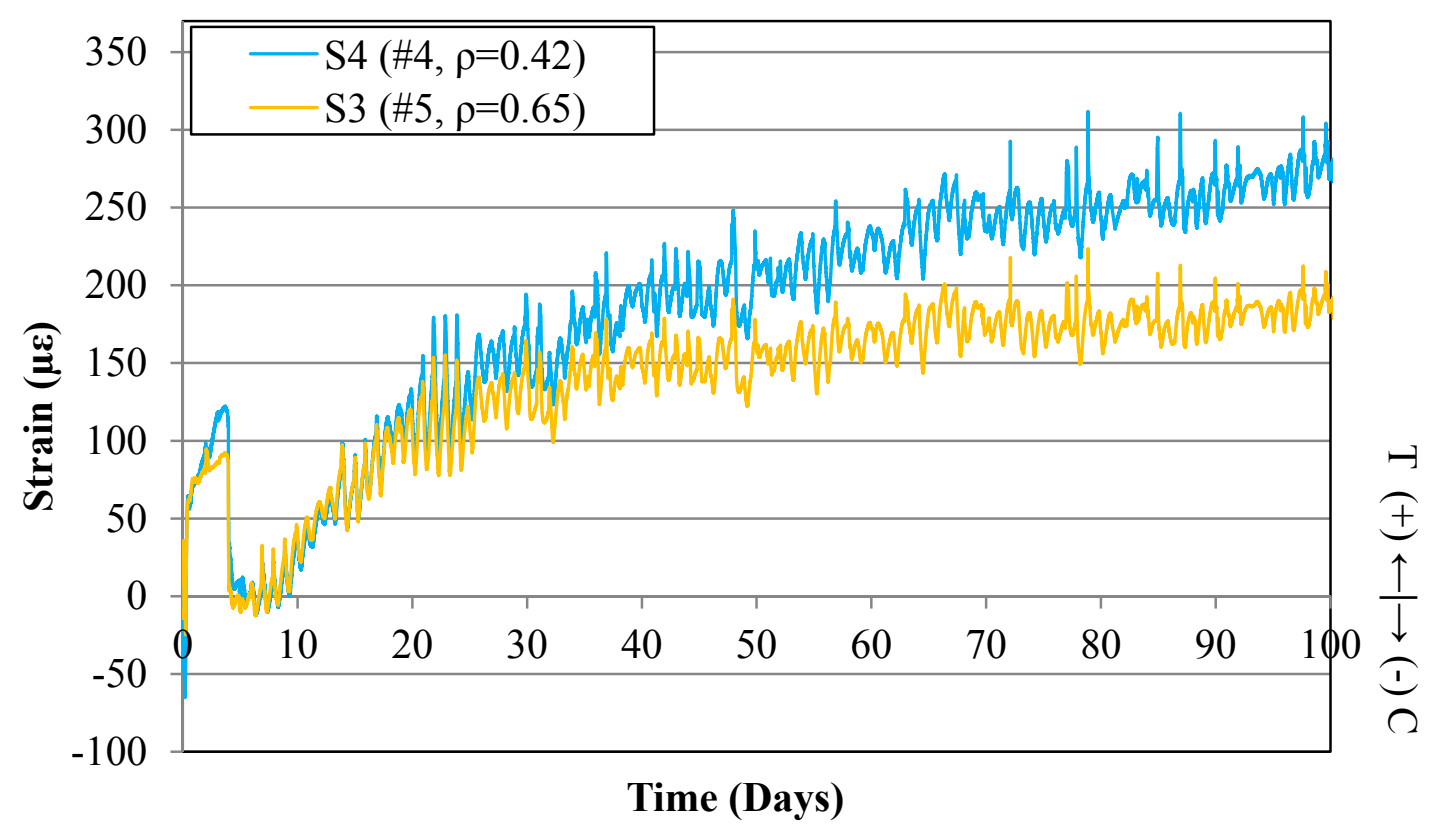

Figure 5.33: Reinforcement strain, 12 in. spacing

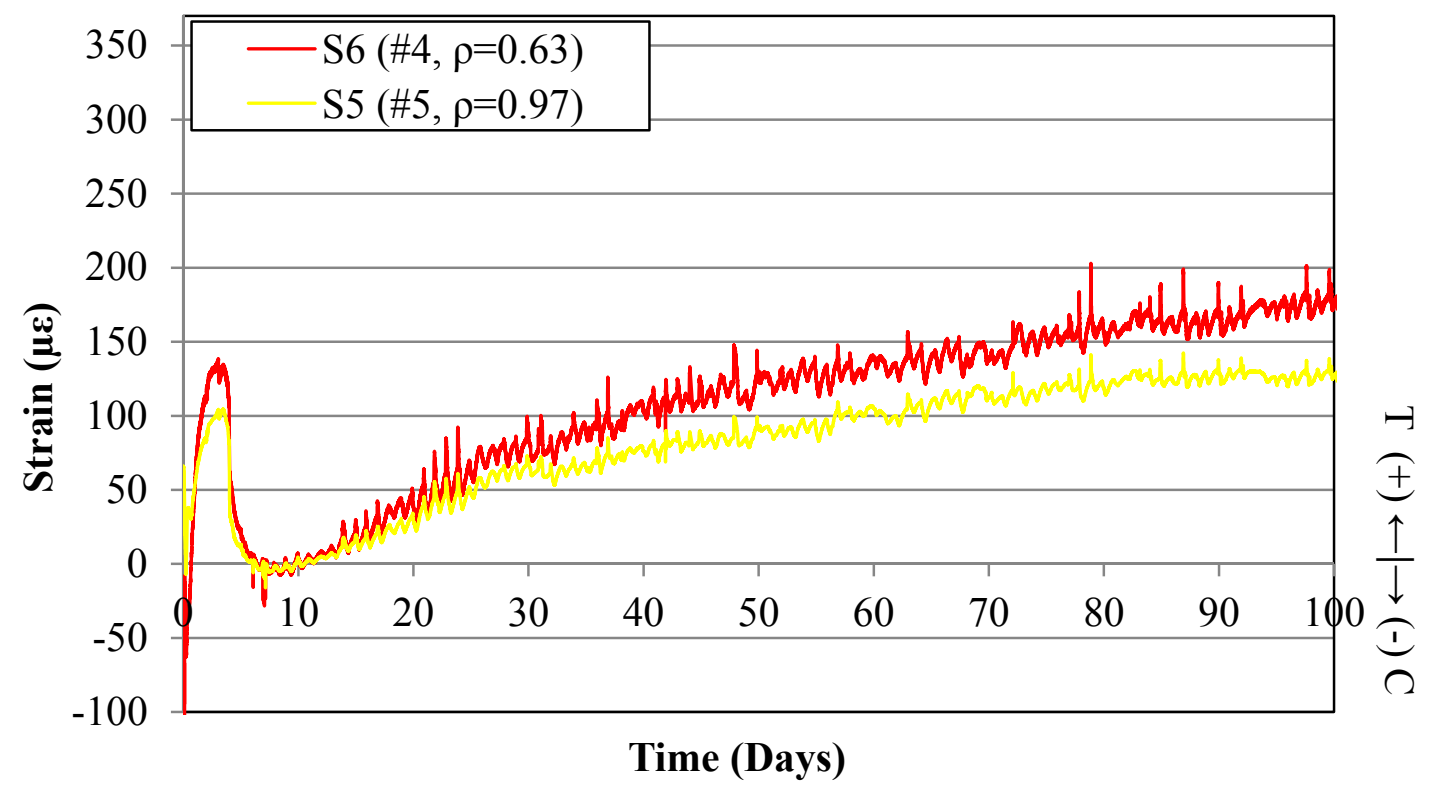

Figure 5.34: Reinforcement strain, 8 in. spacing 
The total strains at Day 100 are presented in Figure 5.35 for all specimens. This figure shows an approximate linear trend for reinforcement ratios above $0.63 \%$. For lower values, a trend was not noticeable. As discussed above, small variations are exhibited in reinforcement ratios below $0.42 \%$ while a significant jump is noted from $0.42 \%$ to $0.63 \%$. It is also interesting to note that for the same reinforcement ratios with different bar sizes and spacing (\#4 at $8 "$ and \#5 at 12"), similar results are obtained.

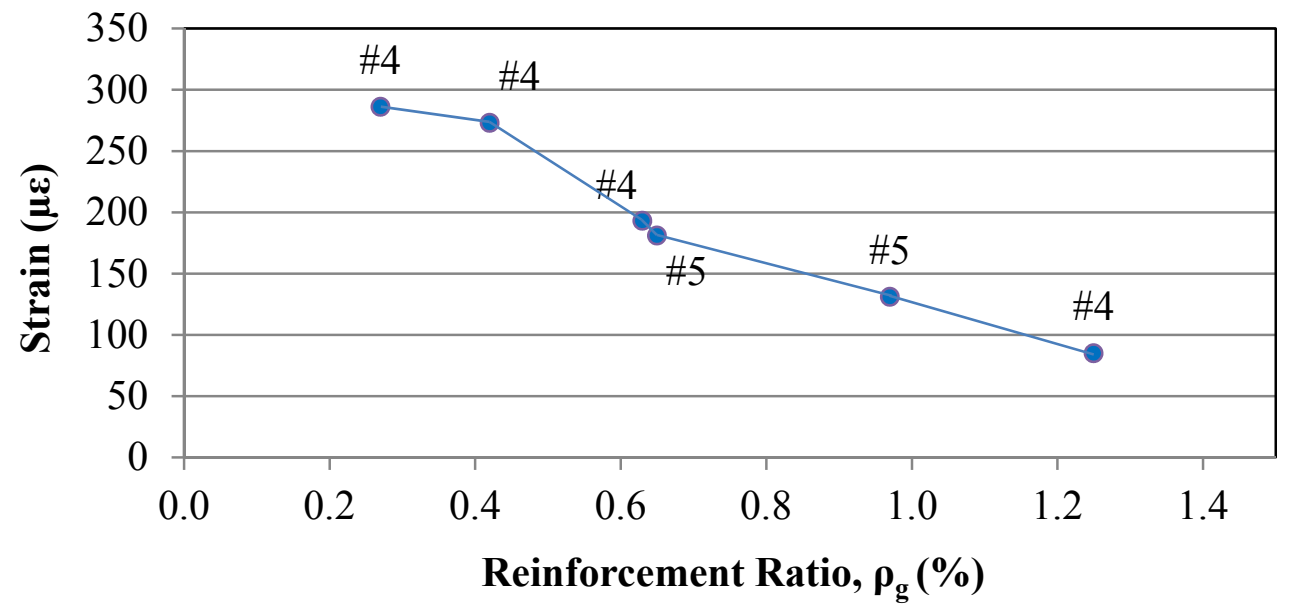

Figure 5.35: Total strains at Day 100

\subsubsection{Reinforcement Spacing}

Specimens 3 and 6 were selected to examine strains in reinforcement with different spacings (12 and 8 in.) while maintaining approximately the same amount of steel. Figure 5.36 compares the behavior of both specimens. For the first 45 days, a significant difference between both specimens was observed. It is possible that this variation was caused by an uneven distribution of forces in the reinforcement at the beginning of the test that was balanced over time. After this point, the strains were almost identical for both reinforcement layouts. As a result, the spacing does not appear to contribute to the reinforcement strains and as evident in Figure 5.35, the amount of reinforcement is the primary variable. 


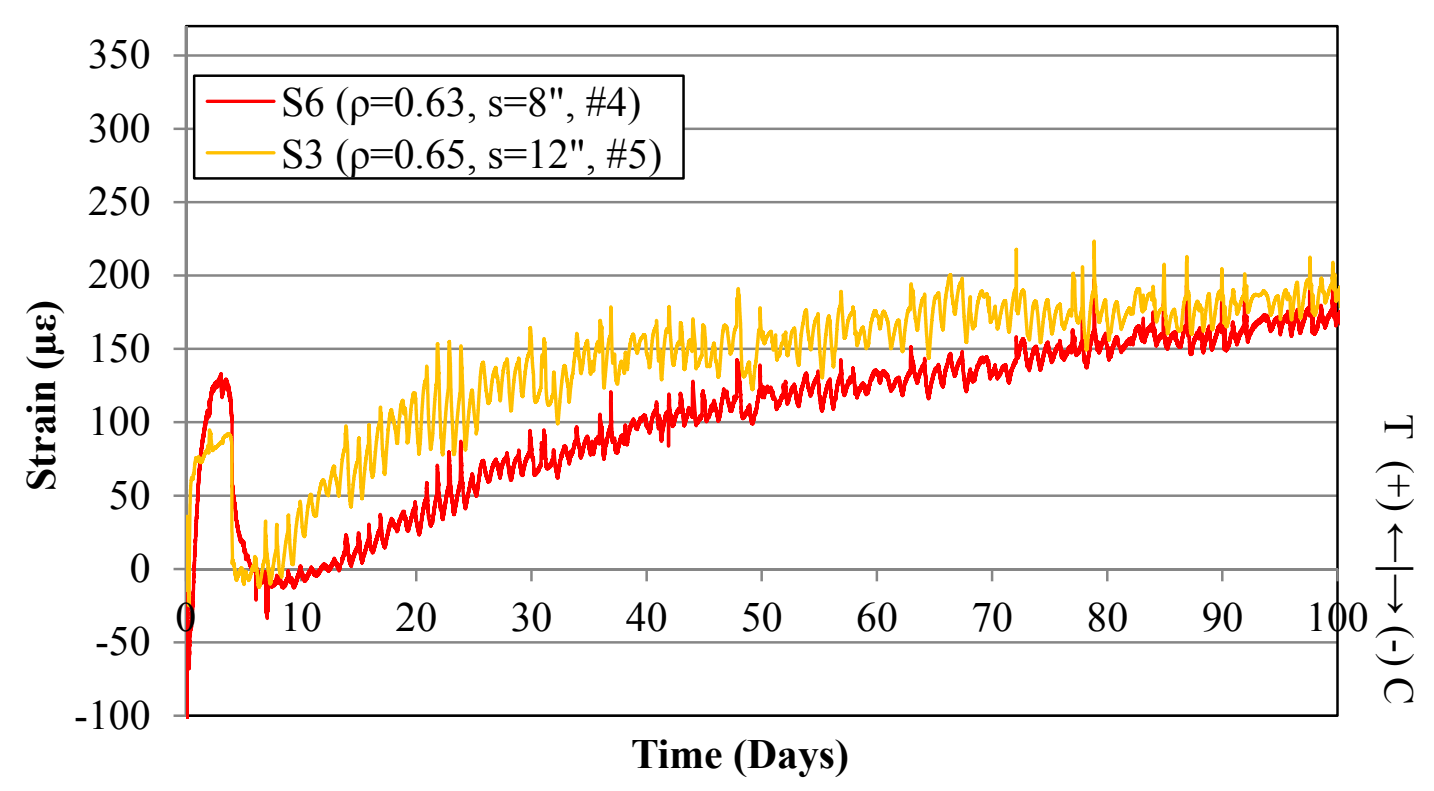

Figure 5.36: Reinforcement strains, equal reinforcement ratio

\subsubsection{Reinforcement Diameter}

The two reinforcement diameters evaluated in this investigation corresponded to \#4 and \#5 bars. As observed in Figure 5.36, strains were approximately the same for both specimens at 100 days considering the same amount of reinforcement $(\rho=0.63 \%$ and $0.65 \%$ ). Based on these results, the reinforcement strain is not significantly affected by the bar diameters. Again, the amount of reinforcement is the primary variable.

\subsubsection{Crack Widths}

Linear potentiometers were embedded in the deck to measure crack openings during the test. However, measurements in several of the specimens were not considered accurate. Large fluctuations and abnormal behaviors were obtained as previously discussed. For this reason, microscope crack measurements were acquired at Day 70 and 100. Table 5.8 presents the crack width difference between Day 70 and 100. The crack growth was not significant during this time period, most likely because the shrinkage rate had already decreased considerably by Day 70. Maximum crack widths are plotted in Figure 3.57. The trend shows a decrease in crack widths as the reinforcement ratio increases. 
Table 5.8: Crack width difference (Day 100 - Day 70)

\begin{tabular}{|c|c|c|c|c|c|}
\hline \multirow{2}{*}{ Specimen } & \multirow{2}{*}{$\rho_{\mathbf{g}}$ (\%) } & \multirow{2}{*}{ Spacing (in.) } & \multirow{2}{*}{$\begin{array}{c}\text { Bar } \\
\text { Size }\end{array}$} & \multicolumn{2}{|c|}{ Crack Width* (in.) } \\
\cline { 5 - 6 } & & & Average & Max. \\
\hline 1 & 0.27 & 18 & $\# 4$ & 0.001 & 0.001 \\
\hline 2 & 1.25 & 4 & $\# 4$ & 0.000 & 0.000 \\
\hline 3 & 0.65 & 12 & $\# 5$ & 0.000 & 0.000 \\
\hline 4 & 0.42 & 12 & $\# 4$ & 0.001 & 0.001 \\
\hline 5 & 0.97 & 8 & $\# 5$ & 0.001 & 0.001 \\
\hline 6 & 0.63 & 8 & $\# 4$ & 0.000 & 0.000 \\
\hline
\end{tabular}

"Note: Computed from difference of Table 5.6 and Table 5.7

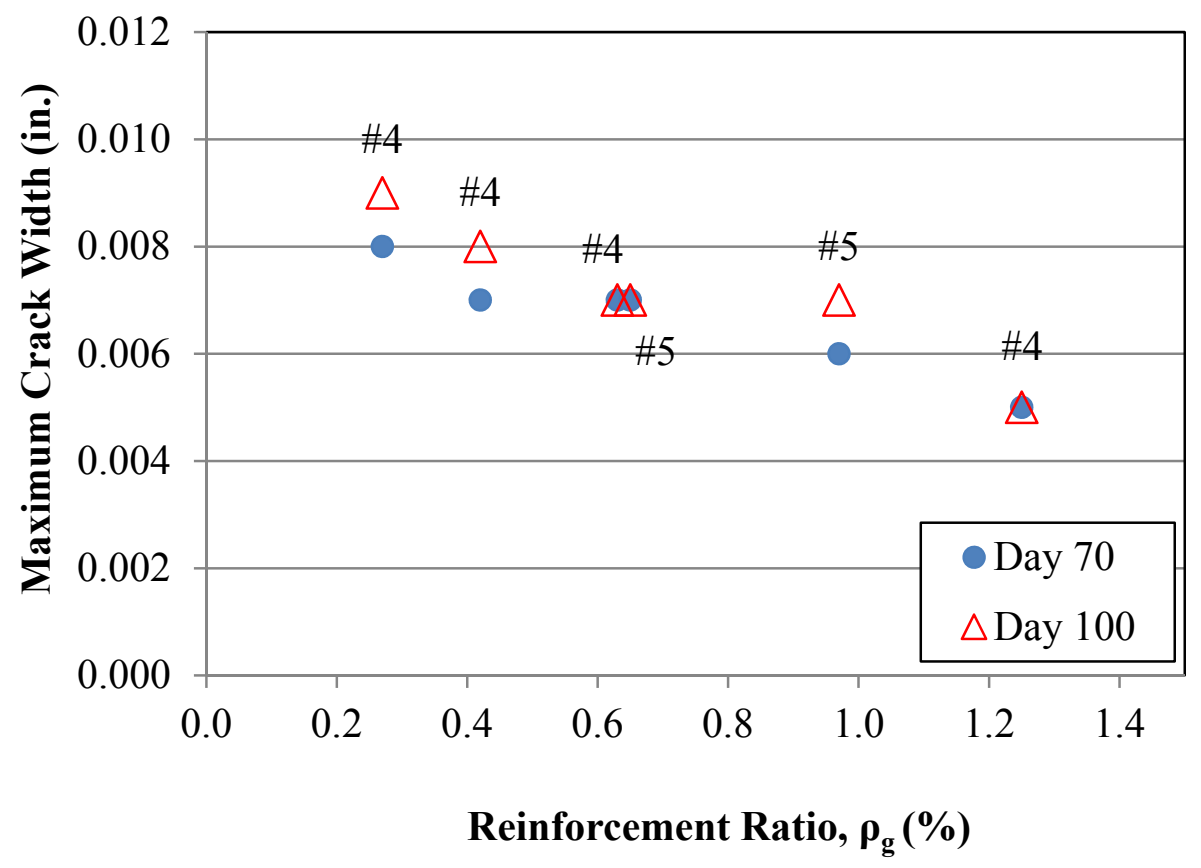

Figure 5.37: Maximum crack width at Day 70 and 100 
Because the linear pots of Specimens 5 and 6 produced stable readings, these readings were compared with the crack width measurements provided by the microscope. The displacements at 100 days were 0.004 and 0.005 in. for Specimens 5 and 6 , respectively as shown in Figure 5.38. From the microscope measurements (Section 5.8.6) the average and maximum width for both specimens were 0.006 and $0.007 \mathrm{in}$., respectively. It should also be noted that variations in crack measurements can be caused by shrinkage of concrete within the stroke of the potentiometer or by other localized effects due to the variability of concrete properties at these locations. Finally, the accuracy and precision of the microscope measurements are subject to human error and interpretation. Considering the accuracy of the microscope to be 0.001 in., these values agree reasonably well with the measurements provided by the linear pots and provide confidence in their readings.

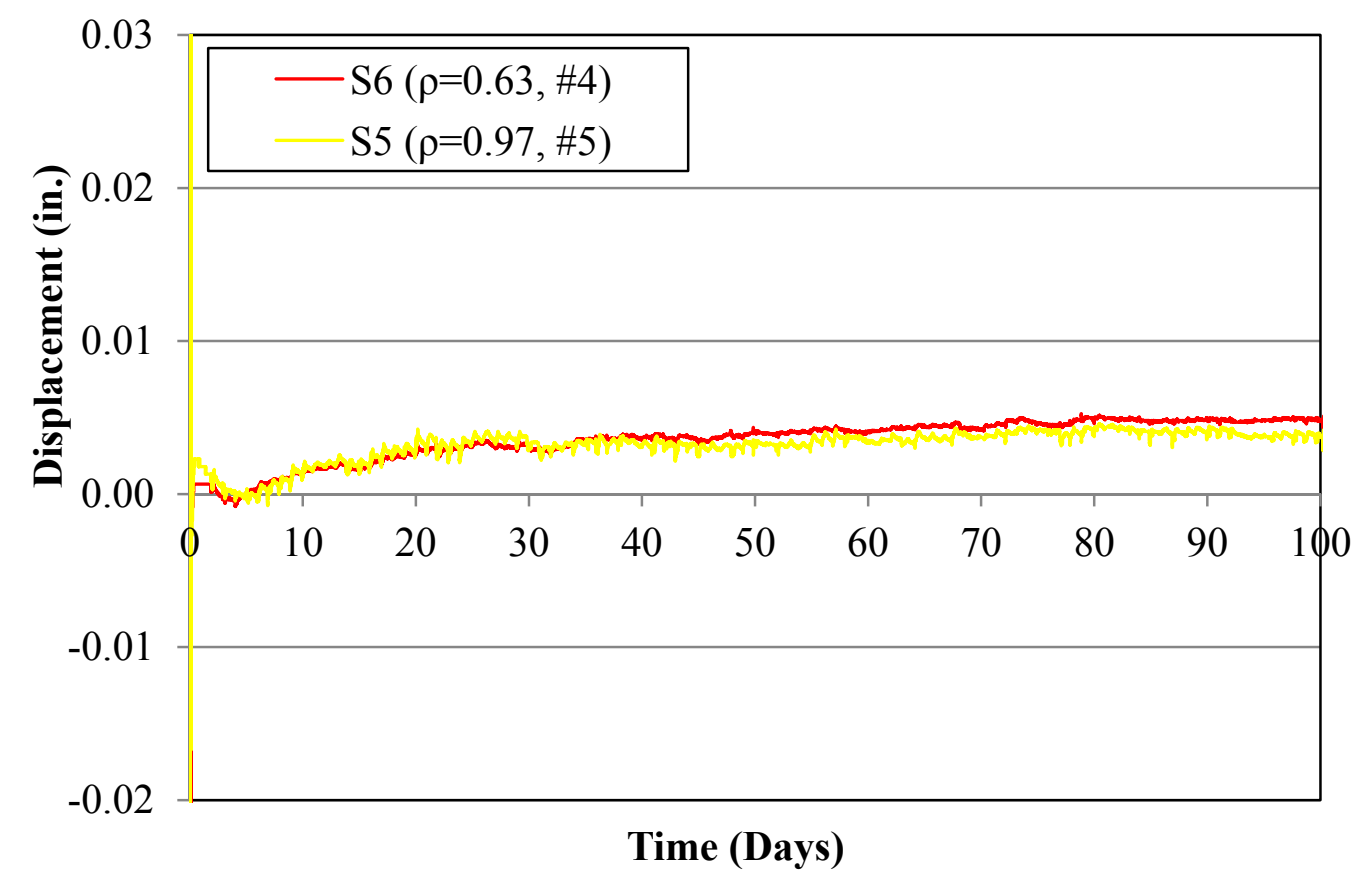

Figure 5.38: Crack width, 8 in. spacing 
To obtain a relationship between strain in the reinforcing steel and the crack widths, potentiometer displacements and reinforcing strains for Specimen 5 and 6 were plotted as illustrated in Figure 5.39 and Figure 5.40, respectively. Potentiometer and strain gage were selected at the same location, near the edge of the specimen. Specimen 5 and 6 were used since the potentiometer displacements were considered accurate. For Specimen 5, a linear equation for these variables was expressed as:

$$
\mu \varepsilon=41000 w-60
$$

Similarly, the linear equation for Specimen 6 was expressed as:

$$
\mu \varepsilon=34000 w-90
$$

Assuming this relationship remains linear, it is estimated that cracks of 0.05 in. and $0.06 \mathrm{in}$. will develop if the steel reaches the yield strength $(60 \mathrm{ksi})$ for Specimen 5 and 6 , respectively. The similarity between these equations indicates that crack width at yield of reinforcement is not significantly affected by differences in bar diameters (\#4 and $\# 5)$ or reinforcement amounts $(0.63 \%$ and $0.97 \%)$. These relationships also indicate that wide crack widths much greater than recommended by ACI 224 will result if yielding of the reinforcement occurs. 


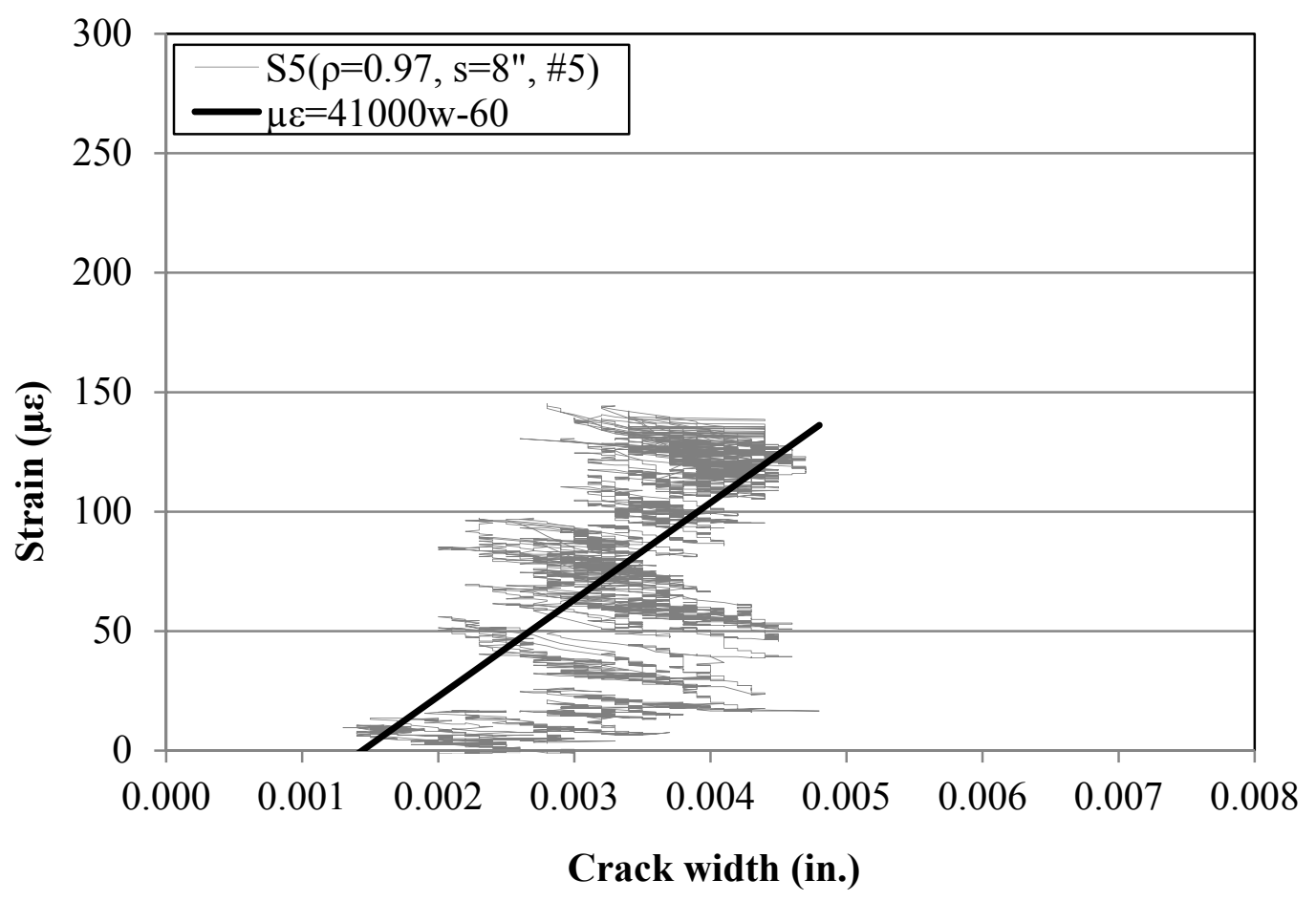

Figure 5.39: Strain vs. crack width, Specimen 5

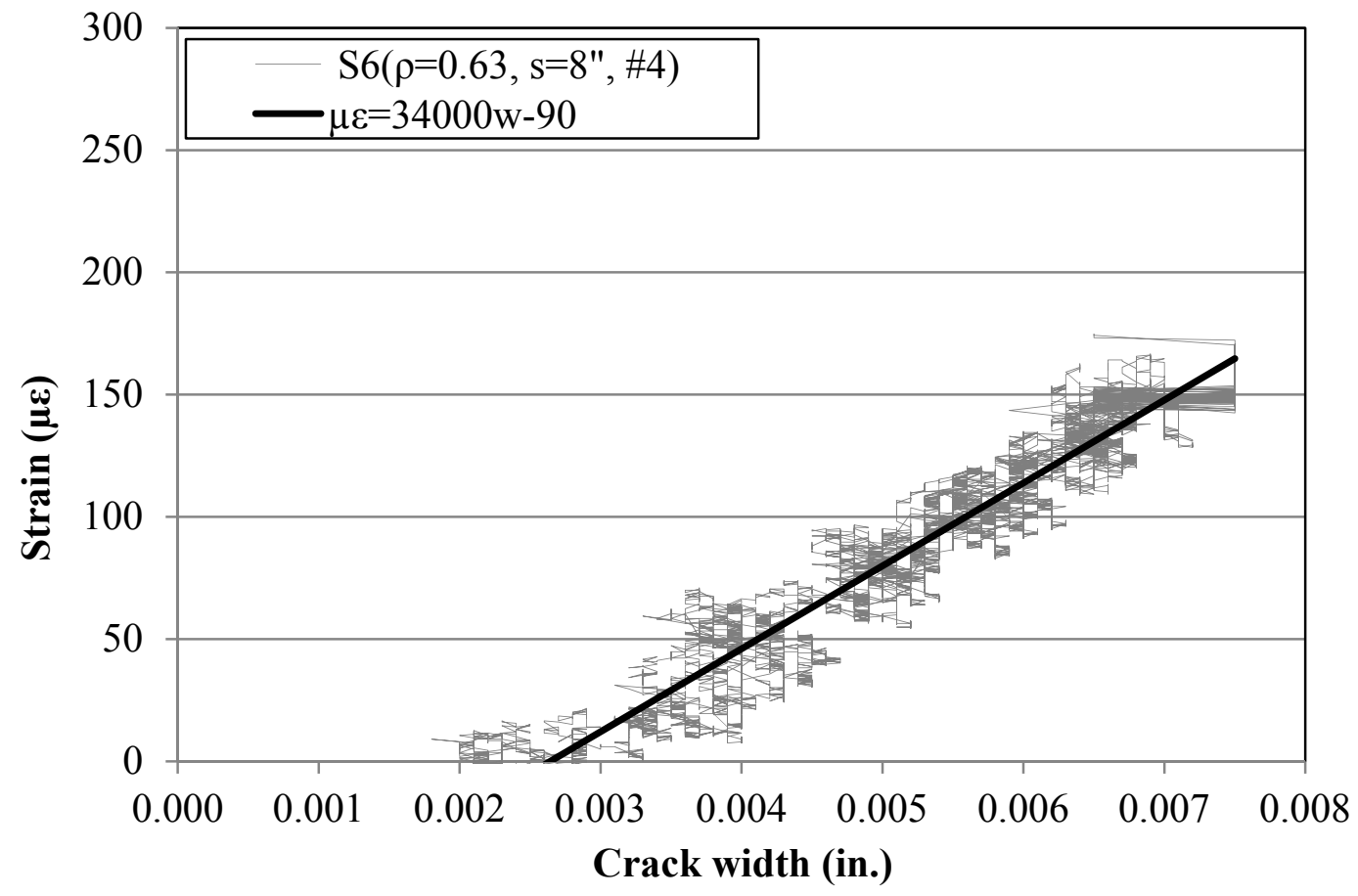

Figure 5.40: Strain vs. crack width, Specimen 6 


\subsubsection{Girder Deflections}

The deflections of the girders were measured at midspan during the test. These displacements are shown in Figure 5.41 for the specimens with $\# 4$ bars. It can be observed that Specimens 1 and 2 had approximately the same deflection. In addition, Specimen 6 had the largest deflection. To further evaluate, the strains obtained at the top flange were examined. The same trend was observed as shown in Figure 5.42. The deflections tend to increase as the reinforcement ratio increases and the spacing decreases with the exception of Specimen 2. This trend is likely explained considering two major factors affecting deflection such as the inertia of the cross section and crack width. Evidently, as the inertia of the cross section increases, deflection decreases. However, the deck deflection is also a function of the crack width. As the crack grows, it elongates the deck and causes an upward deflection that offsets the deflection caused by restrained shrinkage and the composite action between the deck and steel girder. Therefore, as the reinforcement increases, it decreases crack width (increase deflection), but also increases the inertia of the cross section (decrease deflection). The first case is evident in Specimen 1,4 , and 6 . As the reinforcement increases, smaller crack widths are allowed and more deflections are observed. The second case controls in Specimen 2 where a significant increase in the amount of reinforcement (1.25\%) provides a higher moment of inertia and smaller deflections. 


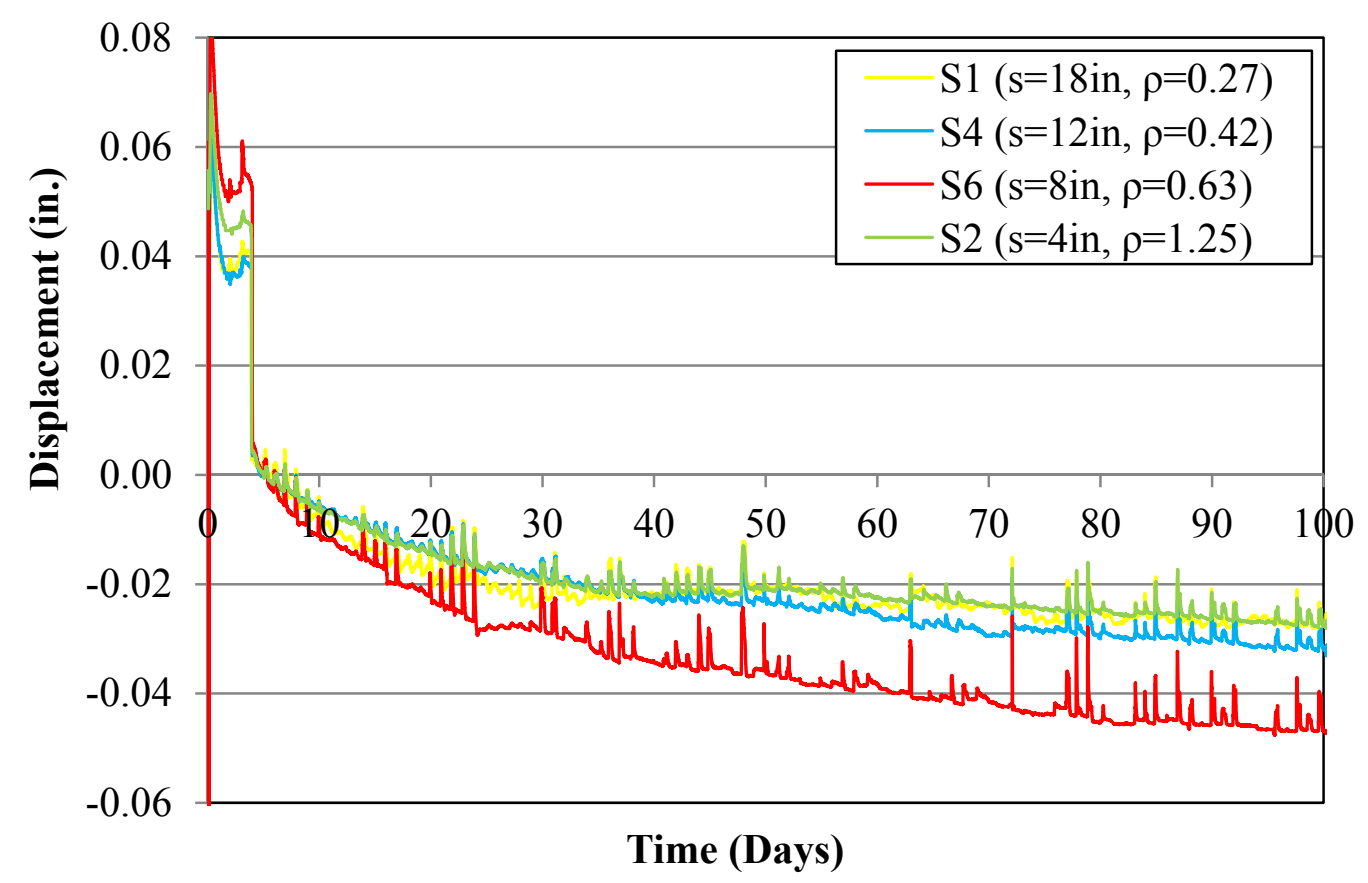

Figure 5.41: Deflection, \#4 bar

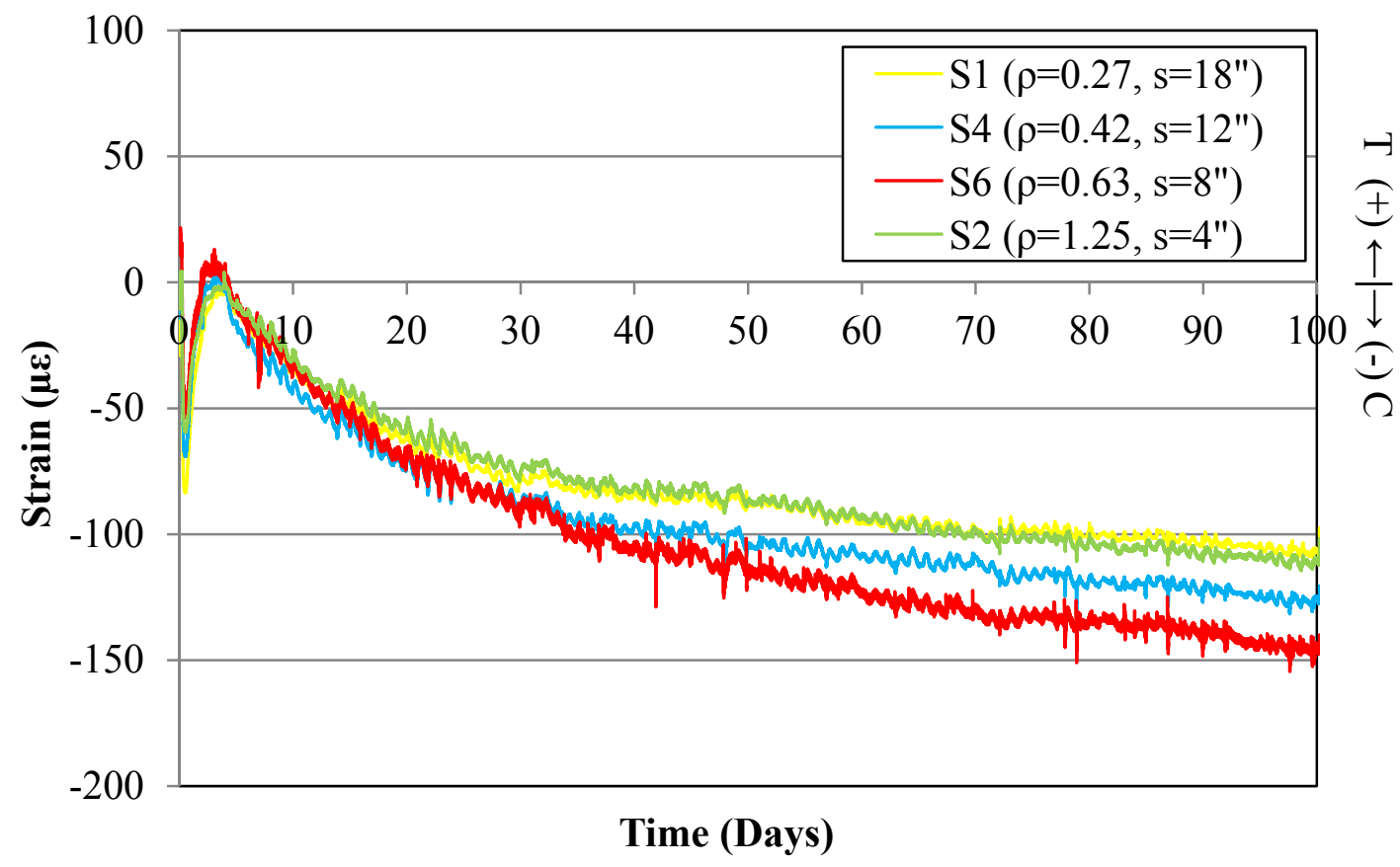

Figure 5.42: Girder strain at top flange, \#4 bar 


\section{$\underline{5.10 \text { Conclusions }}$}

The effectiveness of various reinforcing designs was evaluated to identify the primary variables in the control of crack widths. Primary variables included the reinforcing ratio, bar spacing, and bar diameter. Based on this investigation, the following conclusions are made:

1. No significant steel contribution was observed for reinforcement ratios lower than $0.42 \%$. Specimens with $0.27 \%$ and $0.42 \%$ obtained approximately the same strains in the reinforcement. Only a minimum reduction in shrinkage strain is obtained using these ratios.

2. A linear response was obtained for reinforcement ratios higher than $0.65 \%$. The strain decreases linearly as the reinforcement amount increases. The highest ratio evaluated was $1.25 \%$.

3. The recommended reinforcement ratio provided by Eq. 5.3 (Frosch et al. 2003, 2006) is within the effective range. This expression indicates that $0.63 \%$ reinforcement is required. For the test conducted with $0.65 \%$ reinforcement, a significant reduction in shrinkage strain was observed.

$$
\rho_{g}=\frac{6 \sqrt{f_{c}^{\prime}}}{f_{y}}
$$

4. The strains in the steel reinforcement are primarily controlled by the reinforcement ratio. No significant influence of the bar spacing (8 and 12 in.) and bar diameter (\#4 and \#5) was observed in this investigation.

5. Crack widths provide a similar trend as the strains with respect to the reinforcement ratio. Decks with higher reinforcement ratios exhibited smaller crack widths. 


\section{CHAPTER 6 SUMMARY AND CONCLUSIONS}

\subsection{Introduction}

A large number of bridges across the state of Indiana have exhibited early age deck cracking. This presents a major threat to the lifespan of these bridges, as deck cracking often leads to corrosion of the reinforcing steel by creating a path for water and deicing salts to reach the steel. Therefore, there is a need to develop design and construction guidelines to control deck cracking in newly constructed bridges. In addition, a method to repair deck cracks must be developed to prevent corrosion of the reinforcement in bridges already in service. The objective of this research is to develop effective design, construction, and repair methods for the control of bridge deck cracking.

\subsection{Research Results}

This research project was divided into four phases and detailed results for each phase are outlined below.

\subsubsection{Phase 1: Field Investigation}

The first phase of the study was an investigation of a new bridge that is experiencing significant deck cracking. An in-depth study of the US-50 bridge over the Wabash River was conducted, including a field inspection. Based on this phase of the research, the following conclusions were made:

1. Bridge geometry plays a role in shrinkage cracking. Cracks are rare in regions adjacent to expansion joints, as their presence decreases restraint. Regions 
furthest from expansion joints experience the most restrained shrinkage cracking due to high levels of restraint.

2. Increased deck reinforcement significantly decreases crack widths. The performance of the negative moment region relative to the positive moment region of the US-50 bridge clearly illustrates the improvement of cracking behavior achieved by increasing reinforcement. Furthermore, the reinforcement of the positive moment region did not satisfy the previous recommendations for control of deck cracking as recommended by Frosch et al. (2003 and 2006). The low amount of reinforcement and wide bar spacing in the positive moment region led to significant deck cracking. On the other hand, the reinforcement in the negative moment region did meet the recommendations and resulted in significantly reduced crack widths.

3. Poor weather conditions at the time of casting, such as low or high temperatures, low humidities, and high wind speeds, increase shrinkage cracking. Low temperatures in particular are detrimental because they make wet curing difficult and cause a slow development of concrete strength. The eastbound span of the US-50 bridge experienced significant deck cracking due to poor weather conditions at the time of casting.

\subsubsection{Phase 2: Curing Investigation}

The second phase of the research investigated the influence of wet curing duration, wet curing procedure, and concrete mix on shrinkage. In addition, various sensors were evaluated as potential curing monitoring devices. Based on the results from this phase of the research, the following conclusions were made:

1. Proper wet curing is crucial in preventing early age shrinkage of concrete as it delays the onset of drying shrinkage until the concrete has gained improved tensile strength. Decreased curing duration or improper curing procedures were shown to increase shrinkage and would likely lead to increased restrained shrinkage cracking. 
2. Increasing the duration of wet cure decreases the long term shrinkage. A correlation was observed relating increased wet curing durations to decreased shrinkage at 210 days after the end of wet cure.

3. Modifications to the concrete mix design intended to produce lower shrinkage significantly improved the performance of the concrete. These changes, which included a reduction in the cement and water content and the addition of fly ash, led to decreased shrinkage without significantly reducing the concrete strength. Further, the heat of hydration can also be reduced, thereby reducing thermally induced shrinkage.

4. Embedment strain gages and thermocouples could potentially be installed into bridge decks to quantitatively measure wet curing of the deck.

\subsubsection{Phase 3: Crack Repair Investigation}

The third phase evaluated several crack sealers to provide material type and product recommendations. Macrocell specimens were constructed to investigate the performance of several repair products in preventing corrosion of the reinforcement. The specimens were designed to represent the interior section of a bridge deck and were subjected to tensile stresses until full depth cracks were obtained. Afterwards, cracks were repaired with both gravity feed and overlay repair techniques, and the specimens were restressed to simulate traffic loads prior to initiation of a macrocell corrosion test. The corrosion test was conducted for a duration of 53 weeks. After conclusion of the test, the reinforcement was extracted from the specimens to visually assess the degree of corrosion at crack locations. Based on the results of the first phase, the following conclusions were based on application and final performance:

\section{Application:}

1. The ability of gravity feed crack repair products to fill cracks was improved by applying a pretreatment stripe to all cracks.

2. A standard application procedure is needed, as there is some variation in manufacturer-supplied guidelines. Consistent surface preparation, mixing 
times, pretreatment application, and finishing are necessary for optimal crack repair performance.

3. Among gravity feed repair products, methacrylates were easier to handle than epoxies due to their lower viscosity but required more pretreatment applications.

4. Some failure was observed in the epoxy gravity feed products upon reloading, while all methacrylate gravity feed products withstood the applied loads.

5. All overlays were cracked upon reloading at the location of the original crack.

6. Leaking was observed in some specimens, indicating an inadequate crack repair. The leaking was not specific to a certain repair technique or product.

\section{Repair Performance:}

1. In general, epoxies provided the best performance in preventing corrosion. However, significant variation among products was observed indicating that the type of material alone is not indicative of performance. This variation is likely due to the different physical properties of the materials. Table 6.1 provides a list of top performing products evaluated in this study.

Table 6.1: Products with best performance

\begin{tabular}{|c|c|c|}
\hline Product & Manufacturer & Repair Type \\
\hline MARK 163 FlexoGrid & Poly-Carb & Epoxy Overlay \\
\hline Dural 335 & Euclid / Tamms & Epoxy \\
\hline Sikadur 55 SLV & SikaCorp & Epoxy \\
\hline Epoxesl GS Structural & BASF & Epoxy \\
\hline Pro-Poxy Type III D.O.T & Unitex & Epoxy Overlay \\
\hline HMSLV & Kaufman Products & Epoxy \\
\hline Dural 50 & Euclid / Tamms & Epoxy \\
\hline Bridge Seal & Unitex & Epoxy \\
\hline
\end{tabular}


2. Based on the results, methacrylates exhibited inferior overall performance compared to epoxy repair products.

3. No correlation was evident between corrosion and crack width considering the following crack widths: small (0.010 to $0.013 \mathrm{in}$ ), medium (0.016 to $0.020 \mathrm{in}$ ), and large (0.035 to 0.040 in). For these widths, corrosion does not appear to be significantly influenced by crack widths.

\subsubsection{Phase 4: Crack Control Investigation}

The fourth phase of the investigation evaluated design parameters to effectively control crack widths and mitigate cracking in future construction. Six concrete deck specimens were constructed to evaluate the reinforcement required to optimally control crack widths. A crack was pre-formed at midspan to simulate transverse deck cracking and evaluate crack growth and stresses on the reinforcement at this location. Throughout the test, deck shrinkage and thermal volumetric changes were restrained by composite action between the steel girder and concrete deck. Test variables such as the amount, diameter, and spacing of the reinforcement were investigated to determine their specific contribution in controlling cracking. From results of this phase, the following conclusions were made:

1. No significant control of cracking was observed for reinforcement ratios lower than $0.42 \%$. Specimens with $0.27 \%$ and $0.42 \%$ obtained approximately the same amount of reinforcement strain. Only a minimum reduction in shrinkage strain is obtained using these low reinforcement ratios.

2. A linear response was obtained for reinforcement ratios higher than $0.65 \%$. The strain decreases linearly as the reinforcement amount increases. The highest ratio evaluated was $1.25 \%$.

3. The recommended reinforcement ratio provided by Eq. 6.1 (Frosch et al. 2003, 2006) is within the effective range. This expression indicates that $0.63 \%$ reinforcement is required for $f^{\prime}{ }_{c}=4,000 \mathrm{psi}$ and $f_{y}=60,000 \mathrm{psi}$ as commonly used in bridge decks. For the test conducted with $0.65 \%$ reinforcement, a significant reduction in shrinkage strain was observed. 


$$
\rho_{g}=\frac{6 \sqrt{f_{c}^{\prime}}}{f_{y}}
$$

4. The strains in the steel reinforcement are primarily controlled by the reinforcement ratio. No significant influence of the bar spacing (8 in. and 12 in.) and bar diameter (\#4 and \#5) was observed in this investigation.

5. Crack widths provide a similar trend as reinforcement strains with respect to the reinforcement ratio. Decks with higher reinforcement ratios exhibited smaller crack widths.

\subsection{Design, Construction, and Repair Recommendations}

Based on conclusions made from this research project, the following design, construction, and repair recommendations are made:

\section{Design and Construction of New Bridges:}

1. The amount of deck reinforcement should be calculated according to the following expression:

$$
\rho_{g}=\frac{6 \sqrt{f^{\prime}{ }_{c}}}{f_{y}}
$$

This amount of reinforcement was demonstrated in both the laboratory and field to control crack widths which leads to improved durability of the bridge deck.

2. For special structures where enhanced durability is desired, reinforcement amounts greater than that recommended above should be considered. According to this investigation, greater reinforcement ratios provide for an increased reduction of steel reinforcement strains and crack widths. Therefore, an increased amount of reinforcement will further reduce crack widths.

3. While the existence of an expansion joint may reduce deck cracking due to a decrease in restraint, increasing the number of expansion joints on a bridge deck is not recommended as a solution to cracking due to increases in cost and maintenance, in addition to problems related to leaking of these joints. 
4. Alterations to the concrete mix design used on bridge decks (Class C) are strongly recommended. A reduction in the cement and water contents and the addition of fly ash can significantly reduce the heat of hydration, early age shrinkage, and total shrinkage of the deck.

5. Casting of concrete decks should not be conducted when temperatures below $40^{\circ} \mathrm{F}$ are expected on the day of casting or the 7 days following casting. In addition, weather conditions such as low humidity and high wind speeds should be avoided on the day of casting.

6. Continuous wet cure procedures, initiated as early as possible after concrete placement, should be strictly adhered to, as improper wet curing leads to increased early age shrinkage.

7. A 7 day minimum continuous wet cure is adequate to control early age shrinkage. Long term shrinkage can be reduced by increasing the duration of wet cure. However, the most important benefit is the delay of shrinkage until the concrete has developed sufficient tensile strength. While there is benefit to further increasing the required duration of wet cure, the improved performance would not be significant enough to offset increased costs due to delays in construction.

\section{Repair of Existing Bridges:}

1. A pretreatment stripe should be incorporated into all gravity feed crack repair procedures. This will allow the product to more completely fill the crack and results in an improved repair.

2. All overlay repair should be conducted in conjunction with a gravity feed crack repair as overlays have been shown to crack at the location of the original crack when loaded.

3. The selection of crack repair material should be performed considering crack widths. For narrow cracks, methacrylates should be considered as they provide deeper penetration into the crack than epoxies. For wide cracks ( $>0.016$ in.), epoxies are recommended because of their higher bond strength and their demonstrated performance in this investigation. Methacrylates should not be used 
as a repair solution for the repair of wide cracks ( $>0.016$ in.) as indicated by their poor performance in this investigation. For bridge decks, repair is typically conducted for wide cracks.

4. The repair products listed in Table 6.1 and repeated below can be effectively used for the repair of bridge deck cracks to enhance the durability of the deck. It is important that the application procedures for the product be followed to provide for proper performance of the material.

\begin{tabular}{|c|c|c|}
\hline Product & Manufacturer & Repair Type \\
\hline MARK 163 FlexoGrid & Poly-Carb & Epoxy Overlay \\
\hline Dural 335 & Euclid / Tamms & Epoxy \\
\hline Sikadur 55 SLV & SikaCorp & Epoxy \\
\hline Epoxesl GS Structural & BASF & Epoxy \\
\hline Pro-Poxy Type III D.O.T & Unitex & Epoxy Overlay \\
\hline HMSLV & Kaufman Products & Epoxy \\
\hline Dural 50 & Euclid / Tamms & Epoxy \\
\hline Bridge Seal & Unitex & Epoxy \\
\hline
\end{tabular}




\section{LIST OF REFERENCES}

AASHTO, 2004, “AASHTO LRFD Design Specifications,” $3^{\text {rd }}$ edition, American Association of State Highway Officials, Washington, D.C.

AASHTO, 2002, "Standard Specifications for Highway Bridges," $17^{\text {th }}$ edition,

American Association of State Highway Officials, Washington, D.C.

ACI, 1985, "Debate: Crack Width, Cover, and Corrosion,” Concrete International, v. 7, n. 5, 1985.

ACI Committee 224.1R-07, 2007, "Causes, Evaluation, and Repair of Cracks in Concrete Structures,” American Concrete Institute, Farmington Hills, MI.

ACI Committee 224R-01, 2001, “Control of Cracking in Concrete Structures,” American Concrete Institute, Farmington Hills, MI.

ACI Committee 308-01, 2001, "Guide to Curing Concrete," American Concrete Institute, Farmington Hills, MI.

ACI Committee 318-05, 2005, "Building Code Requirements for Structural Concrete and Commentary,” American Concrete Institute, Farmington Hills, MI.

ACI Committee 318-08, 2008, "Building Code Requirements for Structural Concrete and Commentary,” American Concrete Institute, Farmington Hills, MI.

Aldridge, T.S. 2005, "Structural Behavior of High-Performance Concrete Bridge Decks," Master's Thesis, School of Civil Engineering, Purdue University, May 2005.

Altoubat, S., Lange, D.A. 2001, "Creep, Shrinkage, and Cracking of Restrained Concrete at Early Age," ACI Materials Journal, v. 98, n. 4, 2001, pp. 323-31.

Attanayake, U., Xuemei, L, Ng, S., Aktan, H. 2005, "Penetrating Sealants for Concrete Bridge Decks-Selection Procedure," Journal of Bridge Engineering, vol. 11, no. 5, September 1, 2005.

Bice, J.K. 2006, "Design Methods for Control of Restrained Shrinkage Cracking," PhD Thesis, School of Civil Engineering, Purdue University, December 2006.

Blackman, D., 2002, "Evaluation of Design Methods for the Control of Early Age Bridge Deck Cracking,” Master's Thesis, School of Civil Engineering, Purdue University, May 2002.

French, C.E., Eppers, L.J., Le, Q.T.C., Hajjar, J.F. 1999, “Transverse Cracking in Concrete Bridge Decks," Minnesota Department of Transportation Office of Research Services Report No. MN/RC-1999-05, Minneapolis, Minnesota, January 1999. 
Frosch, R.J., Blackman, D.T., Radabaugh, R.D., 2003, "Investigation of Bridge Deck Cracking in Various Bridge Superstructure Systems," Report No. FHWA/IN/JTRP2002/25, Department of Civil Engineering, Purdue University, February 2003.

Frosch, R.J., Bice, J.K, Erickson, J.B, 2006, "Design Methods for the Control of Restrained Shrinkage Cracking,” Report No. FHWA/IN/JTRP-2006/32, Department of Civil Engineering, Purdue University, September 2006.

Grasley, Z.C., D'Ambrosia M.D., Lange, D.A. 2004, “Internal Relative Humidity and Drying Stress Gradients in Concrete,” Concrete Science and Engineering, 2004.

Grasley, Z.C., Lange, D.A. 2004, "A New System for Measuring the Internal Relative Humidity in Concrete," Cementing the Future, Winter 2004 edition.

Hoffman, J.S. 2008, “Control and Repair of Bridge Deck Cracking,” Master’s Thesis, School of Civil Engineering, Purdue University, August 2008.

Johnson, K., Schultz, A.E., French, C., Reneson, J. 2009, “Crack and Concrete Deck Sealant Performance,” Report No. MN/RC 2009-13, Department of Civil Engineering, University of Minnesota, March 2009.

Krauss, P.D., Rogalla, E.A. 1996, “Transverse Cracking in Newly Constructed Bridge Decks,” NCHRP Report No. 380, Transportation Research Board, National Report Council, Washington, D.C., 1996.

Meggers, D. 1998. "Crack Sealing and Repair of Older Serviceable Bridge Using Polymer Sealers.” Kansas Department of Transportation Bureau of Materials and Research Report No. FHWA-KS-98-4, Topeka, KS, 1998.

Mindess, S., Young, J. F., Darwin, D. 2003, Concrete, Upper Saddle River, NJ, 2003.

National Oceanic and Atmospheric Administration, Unedited Local Climatological Data. $<$ http://cdo.ncdc.noaa.gov/ulcd/ULCD >.

NCHRP Synthesis of Highway Practice 333, 2004, “Concrete Bridge Deck Performance,” Transportation Research Board, National Research Council, Washington, D.C.

Pincheira, J.A., Dorshorst, M.A. 2005, "Evaluation of Concrete Deck and Crack Sealers,” Wisconsin Highway Research Program Report No. WHRP 06-09, Madison, WI, December 3, 2005.

Purvis, R., Babaei, K., Udani, N., Quanbari, A., and Williams, W. 1995, "Premature Cracking of Concrete Bridge Decks: Causes, and Methods of Prevention." Pennsylvania Department of Transportation, Fourth International Bridge Engineering Conference, Washington, D.C., 1995.

Radabaugh, R.D. 2001, “Investigation of Early Age Bridge Deck Cracking,” Master’s Thesis, School of Civil Engineering, Purdue University, May 2001.

Schmitt, T.R., Darwin, D. 1995, “Cracking in Concrete Bridge Decks,” SM Report No. 39, University of Kansas Center for Research, Lawrence, KS, 1995. 
Tia, M., Subramanian, R., Brown, D., Broward, C. 2005, "Evaluation of Shrinkage Cracking Potential of Concrete Used in Bridge Decks in Florida," Florida Department of Transportation Contract No. BC 354-RPWO \#26, Tallahassee, FL, September 2005.

Weiss, J.W., Yang, W., Shah, S.P. 1998," Shrinkage Cracking of Restrained Concrete Slabs" Journal of Engineering Mechanics, v. 124, n. 7, July 1998, pp. 765-774.

Wipf, T.J. 2006, "Corrosion Resistance in Different Steel Reinforcement Types," Iowa Department of Transportation CTRE Project 02-103, May 2006. 
APPENDIX A

REPAIR PRODUCT TECHNICAL DATA SHEETS 
Technical data sheets for all crack repair products used the crack repair investigation are provided.

Table A.1: Crack repair products

\begin{tabular}{|l|l|l|}
\hline Product Name & Manufacturer & Figure \\
\hline SikaPronto 19 TF & SIKA Corp. & A.1 \\
\hline Sikadur 55 SLV & SIKA Corp. & A.2 \\
\hline MARK-127 & Poly-Carb & A.3 \\
\hline MARK-135 Safe-T-Seal & Poly-Carb & A.4 \\
\hline Epoxeal GS Structural & BASF & A.5 \\
\hline Degadeck Crack Sealer Plus & BASF & A.6 \\
\hline Enviroseal & BASF & A.7 \\
\hline Dural 335 & Euclid / Tamms & A.8 \\
\hline Dural 50 & Euclid / Tamms & A.9 \\
\hline Dural 50 LM & Euclid / Tamms & A.10 \\
\hline SurePoxy HMSLV & Kaufman Products & A.11 \\
\hline FX-770 HM LV & Fox Industries & A.12 \\
\hline FX-821 MMA & Fox Industries & A.13 \\
\hline Bridge Seal & Unitex Chemicals & A.14 \\
\hline Mark-163 FlexoGrid & Poly-Carb & A.15 \\
\hline Pro-Poxy Type III D.O.T. & Unitex Chemicals & A.16 \\
\hline
\end{tabular}


Edition 8.2003

Identification no. 309-01T

SikaPronto $19 \mathrm{TF}$

\section{SikaPronto ${ }^{\circledR} 19$ TF (Tack Free)}

New, fast traffic time, high molecular weight methacrylate, crack healer/penetrating sealer

\begin{tabular}{|c|c|}
\hline Description & $\begin{array}{l}\text { SikaPronto } 19 \mathrm{TF} \text { is a 2-component, rapid-curing, solvent-free, high molecularweight methacrylate, crack } \\
\text { healer/penetrating sealer, with an extremely fast traffic time to minimize downtime. }\end{array}$ \\
\hline \multirow[t]{2}{*}{ Where to Use } & $\begin{array}{l}\text { Use on grade, above and below grade on concrete and mortar. SikaPronto } 19 \text { TF seals surface of } \\
\text { concrete from water and chlorides. }\end{array}$ \\
\hline & $\begin{array}{l}\text { For horizontal decks, slabs, patios, driveways, parking garages, and other substrates exposed to foot } \\
\text { and pneumatic-tire traffic. }\end{array}$ \\
\hline Advantages & $\begin{array}{l}\text { - Penetrates cracks by gravity. } \\
\text { - Structurally improves concrete surface. } \\
\text { - Opens to traffic in under } 3 \text { hours. } \\
\text { - Easy-to-use, } 2 \text {-component system. } \\
\text { - Does not produce a vapor barrier. } \\
\text { - Low viscosity for easy, topical applications and excellent penetration into cracks. } \\
\text { - Low odor. } \\
\text { - High bond strength. } \\
\text { - Prolongs life of cracked concrete. }\end{array}$ \\
\hline Coverage & $\begin{array}{l}\text { Typical coverage is } 90-150 \mathrm{sq} \text {. ft./gal. for crack healing and surface sealing. Coverage varies with porosity } \\
\text { and surface profile of substrate. Higher porosity will reduce coverage. }\end{array}$ \\
\hline Packaging & 1 gal. units, $4 /$ carton; 4.5 gal. units. \\
\hline
\end{tabular}

\section{Typical Data (Material and curing conditions @ $73^{\circ} \mathrm{F}\left(23^{\circ} \mathrm{C}\right)$ and $50 \%$ R.H.)}

Shelf Life Component ' $A$ ': 3 months in original, unopened container. Component ' $B$ ': 6 months in original, unopened container.

Storage Conditions Store dry at $40^{\circ}-95^{\circ} \mathrm{F}\left(4^{\circ}-35^{\circ} \mathrm{C}\right)$. Condition material to $65^{\circ}-75^{\circ} \mathrm{F}$ $\left(18^{\circ}-24^{\circ} \mathrm{C}\right)$ before using. Storage at higher temperatures may cause material to pre-polymerize and will reduce shelf life.

Color Dark purple when liquid; light amber after cure.

Mixing Ratio Plant-proportioned kit; mix entire unit.

Methacrylate Monomer Viscosity $25 \mathrm{cps}$ maximum.

Pot Life Approximately 15 minutes.

Bulk Cure Time 90 minutes maximum.

Traffic Time 3 hours maximum.

Flexural Properties (ASTM D-790)

1 day Flexural Strength (Modulus of Rupture) 2,500 psi (17.2 MPa)

Bond Strength (ASTM C-882): Hardened concrete to hardened concrete

2 day (dry cure) Bond Strength 2,100 psi (14.4 MPa)

14 day (moist cure) Bond Strength 2,300 psi (15.8 MPa)

Compressive Properties (ASTM D-695)

Compressive Strength, psi ( $\mathrm{MPa}$ )

$\begin{array}{llll} & 40^{\circ} \mathrm{F}^{\star}\left(4^{\circ} \mathrm{C}\right) & 73^{\circ} \mathrm{F}^{\star}\left(23^{\circ} \mathrm{C}\right) & 90^{\circ} \mathrm{F}^{\star}\left(32^{\circ} \mathrm{C}\right) \\ 1 \text { hour } & - & 1,000(6.8) & 1,900(13.1) \\ 2 \text { hour } & - & 2,300(15.8) & 2,700(18.6) \\ 1 \text { day } & 1,800(12.4) & 2,900(20.0) & 3,500(24.1) \\ 7 \text { day } & 3,500(24.1) & 3,100(21.3) & 4,300(29.6)\end{array}$

Figure A.1: Technical Data Sheet: SikaPronto 19 TF, SIKA Corp. 


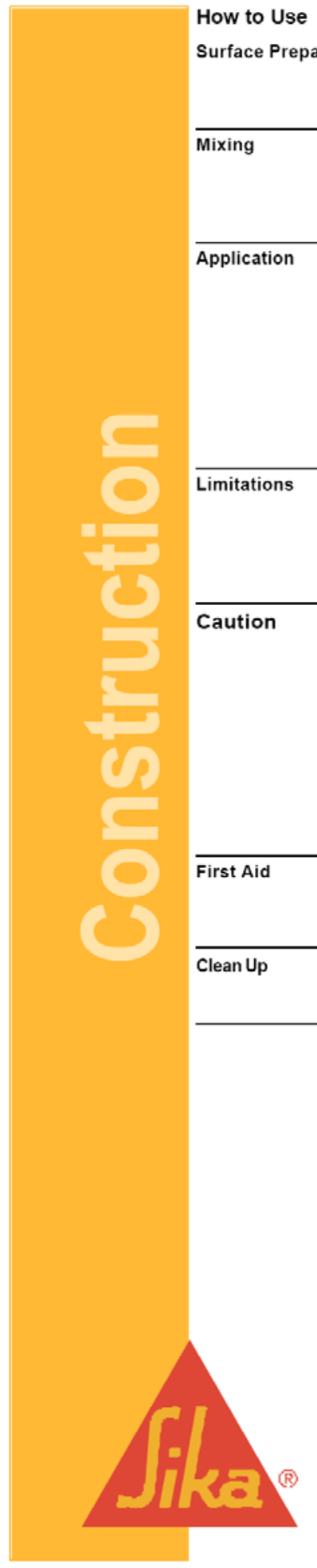
KEEP CONTAINER TIGHTLY CLOSED

Substrate must be clean, sound and free of surface moisture. Remove dust, laitance, grease, oils, curing compounds, waxes, impregnations, foreign particles, coatings and disintegrated materials by mechanical means (i.e., blast cleaning). For best results, substrate should be dry. However, a saturated surface dry condition is acceptable.

Before adding 'B' Component, mix 'A' Component for 30 seconds with a low-speed drill using a Sika paddle. Empty entire contents of ' $B$ ' Component into pail containing ' $A$ ' Component. Mix for 3 minutes with a low-speed drill (400-600 rpm) using a Sika paddle. Caution: Mix only that quantity that can be placed within the pot life. Material should be quickly poured from pail onto concrete surface to prolong working life.

SikaPronto 19 TF is applied to horizontal surfaces by roller, squeegee or broom. Spread material over
area and allow to pond over cracks. Let material penetrate into cracks and substrate; remove excess material leaving no visible surface film. For cracks greater than $1 / 8$ in. $(3 \mathrm{~mm})$ wide, fill crack with ovendried sand before applying SikaPronto 19 TF. Seal cracks from underside, when accessible, to prevent leakage.

A second treatment may be required on very porous substrates. Apply second treatment before broadcasting. After treatment, wait at least 20 minutes at $73^{\circ} \mathrm{F}\left(23^{\circ} \mathrm{C}\right)$; cover with light broadcast of a dry $8 / 20$ or similar sand. Distribute evenly over the surface at a rate of 15 to $20 \mathrm{lbs} . / 100 \mathrm{sq}$. $\mathrm{ft}$. Allow to cure 3 hours at $73^{\circ} \mathrm{F}\left(23^{\circ} \mathrm{C}\right)$. Remove any loose sand and open to traffic. Consult Sika Technical Service for additional information.

- Do not delay broadcasting more than 20 minutes @ $73^{\circ} \mathrm{F}\left(23^{\circ} \mathrm{C}\right)$

- Do not thin. Addition of solvents will prevent proper cure.

- Minimum ambient and substrate temperature $35^{\circ} \mathrm{F}\left(2^{\circ} \mathrm{C}\right)$.

- Minimum age of concrete is 21-28 days, depending on curing and drying conditions

- Sealed concrete surface may appear blotchy due to differential absorption.

- Not clesigned to seal cracks subject to hydrostatic pressure at the time of application.

Component 'A': Irritant; Suspect Carcinogen; Combustible -Contains styrene. Keepawayfrom sparks and open flames. Skin, eye, and respiratory tract irritant. Other targetorgans: CNS, kidney, liver. Avoid contact. Avoid breathing vapors. Use only with adequate ventilation. Styrene is listed by IARC as a possible carcinogen, IARC 2B. (Not listed by NTP.) Use of safety goggles and chemical resistant gloves is recommended. Product may be rapidly absorbed through skin. In case of high vapor concentrations or exceedance of PELs, use an appropriate NIOSH approved respirator. Wash thoroughly after use. Remove contaminated clothing.

Component 'B': Irritant; Organic Peroxide; Combustible - Contains benzoyl peroxide. Skin and eye irritant. Avoid contact. Use only with adequate ventilation. Use of safety goggles and chemical resistant gloves is recommended. In case of high vapor concentrations or exceedance of PELs, use an appropriate NIOSH approved respirator. Wash thoroughly after use. Remove contaminated clothing.

Eyes: Hold eyelids apart and flush thoroughly with water for 15 minutes. Skin: Remove contaminated clothing. Wash skin thoroughly for 15 minutes with soap and water. Inhalation: Remove person to fresh air. Ingestion: Do not induce vomiting. In all cases, contact a physician immediately if symptoms persist.

Ventilate area of spill. Remove sources of ignition. Confine spill. Collect and/or absorb and dispose of in accordance with current, applicable local, state and federal regulations. Remove uncured material from tools and mixing equipment with water. Cured material can only be removed mechanically.
FOR INDUSTRIAL CHILDEREN CONSULT MATERIAL SAFETY DATA SHEET FOR MORE INFORMATION

Sika warrants this product for one year from date of installation to be free from manufacturing defects and to meet the

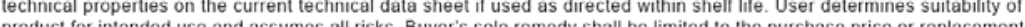
pof product exclusive of labor or cost of labor.

NO OTHER WARRANTIES EXPRESS OR IMPLIED SHALL APPLY INCLUDING ANY WARRANTY OF MERCHANTABILITY OR FITNESS FOR A PARTICULAR PURPOSE. SIKA SHALL NOT BE LIABLE UNDER ANY LEGAL THEORY FOR SPECIAL OR CONSEQUENTIAL DAMAGES.

Visit our website at www.sikausa.com

1-800-933-SIKA NATIONWIDE

Regional Information and Sales Centers. For the location of your nearest Sika sales office, contact your regional center.

\begin{tabular}{|c|c|c|}
\hline $\begin{array}{l}\text { Sika Corporation } \\
\text { 201 Polito Avenue } \\
\text { Lyndhurst, NJ 07071 } \\
\text { Phone: } 800-933.7452 \\
\text { Fax: 201-933-6225 }\end{array}$ & $\begin{array}{l}\text { Sika Canada Inc. } \\
601 \text { Delmar Avenue } \\
\text { Pointe Claire } \\
\text { Quebec H9R } 4 \text { A9 } \\
\text { Phone: } 514-697-2610 \\
\text { Fax: } 514-694-2792\end{array}$ & $\begin{array}{l}\text { Sika Mexicana S.A. de C.V. } \\
\text { Carretera Libre Celaya Km. } 8.5 \\
\text { Corregidora, Queretaro } \\
\text { CP. } 76920 \text { A P } 136 \\
\text { Phone: } 5242250122 \\
\text { Fax: } 5242250537\end{array}$ \\
\hline
\end{tabular}

Figure A.1 (cont.): Technical Data Sheet: SikaPronto 19 TF, SIKA Corp. 
Product Data Sheet

Edition 8.23.2007

Identification no. $389-35 \mathrm{~N}$

Sikadur 55 SLV

\section{Sikadur 55 SLV}

Super low-viscosity, moisture-tolerant epoxy resin, crack healer/penetrating sealer

\begin{tabular}{|c|c|}
\hline Description & $\begin{array}{l}\text { Sikadur } 55 \mathrm{SLV} \text { is a } 2 \text {-component, } 100 \% \text { solids, moisture-tolerant, epoxy crack healer / penetrating sealer, } \\
\text { having a fast tack-free time to minimize downtime. It is a super low-viscosity, high-strength adhesive } \\
\text { formulated specifically for sealing both dry and damp cracks. It conforms to the current ASTM C-881 and } \\
\text { AASHTO M-235 specifications. }\end{array}$ \\
\hline Where to Use & $\begin{array}{l}\text { - Sikadur } 55 \text { SLV structurally repairs cracked concrete. } \\
\text { - For interior slabs and exterior above-grade slabs. } \\
\text { - For elevated horizontal decks, parking garages and other structures exposed to foot and pneumatic tire } \\
\text { traffic. }\end{array}$ \\
\hline Advantages & $\begin{array}{l}\text { - Super low viscosity/low surface tension for excellent penetration into cracks. } \\
\text { - Penetrates cracks by gravity down to } 2 \text { mils }\left(0.002^{\prime \prime} / 0.05 \mathrm{~mm}\right) \text { in width. } \\
\text { - Prolongs life of cracked concrete. } \\
\text { - Penetrates/seals surface of slabs from water absorption, chloride-ion intrusion, and chemical attack. } \\
\text { - Structurally improves concrete surface. } \\
\text { - Can be open to traffic in } 6 \text { hours at } 73^{\circ} \mathrm{F}\left(23^{\circ} \mathrm{C}\right) \text {. } \\
\text { - High bond strength, even in damp cracks. } \\
\text { - U.S. Patent No. (pending) for ultra low viscosity healer/sealer to strengthen cracked concrete. }\end{array}$ \\
\hline Coverage & $\begin{array}{l}1 \text { gal. ( } 3.8 \text { Liters) yields } 231 \mathrm{cu} \text {. in. }\left(3,785 \mathrm{~cm}^{3}\right) \\
\text { Typical coverage is } 150-175 \mathrm{sq} \text {. ft./gal. }\left(3.7-4.3 \mathrm{~m}^{2} / \mathrm{L}\right) \text { for surface sealing. Coverage varies with porosity } \\
\text { and surface profile of substrate. Higher porosity concrete will reduce coverage. For crack healing, follow } \\
\text { Application instructions and allow to pond over cracks. }\end{array}$ \\
\hline Packaging & 3 gal. $(11.35 \mathrm{I})$ unit $={ }^{\prime} A^{\prime}=2$ gal. $(7.6 \mathrm{I})+{ }^{\prime} \mathrm{B}^{\prime}=1$ gal. $(3.8 \mathrm{I})$ \\
\hline
\end{tabular}

Typical Data [Material and curing conditions @ $73^{\circ} \mathrm{F}\left(23^{\circ} \mathrm{C}\right)$ and $50 \%$ R.H.]

Shelf Life 2 years in original, unopened containers

Storage Conditions Store dry at $40^{\circ}-95^{\circ} \mathrm{F}\left(4^{\circ}-35^{\circ} \mathrm{C}\right)$. Condition material to $65^{\circ}-75^{\circ} \mathrm{F}\left(18^{\circ}-24^{\circ} \mathrm{C}\right)$

Color before using.

Clear, amber

Mixing Ratio Component ' $A$ ' : Component ' $B$ ' = 2:1 by volume

Viscosity (Mixed) Approximately $105 \mathrm{cps}$

Pot Life Approximately 20 minutes

Tack-Free Time

$\begin{array}{llll}40^{\circ} \mathrm{F}\left(4^{\circ} \mathrm{C}\right)^{*} & 60^{\circ} \mathrm{F}\left(15^{\circ} \mathrm{C}\right)^{*} & 73^{\circ} \mathrm{F}\left(23^{\circ} \mathrm{C}\right)^{*} & 90^{\circ} \mathrm{F}\left(32^{\circ} \mathrm{C}\right)^{*} \\ >11 \text { hrs. } & 11 \text { hrs. } & 6 \text { hrs. } & 2.5 \text { hrs. }\end{array}$

Tensile Properties (ASTM D-638) $\quad 73^{\circ} \mathrm{F}\left(23^{\circ} \mathrm{C}\right)$

$\begin{array}{lll}7 \text { day } & \text { Tensile Strength } & 7,100 \mathrm{psi}(48.9 \mathrm{MPa}) \\ & \text { Elongation at break } & 10 \%\end{array}$

Bond Strength (ASTM C-882)

Hardened Concrete to Hardened Concrete 2 day (molst cure) 2,500 psi (17.2 MPa)

14 day (molst cure) $2,500 \mathrm{psi}(17.2 \mathrm{MPa}$ )

14 day (moist cure) $1,600 \mathrm{psi}$ (11.0 MPa)

7 day Flexural Strength $\quad 8,500 \mathrm{psi}(58.6 \mathrm{MPa})$

Tangent Modulus of Elasticity $3.2 \times 10^{5} \mathrm{psi}(2,206 \mathrm{MPa})$

Shear Strength (ASTM D-732) 7 day $\quad 5,800 \mathrm{psi}(40.0 \mathrm{MPa})$

Heat Deflection Temperature (ASTM D-648) 7 day

[fiber stress loading $=264 \mathrm{psi}(1.8 \mathrm{MPa}) \quad 110^{\circ} \mathrm{F}\left(43^{\circ} \mathrm{C}\right)$

Water Absorption (ASTM D-570) 7 day (24 hour immersion) $\quad 0.60 \%$

Compressive Properties (ASTM D-695)

Compressive Strength, psi (MPa)

1 day

3 day

7 day

14 day

$40^{\circ} \mathrm{F}\left(4^{\circ} \mathrm{C}\right)^{*} \quad 60^{\circ} \mathrm{F}\left(15^{\circ} \mathrm{C}\right)^{*}$

$000(13.8) \quad 320(2.2)$

7, $600(13.8) \quad 6,500(44.8)$

$9,600(66.2) \quad 11,000(75.8)$

$11,700(80.7) \quad 12,000(82.7)$

$73^{\circ} \mathrm{F}\left(23^{\circ} \mathrm{C}\right)^{*}$

$1,100(7.6)$

$8,300(57.2)$

$10,900(75.1)$

$11,800(81.4)$

$12,000(82.7)$

$90^{\circ} \mathrm{F}\left(32^{\circ} \mathrm{C}\right)^{\star}$

$4,800(33.1)$

$8,000(55.2)$

$8,300(57.2)$

28 day

7 day

$3.0 \times 10^{5}$ psi $(2,068 \mathrm{MPa})$

$10,000(68.9)$

Compressive Modulus

'Material cured and tosted at the temperature indicated.

Figure A.2: Technical Data Sheet: Sikadur 55 SLV, SIKA Corp. 


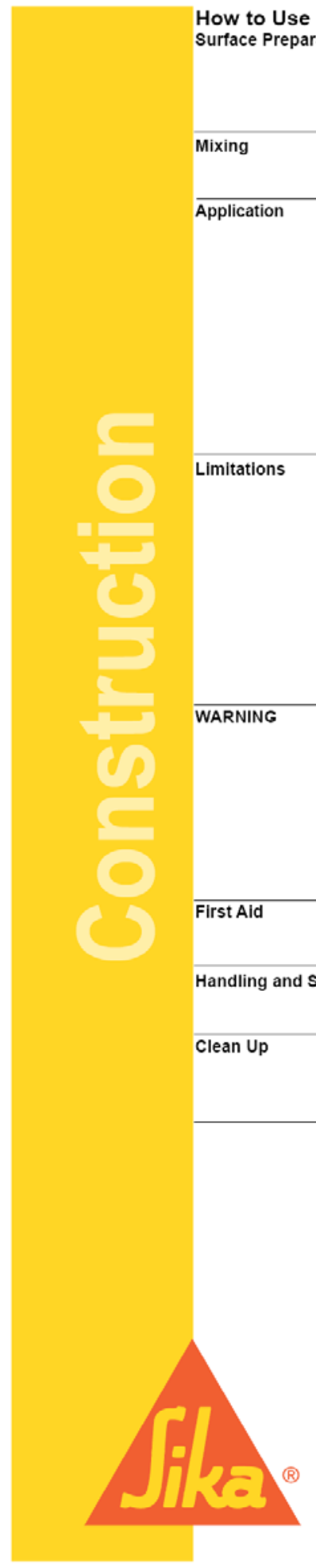

on

compounds compounds, waxes, impregnations, foreign particles, coatings and disintegrated materials by mechanical means (i.e. shotblasting, sandblasting, etc.). For best results, substrate should be dry. Surfaces prepared by Low Pressure Water Cleaning or High Pressure Water Jetting methods should be allowed to dry for 24 hrs. minimum [at $73^{\circ} \mathrm{F}\left(23^{\circ} \mathrm{C}\right)$ ].

Mix 1 part Component ' $B$ ' to 2 parts Component ' $A$ ' by volume into a clean pail. Mix thoroughly for 3 minutes with Sika paddle or jiffy mixer on a low-speed $(400-600 \mathrm{rpm})$ drill until uniformly blended. Mix only that quantity which can be used within its pot life.

To gravity feed cracks: Sikadur 55 SLV is applied to horizontal surfaces by flat squeegee or broom. Spread material over area and allow to pond over cracks. Let material penetrate into cracks and substrate. Remove excess epoxy with roller leaving no visible surface film. For cracks greater than $1 / 8 \mathrm{in}$. $(3 \mathrm{~mm})$ wide, fill crack with oven-dried sand before applying Sikadur 55 SLV Seal cracks from underside, when accessible, to prevent leakage.

A second treatment may be required on very porous substrates. Apply second treatment before broadcasting

After treatment, wait at least 20 minutes at $73^{\circ} \mathrm{F}\left(23^{\circ} \mathrm{C}\right)$. Cover with broadcast of an oven-dried $20 / 40$ silica sand or similar sand Distribute evenly over the surface to excess at a rate of $30-40 \mathrm{lbs} / 100 \mathrm{sq}$. ft. Allow to cure 6 hours minimum at $73^{\circ} \mathrm{F}\left(23^{\circ} \mathrm{C}\right)$. Remove any loose sand and open to traffic once epoxy has cured. Consult Sika Technical Service at 1-800-933-SIKA for additional information.

To pressure inject cracks: Use automated injection equipment. Set appropriate injection ports. Seal ports and cracks with Sikadur 31, Hi-Mod Gel, Sikadur Injection Gel or Sikadur AnchorFix-3/4. When the epoxy adhesive has cured, inject Sikadur 55 SLV with steady pressure. Consult Technical Service at 1-800-933-SIKA for additional information.

- Do not thin. Addition of solvents will prevent proper cure.

- Material is a vapor barrier after cure.

- Do not apply if rain is imminent. Water exposure or humidity will affect surface appearance and may cause surface whitening.

- Not an aesthetic coating. Epoxy will alter in color after exposure to the elements.

- Sealed concrete surface may appear blotchy due to differential absorption.

- Allow sufficient time for the substrate to dry after rain or other inclement conditions

- Application temperature of substrate must be minimum $5^{\circ} \mathrm{F}\left(3^{\circ} \mathrm{C}\right)$ above the dew point.

- Minimum ambient and substrate temperature $40^{\circ} \mathrm{F}\left(4^{\circ} \mathrm{C}\right)$. Maximum application temperature $95^{\circ} \mathrm{F}\left(35^{\circ} \mathrm{C}\right)$.

- Do not inject cracks greater than $1 / 4 \mathrm{in.}$. $(6 \mathrm{~mm})$ Consult Technical Service at 1-800-933-SIKA.

- Minimum age of concrete is 21-28 days, depending on curing and drying conditions.

- Not designed to seal or inject cracks under hydrostatic pressure during application.

Component 'A' - IRRITANT; SENSITIZER. Avoid direct contact. Contains modified epoxy resin and Diglyci-

dyl Ether of Bisphenol A (CAS 25085-99-8). Causes eye irritation. May cause skin/respiratory irrtations. Pro-

longed and/or repeated contact with skin may cause allergic reaction/sensitization. May be harmful if swallowed.

HMIS:H-2, F-1, R-0, PPE-C.

Component ' $B$ ' - CORROSIVE, IRRITANT, SENSITIZER Contains 2,4,6-Tri(Dimethylamino methyl) phenol (90-72-2),

Amines (Mixture) and Benzyl Alcohol (100-51-6). Contact with skin and eyes causes severe burns. Causes eye/skin/respiratory irritation. Prolonged and/or repeated skin contact may cause an allergic reaction/sensitization. Harmful if swallowed. HMIS:H-3, F-1, R-0, PPE-D.

Deliberate concentrations of vapors of 'A' and/or 'B' Components for purposes of inhalation is harmful and can be fatal.

Eyes: Hold eyelids apart and flush thoroughly with water for 15 minutes. Skin: Remove contaminated clothing. Wash skin thoroughly for 15 minutes with soap and water. Inhalation: Remove person to fresh air. Ingestion: Do not induce vomiting. Contact physician. In all cases, contact a physician immediately if symptoms persist.

Avoid direct contact with eves and skin. Wear chemical resistant clothing/gloves/goggles. Avoid breathing vapors. Use with adequate general and local ventilation. If ventilation is poor, use a properly fitted, $\mathrm{NIOSH}$-approved respirator. Wash thoroughly after handling product. Remove contaminated clothing and launder before reuse.

In case of spills ventilate area and contain spill. Collect with absorbent material. Ventilate area. Avoid contact. Dispose of in accordance with current, applicable local, state and federal regulations. Uncured material can be removed with approved solvent. Follow solvent manufacturer's instructions for use and warnings. Cured material (when component ' $A$ ' combined with Component ' $\mathrm{B}$ ') can only be removed by mechanical means.

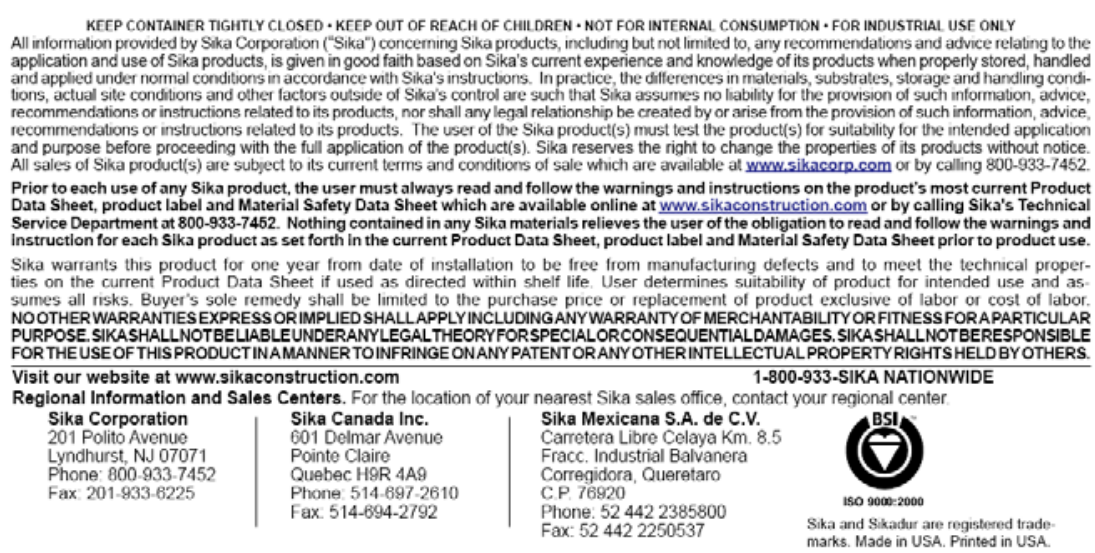

Figure A.2 (cont.): Technical Data Sheet: Sikadur 55 SLV, SIKA Corp. 


\section{DESCRIPTION}

MARK-127 is a gravity fed, crack welding system for concrete structures. MARK - 127 is a solvent-less, low viscosity, polymer system, specially designed to repair horizontal cracks in concrete decks. MARK-127 is a non-flammable material that produces a completely inert and environmentally safe tool to weld cracks in horizontal concrete decks.

MARK-127 provides a unique combination of extremely low viscosity, and low surface tension coupled with a built-in affinity for out the finest hairline cracks. Because of its high strength, cracks welded with MARK-127 become the strongest part of the concrete.

\section{FEATURES}

- A solvent-less system

- Extremely low viscosity and low surface tension provides the deepest penetration of any solvent-less system.

- Built-in affinity for polar concrete surface allows accelerated and rapid penetration into the full depth of the cracks.

- It provides exceptional bond to concrete.

- It has extremely high tensile and compressive strengths. The material is color coded, therefore, proper mixing can be monitored easily.

- Contains no toxic solvents or fumes. It is non-flammable and safe to use. concrete. This allows it to penetrate through-

\section{RECOMMENDED USES}

- Repair and welding of fine horizontal cracks in concrete bridges, parking decks and any horizontal concrete surface through gravity fed surface penetration.

- Increase density of porous concrete when used as a surface treatment. An excellent sealer for extremely porous concrete surfaces prior to the application of subsequent materials.

\section{TECHNICAL DATA}

Properties of Part A and Part B:

$\begin{array}{lll} & \text { PART A } & \text { PART B } \\ \text { Color } & \text { Transparent } & \text { Transparent } \\ & \text { Yellow } & \text { Blue } \\ \text { Percent Solids } & 100 \% & 100 \% \\ \text { Mixing Ratio } & 2 \text { volumes } & 1 \text { volume } \\ \text { Shelf Life } & 2 \text { years } & \text { 2 years }\end{array}$

Properties of Mixed Material: Tested @77'F $\pm 2{ }^{*} \mathrm{~F}$

Color

Viscocity

Initial Set

Initial Cure

Final Cure

Transparent Green $<100 \mathrm{cps}$

$<5$ hrs.

$<12$ hrs.

Properties of Cured Material:

Tensile Strength

(ASTM D-638)

Percent Elongation

$>5000 \mathrm{psi}$

(ASTM D-638)

Compressive Strength $\quad>8000 \mathrm{psi}$

(ASTM D-695)

Compressive Modulus $>150,000 \mathrm{psi}$

(ASTM D-695)

Water Absorption

(ASTM D-570)

Sand Penetration Te

(VADOT Test Meth. 101 Mod.

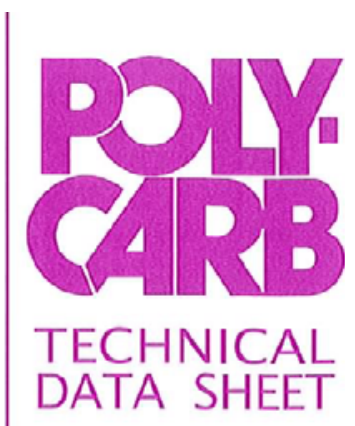

\author{
MARK - 127 \\ GRAVITY FED \\ CRACK \\ WELDING \\ SYSTEM
}

ISO 9001:2000 Certified

POLY-CARB, INC.

33095 Bainbridge Road Cleveland. Ohio 44139 Tel: 440.248 .1223

Fox: 440.248 .1513

125 GNS Cour!

Roberta, Georgia 31078

Tel: 478.836 .2881

All bres WARRANTY: POL..CARB, LNC. wartants to the purchaser of this product that the product is free from manufacturing and design defect. All breach of warranty claims must be submitted to POLY.CARB, INC. the earlier of eid
product shelf life. The purchaser's remedies are limited to replacement of the product.

POLY-CARB, INC. SPECIFICALLY DISAVOWS ANY OTHER REPRESENTATION OR WARRANTY, EXPRESS OR IMIPLIED, OR LIABILITY RELATANG TO THE CONDITION OR USE OF THE PRODLCT, AND IN NO EVENT SHALL POLY.CARB BE LIABLE TO PURCHASER OR ANY

Fox: 478.836 .2949

Toll-Free: 860.POLY.CARB WW.POLY-CARB.COM

Figure A.3: Technical Data Sheet, Mark-127, Poly Carb, Inc. 


\section{METHOD OF APPLICATION}

\section{Storage:}

MATERIAL CONTAINER SHOULD BE STORED AT A TEMPERATURE RANGE OF $65^{\circ} \mathrm{F}-85^{\circ} \mathrm{F}\left(24^{\circ} \mathrm{C}-29^{\circ} \mathrm{C}\right)$.

\section{Surface Preparation:}

Entire surface should be cleaned using shot blast method followed by a thorough air blast with emphasis on the cracks to minimize the chance of debris or dust settlement.

Mixing: Mix two volumes Part $\mathrm{A}$ and one volume Part B (2A:1B) in a clean, dry metal container using a slow speed drill with a "jiffy " mixing paddle, taking care to scrape the sides and bottom of the container continually and not entrapping any air while mixing. Mixing time recommended is approximately $2-3$ minutes. For large projects, continuous meter/mix equipment with temperature control heating devices are highly recommended to provide a uniform and properly mixed material for high production efficiency. Consult POLY-CARB Technical Service for specific recommendations.

Application: Pour mixed material onto properly prepared surface and spread utilizing a squeegee. Front and back movement with a squeegee or a short nap roller is recommended over cracks to enhance the penetration.

Application rate is controlled by the condition and temperature of the deck, porosity of surface, and size and depth of the cracks. Coverage may range from 100 to $150 \mathrm{sq}$. $\mathrm{ft} / \mathrm{gallon}$, to fill and seal the cracks completely.

Silica aggregate should be broadcasted over the treated area after application of MARK-127, just prior to the material becoming tacky- this could happen between 30 minutes and 1 hour, depending on air and surface temperatures. Aggregate is used to provide non-skid characteristics to the surface(approx. $0.6 \mathrm{lb} / \mathrm{sq} / \mathrm{ft}$.). When utilized as a sealer, saturation of MARK127 with aggregate is required (approx. 1 to $1.5 \mathrm{lbs} . / \mathrm{sq} / \mathrm{ft}$ ).

\section{COVERAGE}

$100-150$ square feet per gallon

\section{CLEAN-UP}

MARK-306 is recommended

\section{PACKAGING}

250 gallon totes

50 gallon drums

5 gallon pails

750 gallon unit
150 gallon unit
15 gallon unit

LIMITATIONS

- A minimum temperature of $40^{\circ} \mathrm{F}$ is required for proper curing.

- Dilution of MARK-127 with any solvent is not

recommended, as it will interfere with proper curing inside the cracks.

- Application of MARK-127 is not recommended

under conditions of standing or running water.

- Application of MARK-127 is not recommended

where the cured material is subjected to a dry temperature condition exceeding $210^{\circ} \mathrm{F}$ and/or wet temperature condition of $180^{\circ} \mathrm{F}$.

\section{IMPORTANT NOTE:}

With this technical data sheet, we are making every effort to communicate to you, our valued customer, the proper procedures, properties, and limitations of this product to ensure you a successful installation. This is considered to be an exotic material which is controlled by temperature, proper mixing, surface preparation, and other application conditions. It is most IMPERATIVE that these instructions are understood by all and followed correctly. It is our appeal to you, in case of the slightest doubt, that you call our office and express your concerns to one of our technical service representatives. This action will ensure that all doubts, discrepancies, or misunderstandings are cleared up to aid in the completion of a successful application. Please call us toll free at 1-800-CALL-MIX. We are ready to serve you.

CAUTION

PLEASE READ AND THOROUGHLY UNDERSTAND THE MATERIAL SAFETY DATA SHEET PROVIDED WITH EACH ORDER PRIOR TO BEGINNING WORK. THIS IS INTENDED FOR YOUR SAFETY.

Direct contact with the skin should be avoided as it can cause skin irritation. Protective clothing, goggles and gloves are recommended. In the event of direct contact with the skin, IMMEDIATELY wash with soap and water and REPORT TO A DOCTOR. In case of accidental contact with the eyes, flush IMMEDIATELY with plenty of water and REPORT TO A DOCTOR. FATAL IF TAKEN INTERNALLY. KEEP AWAY FROM OPEN FLAME AND BELOW FREEZING TEMPERATURES.

KEEP OUT OF REACH OF CHILDREN. FOR PROFESSIONAL USE ONLY

The VOC contents as per EPA test method 24 (40 CFR 60, Appendix A) does not exceed $340 \mathrm{~g} / \mathrm{l}$.

Figure A.3 (cont.): Technical Data Sheet, Mark-127, Poly Carb, Inc. 


\section{DESCRIPTION}

MARK - 135 SAFE-T-SEAL is a gravity fed crack welding system for horizontal concrete decks. MARK - 135 SAFE-TSEAL is a solvent-less, low viscosity, polymer system, specially designed to repair horizontal cracks in concrete decks. MARK-135 is a non-flammable material that produces a completely inert and environmentally safe tool to weld cracks in horizontal concrete decks.

MARK-135 provides a unique combination of extremely low viscosity, and low surface tension coupled with a built-in affinity for throughout the finest hairline cracks. Also, due to its carefully regulated drag, it hangs well and properly fills even the slightly wider "hairline cracks'. Because of its high strength, cracks welded with MARK-135 become the strongest part of the concrete surface.

\section{FEATURES}

- A solvent free system

- Extremely low viscosity and low surface tension provides the deepest penetration of any solvent free system.

- Built-in affinity for polar concrete surface allows accelerated and rapid penetration into the full depth of the cracks.

- Due to its affinity for concrete and built-in drag, it is able to effectively fill a broad range of hairline crack sizes.

- It provides exceptional bond to concrete.

- It has extremely high tensile and compressive strengths. The material is color coded, therefore, proper mixing can be monitored easily.

- Contains no toxic solvents or fumes. It is non-flammable and safe to use.

\section{RECOMMENDED USES}

- Repair and welding of fine horizontal cracks in concrete bridges, parking decks and any horizontal concrete surface through gravity fed surface penetration. concrete. This allows it to penetrate

- Increase density of porous concrete when used as a surface treatment. An excellent sealer for extremely porous concrete surfaces prior to the application of subsequent materials. (broadcasting of aggregate is recommended to provide a profile, which enhances the mechanical bond between the sealed surface and subsequent applications.)

\section{TECHNICAL DATA}

Properties of Part A and Part B

\begin{tabular}{lll} 
& PART A & PART B \\
\cline { 2 - 3 } Color & $\begin{array}{c}\text { Transparent } \\
\text { Yellow }\end{array}$ & $\begin{array}{c}\text { Transparent } \\
\text { Blue }\end{array}$ \\
Mixing Ratio & 2 volumes & 1 volume \\
Shelf Life & 2 years & 2 years
\end{tabular}

Properties of Mixed Part A and Part B

Color Transparent Green

Viscosity $\quad 200-230 \mathrm{cps}$

$\left(75^{\circ}+2^{\circ} \mathrm{F}\right)$

Gel Time $24^{\circ} \mathrm{C} \quad 48-52$ Minutes, $200 \mathrm{gms}$

$\left(75^{\circ} \pm 2^{\circ} \mathrm{F}\right)$

Initial Set $24^{\circ} \mathrm{C} \quad 5-6$ hours

$\left(75^{\circ} \pm 2^{\circ} \mathrm{F}\right)$

Initial Cure $24^{\circ} \mathrm{C} \quad 12$ hours

$\left(75^{\circ} \pm 2^{\circ} \mathrm{F}\right)$

Full $\bar{C}$ ure $24^{\circ} \mathrm{C} \quad 48$ hours -7 days

$\left(75^{\circ}+2^{\circ} \mathrm{F}\right)$

Properties of Cured MARK-135 SAFE-T-SEAL

Tensile Strength

Percent Elongation

Shore D Hardness

$3,100-3,400$ psi ASTM D. 638

Water Absorption

$35-40 \%$ ASTM D-638 Compressive Strength $5,500-6,000$ psi ASTM D-693

\section{PACKAGING}

$\begin{array}{lr}50 \text { gallon containers } & 150 \text { gallon units } \\ 5 \text { gallon pails } & 15 \text { gallon unit } \\ 1 \text { gallon can } & 3 \text { gallon unit }\end{array}$

LMMTED WARRANT: FOLYCARB. INC. wattents to the purchaser of this ptoduct that the product is fite from manufacturing and design defects. All breach of wartanty claims must bo subsitted to POLY.CARB, NC. the earlier ef ether within fourteen days of discorery of the defest or expiry of product shelf life. The purchaser's remedies are limited to replacement of the preduch

POLY CARB, INC. SPECIFICALLY DISANOWS ANY OTHER REPRESENTATION OR WARRANTY, EXPRESS OR IMPLIED, OR LIABILITY RFL ATING TO THE CONDIIION OR LSF OF THE PRODLCT, AND IN NO EVFNT GHALL. POIYCARB HF ILABLF TO PUIRCHASER, OR ANY THIRD PARTY, FOR ANY DIRECT OR INDIRECT CONSEQUENTIAL OR INCIDENTAL DAMAGES,
MARK-135

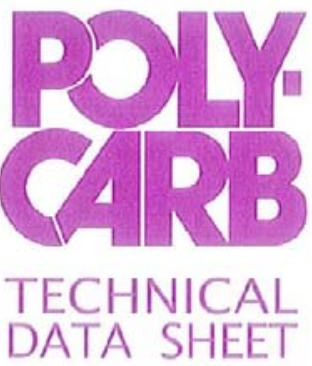

SAFE-T-SEAL

Gravity Fed

Crack Welding

System
ISO 9001:2000 Certified

POLY-CARB, INC.

33095 Bainbridge Road

Cleveland, Ohio 44139

Tel: 440.248 .1223

Fax: 440.248 .1513

125 GNS Court

Roberta, Georgia 31078

Tel: 478.836 .2881

Fax: 478.836 .2949

Toll-Free: 866.POLY.CARB

www.POLYCARB.com

Figure A.4: Technical Data Sheet, Mark-135 SAFE-T-SEAL, Poly Carb, Inc. 
METHOD OF APPLICATION

MATERIAL CONTAINER SHOU LD BE STORED INDOORS AT A TEMPERATURE RANGE OF $75^{\circ} \mathrm{F}-85^{\circ} \mathrm{F}\left(24^{\circ} \mathrm{C}-29^{\circ} \mathrm{C}\right)$ FOR AT LEAST 24 HOURS PRIOR TO USAGE. THE MININIUM STORAGE TEMPERATURE SHOULD BE $75^{\circ} \mathrm{F}-85^{\circ} \mathrm{F}\left(24^{\circ} \mathrm{C}-29^{\circ} \mathrm{C}\right)$ TO INSURF PROPER MIXING AND APPLICATION PROPERTIES.

\section{Surface Preparation:}

For Crack Treatment: Entire surface area should be cleaned with emphasis applied on the cracks, utilizing high-pressure air blast. Any debris or dust settled in the cracks may interfere with the flow of SAFE-T-SEAL.

\section{For Crack Treatment and Sealer}

Applications: Entire surface should be cleaned using shot blast method followed by a thorough air blast, with emphasis on the cracks to minimize the chance of any debris or dust settlement.

Mixing: Mix two volumes Part $\mathrm{A}$ and one volume Part B (2A:1B) in a clean, dry metal container using a slow speed drill with a "jiffy " mixing paddle, taking care to scrape the sides and bottom of the container continually and not entrapping any air while mixing. Five (5) to eight (8)minutes mixing is recommended. For large projects, continuous metering and mixing equipment with temperature control heating devices are highly recommended to provide a uniform and properly mixed material for high production efficiency. Consult POLY-CARB technical service for specific

recommendations.

\section{CLEAN UP}

Cleaning up of all equipment and tools is recommended before the gel time of the system expires. MARK-306 is specially designed for this purpose. A lacquer solvent, xylene, or toluene can also be used for the same purpose.

Application: Pour mixed material onto properly prepared surface and spread utilizing a squeegee. Front and back movement with a squeegee or a short nap roller is recommended over cracks to enhance the penetration.

Application rate is controlled by the condition and temperature of the deck, porosity of surface. and size and depth of the cracks. Coverage may range from 100 to $150 \mathrm{sq}$. ft/gallon, to fill and seal the cracks completely.
Silica aggregate should be broadcasted over the treated area after the application of SAFE-T-SEAL, just prior to the material becoming tacky - this could happen between 30 minutes and 1 hour, depending on air and surface temperature. Aggregate is used to provide non-skid characteristics to the surface (approx. $0.6 \mathrm{lb} / \mathrm{sq}$. ft.). When utilized as a sealer; saturation of MARK-135 with aggregate is required approximately ( 1 to 1.5 lbs./sq.tt.) Sandblasting of the surface may not be necessary for subsequent applications. Consult POLY-CARB's technical service for details.

\section{COVERAGE}

$100-150$ square feet per gallon

\section{LIMITATIONS}

- A minimum temperature of $40^{\circ} \mathrm{F}$ is required for proper curing. - Dilution of MARK-135 SAFE-T-SEAL with any solvent is not recommended, as it will interfere with proper curing inside the cracks. - Application of MARK-135 SAFE-T-SEAL is not recommended under conditions of standing or running water.

- Application of MARK-135 SAFE-T-SEAL is not recommended where the cured material is subjected to a dry temperature condition exceeding $210^{\circ} \mathrm{F}$ and $/$ or wet temperature condition of $180^{\circ} \mathrm{F}$.

\section{IMPORTANT NOTE:}

With this technical data sheet, we are making every effort to communicate to you, our valued customer, the proper procedures, properties, and limitations of this product to ensure you a successful installation. This is considered to be an exotic material which is controlled by temperature, proper mixing, surface preparation, and other application conditions. It is most IMPERATIVE that these instructions are understood by all and followed correctly. It is our appeal to you, in case of the slightest doubt, that you call our office and express your concerns to one of our technical service representatives. This action will ensure that all doubts, discrepancies, or misunderstandings are cleared up to aid in the completion of a successful application. Please call us toll free at 1-800-CALL-MIX. We are ready to serve you.

\section{CAUTION}

PLEASE READ AND THOROUGHLY UNDERSTAND THE MATERIAL SAFETY DATA SHEET PROVIDED WITH EACH ORDER PRIOR TO BEGINNING WORK. THIS IS INTENDED FOR YOUR SAFETY.

Direct contact with the skin should be avoided as it can cause skin irritation. Protective clothing, goggles and gloves are recommended. In the event of direct contact with the skin, IMMEDLATELY wash with soap and water and REPORT TO A DOCTOR. In case of accidental contact with the eyes, flush IMMEDIATELY with plenty of water and REPORT TO A DOCTOR. FATAL IF TAKEN INTERNALLY. KEEP AWAY FRONI OPEN FLAME AND BELOW FREEZING TENIPERATURES.

KEEP OUT OF REACH OF CHILDREN. FOR PROFESSIONAL USE ONLY

The VOC contents as per EPA test method 24 (40 CFR 60. Appendix A) does not exceed $600 \mathrm{~g} / \mathrm{l}$.

\section{Figure A.4 (cont.): Technical Data Sheet, Mark-135 SAFE-T-SEAL, Poly Carb, Inc.}




\section{- BASF}

The Chemical Company

$\begin{array}{ll}\text { PRODUCT DATA } & \\ 3^{030100} & \begin{array}{l}\text { Maintenance of } \\ \text { Concrete }\end{array}\end{array}$

\section{EPOXEAL"' GS STRUCTURAL}

Two-component, ultra low viscosity gravity feed or pressure-

injected epoxy sealer and structural adhesive

Description
EpoXeal' ${ }^{m}$ GS Structural is a two-
component ultra-low-viscosity epoxy
sealer and structural adhesive. Its low-
viscosity formula penetrates deeply
into con-crete to repair damaged
structures. It accepts an aggregate
broadcast to provide a slip-resistant
surface.

Features Benefits

- Surface sealer Reduces chloride intrusion and absorption

- 2 to 1 mix ratio Convenient and easy to mix; meets the mix ratio

- Low viscosity Penetrates deeply for reliable,

complete crack repair

- Accepts aggregate broadcast Produces slip-resistant surface with

aggregate concrete

\section{Yield}

$150 \mathrm{ft}^{2} / \mathrm{gal}\left(3.8 \mathrm{~m}^{2} / \mathrm{L}\right)$ per coat

Coverage will vary depending

on porosity and amount of

deterioration to substrate.

Packaging

3 gal kits:

Two 1 gal (3.8 L) cans of Part A and

One 1 gal (3.8 L) can Part B

15 gal kits:

Two 5 gal (18.9 L) pails of Part A and

One 5 gal (18.9 L) pail of Part B

165 gal drum kits:

Two 55 gal drums (208 L) of Part A

and One 55 gal drum (208 L) Part B

\section{Color}

Part A: clear amber liquid

Part B: clear liquid

Shelf life

2 years when properly stored

Storage

Store in unopened containers in a

cool, clean, dry area.

\section{Where to Use}

APPLICATION

- Sealing cracks in structural concrete

- Consolidation of partially deteriorated and dusting surfaces

- Bridge decks

- Roadways

- Parking and garage decks

- Floors

- Columns and beams

LOCATION

- Interior and exterior

SUBSTRATE

- Concrete

\section{How to Apply}

Surface Preparation

1. Concrete must be cured a minimum of 14 days before application.

2. Concrete must be mechanically profiled and appropriately cleaned before application. Surfaces must be free from dust, grease, curing compounds, waxes, laitance, loose deteriorated concrete, and other unsound materials.

3. All damaged surfaces must be repaired with appropriate repair material.

4. Optimum penetration is achieved with dry concrete.

\section{Mixing}

1. Pre-mix each component thoroughly before mixing together.

2. Place 2 parts by volume of component $A$ with 1 part by volume of component $B$ into a clean mixing container.

3. Mix thoroughly for approximately $3-5$ minutes using a low-speed $(400-500 \mathrm{rpm})$ drill and paddle mixer until uniformly blended.

4. The pot life of EpoXeal ${ }^{\text {mm }}$ GS Structural is

45 minutes.

Figure A.5: Technical Data Sheet, Epoxeal GS Structural, BASF 
METr PROTECTONANO REPAIR PFOOUCT DATA
EPOXEAL" GS STRUCTURAL

Technical Data

Composition

EpoXeal" GS Structural features proprietary epoxy resin technology.

Compliances

- ASTM C 881 Type I, II, IV, V, Grade 1, Class $\mathrm{B}$ and $\mathrm{C}$

- Meets USDA specifications for use in food processing facilities

\begin{tabular}{|c|c|c|c|}
\hline PROPERTY & RESULTS & SPECIFICATION & TEST METHODS \\
\hline Viscosity, cps, approximate & 95 & 2,000 maximum & Brookfleld \\
\hline Pot life, min, approximate & 45 & 30 minimum & ASTM C 881 \\
\hline Bond strength, $\mathrm{psI}(\mathrm{MPa})$ & & & ASTM C 882 \\
\hline 2 days & $2,410(16.6)$ & $1,000(6.9)$ & \\
\hline 14 days & $3,450(23.8)$ & $1,500(10.3)$ & \\
\hline $\begin{array}{l}\text { Absorption, \%, } \\
24 \text { hour Immersion }\end{array}$ & 0.9 & 1.0 maximum & ASTM D 570 \\
\hline Heat deflection, ${ }^{\circ} \mathrm{F}\left({ }^{\circ} \mathrm{C}\right)$ & $122(50)$ & $120(49)$ minimum & ASTM D 648 \\
\hline $\begin{array}{l}\text { Linear coefficient } \\
\text { of shrinkage }\end{array}$ & 0.0021 & 0.005 maximum & ASTM D 2566 \\
\hline Compressive strength, psi (MPa) & $10,800(74.5)$ & $10,000(69)$ minimum & ASTM D 695 \\
\hline Compressive modulus, psi (MPa) & $310,000(2,137)$ & $200,000(1,379)$ & ASTM D 695 \\
\hline Tensile strength, psi (MPa) & $7,100(49.0)$ & 7,000 (48.3) minimum & ASTM D 638 \\
\hline Flexural strength, psi (MPa) & $9,500(65.5)$ & None & ASTM D 790 \\
\hline $\begin{array}{l}\text { Elongation, \%, } \\
\text { at break }\end{array}$ & 2.9 & 1.0 minimum & ASTM D 638 \\
\hline
\end{tabular}

Test results are averages obtained under laboratory conditions. Reasonable variations can be expected.

\section{Application}

1. Apply by brush, roller, squeegee, or airless sprayer.

2. Apply material evenly over surface at $150-$ $200 \mathrm{ft}^{2} / \mathrm{gallon}\left(3.68-4.9 \mathrm{~m}^{2} / \mathrm{L}\right)$ per coat.

3 . Coverage will vary depending on the porosity of the concrete.

4. If injecting cracks, appropriate sealing of cracks and injection ports is necessary. Use appropriately clean and calibrated mechanical injecting equipment.

5. To gravity feed, V-notch the crack, making sure the bottom and sides are sealed. Pour mixed material evenly into crack until full. For cracks greater than $1 / 8^{\prime \prime}(3 \mathrm{~mm})$, fill crack with oven dry sand before applying product.

6. If nonslip surface is desired, aggregate broadcast is mandatory. Distribute sand evenly over surface at a rate of $12-20 \mathrm{lbs}$ per $100 \mathrm{sq} \mathrm{ft}$ $\left(0.59-0.98 \mathrm{~kg} / \mathrm{m}^{2}\right)$.

Clean Up

Clean equipment with Reducer 990 before material sets. Cured material will require mechanical removal.

\section{For Best Performance}

- Do not use when substrate temperature falls below $50^{\circ} \mathrm{F}\left(10^{\circ} \mathrm{C}\right)$

- Keep from freezing.

- Do not thin; solvents will prevent proper curing.

- Injection cracks should not exceed 1/4" (6 mm) in width

- Use only high-quality silica quartz aggregate for broadcast.

- Optimum penetration is achieved with dry concrete.

- EpoXeal"' GS Structural will discolor when exposed to UV light.

- Lower temperatures or higher humidity will slow the cure of EpoXeal" ${ }^{\prime *}$ GS Structural.

- Protect EpoXeal ${ }^{*}$ GS Structural from rain for 24 hours after application at $75^{\circ} \mathrm{F}\left(24^{\circ} \mathrm{C}\right)$.

- Cure time to accept traffic: at $70^{\circ} \mathrm{F}\left(21^{\circ} \mathrm{C}\right)$, 12 hours; at $80^{\circ} \mathrm{F}\left(27^{\circ} \mathrm{C}\right), 6$ hours.

- Make certain the most current versions of product data sheet and MSDS are being used; call Customer Service (1-800-433-9517) to verify the most current version.
- Proper application is the responsibility of the user. Field visits by BASF personnel are for the purpose of making technical recommendations only and not for supervising or providing quality control on the jobsite.

Health and Safety

EPOXEAL"' GS STRUCTURAL PART A

Warning

EpoXeal" GS Structural Part A resin contains epoxy resin, 2-ethylhexyl glycidyl ether.

Risks

May cause skin, eye and respiratory irritation. May cause dermatitis and allergic responses. Potential skin and/or respiratory sensitizer. Ingestion may cause irritation.

\section{Figure A.5 (cont.): Technical Data Sheet, Epoxeal GS Structural, BASF}




\section{Precautions}

Use only with adequate ventilation. Avoid contact with skin, eyes and clothing. Keep container closed when not in use. Wash thoroughly after handling. DO NOT take internally. Use impervious gloves, eye protection and if the TLV is exceeded or used in a poorly ventilated area, use NIOSH/MSHA approved respiratory protection in accordance with applicable Federal, state and local regulations.

First Aid

In case of eye contact, flush thoroughly with water for at least 15 minutes. In case of skin contact,

wash affected areas with soap and water. If irritation persists, SEEK MEDICAL ATIENTION. Remove and wash contaminated clothing. If inhalation causes

physical discomfort, remove to fresh air. If discomfort persists or any breathing difficulty occurs or if swallowed, SEEK IMMEDIATE MEDICAL ATTENTION

Refer to Material Safety Data Sheet (MSDS) for further information.

Proposition 65

This product contains materials listed by the State of California as known to cause cancer, birth defects or other reproductive harm.

voc Content

$0 \mathrm{~g} / \mathrm{L}$ or $0 \mathrm{lbs} / \mathrm{gal}$ less water and exempt solvents when components are mixed and applied per Manufacture's instructions.
EPOXEAL * GS STRUCTURAL PART B

\section{Danger-Corrosive}

EpoXeal" GS Structural Part B contains 4.

nonylphenol; n-aminoethylpiperazine;

poly(oxypropylene)diamine; naphthalene; $2,4,6$ -

tris((dimethylamino)methyl)phenol

Risks

Contact with skin or eyes may cause burns. Ingestion may cause irritation and bums of mouth, throat and stomach. Inhalation of vapors may cause irritation. May cause dermatitis and allergic responses. Potential skin and/or respiratory

sensitizer. Repeated or prolonged contact with skin may cause sensitization. Suspect cancer hazard. Contains material which may cause cancer. Risk of cancer depends on duration and level of exposure. INTENTIONAL MISUSE BY DELIBERATELY INHALING THE CONTENTS MAY BE HARMFUL OR FATAL.

\section{Precautions}

DO NOT get in eyes, on skin or clothing. Wash thoroughly after handling. Keep container closed. DO NOT take internally. Use only with adequate ventilation. DO NOT breathe vapors. Use impervious gloves, eye protection and if the TLV is exceeded or used in a poorly ventilated area, use NIOSH/MSHA approved respiratory protection in accordance with applicable Federal, state and local regulations.
First Aid

In case of eve contact, flush thoroughly with wate for at least 15 minutes. In case of skin contact. wash affected areas with soap and water. If irritation persists, SEEK MEDICAL ATTENTION. Remove and wash contaminated clothing. If inhalation causes physical discomfort, remove to fresh air. If discomfort persists or any breathing difficulty occurs or if swallowed, SEEK IMMEDIATE MEDICAL ATTENTION.

Refer to Material Safety Data Sheet (MSDS) for further information.

Proposition 65

This product contains materials listed by the State of California as known to cause cancer, birth defects or other reproductive harm.

VOC Content

$0 \mathrm{~g} / \mathrm{L}$ or $0 \mathrm{lbs} / \mathrm{gal}$ less water and exempt solvents when components are mixed and applied per Manufacture's instructions.

For medical emergencies only,

call ChemTrec (1-800-424-9300)

Figure A.5 (cont.): Technical Data Sheet, Epoxeal GS Structural, BASF 


\section{- BASF}

The Chemical Company

PRODUCT DATA

$$
7071800 \begin{aligned}
& \text { Concrete } \\
& \text { Rehabilitation }
\end{aligned}
$$

\section{Description}

Degadeck ${ }^{\circledR}$ Crack Sealer Plus is a very low viscosity, low surface tension, solvent free, rapid curing reactive methacrylate resin formulated to penetrate, repair and seal cracks in concrete substrates.

\section{Yield}

$100 \mathrm{ft}^{2} /$ gallon $\left(2.5 \mathrm{~m}^{2} / \mathrm{L}\right)$, depending on number and volume of cracks as well as porosity of concrete.

\section{Packaging}

Degadeck ${ }^{\circledast}$ Crack Sealer Plus is sold by weight and packaged in $38 \mathrm{lb}(17.3$ $\mathrm{kg})$ pails and $396 \mathrm{lb}(180 \mathrm{~kg})$ drums.

This is equivalent to 4.7 gallons ( 17.8

L) and 49 gallons (185.5 L)

respectively.

Color

Clear liquid

Shelf Life

1 year when properly stored

Storage

Store in cool, clean, dry area. Keep out of direct sunlight. Maximum storage temperature is $86^{\circ} \mathrm{F}\left(30^{\circ} \mathrm{C}\right)$. Store in original and unopened container.

\section{DEGADECK $^{\circledR}$ CRACK SEALER PLUS}

Reactive methacrylate resin for sealing cracks and concrete decks
Features

- Fast curing (1 hour)

- UV resistance

- Weather and aging resistant

- 2 component

- Compatible with other Degadeck methacrylate systems

- Protects against water and chloride ion ingress

- Can be used at temperatures ranging from 41 to $104^{\circ} \mathrm{F}$ (5 to $\left.40^{\circ} \mathrm{C}\right)$

\section{Where to Use}

APPLICATION

- Bridge decks

- Parking structures

- Civil engineering applications

- Penetrating flood coat sealer to prevent moisture and ion ingress into substrate

LOCATION

- Exterior

- Horizontal

SUBSTRATE

- Concrete

\section{Benefits}

On highway and bridge projects, allows fast return of traffic flow, contributing directly to worker and driver safety

Exposure to sunlight does not affect product performance

Provides long-lasting service life

User friendly; ease of installation; shelf life stable

Provides complete systems approach to concrete protection

Prevents premature deterioration

Extended application season

\section{How to Apply}

Surface Preparation

1. Inspect the concrete substrate before preparation. Note the location of surface cracks and the presence of contaminants. Concrete surfaces must be dry and free of dust, dirt, oil, wax, curing compounds, efflorescence, laitance, and all other bondbreaking materials.

2. Inspect the underside of the deck for signs of leakage due to full depth cracks.

3. Check weather forecast to ensure dry conditions. Wet substrates must be allowed to dry prior to beginning work.

4. Using a dust-free, mobile shotblaster or gritblaster, brush-blast the substrate to expose surface cracking.

5. Do not use wet preparation methods.

6. Perform a second inspection, noting newly-found surface cracks. Mark these for pre-treatment. Clean out cracks and the deck surface with oil-free compressed air.

Figure A.6: Technical Data Sheet, Degadeck Crack Sealer Plus, BASF 
Technical Data

Composition

Degadeck ${ }^{\circledR}$ Crack Sealer Plus is a reactive methacrylate resin.

Compliances

- Degadeck Crack Sealer Plus is classified under DOT regulations as Resin Solution, UN 1866 Class 3, PG II.
Test Data

\begin{tabular}{lll} 
PROPERTY & RESULTS & TEST METHODS \\
Appearance & Liquid & \\
\hline Specific gravity & 0.97 & DIN 51757 \\
\hline Viscosity, $\mathrm{CP}(\mathrm{mPa}-\mathrm{sec})$, at $73^{\circ} \mathrm{F}\left(23^{\circ} \mathrm{C}\right)$ & $5-15$ & ASTM D 2393 \\
\hline Flash point, ${ }^{\circ} \mathrm{F}\left({ }^{\circ} \mathrm{C}\right)$ & $48(9)$ & DIN 51755 \\
\hline Tensile strength, psi $(\mathrm{MPa})$ & $4,500(31)$ & ASTM D 638 \\
\hline Elongation at break, $\%$ & 5.5 & ASTM D 638 \\
\hline Hardness, Shore D & $>80$ & ASTM D 2240 \\
\hline Water absorption, $\%$ / 24 hrs & 0.60 & ASTM D 570 \\
\hline
\end{tabular}

\section{Mixing}

Degadeck ${ }^{\circledR}$ Crack Sealer Plus must be mixed with the appropriate amount of Powder Hardener just prior to application. Air/substrate temperature determines the amount as follows:

DEGADECK CRACK SEALER (1 GALLON)

\begin{tabular}{lll}
$\begin{array}{l}\text { TEMPERATURE } \\
{ }^{\circ} \mathrm{F}\left({ }^{\circ} \mathrm{C}\right)\end{array}$ & WEIGHT \% & $\begin{array}{l}\text { VOLUME } \\
\text { OUNCES }\end{array}$ \\
\hline $41(5)$ & 5 & 11 \\
\hline $50(10)$ & 4 & 8.5 \\
\hline $59(15)$ & 3 & 6.5 \\
\hline $68(20)$ & 2 & 4 \\
\hline $86(30)$ & 1 & 2 \\
\hline
\end{tabular}

* Please consult BASF Technical Services for applications outside this temperature range.

Using clean, dry plastic buckets, add Powder Hardener to Degadeck ${ }^{\circledR}$ Crack Sealer Plus and mix until dissolved (approximately 1 minute). Mixed Degadeck $^{\circledR}$ Crack Sealer Plus must be applied immediately. Do not exceed 5-gallon (20 L) batch mixes.

\section{Application}

1. Degadeck ${ }^{\odot}$ Crack Sealer Plus is applied as a flood coat in a gravity-fed process by broom or roller

2. The contents of the mixed batch should be immediately poured onto the substrate and worked into cracks by distributing with $1 / 2$ " to $3 / 4$ " $(13-20 \mathrm{~mm})$ nap solvent grade rollers or broom. Do not allow material to pond. Application rate is 100 $\mathrm{ft}^{2} / \mathrm{gal}\left(2.5 \mathrm{~m}^{2} / \mathrm{L}\right)$

3. Do not allow the mixed batch to remain in the mixing vessel. It is advisable to randomly broadcast a 30 mesh $(600 \mu \mathrm{m})$, dry aggregate into the wet, uncured resin at the rate of approximately $4 \mathrm{lb} / 100 \mathrm{ft}^{2}\left(200 \mathrm{~g} / \mathrm{m}^{2}\right)$

4. Working time for Degadeck ${ }^{\oplus}$ Crack Sealer Plus is between 10 and 15 minutes once it has been applied to the substrate. Full cure to specification will be between 45 minutes and 1 hour.

\section{Pre-Treat Wide Cracks}

Cracks over 1/8" (3 mm) should be treated individually prior to deck application. Full depth cracks may require alternative treatment to prevent runoff of resin. Fill wider cracks with dry, 30 mesh silica sand. Mix a small amount of Degadeck ${ }^{\circledR}$ Crack Sealer Plus, pour into cracks and distribute with a paint brush. Squeeze bottles can also be used.

Drying Time

Allow one hour for Degadeck ${ }^{\circledR}$ Crack Sealer Plus to gain full mechanical properties. Check for dryto-touch condition. End result should be a darkercolored, matte finish with a minimal surface film and some loose broadcast aggregate. Open to traffic.

\section{Clean Up}

Clean tools as needed with MMA, acetone, ethy acetate or similar solvents.

\section{For Best Performance}

- Application temperature range of substrate is between 41 and $104^{\circ} \mathrm{F}\left(5\right.$ and $\left.40^{\circ} \mathrm{C}\right)$

- Degadeck $^{\oplus}$ Crack Sealer Plus is NOT a high molecular weight methacrylate (HMWM).

- DO NOT use for vertical surface treatments.

- Degadeck ${ }^{\odot}$ Crack Sealer Plus is a sacrificial film that will wear out over time, however the cracks will continue to be protected.

- Periodically inspect the applied material and repair localized areas as needed. Consult a BASF representative for additional information.

- Make certain the most current versions of product data sheet and MSDS are being used; call Customer Service (1-800-433-9517) to verify the most current version.

- Proper application is the responsibility of the user. Field visits by BASF personnel are for the purpose of making technical recommendations only and not for supervising or providing quality control on the jobsite.

Figure A.6 (cont.): Technical Data Sheet, Degadeck Crack Sealer Plus, BASF 


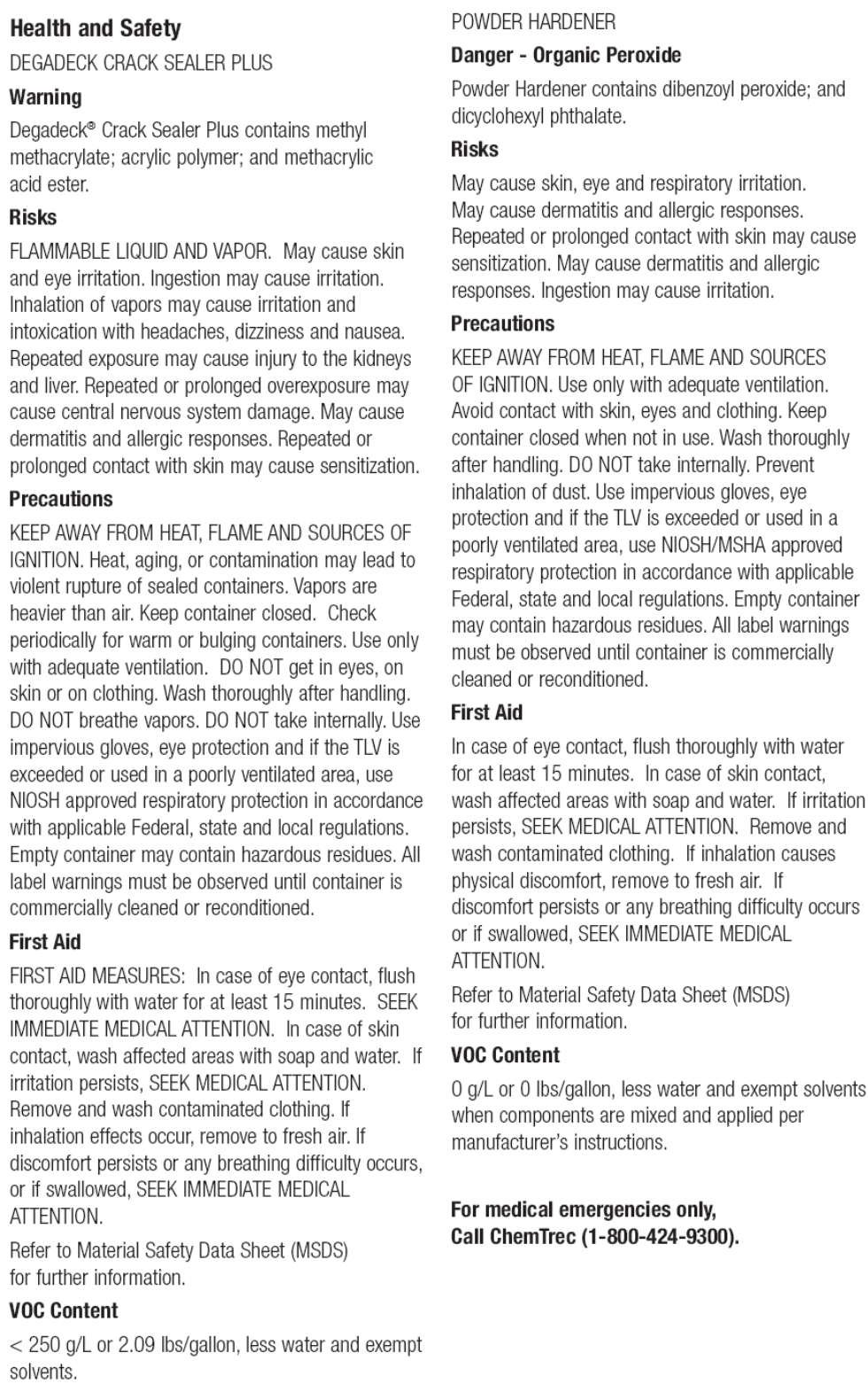

POWDER HARDENER

Danger - Organic Peroxide

Powder Hardener contains dibenzoyl peroxide; and dicyclohexyl phthalate.

Risks

May cause skin, eye and respiratory irritation. May cause dermatitis and allergic responses. Repeated or prolonged contact with skin may cause sensitization. May cause dermatitis and allergic responses. Ingestion may cause irritation.

Precautions

KEEP AWAY FROM HEAT, FLAME AND SOURCES

OF IGNITION. Use only with adequate ventilation. Avoid contact with skin, eyes and clothing. Keep container closed when not in use. Wash thoroughly after handling. DO NOT take internally. Prevent inhalation of dust. Use impervious gloves, eye protection and if the TLV is exceeded or used in a poorly ventilated area, use NIOSH/MSHA approved respiratory protection in accordance with applicable Federal, state and local regulations. Empty container may contain hazardous residues. All label warnings must be observed until container is commercially cleaned or reconditioned.

\section{First Aid}

In case of eye contact, flush thoroughly with water for at least 15 minutes. In case of skin contact, wash affected areas with soap and water. If irritation persists, SEEK MEDICAL ATTENTION. Remove and wash contaminated clothing. If inhalation causes physical discomfort, remove to fresh air. If discomfort persists or any breathing difficulty occurs or if swallowed, SEEK IMMEDIATE MEDICAL ATTENTION.

Refer to Material Safety Data Sheet (MSDS) for further information.

\section{vOC Content}

$0 \mathrm{~g} / \mathrm{L}$ or $0 \mathrm{lbs} / \mathrm{gallon}$, less water and exempt solvents when components are mixed and applied per manufacturer's instructions.

For medical emergencies only,

Call ChemTrec (1-800-424-9300).

Figure A.6 (cont.): Technical Data Sheet, Degadeck Crack Sealer Plus, BASF 


\section{- BASF}

The Chemical Company

PRODUCT DATA

$\begin{array}{lll}7071916 & \begin{array}{l}\text { Water } \\ \text { Repellents }\end{array} & \text { ENVIROSEAL } \\ & \text { Clear, water-based } 40 \% \text { silane penetrating sealer }\end{array}$

\section{Description}

Enviroseal ${ }^{\circledR} 40$ is a clear, water-based, 40\% alkylalkoxysilane penetrating sealer. It provides long-lasting protection against moisture intrusion, freeze/thaw cycles, and chloride intrusion. It is ideal for traffic-bearing surfaces.

Yield

Concrete:

$100-200 \mathrm{ft}^{2} / \mathrm{gal}\left(2.4-4.8 \mathrm{~m}^{2} / \mathrm{L}\right)$ Brick:

$100-200 \mathrm{ft}^{2} / \mathrm{gal}\left(2.4-4.8 \mathrm{~m}^{2} / \mathrm{L}\right)$

Always apply a test area to determine actual coverage rates. Coverage rates will vary greatly with the porosity of the substrate.

\section{Packaging}

5 gallon (19 L) pails

54 gallon (205 L) drums

Color

Milky white liquid; clear when dry

Shelf Life

18 months when properly stored

Storage

Store in unopened containers in a clean, dry area between 35 and $110^{\circ}$ $\mathrm{F}\left(2\right.$ and $\left.43^{\circ} \mathrm{C}\right)$

\section{Features}

- Water based, VOC compliant

- Excellent penetration

- $40 \%$ silane

- Breathable

- Transparent, nonstaining

- One component

Where to Use

APPLICATION

- Parking garages

- Stadiums

- Bridge decks

- Concrete highway road surfaces

- Ramps and barrier rails

- Stadiums

- Cooling towers

- Many other reinforced concrete structures LOCATION

- Horizontal and vertical

- Exterior or interior

- Above grade SUBSTRATE

- Concrete substrates: architectural, glass-fiberreinforced, precast, cast in place, slicia fume

- New and existing concrete

\section{Benefits}

Environmentally friendly

Protects against damage from moisture intrusion and chloride ion penetration Ideal for traffic-bearing surfaces Allows interior moisture to escape without damaging sealer Does not alter surface appearance Easy to apply; saves labor

\section{How to Apply}

Surface Preparation

1. Verify substrate has properly cured. Concrete should obtain $80 \%$ of design strength, typically achieved within $14-28$ days.

2. Clean concrete surfaces of all sand, surface dust and dirt, oil, grease, chemical films and coating,s and other contaminants prior to application. Use waterblast, sandblast, or shotblast as necessary to achieve the desired surface condition.

3. Surface, air, and material temperatures should be 40 to $110^{\circ} \mathrm{F}\left(4\right.$ to $\left.43^{\circ} \mathrm{C}\right)$ during application. Do not apply Enviroseal ${ }^{\circledR} 40$ when temperatures are expected to fall below $40^{\circ} \mathrm{F}\left(4^{\circ} \mathrm{C}\right)$ within 12 hours.

4. Surfaces to be treated can be slightly damp; however, a dry surface is suggested for maximum penetration of sealer. Do not apply Enviroseal ${ }^{\circledR} 40$ if standing water is visible on the surface to be treated. 5. Crack control, caulking, patching, and expansion joint sealants can be installed before or after application of the sealer. Allow a minimum of $6-12$ hours curing time for caulking and sealant materials (or until they have skinned over) before applying Enviroseal ${ }^{\oplus} 40$.

Figure A.7: Technical Data Sheet, Enviroseal 40, BASF 
Technical Data

Composition

Enviroseal ${ }^{\circ} 40$ is a water-based alkylalkoxysilane

sealer.

Compliances

- Alberta DOT, Type 1b

Typical Properties

PROPERTY

Solids and active

ingredients, $\%$ by weight

Specific gravity, $77^{\circ} \mathrm{F},\left(25^{\circ} \mathrm{C}\right) \quad 0.95$

Density, IbS/gal 7.9

Penetration, in (mm), average $0.24(6.1)$

depth, depending upon substrate

\begin{tabular}{|c|c|c|}
\hline PROPERTY & RESULTS & TEST METHOOS \\
\hline Flash point, ${ }^{\circ} \mathrm{F}\left({ }^{\circ} \mathrm{C}\right)$ & $>200(>93)$ & ASTM D 3278, SETA \\
\hline VOC content, Ib/gal $(g / L)$ & $<2.92(<350)$ & EPA Method 24 \\
\hline $\begin{array}{l}\text { Water absorption, \% } \\
48 \text { hours } \\
50 \text { days }\end{array}$ & $\begin{array}{l}0.42 \\
1.2\end{array}$ & ASTM C 642 \\
\hline $\begin{array}{l}\text { Scaling resistance rating, } \\
\text { non-air-entrained concrete, } \\
100 \text { cycles treated concrete }\end{array}$ & 0 - No Scaling & ASTM C 672 \\
\hline $\begin{array}{l}\text { Resistance to chloride-ion } \\
\text { penetration, libs/yod }\left(\mathrm{kg} / \mathrm{m}^{\prime}\right) \\
\text { Criterla of } 1.5 \text { at } 1 / 2^{\prime \prime}(13 \mathrm{~mm}) \\
\text { Criteria of } 0,75 \text { at } 1^{\prime \prime}(25 \mathrm{~mm})\end{array}$ & $\begin{array}{l}<0.52(<0.31) \\
0.00(0.00)\end{array}$ & AASHTO T 259 and T 260 \\
\hline Water weight gain, \% reduction & 85 - exceeds criteria & $\begin{array}{l}\text { NCHRP } 244 \\
\text { Serles II-cube test }\end{array}$ \\
\hline Absorbed chloride, \% reduction & 87 - exceeds criteria & $\begin{array}{l}\text { NCHRP } 244 \\
\text { Series II-cube test }\end{array}$ \\
\hline Absorbed chloride, \% reduction & 99 - exceeds criteria & $\begin{array}{l}\text { NCHPP } 244 \\
\text { Series IV - Southern climate }\end{array}$ \\
\hline $\begin{array}{l}\text { Water repellent performance, \% } \\
\text { Initial performance } \\
\text { Post-abrasion performance }\end{array}$ & $\begin{array}{l}89 \\
89.4\end{array}$ & $\begin{array}{l}\text { Alberta Transportation and Utilities } \\
\text { Procedures - Type 1b }\end{array}$ \\
\hline
\end{tabular}

Test results are averages obtained at a coverage rate of $125 \mathrm{ff} / \mathrm{gal}(3.12 \mathrm{~m} / 3.8 \mathrm{~L})$ under laboratory conditions.

Reasconabla variations can be expected.

Figure A.7 (cont.): Technical Data Sheet, Enviroseal 40, BASF 


\section{Application}

1. Test a small area of surface (generally a 5 by $5 \mathrm{ft}[1.5$ by $1.5 \mathrm{~m}]$ section) before starting general application of any clear penetrating sealer ensure desired results and coverage rates. Allow 5 -

7 days for the product to fully react before evaluating.

2. Stir material thoroughly before and during application.

3. Apply to saturation. Apply by low-pressure nonatomizing spray or, if desired on horizontal surfaces, by pouring, followed by a squeegee or a broom for even distribution

Drying Time

Typical drying time for Enviroseal ${ }^{\circ} 40$ is 4 hours at $70^{\circ} \mathrm{F}\left(21^{\circ} \mathrm{C}\right)$ and $50 \%$ relative humidity. Cooler temperatures or higher relative humidity can exten the drying time.

Clean Up

Clean equipment and tools with hot soapy water. Overspray can be cleaned immediately with hot soapy water. Dried residue can be cleaned with a mild citric acid or very hot water, then scrubbed with a plastic sponge.
For Best Performance

- Keep material from freezing.

- Do not dilute Enviroseal 40 .

- Do not apply during inclement weather or when inclement weather is anticipated within 12 hours.

- To prevent damage to nearby shrubbery and landscaping, cover or protect with drop cloth.

- Enviroseal ${ }^{3} 40$ may leave a temporary slippery surface for up to several hours after application. Therefore, traffic-bearing surfaces should not be reopened until the treated surface is dry.

- Variations in the texture and porosity of the substrate will affect the coverage and performance of the product.

- Enviroseal ${ }^{2} 40$ will not inhibit water penetration through unsound or cracked surfaces or surfaces with defective flashing, caulking, or structural waterproofing.

- Line striping can be done after application of the sealer

- Make certain the most current versions of product data sheet and MSDS are being used; call Customer Service (1-800-433-9517) to verify the most current versions.

- Proper application is the responsibility of the user. Field visits by BASF personnel are for the purpose of making technical recommendations only and not for supervising or providing quality control on the jobsite.
Health and Safety

ENVIROSEAL ${ }^{\circ} 40$

Caution

Enviroseal ${ }^{\circ} 40$ contains alkoxysilane.

\section{Risks}

May cause skin, eye or respiratory irritation.

Ingestion may cause irritation.

Precautions

KEEP OUT OF THE REACH OF CHILDREN. Avoid contact with skin, eyes, and clothing. Wash thoroughly after handling. Keep container closed when not in use. DO NOT take internally. Use only with adequate ventilation. Use impervious gloves, eye protection and if the TLV is exceeded or used in a poorly ventilated area, use NIOSH/MSHA approved respiratory protection in accordance with applicable federal, state and local regulations.

\section{First Aid}

In case of eye contact, flush thoroughly with water for at least 15 minutes. In case of skin contact, wash affected areas with soap and water. If irritation persists, SEEK MEDICAL ATTENTION. Remove and wash contaminated clothing. If inhalation causes physical discomfort, remove to fresh air. If discomfort persists or any breathing difficulty occurs or if swallowed, SEEK IMMEDIATE MEDICAL ATTENTION.

Refer to Material Safety Data Sheet (MSDS) for further information.

Proposition 65

This product contains material listed by the state of California to cause cancer, birth defects, or other reproductive harm.

v0c Content

Less than $2.92 \mathrm{lbs} / \mathrm{gal}$ or $350 \mathrm{~g} / \mathrm{L}$, less water and exempt solvents.

For medical emergencies only,

call ChemTrec (1-800-424-9300)

\section{Figure A.7 (cont.): Technical Data Sheet, Enviroseal 40, BASF}




\section{DURAL ${ }^{\circledR} 335$}

Ultra low Viscosity, Penetrating Epoxy Crack Healer-Sealer

\section{DESCRIPTION}

DURAL 335 is a solvent free, two component, moisture insensitive, ultra low viscosity epoxy sealer.

\section{Primary APPLICATIONS}

Used interior and exterior to seal slabs, gravity feed resin into cracks and pressure inject cracks on:

- Bridge decks

- Parking garage decks and ramps

- Airport runways

- Roadways

\section{FEATURES/BENEFITS}

- Penetrating epoxy crack healer-sealer

- Alternative to hazardous methylmethacrylates

- Solvent free, no odor

- Ultra low viscosity

- High Strength

- Moisture Insensitive

- Protects treated surface from salts, chemicals, and water absorption

\section{TECHNICAL INFORMATION}

Material Properties@ $75^{\circ} \mathrm{F}\left(24^{\circ} \mathrm{C}\right), 50 \%$ R.H.

Mixing Ratio (A: $B)$ by volume

Mixed Viscosity, cps

Gel Time (100 gms), mins.

Pot life ( 1.25 gal unit), mins.

Tensile Strength, ASTM D 638, psi (MPa)

Tensile Modulus, psi (MPa)

Tensile Elongation, \%, ASTM D 638

Compressive Strength, psi (MPa), mortar

ASTM C 109 (3 parts sand)

Values presented are typical laboratory data

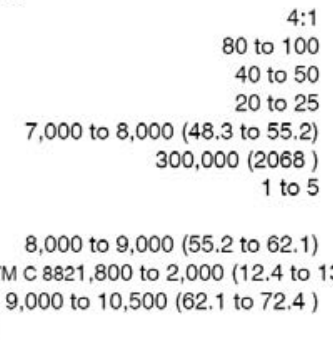

\section{PACKaging}

DURAL 335 is available in 1.25 gal $(4.73 \mathrm{~L})$ and 5 gal $(19.9 \mathrm{~L})$ units.

\section{SHELF LIFE}

1 year in original, unopened package.

\section{COVERAge}

Slab sealing: 100 to $200 \mathrm{ft}^{2} / \mathrm{gal}\left(2.45\right.$ to $\left.4.91 \mathrm{~m}^{2} / \mathrm{L}\right)$ for typical concrete surfaces. Crack grouting: Coverage depends on extent and depth of cracking.

\section{DIRECTIONS FOR USE}

Surface Preparation: Surface must be structurally sound, clean, dry and free of laitance, dust, dirt, oil, coatings, form release agents and other contaminants. Remove contamination by sandblasting or shotblasting.

The Euclid Chemical Company

19218 Redwood Rd. C Cleveland, $\mathrm{OH} 44110$

Phone: [216] 531-9222 • Toll-free: [800] 321-7628 • Fax: [218] 531-9596

An RPIn Company www.euclidchemical.com

\section{Figure A.8: Technical Data Sheet, Dural 335, Euclid Chemical}


Remove defective concrete, honeycomb, cavities, joint cracks and voids by routing to sound material. Rebuild areas with suitable patching materials.Smooth, precast and formed concrete surfaces must be cleaned, roughened and made absorptive by sandblasting or shotblasting. Blow debris and residue out of cracks and from the surface with a moisture-free and oil-free air jet. Mask expansion joint sealants to prevent adhesion of DURAL 335 to the joint surface. Surfaces and cracks must be completely dry before DURAL 335 application to obtain maximum penetration. For further information contact your local Euclid Chemical representative.

Mixing: Premix Part A and Part B. Combine 4 parts by volume of Part A (Base) to 1 part by volume of Part B (Hardener) in a clean container, and mix thoroughly with a slow speed motor and "Jiffy" Mixer. Scrape the bottom and side of the mixing container at least once. Do not aerate mixture.

Application: Sealing slabs: Pour the mixed DURAL 335 onto the prepared surface in a wave form and distribute evenly with a short nap roller or squeegee to fill voids, cracks and porous areas. Before the resin becomes tacky, use a squeegee on a smooth surface and a broom on textured surfaces to remove any excess resin that has not penetrated the surface. To improve skid resistance of the surface or where subsequent topping or coating application is desired, broadcast 0.2 to $0.8 \mathrm{lbs} / \mathrm{yd}^{2}\left(.11\right.$ to $\left..43 \mathrm{~kg} / \mathrm{m}^{2}\right)$ of silica sand not earlier than two hours (at $75^{\circ} \mathrm{F}\left[24^{\circ} \mathrm{C}\right]$ ) after application of DURAL 335 but before the DURAL 335 begins to become tack free. Ensure that the coating or toppings are applied within the recoat window of the application conditions. Grouting cracks: Gravity feed:Pour neat mixed DURAL 335 into vee-notched cracks until completely filled. Pressure injection: Set appropriate injection ports depending on the system used. Seal around port and surface of crack using a Euclid Chemical Fast Set Epoxy Gel. Inject neat resin using automated (2 part Injection unit) or manual methods (caulking gun). Maintain slow steady pressure until the crack is filled with the injection resin.

\section{CLEAN-UP}

Clean tools and equipment immediately following use with methyl ethyl ketone or xylene. Clean spills or drips while still wet with the same solvent. Dried DURAL 335 will require mechanical abrasion for removal.

\section{PRECAUTIONS/LIMitations}

- Store at tempatures between $50^{\circ} \mathrm{F}$ to $90^{\circ} \mathrm{F}\left(10^{\circ} \mathrm{C}\right.$ to $\left.32^{\circ} \mathrm{C}\right)$.

- Do not store below $50^{\circ} \mathrm{F}\left(10^{\circ} \mathrm{C}\right)$.

- Apply DURAL 335 when surface and ambient temperatures are between $50^{\circ} \mathrm{F}$ to $90^{\circ} \mathrm{F}\left(10^{\circ} \mathrm{C}\right.$ to $\left.32^{\circ} \mathrm{C}\right)$.

- In some cases, on highly porous surfaces, a second coat may be required.

- If a second coat is required contact your local Euclid Chemical representative for a recommendation.

- Multiple applications of DURAL 335 at $75^{\circ} \mathrm{F}\left(24^{\circ} \mathrm{C}\right)$ must be within 24 hours of the preceding application.

- Excess DURAL 335 left on the concrete surface will reduce skid resistance.

- Apply a test area to confirm suitability. DURAL 335 is not intended for sealing cracks under hydrostatic pressure.

- Allow new concrete to cure 28 days before DURAL 335 application.

- In all cases, consult the Material Safety Data Sheet before use.

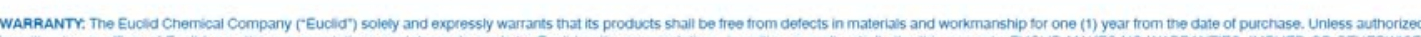

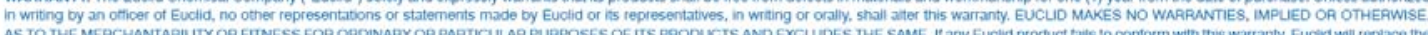

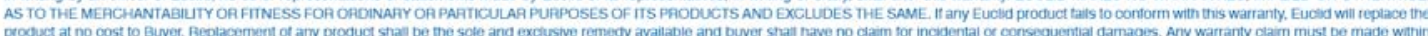

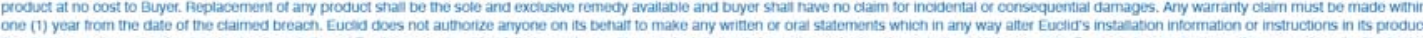
interature or on its packaging labets. Any installation of Euclid produots whion talls to contorm with such installation intormation or instructions shall void this warranty. Product demonstrations, if any, are done for illustrative purposes only and do not consititue a warrantly $a$ warranty alteration of any kind. Buyer strall be solely responsibte for determining the sultability of Fuclids products tor the Buyer's intended purposes.

Figure A.8 (cont.): Technical Data Sheet, Dural 335, Euclid Chemical 


\section{DURAL 50}

\section{ULTRA LOW VISCOSITY ACRYLATED EPOXY}

\section{DESCRIPTION}

DURAL 50 is a $100 \%$ solids, two component acrylated epoxy resin formulation.

\section{Primary APPLications}

- Bridge decks

- Parking decks

- Consolidation of porous and dusting surfaces

- Reduces water absorption

\section{FEATURES/BENEFITS}

- High strength

- Penetrates cracks by gravity

- Deep penetrating

- Strengthens concrete surfaces

- Heal and seals concrete
- Reduces chloride penetration

- Pressure injection

- Gravity feed hairline cracks

- Contractor friendly

- Does not contain styrene

- Does not contain peroxides

- Not flammable

- Moisture tolerant

\section{TECHNICAL INFORMATION}

Material Properties@ $7^{\circ} \mathrm{F}\left(24^{\circ} \mathrm{C}\right)$ and $50 \%$ RH

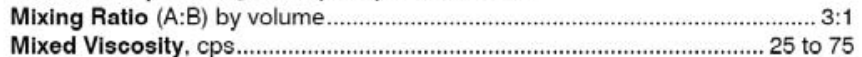

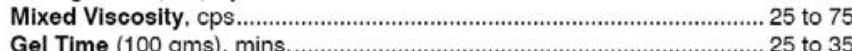

Tack Free, hours.

Tensile Strength, ASTM D 638, psi (MPa) .............................

Elongation, ASTM D 638, \% ............................................................. 2 to 6

Compressive Strength, ASTM D 695, psi (MPa) .........7,000 to 8,000 (48.3 to 55.2)

Compressive Strength ( 3 parts sand)

mortar, ASTM C 109, psi (MPa).

$.8,000$ to $9,000(55.2$ to 62.1$)$

Slant Shear Bond Strength

ASTM C882, psi (MPa) (concrete failure) ........................1,800 to 2,000(12.4 to 13.8)

Flexural Strength, ASTM D 790, psi (MPa) ..................9,000 to 10,500 (62.1 to 72.4$)$

Values presented are typical laboratory data

\section{PACKAGING}

DURAL 50 is packaged in 4 gal ( $15.5 \mathrm{~L}) /$ case contractor kits, 20 gal $(75.71 \mathrm{~L})$ and 200 gal $(757.08 \mathrm{~L})$ units.

\section{SHELF LIFE}

2 years in original, unopened package.

COVERAGE

Slab Sealing: 100 to $200 \mathrm{ft}^{2} / \mathrm{gal}$ ( 2.45 to $4.91 \mathrm{~m}^{2} / \mathrm{L}$ ) for the first coat (typical concrete surface). 150 to $300 \mathrm{ft}^{2} / \mathrm{gal}$ ( 3.68 to $7.36 \mathrm{~m}^{2} / \mathrm{L}$ ) for a second coat in cases of extensive cracking or high porosity. Crack Grouting: Coverage will be determined by depth and length of cracks.

Note: Coverage rates are approximate and for estimating purposes only. Surface temperature, texture and porosity will determine actual material requirements.

\section{DIRECTIONS FOR USE}

Surface Preparation: Concrete must be structurally sound, clean, dry and free of laitance, dust, dirt, oil, coatings, form release agents and other contaminants. The preferred method of surface preparation is abrasive blasting.

\section{The Euclid Chemical Company}

19218 Redwood Rd. Cleveland, $\mathrm{OH} 44110$

Phone: [216] 531-9222 - Toll-free: [800] 321-7628 - Fax: [216] 531-9596

An RPIn Company www.euclidchemical.com

Figure A.9: Technical Data Sheet, Dural 50, Euclid Chemical 
Remove defective concrete, honeycombs, cavities, joint crack voids and other defects by routing to sound material. Rebuild areas with suitable patching materials. Smooth, pre-cast and formed concrete surfaces must be cleaned, roughened and made absorptive by abrasive blasting or shot blasting. Blow debris and residue out of cracks and from the surface with a moisture-free and oil-free air jet. Mask expansion joint sealants to prevent adhesion of DURAL 50 to the joint surface. Surfaces and cracks must be completely dry before DURAL 50 application to obtain penetration. For further information contact your local Euclid Chemical representative.

Mixing: Premix Part A and Part B. Combine 3 parts by volume of Part A with 1 part by volume of Part B. Mix thoroughly with a slow speed motor and mixing blade. A $1 / 2$ " $(13 \mathrm{~mm})$ drill and "Jiffy" mixer is acceptable. Do not aerate mixture.

Application: Sealing concrete slabs: Pour or pump mixed DURAL 50 onto the prepared surface in a wave form and spread with a short nap roller or squeegee to fill voids, cracks and porous areas. A second application may be required on highly porous or severely cracked concrete. If required, the second coat should be applied within 24 hours. Broadcast silica sand into the surface to provide an anti-skid surface or where subsequent toppings or coatings will be applied. Apply the silica sand $\left(0.2\right.$ to $\left.0.8 \mathrm{lbs} / \mathrm{yd}^{2}\right)\left(.10\right.$ to $\left..43 \mathrm{~kg} / \mathrm{m}^{2}\right)$ (depending on the desired surface) not earlier than 2 hours at $75^{\circ} \mathrm{F}\left(24^{\circ} \mathrm{C}\right)$ after application of DURAL 50 , but before the DURAL 50 becomes tack free. Ensure that subsequent coatings or toppings are applied within the recoat window of DURAL 50 (a 24 hour recoat window at $75^{\circ} \mathrm{F}\left(24^{\circ} \mathrm{C}\right.$ ). Grouting cracks: Gravity feed: Pour neat mixed DURAL 50 into vee-notched cracks until completely filled. Pressure injection: Set appropriate injection ports depending on the system used. Seal around port and surface crack using Duralcrete Gel or Dural Fast Set Epoxy Gel. Inject neat resin using automated or manual injection equipment. Maintain slow steady pressure until the crack is filled with the injection resin.

\section{Clean-Up}

Clean tools and equipment immediately following use with xylene or methyl ethyl ketone. Clean drips and over spray while still wet with the same solvent. Cured DURAL 50 will require mechanical abrasion for removal.

\section{PRECAUTIONS/LIMITATIONS}

- Store at tempatures between $50^{\circ} \mathrm{F}$ to $90^{\circ} \mathrm{F}\left(10^{\circ} \mathrm{C}\right.$ to $\left.32^{\circ} \mathrm{C}\right)$.

- Do not store below $50^{\circ} \mathrm{F}\left(10^{\circ} \mathrm{C}\right)$.

- Do not mix or apply DURAL 50 at temperatures below $50^{\circ} \mathrm{F}\left(10^{\circ} \mathrm{C}\right)$ or when rain is expected within 12 hours after application.

- Multiple applications of DURAL 50 must be within 24 hours of the preceding application.

- DURAL 50 is not intended for sealing cracks under hydrostatic pressure.

- Apply only to dry concrete and to concrete which has cured for at least 28 days.

- In all cases, consult the Material Safety Data Sheet before use.

WARRANTY. The Euclid Chemical Compary ("Eucid") solety and expressly wartants that its products shall be tree from deffocts in materials and workmanship for one (1) year from the date of purchase. Unwess authorized in writing by an omcer of Euclid, no other representations of statements made by Euclid of ins representatives, in writing of ofally, shall atter this warranty. EUCUD MAKES NO WAARANTIES, IMPUED OA OTHERWISE. AS TO THE MERCHANTABIUTY OR FITNESS FOR ORDINAPY OR PARTICULAR PURPOSES OF ITS PRODUCTS AND EXCLUDES THE SAME. If any Euclid product tails to contorm with this warranty, Euclid will replace the product at no cost to Buyec. Replacement of any product shall be the sole and exclusive remedy available and buyer shal have no cialim tor incidental or consequential damages. Any warranty clalim must be made within

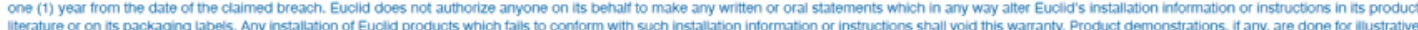
purposes only and do not consitute a warranty or warranty alteration of ary kind. Duyer shall be solety responsible for determining the sultablity of Euclide's products tor the Buyer's intended purposes.

\section{Figure A.9 (cont.): Technical Data Sheet, Dural 50, Euclid Chemical}




\section{DURAL 50 LM}

\section{Ultra Low Viscosity Low Modulus Epoxy}

\author{
FEATURES AND BENEFITS: \\ - Low Modulus \\ - Penetrates cracks by gravity \\ - Deep Penetrating \\ - Strengthens concrete surfaces \\ - Heal and seals concrete \\ - Contractor Friendly \\ Two year shelf life \\ Does not contain Styrene \\ Does not contain Peroxides \\ Not a Flammable \\ Moisture Tolerant
}

APPLICATIONS:

- Bridge Decks

- Parking Decks

- Consolidation of porous and dusting surfaces

- Reduce water absorption

- Reduce chloride penetration

- Pressure injection

- Gravity feed hairline cracks

COMPOSITION \& MATERIAL: DURAL $50 \mathrm{LM}$ is a $100 \%$ solids, two component acrylated epoxy resin formulation.

SURFACE PREPARATION: Concrete must be structurally sound, clean, dry and free of laitance, dust, dirt, oil, coatings, form release agents and other contaminants. The preferred method of surface preparation is abrasive blasting. Remove defective concrete, honeycombs, cavities, joint crack voids and other defects by routing to sound material. Rebuild areas with suitable patching materials. Smooth, pre-cast and formed concrete surfaces must be cleaned, roughened and made absorptive by abrasive blasting or shot blasting. Blow debris and residue out of cracks and from the surface with a moisturefree and oil-free air jet. Mask expansion joint sealants to prevent adhesion of DURAL $50 \mathrm{LM}$ to the joint surface. Surfaces and cracks must be completely dry before DURAL 50 LM application to obtain penetration. For further information contact Tamms Technical Service Centers.

\begin{tabular}{|ll|}
\hline \multicolumn{2}{|c|}{ MATERIAL PROPERTIES } \\
@ $\mathbf{7 5}^{\circ} \mathbf{F}\left(\mathbf{2 5}^{\circ} \mathbf{C}\right)$ AND 50\% RH \\
Mixing Ratio (A : B) by volume & $2: 1$ \\
Mixed Viscosity, cps & $80-120$ \\
Gel Time (200 gms), mins. & 35 \\
Tack Free, hours & $3-5$ \\
Tensile Elongation & $65 \%$ \\
Tensile Strength & $527 \mathrm{psi}$ \\
& \\
Values presented are typical laboratory data \\
\hline
\end{tabular}

MIXING INSTRUCTIONS: Premix Part A and Part B. Combine 1 parts by volume of Part $A$ with 1 part by volume of Part B. Mix thoroughly with a slow speed motor and mixing blade. A $1 / 2$ inch drill and Jiffy mixer is acceptable. Do not aerate mixture.

APPLICATION TECHNIQUES: For sealing concrete slabs: Pour or pump mixed DURAL $50 \mathrm{LM}$ onto the prepared surface in a wave form and spread with a short nap roller or squeegee to fill voids, cracks and porous areas. A second application may be required on highly porous or severely cracked concrete. If required, the second coat should be applied within 24 hours. Broadcast silica sand into the surface to provide an anti-skid surface or where subsequent toppings or coatings will be applied. Apply the silica sand (0.2-0.8 $\mathrm{lbs} / \mathrm{sq}$ yd depending on the desired surface) not earlier than 2 hours (at $75^{\circ} \mathrm{F}$ ) after application of DURAL $50 \mathrm{LM}$, but before the DURAL 50 LM becomes tack free. Ensure that subsequent coatings or toppings are applied within the recoat window of DURAL $50 \mathrm{LM}$ ( a 24 hour recoat window at $75^{\circ} \mathrm{F}$ ). Grouting cracks, Gravity feed: Pour neat mixed DURAL $50 \mathrm{LM}$ into vee-notched cracks until completely filled. Pressure injection: Set appropriate injection ports depending on the system used. Seal around port and surface crack using Duralcrete Gel or Dural Fast Set Epoxy Gel. Inject neat resin using automated or manual injection equipment. Maintain slow steady pressure until the crack is filled with the injection resin. For complete details, consult Tamms' guide Specification on "Epoxy pressure injection of Structural Concrete".

COVERAGE: Coverage rates are approximate and for estimating purposes only. Surface temperature, texture and porosity will determine actual material requirements

Figure A.10: Technical Data Sheet, Dural 50 LM, Euclid Chemical 
Slab Sealing: $100-200$ sq. ft./gal. for first coat for typical concrete surface. 150-300 sq. ft./gal. for second coat in cases of extensive cracking or high porosity. Crack Grouting: Coverage will be determined by depth and length of cracks.

CLEAN UP: Clean tools and equipment immediately following use with xylene or methyl ethyl ketone. Clean drips and over spray while still wet with the same solvent. Cured DURAL $50 \mathrm{LM}$ will require mechanical abrasion for removal.

PACKAGING \& STORAGE: DURAL 50 LM is available in 3 gallon kits, 15 gallon units \& 150 gallon units. Store at between $50^{\circ}$ and $90^{\circ} \mathrm{F}$. Protect from moisture. Shelf life is 2 years in unopened containers and in protected storage. The freight class is 60 .

CAUTIONS: Do not mix or apply DURAL $50 \mathrm{LM}$ at temperatures below $50^{\circ} \mathrm{F}$ or when rain is expected within 12 hours after application. Multiple applications of DURAL 50 LM must be within 24 hours of the preceding application. DURAL $50 \mathrm{LM}$ is not intended for sealing cracks under hydrostatic pressure. Apply only to dry concrete and to concrete which has cured for at least 28 days. Store at temperatures above $50^{\circ} \mathrm{F}$.

ENVIRONMENTAL AND SAFETY PRECAUTIONS: Component A contains epoxy resins. Vapors can cause respiratory irritation. Contact may cause skin or eye irritation. Can cause sensitization after prolonged or repeated exposure. Use safety goggles and chemical resistant gloves. Use only with adequate ventilation. Component B contains amines and is CORROSIVE. Contact with eyes and skin may cause severe burns. Can cause sensitization after prolonged or repeated use. Use of safety goggles and chemical resistant gloves is highly recommended. Use only with adequate ventilation.

First Aid: In case of skin contact, wash immediately and thoroughly with soap and water. For eye contact, flush immediately with water for 15 minutes and consult a physician immediately. For respiratory problems, remove person immediately to fresh air.

Disposal: Collect with absorbent material. Dispose of in accordance with current local, state and federal regulations.

READ MATERIAL SAFETY DATA SHEET BEFORE USING. MATERIAL IS FOR INDUSTRIAL USE ONLY. KEEP AWAY FROM CHILDREN. EMERGENCY RESPONSE PHONE NUMBERS ARE (800) 862-2667 TAMMS OR (800) 424-9300 CHEMTREC.
TECHNICAL SERVICE: For application procedures, surface conditions or other questions not answered please contact:

\section{TAMMS INDUSTRIES}

3835 State Route 72, Kirkland, IL 60146

Phone: 800-862-2667 Fax: 815-522-2323

www.tamms.com

WARRANTY: Seller warrants that its products do not infringe upon any copyright, patent, trademark, or trade secret nor violate the proprietary information rights of any third party. Seller warrants that its products will conform to and perform in accordance with the product's specifications. THE FOREGOING WARRANTIES ARE IN LIEU OF ALL OTHER WARRANTIES EXPRESSED OR IMPLIED INCLUDING BUT NOT LIMITED TO THOSE CONCERNING MERCHANTABILITY AND FITNESS FOR A PARTICULAR PURPOSE. Because of the difficulty of ascertaining and measuring damages hereunder, it is agreed that except for claims for bodily injury, the seller's liability to the buyer or any other third party for any losses or damages, whether direct or otherwise, arising out of the purchase of the product from the seller by the buyer shall not exceed total amount billed and billable to the buyer for the product. IN NO EVENT WILL THE SELLER BE LIABLE FOR ANY LOSS OF PROFITS OR OTHER SPECIAL OR CONSEQUENTIAL DAMAGES, EVEN IF SELLER HAS BEEN ADVISED OF THE POSSIBILITY OF SUCH DAMAGES.

TAMMS INDUSTRIES Kirkland, IL 60146

$5 / 2006$

Figure A.10 (cont.): Technical Data Sheet, Dural 50 LM, Euclid Chemical 

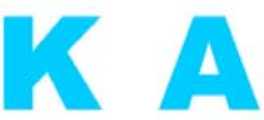

PRODUCT

INFORMATION
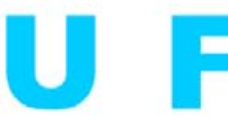

KAUFMAN
PRODUCTS

INC.

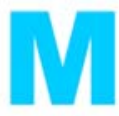

3811 CURTIS AVENUE
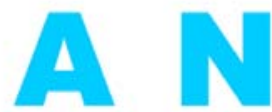

BALTIMORE,

$410-354-8600$ 21226-1131

www.kaufmanproducts.net
SurePoxy HMSLV

\section{Description}

SurePoxy HMSLV is a new, extremely low viscosity, two component, $100 \%$ solids high modulus epoxy adhesive, and healer/penetrating sealer. Users will notice that SurePoxy HMSLV is $60-85 \%$ lower in viscosity than other low viscosity epoxy products. This epoxy system is insensitive to moisture before, during and after cure.

\section{Uses}

SurePoxy HMSLV is recommended neat as a healer and/or penetrating sealer for above and below grade structural repairs of horizontal decks. slabs, patios, driveways, parking garages. By gravity feed or pressure injection of cracks in structural concrete, masonry, wood, etc., it will rebond cracks, delamination and hollow planes in concrete. It will penetrate cracks and develop a high bond strength upon curing, thereby allowing the normal transfer of loads designed in the original structure. Due to its extremely low viscosity, HM-

SLV can penetrate deeper into smaller cracks than normal low viscosity epoxies.

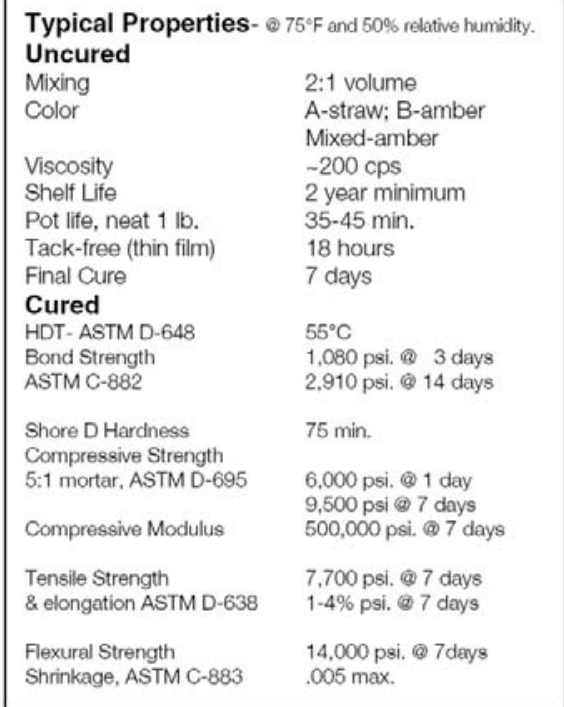

\section{Specifications}

ASTM C-881, Types I, II, IV \& V, Grade 1, Class C

AASHTO M-235, Types I \& II, Grade 1.

Class C

$\begin{array}{cl}\text { Packaging } & \\ 2.84 \text { Liter } & \text { (.75 gal. unit) } \\ 11.36 \text { Liter } & \text { ( } 3 \text { gal. unit) } \\ 56.78 \text { Liter } & \text { (15 gal. unit) } \\ 450 \mathrm{ML} & \text { (16.5 oz. 029 gal.) cartridges } \\ & \text { (6 per carton) }\end{array}$

\section{Storage Conditions}

Store dry at $40-95^{\circ} \mathrm{F}$. Condition material to $65-85^{\circ} \mathrm{F}$ before using.

\section{Directions}

\section{Surface Preparation}

Concrete -Surface must be clean and sound. It may be dry or damp but free of standing water. Remove oil, wax, curing compound, laitance, and other foreign matter as per ASTM D-4258 and D-4259. Waterblasting followed by shotblasting is the preferred method of preparation to provide a fractured aggregate profile. Also satisfactory are sandblasting or shotblasting individually. Acid etching according to ASTM D-4260 with $1520 \%$ muriatic acid solution can be used as an alternative. Wash acid and loose mortar off with high pressure water until slush is removed. Test with litmus paper to be sure acid is removed. Final rinse with $1 \%$ ammonia solution is beneficial.

Steel - Sandblast to appropriate finish.

Expansion/control joints, joint sealants, floor drains and floor termination joints require special attention. SurePoxy HMSLV will not usually adhere to sealant joints. Test first.

\section{Proportioning/Mixing}

The volumetric ratio of HMSLV is 2:1 (A:B). To mix, proportion 2 parts $\mathrm{A}$ and 1 part $\mathrm{B}$ into a clean pail. Mix thoroughly for 3 minutes, with paddle or low speed (400 to $600 \mathrm{rpm}$ ) drill until blend is uniform color.

For professional use only. Not for sale to or use by the general public.

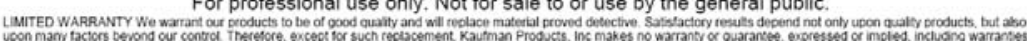

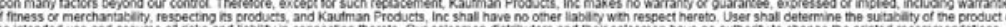

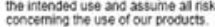

\section{Figure A.11: Technical Data Sheet, SurePoxy HMSLV, Kaufman Products, Inc.}




\section{Coverage}

Typical coverage is $90-150 \mathrm{ft}^{2} / \mathrm{gal}$. For crack healing and surface sealing. Coverage varies with porosity and surface profile of substrate. Higher porosity will reduce coverage.

\section{Application}

Apply to horizontal surfaces by roller, squeegee or broom. Spread material over area and allow to pond over cracks. Let material penetrate into cracks and substrate. Remove excess leaving little visible surface film. A second application may be required on very porous substrates. If a second treatment is required, apply within 24 hours of the first one. After final treatment, wait at least 20 minutes but less than 2 hours at $73^{\circ} \mathrm{F}$ and cover with a light broadcast of a dry $8 / 20$ or similar sand at $15-20 \mathrm{lbs}$. Per $100 \mathrm{ft}^{2}$. Remove loose sand before opening to traffic. The excess material removed from the floor can be stored in the original containers and allowed to harden. Once hardened, it is non-hazardous and can be disposed off by depositing in standard trash receptacles.
Gravity feed

For cracks greater than 1/8" wide, fill crack with oven-dried sand before applying SurePoxy HMSLV. Gravity feeding cracks: If crack goes through the entire surface requiring repair, seal underside with proper SurePoxy Gel. Pour neat SurePoxy HMSLV into V-notched crack. Continue pouring until cracks are completely filled.

Pressure Injection

Pressure injecting cracks: Insert ports into cracks and seal injection ports and crack surfaces with proper SurePoxy Gel. Allow to harden sufficiently and then use automated injection equipment or manual method to inject through injection ports.

\section{Precautions}

Do not thin. Pot life may vary due to different temperatures. Not for injecting of cracks under hydrostatic head. Material is a vapor barrier after cure. Read Material Safety Data before using Please refer to the General Epoxy Instructions for complete details for proper application during cold and hot weather.

\section{Figure A.11 (cont.): Technical Data Sheet, SurePoxy HMSLV, Kaufman Products, Inc.}




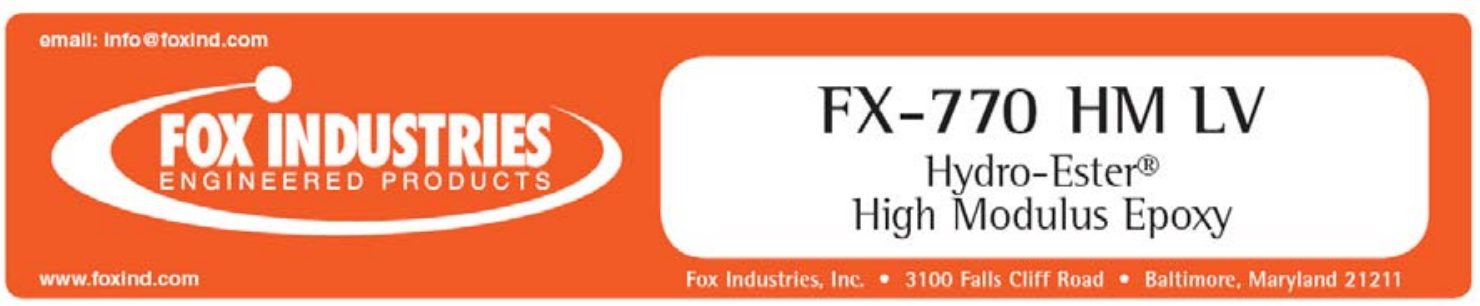

DESCRIPTION:

FX-770 HM LV Hydro-Ester ${ }^{(3)}$ is a two component, $100 \%$ solids, moisture insensitive epoxy resin system, mixed at a 2 to 1 ratio, with a very low viscosity for penetrating cracks. FX-770 HM LV exceeds the requirements of ASTM C 881 87, Types I, II, Grade 1, Class " $\mathrm{B}$ " and "C".

\section{ADVANTAGES:}

- High strengths.

- Low viscosity permits easy flow crack grouting by gravity feed or pressure injection.

- May be injected below water.

- May be used in temperatures as low as $40^{\circ} \mathrm{F}\left(4^{\circ} \mathrm{C}\right)$.

PHYSICAL PROPERTIES:

\begin{tabular}{|c|c|c|}
\hline \multirow{3}{*}{ Color } & \multicolumn{2}{|c|}{ Component A - Light Straw } \\
\hline & \multicolumn{2}{|c|}{ Component B - Clear } \\
\hline & \multicolumn{2}{|c|}{ Mixed - Clear (transparent) } \\
\hline Viscosity & \multicolumn{2}{|c|}{$100 \mathrm{cps} @ 77^{\circ} \mathrm{F}\left(25^{\circ} \mathrm{C}\right)$} \\
\hline Pot Life (neat) & \multicolumn{2}{|c|}{$30 \mathrm{~min} .975^{\circ} \mathrm{F}\left(24^{\circ} \mathrm{C}\right)$} \\
\hline Tack-Free (thin film) & \multicolumn{2}{|c|}{5 hrs. @ $75^{\circ} \mathrm{F}\left(24^{\circ} \mathrm{C}\right)$} \\
\hline Full Cure & \multicolumn{2}{|c|}{7 days @ $75^{\circ} \mathrm{F}\left(24^{\circ} \mathrm{C}\right)$} \\
\hline \multicolumn{3}{|c|}{$\begin{array}{l}\text { Linear Coefficient of Shrinkage } \\
\text { on cure ASTM D } 2566 \quad 0.005 \\
\text { Slant Shear } \\
\text { Bond Strength }\end{array}$} \\
\hline $\begin{array}{l}2 \text { Day } \\
14 \text { Day }\end{array}$ & $\begin{array}{l}1,000 \mathrm{psi} \\
1,500 \mathrm{psi}\end{array}$ & $\begin{array}{l}6.8 \mathrm{MPa} \\
10.3 \mathrm{MPa}\end{array}$ \\
\hline $\begin{array}{l}\text { Compressive Strength } \\
\text { ASTM D } 6957 \text { day }\end{array}$ & \multicolumn{2}{|l|}{$\begin{array}{l}8,000 \mathrm{psi} \\
\text { @ } 75^{\circ} \mathrm{F}\left(24^{\circ} \mathrm{C}\right)\end{array}$} \\
\hline $\begin{array}{l}\text { Tensile Strength } \\
\text { ASTM D } 638\end{array}$ & \multicolumn{2}{|r|}{$41.3 \mathrm{MPa}$} \\
\hline Tensile Elongation & \multicolumn{2}{|l|}{$2 \%$} \\
\hline \multicolumn{3}{|l|}{ ASTM D 638} \\
\hline \multicolumn{3}{|c|}{$\begin{array}{l}\text { Compressive Strength, Mortar } \\
\text { ASTM C } 109 \text { (with } 4 \text { parts FX-700) }\end{array}$} \\
\hline 7 Days & 7,000 psi & 55.16 \\
\hline Shelf Life & 2 years & \\
\hline
\end{tabular}

WHERE TO USE:

Use neat for grouting damp and dry cracks or as a penetrating sealer on concrete.

Mix with 3 parts FX-700 Epoxy Extender to grout base plates, set anchor bolts, or to fill the annular void in the FX-70 Inert Corrosion-Free System for pile protection and restoration.

Mix with 4 parts FX-700 for a self-leveling grout.

Mix with up to 5 parts of FX-700 for a patching mortar.

\section{SURFACE PREPARATION:}

Remove dust, laitance, grease and curing compounds from concrete surface by sandblasting or wire brushing. Cracks may be dry, damp, or wet

MIXING:

Material should range between $65^{\circ} \mathrm{F}\left(18^{\circ} \mathrm{C}\right)$ and $75^{\circ} \mathrm{F}\left(24^{\circ} \mathrm{C}\right)$ to facilitate ease of mixing. Stir each component lightly prior to proportioning. Mix 2 parts Component " $A$ " with 1 part Component "B". Mix thoroughly for 2-3 minutes with FX-Mixing Paddle and low speed drill until color is uniform. When mixed with FX-700, color of mixed material is gray in color.

\section{APPLICATION:}

Automatic Pressure Injection: Use FX Automatic Pressure Injection Machine as shown in FN-101.

Manual Pressure Injection: Place one-way polyethylene valves every $12^{\prime \prime}$ to $36^{\prime \prime}$ along length of crack. Seal surface of crack to be grouted with FX-763 Trowel Grade. Pump FX-770 HM LV into lowest one-way valve. When epoxy reaches next highest valve, move up and repeat procedure. Pull valves after cure.

Penetrating Sealer: Apply mixed material with rubber squeegee or roller. Allow time to penetrate. Squeegee off excess while still liquid.

Patching: Apply neat FX-770 HM LV to prime clean sound substrate. Mix blended epoxy with FX-700 or FX-701 Filler and trowel in place.

Anchor Bolt Grouting: Diameter of hole should be minimum of $1 / 2$ " larger than that of bolt.

(continued on back) 
YIELD:

One gallon of mixed FX-770 HM LV will yield approximately:

$750 \mathrm{cu}$. in. when mixed w/3 gallons FX-700 - very pourable

$925 \mathrm{cu}$. in. When mixed w/4 gallons FX-700 - self-leveling

$1100 \mathrm{cu}$. in. when mixed w/5 gallons FX-700 - masonry mortar

\section{LIMITATIONS:}

Do not thin FX-770 HM LV. Solvents will prevent proper cure. Do not use for bonding new to plastic concrete, use FX-752. Substrate temperature and ambient temperature must not be below $40^{\circ} \mathrm{F}\left(4^{\circ} \mathrm{C}\right)$. Exposure to elevated temperatures for prolonged periods is not recommended.

Epoxy resin (A Component) may crystallize. Heating material to $120^{\circ} \mathrm{F}$ and stirring will reconstitute material to original condition. Allow to cool before using

CAUTION:

WARNING! "A" Component contains epoxy resin. DANGER! " $\mathrm{B}$ " Component contains alkaline amines; strong sensitizer. May cause skin sensitization or other allergic responses. Use with good ventilation, particularly if material is heated or sprayed. Prevent all contact with skin or eyes. Wear protective clothing, goggles, gloves and/or barrier creams. Keep container closed when not in use. Wash thoroughly after handling.

\section{FIRST AID:}

In case of skin contact, immediately wash with soap and water. in case of eye contact, flush eyes with copious amounts of water for at least fifteen (15) minutes. Remove contaminated clothing shoes. if irritation persists, seek medical attention. Wash clothing before reuse.

\section{Figure A.12 (cont.): Technical Data Sheet, FX-770 HM LV, Fox Industries}




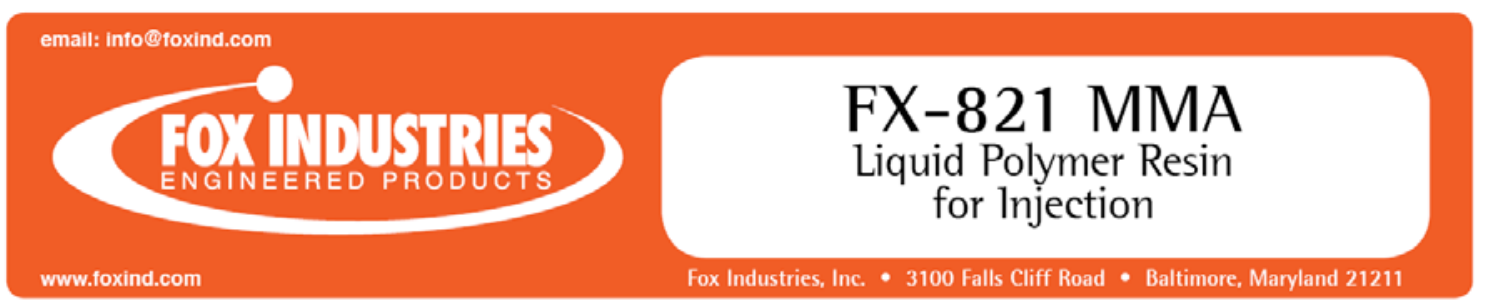

DESCRIPTION:

FX-821 Liquid MMA Polymer Resin for Injection or as a penetrating sealer, is a two component MMA resin of extremely low viscosity that will penetrate into concrete cracks as fine as 0.003 inches. The resin polymerizes in place and seals and strengthens existing porous concrete. Winter and summer formulations are available depending on ambient conditions.

ADVANTAGES:

* Extremely low viscosity

* Potlife can be adjusted to control gel time

* Has been used with patented vacuum injection process

* Bond strength to concrete exceeds concrete tensile strength

- Winter formula can be used on dry surfaces at temperatures as low as $-20^{\circ} \mathrm{F}$

PHYSICAL PROPERTIES:

\begin{tabular}{lll} 
Color & Amber \\
Viscosity & $10 \mathrm{cps}$ \\
Gel Time & \multicolumn{2}{c}{40 minutes summer mix } \\
& 10 minutes winter mix \\
Cure Time & 24 hours @ $50^{\circ} \mathrm{F}\left(10^{\circ} \mathrm{C}\right)$ \\
Adhesion to Concrete & $2,000 \mathrm{psi}$ & $13.79 \mathrm{Mpa}$ \\
Compressive Strength & 7 days & \\
& $12,000 \mathrm{psi}$ & $96.53 \mathrm{Mpa}$ \\
Tensile Strength & 7 days & \\
& $5,000 \mathrm{psi}$ & $34.47 \mathrm{Mpa}$ \\
Flex. Strength & $12,000 \mathrm{psi}$ & $82.74 \mathrm{Mpa}$ \\
Linear Shrinkage & $1 \%$ &
\end{tabular}

SURFACE PREPARATION:

Concrete cracks to receive FX-821 (MMA) must be clean, dry and sound. The drier the concrete, the deeper the penetration into fine cracks. Clean cracks using vacuum or compressed air to remove debris from cracks. Compressors must employ inline traps or filters to prevent water or oil from contaminating crack.

MIXING:

One bottle of $B$ Component is mixed with 1 gallon $A$ Component. Open Component $A$ and put Component $B$ (initiator) paste into Component A container (one 100 gram bottle of $B$ for each 1 gallon of $A$, or five 100 gram bottles of $B$ for each five gallon unit of A). Mix for 2-3 minutes with a low speed drill and FX-Mixing Paddle. Apply immediately after mixing.
APPLICATION:

To seal flat surfaces, pour out mixed material and spread evenly with squeegee, roller, or brush. Do not leave puddles. To seal cracks, use vacuum or pressure injection machines, Simple caulking guns may be used for low pressure through handguns.

For patching of wide cracks, Cabosil or similar thickening agents may be added up to $5 \%$ by weight of FX-821 MMA. For pothole patching, dry pack with a mixture of coarse and fine aggregates Pour the mixed FX-821 to saturate the dry packed surfaces.

\section{COVERAGE:}

Coverage depends on porosity of concrete or masonry surface. 150 to 200 square feet is the normal range.

\section{LIMITATIONS:}

Do not leave puddles which can cause slippery surface. To prevent slippery surfaces, broadcast dry silica sand for FX-701 Filler. Do not apply to a damp or wet surface. Do not use below $-20^{\circ} \mathrm{F}$.

\section{SHELF LIFE:}

1 year. Product must be stored below $80^{\circ} \mathrm{F}$ to prevent polymerization of liquid and loss of activity of initiator.

\section{PACKAGING:}

1 gallon (3.8 L), 5 gallon (18.9 L) units or 54 gallon (204.4 L) drums.

CAUTION:

DANGER! FLAMMABLE! A Component contains Methyl Methacrylate. B Componentcontains Benzoyl Peroxide. Use only with good ventilation. Avoid inhalation of vapor. Prevent all contact with eyes, skin and clothing. Wash thoroughly after handling. Keep containers closed when not in use.

FIRST AID IN CASE OF CONTACT:

If contact with skin occurs, wash immediately with soap and water, and contact a physician. If contact with eyes, immediately flush with plenty of water for at least 15 minutes. Remove contaminated clothing and shoes. Call a physician. Wash clothing before reuse and discard contaminated shoes.

WEAR PROTECTIVE CLOTHING, GOGGLES, GLOVES AND/OR BARRIER CREAMS.

\section{PHONE 410-243-8856


INTEET BRIDGE SEAL

TWO COMPONENT, PENETRATING EPOXY HEALER SEALER

BENEFITS:

- Super Low Viscosity Enabling Greater Crack Penetration \& Structural Healing

$100 \%$ Effective Against Chloride Ion Penetration

- Safer Mixing than Methacrylates

Economical

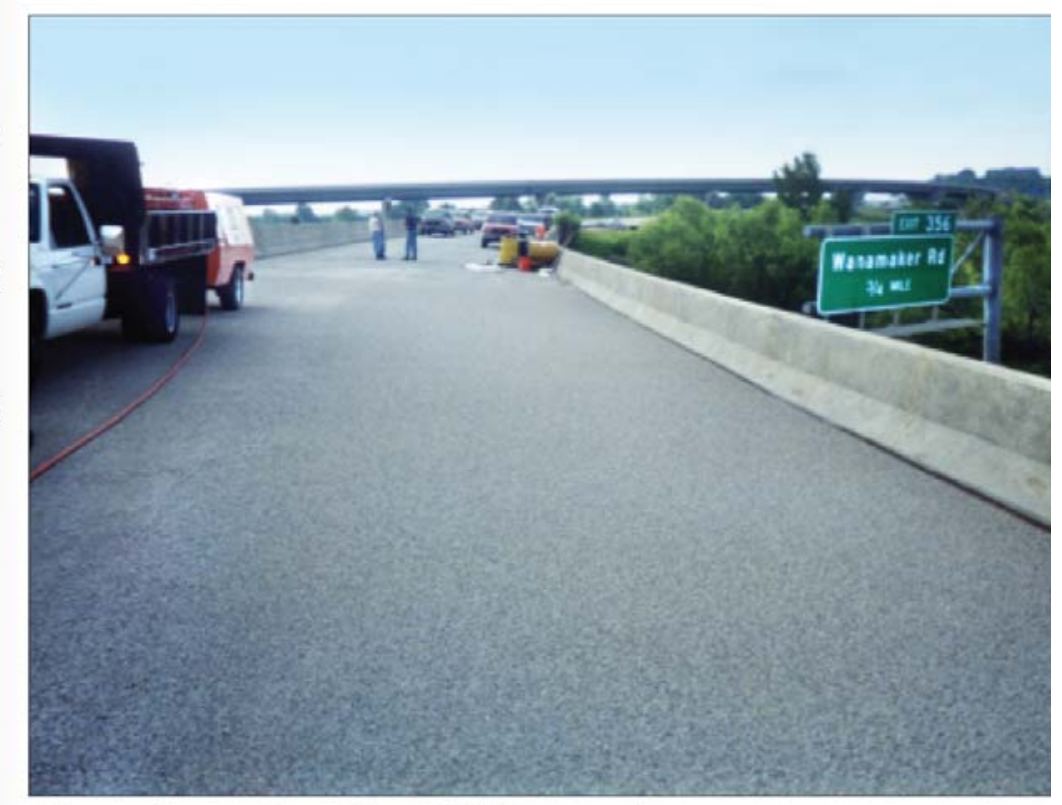

\section{Premium Quality Without the}

Costs or Risks of Methacrylates!

\begin{tabular}{|c|c|c|c|c|c|}
\hline & BAIDGE SEAL & $\begin{array}{l}\text { Urethane } \\
\text { Deck Coatings }\end{array}$ & $\begin{array}{l}\text { Siloxanes/ } \\
\text { Silanes }\end{array}$ & $\begin{array}{l}\text { 3 Component } \\
\text { HMWMMA's }\end{array}$ & Linseed Oils \\
\hline Bond Strength & EXCELLENT & FAIR & NONE & POOR & NONE \\
\hline Tensile Strength & EXCELLENT & POOR & N/A & FAIR & N/A \\
\hline Waterproofs Surface & EXCELLENT & GOOD & GOOD & GOOD & FAIR \\
\hline Fills Cracks & EXCELLENT & GOOD & NONE & GOOD & NONE \\
\hline $\begin{array}{l}\text { Volatile when } \\
\text { Improperly Mixed }\end{array}$ & NO & NO & N/A & YES & $N / A$ \\
\hline Moisture Sensitive & NO & YES & YES & YES & YES \\
\hline
\end{tabular}

Figure A.14: Technical Data Sheet, Bridge Seal, Unitex Chemicals 


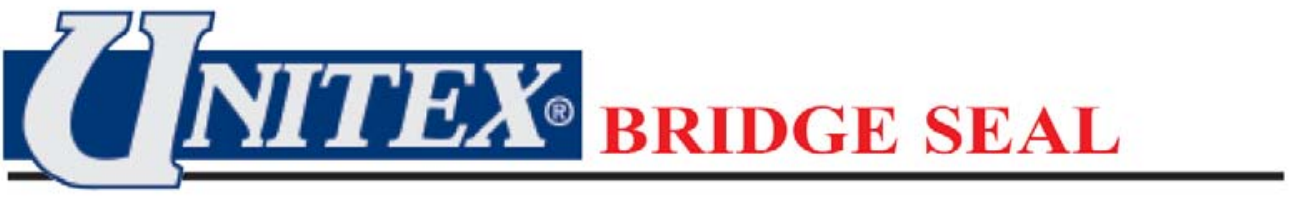

\section{- DESCRIPTION}

BRIDGE SEAL is a highly penetrating, fluorescent, two component epoxy healer/sealer which when applied to cracked bridge decks, structurally seals the cracks against moisture and chloride ion intrusion, prolonging the life of the bridge. Its rapid cure time allows traffic to reopen in four hours. BRIDGE SEAL illuminates under black light providing evidence of penetration into the finest hairline cracks in the concrete

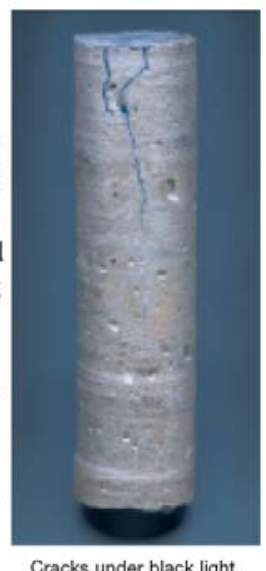

Cracks under black light.
USES

- Bridge Decks

- Parking Decks

- Floors

- Columns \& Beams in Splash Zones

- Consolidation of Porous \& Dusting Surfaces

\section{COVERAGE}

Coverage rate depends on porosity of concrete. Broom finished: $65-100$ sq. ft. / gal. $6.0-9.3$ sq. m. / L. Steel-troweled: $150-200$ sq. ft. / gal. $13.9-18.6 \mathrm{sq} . \mathrm{m} . / \mathrm{L}$.

\section{COMPLIANCES}

Federal EPA V.O.C. $<250 \mathrm{~g} / \mathrm{L}$

AASHTO T-259 Chloride Ion Penetration Resistance ( 90 day ponding)

\section{APPLICATION}

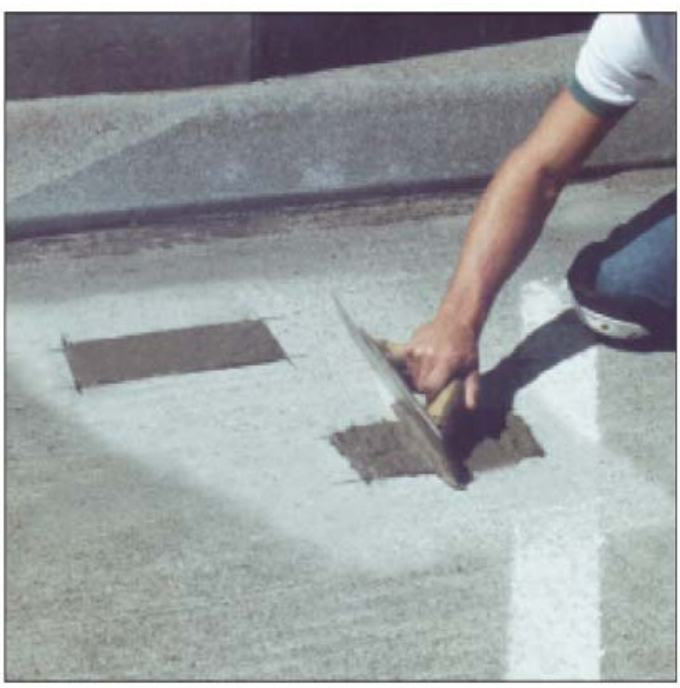

STEP 1: Repair all delaminations with PRO-POXY 50 and deteriorated areas with PRO-POXY 2500 prior to using BRIDGE SEAL.

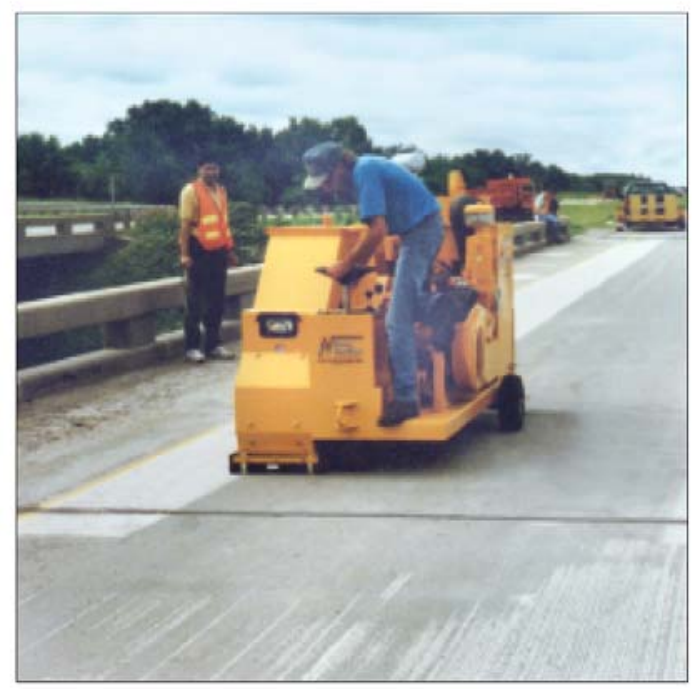

STEP 2: Clean concrete by shot or sand blasting. Blow off with high pressure oil-free air. Surface must be clean, dry, and free of frost.

Figure A.14 (cont.): Technical Data Sheet, Bridge Seal, Unitex Chemicals 


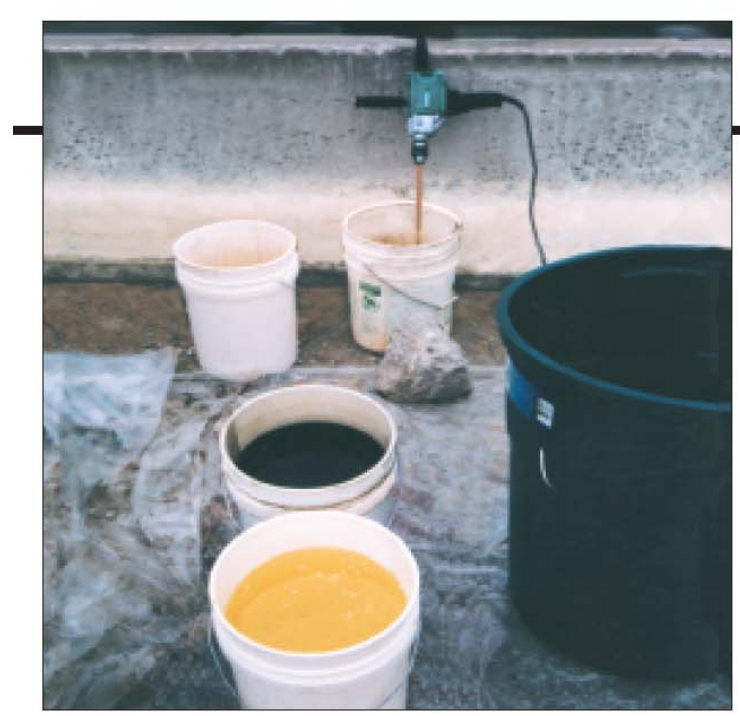

STEP 3: Mechanically mix two components 1:1 by volume with Jiffy mixer and variable speed drill $300 \mathrm{rpm}$ for a minimum of 3 minutes.

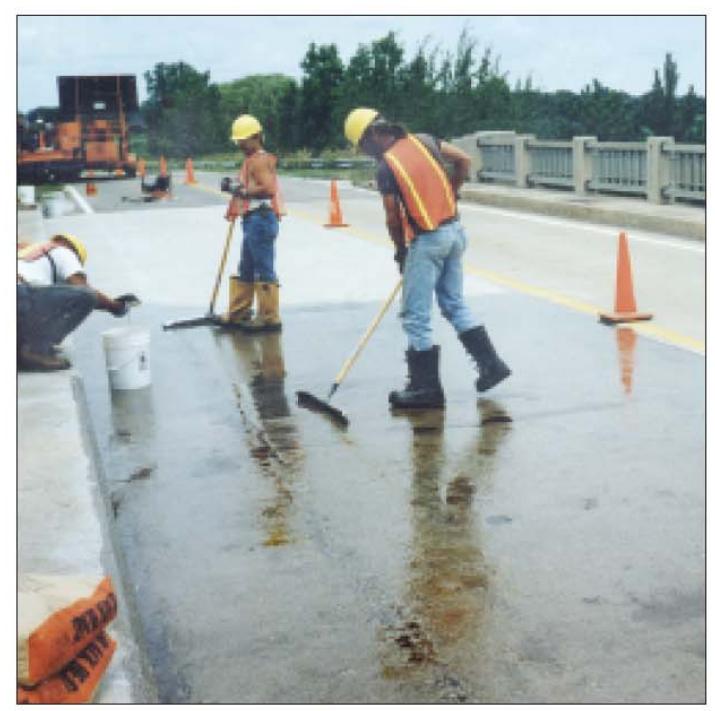

STEP 5: Immediately distribute evenly and work into concrete for a minimum of 5 minutes for maximum penetration. Keep ponding BRIDGE SEAL into cracks until refusal. Remove all excess with a squeegee on smooth surfaces and a broom on textured surfaces. Surface should appear damp but with no film build-up or ponding prior to broadcast of the sand.

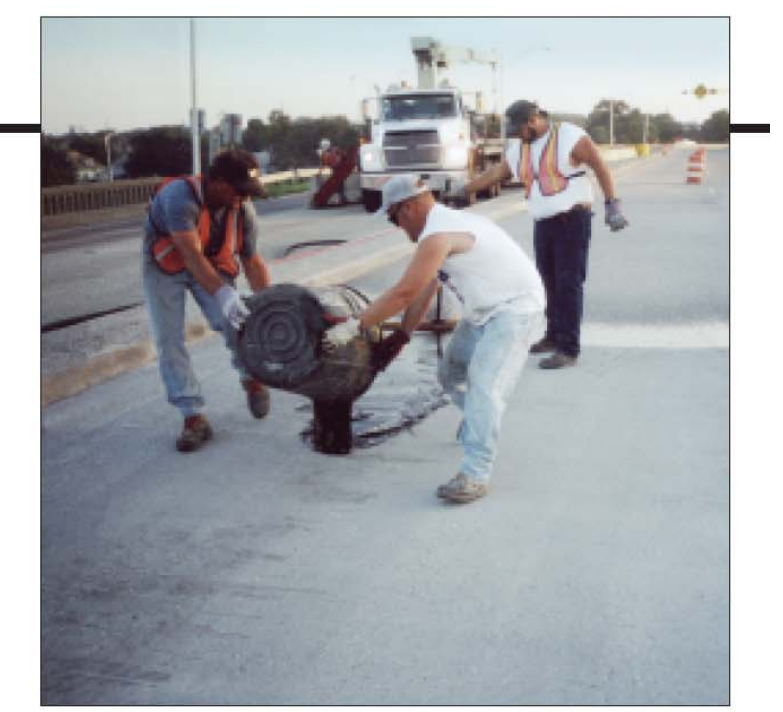

STEP 4: Within 5 minutes, pre-treat larger cracks and then flood coat BRIDGE SEAL onto the bridge deck.

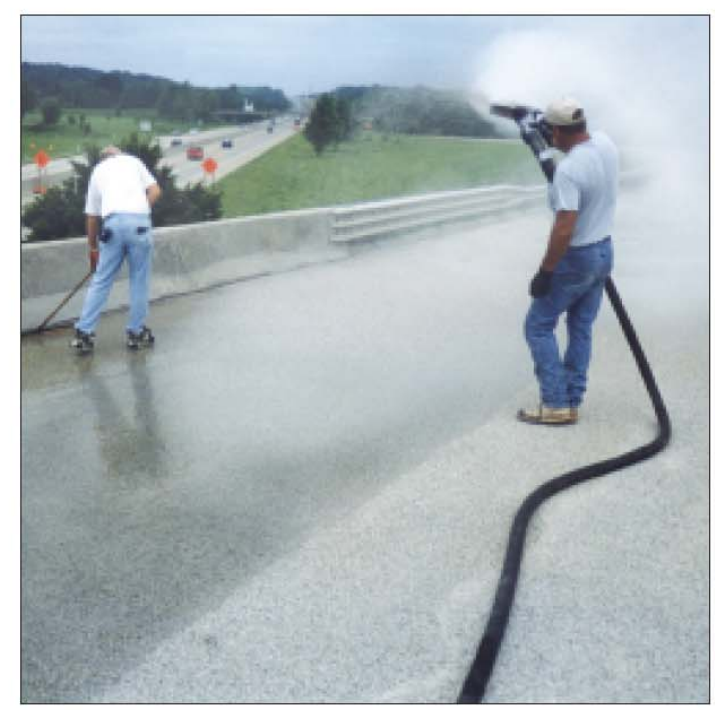

STEP 6: Before BRIDGE SEAL gels, broadcast ovendried silica sand to refusal. Blow-off excess sand after fully cured before reopening to traffic.

Figure A.14 (cont.): Technical Data Sheet, Bridge Seal, Unitex Chemicals 


\section{PACKAGING}

2 gal / 7.6 L units (2 one gallon cans)

$10 \mathrm{gal} / 37.8 \mathrm{~L}$ units (2 five gallon pails)

$110 \mathrm{gal} / 416 \mathrm{~L}$ units (2 fifty-five gallon drums)

\section{LIMITATIONS}

- Store BRIDGE SEAL at $50^{\circ}-80^{\circ} \mathrm{F}$ or $10^{\circ}-27^{\circ} \mathrm{C}$.

- Condition BRIDGE SEAL to $65^{\circ}-80^{\circ} \mathrm{F}$ or $18^{\circ}-27^{\circ} \mathrm{C}$.

- Minimum application temperature: $40^{\circ} \mathrm{F}$ or $4^{\circ} \mathrm{C}$

- Shelf Life - 1 year in original unopened container.

- Gel Time at $72^{\circ} \mathrm{F}\left(22^{\circ} \mathrm{C}\right)$ - In 6 gram mass: $1 \mathrm{hr}$ In thin film: $20 \mathrm{~min}$

- Curing Time - Approx. 4 hrs. at substrate temp. of $77^{\circ} \mathrm{F}$ or $22^{\circ} \mathrm{C}$.

- Maximum of 1 flood coat application.

- Do not apply over curing compounds.

- Apply to dry and fully cured concrete only.

- Compressed air equipment must have an oil/air separator.

- Do not flood coat slab on grade in freezing climates.

\section{CLEAN-UP}

- Ventilate area.

- Confine spills.

- Collect with absorbent material.

- Flush area with water.

- Uncured BRIDGE SEAL can be removed with Unitex CITRI-CLEAN.

- Cured BRIDGE SEAL can only be removed mechanically.

\section{FIRST AID}

Cured BRIDGE SEAL is innocuous.

For uncured BRIDGE SEAL:

\section{Skin Contact}

- Remove contaminated clothing.

- Remove product with a dry cloth or paper towel.

- Wash skin area thoroughly with soap and water. (Solvents should not be used because they carry product into the skin.)

\section{Eye Contact}

- Flush eyes immediately with water for a minimum of 15 minutes.

\section{Respiratory Problems}

- Seek fresh air and/or medical attention.

\section{CAUTIONS}

- Keep away from heat, sparks, and open flame.

- Flammable Liquid, Corrosive UN2924.

- Use only with adequate ventilation.

- Avoid all contact with skin and eyes.

- Avoid breathing vapors.

- For Industrial Use Only.

- Not for internal consumption.

- Keep out of reach of children.

- Use safety gloves, goggles, and NIOSH/MSHA approved organic vapor respirator if ventilation is inadequate.

- Do not thin with solvents.

Disclaimer of Warranties: Neither manufacturer nor seller have any knowledge or control concerning the purchaser's use of the product. No expressed warranty is made by manufacturer or seller with respect to the results of any use of the product or container that the product comes in. No implied warranties including, but not limited to, an implied warranty of merchantability or an implied warranty of fitness for a particular purpose are made with respect to the product. Neither manufacturer nor seller assume any liability for personal injury, loss or damage resulting from the use of the product. In the event that the product shall prove defective, buyer's exclusive remedy shall be as follows: Seller or manufacturer shall, upon request of buyer, replace any quantity of the product which is proven to be defective or shall, at its option, refund the purchase price of the product upon return of the product. Manufacturer shall not be responsible for use of this product in a manner to infringe on any patent held by others.

Contact UNITEX Technical Services for further information or installation instructions. 


\section{DESCRIPTION}

MARK-163 FLEXOGRID Overlay System is a hybridized copolymer formulated through a unique chemical combination of epoxy and urethane molecules specially designed to provide a flexible, yet strong waterproofing and de-slicking system for highway bridge decks.

MARK-163 FLEXOGRID Overlay System is placed as an overlay over the entire deck at a minimum thickness of $6.35 \mathrm{~mm}-9.53 \mathrm{~mm}\left(1 / 4^{\prime \prime}-3 / 8^{\prime \prime}\right)$.

MARK-163 FLEXOGRID Overlay System is designed to accommodate slight movements of the concrete structure due to heavy traffic and extreme changes in weather conditions. Flexibility is least affected by normal summer and winter temperature changes.

MARK-163 FLEXOGRID Overlay System consists of a $100 \%$ solids, two-part liquid polymer system to be mixed on the job site and a blend of specially selected aggregate to be broadcast on the spread liquid.

MARK-163 FLEXOGRID Overlay System is available for application at temperatures of $10^{\circ} \mathrm{C}\left(50^{\circ} \mathrm{F}\right)$ and above.

\section{RECOMMENDED USES}

MARK-163 FLEXOGRID Overlay System is used for the waterproofing and skid proofing of:

* $\quad$ Bridge decks, parking decks and observation decks.

* Other weather-exposed concrete structures requiring waterproofing and skid resistant qualities along with flexibility to accommodate any minor movements under the overlay, such as vibrations, thermal shock, freeze and thaw cycle, and expansion or contraction due to weather.

* High abuse, heavy traffic industrial floors.

* Asphalt and concrete entrance and exit ramps.

* Steel plate or filled grid decks.

LIMITE WARRANT: POLYCCARB, INC, warrants to the purchaser of this product that the product is free from manafacturing and design deficls.

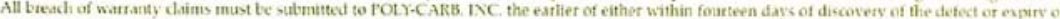
product shelf life. The purchaser's remedies are limethd to replacement of the product.

FOLY.CARB, NC, SPECHFICALLY DISANOWS ANY OIHER REPRESENTATION OR WARRANTY, EXPRESS OR ISPLIED, OR LIABHLITY RELATSG TO THE CONOIION OR LSE OF THE FRODLCT. AND IN NO EVENT SHAIL FOHY.CARB BF IIABI F TO PL RCHASFR, OR ANY

hs/HN 04-141

MARK-163 TDS

Page 1 of 6

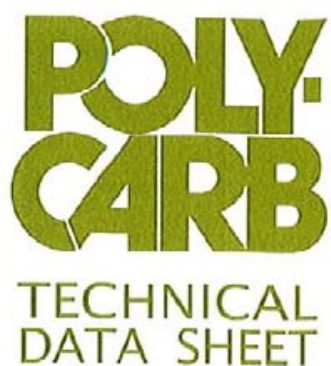

MARK-163

FLEXOGRID

Non-Skid Flexible Hybridized

Co-polymer Overlay

1SO 9001:2000 Certificd

POLY-CARB, INC.

33095 Bainbridge Road Cleveland. Ohio 4413 ?

Tel: 440.248 .1223

$\operatorname{Fax} 440.248 .1513$

125 GNS Court

Roberta. Georgia 31078

Tel: 478.836 .2881

Fax 478.836 .2949

TOll-Free: 866.POLYCARB

WWW POLYCARB.COM

Figure A.15: Technical Data Sheet, Mark-163 FLEXOGRID, Poly-Carb, Inc. 


\section{FEATURES}

* Completely non-porous

* A $100 \%$ solids system hence does not have solvent fumes

* Excellent bond to metal, concrete and asphalt surfaces

* $\quad$ Maintains skid number well above 50 for an extended period of time

* Application methods do not require troweling; therefore, the density of the overlay is independent of troweling pressures and techniques.

* $\quad$ Fast curing system allows traffic to be resumed within hours

* Variety of textures and non-skid qualities can be obtained by varying the aggregate

* Due to inherent flexibility, allows absorption of shocks and minor crack movement

* $\quad$ Flexibility is least affected at extremely low temperatures

\section{TECHNICAL DATA}

Properties of MARK-163 Part A and Part B

\section{PART A}

Amber

2 volumes

$100 \%$

2 years

\section{$\underline{\text { PART B }}$}

Amber

1 volume

$100 \%$

2 years

Percent Solid

Shelf Life

Properties of MARK-163 Mixed Part A and Part B

Color

Gel Time $25^{\circ} \mathrm{C}\left(75^{\circ} \pm 2^{\circ} \mathrm{F}\right)$

Gel Time $25^{\circ} \mathrm{C}\left(75^{\circ} \pm 2^{\circ} \mathrm{F}\right)$

(with aggregate)

Initial Set $25^{\circ} \mathrm{C}\left(75^{\circ}+2^{\circ} \mathrm{F}\right)$

Final Cure $25^{\circ} \mathrm{C}\left(75^{\circ} \pm 2^{\circ} \mathrm{F}\right)$
Amber

22-31 minutes (100 gms.)

1.5 hours

6 hours

48 hours-7 days

(See Section 6 under "Application" for curing properties at various temperatures)

Properties of Cured MARK-163

Adhesion of Concrete

Shore D Hardness

Compressive Strength $\quad 48.3-62.1 \mathrm{MPa}$

Tensile Strength

Tensile Elongation

Water Absorption - Max.

Abrasion Resistance - Wear Index

CS-17 Wheel, 1,000 cycle, 1,000 gms

Flexural creep at low temperature

Total movement in 7 days
$100 \%$ Failure

$65+5$

$(7, \overline{000}-9,000 \mathrm{psi})$

$(>2,500 \mathrm{psi})$

$35 \pm 5$

$0.2 \%$

75-85 milligrams

$0.165 \mathrm{~mm}, \mathrm{~min}$.

(.0065 inches, min.)
ASTM D-4541/ACI-503R

ASTM D2240-75

ASTM C-109

ASTM D638-82

ASTM D638-82

ASTM D-570

ASTM C-501

California Test 419

Figure A.15 (cont.): Technical Data Sheet, Mark-163 FLEXOGRID, PolyCarb, Inc. 


\section{SELECTION OF AGGREGATE}

Choice of aggregates would depend on the wear and skid resistance qualities required. The type of aggregate recommended for the bridge overlay system is:

MARK-371

Glacial Gravel

$\mathrm{SiO}_{2}$

$\mathrm{Al}_{2} \mathrm{O}_{3}$

$\mathrm{Fe}_{2} \mathrm{O}_{3}$

$\mathrm{CaO}$

$\mathrm{MgO}$

$\mathrm{Na} 2 \mathrm{O}$

$\mathrm{K}_{2} \mathrm{O}$

Combined alkali

Ignition loss

\author{
Basalt Quartzite Granite \\ $\%$ by Weight
}

75.03

11.49

3.57

2.84

1.59

2.58

0.99

1.11

0.72

MARK-371

Passing U.S. Standard Sieve
Basalt Quartzite Granite $\%$ by Weight

$\%$ No. 6

$\%$ No. 10

$\%$ No. 20
$100 \%$

$10-35 \%$

$0-3 \%$

\section{METHOD OF APPLICATION}

MATERIAL CONTAINERS ARE RECOMMENDED TO BE STORED IN A TEMPERATURE RANGE OF $75^{\circ} \mathrm{F}$ TO $85^{\circ} \mathrm{F}\left(24^{\circ} \mathrm{C}\right.$ TO $\left.30^{\circ} \mathrm{C}\right)$ FOR AT LEAST 24 HOURS PRIOR TO USAGE TO ENSURE PROPER MIXING AND APPLICATION PROPERTIES.

Surface Preparation: The entire deck or concrete surface in question must be sounded for subsurface delaminations. The delaminated areas are marked and repaired.

Concrete: The entire deck shall be shotblasted (using equipment such as Turboblast) to remove the contaminated concrete as well as any weak surface layer in the case of newly placed concrete. Sandblasting can be used as an alternative to shotblasting although the sandblasting methods DOES NOT provide a uniform and dust-free surface. Therefore, sandblasting should only be used where the shotblasting method is not practical or possible.

Asphalt: The entire area must be power washed $20.7-48.3 \mathrm{MPa}(3,000-7,000 \mathrm{psi})$ to remove all dirt, grime, and loose contaminants, at least 24 hours prior to application of FLEXOGRID.

Steel: The steel surface shall be sand blasted or shot blasted to "near white - SSPC-SP10". All cleaned surfaces shall be blown with dry compressed air and overlayed before any "flash" rusting is observed. 
Repair of Cracks: If excessive cracks are observed on concrete decks, then it is recommended that POLY-CARB's MARK-135 SAFE-T-SEAL be used. SAFE-T-SEAL is a gravity fed crack welding system that is $100 \%$ solids, free of any solvents or toxic fumes and odor. SAFE-T-SEAL is also recommended for steel grid filled with concrete decks as a pre-treatment prior to application of FLEXOGRID.

Repair of Spalled Areas: All weak and spalled concrete areas shall be marked and a one to two inch saw cut shall be made prior to jackhammering the non-structural concrete. Care should be taken not to slice or cut the steel rebar while saw cutting the marked area. These areas shall be sandblasted followed by an air blast to remove any loose dust.

For very large and massive patches, MARK-205 (Superplasticized Concrete) with an epoxybonding agent (MARK-25.3) is recommended.

Magnesium phosphate concrete is not recommended for patching prior to the application of MARK-163 FLEXOGRID overlay due to the incompatibility resulting in poor bond between the FLEXOGRID SYSTEM and the magnesium phosphate concrete.

\section{APPLICATION OF FLEXOGRID OVERLAY}

The overlay system shall be applied on all deck areas using metering, mixing, and distribution machinery approved by the hybridized co-polymer manufacturer. The application machine shall feature positive displacement volumetric metering pumps. Controlled by a hydraulic system and having a 37.85 liters (10 gallon) per minute minimum total output. The resin shall be stored in temperature controlled reservoirs and maintaining $37.8^{\circ} \mathrm{C} \pm 4^{\circ} \mathrm{C}\left(100^{\circ} \mathrm{F} \pm 10^{\circ} \mathrm{F}\right)$ to insure optimum mixing. In line mixing shall be motionless so as to not overly shear the material.

Mixing: For manual application, mix two volumes of Part A with one volume of Part B (2A: 1B) in a clean, dry metal container. A $1.27 \mathrm{~cm}(1 / 2 \mathrm{inch})$ high torque slow speed drill (300 R.P.M. max.) with a jiffy mixer is recommended. Take care to not entrap air in the system during mixing. Three to four minutes of thorough mixing is recommended.

The mixed material should be transferred into another clean and dry container to carry to the job. The remainder in the original container should be scraped out and transferred into the fresh batch. This process reduces chances of transferring small pockets of unmixed material on the concrete deck.

Application: Use the following steps for application of mixed material and aggregate.

1. Spread the mixed material on the surface using squeegees covering $0.86 \mathrm{~m}^{2} /[$ (35 square feet) per gallon in the first of two coats. It is recommended that the area shall be premarked to guide the use of mixed material providing recommended coverage.

2. The aggregate shall be broadcasted at a rate of $8.14 \mathrm{~kg} / \mathrm{m}^{2}\left(15 \mathrm{lbs} . / \mathrm{yd} .{ }^{2}\right)$ on the freshly placed hybridized co-polymer material within approximate time limits under the existing temperature conditions as described below in No. 6. For best results, the aggregate shall be broadcasted by truck mounted pneumatic or mechanical equipment capable of dispensing the aggregate onto the deck in a uniform manner as directed by the hybridized co-polymer manufacturer.

hs/HN 04-141 MARK-163 TDS Page 4 of 6

Figure A.15 (cont.): Technical Data Sheet, Mark-163 FLEXOGRID, PolyCarb, Inc. 
For smaller areas a garden fertilizer spreader may be used for spreading the aggregate. A lateral type unit is preferred to a circular spreader. The entire liquid surface shall be covered completely (to saturation) with the aggregate.

3. If required, as recommended by the manufacturer, the applied aggregate shall be uniformly compacted by the use of a lightweight, hand-driven roller.

4. Once this coat obtains the initial set, excess aggregate must be removed. A high-powered vacuum or sweeper may be used for aggregate cleanup.

5. The second application of mixed Parts A and B Overlay System shall be applied at a rate of $0.37-0.49 \mathrm{~m}^{2} / \mathrm{C}(15-20 \mathrm{ft} .2 /$ gal. $)$, followed by the broadcasting of aggregate at a rate of $8.14 \mathrm{~kg} / \mathrm{m}^{2}$ (15 pounds per yard ${ }^{2}$ ).

6. The maximum time allowed between application and broadcast of aggregate at temperature of:

$$
\begin{array}{ll}
90^{\circ} \mathrm{F}\left(32^{\circ} \mathrm{C}\right) & 10 \text { minutes } \\
80^{\circ} \mathrm{F}\left(27^{\circ} \mathrm{C}\right) & 15 \text { minutes } \\
70^{\circ} \mathrm{F}\left(21^{\circ} \mathrm{C}\right) & 20 \text { minutes } \\
60^{\circ} \mathrm{F}\left(16^{\circ} \mathrm{C}\right) & 25 \text { minutes } \\
50^{\circ} \mathrm{F}\left(10^{\circ} \mathrm{C}\right) & 35 \text { minutes }
\end{array}
$$

7. The minimum ambient temperature required for proper curing: $10^{\circ} \mathrm{C}\left(50^{\circ} \mathrm{F}\right)$.

NOTE:Any exceptions to the above specified procedure must have the approval of POLY-CARB, INC.

\section{COVERAGE}

\section{FLEXOGRID Overlay}

- Liquid***

$$
\text { 1st application - } 0.86 \mathrm{~m}^{2} / \mathrm{l}\left(35 \mathrm{ft} \mathrm{f}^{2} /\right. \text { gallon) }
$$

2nd application - $0.37 \mathrm{~m}^{2} / \mathrm{C}(15 \mathrm{ft}$. 2/gallon)

** The coverage rate is a good first estimate. This presupposes a flat deck, the specified aggregate, and a temperature of $80^{\circ} \mathrm{F}$. A grooved deck or a colder temperature may require more material.

- Aggregate

1st application - $8.14 \mathrm{~kg} / \mathrm{m}^{2}(15 \mathrm{lbs} . / \mathrm{yd} 2)$

2nd application $-8.14 \mathrm{~kg} / \mathrm{m}^{2}(15 \mathrm{lbs} . / \mathrm{yd} 2)$

\section{PACKAGING}

\section{FLEXOGRID Overlay}

- Liquid

Bulk Tank

$189.2 \ell$ (50 gallon) containers

$18.9 \ell$ ( 5 gallon) container
11355 C (3,000 gallons) (machine applications only)

567.7 ( 150 gallon) unit

$56.8 \mathrm{C}$ (15 gallon) unit

hs/HN 04-141

MARK-163 TDS

Page 5 of 6

Figure A.15 (cont.): Technical Data Sheet, Mark-163 FLEXOGRID, PolyCarb, Inc. 
- Aggregate

MARK-371

$45.4 \mathrm{~kg}(100 \mathrm{lb}$.) bags $\quad 30 \mathrm{bags} /$ pallet

Bulk

$1360.8 \mathrm{~kg}(3,000 \mathrm{lbs}) / \mathrm{bag}$

\section{CLEAN UP}

Cleaning of all equipment and tools is recommended before the gel time of the system expires. MARK-306 is specially designed for this purpose. A lacquer solvent or xylol can also be used for the same purpose.

\section{LIMITATIONS}

* $\quad$ Should not be used over magnesium phosphate-type of patching material.

* Use washed and dried aggregate only.

* At the time of application, the substrate and air temperature should be at least $10^{\circ} \mathrm{C}\left(50^{\circ} \mathrm{F}\right)$ and expected to rise to $15.6^{\circ} \mathrm{C}\left(60^{\circ} \mathrm{F}\right)$ or above.

* Do not thin the hybridized co-polymer with any solvent, as this will prevent proper curing.

* Excessive moisture on the concrete surface at time of application can interfere with proper bonding due to vapor pressure.

\section{IMPORTANT NOTE}

With this technical data sheet, we are making every effort to communicate to you, our valued customer, the proper procedures, properties and limitations of this product to ensure you a successful installation. This is considered to be an exotic material, which is controlled by temperature, proper mixing, surface preparation, and other application conditions. It is most IMPERATIVE that these instructions are understood by all and followed correctly. It is our appeal to you, in case of the slightest doubt, that you call our office and express your concerns to one of our technical service representatives. This action will ensure that all doubts, discrepancies, or misunderstandings are cleared up to aid in the completion of a successful application. Please call us toll free at 1-800-CALL MIX. We are ready to serve you.

PLEASE READ AND THOROUGHLY UNDERSTAND THE MATERIAL SAFETY DATA SHEET PROVIDED WITH EACH ORDER PRIOR TO BEGINNING WORK. THIS IS INTENDED FOR YOUR SAFETY.

Direct contact with the skin should be avoided as it can cause skin irritation. Protective clothing, goggles, and gloves are recommended. In the event of direct contact with the eyes, flush immediately with plenty of water and report to a doctor. FATAL IF TAKEN INTERNALLY. KEEP AWAY FROM OPEN FLAME AND FROM FREEZING TEMPERATURES.

\section{KEEP OUT OF REACH OF CHILDREN}

The VOC contents per EPA test method 24 (40 CFR 60, Appendix A) do not exceed $150 \mathrm{~g} / \mathrm{L}$. 


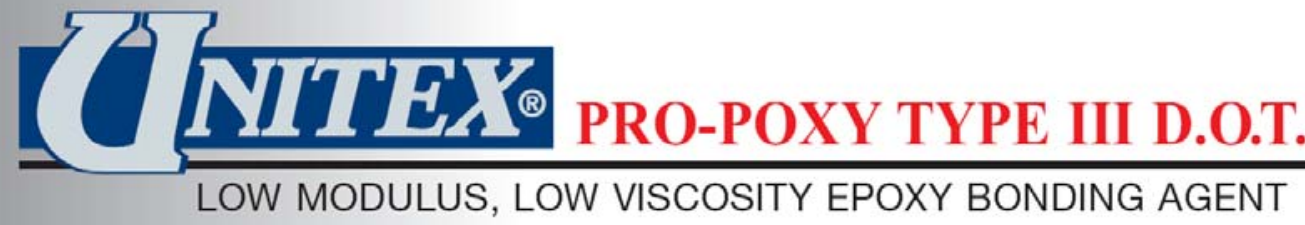

BENEFITS:

- Meets AASHTOAGC-ARTBA Taskforce 34, Oct. 1995

- Meets ASTM-C-881-90, Type III, Classes B \& C

- Excellent Bond Strength

- Low Modulus

- Low Viscosity

- High Early Strength

- Easy to Mix 1:1 Ratio

- Moisture Insensitive

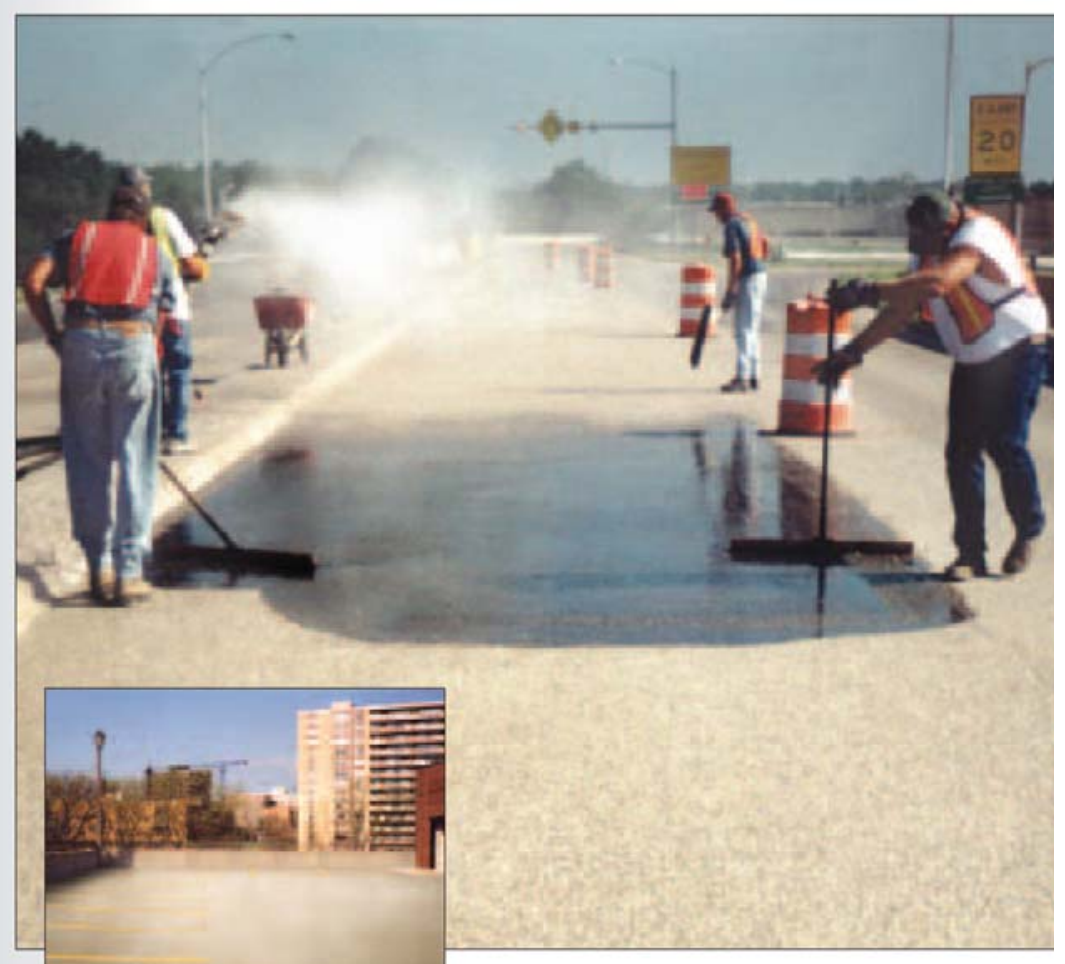

Keep traffic moving with PRO-POXY TYPE III D.O.T. !

- Non-Flammable

Figure A.16: Technical Data Sheet, Pro-Poxy Type III D.O.T., Unitex Chemicals 


\section{PRO-POXY TYPE III D.O.T.}

DESCRIPTION

PRO-POXY TYPE III D.O.T./U is a solvent-free, moisture insensitive, $100 \%$ solids, low modulus, two component bonding agent. It meets ASTM-C-881 Type III, Grade 2, Classes B \& C. It also meets USDA specifications for use in food processing areas.

Excellent for use as binder for concrete skid-resistant overlays on bridges and elevated slabs.

USES

- Bonding skid-resistant overlays to bridges and elevated slabs - Patching concrete as epoxy mortar

\begin{tabular}{|c|c|c|c|}
\hline \multirow{2}{*}{$\begin{array}{l}\text { PROPERTIES } \\
\text { And } \\
\text { TESTING }\end{array}$} & \multicolumn{3}{|c|}{ RESIN PROPERTIES } \\
\hline & LABORATORY TESTS & RESULTS & $\begin{array}{l}\text { ASTM C-881 } \\
\text { SPECIFICATIONS }\end{array}$ \\
\hline & $\begin{array}{l}\text { Mix Ratio } \\
\text { D-695 Compressive Modulus } \\
\text { D-638 Tensile Strength } \\
\text { D-638 Tensile Elongation } \\
\text { C-882 Bond Strength (14 day cure) } \\
\text { D-570 Absorption } \\
\text { C-881 Gel Time } \\
\text { C-881 Brookfield Visc. RV3 @20rpm } \\
\text { D-2240 Shore D Hardness } \\
\text { C-883 Shrinkage } \\
\text { C-884 Thermal Compatibility } \\
\text { AASHTO T-277 Chloride lon Permeability }\end{array}$ & $\begin{array}{l}1: 1 \text { by volume } \\
64,820 \\
2,610 \text { psi } \\
49 \% \\
3,470 \text { psi } \\
0.19 \% \\
30 \text { minutes } 1 \\
4000 \text { cps } \\
69 \\
\text { Pass } \\
\text { Pass } \\
0.9 \text { coulombs }\end{array}$ & $\begin{array}{l}\text { None } \\
130,000 \text { max. } \\
\text { None } \\
30 \% \text { min. } \\
1,500 \text { psi min. } \\
1.0 \% \text { max. } \\
30 \text { minutes min. } \\
100,000 \text { cps max. } \\
\text { None } \\
\text { Pass } \\
\text { None } \\
\text { None }\end{array}$ \\
\hline & \multicolumn{3}{|c|}{$\begin{array}{l}\text { GROUT PROPERTIES } \\
\text { Sand to Resin }-3.5: 1 \text { by volume }\end{array}$} \\
\hline & $\begin{array}{l}\text { C- } 579^{2} \text { Compressive Strength } 3 \text { hrs } \\
\text { C- } 579^{2} \text { Compressive Strength } 24 \text { hrs } \\
\text { C- } 579^{2} \text { Compressive Strength } 48 \text { hrs (Moist Cure) }\end{array}$ & $\begin{array}{l}1100 \mathrm{psi} \\
7500 \mathrm{psi} \\
7000 \mathrm{psi}\end{array}$ & $\begin{array}{l}\text { N/A } \\
\text { N/A } \\
\text { N/A }\end{array}$ \\
\hline
\end{tabular}

PACKAGING

$1 \mathrm{gal} / 3.8 \mathrm{~L}$ units $(2-.5 \mathrm{gal}$ cans $)$

$2 \mathrm{gal} / 7.6 \mathrm{~L}$ units ( $2-1 \mathrm{gal}$ cans $)$
$10 \mathrm{gal} / 37.9 \mathrm{~L}$ units ( $2-5$ gal pails)

$110 \mathrm{gal} / 416.4 \mathrm{~L}$ units (2 - $55 \mathrm{gal}$ drums)

\section{COVERAGE}

\begin{tabular}{|c|c|c|}
\hline \multicolumn{3}{|c|}{ MINIMUM EPOXY \& AGGREGATE COVERAGE RATES } \\
\hline & EPOXY RATE & AGGREGATE RATE \\
\hline COURSE 1 & $1 \mathrm{gal} / 40 \mathrm{sq} \mathrm{ft}$ minimum $\left(1 \mathrm{~L} / \mathrm{m}^{2}\right)$ & $10 \mathrm{lbs} / \mathrm{sq}$ yd $\left(5.4 \mathrm{~kg} / \mathrm{m}^{2}\right)$ \\
\hline COURSE 2 & $1 \mathrm{gal} / 20 \mathrm{sq} \mathrm{ft}$ minimum $\left(2 \mathrm{~L} / \mathrm{m}^{2}\right)$ & $14 \mathrm{lbs} / \mathrm{sq}$ yd $\left(7.6 \mathrm{~kg} / \mathrm{m}^{2}\right)$ \\
\hline \multicolumn{3}{|c|}{ MORTAR COVERAGE RATES } \\
\hline & \multicolumn{2}{|l|}{$\begin{array}{l}\text { MIXED EPOXY/AGGREGATE RATE } \\
1 \mathrm{gal} / 808 \mathrm{cu} \text { in }(3.8 \mathrm{~L} / 317 \mathrm{cu} \mathrm{cm})\end{array}$} \\
\hline
\end{tabular}

\section{Figure A.16 (cont.): Technical Data Sheet, Pro-Poxy Type III D.O.T., Unitex} Chemicals 

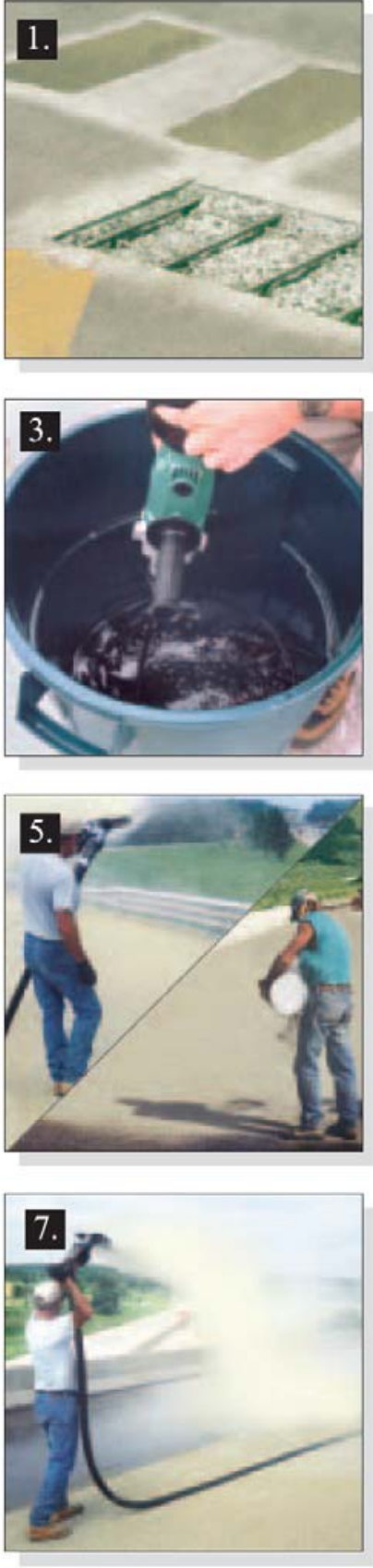
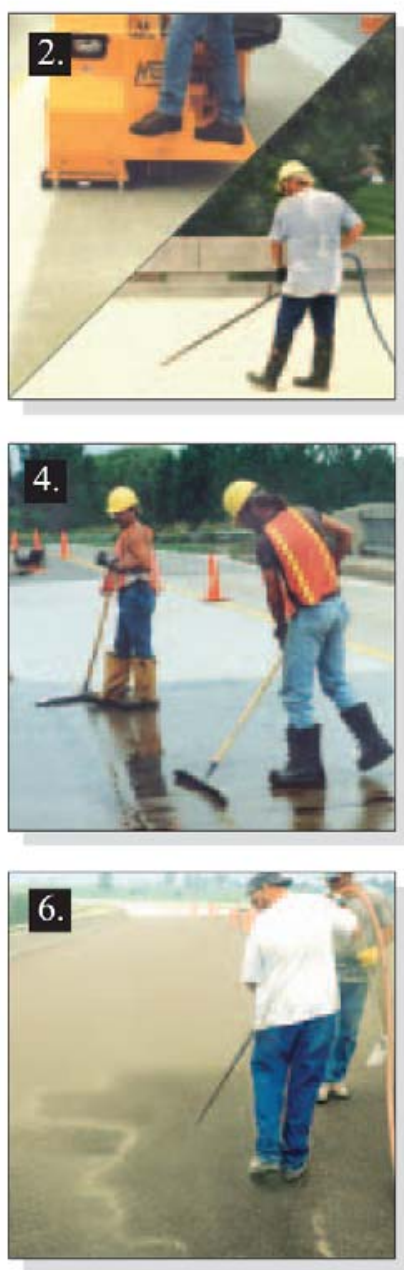

\begin{tabular}{|c|c|c|c|c|c|c|}
\hline \multicolumn{7}{|c|}{ MINIMUM CURING TIMES OF PRO-POXY TYPE III D.O.T./U OVERLAY } \\
\hline & \multicolumn{6}{|c|}{ Average Temperatures of Overlay Components \& Substrate } \\
\hline & $\begin{array}{l}60-64^{\circ} \mathrm{F} \\
16-18^{\circ} \mathrm{C} \\
\end{array}$ & $\begin{array}{l}65-69^{\circ} \mathrm{F} \\
19-21^{\circ} \mathrm{C}\end{array}$ & $\begin{array}{l}70-74^{\circ} \mathrm{F} \\
22-23^{\circ} \mathrm{C}\end{array}$ & $\begin{array}{l}75-79^{\circ} \mathrm{F} \\
24-26^{\circ} \mathrm{C}\end{array}$ & $\begin{array}{l}80-84^{\circ} \mathrm{F} \\
27-29^{\circ} \mathrm{C}\end{array}$ & $\begin{array}{l}85+{ }^{\circ} \mathrm{F} \\
29+{ }^{\circ} \mathrm{C} \\
\end{array}$ \\
\hline $\begin{array}{l}\text { Min. Cure Time } \\
\text { COURSE } 1\end{array}$ & $4 \mathrm{hrs}$ & $3 \mathrm{hrs}$ & $2.5 \mathrm{hrs}$ & 2 hrs & $1.5 \mathrm{hrs}$ & $1 \mathrm{hr}$ \\
\hline $\begin{array}{l}\text { Min. Cure Time } \\
\text { COURSE } 2\end{array}$ & $6-5 \mathrm{hrs}$ & $5 \mathrm{hrs}$ & $4 \mathrm{hrs}$ & $3 \mathrm{hrs}$ & $3 \mathrm{hrs}$ & $3 \mathrm{hrs}$ \\
\hline
\end{tabular}

Figure A.16 (cont.): Technical Data Sheet, Pro-Poxy Type III D.O.T., Unitex Chemicals 


\section{LIMITATIONS}

- Concrete must be saturated surface dry(SSD) before applying PRO-POXY TYPE III D.O.T.

- PRO-POXY TYPE III D.O.T. is a vapor barrier after curing.

- Do not thin with solvents.

- Minimum age of concrete must be 28 days prior to applying PRO-POXY TYPE III D.O.T. as an overlay.

- Minimum age of concrete must be 5-7 days, depending on curing and drying conditions, prior to applying PRO-POXY TYPE III D.O.T. as a mortar.

- Shelf Life - 2 years in unopened original container.

\section{CAUTION}

- Component A - Irritant

- Component B - Corrosive

- Product is a strong sensitizer. Use of safety goggles and chemical resistant gloves are recommended.

- Use of a NIOSH/OSHA organic vapor respirator is recommended if ventilation is inadequate.

- Avoid breathing vapors.

- Avoid skin contact.

\section{FIRST AID}

EYE CONTACT: Flush immediately with water for at least 15 minutes. Contact physician immediately.

RESPIRATORY CONTACT: Remove person to fresh air.

SKIN CONTACT: Remove any contaminated clothing. Remove epoxy immediately with a dry cloth or paper towel. Solvents should not be used as they carry the irritant into the skin. Wash skin thoroughly with soap and water.

CURED EPOXY RESINS ARE INNOCUOUS.

\section{Cleanup}

EQUIPMENT: Uncured material can be removed with citrus cleaner or other approved solvent. Cured material can only be removed mechanically.

MATERIAL: Collect with absorbent material. Flush area with water. Dispose of in accordance with local, state, and federal disposal regulations.

\begin{abstract}
Disclaimer of Warranties: Neither manufacturer nor seller have any knowledge or control concerning the purchaser's use of the product. No expressed warranty is made by manufacturer or seller with respect to the results of any use of the product or container that the product comes in. No implied warranties including, but not limited to, an implied warranty of merchantability or an implied warranty of fitness for a particular purpose are made with respect to the product. Neither manufacturer nor seller assume any liability for personal injury, loss or damage resulting from the use of the product. In the event that the product shall prove defective, buyer's exclusive remedy shall be as follows: Seller or manufacturer shall, upon request of buyer, replace any quantity of the product which is proven to be defective or shall, at its option, refund the purchase price of the product upon return of the product. Manufacturer shall not be responsible for use of this product in a manner to infringe on any patent held by others.
\end{abstract}


APPENDIX B

ELECTRIC CURRENT MEASUREMENT - REPAIR PRODUCTS 


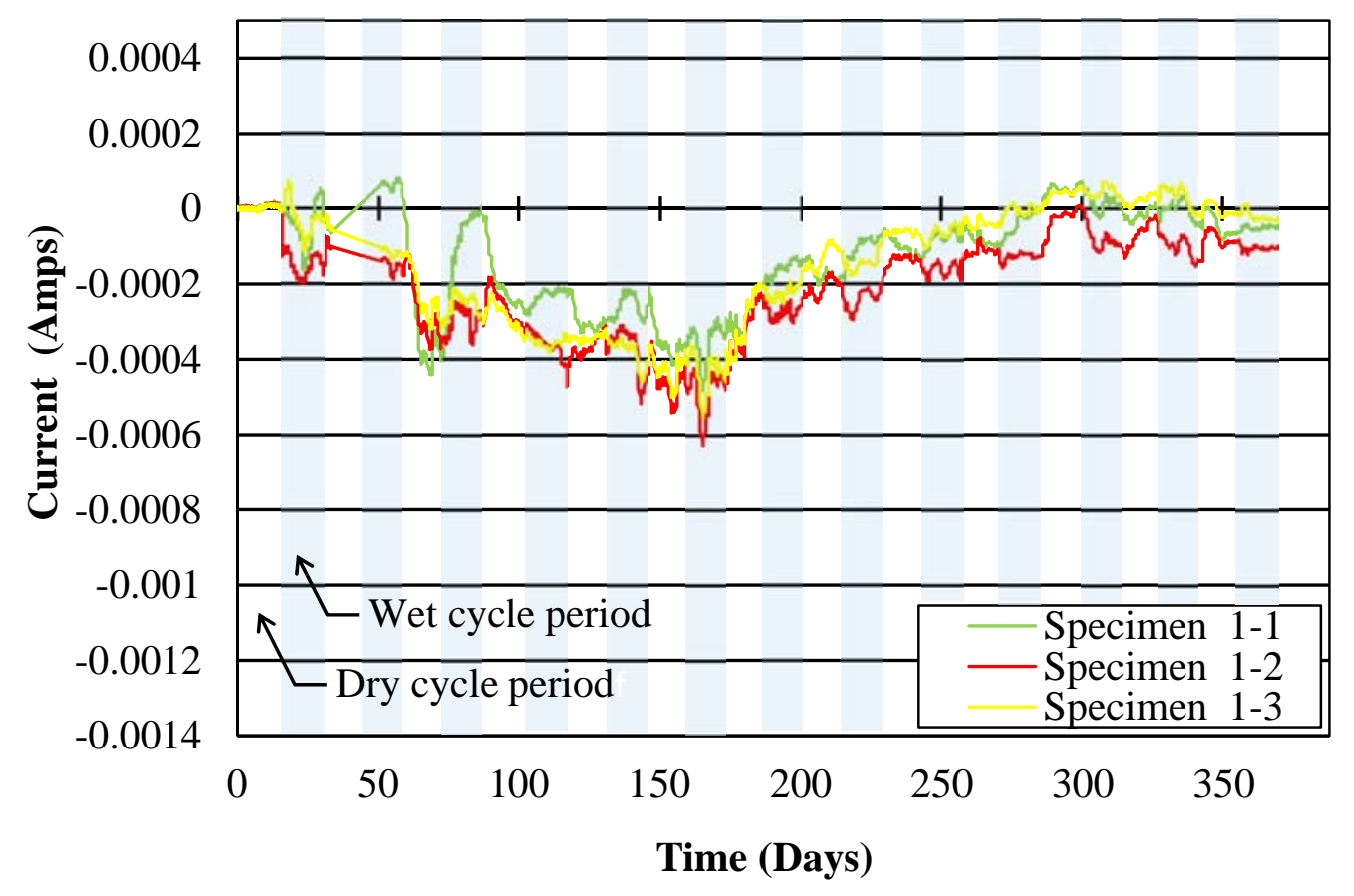

Figure B.1: BASF - Epoxeal (Epoxy)

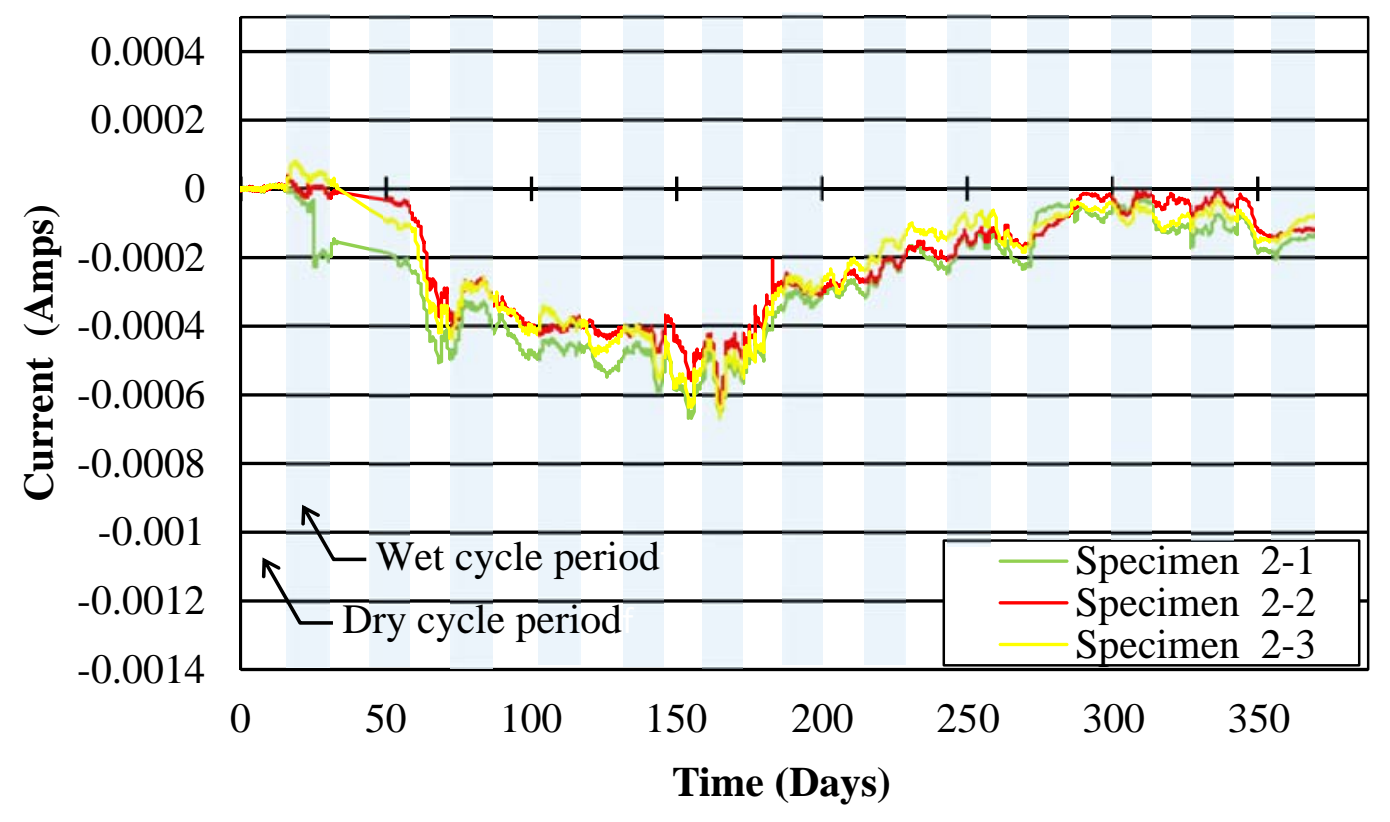

Figure B.2: BASF - Degadeck (Methacrylate) 


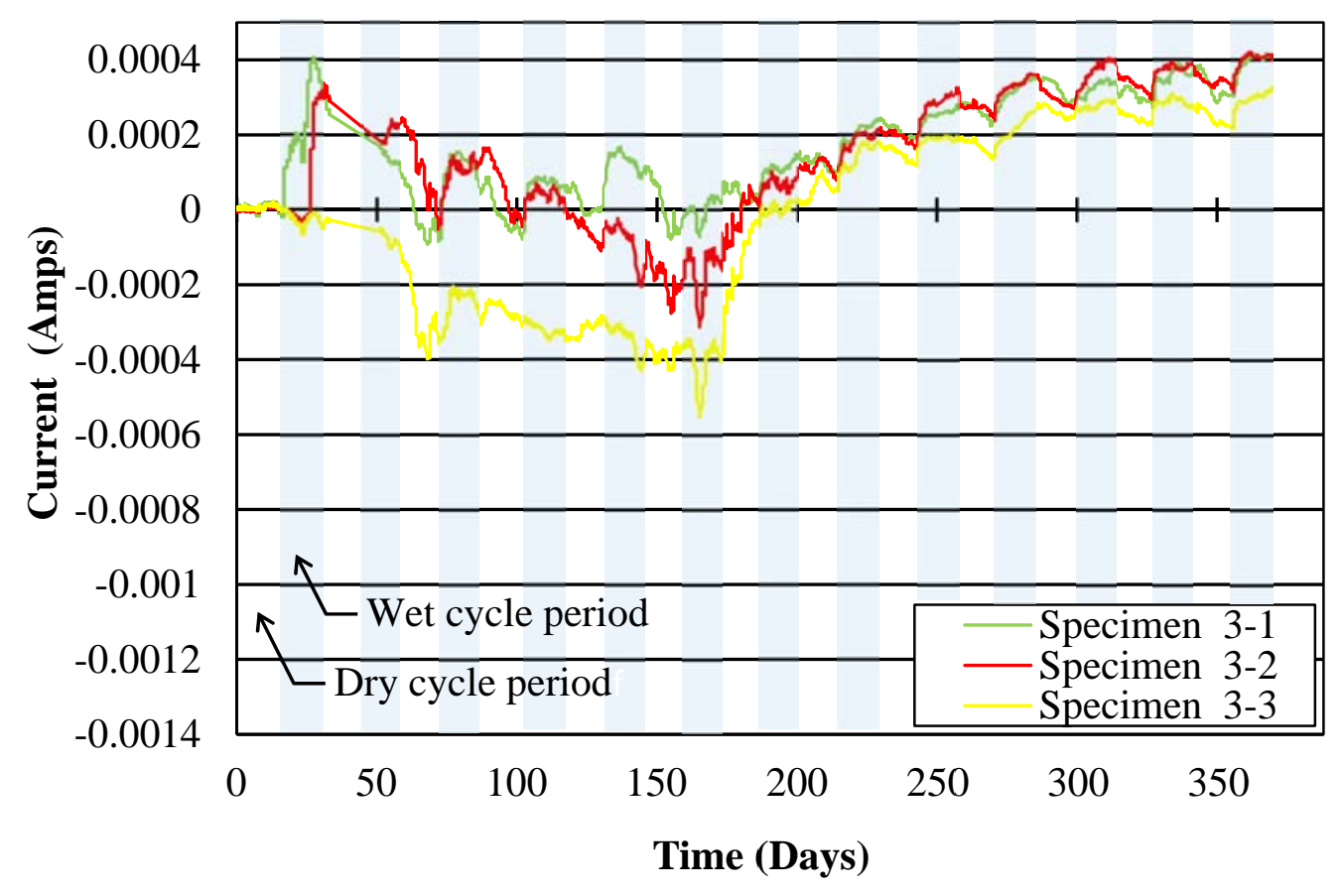

Figure B.3: BASF - Enviroseal (Waterproofer)

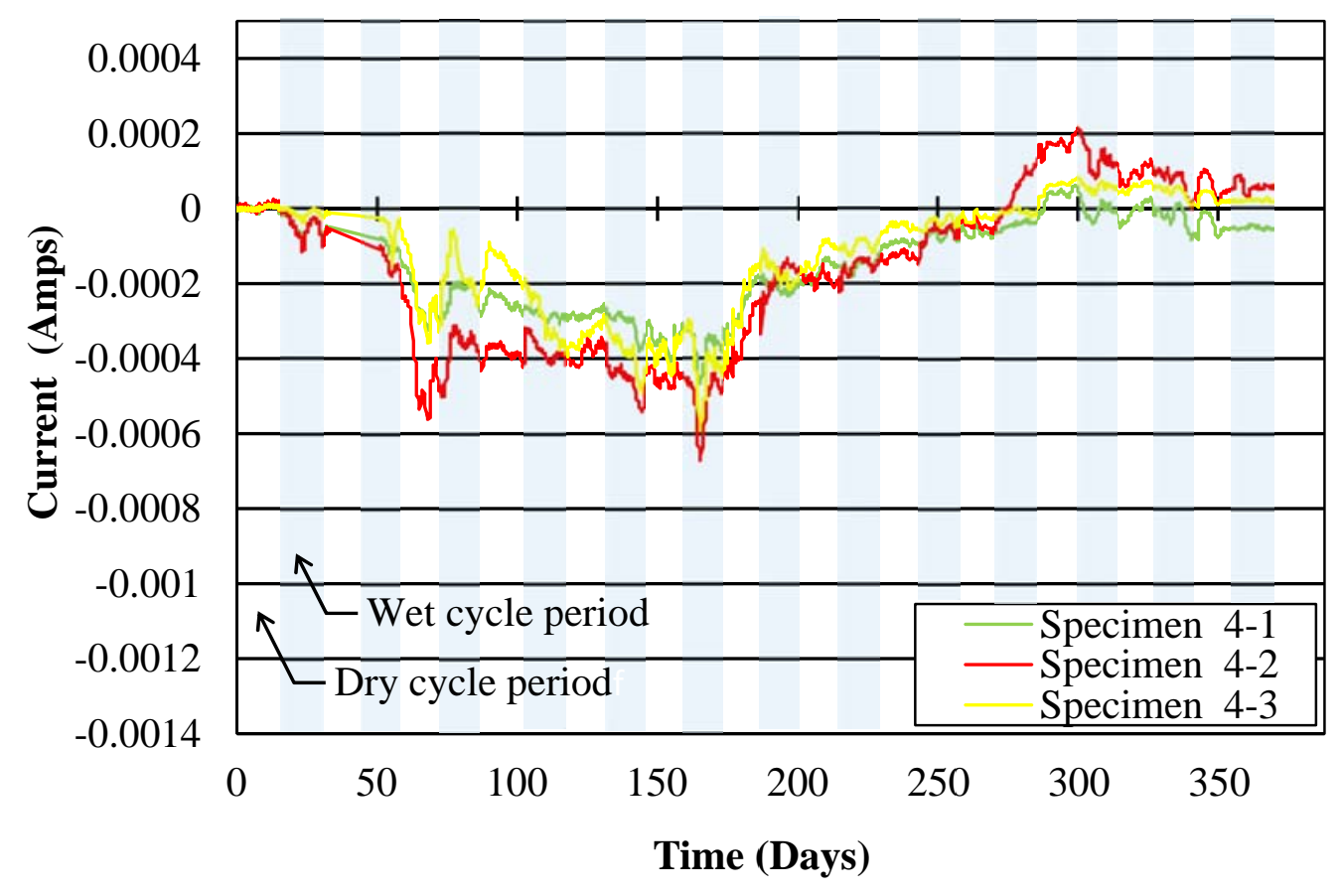

Figure B.4: Euclid/Tamms - Dural 335 (Epoxy) 


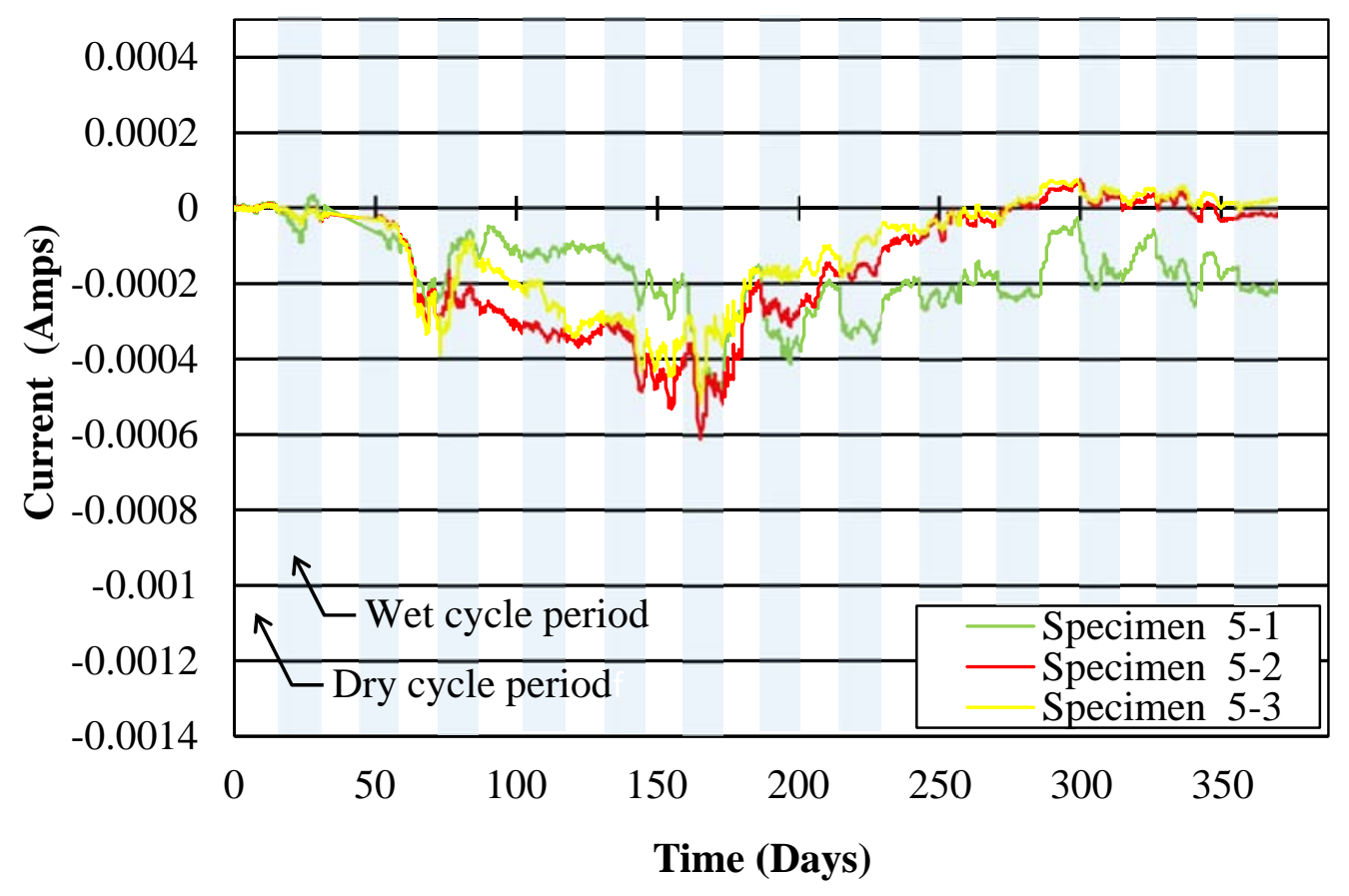

Figure B.5: Euclid/Tamms - Dural 50 (Epoxy)

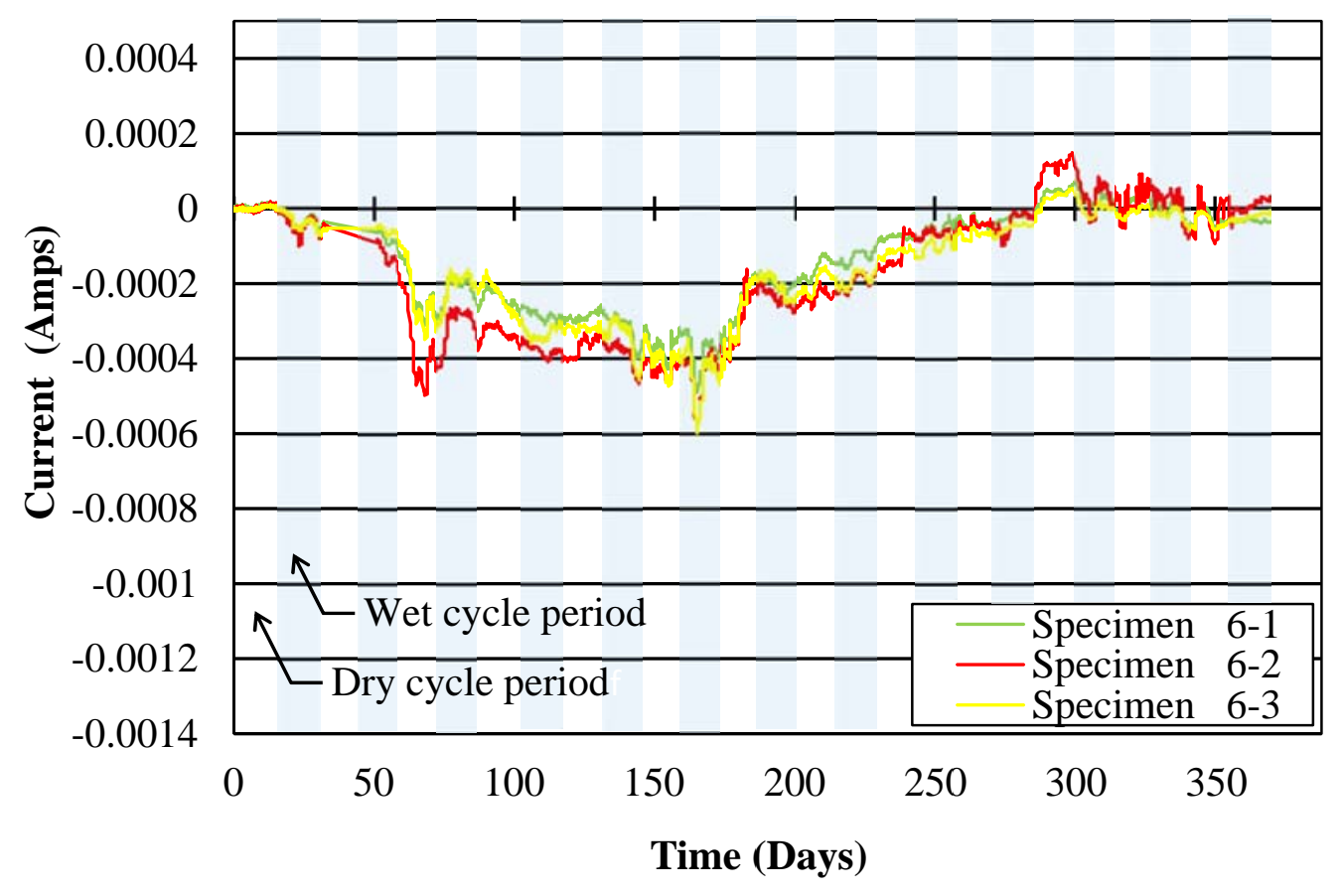

Figure B.6: Euclid/Tamms - Dural 50 LM (Epoxy) 


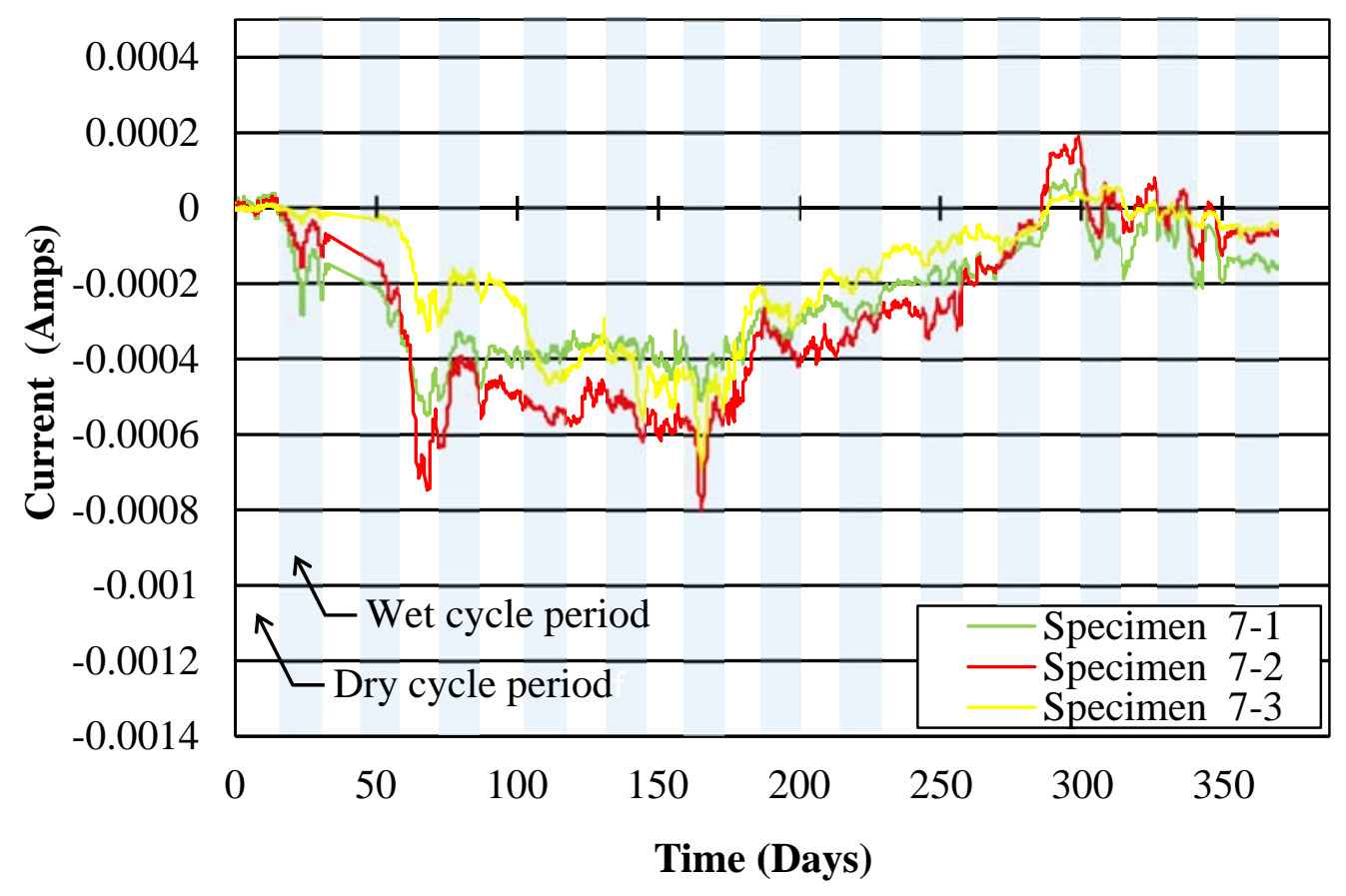

Figure B.7: Fox Industries - FX 770 HM LV (Epoxy)

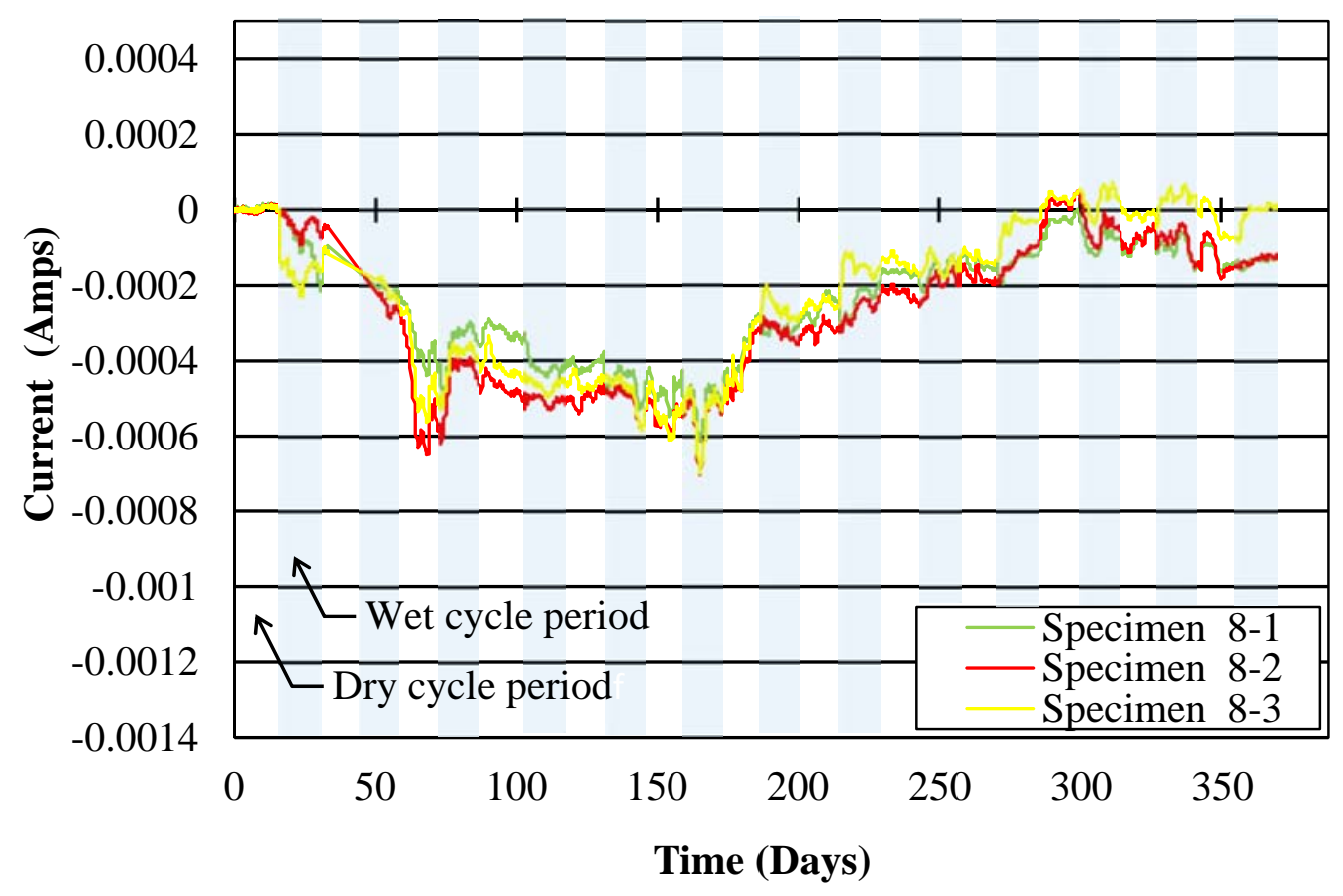

Figure B.8: Fox Industries - FX 821 MMA (Methacrylate) 


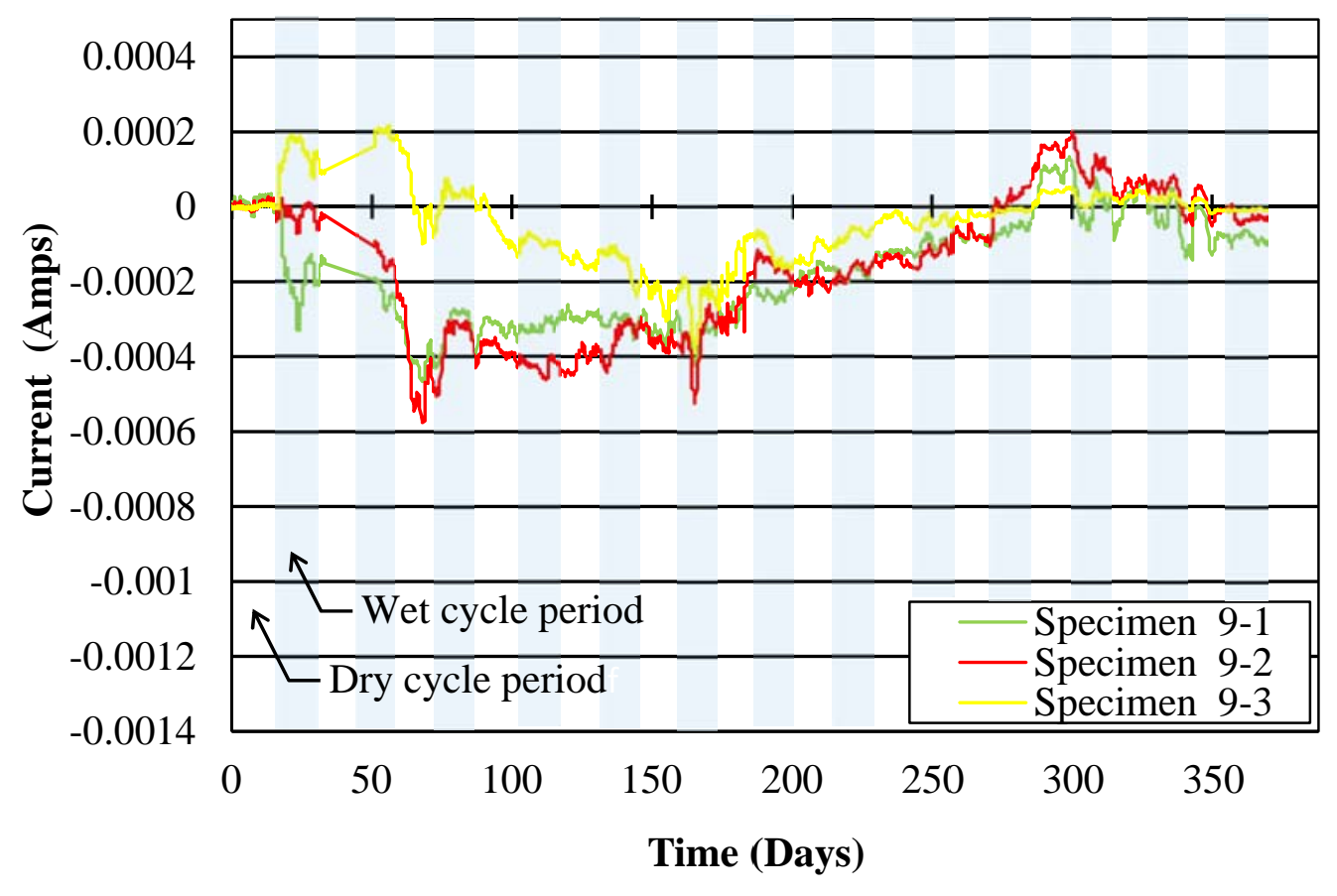

Figure B.9: Kaufman Products - SurePoxy HMSLV (Epoxy)

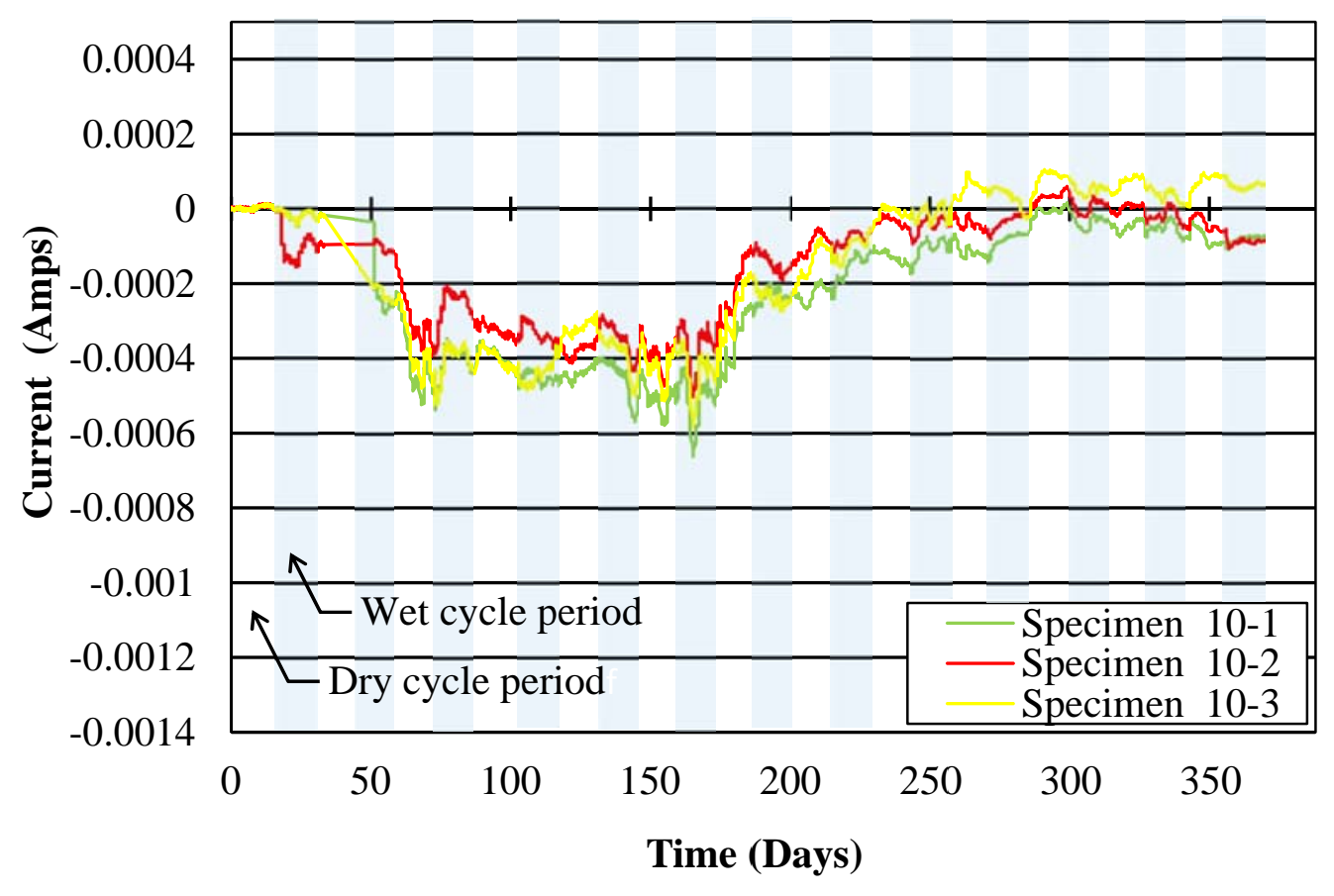

Figure B.10: PolyCarb - MARK 127 (Epoxy) 


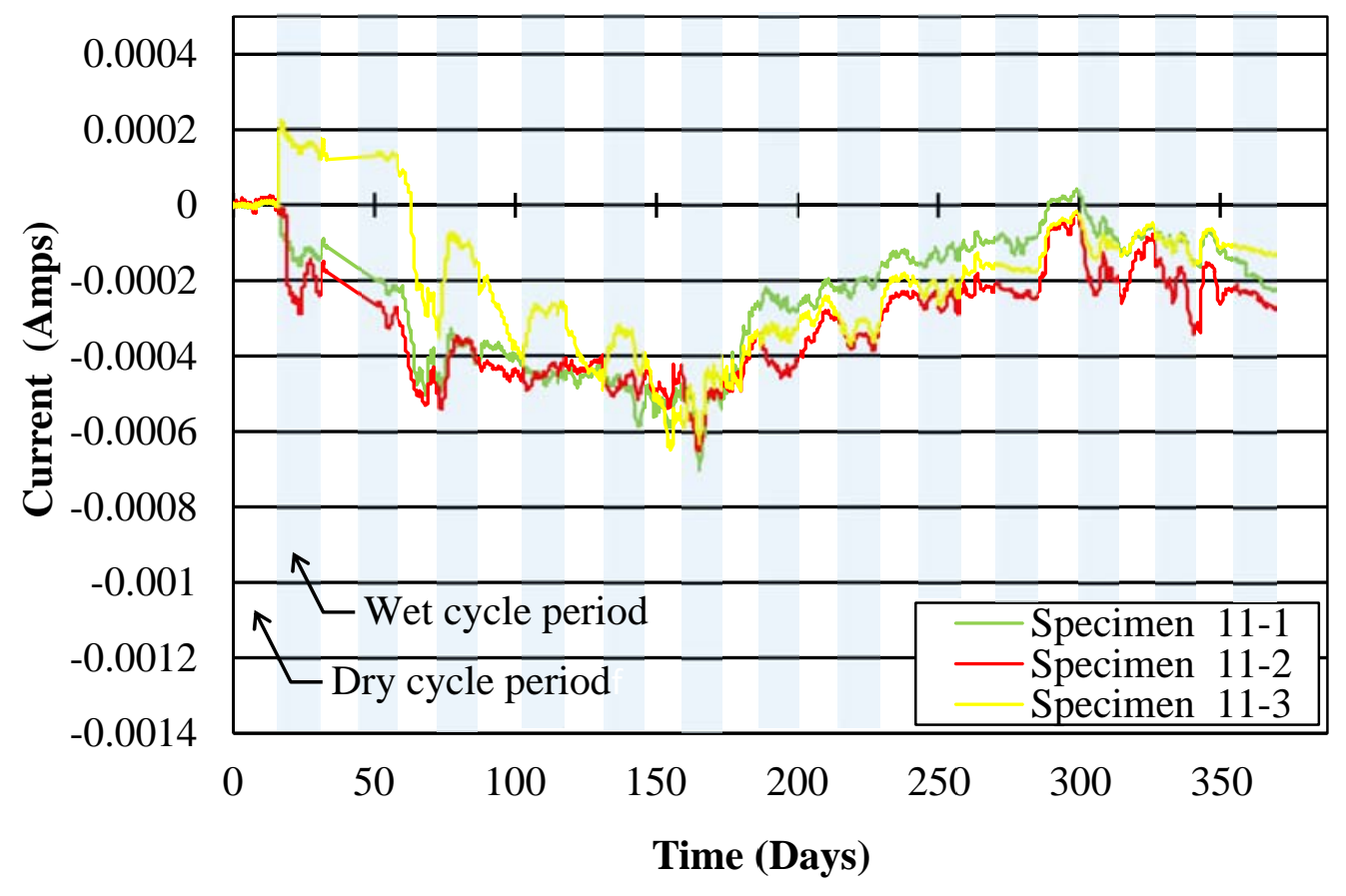

Figure B.11: PolyCarb - MARK 135 Safe-T-Seal (Epoxy)

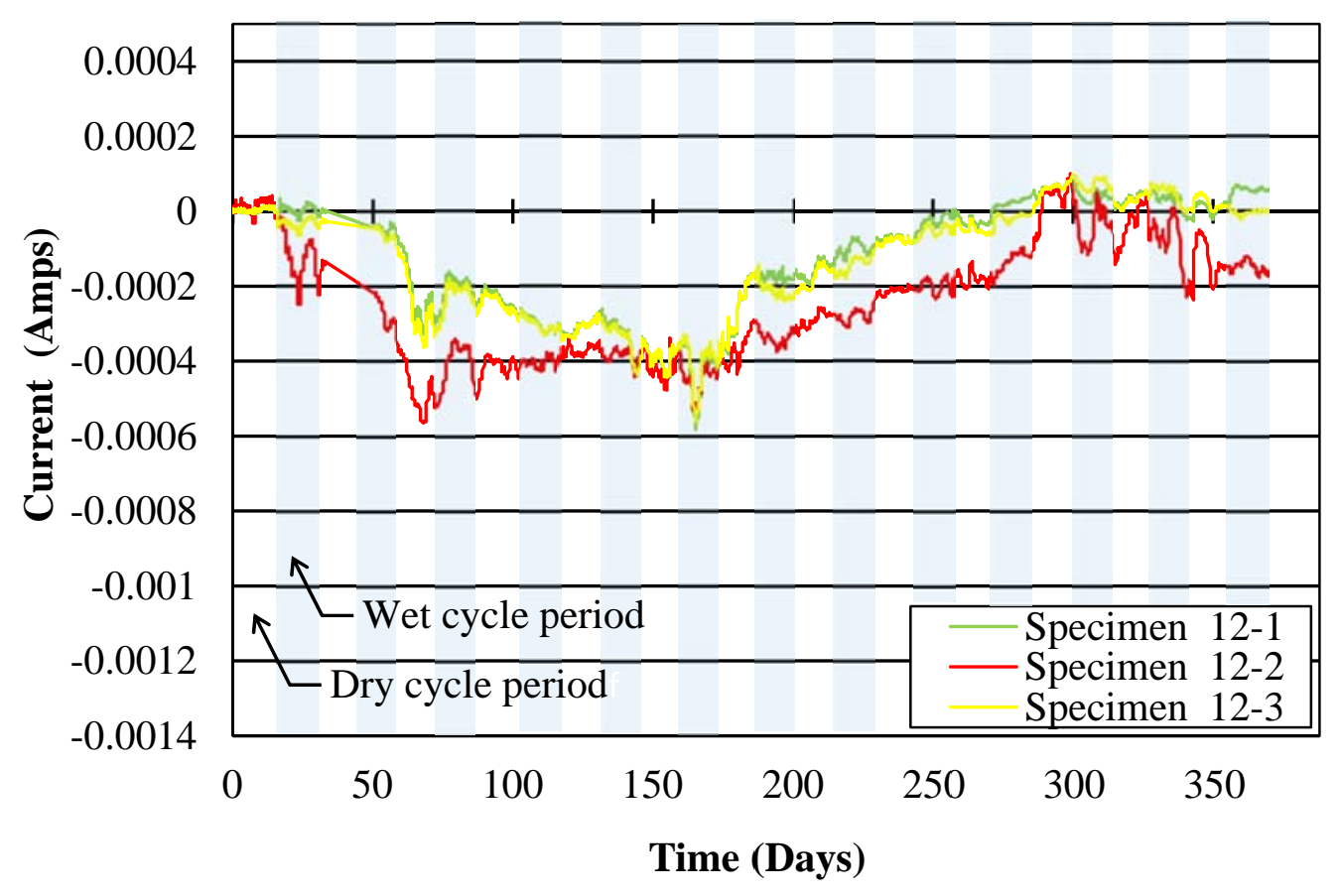

Figure B.12: PolyCarb - MARK 163 FlexoGrid (Epoxy Overlay) 


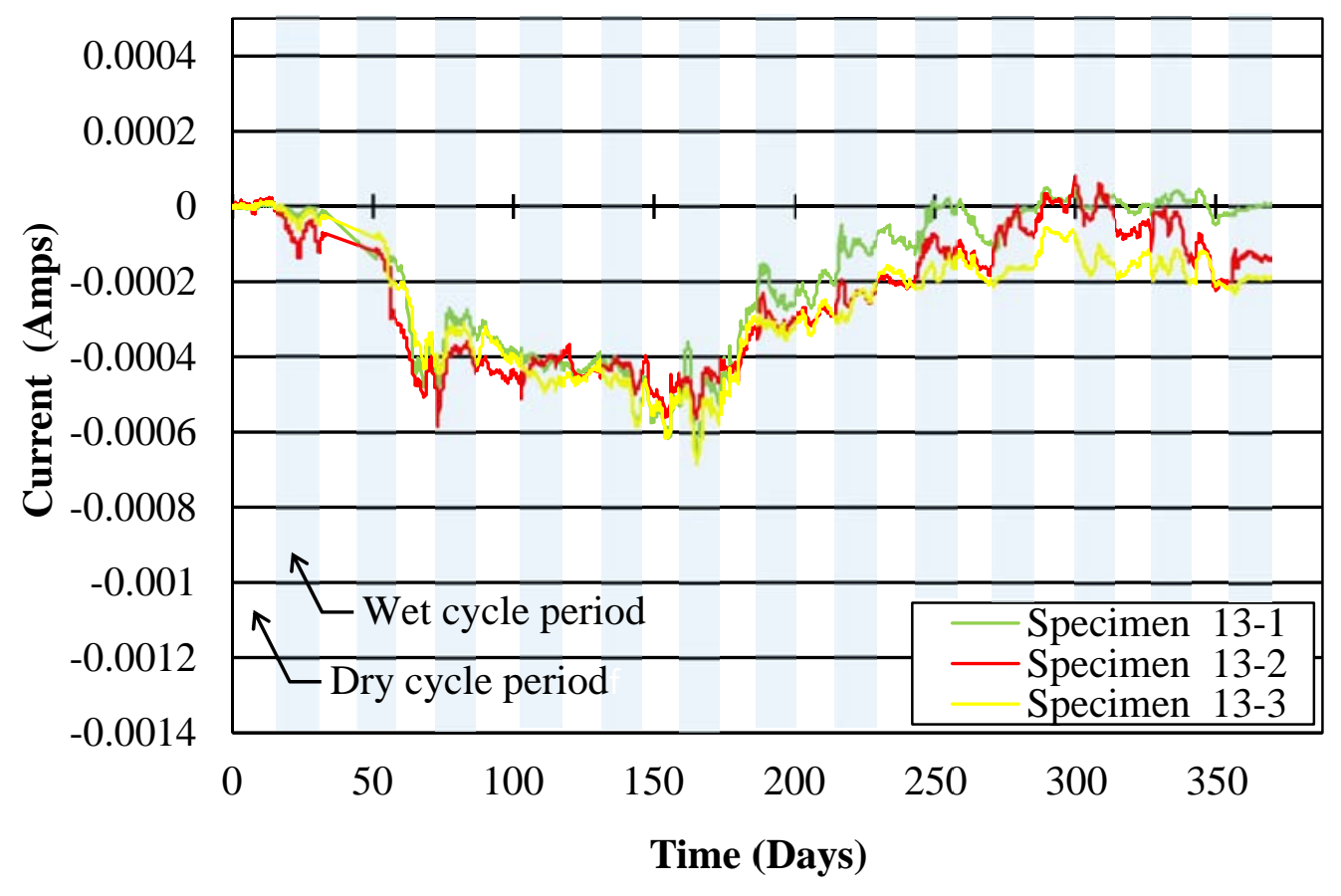

Figure B.13: SikaCorp. - SikaPronto 19 (Methacrylate)

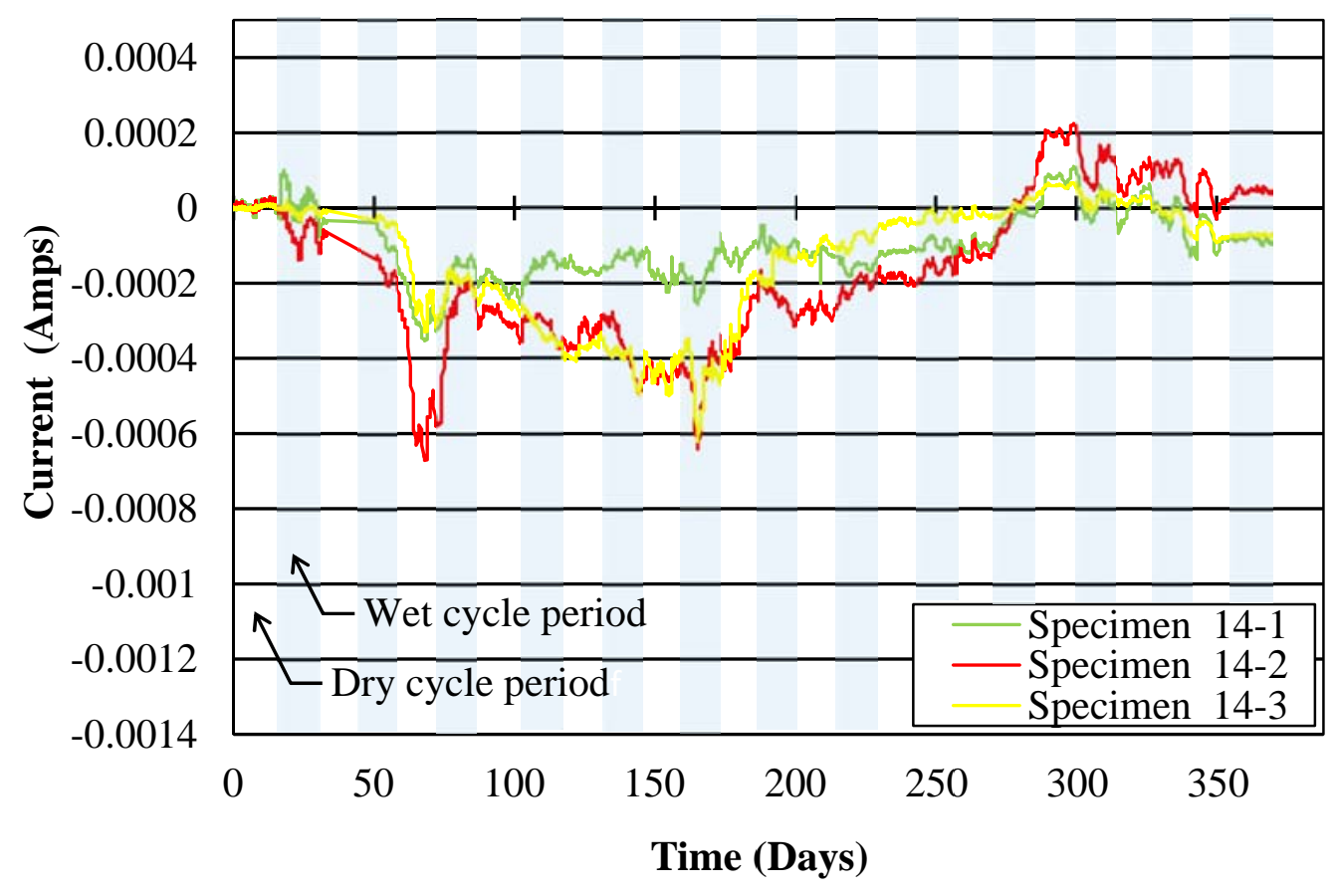

Figure B.14: SikaCorp. - Sikadur 55 SLV (Epoxy) 


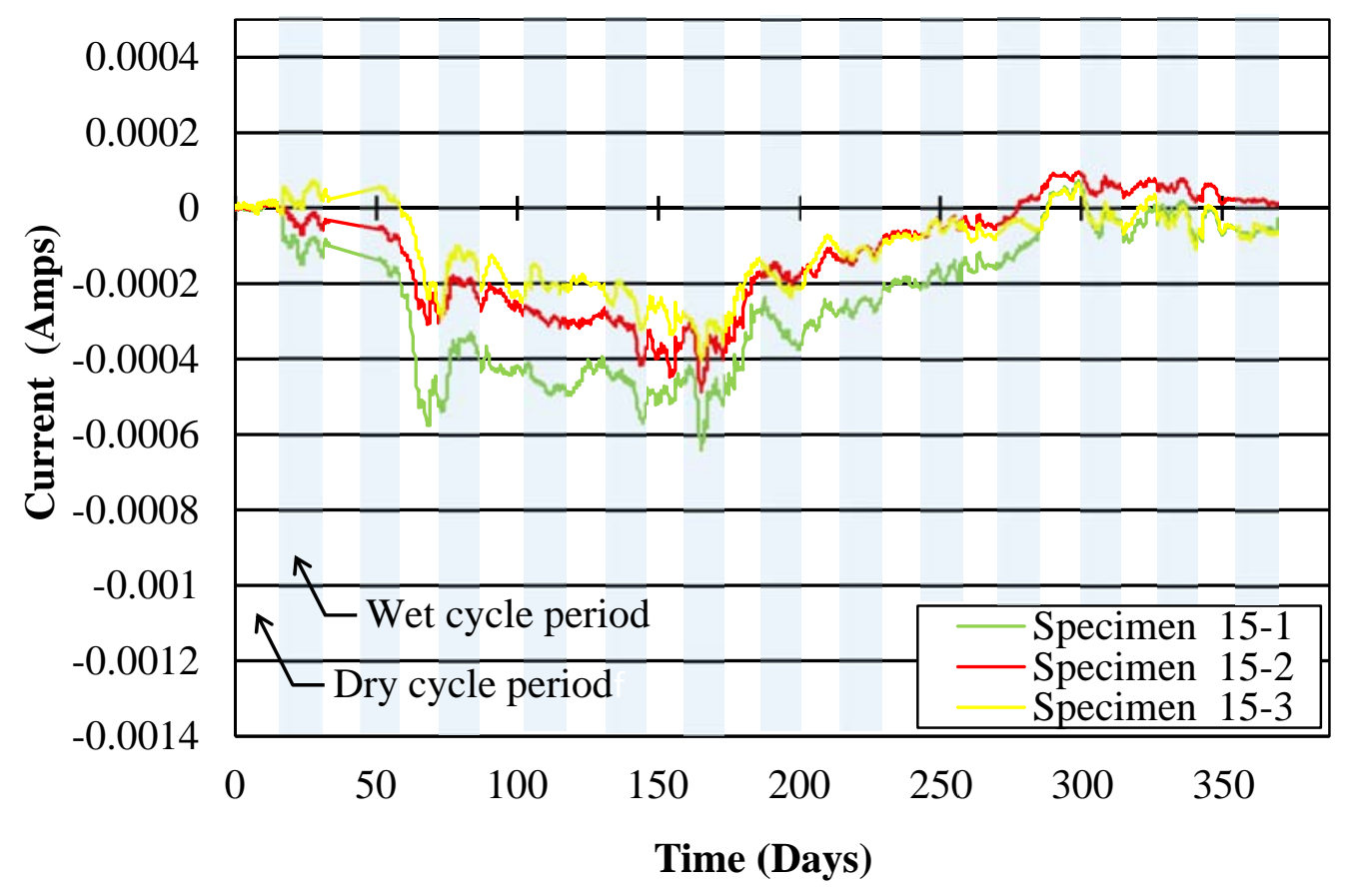

Figure B.15: Unitex Chemicals - Bridge Seal (Epoxy)

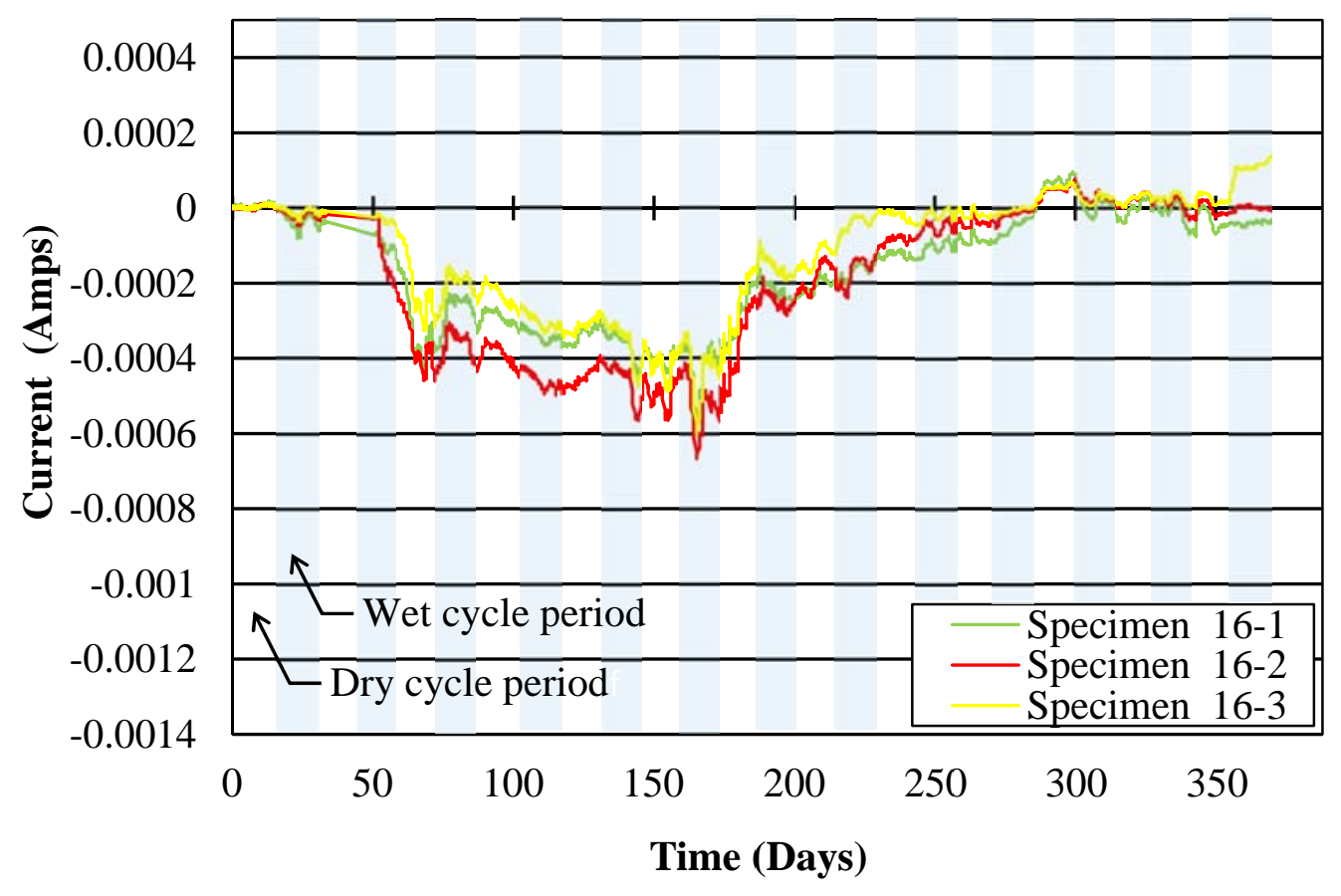

Figure B.16: Unitex Chemicals - ProPoxy Type III D.O.T. (Epoxy Overlay) 


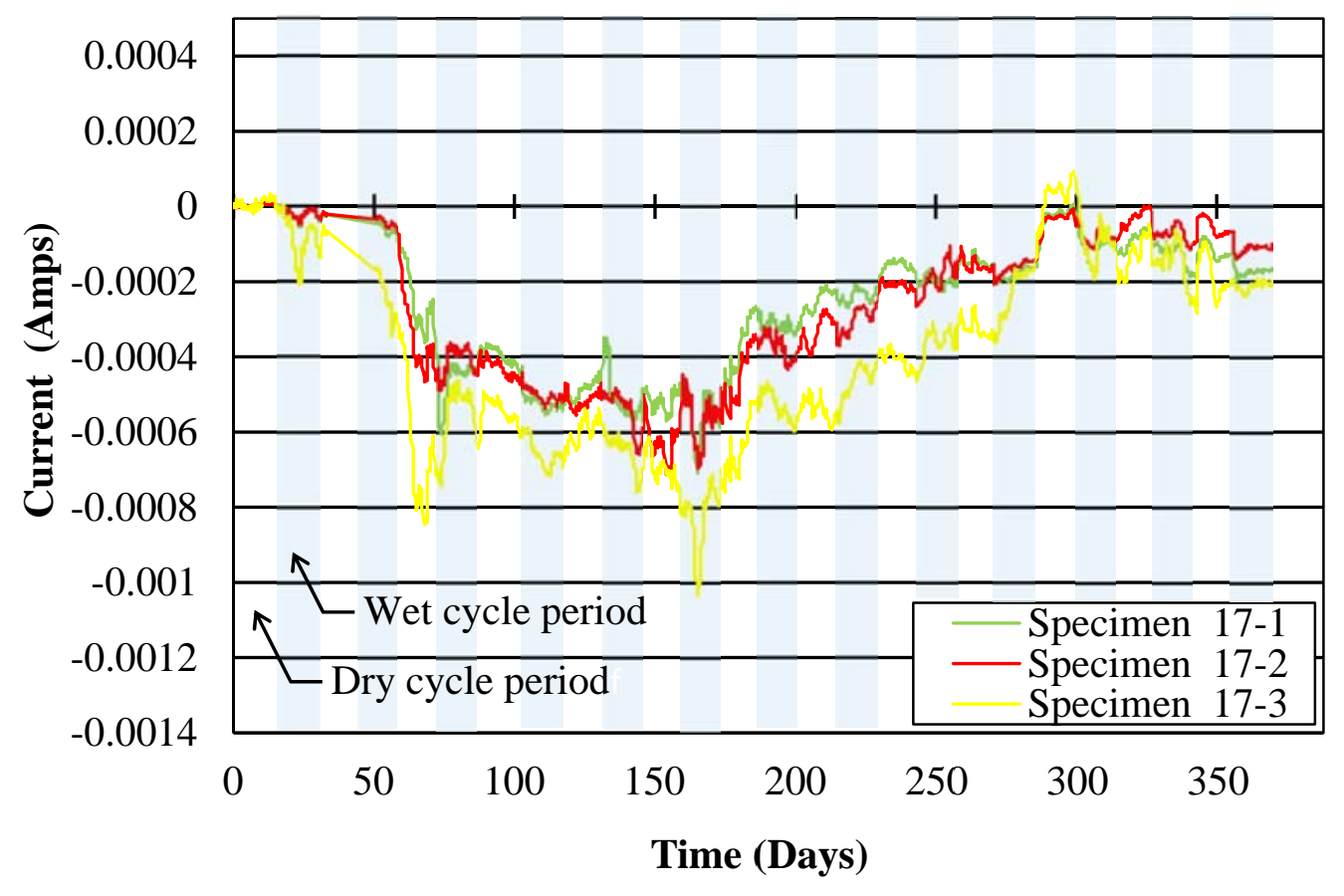

Figure B.17: No Repair 1 - Small Cracks

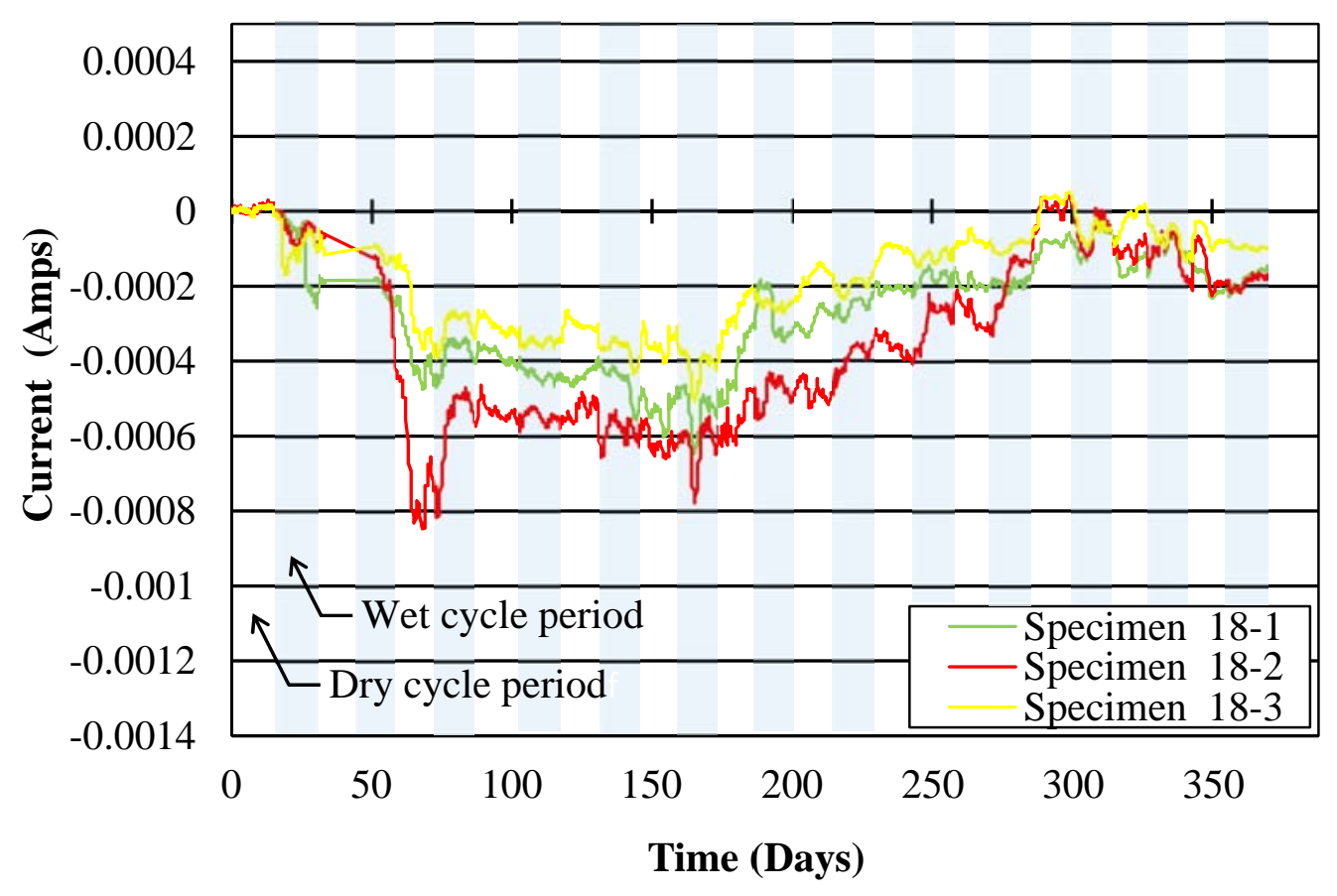

Figure B.18: No Repair 2 - Medium Cracks 


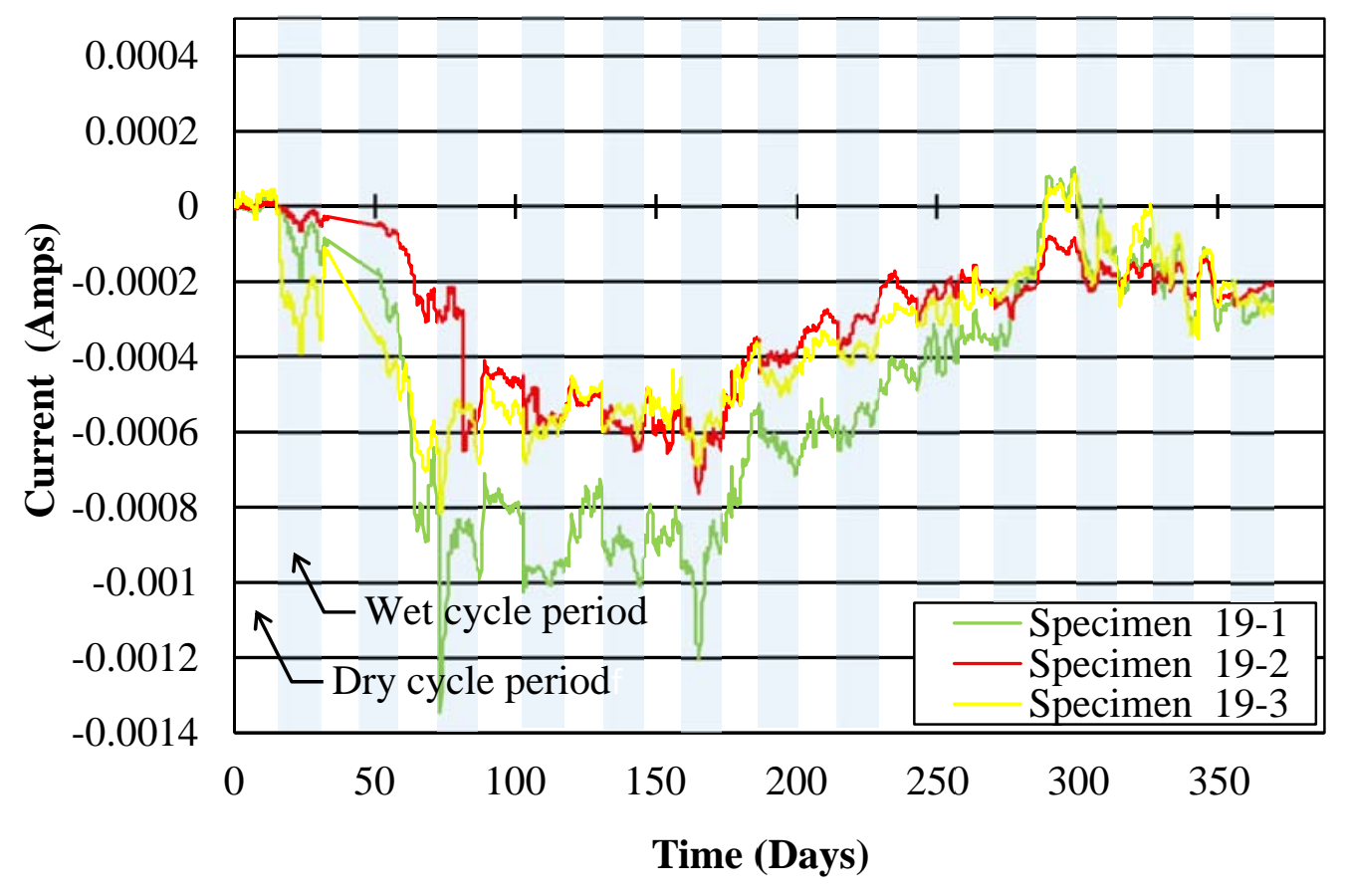

Figure B.19: No Repair 3 - Large Cracks 
APPENDIX C

VISUAL ASSESSMENT - REPAIR PRODUCTS 
Table C.1: Average corrosion for each specimen - Visual examination

\begin{tabular}{|c|c|c|c|c|}
\hline \multirow{2}{*}{ Product } & \multirow{3}{*}{ Manufacturer } & \multirow{2}{*}{ Repair Type } & Specimen & Assessment \\
Average
\end{tabular}


Table C.1(continued): Average corrosion for each specimen - Visual examination

\begin{tabular}{|c|c|c|c|c|}
\hline Product & Manufacturer & Repair Type & Specimen & $\begin{array}{c}\text { Assessment } \\
\text { Average }\end{array}$ \\
\hline \multirow{3}{*}{ Dural 50 LM } & \multirow{3}{*}{ Euclid / Tamms } & \multirow{3}{*}{ Epoxy } & 17 & 1.25 \\
\hline & & & 39 & 1.00 \\
\hline & & & 56 & 2.33 \\
\hline \multirow{3}{*}{\multicolumn{2}{|c|}{ Large Cracks ( 0.035 to 0.040 in.) }} & \multirow{3}{*}{ None } & 31 & 3.25 \\
\hline & & & 21 & 0.75 \\
\hline & & & 1 & 0.75 \\
\hline \multirow{3}{*}{\multicolumn{2}{|c|}{ Small Cracks (0.010 to 0.013 in.) }} & \multirow{3}{*}{ None } & 48 & 1.83 \\
\hline & & & 28 & 1.67 \\
\hline & & & 32 & 1.33 \\
\hline \multirow{3}{*}{ Mark 135} & \multirow{3}{*}{ Poly-Carb } & \multirow{3}{*}{ Epoxy } & 52 & 1.83 \\
\hline & & & 8 & 1.67 \\
\hline & & & 26 & 1.50 \\
\hline \multirow{3}{*}{\multicolumn{2}{|c|}{ Medium Cracks (0.016 to 0.020 in.) }} & \multirow{3}{*}{ None } & 18 & 2.75 \\
\hline & & & 35 & 1.33 \\
\hline & & & 13 & 1.00 \\
\hline \multirow{3}{*}{ Mark 127} & \multirow{3}{*}{ Poly-Carb } & \multirow{3}{*}{ Epoxy } & 53 & 2.75 \\
\hline & & & 24 & 1.67 \\
\hline & & & 30 & 1.50 \\
\hline \multirow{3}{*}{ Pronto 19} & \multirow{3}{*}{ SkaCorp } & \multirow{3}{*}{ Methacrylate } & 60 & 1.83 \\
\hline & & & 9 & 1.50 \\
\hline & & & 22 & 2.75 \\
\hline \multirow{3}{*}{ DegaDeck } & \multirow{3}{*}{ BASF } & \multirow{3}{*}{ Methacrylate } & 20 & 5.75 \\
\hline & & & 50 & 2.17 \\
\hline & & & 27 & 2.50 \\
\hline \multirow{3}{*}{ Enviroseal } & \multirow{3}{*}{ BASF } & \multirow{3}{*}{ Waterproofer } & 10 & 0.67 \\
\hline & & & 45 & 1.00 \\
\hline & & & 44 & 0.75 \\
\hline
\end{tabular}

